\title{
DESAFIOS E ESTRATÉGIAS \\ PARA SEGURANÇA \\ ALIMENTAR MUNDIAL
}

\section{ORGANIZAÇÃO}

NEIDE KAZUE SARUGAWA SHINOHARA FÁBIO HENRIQUE P. C. DE OLIVEIRA

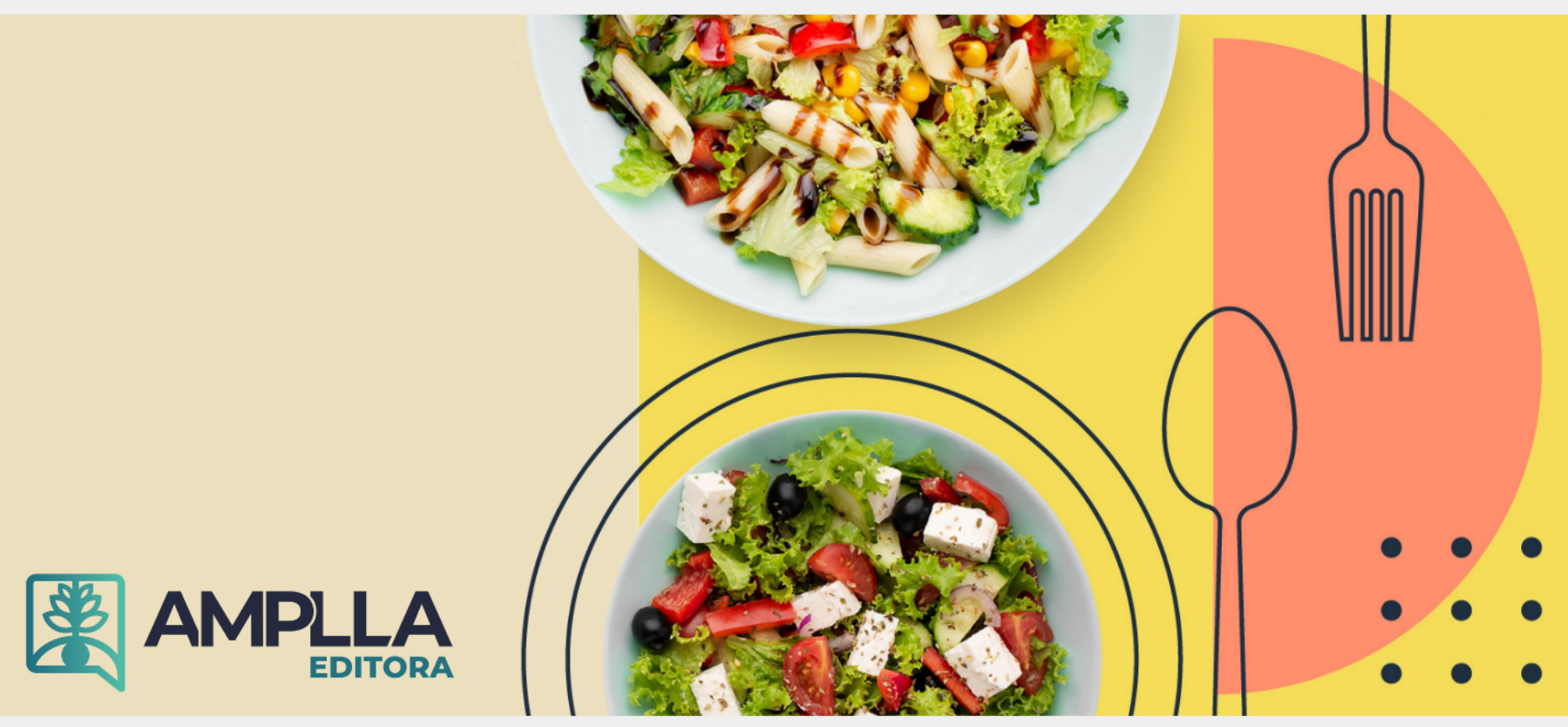




\section{DESAFIOS E ESTRATÉGIAS \\ PARA SEGURANÇA \\ ALIMENTAR MUNDIAL}

\section{ORGANIZAÇÃO}

NEIDE KAZUE SARUGAWA SHINOHARA FÁBIO HENRIQUE P. C. DE OLIVEIRA

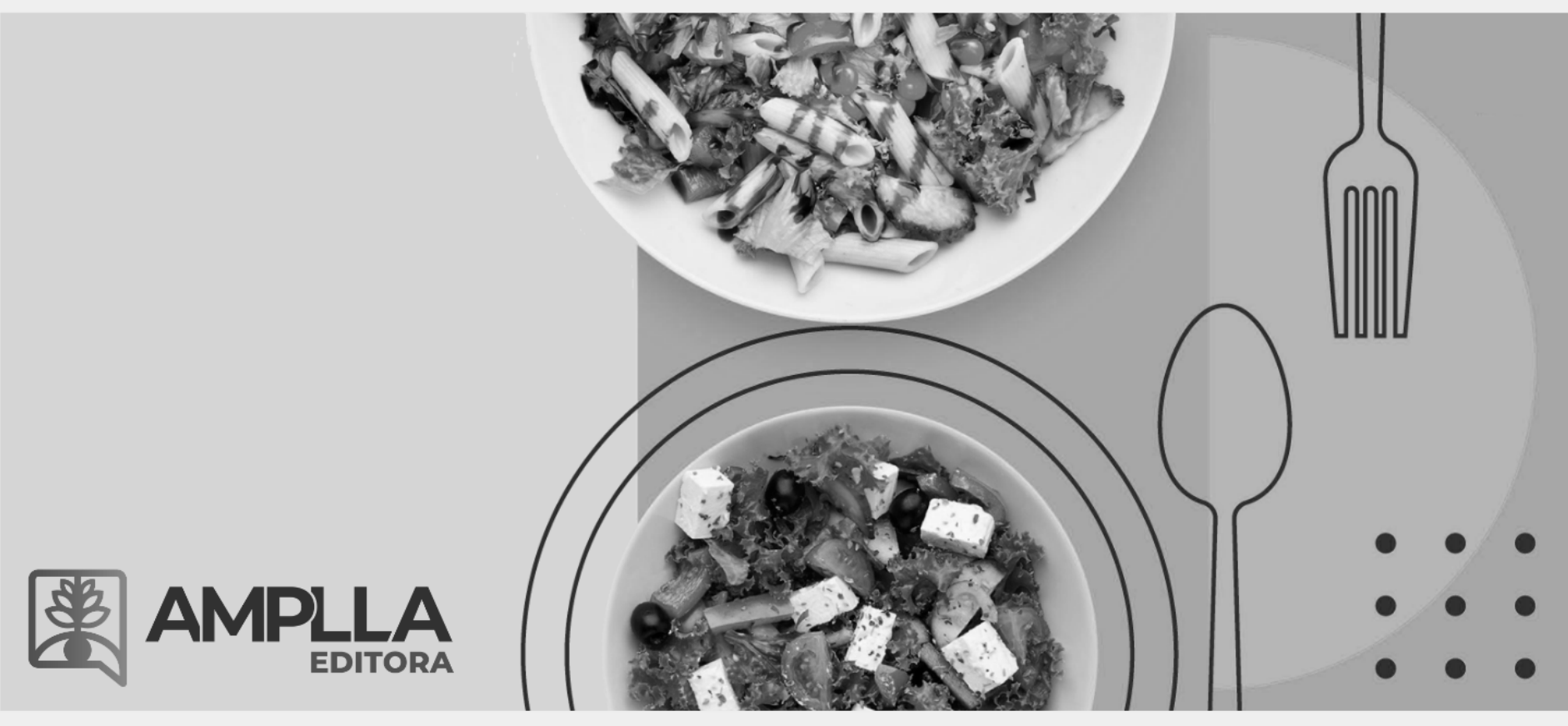




\section{AMPLLA}

2022 - Editora Amplla

Copyright (C) Editora Amplla

Editor Chefe: Leonardo Pereira Tavares

Design da Capa: Editora Amplla

Diagramação: Higor Costa de Brito

Desafios e estratégias para segurança alimentar mundial está licenciado sob CC BY 4.0.

(c) (i) Esta licença exige que as reutilizações deem crédito ao criador. Ele permite que os reutilizadores distribuam, remixem, adaptem e construam o material em qualquer meio ou formato, mesmo para fins comerciais.

O conteúdo da obra e seus dados em sua forma, correção e confiabilidade são de responsabilidade exclusiva dos autores, não representando a posição oficial da Editora Amplla. É permitido o download da obra e o compartilhamento desde que sejam atribuídos créditos aos autores. Todos os direitos para esta edição foram cedidos à Editora Amplla.

ISBN: $978-65-88332-78-8$

DOI: $10.51859 / a m p l l a . d e s 1788-0$

Editora Amplla

Campina Grande - PB - Brasil contato@ampllaeditora.com.br www.ampllaeditora.com.br

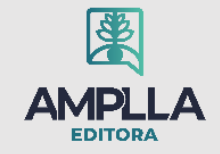

2022 


\section{CONSELHO EDITORIAL}

Andréa Cátia Leal Badaró - Universidade Tecnológica Federal do Paraná Andréia Monique Lermen - Universidade Federal do Rio Grande do Sul Antoniele Silvana de Melo Souza - Universidade Estadual do Ceará Bergson Rodrigo Siqueira de Melo - Universidade Estadual do Ceará Bruna Beatriz da Rocha - Instituto Federal do Sudeste de Minas Gerais Caio César Costa Santos - Universidade Federal de Sergipe Carina Alexandra Rondini - Universidade Estadual Paulista Carla Caroline Alves Carvalho - Universidade Federal de Campina Grande Carlos Augusto Trojaner - Prefeitura de Venâncio Aires Carolina Carbonell Demori - Universidade Federal de Pelotas

Cícero Batista do Nascimento Filho - Universidade Federal do Ceará

Clécio Danilo Dias da Silva - Universidade Federal do Rio Grande do Norte

Daniela de Freitas Lima - Universidade Federal de Campina Grande

Denise Barguil Nepomuceno - Universidade Federal de Minas Gerais

Dylan Ávila Alves - Instituto Federal Goiano

Edson Lourenço da Silva - Instituto Federal de Educação, Ciência e Tecnologia do Piauí Elane da Silva Barbosa - Universidade Estadual do Ceará

Érica Rios de Carvalho - Universidade Católica do Salvador

Gilberto de Melo Junior - Instituto Federal do Pará

Higor Costa de Brito - Universidade Federal de Campina Grande

Italan Carneiro Bezerra - Instituto Federal da Paraíba

Ivo Batista Conde - Universidade Estadual do Ceará

Jaqueline Rocha Borges dos Santos - Universidade Federal Rural do Rio de Janeiro Jessica Wanderley Souza do Nascimento - Instituto de Especialização do Amazonas João Henriques de Sousa Júnior - Universidade Federal de Santa Catarina João Manoel Da Silva - Universidade Federal de Alagoas

João Vitor Andrade - Universidade de São Paulo

Joilson Silva de Sousa - Instituto Federal do Rio Grande do Norte José Cândido Rodrigues Neto - Universidade Estadual da Paraíba Jose Henrique de Lacerda Furtado - Instituto Federal do Rio de Janeiro Josenita Luiz da Silva - Faculdade Frassinetti do Recife Josiney Farias de Araújo - Universidade Federal do Pará Karina de Araújo Dias - SME/Prefeitura Municipal de Florianópolis Laíze Lantyer Luz - Universidade Católica do Salvador Lindon Johnson Pontes Portela - Universidade Federal do Oeste do Pará Lucas Capita Quarto - Universidade Federal do Oeste do Pará Lúcia Magnólia Albuquerque Soares de Camargo - Unifacisa Centro Universitário Luciana de Jesus Botelho Sodré dos Santos - Universidade Estadual do Maranhão Luís Paulo Souza e Souza - Universidade Federal do Amazonas Luiza Catarina Sobreira de Souza - Faculdade de Ciências Humanas do Sertão Central Manoel Mariano Neto da Silva - Universidade Federal de Campina Grande Marcelo Alves Pereira Eufrasio - Centro Universitário Unifacisa Marcelo Williams Oliveira de Souza - Universidade Federal do Pará Marcos Pereira dos Santos - Faculdade Rachel de Queiroz Marcus Vinicius Peralva Santos - Universidade Federal da Bahia Marina Magalhães de Morais - Universidade Federal de Campina Grande Nadja Maria Mourão - Universidade do Estado de Minas Gerais Natan Galves Santana - Universidade Paranaense Nathalia Bezerra da Silva Ferreira - Universidade do Estado do Rio Grande do Norte Neide Kazue Sakugawa Shinohara - Universidade Federal Rural de Pernambuco Neudson Johnson Martinho - Faculdade de Medicina da Universidade Federal de Mato Grosso Patrícia Appelt - Universidade Tecnológica Federal do Paraná Paulo Henrique Matos de Jesus - Universidade Federal do Maranhão 
Rafael Rodrigues Gomides - Faculdade de Quatro Marcos

Reângela Cíntia Rodrigues de Oliveira Lima - Universidade Federal do Ceará

Rebeca Freitas Ivanicska - Universidade Federal de Lavras

Renan Monteiro do Nascimento - Universidade de Brasília

Ricardo Leoni Gonçalves Bastos - Universidade Federal do Ceará

Rodrigo da Rosa Pereira - Universidade Federal do Rio Grande

Sabrynna Brito Oliveira - Universidade Federal de Minas Gerais

Samuel Miranda Mattos - Universidade Estadual do Ceará

Shirley Santos Nascimento - Universidade Estadual Do Sudoeste Da Bahia

Silvana Carloto Andres - Universidade Federal de Santa Maria

Silvio de Almeida Junior - Universidade de Franca

Tatiana Paschoalette Rodrigues Bachur - Universidade Estadual do Ceará

Telma Regina Stroparo - Universidade Estadual do Centro-Oeste

Thayla Amorim Santino - Universidade Federal do Rio Grande do Norte

Virgínia Maia de Araújo Oliveira - Instituto Federal da Paraíba

Virginia Tomaz Machado - Faculdade Santa Maria de Cajazeiras

Walmir Fernandes Pereira - Miami University of Science and Technology

Wanessa Dunga de Assis - Universidade Federal de Campina Grande

Yasmin da Silva Santos - Fundação Oswaldo Cruz 


\section{AMPLLLA}

\section{2 - Editora Amplla}

Copyright @ Editora Amplla

Editor Chefe: Leonardo Pereira Tavares

Design da Capa: Editora Amplla

Diagramação: Higor Costa de Brito

Dados Internacionais de Catalogação na Publicação (CIP)

Desafios e estratégias para segurança alimentar mundial [livro eletrônico] / organização Neide Kazue Sakugawa Shinohara;

Fábio Henrique Portella Corrêa de Oliveira. -- Campina Grande : Editora Amplla, 2022.

$324 \mathrm{p}$.

Formato: PDF

ISBN : $978-65-88332-78-8$

1. Alimentos. 2. Culinária. 3. Segurança alimentar. I. Shinohara, Neide Kazue Sakugawa. II. Oliveira, Fábio Henrique Portella Corrêa de. III. Título.

Sueli Costa - Bibliotecária - CRB-8/5213

(SC Assessoria Editorial, SP, Brasil)

Índices para catálogo sistemático:

1. Alimentação 613.2

\section{E⿱⺈ \\ AMPLLA}

2022 


\section{PREFÁCIO}

A preocupação quanto à Segurança Alimentar (Food Security) surgiu decorrente das sequelas da Segunda Guerra Mundial, causando flagelos humanos e impactos devastadores no meio ambiente. Os países envolvidos nesse conflito de escala global ficaram sem condições de produzir alimentos para abastecer as populações, o que gerou grande desordem social e econômica. Esse momento avassalador na história humana trouxe a conscientização universal que a garantia na oferta de alimentos e água potável para a população mundial ajudaria na busca da paz e harmonia entre as nações de diferentes etnias, culturas e de poder econômico.

Os Objetivos de Desenvolvimento Sustentável (ODS), adotado em 2015 pelas Nações Unidas, compreende 17 Objetivos Globais. Foi uma chamada universal para acabar com a pobreza, proteger o planeta e garantir que até 2030 todas as pessoas desfrutem de paz, prosperidade econômica e justiça social. Infelizmente, grande parte da população global ainda consome pouco para atender às necessidades nutricionais básicas, devido às dificuldades de acesso a tecnologias eficientes e práticas resilientes, que levaria a uma economia mais eficiente em termos de gerenciamento dos alimentos, para assim combater a insegurança alimentar.

O termo Segurança Alimentar é uma concepção abrangente e intersetorial que define diretrizes e metas para garantia ao direito humano quanto ao acesso regular e permanente de alimentos de qualidade e quantidade adequados, na promoção de uma vida saudável e ativa. A descoberta de novas tecnologias, recurso humano qualificado e apoio financeiro de toda a sociedade, são necessários para alcançar os Objetivos Globais em todos os contextos necessários para prolongar a vida das futuras gerações na terra, com responsabilidade e senso de justiça igualitário.

As ações da Segurança Alimentar envolvem projetos em todos os estratos da sociedade civil organizada, precisando de consenso, alinhamento e compromisso com políticas de estado em nível global. As metas são obtidas com recursos e instrumentos de avaliação reconhecidos pela comunidade acadêmica, monitoramento constante, envolvendo programas, ações da gestão pública, da sociedade, instituições de ensino, 
uma vez que trata-se de participações conjuntas, para garantir a soberania alimentar de sua população.

Na perspectiva das ações da soberania, os programas de qualidade e gestão de riscos transmitidos por alimentos devem ser adotados para garantia do Alimento Seguro (Food Safety), porque além de fornecer nutrientes importantes ao organismo, faz-se necessário adotar barreiras sanitárias, para que os alimentos estejam livres de microrganismos patogênicos ou deteriorantes, metabólitos tóxicos, produtos químicos e corpos estranhos em concentrações que possam vir a causar doenças transmitidas por alimentos. A garantia da condição do alimento produzido deve garantir a qualidade desde o campo até a mesa do consumidor.

Diante da globalização alimentar atual, o Estado Brasileiro empenha-se na promoção de cooperação técnica com outros países, contribuindo assim para a realização do direito humano à alimentação segura no plano internacional, através de práticas de produção mais sustentáveis. O cumprimento das boas práticas agrícolas, adoção de sistemas de produção resiliente, manipulação de alimentos seguro, garantia de inocuidade e adoção das ferramentas de rastreabilidade, são ações e informações compartilhadas entre os países.

Os capítulos deste volume são contribuições científicas atualizadas abordando os Desafios e Estratégias para Segurança Alimentar Mundial, a partir dos diferentes ramos das ciências, compartilhando reflexões multidisciplinares que visam a promoção de estratégias para lidar com os desafios da segurança alimentar no Brasil e no mundo.

Desejamos a todos uma leitura proveitosa dos bons frutos acadêmicos que foram gerados e aqui generosamente compartilhados.

Neide Kazue Sakugawa Shinohara Graduação em Farmácia-bioquímica e Tecnologia em Gastronomia. Especialização em Bioética, Mestrado em Nutrição, Doutorado em Ciências Biológicas.

Fábio Henrique Portella Corrêa de Oliveira Graduação em Bacharelado em Ciências Biológicas. Mestrado em Biotecnologia de Produtos Bioativos e doutorado em Botânica. 


\section{SUMÁRIO}

CAPÍTULO I - AVALIAÇÃO MICROBIOLÓGICA DE CHARQUES COMERCIALIZADOS EM SUPERMERCADOS E FEIRA LIVRE NO MUNICÍPIO DE VITÓRIA DE SANTO ANTÃO (PERNAMBUCO, BRASIL)

CAPÍTULO II - ANÁLISE DE FUNGOS EM AMENDOINS COMERCIALIZADOS NO MUNICÍPIO DE IPOJUCA (PERNAMBUCO-BRASIL)

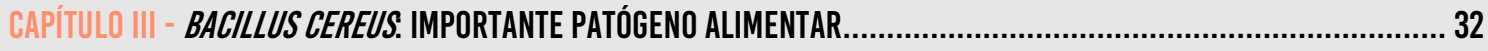

CAPÍTULO IV - QUEIJO MUÇARELA: AVALIAÇÃO DO PERFIL MICROBIOLÓGICO ............................................................ 46

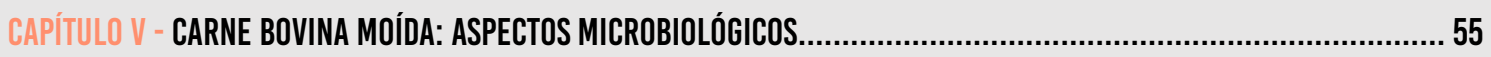

CAPÍTULO VI - UM ESTUDO SOBRE A QUALIDADE MICROBIOLÓGICA DE CARNE DE FRANGO NO BRASIL.............................. 63

CAPITULO VII - AVALIACCÃO DA SEGURANÇA MICROBIOLÓGICA E DO PERFIL DE BACTÉRIAS PRODUTORAS DE HISTAMINA EM CAVALA (SCOMBEROMORUS CAVALLA) E DOURADO (SALMINUS BRASILIENS/S) COMERCIALIZADOS EM MACEIÓ, ALAGOAS, BRASIL

CAPITULO VIII - CONTROLE BIOLÓGICO DE PODRIDÃO EM FRUTOS DE TOMATE ....................................................... 86

CAPITTULO IX - CRAVO-DA-ÍNDIA E CANELA COMO SABORIZANTES NA FORMULAÇÃO DE DOCES DE ABÓBORA ..................... 97

CAPITULO X - ANÁLISE SENSORIAL E ACEITABILIDADE DE IOGURTES FORTIFICADOS COM EXTRATO DE PRÓPOLIS VERMELHA DO MANGUEZAIS DE ALAGOAS

CAPÍTULO XI - DESENVOLVIMENTO E CARACTERIZAÇ̃̃O FísICO-QUÍMICA DE MACARRÃO COM SUBSTITUIÇÃO PARCIAL DA FARINHA DE TRIGO POR FARINHA DE POLPA DE BARU

CAPITULO XII - DETERMINAÇ̃̃O DE AMINAS BIOGÊNICAS EM QUEIJO DE COALHO ARTESANAL SUPLEMENTADO COM EXTRATO DE PRÓPOLIS VERMELHA DE ALAGOAS.

CAPITULO XIII - TOMATE ( YCOPERSICON ESCULENTUM E OS PRODUTOS DERIVADOS À BASE DE TOMATE........................158

CAPÍTULO XIV - ANTIOXIDANTES NATURAIS COMO ALTERNATIVA PARA AUMENTAR VIDA DE PRATELEIRA ......................... 171

CAPÍTULO XV - ESTUDO DE FATORES RELEVANTES NA MATERIA PRIMA UTILIZADA NA COMPOSIÇÃO DA CARNE MECANICAMENTE SEPARADA DE AVES.

CAPITULO XVI - SUPLEMENTOS ALIMENTARES À BASE DE PLANTAS MEDICINAIS: UMA REVISÃO DE LITERATURA NO ÂMBITO DA TOXICOLOGIA CLÍNICA

CAPÍTULO XVII - A PROPAGAÇÃO DE CONCEITOS ERRÔNEOS NA ROTINA ALIMENTAR PARA PRATICANTES DE EXERCíCIOS FISICOS

CAPITULO XVIII - O CONSUMO DE ALIMENTOS FUNCIONAIS E COMPOSTOS BIOATIVOS NA PRÁTICA DE ATIVIDADES FÍSICAS E NA PROMOÇÃO DE SAÚDE

CAPÍTULO XIX - COMPORTAMENTO E ALIMENTAÇ̃̃O DA POPULAÇÃO DE PARAUAPEBAS (PA) DURANTE O ISOLAMENTO SOCIAL EM DECORRÊNCIA DA PANDEMIA DA COVID-19 
CAPÍTULO XX - A GARANTIA DO DIREITO HUMANO À ALIMENTAÇÃO ADEQUADA E SAUDÁVEL EM TEMPOS PANDÊMICOS DE COVID-19: ALGUMAS QUESTÕES ESSENCIAIS

CAPÍTULO XXI - HÁBITOS ALIMENTARES DE ALUNOS DE UMA ESCOLA PÚBLICA DE TERESINA-PI: UMA PROPOSTA INTERDISCIPLINAR NO CURSO DE LICENCIATURA EM CIÊNCIAS BIOLÓGICAS .255

CAPÍTULO XXII - O REFLEXO CULTURAL DA IMIGRAÇÃO ITALIANA NA GASTRONOMIA BRASILEIRA 271

CAPÍTULO XXIII - CULTURA E CRENDICE POPULAR - HÁBITOS ALIMENTARES BASEADOS NA CIÊNCIA, SABEDORIA E PRÁTICA POPULAR

CAPÍTULO XXIV - TAILÂNDIA: TERRA DOS SABERES E AROMAS QUE SEDUZEM A CULINÁRIA MUNDIAL .297

CAPITULO XXV - PENÍNSULA COREANA: HISTÓRIA E GASTRONOMIA .310 


\section{CAPITULO}

\section{AVALIAÇÃO MICROBIOLÓGICA DE CHARQUES COMERCIALIZADOS EM SUPERMERCADOS E FEIRA LIVRE NO MUNICÍPIO DE VITÓRIA DE SANTO ANTÃO (PERNAMBUCO, BRASIL)}

DOI: 10.51859/AMPLLA.DES1788-1

Flávia Roberta Pereira Silva Tavares ${ }^{1}$ Fábio Henrique Portella Corrêa de Oliveira ${ }^{2}$

${ }^{1}$ Graduada do curso de Nutrição da Universidade Integrada da Vitória de Santo Antão - UNIVISA

${ }^{2}$ Professor do Departamento de Nutrição. Universidade Integrada da Vitória de Santo Antão - UNIVISA

\section{RESUMO}

Surtos de doenças transmitidas por alimentos não são raros ao redor do mundo. Por este motivo é importante monitorar padrões microbiológicos dos alimentos, para avaliar sua qualidade e os riscos à saúde associados a contaminações microbiológicas. $O$ charque é um produto cárneo salgado e seco, obtido por desidratação da carne bovina, preservando-se, assim, por longo tempo. Apesar da tecnologia de produção do charque, ainda pode haver contaminação e crescimento de microrganismos, a qualidade microbiológica dos alimentos deve ser assegurada pelo seu produtor. No presente trabalho objetivou-se avaliar a qualidade microbiológica de carne de charque comercializadas a granel na Cidade de Vitória de Santo Antão. Foram analisadas 04 amostras de charque adquiridas em estabelecimentos comerciais e feiras-livres. Destes foi avaliada a presença de Coliformes Totais, para avaliar possíveis contaminações por manipulação excessiva. Os resultados foram satisfatórios para o parâmetro avaliado em todas as amostras analisadas.

Palavras - chaves: Carne de charque. Análise microbiológica. Coliformes. 


\section{INTRODUÇ̃̃o}

As doenças transmitidas por alimentos (DTA) são causadas pela ingestão de alimentos ou água contaminados por agentes patogênicos, toxinas produzidas por patógenos, substâncias químicas ou que contenham na sua composição compostos naturalmente tóxicos, ou seja, ingestão de alimentos que apresentem perigos biológicos, químicos e/ou físicos (GARCIA; DUARTE, 2014).

Existem aproximadamente 250 patógenos alimentares. Normalmente, os alimentos envolvidos em contaminações, não possuem alterações organolépticas, estando com aparência, odor e sabor normais, dificultando a percepção, pelo consumidor, que o alimento está contaminado e pode ser uma fonte de perigo para a saúde. Alimentos que possuem alterações sensoriais dificilmente causam doenças alimentares, por serem facilmente rejeitados pelos consumidores (RITTER; TONDO, 2014).

De acordo com o Ministério da Saúde (MS), entre os anos de 2008 a 2018 foram registrados no Brasil, 6.809 casos de surtos de doenças alimentares, que ocasionaram 99 óbitos e deixaram 120.584 doentes. As regiões que apresentaram maior número de casos foram o sudeste e nordeste com $41,69 \%$ e $23,68 \%$ do total de casos, respectivamente (SOUZA, 2019).

O charque é um produto obtido pela salga de pedaços de carne desossada, que passa por um processo de secagem, sob condições que permitam sua conservação a temperatura ambiente (BRASIL, 2000). Para obter o charque, a carne passa por processamentos com o objetivo de promover a diminuição da atividade de água nos tecidos, através da adição de cloreto de sódio e da etapa de secagem ao sol. Com isso, o desenvolvimento de microrganismos patogênicos pode ser minimizado (GOMEZ, 2006).

O charque é um dos produtos mais tradicionais do Brasil, com grande aceitação pela população. Surgiu por volta do século XVIII, na região Nordeste, como forma de contornar as dificuldades decorrentes da alta perecibilidade da carne, agravada por fatores como a sazonalidade da oferta da carne bovina e dificuldade de distribuição e armazenamento devido ao clima quente e a grande extensão territorial (PARDI et al; 1996). Possui a vantagem de não necessitar da utilização da cadeia do frio para sua 
conservação, sendo uma interessante fonte de proteína de origem animal, que pode ser distribuída a longas distâncias, atendendo populações carentes de alimentos (APMV, 2016).

As carnes bovinas salgadas, a exemplo do charque, são altamente manipulados durante o processamento tecnológico, aumentando o risco de contaminação por microrganismos patogênicos. Ficam expostos no ambiente durante a etapa de secagem, estando suscetíveis também à contaminação por materiais estranhos e insetos. Além disso, ocorre também a manipulação nos pontos de venda, seja por manipuladores durante o fracionamento e embalagem, ou pelos consumidores no momento da escolha, aumentando o risco de contaminação microbiana (PENHA, 2017).

O uso de matéria-prima contaminada e condições de higiene insatisfatória pode resultar em um produto com alto teor de contaminação. No caso de não conseguir destruir esses micro-organismos durante seu processamento, distribuição e comercialização, a interferência destes contaminantes podem reduzir a qualidade e aumentar o risco de provocar surtos (ABRANTES et al., 2014).

Por ser um produto de fácil aceitação pelos consumidores, frequentemente sua comercialização ocorre em mercado públicos, nos quais, nem sempre, as boas práticas de manipulação são obedecidas. Apesar de ser um produto com baixa atividade de água, em virtude da desidratação, a carne de charque apresenta riscos de contaminação por microrganismos patogênicos. De acordo com a Resolução de Diretoria Colegiada (RDC 12/2001) do Ministério da Saúde, em produtos cárneos maturados, incluindo charques, eram exigidas análises de coliformes a $45^{\circ} \mathrm{C}$, estafilococos coagulase-positivos, cujas concentrações máximas permitidas eram de $10^{3}$ UFC.g ${ }^{-1}, 5 \times 10^{3}$ UFC/g e exigia-se ausência de Salmonella em 25g de amostra.

Em 23 de dezembro de 2019 foi publicada a RDC N³31 que trata sobre padrões microbiológicos dos alimentos e sua aplicação, que passaram a vigorar em substituição a RDC 12. A RDC 331 juntamente com a Instrução Normativa № 60, de mesma data de publicação, estabelecem os novos padrões microbiológicos de alimentos, com critérios que definem a aceitabilidade de um lote ou processo (BRASIL, 2019).

Entre as principais modificações observadas para carne de charque na nova legislação, especificamente nos padrões microbiológicos apresentados na IN 60/2019, destaca-se a substituição a pesquisa por Coliformes $45^{\circ}$ (abordados na IN 12/2001) pela 
pesquisa de Escherichia coli, tendo em vista que este microrganismo é comumente associado a surtos de doenças vinculadas a alimentos (DVAs).

Concentrações de microrganismos maiores do que as permitidas pela legislação podem indicar o uso de matérias-primas contaminadas durante o processamento do alimento ou erros durante o armazenamento, transporte e manuseio. Os três grupos bacterianos citados anteriormente são potencialmente patogênicos e podem causar doenças transmitidas por alimentos (DTA).

Do ponto de vista da saúde pública, o potencial patogênico destes microrganismos é agravado pois todos eles são mesófilas, significando que crescem satisfatoriamente à temperatura ambiente. Ao se considerar que os mercados públicos são ambientes fechados, com grande circulação de pessoas e temperaturas ambiente elevadas, o risco de crescimento destas bactérias deve ser considerado.

Apesar deste risco iminente, a literatura científica é escassa com relação a avaliações microbiológicas de carnes de charque comercializadas em mercados públicos e supermercados, sendo uma importante lacuna que precisa ser preenchida para garantir a qualidade do produto e evitar surtos de doenças transmitidas pelo consumo destes alimentos contaminados.

Diante deste cenário, este trabalho foi conduzido com o objetivo de avaliar as condições microbiológicas das carnes de charque comercializadas em feiras livres e supermercados do município de Vitória de Santo Antão (Pernambuco-Brasil) no que diz respeito a presença de Coliformes totais, uma vez que este microrganismo é utilizado como indicativo de falhas de higiene ou contaminação por manuseio.

\section{METODOLOGIA}

Quatro amostras de carne de charque foram adquiridas em feira livre e em supermercados, escolhidos aleatoriamente no município de Vitória de Santo Antão (Pernambuco, Brasil). Foram adquiridos aproximadamente $100 \mathrm{~g}$ de cada amostra e transportados, sem acondicionamento adicional, até o laboratório. As análises microbiológicas do charque foram realizadas no laboratório da Centro Universitário da Vitória de Santo Antão. 
Foram obtidos, assepticamente aproximadamente $25 \mathrm{~g}$ de cada amostra, e transportados para frascos contendo $225 \mathrm{~mL}$ de solução salina fisiológica ( $\mathrm{NaCl} 0,9 \%$ ), seguindo a homogeneização e diluições seriadas.

De cada diluição foram inoculados, pelo método spread plate, $1 \mathrm{~mL}$ de amostra em meio ágar MacConkey, e incubados por 24 horas a $35^{\circ} \mathrm{C}$ para determinação de coliformes totais.

Após o período de incubação, realizou-se a leitura dos resultados, primeiro avaliando o resultado da etapa presuntiva e, em caso de crescimento microbiano, seguia-se para a etapa quantitativa da interpretação, na qual as colônias típicas presentes nas placas seriam contadas, considerando-se os fatores de diluição de cada amostra.

\section{RESULTADOS E DISCUSSÃO}

Não foi observado crescimento de colônias em nenhuma das placas inoculadas, como pode ser evidenciado na Figura 1, que corrobora os estudos de Ambiel (2004 Pág. 34-53), que em estudos com carne de sol, evidenciou que a adição de cloreto de sódio retarda o crescimento microbiano, além de reduzir a atividade de água, mantendo o pH estável e garantindo a aceitação perante o consumidor com relação às características organolépticas.

Figura 01 - Placas após incubação, indicando ausência de crescimento microbiano em todas as diluições realizadas

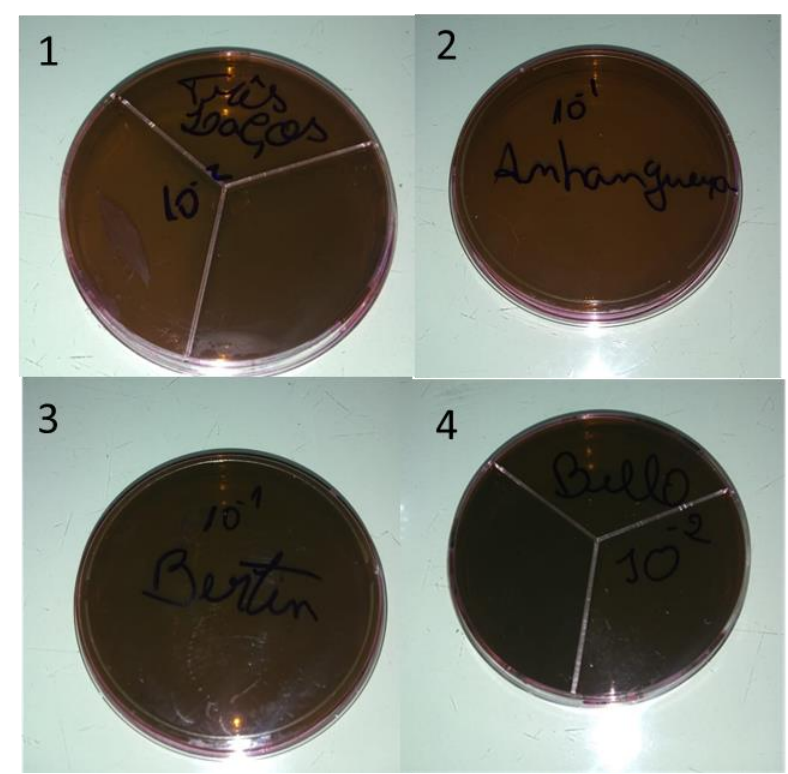

Fonte: Autoria própria. 
A migração do cloreto de sódio para o interior das fibras induz a uma diminuição da atividade de água, um dos fatores intrínsecos mais favoráveis ao desenvolvimento de microrganismos. Com isso, ocorre a redução da velocidade das reações indesejáveis, proporcionando assim, um maior tempo de prateleira do produto elaborado. A adição de sal, aliada com a baixa atividade de água e a temperatura de secagem utilizada no processamento do charque, são fatores que condicionam a catalisação do processo de oxidação lipídica do produto, no qual o sal aumenta a atividade catalítica do ferro e reduz a atividade de enzimas antioxidantes, e a baixa atividade de água facilita as interações entre os componentes do alimento (AZEVEDO, 2008).

Em seus estudos com carne de sol, Assis et al. (2019) encontraram resultados diferentes dos encontrados neste estudo. Os autores mostraram que houve crescimento de coliformes e outros microrganismos avaliados. O estudo aponta que o baixo percentual de cloreto de sódio adicionado no processamento da carne manteve a atividade de água, facilitando o crescimento microbiano. Além disso, a alta exposição ao ambiente contribuiu para as altas contagens dos microrganismos pesquisados.

Variações nos valores de atividade de água e de etapas de processamento da carne de sol podem ser justificadas pela forma artesanal de produção e não definição de padrões para o produto. Entretanto, é importante destacar que o decreto brasileiro $\mathrm{N}^{\circ} 9.013 / 2017$ define charque como um produto com 40 a $50 \%$ de umidade, 10 a $20 \%$ de sal, e atividade de água entre 0,70 a 0,75 (SANTOS; HENTGES, 2015), fatores que dificultam o crescimento microbiano e o não cumprimento dos padrões estabelecidos podem tornar o produto impróprio para a comercialização.

Santos et al. (2017) estudaram os métodos de conservação aplicados às carnes bovinas salgadas, a desidratação e secagem por salga, com adição de cloreto de sódio, nitrato e o nitrito de sódio e constataram que estes métodos são eficazes pois obtevese resultados negativos para crescimento dos microrganismos indicadores de contaminação, pode-se concluir que tratam-se de métodos satisfatórios, que agregam aos consumidores produtos de qualidade e com propriedades sensoriais desejáveis. A desidratação, secagem e salga são métodos eficazes, associados as boas práticas de processamento, conferem qualidade ao produto com garantia da segurança alimentar para o consumidor, além de aumentar o tempo de prateleira. 
Com os resultados obtidos observou-se que todas as amostras encontravam-se dentro dos padrões microbiológicos, no entanto, o resultado não significa que os produtos estudados estão isentos de microbiota, significa apenas que o microrganismo apresenta uma concentração muito inicial, tornando impossível a detecção pelo estudo, uma vez que há manipulação durante o fracionamento e seleção do produto durante a comercialização.

\section{CONCLUSÕES}

Os resultados obtidos a partir das análises realizadas evidenciaram que os produtos estão de acordo com os padrões exigidos, no que diz respeito a presença de Coliformes, não apresentando índices de contaminação por este microrganismo, estando os produtos próprios para consumo.

\section{AGRADECIMENTOS}

Ao Centro Universitário de Vitória de Santo Antão - UNIVISA

\section{REFEREENCIAS}

ABRANTES, M. R.; SOUSA, A. C. P.; ARAÚJO, N. K. S.; SOUSA, E. S.; OlIVEIRA, A. R. M.; SILVA, J. B. A, Avaliação Microbiológica de Carne de Charque Produzida Industrialmente. Universidade Federal Rural do Semi-Árido, Arq. Inst. Biol., São Paulo, v.81, n.3, p. 282-285, 2014.

ACADEMIA PERNAMBUCANA DE MEDICINA VETERINÁRIA (APMV). Consumo atual do charque e similares. Academia Pernambucana de Medicina Veterinária, n. 1, ano 5, p. 8, 2016.

$A M B I E L, C$. Efeitos das concentrações combinadas de cloreto e lactato de sódio na qualidade e conservação de um sucedâneo da carne de sol. Dissertação (Mestrado em Tecnologia de Alimentos). Universidade Estadual de Campinas, Campinas, 2004.

ASSIS, D.C.S.; SANTOS, T.M.; ORNELLAS, C.B.D.; DRUMMOND, A.F.; MAGALHÃES, F.C.; SANTOS, W.L.M. Caracterização microbiológica, físico-química e das condições de produção e comercialização da carne de sol de Salinas, Minas Gerais. Arq. Bras. Med. Vet. Zootec., v.71, n.6, p.1985-1992, 2019.

AZEVEDO, P. R. A. de. O valor nutricional da carne. Revista Nacional da Carne, São Paulo, no 372, p.18-29, 2008. 
BRASIL. Ministério da Agricultura, Pecuária e Abastecimento. Instrução Normativa no 22- Anexo II de 31 de julho de 2000. Regulamento Técnico de Identidade e Qualidade de Carne Bovina Salgada Curada Dessecada ou Jerked beef. Diário Oficial da União, Brasília, DF, 31 de julho. 2000.

Resolução RDC no 12 de 02 de janeiro de 2001. Regulamento técnico sobre os padrões microbiológicos para alimentos. Diário Oficial da República Federativa do Brasil, Poder Executivo, Brasília, DF, 10 de janeiro de 2001.

BRASIL. Decreto n. 9.013, de 29 de março de 2017. Dispõe sobre o regulamento da inspeção industrial e sanitária de produtos de origem animal. Diário Oficial da União, Brasília, Seção 1, 30 mar. 2017. BRASIL

BRASIL. Ministério da saúde-MS. Agência Nacional de Vigilância Sanitária - ANVISA. Resolução De Diretoria Colegiada - RDC № 331, de 23 de dezembro de 2019. Dispõe sobre os padrões microbiológicos de alimentos e sua aplicação.

BRASIL. Ministério da Saúde-MS. Agência Nacional de Vigilância Sanitária - ANVISA. Instrução Normativa Nº6 de 23 de dezembro DE 2019. Estabelece as listas de padrões microbiológicos para alimentos.

GARCIA, D.P; DUARTE, D.A. Perfil epidemiológico de surtos de doenças transmitidas por alimentos ocorridos no Brasil. Revista Eletrônica Acervo Saúde (REAS), v. 6, n. 1, p. 545-554, 2014.

GOMEZ, C.H.M.P. Jerked beef fermentado. Desenvolvimento de nova tecnologia de processamento. 2006. 101f. Dissertação (Mestrado em Ciência de Alimentos do Departamento de Tecnologia de Alimentos e Medicamentos) - Universidade Estadual de Londrina, 2006.

PARDI, M. C.; SANTOS, I. F.; SOUZA, E. R.; PARDI, H. S. Ciência e Tecnologia da Carne. 1a edição, Goiás, Editora UFG. v.1, p.590. 1996.

PENHA, J. C. Q. Avaliação da qualidade microbiológica, físico-química e parasitológica da carne bovina salgada comercializada em estabelecimentos e feiras livres na zona norte do município do Rio de Janeiro. Dissertação (Mestrado em Vigilância Sanitária). Dissertação (Mestrado em vigilância sanitária) Fundação Oswaldo Cruz, Instituto Nacional de Controle de Qualidade Em Saúde, Programa de Pós Graduação em Vigilância Sanitária, Rio de Janeiro, 2017.

RITTER, A.C.; TONDO, E.C. Foodborne illnesses in Brazil: control measures for 2014. FIFA World Cup travellers. Journal of Infections in Developing Countries, v. 8, n. 3, p. 254-257, 2014.

SANTOS, J.C.; BUENO, S.M.; ALMEIDA, C.B. Avaliação dos métodos de conservação de carnes bovinas salgadas e análise microbiológica. Revista União das faculdades dos Grandes Lagos, v. 1, n. 12017. 
SANTOS, L. M. A.; HENTGES, L. C. Avaliação Físico Química e Microbiológica de Carne Seca (Charque). Trabalho de conclusão de curso Universidade Tecnológica Federal do Paraná - Medianeira 2015.

SOUZA, M. Doenças Transmitidas por Alimentos no Brasil: uma revisão de literatura. Trabalho de conclusão de Curso (Bacharel em Farmácia), Centro Universitário São Lucas, Ji-Paraná- Rondônia, 2019. 


\section{CAPITULO II}

\section{ANค́LISE DE FUNGOS EM AMENDOINS COMERCIALIZADOS NO MUNICÍPIO DE IPOJUCA (PERNAMBUCO-BRASIL)}

DOI: 10.51859/AMPLLA.DES1788-2

Bárbara Dalline Jaques Cavalcante ${ }^{1}$ Fabio Henrique Portella Corrêa De Oliveira ${ }^{2}$

${ }^{1}$ Graduanda do curso de Bacharelado em Farmácia. Centro Universitário São Miguel.

2 Doutor em Botânica - Universidade Federal Rural de Pernambuco (UFRPE).

\section{RESUMO}

O amendoim (Arachis hypogaea L.) é uma oleaginosa mundialmente consumida, graças às suas propriedades nutricionais. Além de torrado ou cozido, outras apresentações deste alimento costumam ser consumidas, tais como pastas, farinhas, doces, óleos, dentre outras. Devido, principalmente, à sua baixa atividade de água, o amendoim é facilmente contaminado por fungos, muitos dos quais potencialmente produtores de micotoxinas, que podem ser prejudiciais à saúde humana. Este estudo teve como objetivo analisar a presença de fungos em amostras de amendoins comercializadas na forma a granel e industrializada no município de Ipojuca (Pernambuco, Brasil) Foram realizadas análises microbiológicas para verificação da presença de bolores e leveduras nas amostras de amendoim. As três amostras foram inoculadas por plaqueamento direto no meio de cultura Ágar Batata Dextrose (BDA) e incubadas durante cinco dias a $25^{\circ} \mathrm{C}$, os resultados foram expressos como Presença (P) ou Ausência (A) Em todas as amostras foi observado crescimento de fungos, a identificação do microrganismo foi realizada por microscopia, a partir da qual constatou-se presença e Rhizopus sp na amostra de amendoim a granel, e outras leveduras nas demais amostras. Como não foram identificados fungos produtores de micotoxinas, as amostras atendem a RDC $274 / 2002$ da ANVISA, que estabelece VMP de $20 \mu \mathrm{g} / \mathrm{kg}$ de aflatoxinas totais em amendoins. Porém, deve-se atentar para a presença de outros microrganismos como o Rhizopus sp, que apesar de terem hábitat terrestre, algumas espécies são oportunistas e podem provocar prejuízo à saúde humana.

Palavras-chave: Arachis hypogaea. amendoim. aflatoxinas. Rhizopus sp. 


\section{INTRODUÇÃO}

O amendoim é um fruto originado de uma planta dicotiledônea, cujas espécies de maior relevância econômica são Arachish hypogaea L. , A. prostrata Benth e A. nhambiquarae Hoehne, sendo A. hypogaea a que geralmente é cultivada e comercializada. É uma oleaginosa de alto valor nutricional, por ser fonte de carboidratos, óleos, proteínas e fibras, sendo comum na alimentação, principalmente dos brasileiros (GABRIEL, 2017).

O solo é depósito natural de muitos microrganismos, dentre eles fungos filamentosos, como o gênero Aspergillus, que atua como um dos principais contaminantes de vários grãos, como o amendoim, uma vez que, seu fruto desenvolvese de forma subterrânea. Contaminação esta que pode ocorrer em diferentes etapas, desde o cultivo ao armazenamento, que se dá pelo uso de sementes contaminadas, gerando plantas doentes ou mesmo pelo armazenamento em local inadequado. Várias espécies de Aspergillus, bem como outros fungos, são potencialmente produtores de micotoxinas, que são metabólitos secundários passíveis de causarem efeitos tóxicos em humanos e animais. A contaminação de alimentos por micotoxinas tem sido relatada no mundo todo, principalmente em alimentos agroalimentares, como grãos e cereais (ZORZETE, 2010; PEREIRA et al., 2018).

Atualmente um maior número de pessoas tem se preocupado com a saúde e buscado melhores hábitos, que geralmente resume-se, a combinação entre alimentação balanceada e a prática de exercícios. Em função disto, muitas pessoas têm consumido cada vez mais, cereais e oleaginosas, onde geralmente a principal fonte de busca por estes alimentos, são as lojas de produtos naturais. Uma vez que estas costumam oferecer preço mais competitivo, além de prometer ao consumidor, "produtos menos processados". É nessa promessa do menos processado onde surgem diversas preocupações com a segurança e qualidade destes grãos, vistos que devido sua natureza, as oleaginosas e cereais são mais suscetíveis a contaminação fúngica, e sendo alguns fungos produtores de micotoxinas (VECCHIA, 2007; MAZIERO, 2010).

A maior preocupação é com os grãos vendidos a granel e sua origem, pois pequenos comerciantes, na maioria dos casos, tendem a comprar de pequenos produtores rurais, que geralmente não tem controle de qualidade, tão pouco selo da 
ABICAB (Associação Brasileira da Indústria de Chocolates, Amendoim e Balas), que garante a qualidade e procedência do alimento (INMETRO, 2012).

Visando à segurança alimentar da população consumidora, este trabalho tem como objetivo, coletar amostras de grãos de amendoim vendidos a granel comercializados no município de Ipojuca (Pernambuco, Brasil) para analisar quanto a presença de fungos com potencial patogênico a humanos, onde simultaneamente será analisada amostra de processamento industrial, como comparativo. A partir dos resultados obtidos, verificar se estes produtos são seguros e atendem aos limites estabelecidos pela ANVISA nas normas de segurança e controle de qualidade do alimento.

\section{REVISÃO BIBLIOGRÁFICA}

\subsection{AMENDOIM}

A espécie Arachis hypogaea L. tem origem na América do Sul, e já era cultivada desde os indígenas, antes da chegada dos Europeus. O gênero Arachis possui cerca de 80 espécies, desde o Brasil até a Argentina (SANTOS; FREIRE; SUASSUNA, 2009).

O fruto do amendoim é rico em óleo, proteínas e vitaminas, sendo uma importante fonte de energia e aminoácidos para alimentação humana. Leguminosa genuinamente sul-americana, ela produz um dos grãos mais consumidos do mundo atual. Está entre uma das oleaginosas mais cultivadas no Brasil, estando próximo a soja e feijão (SUASSUNA, 2014).

Sua principal forma de consumo é por meio dos grãos, torrados ou cozidos. A farinha, contudo, é altamente proteica e pode ser utilizada de várias maneiras, como na panificação e confecção de doces e salgados. Na indústria os grãos podem ser utilizados para obtenção de óleo e farelo, na fabricação de produtos alimentícios, no ramo de conservas e na indústria farmacêutica. A qualidade do seu óleo é superior ao do azeite de oliva, o que pode ajudar na prevenção de doenças cardíacas. Além disso, os grãos apresentam grandes concentrações de vitamina $\mathrm{E}$, (um antioxidante que previne câncer, diabetes e doenças autoimunes) e de proteína, podendo substituir a carne em países onde há escassez desse alimento (SUASSUNA, 2014). 
Porém, essa planta de pequeno porte em que os frutos se formam abaixo do solo, é bastante suscetível ao crescimento do Aspergillus flavus, uma vez que o fungo existe em abundância no solo. Por este motivo, o amendoim é tão propício ao crescimento de aflatoxinas (PEIXOTO, 2008; ZORZETE, 2010).

\subsection{FUNGOS}

Entende-se como fungos, os bolores (mofo) e as leveduras, eles são seres eucariontes pertencentes ao Reino Fungi, onde geralmente os mais conhecidos são, o Penicillium e Aspergillus. Os fungos fazem parte da microbiota natural de vários alimentos, porém, em determinadas condições, de umidade, pH, temperatura, incidência de luz e disponibilidade de carboidratos, estes fungos podem ser produtores de micotoxinas (TORTORA et al., 2017).

\subsection{MICOTOXINAS}

Micotoxinas são definidas como substâncias químicas tóxicas produzidas por fungos (Aurélio, 2010). Este termo é utilizado para nomear um grupo de compostos, metabólitos secundários produzidos por algumas espécies de fungos durante seu crescimento. Estes metabolitos podem estar presentes em diversos grupos de alimentos (IAMANAKA \& OLIVEIRA \& TANIWAKI, 2013).

A produção dos metabólitos está diretamente relacionada ao crescimento fúngico, porém, as micotoxinas podem permanecer no alimento mesmo após eliminação do fungo que a produziu. Geralmente, os principais fungos ligados a ocorrência natural de toxinas são os gêneros, Aspergillus, Penicillium e Fusarium (BENETT \& KLICH, 2003).

Estudos apontam a existência em média de 400 diferentes micotoxinas. Elas podem conter características teratogênicas, mutagênicas, carcinogênicas e alergênicas. As principais micotoxinas são, Aflatoxinas, Fumonisinas, Tricotecenos, Zearalenona, Citrinina, Ocratoxina A e Patulina (FORSYTHE, 2013).

\subsubsection{AFLATOXINAS (AFLA)}

Foi a primeira toxina de interesse da agricultura comercial, quando em 1962, na Inglaterra, durante a investigação da morte de uma população de perus jovens, descobriu-se que a causa da morte havia sido a contaminação da torta de amendoim, 
usada na alimentação das aves, por um metabólito secundário produzido pelo fungo Aspergillus flavus. A nomenclatura foi dada segundo seu agente produtor (Aspergillus flavus toxina) (FREIRE et al, 2007). As principais aflatoxinas conhecidas são denominadas de $B 1, B 2$, G1 e G2, com base na fluorescência das toxinas sob luz ultravioleta ( $B=B$ lue, $\mathrm{G}=$ Green) e na sua mobilidade durante a realização de cromatografia de camada delgada.

Os substratos mais favoráveis ao crescimento desses fungos produtores de (AFLA), são, cereais, especiarias, sementes oleaginosas e amêndoas (BENETT \& KLICH, 2003; PINHEIRO et al., 2017).

Fumonisinas - são metabólitos produzidos por F. verticillioides, F. proliferatum além de outras espécies de Fusarium menos frequentes. Engloba o grupo de substâncias denominadas de B1 (FB1, FB2, FB3 e FB4), A1, A2, A3, AK1, C1, C3, C4, P1, P2, P3, PH1a e PH1b.

A presença de fumonisinas em grãos de milho, tem sido relacionada ao crescente número de câncer de esôfago em habitantes do Sul da África, China e Itália. Além de estar associada a disfunções em várias espécies de animais (IAMANAKA et al., 2013).

A doença dos equinos leucoencefalomalácea (LEME) tem sido reconhecida estar associada com o milho contaminado por $F$. verticillioides. A LEME causa uma necrose líquida massiva dos hemisférios cerebrais, assim a doença envolve manifestações neurológicas incluindo movimentos anormais (FORSYTHE, 2013).

\subsubsection{OCRATOXINA A (OTA)}

Foi descoberta como um metabólito de Aspergillus ochraceus, em 1965, durante estudos para identificar novas micotoxinas. Em pouco tempo foi isolada de uma amostra de grão de milho nos Estados Unidos e reconhecida como altamente nefrotóxica, estando associada a nefropatias em todos os animais estudados.

A OTA vem sendo encontrada em trigo, grãos de café, centeio, aveia, cevada e outros produtos de consumo humano e animal. Como o Aspergillus niger, um dos produtores de OTA é largamente utilizado na produção industrial de ácido cítrico e enzimas para o consumo humano, é preciso garantir que estes não sejam produtores de Ocratoxina A (BENETT \& KLICH, 2003; CORRÊA, 2018). 


\subsection{FATORES QUE FAVORECEM O CRESCIMENTO DOS FUNGOS PRODUTORES DE MICOTOXINAS}

Além da presença de substratos, como cereais, oleaginosas, condimentos, e grãos de interesse alimentício, a condição ideal de fatores, como, umidade, temperatura, e pH contribuem de forma direta para o desenvolvimento e crescimento de fungos produtores de micotoxinas (SILVA, 2017).

Os principais fungos produtores de micotoxinas, podem crescer em substratos que apresentem de 13 a $18 \%$ de umidade. O fator umidade associado a altas temperaturas são considerados o principal fator de crescimento de fungos de diferentes gêneros em grãos, estas são condições geralmente encontradas no armazenamento destes grãos (NEOPROSPECTA, 2019).

Estudos apontam o uso de microrganismos que podem ser utilizados para o controle de crescimento fúngico durante o armazenamento de grãos pós-colheita. Dentre os microrganismos capazes de promover esta competitividade com fungos toxinogênicos, verificou-se que a levedura Pichia guillermondii apresentou maior potência (OLIVEIRA, 2019).

As micotoxinas podem afetar um amplo grupo de alimentos, tais como, as oleaginosas, leguminosas, cereais e ainda algumas frutas. Na tabela 1, abaixo podemos observar os principais tipos de micotoxinas que contaminam grãos.

Tabela 1 - Principais tipos de micotoxinas e grãos que geralmente são contaminados

\begin{tabular}{|c|c|}
\hline Micotoxinas & Grãos contamináveis \\
\hline Aflatoxinas & amendoim, milho e trigo \\
\hline Fusarium & soja, trigo e cevada \\
\hline Ocratoxina & café e cevada \\
\hline Zearalenona & moja e milho trigo \\
\hline Patulina & milho e soja \\
\hline Oosporeia & arroz e cevada \\
\hline Sterigmatocistina & trigo e arroz \\
\hline Fumonisina & \\
\hline
\end{tabular}

Fonte: IMETRO, 2012.

VECCHIA \& FORTES (2007) realizaram um estudo identificação de fungos em granola comercial, e constataram a presença de A. niger, Aspergillus flavus e Penicillium 
spp., importantes produtores de micotoxinas, tanto em amostras de graneis como de embalagens lacradas.

MARQUES et al. (2009) identificou a presença de aflatoxinas em grãos de milho ainda presos as espigas, antes da colheita. BONIFÁCIO et al. (2015), concluiu que o amendoim comercializado a granel no município de Ji-Paraná, apresentam contaminação por fungos dos gêneros: Aspergillus, Cladosporium, Penicillium, Rhizopus e Leveduras.

Os fungos necessitam de condições especificas para poderem colonizar um alimento, alguns dos aspectos que devem ser considerados são: temperatura, umidade do substrato, processamento, oxigenação no armazenamento, e a presença de agentes competidores. Os fatores que favorecem a produção de micotoxinas são: umidade, temperatura, pH e composição química do alimento (CARDOSO FILHO, 2016).

\subsection{LEGISLAÇÃO}

A Agência Nacional de Vigilância Sanitária (ANVISA), estabelece normas para garantir a segurança de alimentos no Brasil.

Segundo a RDC $n^{\circ} 274 / 2002$, a concentração total de aflatoxinas no amendoim deve ser menor ou igual a $20 \mu \mathrm{g} / \mathrm{kg}$ de aflatoxinas totais. Resultados superiores implicam na rejeição do lote (ANVISA, 2002).

$\mathrm{Na}$ RDC, é imposto limite de $20 \mu \mathrm{g} / \mathrm{kg}$ de Aflatoxinas B1, B2, G1, G2 em amendoins e seus derivados, como, manteigas, doces e pastas de amendoim $C \mathrm{n}^{\circ}$ 07/2011 (ANVISA, 2011).

\section{METODOLOGIA}

Trata-se de um estudo experimental, descritivo, que será realizado no Laboratório de Microbiologia/Microscopia II do Centro Universitário São Miguel (UNISÃOMIGUEL). As amostras de amendoim serão obtidas em pontos comerciais do município de Ipojuca-PE, situados na Região Metropolitana do Recife (RMR). Deveram ser compradas duas amostras de $100 \mathrm{gr}$ de amendoim a granel em diferentes lojas de grande fluxo no município, escolhidas aleatoriamente. A marca de amendoim industrializado com sal usado como amostra, foi escolhida por ser a mais consumida na localidade. 
Após selecionadas e identificadas, as amostras devem ser higienizadas com água estéril e secadas em papel toalha. Pelo método de plaqueamento direto (PITT \& HOCKING, 2009), será semeado 05 grãos por placa de Petri, contendo o meio Ágar Batata Dextrose acidificado com ácido tartárico na concentração de 10,0\% (BDA acidificado), para o isolamento seletivo e contagem de leveduras e bolores totais em alimentos. As placas ficarão incubadas por 5 dias a $25^{\circ} \mathrm{C}$.

O meio de cultura Ágar Batata Dextrose acidificado (BDA acidificado), apesar de muito utilizado para contagem de bolores e leveduras em alimentos, não é um meio de diferenciação, logo, para identificação do microrganismo são necessários testes bioquímicos e microscópicos, neste estudo utilizaremos microscopia óptica para identificação de fungos (MERCK MILLIPORE).

A análise da taxa de infecção em percentual de cada amostra será dada pela média aritmética do número de grãos contaminados nas 2 repetições presentes de cada amostra. Cada grão contaminado representará 10,0\% de contaminação. Cada uma das 3 amostras recebeu códigos para identificação (Tabela 2).

Tabela 2 - Codificação utilizada para identificação das amostras de amendoins comercializados a granel ou industrializados no município de Ipojuca (Pernambuco, Brasil) durante o período de estudo.

\begin{tabular}{|c|c|}
\hline Código & Amostra \\
\hline A1 & Amendoim S/ sal granel \\
\hline A2 & Amendoim S/ sal granel \\
\hline A3 & Amendoim C/ sal Industrializado \\
\hline
\end{tabular}

Fonte: Autoria própria.

A identificação das colônias típicas ocorrerá por microscópio óptico, utilizando o corante azul de metileno 1\%, seguindo a chave dicotômica de identificação proposta por HENNING (2015) em seu Guia prático para identificação de fungos.

\section{RESULTADOS E DISCUSSÃO}

Dentre as amostras de amendoim analisadas, 1 é de origem industrial, enquanto 2 foram graneis oriundas de lojas localizadas em Ipojuca - PE. Em todas as amostras houve presença de crescimento de fungos. Portanto, apenas a amostra A1 apresentou presença de bolores, enquanto nas demais, foi observada apenas presença de leveduras (Tabela 3). 
Tabela 3 - Presença $(P)$ ou ausência $(A)$ de bolores e leveduras nas amostras de amendoins comercializados a granel ou industrializados no município de Ipojuca (Pernambuco, Brasil) durante o período de estudo.

\begin{tabular}{|c|c|c|}
\hline Amostra & Bolor & Levedura \\
\hline A1 & P & P \\
\hline A2 & A & P \\
\hline A3 & A & P \\
\hline
\end{tabular}

Fonte: Autoria própria.

Todas as colônias foram analisadas ao microscópio óptico e pode-se constatar que o bolor presente na amostra A1 pertence ao gênero Rhizopus sp., (Figura 1). As colônias de leveduras não foram identificadas em níveis taxonômicos inferiores, sendo expressas neste trabalho como leveduras.

Figura 1 - Amostra A1. A:colônias crescidas em meio BDA. B: Imagem em microscopia óptica (40x) de Rhizopus sp., onde pode observar as hifas cenocíticas e presença de esporângios. Utilize os estilos pré-definidos para identificar os tópicos

A

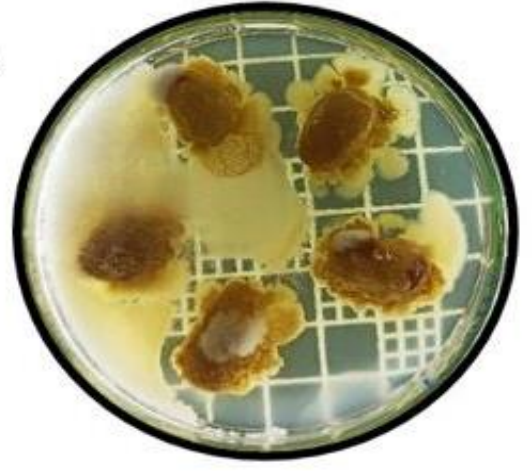

B

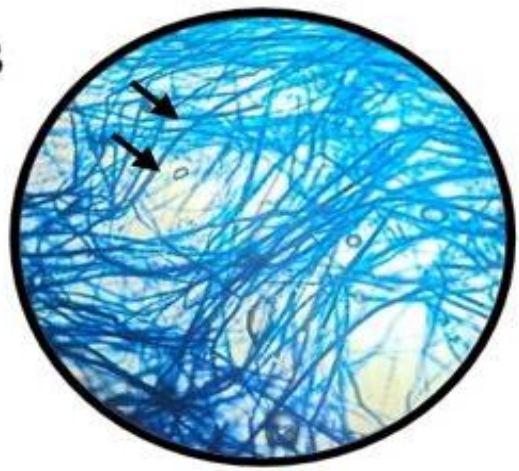

Fonte: Autoria própria.

O Rhizopus sp é um fungo encontrado em alimentos com baixa atividade de água. Caracteriza-se por possuir hifas cenocítica, esporângio globoso, volumoso, com columela grande e esporangióforo não ramificado. Este fungo é comumente encontrado no solo, e tem sido responsável pela deterioração de diversos vegetais, como, amendoim, soja, maçãs, batata doce, ervilhas e goiabeiras (CARVALHO et al., 2018).

Apesar de o Rhizopus sp. não ser um produtor de micotoxinas, a presença deste fungo em alimentos desperta preocupação, visto que, apesar de ser relativamente raro, existem registros na literatura que mostram que ele se comporta como oportunista, podendo comprometer a saúde de indivíduos, principalmente com sistema imune 
comprometido, tais como idosos, pacientes com AIDS ou fazendo uso de corticoides, como atualmente observados em pacientes graves com acometidos com Covid-19 (TORTORA et al., 2017; BARROS, 2018).

Em 2018, foi relatado o caso de infecção por Rhizopus sp em paciente do sexo feminino, 7 meses, portadora de Amiotrofia Muscular Espinhal (AME). A infecção desenvolveu-se nas regiões malares e apresentou centro necrótico, sendo necessário realizar desbridamento cirúrgico e tratamento por 28 dias com antifúngico anfotericina B para recuperação (ALVES et al, 2019).

KANWAR et al., 2021 relatou recentemente que um homem de 56 anos, portador de doença renal terminal, foi hospitalizado com fadiga e falta de ar, evoluindo para fadiga generalizada, derrame pleural, pneumonia cavitaria e necrose. Ao realizar hemocultura, foram detectadas infiltrações fúngicas nos pulmões ocasionadas pela espécie R. azygosporus. (KANWAR et al., 2021).

Os resultados obtidos neste trabalho nos permitiram levantar um alerta quanto uma falha presente nas determinações exigidas pela legislação vigente, visto que a RDC 274/2002 e RDC 07/2011, determinam o limite permitido de aflatoxinas em grãos de amendoim e derivados, respectivamente, não exigindo identificação taxonômicas dos bolores e leveduras encontrados nas amostras, o que permitiria determinar o real risco de patogenicidade presente nas amostras (ANVISA, 2002; ANVISA, 2011).

Segundo a RDC 274/2002, as amostras analisadas no presente estudo são seguras ao consumo, uma vez que não foram identificados fungos produtores de aflatoxinas. Porém, evidências cientificas mostram o risco de infecção fúngica aos quais os consumidores podem estar expostos, sobretudo, indivíduos portadores de comorbidades, ao consumir amendoim contaminado por Rhizopus sp. (CARVALHO et al., 2018).

A contaminação por de bolores e leveduras neste tipo de alimento pode ocorrer em uma ou várias etapas do processamento, como colheita, armazenamento e transporte. Especialmente a colheita, devido ao fato de o solo ser habitat de diversos organismos, além da adição de esterco e a rotatividade ou consórcio com outras culturas (OLIVEIRA; ARRIEL, 2019). 


\section{CONCLUSÃO}

Verificou-se que as amostras de amendoim comercializados a forma de granel na cidade de Ipojuca-PE, não apresentam boa qualidade sanitária, uma vez que apresentou alta taxa de contaminação fúngica totais. Mesmo não tendo sido identificados fungos produtores de aflatoxinas atendendo a RDC 274/2002 e RDC 07/2011 da ANVISA, que trata da concentração de aflatoxinas. Sugiro que estudos posteriores sejam realizados, a fim de verificar o real gral de contaminação fúngica e toxicidade presente em amostras de amendoim. Visando assim priorizar a qualidade e segurança dos produtos vendidos nesta região.

\section{REFERÊNCIAS}

ALVES, Aline Mara da Silva et al. Relato de caso: infecção cutânea por Rhizopus sp em paciente pediátrico. Residência Pediátrica, Campo Grande - MS, 2019 v. 9, n. 18, ed. 3, p. 296-298, mar. 2019.

AGÊNCIA NACIONAL DE VIGILÂNCIA SANITÁRIA - ANVISA. RDC n 274, de 15 de outubro de 2002. Brasília, 2002. Disponível em:<http://www.anvisa.gov.br> Acesso em:12 set. 2020.

BARROS, Patrícia Fraga. Mucormicose oral: relato de caso clínico. Orientador: Mário Rogério Lima Mota. 2018. 20 p. Trabalho de Conclusão de Curso (Odontologia) Faculdade de Farmácia, Odontologia e Enfermagem, Universidade Federal do Ceará., Fortaleza, 2018.

BENNETT JW, KLICH M. Mycotoxins. American Society For Microbiology Journals, New Orleans, Louisiana, jul. 2003.

BONIFÁCIO, Tatiana Zorzanello et al. Avaliação da contaminação fúngica em amendoim comercializado a granel no município de JI-Paraná/RO. South American Journal of basic education, technical and technological, v. 2, n. 1, 2015.

CARDOSO FILHO, Francisco das Chagas; DE CALDAS, Mikaela Lopes; MURATORI, Maria Christina Sanches. Fungos e aflatoxinas em cereais: Uma revisão. Revista de Ciência Veterinária e Saúde Pública, v. 2, n. 2, p. 122-130, jun. 2015.

DE CARVALHO, Hellen Karin; MARTINS, Débora Lemos; JUNIOR, Diniz Pereira Leite. de et al. Isolamento e identificação de microrganismos fúngicos em alimentos em grãos conservados e expostos em feiras livres e supermercados das cidades de Cuiabá e Várzea Grande/MT. 2018. 18 p. Trabalho de Conclusão de Curso (Biomedicina) - Centro Universitário de Várzea Grande (UNIVAG), Várzea Grande, Mato Grosso, Brasil, 2018. 
FORSYTHE, Stephen J. Microbiologia da segurança dos alimentos. Artmed Editora, 2013.

GABRIEL, D. Pragas do amendoim. Agência Paulista de Tecnologia dos Agronegócios, Campinas, SP. Brasil., jul. 2016.

HENNING, Ademir Assis. Guia prático para identificação de fungos mais frequentes em sementes de soja. Londrina: Embrapa Soja, 2015., 2015.

IAMANAKA, Beatriz Thie; OLIVEIRA, Idjane Santana; TANIWAKI, Marta Hiromi. Micotoxinas em alimentos. Anais da Academia Pernambucana de Ciência Agronômica, v. 7, p. 138-161, 2013.

INMETRO. Diretoria de Alimentos e Toxicologia. Resolução n. 89 de 28 de julho de 2000 da Agência Nacional de Vigilância Sanitária (ANVISA). In: <http://www.inmetro.gov.br/>. Acesso em: 12 set. 2020.

KANWAR, Anubhav et al. A Fatal Case of Rhizopus azygosporus Pneumonia Following COVID-19. Journal of Fungi, USA, v. 7, n. 3, ed. 174, p. 1-6, fev. 2021.

MAZIERO, Maike Taís; BERSOT, L. Dos S. Micotoxinas em alimentos produzidos no Brasil. Revista Brasileira de Produtos Agroindustriais, v. 12, n. 1, p. 89-99, 2010.

MERCK MILLIPORE. Technical Data Sheet: Potato Dextrose Agar. Darmstadt, Germany, p. 3. (1.10130.0500). Disponível em: <http://www.merckmillipore.com>. Acesso em: 08 set. 2020.

NEOPROSPECTA, Fungos, micotoxinas e a indústria de alimentos.Abr. 2019. Disponível em: <http://blog.neoprospecta.com/fungos-micotoxinas-industria-alimentos/> Acesso em: 06 dez. 2020.

OLIVEIRA, Anderson Ramos de; ARRIEL, Nair Helena Castro. As principais oleaginosas da agricultura familiar: Cultivo do amendoim. In: Agricultura familiar dependente de chuva no semiárido. 1. ed. Brasília, DF: Embrapa, 2019. cap. 3, p. 108-112.

PEIXOTO, Clovis Pereira et al. Características agronômicas e produtividade de amendoim em diferentes espaçamentos e épocas de semeadura no recôncavo baiano. Bragantia, v. 67, n.3, p. 673-684, 2008.

PEREIRA, Brendha Soares et al. Pesquisa de aflatoxinas e fungos toxigênicos em amendoins comercializados em Curitiba/PR e região metropolitana. Cadernos da Escola de Saúde, v. 18, n. 1, p. 45-55, 2018.

DOS SANTOS, R. C.; FREIRE, R. M. M.; SUASSUNA, T. Amendoim: o produtor pergunta, a Embrapa responde. Área de Informação da Sede-Col Criar Plantar ABC 500P/500R Saber (INFOTECA-E), 2009.

SILVA, Neusely da. Et al. Manual de métodos de análise microbiológica de alimentos e água 5 ed. São Paulo: Blucher,2017. 
SUASSUNA, T. D. M. F. Sistema de Produção de Amendoim. Empresa Brasileira de Pesquisa Agropecuária - EMBRAPA. Campina Grande/PB. p. 63. 2014.

TORTORA, Gerard J. et al. Interação entre micróbio e hospedeiro: Mecanismos microbianos de patogenicidade. In: PROPRIEDADES patogênicas de fungos, protozoários, helmintos e algas: Fungos. 12. ed. [S. I.]: Artmed, 2017. cap. 15, p. 417-438.

VECCHIA, Andréia Dalla; CASTILHOS-FORTES, Raquel de. Contaminação fúngica em granola comercial. Food Science and Technology, v. 27, p. 324-327, 2007.

ZORZETE, Patrícia. Fungos, micotoxinas e fitoalexina em variedades de amendoim do plantio ao armazenamento. 2010. Tese de Doutorado. Universidade de São Paulo. 


\title{
capitulo ill
}

\section{BACILLUS CEREUS: IMPORTANTE PATÓGENO ALIIMENTAR}

DOI: 10.51859/AMPLLA.DES1788-3

\author{
Thaynna Leocádio Trajano Lacerda Sousa ${ }^{1}$ \\ Indira Maria Estolano Macedo ${ }^{1}$ \\ Maria Karollyna Gomes da Silva ${ }^{2}$ \\ Gerlane Souza de Lima ${ }^{3}$ \\ Aline Gomes Santana 4 \\ Neide Kazue Sakugawa Shinohara ${ }^{5}$
}

\footnotetext{
${ }^{1}$ Mestre em Ciência e Tecnologia de Alimentos. Programa de Pós-Graduação em Ciência e Tecnologia de Alimentos UFRPE

${ }^{2}$ Mestranda em Ciência e Tecnologia de Alimentos. Programa de Pós-Graduação em Ciência e Tecnologia de Alimentos - UFRPE

${ }^{3}$ Mestre em Nutrição. Programa de Pós-Graduação em Nutrição - UFPE

${ }^{4}$ Mestre em Consumo, Cotidiano e Desenvolvimento Social. Programa de Pós-Graduação em Consumo, Cotidiano e Desenvolvimento Social - UFRPE

${ }^{5}$ Professor Adjunto do Departamento de Tecnologia Rural. Universidade Federal Rural de Pernambuco- UFRPE
}

\section{RESUMO}

O Bacillus cereus pertence ao grupo de bactérias Gram positivas, patogênicas, termodúricas, formadora de esporos e comportamento psicotrófico. B. cereus está amplamente distribuída no ambiente e está relacionada a severos surtos de toxinfecção de origem alimentar, pela capacidade de provocar patologias conhecidas como síndromes emética e diarreica. O estudo se propõe a fazer uma revisão sobre Bacillus cereus sensu stricto, seu perfil toxigênico, casos de intoxicações alimentares, medidas de controle, legislações vigentes para controle de qualidade nos alimentos e as metodologias utilizadas para sua detecção, apresentando assim uma visão geral sobre a capacidade de provocar surtos alimentares.

Palavras-chave: Bacillus cereus. Síndromes diarréica e emética. Toxigenicidade. 


\section{INTRODUÇÃO}

A Lei Orgânica da Saúde conceitua Vigilância Epidemiológica (VE) como um conjunto de ações que proporciona o conhecimento, a detecção ou prevenção de qualquer mudança nos fatores determinantes e condicionantes da saúde individual ou coletiva, com a finalidade de recomendar e adotar as medidas de prevenção e controle das doenças ou agravos à saúde (BRASIL, 2010).

Doenças transmitidas por alimentos (DTA) constituem um grande problema de saúde pública, tanto no Brasil como em escala mundial, sendo essas doenças responsáveis por elevados custos econômicos e sociais, devido à alta taxa de morbimortalidade e desconfiança dos consumidores. Entre as causas mais frequentes de contaminação dos alimentos, destacam-se a manipulação, transporte e a conservação inadequadas dos mesmos, além da possibilidade de contaminação cruzada entre produtos crus e processados (WELKER et al., 2010; CORTÉS-SANCHEZ; DIAZRAMÍREZ; SALGADO-CRUZ, 2017).

Na questão quanto ao risco biológico através dos alimentos, temos o Bacillus cereus como um importante grupo de bactéria que está amplamente distribuído no meio ambiente. São bastonetes Gram-positivos, aeróbios ou facultativos, com capacidade de esporulação e produção de enterotoxinas potencialmente patogênicas, estando envolvidos em diversos surtos transmitidos por alimentos no Brasil (SILVA et al., 2017).

O B. cereus foi isolado e descrito primeiramente em 1887 por Plazikowski. O reconhecimento epidemiológico como agente causador de intoxicação alimentar ocorreu somente após as publicações de Hauge em 1950, após grave surto nos EUA, em que foi isolado o B. cereus em molhos caseiros (JAY, 2005; SAVINI, 2016).

Estima-se que $B$. cereus produz metabólitos enterotoxigênicos com inóculos que variam nas concentrações de 105 a $108 \mathrm{UFC} / \mathrm{g}^{-1}$ do alimento. A contaminação e a multiplicação de $B$. cereus nos alimentos se dá por falhas nas práticas de manipulação, cocção e armazenamento inadequados, levando ao risco sanitário elevado junto ao consumidor (CORTÉS-SANCHEZ; DIAZ-RAMÍREZ; SALGADO-CRUZ, 2017).

O grupo $B$. cereus é um termo que indica uma subdivisão altamente homogênea dentro do gênero Bacillus, compreendendo nas espécies conhecidas estirpe tipo $B$. 
cereus sensu stricto, a cepa ATCC 14579 da coleção de Cultura Americana (American Type Culture Collection), sendo originalmente cultivada a partir de isolado de ambiente de estábulo (SAVINI, 2016).

O gênero Bacillus é responsável por diversos tipos de infecções severas não intestinais e potencialmente letais em humanos. A espécie aureus é uma das principais responsáveis por intoxicação alimentar, caracterizando as Síndromes Diarreica e a Emética. Essas DTA estão classificadas no grupo III de risco, que inclui doenças de perigo moderado, usualmente de curta duração e sem ameaça de morte ou sequelas, com sintomas autolimitados, mas que provocam severo desconforto, ou risco à integridade física, principalmente nas pessoas vulneráveis (ICMSF, 2002; SILVA et al., 2017).

Assim existe uma preocupação quando se isola B. cereus de uma amostra clínica, geralmente é difícil rotulá-lo como um patógeno ou um inocente contaminante, então os isolados devem ser cuidadosamente avaliados, pois dentro das estirpes patogênicas pertencentes ao grupo de $B$. cereus está o temido $B$. anthracis, em outrora usado como arma biológica (TRABULSI; ALTERTHUM, 2015; SAVINI, 2016; TORTORA; FUNKE; CASE, 2016).

O presente estudo faz uma breve revisão sobre a espécie Bacillus cereus, seu perfil toxigênico, intoxicações alimentares provocadas por esses microrganismos, medidas de controle, e as metodologias oficiais empregadas para sua caracterização e identificação taxonômica.

\section{CARACTERIZAÇÃO DO B. CEREUS}

A palavra cereal deriva da Deusa Romana Ceres, divindade da agricultura (McGEE, 2011). Segundo Savini (2016), a designação do microrganismo que no latim significa, bacilo na forma de "vareta pequena" e cereus, "como cera", se deu pela facilidade de reconhecimento fenótipo do B. cereus, que macroscopicamente no meio de cultura ágar sangue formam colônias que se assemelham a cera de uma vela derretida, e quando observadas em um microscópio têm a forma de um bastão.

Pertencente à família Bacillaceae, B. cereus caracteriza-se como Gram-positivo, presença de flagelos peritríquios, aeróbios e anaeróbios facultativo, pode ter comportamento mesófilo, psicrotrófico e termotolerante, produtor de esporos que podem ser centrais ou subterminais, catalase positiva, capacidade de esporulação, pH 
ótimo 6,0 a 7,0 e atividade de água ótima em torno de 0,93. Tem como hábitat natural o solo, mas apresenta distribuição ubiquitária, podendo ser isolado de várias matériasprimas, dentre esses diferentes grupos de alimentos, aqueles fonte de carboidratos (RAJKOWSKI; BENNETT, 2003; JAY, 2005; FRANCO; LANDGRAF, 2008).

Em geral, as cepas de Bacillus cereus apresentam estreita relação filogenética, com base em análise (16S rRNA) para várias outras espécies do gênero Bacillus. O que pode ser chamado de $B$. cereus sensu lato, não se refere a apenas uma bactéria, mas representa um amplo conjunto de microrganismos, dentre esses inclui-se o grupo com oito espécies B. cereus sensu stricto que compreende: Bacillus anthracis; Bacillus mycoides; Bacillus pseudomycoides; Bacillus thuringiensis; Bacillus weihenstephanensis; Bacillus cytotoxicus; Bacillus toyonensis, são estirpes com semelhança de mais de $97 \%$ no DNA, entre essas espécies (SÁNCHEZ; CORREA; SANDOVAL, 2016; SAVINI, 2016).

\section{BACILLUS CEREUS SENSU STRICTO}

O B. anthracis poderoso patógeno, devido a capacidade de virulência e infectividade, por ser usado como arma biológica de massa, causando a doença conhecida por carbúnculo (característica em ruminantes). Sua transmissão pode ocorrer através do contato pele/pele e exposição inalatória, podendo apresentar manifestações cutânea ou gastrointestinal. A forma gastrointestinal é caracterizada por febre e estado de choque, dores abdominais, vômitos e diarreia sangrenta durando uma média de 2 a 7 dias, contribuindo para uma elevada taxa de mortalidade (SILVA, 2010).

O B. mycoides e B. pseudomycoides podem ser diferenciados das demais espécies devido sua base fenotípica apresentar forma rizoidal, no entanto esta estirpe não é citada como causadora de DTAs. O B. thuringiensis é caracterizado pela capacidade de exibir propriedades inseticidas e, portanto, é usado comercialmente como agente microbiano de biocontrole. Uma das estirpes que apresentam atividade em baixas temperaturas é o Bacillus weihenstephanensis, logo são considerados psicrotróficos, crescendo em temperaturas de $4^{\circ} \mathrm{C}-7^{\circ} \mathrm{C}$, assim como os $B$. mycoides e B. pseudomycoides parecem ser de baixo potencial patogênico (SILVA, 2010).

O Bacillus toyonensis é considerado um probiótico, ingrediente ativo da preparação TOYOCERIN $\left({ }^{\circledR}\right)$, aditivo para uso em nutrição animal. Foi inicialmente classificada como B. cereus, entretanto ela mostrou significativas diferenças genômicas, 
que eram grandes o suficiente (valores de ANI abaixo de 92\%) para permitir que ela fosse considerada como uma espécie diferente dentro do grupo (JIMÉNEZ, 2013).

Sendo assim torna-se um dilema definir quais são as espécies que compõem o grupo B. cereus, principalmente quanto a ser patogênico ou não. Estudos filogenéticos não são capazes de distinguir os principais fatores patogênicos, pois esses não se correlacionam com a filogeneticamente dependendo de marcadores cromossômicos. Uma das alternativas atuais é o sequenciamento da toxina, dessa forma é possível encontrar quais microrganismos podem ser patogênicos. Com o estudo das toxinas, foram incluídas as cepas B. cereus NVH 391/98, responsável por três casos de síndrome diarreica. Essas novas espécies encontradas foram denominadas informalmente de "Bacillus cytotoxicus", que possuem variantes da toxina CytK-1. Algumas dessas espécies são termotolerantes capazes de formar fortes aglomerados, o que diferencia das outras na hora da observação em placa, essa cepa foi isolada durante um surto de intoxicação alimentar grave na França em 1998 (SAVINI, 2016).

\section{FORMA DE RESISTÊNCIA}

A formação de esporos para os microrganismos é uma resposta de algumas bactérias e fungos frente a condições adversas do meio ambiente, isso confere uma resistência e sobrevida desses microrganismos. A formação do esporo se dá pela desidratação da célula bacteriana e da formação de uma parede protetora e resistente, logo ocorre a suspensão completa da atividade metabólica, garantindo a sobrevivência em ambientes fastidiosos (CRONIN; WILKINSON, 2008). O B. cereus é considerado um microrganismo termodúrico, uma vez que seus esporos podem sobreviver aos processamentos térmicos utilizados na indústria de alimentos, onde o valor $D$ pode chegar até $121^{\circ} \mathrm{C}$ entre 0,03 e 2,35 minutos e o valor $Z$ entre $7,9 \circ \mathrm{C}$ e 9,9 $9 \mathrm{C}$ (em tampão fosfato $0,05 \mathrm{M})$. No caldo de arroz a $100^{\circ} \mathrm{C}$, por sua vez, o esporo da bactéria resiste cerca de 4,2 a 6,3 minutos (JAY, 2005; FRANCO; LANDGRAF, 2008).

Os endósporos de $B$. cereus são resistentes a condições ambientais extremas, tais como, desidratação e sanitizantes usados para a limpeza e desinfecção. Em condições favoráveis de umidade, temperatura e composição de nutrientes, os esporos podem germinar e se multiplicar nos alimentos processados. A termorresistência dos esporos de $B$. cereus pode variar de acordo com a estirpe natural ou contaminante 
acompanhante nos processos de produção (CRONIN; WILKINSON, 2008; ABEE et al., 2011).

\section{PERFIL TOXIGÊNICO}

B. cereus possui sua patogenicidade associada a produção de toxinas, sendo elas: três tipos diarreica, uma toxina emética, quatro tipos de hemolisinas e três tipos diferentes de fosfolipase $C$, sendo as causadoras de DTAs, a diarreica e a emética (DREWNOWSKA et al., 2020). Estas toxinas são produzidas a partir de enzimas extracelulares, produtoras de fosfolipases e suas diversas outras enzimas extracelulares degradadoras dos alimentos como protease, amilases, lecitinases, sendo esta última característica utilizada na identificação laboratorial do microrganismo (KONEMAN et al., 2001). Os principais fatores de virulência do B. cereus, são os complexos protéicos extracelulares, como a hemolisina ( $h b L)$ e a enterotoxina não-hemolítica (nhE), embora ocorra também fatores tóxicos formados por peptídeos menores ou até mesmo aminoácidos como no caso da cereulida e citotoxina K (CytK) respectivamente (SAVINI, 2016).

A Hemolisina BL (hbL), responsável pela síndrome da diarreia, é um complexo tripado $B, 11$ e 12. Essa enzima causa hemólise, dermonecrose, permeabilidade vascular, além de ter atividade enterotóxica produzida durante a fase logarítmica de crescimento, sendo necessário uma concentração de $10^{7}$ células $/ \mathrm{mL}$, sua produção é favorecida num $\mathrm{pH}$ de 6 a 8,5. Diversas linhagens de bactéria têm se mostrado capazes de produzir toxina entre 6 e 21 ำ. A enterotoxina não hemolítica (nhE) só foi relacionada também com a síndrome diarreica mais tarde após uma intoxicação alimentar na Noruega devido ao consumo de ensopado em 1995 (JAY, 2005; ARNENSEN et al., 2008).

A cereulida é um ionóforo, peptídeo insolúvel em água e está diretamente relacionada a um peptídeo antibiótico (a valinomicina), essa toxina induz a formação de vacúolo em células Hep-2. As linhagens que produzem essa toxina são associadas à síndrome emética e crescem no intervalo de temperatura de $15^{\circ} \mathrm{C}$ a $50^{\circ} \mathrm{C}$, com o ponto ótimo de $35^{\circ} \mathrm{C}$ e $40^{\circ} \mathrm{C}$. As toxinas produzidas por estirpes de B. cereus são termotolerantes elas resistem a aquecimento durante $30 \mathrm{~min}$ em $121^{\circ} \mathrm{C}$ (JAY, 2005; SAVINI, 2016). 
Em 1998, após um surto de intoxicação alimentar na França, foi isolada de uma estirpe de Bacillus cereus a citotocina K, também com atividade hemolítica, podem ocorrer em diferentes formas a CytK 1 e CytK 2 e sua virulência depende do nível de expressão da toxina em determinados alimentos, estudos para identificação dessas toxinas são feitos para diferenciar estirpes de Bacillus cereus sensu stricto (SENESI, GHELARDI, 2010; SAVINI, 2016).

\section{INTOXICAÇÕES ALIMENTARES}

A contaminação dos alimentos pelo $B$. cereus acontece principalmente na manipulação dos alimentos, mas pode ocorrer em outras etapas como, processamento, estocagem ou distribuição, podendo o microrganismo se desenvolver e causar doenças de origem alimentar. O aumento dos riscos de contaminação de diversos alimentos ocorre mediante alguns fatores: preparo de grandes quantidades de alimentos, exposição dos alimentos a temperaturas inadequadas junto à falta de higienização eficiente, tempo entre preparo e consumo, e a utilização de cozinhas de grande porte que são ambientes favoráveis para o aparecimento dessa bactéria, devido a longa espera para que uma grande quantidade de alimento resfrie (MENDES et al., 2011).

O B. cereus é responsável por dois tipos de doenças de origem alimentar: a síndrome diarréica, provocada por uma enterotoxina produzida no intestino do hospedeiro; e a síndrome emética, uma intoxicação atribuída a uma toxina pré-formada no alimento (MARTINO et al., 2010; SENESI; GHELARDI, 2010).

A síndrome diarreica se assemelha a intoxicação alimentar causada por Clostridium perfringens, essa síndrome já foi relatada a partir de contagens de $10^{5}$ UFC/g. É causada pela ingestão de alimentos contaminados por B. cereus ou com seus esporos. Ao serem ingeridas, essas bactérias se proliferam rapidamente e produzem toxinas assim que penetram no intestino. A intoxicação está ligada a uma enzima extracelular hbL e a nhE que age sobre a mucosa intestinal, como uma verdadeira enterotoxina. Entretanto essas toxinas são instáveis, e facilmente destruídas pelo calor (60ํㅡ por cinco minutos) assim como ação enzimática da tripsina (JAY, 2005; FRANCO; LANDGRAF, 2008). Os sintomas manifestam-se 6 a 16 horas e a duração é de 6 a 12 horas, e são caracterizados por náusea com rara ocorrência de vômitos, dores 
abdominais intermitentes, tenesmo, fezes aquosas e geralmente não há febre (ARNENSEN, et al., 2008).

Segundo Jay (2005), os alimentos que são potencialmente relacionados com a síndrome diarreica são os pratos à base de cereais, contendo milho e amido de milho, purê de batata, vegetais, carne moída, linguiça de fígado, bolinho de carne moída, leite, queijos, carne assada, pratos à base de arroz ao estilo indonésio, pudins, sopas. De acordo com Sánchez, Correa e Sandoval (2016), o B. cereus possui a habilidade de produzir a enzima amilase que permite hidrolisar carboidratos e utilizar como fonte de carbono para seu crescimento.

A síndrome emética é caracterizada por ocorrência de náuseas e vômito até 2 horas após o consumo do alimento contaminado, ocorrendo pela ingestão da toxina préformada no alimento, sendo mais grave e aguda que a síndrome diarreica. O período de incubação é de 1 a 6 horas, e a toxina responsável pela síndrome é um peptídeo produzido durante o crescimento de estirpes de Bacillus cereus no alimento, a cereulida. Esta toxina é muito resistente às condições ambientais adversas como aquecimento a $126^{\circ} \mathrm{C}$ por 90 minutos; variação extrema de $\mathrm{pH}$, suportando intervalo 2 a 11; desidratação e a ação de enzimas digestivas humanas. No entanto, o número de células bacterianas necessárias para produzir a toxina responsável pela ocorrência da síndrome emética ainda não está bem estabelecido, entretanto a literatura descreve que a contagem de células de $B$. cereus deve ser maior para a síndrome emética que a necessária para a ocorrência da síndrome diarreica (JAY, 2005; FRANCO; LANDGRAF, 2008; ARNENSEN et al., 2008).

Ambas as síndromes apresentam duração dos sinais clínicos por cerca de 24 horas. Toda a população é suscetível de intoxicação por B. cereus, mas a intensidade de sintomas varia de indivíduo para indivíduo. Os sintomas são mais severos em crianças, em idosos e em indivíduos imunodeprimidos (SENESI; GHELARDI, 2010). Recomenda-se beber muita água durante qualquer uma das síndromes para evitar o risco de desidratação severa, em alguns casos, pode ser necessário o uso de antibióticos de forma a aliviar os sintomas mais graves e perigosos. Para o controle dessas doenças no meio alimentar são sugeridas medidas que promovam o arrefecimento rápido dos alimentos que vão ser armazenados a temperaturas de refrigeração, para que não ocorra germinação de esporos. Assim como sugere-se que o reaquecer dos alimentos 
seja realizado em temperaturas superiores a $65^{\circ} \mathrm{C}$ antes de serem servidos, em recomendação geral, a aplicação das Boas Práticas de Fabricação (FRANCO; LANDGRAF, 2008; FORSYTHE, 2013).

A determinação da Resolução de Diretoria Colegiada da ANVISA, RDC №12 (BRASIL, 2001), considera apenas a avaliação do Bacillus cereus em leite em pó instantâneo e integral, permitindo uma contagem de até $5 \times 10^{3}$, mesmo que sejam comuns as doenças relacionadas a esses microrganismos, estarem associadas principalmente a arroz frio ou quente, e outros alimentos também ricos em carboidratos como amido além do leite. Atualmente esta resolução foi substituída por duas resoluções, a RDC 331 de 23 de dezembro de 2019 (BRASIL, 2019) e a Instrução Normativa no 60 (BRASIL, 2019), estabelecendo assim o novo padrão microbiológico para alimentos.

Conforme a nova legislação, as determinações do parâmetro B. cereus, tiveram algumas ampliações entre grupos de alimentos e o limite máximo permitido, oferecendo uma maior segurança alimentar para os consumidores. Conforme a Tabela 1, podemos observar que este parâmetro tem obrigatoriedade de investigação junto a grupos de alimentos como: produtos de panificação, massas, produtos semielaborados e prontos para o consumo.

Tabela 1 - Grupos de alimentos com exigência legal para a deteç̧ão de Bacillus cereus, limites de tolerância, conforme preconiza Instrução Normativa no 60 (BRASIL, 2019)

\begin{tabular}{|l|l|c|c|}
\hline \multicolumn{1}{|c|}{ Grupo de Alimento } & \multicolumn{1}{|c|}{ Categoria específica } & $\begin{array}{c}\text { Mínimo } \\
\text { UFC/g }\end{array}$ & $\begin{array}{c}\text { Máximo } \\
\text { UFC/g }\end{array}$ \\
\hline $\begin{array}{l}\text { 4- Outros produtos } \\
\text { vegetais }\end{array}$ & c) Tofu, sufu e similares, refrigerados & $10^{2}$ & $10^{3}$ \\
\hline $\begin{array}{l}\text { 13- Alimentos } \\
\text { Infantis }\end{array}$ & $\begin{array}{l}\text { a) Fórmulas infantis em pó para } \\
\text { lactentes (até seis meses de idade), } \\
\text { fórmulas infantis destinadas a } \\
\text { necessidades dietoterápicas } \\
\text { específicas, fórmulas de nutrientes }\end{array}$ & 50 & $5 \times 10^{2}$ \\
\hline $\begin{array}{l}\text { 13- Alimentos } \\
\text { Infantis }\end{array}$ & $\begin{array}{l}\text { b) Fórmulas infantis em pó de } \\
\text { seguimento para lactentes e crianças } \\
\text { de primeira infância e outros alimentos } \\
\text { especialmente formulados para } \\
\text { lactentes e crianças de primeira } \\
\text { infância }\end{array}$ & 50 & $5 \times 10^{2}$ \\
\hline $\begin{array}{l}\text { 13- Alimentos } \\
\text { Infantis }\end{array}$ & $\begin{array}{l}\text { c) Alimentos à base de cereais para } \\
\text { alimentação infantil }\end{array}$ & 50 & $5 \times 10^{2}$ \\
\hline
\end{tabular}




\begin{tabular}{|l|l|c|c|}
\hline \multicolumn{1}{|c|}{ Grupo de Alimento } & \multicolumn{1}{|c|}{ Categoria específica } & $\begin{array}{c}\text { Mínimo } \\
\text { UFC/g }\end{array}$ & $\begin{array}{c}\text { Máximo } \\
\text { UFC/g }\end{array}$ \\
\hline $\begin{array}{l}\text { 14- Fórmulas para } \\
\text { nutrição enteral }\end{array}$ & $\begin{array}{l}\text { a) Fórmula padrão para nutrição } \\
\text { enteral, fórmula modificada para } \\
\text { nutrição enteral e módulo para } \\
\text { nutrição enteral em pó }\end{array}$ & 50 & $5 \times 10^{2}$ \\
\hline $\begin{array}{l}\text { 19- Cereais, farinhas, } \\
\text { massas alimentícias e } \\
\text { produtos de } \\
\text { panificação }\end{array}$ & a) Farinhas, amidos, féculas e fubás & $10^{2}$ & $10^{3}$ \\
\hline $\begin{array}{l}\text { 19- Cereais, farinhas, } \\
\text { massas alimentícias e } \\
\text { produtos de } \\
\text { panificação }\end{array}$ & $\begin{array}{l}\text { c) Massas alimentícias frescas e } \\
\text { produtos semielaborados, com ou sem } \\
\text { recheio, com ou sem cobertura (pão } \\
\text { de queijo, pão de batata, pizza, } \\
\text { pastéis), refrigerados ou congelados }\end{array}$ & $10^{2}$ & $10^{3}$ \\
\hline $\begin{array}{l}\text { 19- Cereais, farinhas, } \\
\text { massas alimentícias e } \\
\text { produtos de } \\
\text { panificação }\end{array}$ & $\begin{array}{l}\text { f) Produtos à base de amidos, farinhas, } \\
\text { féculas e fubás, semielaborados e } \\
\text { misturas em pó com ou sem ovos para } \\
\text { bolos, pães, tortas, empadas, pizzas, } \\
\text { preparações para empanar, estáveis à } \\
\text { temperatura ambiente }\end{array}$ & $10^{2}$ & $10^{3}$ \\
\hline $\begin{array}{l}\text { 22- Alimentos } \\
\text { semielaborados e } \\
\text { prontos para } \\
\text { consumo }\end{array}$ & $\begin{array}{l}\text { b) Alimentos prontos para o } \\
\text { consumo* }\end{array}$ & $\begin{array}{l}10^{2} \\
\text { Sonsonte para almentos }\end{array}$ & $5 \times 10^{2}$ \\
\hline
\end{tabular}

* Somente para alimentos à base de cereais ou molhos

Fonte: IN no 60 de 2019 (BRASIL, 2019)

Na tabela 1, observamos que os alimentos que são à base de cereais e alimentos para público infantil são os grupos de alimentos que têm a obrigatoriedade de investigação para $B$. cereus, haja visto que os cereais são fontes de carboidratos e portanto substrato ideal para a multiplicação desse patógeno, decorrente da habilidade dessa bactéria em sintetizar amilase para degradar o amido da composição desses grupos alimentares. Quanto a alimentação infantil, ressaltamos que em algumas formulações consta a incorporação de amido como espessante, o que aumenta o risco de contaminação cruzada de microrganismos frente a um público considerado imunodeficiente, devido ainda apresentar sistema imunológico imaturo.

\section{METODOLOGIAS DE DETERMINAÇÃO EM ALIMENTOS}

O método tradicional mais empregado é a contagem diretamente em placa contendo Ágar manitol gema de ovo poliximizina (MYP), metodologia aprovada pela 
American Public Health Association (BENNETT, 2015), quando positivo é caracterizado por colônia com forte reação de lecitinase, apresentando um grande halo de precipitação, de cor rosa leitosa, devido a não fermentação do manitol, resposta típica que caracteriza o B. cereus no meio de cultura MYP. Outro meio recomendado é o Ágar Kim-Goepfert (KG), as colônias apresentam precipitação como no meio MYP, sem coloração diferencial. A diferenciação de grupos B. cereus, ocorre por testes bioquímicos complementares como provas de confirmação para o grupo de $B$. cereus e diferenciação das outras espécies do grupo (SILVA, 2017).

A forma de detecção tradicional para Bacillus cereus como, enumeração e a diferenciação, não discriminam de forma confiável entre os isolados, para isso recomenda-se o uso do método tradicional combinando com ferramentas de base molecular, para que se possa melhorar essa capacidade de identificação. Atualmente as cepas do grupo B. cereus são devidas pelos genes específicos das toxinas que possuem. Estes genes podem ser detectados com técnicas moleculares padrão, como amplificação DNA e sequenciamento. Os métodos de identificação por PCR foram desenvolvidos especialmente para B. anthracis por causa de seu potencial de bioterrorismo. 0 desenvolvimento de PCR multiplex em tempo real para identificar e diferenciar $B$. anthracis tipos de virulência, tiveram grande relevância no avanço de métodos de detecção rápidos e confiáveis (SAVINI, 2016).

Os ensaios de reação em cadeia da polimerase (PCR) em tempo real foram aplicados a enumeração das estirpes de B. cereus (MARTíNEZ-BLANCH, 2003; CEUPPENS, 2010; DZIECIOL, et al., 2013), mas as dificuldades surgem com a presença de diferentes estados das células, vegetativas ou esporuladas, vivos ou mortos. Para Li et al. (2016), a modernização de medições da expressão genética consiste em usar matrizes complexas, como o próprio alimento, dessa forma é possível observar como é a interação dessas bactérias com vários tipos de matrizes, aliado ao uso de PC. Pesquisas devem ser realizadas de maneira a otimizar as técnicas de PCR, garantindo melhor reprodutibilidade e confiabilidade dos resultados.

\section{CONSIDERAÇÕES FINAIS}

Como o estudo mostrou, esse microrganismo é um potencial agente toxigênico alimentar e está presente em diversos ambientes e em diferentes matrizes alimentares. 
Entretanto sua classificação e identificação necessita de estudos mais profundos, devido a multiplicidade desse grupo de bactérias que estão em constante mutação, podendo evoluir para cepas mais virulentas. O aprimoramento de técnicas de identificação genéticas junto à rapidez do processo de detecção se faz necessário, pois pode prevenir perdas econômicas na indústria e agravos junto aos consumidores, minimizando assim riscos sanitários que podem repercutir na saúde pública.

\section{REFERÊNCIAS}

ABEE, T. et al. Germination and outgrowth of spores of Bacillus cereus group members: diversity and role of germinant receptors. Food Microbiology, v. 28, p. 199-208, 2011.

ARNESEN, L. P. S.; FAGERLUND, A.; GRANUM, P. E. From soil to gut: Bacillus cereus and its food poisoning toxins. FEMS Microbiology Review, v. 32 p. 579-606, 2008.

BRASIL. Instrução Normativa no 60 de 23 de dezembro de 2019. Estabelece a lista de padrões microbiológicos para alimentos. Brasília, 2019. Disponível em: <https://www.in.gov.br/web/dou/-/instrucao-normativa-n-60-de-23-dedezembro-de-2019-235332356>. Acesso em: 15 ago 2021.

BRASIL. Ministério da Saúde. Secretaria de Vigilância em Saúde. Departamento de Vigilância Epidemiológica. Doenças Infecciosas e Parasitárias. 8. ed. rev. Brasília: Ministério da Saúde, 2010.

BRASIL. Resolução da Diretoria Colegiada - RDC no 12 de 2 de janeiro de 2001 da ANVISA. Regulamento Técnico sobre Padrões Microbiológicos para Alimentos. Brasília, 2001. Disponível em: <https://www.gov.br/agricultura/ptbr/assuntos/inspecao/produtos-vegetal/legislacao-1/biblioteca-de-normasvinhos-e-bebidas/resolucao-rdc-no-12-de-2-de-janeiro-de-2001.pdf/view>. Acesso em: 15 ago 2021.

BRASIL. Resolução da Diretoria Colegiada - RDC no 331, de 23 de dezembro de 2019. Dispõe sobre os padrões microbiológicos e para alimentos e sua aplicação. Brasília, 2019. Disponível em: <https://www.in.gov.br/en/web/dou/-/resolucaordc-n-331-de-23-de-dezembro-de-2019-235332272>. Acesso em: 15 ago 2021.

CEUPPENS, S. et al. Quantification methods for Bacillus cereus vegetative cells and spores in the gastrointestinal environment. J. Microbiol Methods. v. 83, p. 20210. 2010.

CORTÉS-SÁNCHEZ, A. D. J.; DÍAZ-RAMÍREZ, M.; SALGADO-CRUZ M. D. L. P. Bacillus cereus: Alimentos, salud y biotecnología. Agroproductividad, v.10, n. 10, p. 3-9, 2017. 
CRONIN, U. P.; WILKINSON, M. G. Bacillus cereus endospores exhibit a heterogeneous response to heat treatment and low-temperature storage. Food Microbiology, v. 25 , n. 2 , p. $235-243,2008$.

DREWNOWSKA, J. M. et al. Potencial enterotoxicidade de isolados filogeneticamente diversos de Bacillus cereus sensu lato de diferentes localizações geográficas. Microbiologia aplicada e ambiental, v. 86, n. 11, p. e03032-19, 2020.

DZIECIOL, M. et al. A diagnostic real-time PCR assay for quantification and differentiation of emetic and non-emetic Bacillus cereus in milk. Food Control, v.32, p.176-85, 2013.

FORSYTHE, S. J. Microbiologia da Segurança dos Alimentos. Porto Alegre: Artmed, 2013.

FRANCO, B. D. G. M.; LANDGRAF, M. Microbiologia dos alimentos. São Paulo: Atheneu, 2008.

ICMSF. Internetional Commission on Microbiological Specifications for Foods. Microrganisms in Food 7. Micobiological Testing in Food Safty Management. Kluwer Academic/Plenum Publishers, New York (ISBN: 0-306-47262-7), 2002.

JAY, J. M. Microbiologia de Alimentos. 6 ed. Porto Alegre: Artmed, 2005.

JIMÉNEZ, G. et al. Description of Bacillus toyonensis sp. nov., a novel species of the Bacillus cereus group, and pairwise genome comparisons of the species of the group by means of ANI calculations. Syst Appl Microbiol journal, v. 36, p. 383, 2013.

KONEMAN, E. W. et al. Diagnóstico Microbiológico. Texto e Atlas colorido, Rio de Janeiro: Medsi, 5 ed., 1660 p., 2001.

LI, F. et al. Distribution and expression of the enterotoxin genes of Bacillus cereus in food products from Jiangxi Province, China. Food Control. v. 67, p. 155-162. 2016.

MARTÍNEZ-BLANCH, J. F. et al. Development of a real-time PCR assay for detection and quantification of enterotoxigenic members of Bacillus cereus group in food samples. International Journal of Food Microbiology. v. 35, p. 15-21, 2009.

MARTINO, T. K. et al. Bacillus cereus y su implicación en la inocuidad de los alimentos.: Parte II. Revista Cubana de Salud Pública, v. 36, n. 1, p. 139-148, 2010.

McGEE, H. Comida \& Cozinha: Ciência e Cultura da Culinária. São Paulo: WMF Martins Fontes, 2011.

MENDES, R. A.; COELHO, A. I. M.; AZEREDO, R. M. C. Contaminação por Bacillus cereus em superfícies de equipamentos e utensílios em unidade de alimentação e nutrição. Ciência \& saúde coletiva, v. 16, n. 2, p. 3933-3938, 2011. 
RAJKOWSKI, K. T.; BENNET, R. W. Bacillus cereus. International hand book of foodborn, Marcel Dekker, 2003.

SÁNCHEZ, J.; CORREA, M.; CASTAÑEDA, L. Bacillus cereus un patógeno importante en el control microbiológico de los alimentos: um patógeno importante no controle microbiológico dos alimentos. Revista Facultad Nacional de Salud Pública, v. 34, n. 2, p.230-242. 2016.

SAVINI, V. The Diverse Faces of Bacillus Cereus. Academic Press is an imprint of Elsevier. London, (ISBN: 978-0-12-801474-5), 2016.

SILVA, N. et al. Manual de métodos de análise microbiológica de alimentos e água. São Paulo: Blucher, 2017.

SENESI, S.; GHELARDI, E. Production, secretion and biological activity of Bacillus cereus enterotoxins. Toxins, v. 2, p. 1690-1703, 2010.

TORTORA, G. J.; FUNKE, B. R.; CASE, C. L. Microbiologia. Porto Alegre: Artmed, 2015.

TRABULSI, L. R.; ALTERTHUM, F. Microbiologia. São Paulo: Atheneu, 2015.

WELKER, C. A. D. et al. Análise microbiológica dos alimentos envolvidos em surtos de doenças transmitidas por alimentos (DTA) ocorridos no estado do Rio Grande do Sul, Brasil. Revista Brasileira de Biociências, Porto Alegre, v. 8, n. 1, p. 44-48, 2010. 


\title{
CAPITULO IV \\ QUEIJO MUÇARELA: AVALIAÇÃO DO PERFIL MICROBIOLÓGICO
}

DOI: 10.51859/AMPLLA.DES1788-4

\author{
Kalita Gabrielly De Sousa Coelho ${ }^{1}$ \\ Thamiris Silva de Sousa ${ }^{2}$ \\ Luana Cristhiny Silva da Costa ${ }^{3}$ \\ Claudete Rosa da Silva ${ }^{4}$ \\ Fábio Israel Martins Carvalho ${ }^{5}$ \\ Priscilla Andrade Silva ${ }^{6}$
}

\footnotetext{
1 Graduanda do Curso de Zootecnia. Universidade Federal Rural da Amazônia - UFRA

${ }^{2}$ Graduanda do Curso de Zootecnia. Universidade Federal Rural da Amazônia - UFRA

${ }^{3}$ Graduanda do Curso de Agronomia. Universidade Federal Rural da Amazônia - UFRA

${ }^{4}$ Professora do Campus de Parauapebas. Universidade Federal Rural da Amazônia - UFRA

5 Professor do Campus de Parauapebas. Universidade Federal Rural da Amazônia - UFRA

${ }^{6}$ Professora do Campus de Parauapebas. Universidade Federal Rural da Amazônia - UFRA
}

\section{RESUMO}

Apesar do queijo muçarela ter um alto valor nutritivo e ser um dos mais consumidos no Brasil, o mesmo apresenta diversos surtos de intoxicação alimentar, por ser um derivado lácteo, tornando-o muito susceptível à proliferação de bactérias indesejáveis (patogênicas e deterioradoras), podendo assim, trazer grandes problemas relacionados a saúde humana. Dessa forma, objetivou-se com essa revisão de literatura, avaliar dez artigos, nos quais os mesmos apresentam informações relevantes sobre análises microbiológicas do queijo muçarela. E consequentemente foram observados problemas em vários setores de produção dos queijos: na fabricação, nos utensílios, no transporte, na refrigeração, falta de higiene no preparo, na embalagem, na ordenha entre outros. Por isso é importante manter uma boa fiscalização sanitária, por ser um alimento de fácil contaminação e muito consumido.

Palavras-chave: Intoxicação. Derivado lácteo. Fiscalização. Contaminação 


\section{INTRODUÇÃO}

O queijo muçarela é o tipo de queijo mais produzido no Brasil e é amplamente utilizado na culinária, devido sua praticidade no fatiamento e facilidade de derretimento (COELHO et al., 2012).

A muçarela é um queijo famoso mundialmente, sendo de sabor suave, de massa macia, é composto por 46 a $49 \%$ de umidade, sua fabricação se concentra principalmente no sul da Itália. inicialmente, era desenvolvido somente com leite de búfala, mas com o passar do tempo foi massificado pela utilização do leite de vaca. Sendo consumido enquanto fresco, com pouca ou nenhuma maturação (ALBUQUERQUE e COUTO, 2002).

A contaminação do queijo pode estar associada a alguns fatores relacionados às etapas utilizadas em sua fabricação, tais como: pasteurização do leite, coagulação, corte do coágulo, dessoragem, enformagem, salga, maturação e embalagem. Em relação à muçarela, inclui-se ainda a fase de filagem (CASTRO et al., 2012).

De acordo com Fagnani et al. (2013) e Pinto et al. (2009) apesar da produção do queijo do tipo muçarela incluir etapas que contribuem para redução da carga microbiana (Pasteurização e Filagem), posteriormente, o mesmo sofre intensa manipulação até a etapa final de produção, que se não for realizada mediante boas práticas de fabricação e higiene favorece a sua contaminação.

Devido aos grandes índices de surtos alimentares que vem ocorrendo nos últimos anos, os consumidores estão mais atentos aos produtos que adquirem, exigindo alimentos com maior controle de qualidade, aumentando assim a competitividade entre as indústrias (LEMBI et al., 2020).

Considerando que o queijo tipo muçarela pode transmitir diversos patógenos, a revisão de literatura teve o objetivo de avaliar a qualidade microbiológica desse tipo de queijo e identificar alguns contaminantes nesse produto.

\section{REFERENCIAL TEÓRICO}

\subsection{IMPORTÂNCIA E QUALIDADE NUTRICIONAL DO QUEIJO MUÇARELA}

A qualidade dos queijos estimula a aprovação e aquisição dos consumidores. Uma das mais importantes atividades na indústria de laticínios é a fabricação de queijos, 
sobretudo, nas regiões sul e sudeste do Brasil, cuja produção se concentra principalmente em indústrias de pequeno e médio porte (QUINTANA e CARNEIRO, 2007).

O queijo muçarela tem uma cor amarelada, seu sabor é um pouco ácido, quando embalado vem em pequenas filagens para facilitar seu manuseio e seu cheiro e sabor são característicos (COELHO et al., 2012). De acordo com Perry (2004) o queijo tem em sua composição elevado teor de proteínas, lipídios, carboidratos, sais minerais, cálcio, fósforo e vitaminas, logo é um alimento bastante nutritivo.

Segundo o Ministério da Agricultura, Pecuária e Abastecimento (MAPA), o queijo é definido como: "Um produto fresco ou maturado obtido por separação parcial do soro do leite ou leite reconstituído, ou de soros lácteos coagulados pela ação física do coalho, de enzimas específicas, de bactérias específicas, de ácidos orgânicos, isolados ou combinados, todos de qualidade aceitável para o uso alimentar, com ou sem adição de substâncias alimentícias, condimentos ou aditivos" (BRASIL, 1996).

Uma vez que as Boas Práticas de Fabricação (BPF) e medidas de sanitização são importantes para a produção de produtos de qualidade (APOLINÁRIO et al., 2014), a contaminação microbiológica no queijo muçarela representa um sério perigo para a saúde do consumidor e acarreta grandes prejuízos econômicos (RAIMANN, 2011). A ingestão desses queijos contaminados pode trazer consequências para a saúde da população, como, por exemplo, as gastroenterites, tornando-se, portanto, um problema de saúde pública (APOLINÁRIO et al., 2014).

\subsection{ASPECTOS CONTAMINANTES DO QUEIJO MUÇARELA}

A contaminação deste tipo de queijo pode estar associada a alguns fatores relacionados às etapas utilizadas em sua fabricação como, a pasteurização do leite, coagulação, corte do coágulo, dessoragem, filagem, enformagem, salga, maturação e embalagem. A grande manipulação do produto, e o contato com diferentes equipamentos e superfícies, aumenta, pois, o risco de contaminação microbiológica (PINTO et al., 2009).

A bactéria Staphylococcus aureus produz, por sua vez, toxinas em alimentos cozidos o que é potencial indicador de condições de fabricação inadequadas. Esta 
bactéria pode causar infeç̧ões ou intoxicações alimentares nos seres humanos e sua importância tem sido ressaltada nos últimos tempos (FONSECA et al., 2010).

Já a presença de coliformes nos queijos está diretamente relacionada com a qualidade do leite e a presença desses microrganismos provoca alterações no leite, tais como a degradação das gorduras, além de tornar o alimento impróprio para o consumo, podendo se tornar um veículo de doenças, sendo ainda possível a contaminação em qualquer etapa do processo de fabricação do queijo muçarela (FREITAS, 2015).

Dessa forma, a presença desses microrganismos nos alimentos, poderá indicar falta de condições adequadas no tratamento térmico, de sanitização dos equipamentos e manuseio inadequado, sendo que, em alimentos processados, a presença dos coliformes indicam processamento inadequado ou uma contaminação pósprocessamento (CASTRO et al., 2012).

O leite utilizado na produção de queijos frescos deve ser pasteurizado. Já os queijos maturados, pode-se utilizar leite cru desde que sejam respeitados os prazos de maturação e utilizadas boas práticas de fabricação, que incluem desde a exigência de utilizar somente leite de boa qualidade até a rigorosa higiene no local de fabricação. Por isso, é importante a conscientização dos profissionais do setor em todos as etapas, para a implantação de programas de boas práticas de fabricação e do controle permanente dos processos e seus pontos críticos de controle (PERRY, 2004).

\section{METODOLOGIA}

Foi realizada uma revisão de literatura sobre as avaliações microbiológicas em queijo tipo muçarela. Foram selecionados e analisados dez artigos, levando em consideração as análises microbiológicas realizadas. Os referidos autores foram: Duarte et al. (2011); Castro et al. (2012); Fagnani et al. (2013); Losito et al. (2014); Reges et al. (2017); Reges et al. (2018); Reginato et al. (2019); Gasparotto et al. (2019); Lembi et al. (2020); Mukhtar et al. (2020).

A revisão sistemática da literatura foi realizada, entre maio e setembro de 2021, por meio do portal da revista. Capes e BVCA (Biblioteca Virtual em Ciências Agrárias) utilizando pesquisa avançada com a combinação dos descritores "Análises microbiológicas, qualidade nutricional do queijo, aspectos contaminantes do queijo", nos idiomas português e inglês. Essas bases de dados e bibliotecas digitais foram 
escolhidas por serem referência para muitos pesquisadores brasileiros, concentrando periódicos bem qualificados a nível nacional e internacionalmente.

A seleção dos artigos baseou-se nos seguintes critérios: publicações nacionais e internacionais que responderam a busca avançada, sem restrição de período de tempo, com vistas a compreender a historicidade das pesquisas sobre a temática. Ressalta-se que, apesar da ausência de restrição de tempo, todos os artigos encontrados se enquadraram no intervalo de publicações realizadas entre os anos de 2003 e 2020.

\section{RESULTADOS E DISCUSSÕES}

Os dados obtidos na pesquisa literária seguem expostos na Tabela 1 - Nas normas estabelecidas pela Agência Nacional de Vigilância Sanitária, a Resolução RDC no12 de 02 de janeiro de 2001 estipula um valor limite para cada microrganismo analisado de acordo com a porcentagem de umidade do produto, sendo a muçarela um queijo que apresenta teor de umidade intermediário (entre 36 e 46\%) (BRASIL, 2001).

Tabela 1 - Dados da literatura para os valores encontrados para Coliformes Totais e presença de Staphylococus aureus.

\begin{tabular}{|c|c|c|}
\hline Autores & $\begin{array}{l}\text { Coliformes Totais } \\
\text { (UFC/g) }\end{array}$ & $\begin{array}{c}\text { Staphylococcus aureus } \\
\text { (UFC/g) }\end{array}$ \\
\hline Duarte et al. (2011) & -------------- & $1,34 \times 10^{1}$ a $1,47 \times 10^{3}$ \\
\hline Castro et al. (2012) & ------------- & $8,1 \times 10^{2}$ a $7,3 \times 10^{3}$ \\
\hline Fagnani et al. (2013) & $1,3 \times 10^{1}$ a $1,98 \times 10^{5}$ & 7,51 × $10^{1}$ a $9,0 \times 10^{1}$ \\
\hline Losito et al. (2014) & $4,6 \times 10^{4}$ a $1,1 \times 10^{6}$ & -------- \\
\hline Reges et al. (2017) & $3,1 \times 10^{2}$ a $5,7 \times 10^{2}$ & $4,1 \times 10^{2}$ a $2,9 \times 10^{3}$ \\
\hline Reges et al. (2018) & ----------- & $8,1 \times 10^{1}$ a $3,2 \times 10^{3}$ \\
\hline Reginaldo et al. (2019) & $<1,0 \times 10^{1}$ a $2,0 \times 10^{6}$ & $<1,0 \times 10^{1}$ \\
\hline Gasparotto et al. (2019) & ----------- & $>5,1 \times 10^{3}$ \\
\hline Lembi et al. (2020) & * SVC & $1,0 \times 10^{3}$ \\
\hline Mukhtar et al. (2020) & $2,4 \times 10^{1}$ a $3,7 \times 10^{1}$ & ------------ \\
\hline
\end{tabular}

Segundo Castro et al. (2012) o queijo, dentre os produtos derivados do leite, é considerado um veículo frequente de patógenos de origem alimentar e, em especial, os queijos frescos artesanais por serem, na maioria das vezes, elaborados a partir de leite não pasteurizado e não sofrerem processo de maturação. A contaminação microbiana desses produtos assume destacada relevância tanto para a indústria, pelas perdas 
econômicas, como para a Saúde Pública, pelo risco de causar doenças transmitidas por alimentos.

A RDC № 12, de 02 de janeiro de 2001 (BRASIL, 2001) não estabelece valores para o grupo dos coliformes totais, deste modo, utilizou-se como referência a Portaria n. 146/96 (BRASIL, 1996) que considera queijos do tipo muçarela impróprios para consumo aqueles que apresentarem contagens de coliformes totais acima de 1,0 $\times 10^{4}$ UFC/g. A presença de coliformes nos alimentos indica que pode ter ocorrido contaminação durante o processo de fabricação ou após o processamento (SANTOS et al., 2009).

Os coliformes totais compreendem bactérias ambientais que são amplamente conhecidas por indicar as condições higiênico-sanitárias em que o alimento foi produzido. Sua presença em queijos do tipo muçarela pode indicar que a pasteurização empregada no processo foi ineficaz, já que esses microrganismos são sensíveis a temperatura utilizada na pasteurização, ou que houve contaminação após essa etapa, possivelmente relacionada a manipulação inadequada (BELOTI, 2015; OLIVEIRA et al., 2017).

Resultados dentro da legislação para Staphylococcus aureus coagulase positiva são importantes, uma vez que esse microrganismo possui capacidade de produzir enterotoxinas, que quando ingeridas podem desencadear um quadro de intoxicação, que geralmente é acompanhado de sintomas que inclui náuseas, vômitos, cólicas e diarreia (WONG; BERGDOLL, 2002; GERMANO; GERMANO, 2001). A atual legislação brasileira determina ausência de Salmonella sp, em 25 gramas de queijo muçarela (BRASIL, 2001)

Assim, podemos afirmar a importância de intensificar treinamentos com os manipuladores de alimentos, juntamente com a adoção das boas práticas de fabricação (BPF), usando sempre os equipamentos de proteção individual, como, máscara, jaleco, toucas e luvas para evitar uma contaminação através das bactérias presentes na pele, boca e fossas nasais, além dos cuidados básicos de higiene como a lavagem das mãos, a fim de assegurar a qualidade do produto (LEMBI et al., 2020). 


\section{CONSIDERAÇÕES FINAIS}

Todos os artigos avaliados, apresentaram contaminação, logo estão fora dos padrões exigidos pela Agência Nacional de Vigilância Sanitária (ANVISA), tornando inviável o seu consumo devido ao risco a saúde. Foi encontrado problemas em vários setores como: na fabricação, nos utensílios, no transporte, má refrigeração, falta de higiene no preparo, na embalagem, na ordenha entre outros. Por isso a importância de se manter uma boa fiscalização sanitária, pois o queijo é um alimento de fácil contaminação.

\section{REFERÊNCIAS}

Albuquerque, L. C.; COUTO, M. A. C. L. Site Ciência do Leite: Ano I, 2001/2002. Juiz de Fora: [s.e.], 2002. p.9-36.

APOLINÁRIO, T. C. C.; DOS SANTOS, G. S.; LAVORATO, J. A. A. Avaliação da qualidade microbiológica do queijo minas frescal produzido por laticínios do estado de Minas Gerais. Revista do Instituto de Laticínios Cândido Tostes, v. 69, n. 6, p. 433-442, 2014. DOI: http://dx.doi.org/10.14295/2238-6416. v69i6.290

BELOTI, V.; TAMANINI, R.; NERO, L. A.; MOREIRA, M. A. S.; DA SILVA, L. C. C.; FAGNANI, R.; REIS, K. T. M. G. Leite: obtenção, inspeção e qualidade. Londrina: Editora Planta, p. 51-107, 2015. ISBN-10: 8599144073

BRASIL (2001). Agência Nacional de Vigilância Sanitária - Anvisa. Regulamento Técnico sobre Padrões Microbiológicos para Alimentos. Resolução RDC №12, de 02 de janeiro de 2001, Diário Oficial [da] União, Brasília, no 7, 10 jan. 2001. Seção 1, p. 4553.

BRASIL. ANVISA - Agência Nacional de Vigilância Sanitária. Legislação de Boas Práticas de Fabricação. Disponível em: https://www.in.gov.br/en/web/dou/-/resolucao-rdc-n301-de-21-de-agosto-de-2019-211914064 Acesso em: 21 mar. 2009.

BRASIL. Ministério da Agricultura, Pecuária e Abastecimento, Departamento de Inspeção de Produtos de Origem Animal, Portaria № 146, de 07 de março de 1996. Diário Oficial da União, Brasília, 11 de março de 1996, Seção 1, 1996.

CASTRO, A. C. S.; JÚNIOR, W. R. P.; TÁPIA, D. M. T.; CARDOSO, L. G. V. Avaliação da qualidade físico-química e microbiológica de queijos do tipo mussarela comercializados no ceasa de vitória da conquista-BA. Brazilian Journal of Food \& Nutrition/Alimentos e Nutrição, v. 23, n. 3, 2012. ISSN 2179-4448.

COELHO, K. O.; MESQUITA, A. J. D.; MACHADO, P. F.; OLIVEIRA, A. N. D.; SOUZA, C. M. D.; MEYER, P. M. Níveis de células somáticas sobre a proteólise do queijo 
Mussarela. Revista Brasileira de Saúde e Produção Animal, v. 13, p. 682-693, 2012. ISSN 15199940

DUARTE, T. S.; DE LIMA BARBOSA, L. P. J.; BARBOSA, F. H. F. Avaliação microbiológica para detecção de Staphylococcus aureus em quatro marcas de queijo tipo mussarela comercializadas no município de Luz, Minas Gerais. Ciência Equatorial, v. 1, n. 1, 2011. ISSN 2179-9563.

FAGNANI, R.; BATTAGLINI, A. P. P.; BELOTI, V.; DUNGA, K. da S. Sources of microbiological contamination during mozarella cheese production. Brazilian Journal of Veterinary Medicine, v. 35, n. 3, p. 217-223, 2013. Disponível em: https://rbmv.org/BJVM/article/view/619 . Acesso em: 13 sep. 2021.

FONSECA, S. F.; RAMOS JR, C. R. R.; SOQUETTA, M. B.; STEURER, F.; CASALINI, J.; BARBOSA, E. G.; MACHADO, M. R. G. Qualidade microbiológica de queijo Tipo Mussarela ralado comercializado a granel. In: CIC, 18.; ENPOS, 11.; AMOSTRA CIENTíFICA, 1., 2009, Pelotas. Anais... Pelotas-RS: Universidade Federal de Pelotas/UFPel, 2009. p 1-5. Disponível em: http://www.ufpel.tche.br/cic/2009/cd/pdf/CA/CA_01688.pdf Acesso em: 02 nov. 2010.

FREITAS, M. P. Avaliação microbiológica de queijos artesanais produzidos na cidade de Taió, Santa Catarina. Saúde e meio ambiente: revista interdisciplinar, v. 4, n. 2, p. 103114, 2015. doi: http://dx.doi.org/10.24302/sma.v4i2.869

GASPAROTTO, P. H. G. Avaliação microbiológica para detecção de Staphylococcus aureus em queijos tipo Muçarela. Revista Ciência e Saúde Animal, v. 1, n. 1, 2019. DOI: https://doi.org/10.6084/m9.figshare.11312459.v2

GERMANO, P.M.L.; GERMANO, M.I.S. Agentes bacterianos de toxinfecções. In: Germano PML, Germano MIS, editores. Higiene e Vigilância Sanitária de Alimentos. São Paulo: Livraria Varela; 2001. p.199-258.

LOSITO, F.; ARIENZO, A.; BOTTINI, G.; PRIOLISI, F. R.; MARI, A.; ANTONINI, G. Microbiological safety and quality of Mozzarella cheese assessed by the microbiological survey method. Journal of Dairy Science, v. 97, n. 1, p. 46-55, 2014. DOI: http://dx.doi.org/10.3168/jds.2013-7026

MUKHTAR, H.; YAQUB, S.; UL HAQ, I. Production of probiotic Mozzarella cheese by incorporating locally isolated Lactobacillus acidophilus. Annals of Microbiology, v. 70, n. 1, p. 1-13, 2020. DOI: https://doi.org/10.1186/s13213-020-01592-7

OLIVEIRA, A. M.; KURIHARA, R. Y.; DA SILVA, F. F.; DE GODOI SILVA, F.; JÚNIOR, J. C. R.; BELOTI, V. Condições higiênico-sanitárias da produção de queijos tipo mussarela e minas frescal comercializados no norte do Paraná. Revista do instituto de laticínios Cândido Tostes, v. 72, n. 1, p. 40-47, 2017. DOI:https://doi.org/10.14295/22386416.v72i1.556 
PERRY, K. S. P. Queijos: aspectos químicos, bioquímicos e microbiológicos. Química Nova, São Paulo, v. 27, n. 2, p. 293-300, 2004 DOI: https://doi.org/10.1590/S010040422004000200020

PINTO, M. S.; FERREIRA, C. L. D. L. F.; MARTINS, J. M.; TEODORO, V. A. M.; DOS SANTOS PIRES, A. C.; FONTES, L. B. A.; VARGAS, P. I. R. Segurança alimentar do queijo minas artesanal do Serro, Minas Gerais, em função da adoção de boas práticas de fabricação. Pesquisa Agropecuária Tropical, p. 342-347, 2009. e-ISSN 1983-4063

QUINTANA, R. C.; CARNEIRO, L. C. Avaliação das condições higiênico-sanitárias dos queijos minas frescal e mussarela produzidos na cidade de Morrinhos - GO. Revista Brasileira de Saúde e Produção Animal. v. 8, n.3, p. 205-211, 2007. ISSN: 1519-9940

RAIMANN, V. I. Avaliação microbiológica de queijos mussarela produzidos na Região Sudoeste do Paraná. Monografia (Especialização) - Universidade Federal do Paraná, Curitiba, 2011

REGES, J. T. A.; RODRIGUES, A. C. B.; SILVA, C. J.; SANTOS, S. M.; MAIA, A. C. A. C.; TAVARES, W. R. V.; JESUS, M. N.; SILVA, S. D. R. Qualidade microbiológica e físico química do queijo mussarela a granel comercializadas em Jataí (Goiás, Brasil). Revista Colombiana de Investigaciones Agroindustriales, v. 4, p. 69-77, 2017. DOI: $10.23850 / 24220582.767$

REGES, J. T. A.; FARIAS, A. M.; SILVA, R. M. P.; COSTA, A. C. D. A.; CAVALCANTE, L. S. PHYSICAL-CHEMICAL AND MICROBIOLOGICAL QUALITY OF SLICED MUSHROOM CHEESE. Revista Agrotecnologia-Agrotec, $2018 . \quad$ Doi: https://doi.org/10.12971/2179-5959/agrotecnologia.v9n2p1-8

REGINATO, A. M.; VALIATTI, T. B.; SOBRAL, F. D. O. S.; ROMÃO, N. F. Avaliação microbiológica de queijo tipo mussarela fatiado comercializado em supermercados do município de Ji-Paraná-Rondônia. Revista Brasileira de Higiene e Sanidade Animal, v. 13, n. 1, p. 89-97, 2019. ISSN: 1981-2965

SANTOS LEMBI, M. K.; LIUTTI, J. T.: SABEC, G. Z.: DOS SANTOS KAWAMOTO, K. T. V. Análise microbiológica de queijo industrializado do tipo mussarela e condutas para obtenção de qualidade no seu processamento. Brazilian Journal of Health Review, v. 3, n. 3, p. 4951-4964, 2020. DOI: https://doi.org/10.34119/bjhrv3n3-078

SANTOS-KOELL, F. T.; MATTANA, A.; HERMES, E. Avaliação microbiológica do queijo tipo mussarela e queijo colonial comercializado na região oeste do Paraná. Revista Brasileira de Tecnologia Agroindustrial, v. 3, n. 2, p. 66-74, 2009. DOI:10.3895/S1981-36862009000200008

WONG, A. C. L.; BERGDOLL, M. S. Staphylococcal food poisoning. In: CLIVER, DO; RIEMANN, H.P. Foodborne Diseases. 2.ed. Amsterdam: Academic Press, 2002. p.231-248. 


\title{
CAPITULO $V$ \\ CARNE BOVINA MOÍDA: ASPECTOS MICROBIOLÓGICOS
}

DOI: 10.51859/AMPLLA.DES1788-5

\author{
Mariane Alves da Silva ${ }^{1}$ \\ Thaynara Ribeiro Carneiro da Silva ${ }^{2}$ \\ Luana Cristhiny Silva da Costa ${ }^{3}$ \\ Claudete Rosa da Silva ${ }^{4}$ \\ Fábio Israel Martins Carvalho ${ }^{5}$ \\ Priscilla Andrade Silva ${ }^{6}$
}

\footnotetext{
${ }^{1}$ Graduanda do Curso de Zootecnia. Universidade Federal Rural da Amazônia - UFRA

${ }^{2}$ Graduanda do Curso de Zootecnia. Universidade Federal Rural da Amazônia - UFRA

${ }^{3}$ Graduanda do Curso de Agronomia. Universidade Federal Rural da Amazônia - UFRA

${ }^{4}$ Professora do Campus de Parauapebas. Universidade Federal Rural da Amazônia - UFRA

5 Professor do Campus de Parauapebas. Universidade Federal Rural da Amazônia - UFRA

${ }^{6}$ Professora do Campus de Parauapebas. Universidade Federal Rural da Amazônia - UFRA
}

\section{RESUMO}

O Brasil possui o maior rebanho bovino do mundo com 14,3\% (do rebanho mundial) e 217 milhões de cabeças de gado. A carne contém vitaminas do complexo $B$, fontes de proteínas, aminoácidos, sais minerais e ferro. A carne moída é bastante consumida pela população devido seu custo ser acessível. Entretanto, tal alimento após o processo de moagem da carne in natura fica mais favorável para a contaminação de microrganismos devido seu $\mathrm{pH}$ ser próximo a neutralidade. A carne moída sendo consumida em condições inadequadas, ou seja, no caso contaminada pode causar doenças na população pelos microrganismos patogênicos. O presente estudo teve como objetivo analisar 10 artigos e evidenciar os aspectos contaminantes da carne bovina moída comercializada e/ou produzida, em diferentes municípios e regiões, avaliando suas análises microbiológicas. Para a avaliação microbiológica foram discutidos os seguintes microrganismos, Staphylococcus aureus e Salmonella spp. Todos os trabalhos avaliados não apresentaram os padrões recomendados pela legislação, classificando o alimento como um produto em condições sanitárias insatisfatórias e impróprios para o consumo devido ao alto nível de contaminação.

Palavras-chave: Contaminação. Patogênicos. Normas sanitárias. 


\section{INTRODUÇÃO}

A carne bovina é um alimento essencial para a alimentação humana, pois fornece uma das principais fontes de proteínas, vitaminas, ácidos graxos e gorduras, favorecendo a participação da dieta humana (OLIVEIRA et al., 2017). Mesmo sendo um produto de alta nutrição, quando entra em processo de moagem, é mais propício estar em contato com a proliferação de microrganismos, pela elevada atividade de água e pH próximo a neutralidade $(5,8$ a 6,2$)$. Com uso de equipamentos mal higienizados, a não limpeza da bancada também pode proporcionar multiplicação aos microrganismos, beneficiando a contaminação da carne durante a atividade de moagem (RIBEIRO et al, 2020). Com a ineficiência de higiene e sanitização do ambiente onde está a carne, têmse um aumento significativo dos microrganismos, com a ingestão das mesmas, com cuidados inapropriados, faz com que a carne se torne um veículo de Doenças Transmitidas por Alimentos (DTA's) para o consumidor (ALCÂNTARA et al., 2020). Através de análises físico - químicas, bacteriológicas e microbiológicas, é possível detectar as devidas contaminações presentes, por exemplo Staphylococcus aureus e Salmonella spp.

\section{REFERENCIAL TEÓRICO}

\subsection{IMPORTÂNCIA E QUALIDADE NUTRICIONAL DA CARNE MOÍDA BOVINA}

A indústria de carne bovina tem uma grande importância dentro e fora do mercado brasileiro. O Brasil em 2020, foi o maior do mundo em termos de rebanho bovino com 14,3\% (rebanho mundial) e 217 milhões de cabeças de gado. Embora o país seja o maior produtor de bovinos no mundo e o maior exportador desta carne, se adicionarmos a produção de suínos e aves, o Brasil tende a ocupar a terceira posição mundial no mercado internacional, correspondendo em 2020 a 9,2\% (ou 29 milhões de toneladas) da produção, atrás da China e dos Estados Unidos (ABIEC, 2021; MAPA, 2021).

A carne moída bovina é integrada na alimentação de uma grande parte da população brasileira. De acordo com Monteiro et al. (2018) a carne tem vitaminas do complexo B e possui fontes de proteínas com alto valor biológico, aminoácidos essenciais e sais minerais, em particular as carnes vermelhas, pois contêm ferro de alta 
biodisponibilidade. Além disso, a carne moída é bem versátil e seu custo benefício é acessível. Sendo bastante aceita na mesa do consumidor por sua praticidade e diversidade dentro da culinária.

Segundo o Anexo II da Instrução Normativa № 83, de 21 de novembro de 2003, a carne moída é um subproduto obtido a partir da moedura de massas musculares de carcaças e sua venda é permitida somente se a moagem for realizada na presença do consumidor (LIMA et al., 2021; ROSINA et al., 2013; JÚNIOR et al., 2018).

Porém, esta reúne inúmeras peculiaridades relacionadas à carga microbiana, uma vez que, ao passar por um processamento intenso de moagem, apresenta maior área de superfície e facilita o acesso e multiplicação de microrganismos. A composição rica em água, proteínas, substâncias não-proteicas solúveis e gorduras dos produtos cárneos in natura, juntamente com o pH favorecem o crescimento microbiano, que quando não bem controlados, podem causar prejuízos econômicos e afetar a saúde dos consumidores (ALCANTRA et al., 2020).

Por ser amplamente consumida, é de suma importância oferecer ao consumidor um produto de adequada qualidade microbiológica, já que este pode ser responsável por ocasionar doenças para a população que dela faz uso (ROSINA; MONEGO, 2013). A qualidade da carne depende de vários fatores tais como, forma de manejo, tecnologia aplicada na produção dos animais, forma de abate, processamento, armazenamento, transporte e as condições de comercialização.

\subsection{ASPECTOS CONTAMINANTES DA CARNE MOÍDA}

A carne bovina, em especial a moída, contém grande potencial de contaminação, isso pode ser explicado por ser um insumo originado de vários cortes e serem excessivamente manipulados em seu processamento, além do que, ficam por longos períodos sob temperaturas ambientes. O processo de moagem da carne in natura favorece a contaminação por microrganismos, pois aumenta sua superfície de contato e proporciona a incorporação de resíduos de moagens anteriores (LEÃO et al., 2015). Devido ao seu pH ser próximo a neutralidade e a sua composição nutricional, a carne moída é propícia a ser um ótimo meio para microrganismos. De acordo com os relatos nas literaturas, o local onde é vendido esse alimento, se não possuir uma boa higienização dos equipamentos, das bancadas, principalmente dos moedores, serão 
cruciais para a contribuição na contaminação microbiana dos mesmos (RIBEIRO et al., 2020).

Com base no Monteiro et al. (2018), a contaminação da carne moída por microrganismos patogênicos e deterioradores tem potencial em afetar a qualidade do alimento, o seu tempo de conservação e principalmente colocar até mesmo a saúde do consumidor em riscos. $O$ consumo desse insumo contaminado pode acarretar em graves patologias na população, como dor de estômago, febre, náuseas, vômitos e diarreias, diferenciando de acordo com o tipo de ação do microrganismo, da quantidade consumida e do sistema imune do indivíduo, evidenciando a relevância da avaliação higiênico-sanitária deste produto.

Diante do exposto, houve uma necessidade em realizar análises físico-químicas, bacteriológicas e microbiológicas nesse alimento, por grande parte dos trabalhos avaliados.

\section{METODOLOGIA}

Foi realizado uma revisão de literatura sobre microbiologia em carne moída bovina. Foram selecionados e analisados 10 artigos, levando em considerando as análises microbiológicas sendo eles: Rosina \& Monego (2013), Nascimento et al. (2014), Leão et al. (2015), Oliveira et al. (2017), Monteiro et al. (2018), Silva-Júnior al. (2018), Amorim et al. (2019), Alcântara et al. (2020), Ribeiro et al. (2020) e Lima et al. (2021).

A revisão sistemática da literatura foi realizada, entre maio e setembro de 2021, por meio do portal da revista. Capes e BVCA (Biblioteca Virtual em Ciências Agrárias) utilizando pesquisa avançada com a combinação dos descritores "Análises microbiológicas, qualidade nutricional da carne, aspectos contaminantes da carne". Essas bases de dados e bibliotecas digitais foram escolhidas por serem referência para muitos pesquisadores brasileiros, concentrando periódicos bem qualificados a nível nacional e internacionalmente.

A seleção dos artigos baseou-se nos seguintes critérios: publicações nacionais e internacionais que responderam a busca avançada, sem restrição de período de tempo, com vistas a compreender a historicidade das pesquisas sobre a temática. Ressalta-se que, apesar da ausência de restrição de tempo, todos os artigos encontrados se enquadraram no intervalo de publicações realizadas entre os anos de 2003 e 2020. 


\section{RESULTADOS E DISCUSSÕES}

Os dados obtidos das análises microbiológicas da carne moída referentes aos dez artigos seguem expostos na Tabela 1.

Tabela 1 - Dados da literatura para os valores encontrados para Coliformes Totais, Coliformes Termotolerantes e pesquisa de Salmonella spp.

\begin{tabular}{|c|c|c|c|}
\hline Autores & $\begin{array}{l}\text { Coliformes Totais } \\
\text { (NMP/g) }\end{array}$ & $\begin{array}{c}\text { Coliformes } \\
\text { Termotolerantes } \\
\text { (NMP/g) }\end{array}$ & $\begin{array}{c}\text { Salmonella spp. } \\
(25 \mathrm{~g})\end{array}$ \\
\hline Rosina \& Monego (2013) & $3,0 \times 10^{2}$ a $1,1 \times 10^{3}$ & $<3,0 \times 10$ a $1,1 \times 10^{3}$ & Ausência \\
\hline Nascimento et al. (2014) & $2,4 \times 10^{2}$ a $>1,1 \times 10^{4}$ & $9,3 \times 10^{1} a>1,1 \times 10^{4}$ & Presença \\
\hline Leão et al. (2015) & $0,0 \times 10^{1}$ a $2,4 \times 10^{6}$ & $0,0 \times 10^{1} a>2,4 \times 10^{3}$ & Presença \\
\hline Oliveira et al. (2017) & $>2,5 \times 10^{2}$ a $8,0 \times 10^{4}$ & $2,5 \times 10^{1}$ a $4,0 \times 10^{2}$ & Presença \\
\hline Monteiro et al. (2018) & $0,5 \times 10^{1}$ a $8,8 \times 10^{2}$ & $0,1 \times 10^{1}$ a $4,7 \times 10^{2}$ & Presença \\
\hline Silva-Júnior al. (2018) & ----- & ----- & Presença \\
\hline Amorim et al. (2019)) & ----- & ----- & Presença \\
\hline Alcântara et al. (2020) & $9,2 \times 10^{1}$ a $5,3 \times 10^{3}$ & $3,6 \times 10^{1}$ a $5,3 \times 10^{3}$ & Presença \\
\hline Ribeiro et al. (2020) & $<3,0 \times 10^{1}$ a $9,3 \times 10^{1}$ & $<3,0 \times 10^{1}$ a $9,2 \times 10^{1}$ & Presença \\
\hline Lima et al. (2021) & $<3,0 \times 10^{1}$ a $1,1 \times 10^{3}$ & ------ & Presença \\
\hline \multicolumn{4}{|l|}{ Legislação para } \\
\hline $\begin{array}{l}\text { Coliformes Totais e } \\
\text { Termotolerantes } \\
\text { (BRASIL, 2001) }\end{array}$ & $0,5 \times 10^{2} \mathrm{NMP} / \mathrm{g}$ & $10^{2} \mathrm{NMP} / \mathrm{g}$ & ------ \\
\hline
\end{tabular}

NMP - Número Mais Provável.

Diante da Comissão Nacional de Normas e Padrões para Alimentos, de 1978, referente a carne crua, temos os limites de $10^{2} \mathrm{NMP} / \mathrm{g}$ para coliformes totais a $35^{\circ} \mathrm{C}$ e $5,0 \times 10^{2} \mathrm{NMP} / \mathrm{g}$ para coliformes termotolerantes a $45^{\circ} \mathrm{C}$. Entretanto, se consideramos a Resolução RDC $n^{\circ} 12$ de 02 de janeiro de 2001 da ANVISA (BRASIL, 2001), que estabelece os Padrões Microbiológicos Sanitários para Alimentos, normatiza o limite de 0,5 x 10 NPM por grama de Coliformes Termotolerantes a $45^{\circ} \mathrm{C}$ (produtos cárneos crus, resfriados ou congelados) e não citam os Coliformes Totais a $35^{\circ} \mathrm{C}$ (carne in natura). Com base nos resultados obtidos e expostos na tabela 1., Nascimento et al. (2014), verificouse que em $50 \%$ das amostras os valores estavam fora do limites máximos estabelecidos, apresentando Coliformes a $45^{\circ} \mathrm{C} \geq 1500 \mathrm{NMP} / \mathrm{g}$ e 37,5\% $\geq 240 \mathrm{NMP} / \mathrm{g}$, e todas as amostras para Coliformes a $35^{\circ} \mathrm{C} \geq 240 \mathrm{NMP} / \mathrm{g}$, em relação a presença de Salmonella spp. foi encontrado em $50 \%$ das amostras analisadas e indícios de contaminação por Escherichia coli, ainda foi visto, indicadores de vida útil e qualidade da carne através das análises de Bactérias Heterótrofas Mesófilas com resultados satisfatórios segundo as 
normativas. Contudo, os resultados de forma geral, propuseram discordâncias nas condições higiênicas e sanitárias estabelecidos pela a ANVISA.

Os valores encontrados no estudo de Monteiro et al. (2018) evidenciaram uma baixa qualidade microbiológica na carne, com valores fora dos padrões determinados e presença de Salmonella spp., sendo assim, inadequadas para o consumo. O mesmo sucedeu para Alcântara et al. (2020), com altos valores de contagens de coliformes $35^{\circ} \mathrm{C}$ e $45^{\circ} \mathrm{C}$ e S. aureus, também presença de Salmonella spp., indicando condições higiênicas deficientes de fabricação e manipulação do insumo. Observou-se a presença de coliformes totais e termotolerantes em praticamente todas as amostras de Leão et al.(2015) com valores fora do estabelecido, além de Salmonella spp. em 25\% das amostras, houve a incidência de $S$. aureus e bolores e leveduras.

Oliveira et al. (2017), Ribeiro et al. (2020), Silva-Júnior (2018) e Amorim et al. (2019) também identificaram em suas literaturas, a presença de Salmonella spp. e valores em desacordo com o ideal. Sendo o único a ter ausência de Salmonella spp. o estudo de Rosina \& Monego (2013) que apresentou valores dentro dos padrões estabelecidos pela legislação vigente para carne bovina moída. No entanto, as análises microbiológicas relataram uma alta contaminação microbiana da carne bovina moída comercializadas em diferentes localidades, evidenciando as más condições higiênicosanitárias das mesmas.

Os resultados obtidos neste estudo demonstram a necessidade da implementação e monitorização de cuidados higiênicos pelos estabelecimentos e a fiscalização contínua pelos órgãos competentes, a fim de promover melhor controle de qualidade da carne moída comercializada e a redução das doenças de origem alimentar. (RIBEIRO et al., 2020).

\section{CONSIDERAÇÕES FINAIS}

Todos os dez trabalhos analisados em suas respectivas localidades, consideraram as carnes bovinas moídas comercializadas e/ou produzidas inapropriadas para o consumo, pois não apresentaram valores dentro dos padrões da ANVISA, tendo um elevado risco de contaminações.

Diante do exposto nas literaturas, faz-se necessário a adoção de medidas preventivas em toda a cadeia produtiva, por meio de implantação de matadouros 
inspecionados, boas práticas de manipulação do alimento, monitorização de cuidados higiênicos pelos estabelecimentos e a fiscalização contínua pelos órgãos competentes, no sentido de promover um controle de qualidade da carne moída comercializada e a redução das doenças de origem alimentar. Ademais, toda a população deve ser orientada no que diz respeito a cocção desse insumo. Promovendo assim melhorias na qualidade do produto comercializado e principalmente na saúde dos consumidores.

\section{REFERÊNCIAS}

ABIEC. Associação Brasileira das Indústrias Exportadoras de Carne, 2020. Ciência e Tecnologia de Alimentos. Disponível em: http://www.abiec.com.br/wpcontent/uploads/RELEASE_EXPORTACOESBRASILEIRAS-DE-CARNE BOVINA_CONSOLIDADO2020_ABIEC Acesso em: 24 de junho de 2021.

ALCÂNTARA, Bruna Lopes de et al. Qualidade bacteriológica e físico-química da carne bovina moída comercializada em supermercados e casas atacadistas no município de Belém/PA. Higiene Alimentar, e1011-e1011, 2020. http://dx.doi.org/10.37585/HA2020.02bacteriologica

AMORIM, J. R. B.; BOTELHO, L. F. R.; FIUZA, A. P. P. Perfil sanitário e microbiológico da carne moída comercializada em hipermercados. Revista do COMEIA, v. 1, n. 1, p. 61-71, 2019. http://dx.doi.org/10.34117/bjdv6n3-330.

BRASIL. Ministério da Saúde Agência Nacional de Vigilância Sanitária. Resolução $\mathrm{n}^{\circ} 12$ de 02 de janeiro de 2001. Aprova o regulamento técnico sobre padrões microbiológicos para alimentos. Diário Oficial da União. Brasília, 10 jan. 2001. Disponível em: http://portal.anvisa.gov.br/documents/33880/2568070/RDC_12_2001.pdf/15ff ddf6-3767-4527-bfac-740a0400829b. Acesso em: 04 set. 2021.

LEÃO, Sydney Correia et al. Qualidade microbiológica e parasitológica da carne moída comercializada em Aracaju/SE. Brazilian Journal of Food Research v, v. 6, n. 2, p. 15-22, 2015. http://dx.doi.org/10.14685/rebrapa.v6i2.213

LIMA, Joyce Almeida et al. Análise da qualidade da carne moída comercializada em um município no interior da Paraíba. Research, Society and Development, v. 10, n. 4, p. e27610414148-e27610414148, 2021. 10.33448/rsd-v10i4.14148.

MAPA, Ministério da Agricultura, Pecuária e Abastecimento, 2021. [ ]. Disponível em: http://www.agricultura.gov.br/noticias/exportacoes-do-agroultrapassam-abarreira-dos-us-100-bilhoes-pela-segunda-vez Acesso em: 02 de junho de 2021. 
MONTEIRO, Erika da Silva. et al. Qualidade microbiológica de carne bovina moída comercializada em supermercados do Distrito Federal, Brasil. Revista Brasileira de Higiene e Sanidade Animal, v. 12, n. 4, p. 520-530, 2018. DOI: http://dx.doi.org/10.5935/rbhsa.v12i4.467.

NASCIMENTO, Micael Valtoni Dantas do et al. Avaliação da qualidade microbiológica da carne moída fresca comercializada no mercado central em Campina GrandePB. Revista Saúde \& Ciência Online, v. 3, n. 1, p. 56-68, 2014. 10.31533/pubvet.v12n10a199.1-7

OLIVEIRA, Maria Santos et al. Qualidade físico-química e microbiológica da carne moída de bovino em açougues. Revista Electrónica de Veterinaria, v. 18, n. 12, p. 1-13, 2017.

ROSINA, A.; MONEGO, F. Avaliação microbiológica da carne bovina moída nas redes de supermercados de Canoinhas/SC. Saúde e meio ambiente: revista $\begin{array}{llllll}\text { interdisciplinar, } & \text { v. } & 2, & \text { n. } & 2, & \text { p. }\end{array}$ https://doi.org/10.24302/sma.v2i2.468

RIBEIRO, A.C.N et al. 2020. Análise microbiológica de carne bovina moída comercializada em Governador Valadares/MG. Journal of Applied Pharmaceutical Sciences. Disponível em: www.pubvet.com.br Acesso em: 03 de junho 2021.

SILVA-JÚNIOR, Antonio Carlos et al. Análises microbiológicas de carne bovina moída comercializada em supermercados. PubVet, v. 12, p. 131, 2018. http://dx.doi.org/10.31533/pubvet.v12n10a199.1-7 


\title{
CAPITULO VI
}

\section{UM ESTUDO SOBRE A QUALIDADE MICROBIOLÓGICA DE CARNE DE FRANGO NO BRASIL}

\author{
DOI: 10.51859/AMPLLA.DES1788-6
}

\author{
Janaína de Oliveira Pinho ${ }^{1}$ \\ Rosinelle Silva Reis ${ }^{2}$ \\ Luana Cristhiny Silva da Costa ${ }^{3}$ \\ Ernestina Ribeiro dos Santos Neta 4 \\ Fábio Israel Martins Carvalho ${ }^{5}$ \\ Priscilla Andrade Silva ${ }^{6}$
}

\footnotetext{
${ }^{1}$ Graduanda do Curso de Zootecnia. Universidade Federal Rural da Amazônia - UFRA

${ }^{2}$ Graduanda do Curso de Zootecnia. Universidade Federal Rural da Amazônia - UFRA

${ }^{3}$ Graduanda do Curso de Agronomia. Universidade Federal Rural da Amazônia - UFRA

${ }^{4}$ Professora do Campus de Parauapebas. Universidade Federal Rural da Amazônia - UFRA

${ }^{5}$ Professor do Campus de Parauapebas. Universidade Federal Rural da Amazônia - UFRA

${ }^{6}$ Professora do Campus de Parauapebas. Universidade Federal Rural da Amazônia - UFRA
}

\section{RESUMO}

A avicultura exerce papel fundamental no sistema agrícola, devido ao aumento do consumo de produtos avícolas, que colocam o Brasil em destaque mundial na produção e exportação desses produtos, atingindo essa proporção devido ao custo-benefício. No entanto, a carne de frango apresenta características propícias para proliferação de microrganismos. Portanto, o objetivo da elaboração dessa revisão é levantar dados científicos disponíveis sobre a qualidade microbiológica da carne de frango no Brasil e relacionar com o regulamento estabelecido pela ANVISA - Agência Nacional de Vigilância Sanitária. Nos estudos citados na literatura verificou-se que amostras coletadas em diferentes estabelecimentos e regiões do Brasil, apresentaram ocorrências de coliformes totais, termotolerantes na carne de frango, além da presença de Salmonella spp., Staphylococcus aureus e Staphylococcus coagulase positiva, dentre eles algumas análises apresentaram carga microbiológica acima do estabelecido pela legislação vigente. Dessa forma, esses resultados representam negligência sanitária e potencial risco à saúde pública. Ressaltando a necessidade de fiscalização eficiente e a revisão da legislação em vigor.

Palavras-chave: Avicultura. Coliformes. Salmonella. Staphylococcus. 


\section{INTRODUÇ̃̃o}

A avicultura tem papel fundamental na economia e ecologia do sistema agrícola (PERINI et al., 2021), em virtude do aumento do consumo de produtos avícolas nas últimas décadas, com destaque para o Brasil, líder mundial nas exportações de frango (4,2 milhões de toneladas), atendendo mais de 150 países. Quanto a produção de frango, o Brasil também exerce papel significativo como segundo maior produtor com 13,2 milhões de toneladas em 2019, ocupando $13 \%$ do mercado mundial de produção de carne de frango (ABPA, 2020).

Os produtos avícolas ganharam essa proporção devido ao baixo preço, versatilidade do preparo, por não possuir restrições religiosas, além da qualidade nutricional, representado como fonte de alto teor proteína, baixo teor de gordura, vitaminas do complexo B e minerais (WANG et al., 2018). No entanto, em razão da composição química, elevada atividade de absorção de água, disponibilidade de nutrientes e $\mathrm{pH}$ próximo a neutralidade, representam características propícias à proliferação de microrganismos, que podem causar deterioração do produto, acarretando perdas econômicas e risco à saúde humana, devido a possível presença de patógenos (MEHDIZADEH; LANGROODI, 2019).

À vista disso, é necessário manter o monitoramento da segurança dos produtos avícolas, garantindo a proteção do consumidor e qualidade dos produtos alimentícios, principalmente no que diz respeito à segurança higiênico-sanitária na cadeia produtiva de alimentos, bem como às necessidades específicas dos diferentes mercados. Portanto, objetiva-se com esta revisão realizar o levantamento de dados científicos disponíveis na literatura a respeito da qualidade microbiológica da carne de frango no Brasil, relacionando os resultados com o Regulamento de Padrões Microbiológicos e Sanitários para Alimentos, RDC n¹2/2001, estabelecido pela ANVISA - Agência Nacional de Vigilância Sanitária.

\section{METODOLOGIA}

Foi realizado uma revisão de literatura sobre microbiologia em carne de frango. Foram selecionados e analisados vários artigos, levando em considerando as análises 
microbiológicas sendo eles: Pimentel et al. (2019), Sales et al. (2014), Menezes et al. (2018), Muchinski \& Degenhardt (2016), Oliveira et al. (2009).

A revisão sistemática da literatura foi realizada, entre maio e setembro de 2021, por meio do portal da revista. Capes e BVCA (Biblioteca Virtual em Ciências Agrárias) utilizando pesquisa avançada com a combinação dos descritores "Análises microbiológicas, qualidade nutricional da carne de frango, aspectos contaminantes da carne de frango". Essas bases de dados e bibliotecas digitais foram escolhidas por serem referência para muitos pesquisadores brasileiros, concentrando periódicos bem qualificados a nível nacional e internacionalmente.

A seleção dos artigos baseou-se nos seguintes critérios: publicações nacionais e internacionais que responderam a busca avançada, sem restrição de período de tempo, com vistas a compreender a historicidade das pesquisas sobre a temática. Ressalta-se que, apesar da ausência de restrição de tempo, todos os artigos encontrados se enquadraram no intervalo de publicações realizadas entre os anos de 2009 e 2021.

\section{RESULTADOS E DISCUSSÕES}

A carne e seus derivados apresentam inúmeros benefícios, mas estão sujeitos a ocorrência de reações químicas, físicas e microbiológicas que podem afetar as características organolépticas. A ocorrência e proliferação de microrganismos está associado a fatores intrínsecos e extrínsecos que podem ocorrer desde a criação, abate e/ou manejo das carcaças no comércio, podendo tornar-se veículo de transmissão de inúmeros microrganismos (DOUROU et al., 2021), que podem ser patogênicos aos seres humanos. Por essa razão, estudos científicos são realizados a fim de analisar a presença de microrganismos que podem ser nocivos à saúde pública.

Na Tabela 1 estão dispostos os valores averiguados nos artigos avaliados sobre as análises microbiológicas em carnes de frango. Pimentel et al. (2019) avaliou amostras coletadas em três estabelecimentos de feiras livres de Castanhal, Pará. Sales et al. (2014) quantificou amostras coletadas em dez supermercados de Curitiba, Paraná. Menezes et al., 2018 estudou amostras coletadas em frigoríficos sob a Inspeção Federal e Estadual nas mesorregiões de Minas Gerais (Salmonella presente em 22 carcaças de 240 avaliadas). Já Muchinski e Degenhardt (2016) observaram os microrganismos presentes em amostras coletadas em sete estabelecimentos de Xanxerê, Santa Catarina. Oliveira 
et al. (2009) averiguou as amostras coletadas em frigoríficos sob Inspeção Federal de Belo Horizonte, Minas Gerais.

A presença de coliformes totais em alimentos são indicadores sanitários, uma vez que presentes pode-se inferir que outros patógenos podem ser encontrados (Menezes et al., 2018). A legislação brasileira estabelece apenas a contagem de coliformes termotolerantes como padrão biológico para carcaças de frango congeladas ou resfriadas, considerando o nível máximo de $10^{4}$ UFC/g (BRASIL., 2001). Nos achados da literatura as amostras coletadas em diferentes estabelecimentos e regiões do Brasil, apresentaram ocorrências de coliformes totais e termotolerantes na carne de frango. $O$ estudo realizado por Menezes et al. (2018), em frigoríficos com inspeção federal e estadual nas mesorregiões do estado de Minas Gerais, apresentou resultados de análises microbiológicas acima do limite estabelecido pela legislação (Tabela 1).

Tabela 1 - Análises microbiológicas de amostras de carne de frango em diferentes estabelecimentos do Brasil

\begin{tabular}{|c|c|c|c|c|c|}
\hline Autores & Cortes & $\begin{array}{c}\text { Coliformes } \\
\text { Totais (NMP/g) }\end{array}$ & $\begin{array}{c}\text { Coliformes } \\
\text { Termotolerantes } \\
\text { (NMP/g) }\end{array}$ & $\begin{array}{l}\text { Salmonella } \\
\text { spp. (25g) }\end{array}$ & $\begin{array}{c}\text { Staphylococcus } \\
\text { spp. (UFC/g) }\end{array}$ \\
\hline $\begin{array}{l}\text { Pimentel et al. } \\
\text { (2019) }\end{array}$ & $\begin{array}{c}\mathrm{NE}, \text { in } \\
\text { natura }^{1}\end{array}$ & $\begin{array}{c}1,5 \times 10^{2} a>1,1 \\
\times 10^{3}\end{array}$ & $<0,3 \times 10$ a $1,1 \times 10^{3}$ & Ausência & ----- \\
\hline $\begin{array}{l}\text { Sales et al. } \\
(2014)\end{array}$ & $\begin{array}{l}\text { Peito, } \\
\text { resfriado }\end{array}$ & 0,0 a $3,4 \times 10$ & 0,0 a $3,0 \times 10^{3}$ & ----- & ----- \\
\hline $\begin{array}{l}\text { Menezes et al. } \\
(2018)\end{array}$ & $\begin{array}{l}\text { Carcaça, } \\
\text { resfriada }\end{array}$ & $\begin{array}{c}1,0 \times 10^{2} \text { a } 2,0 \\
\times 10^{7}\end{array}$ & $1,0 \times 10^{2}$ a $9,7 \times 10^{6}$ & Presença & $\begin{array}{c}6,4 \times 10^{2} a \\
1,0 \times 10^{6}\end{array}$ \\
\hline $\begin{array}{l}\text { Muchinski \& } \\
\text { Degenhardt } \\
(2016)\end{array}$ & $\begin{array}{c}\text { Asa, } \\
\text { temperada }\end{array}$ & ----- & $\begin{array}{c}<1,0 \times 10^{1} \mathrm{a} \\
1,6 \times 10^{3}\end{array}$ & Ausente & $\begin{array}{c}<1,0 \times 10 \text { a } \\
2,7 \times 10^{3}\end{array}$ \\
\hline $\begin{array}{l}\text { Oliveira et al. } \\
(2009)\end{array}$ & $\begin{array}{l}\text { Peito, } \\
\text { resfriado }\end{array}$ & $\begin{array}{c}<0,5 \times 10 a \\
2,9 \times 10\end{array}$ & $<0,5 \times 10$ a $2,9 \times 10$ & Presença & ----- \\
\hline \multicolumn{6}{|l|}{ Legislação RDC } \\
\hline $\begin{array}{l}\text { no } 12 \text { (BRASIL, } \\
\text { 2001) }\end{array}$ & & ----- & $10^{4} \mathrm{NMP} / \mathrm{g}$ & ----- & ------ \\
\hline
\end{tabular}

"Presença em 25g; NE = Não Especificado.

Também foram encontradas ocorrências de Salmonella spp. No estudo realizado por Oliveira et al. (2009), houve ocorrência em 25g, ultrapassando os limites estabelecidos para registro e fiscalização de produtos alimentícios, estabelecidos pela legislação vigente (BRASIL, 2001). Destaca-se que a Salmonella é causadora de graves toxinfecções alimentares, sendo que os produtos avícolas são os principais veículos de transmissão em humanos. A contaminação dos produtos alimentícios pode ocorrer 
tanto na fase primária, quanto nas fases posteriores da cadeia de abastecimento (LI et al., 2019). Entre as doenças causadas pelo gênero estão a febre tifoide, febres entéricas e enterocolites (salmoneloses). No sistema avícola, a Salmonella pode reduzir a performance produtiva, comprometer cerca de $24 \%$ do ganho de peso e aumentar a taxa de conversão alimentar em aproximadamente 12\% (ALJUMAAH et al., 2020). Devido ao risco da contaminação por Salmonella em carnes de aves, foi instituído pelo Ministério da Agricultura, Pecuária e Abastecimento (MAPA) a Instrução Normativa $\mathrm{n}^{\circ} 20$, de 2016, o controle e monitoramento de Salmonella spp. em estabelecimentos avícolas comerciais e de abate, com intuito de reduzir a prevalência e estabelecer nível adequado de proteção ao consumidor (BRASIL, 2016).

No entanto, as condições de manejo na criação, a manipulação nas operações de abate tem influência na ocorrência e quantidade encontrada na carne de frango e sua ocorrência demonstra a necessidade de medidas de controle e garantia da segurança alimentar. Portanto, foi utilizada irradiação em diferentes doses, onde constatou-se que a dosagem de 1,5KGy foi eficiente para eliminar a presença de Salmonella spp. em 25g de amostra, além de reduzir a população de coliformes totais e termotolerantes (OLIVEIRA et al., 2009).

As amostras analisadas para Staphylococcus apresentaram resultados positivos, em que se relata alta carga microbiológica desse microrganismo, sendo que o gênero é um dos patógenos que mais causam surtos de origem alimentar no Brasil (GUTIÉRREZ et al., 2012), ressaltando o risco à saúde pública e a necessidade de fiscalização sanitária.

O consumo de alimentos contaminados com toxinas produzidas por S. aureus pode levar à intoxicação alimentar estafilocócica, podendo causar gastroenterites graves, náuseas, vômitos, diarreia e dor abdominal em 1 a 6 horas após a ingestão de alimentos contaminados (SILVA et al., 2019). A temperatura de proliferação das bactérias do gênero ocorre entre $7^{\circ} \mathrm{C}$ a $47,8^{\circ} \mathrm{C}$ com $7,5 \%$ a $15 \%$ de $\mathrm{NaCl}$, mas não competem bem com outros microrganismos (ROTANA et al., 2021). Por essa razão o gênero encontra meio adequado em carnes temperadas, devido a concentração de sal mais elevada, que inibe outros microrganismos patógenos e deteriorantes. A legislação em vigor não estabelece parâmetros microbiológicos para Staphyloccocus em carnes resfriadas, ou congeladas, "in natura", de aves (carcaças inteiras fracionadas ou cortes) e não há padrão determinado para esse microrganismo nos produtos. 


\section{CONSIDERAÇÕES FINAIS}

Desde a criação, abate até o manejo de carcaças nos comércios ocorre exposição do produto alimentício à patógenos, apontando que a ocorrência de microrganismos está amplamente presente não só na produção, mas também nos produtos finais. A ocorrência e as altas contagens de coliformes termotolerantes e de Staphyloccocus, e a presença de Salmonella spp., representam negligência sanitária e potencial risco à saúde pública. É necessário que a fiscalização aconteça de forma eficiente e a legislação em vigor seja revisada, a fim de estabelecer o monitoramento de outros microrganismos que ainda não são considerados na análise de carne de aves. Por fim, vale destacar a necessidade da elaboração de estudos com medidas de controle e garantia da segurança alimentar, devido à sua importância para a saúde pública.

\section{REFERÊNCIAS}

ABPA, Associação Brasileira de Proteína Animal. Relatório anual da Associação Brasileira de Proteína Animal, 2020.

ALJUMAAH, Mashael R. et al. Effects of phytobiotic feed additives on growth traits, blood biochemistry, and meat characteristics of broiler chickens exposed to Salmonella typhimurium. Poultry Science, v. 99, n. 11, p. 5744-5751, 2020. https://doi.org/10.1016/j.psj.2020.07.033

BRASIL. Agência Nacional de Vigilância Sanitária - ANVISA. Resolução RDC no 12, de 2 de janeiro de 2001. Regulamento técnico sobre os padrões microbiológicos para alimentos.

BRASIL. Ministério da Agricultura, Pecuária e Abastecimento. Instrução Normativa $n^{\circ} 20$, de 21 de outubro de 2016. Diário Oficial da União. Brasília de 25 out. 2016. Seção 1, p.13.

DOUROU, Dimitra et al. Microbiota of Chicken Breast and Thigh Fillets Stored under Different Refrigeration Temperatures Assessed by Next-Generation Sequencing. Foods, v. 10, n. 4, p. 765, 2021. DOI: https://doi.org/10.3390/foods10040765

GUTIÉRREZ, Diana et al. Sensibilidade de fago e transporte de profago em Staphylococcus aureus isolado de alimentos na Espanha e Nova Zelândia. Jornal Internacional de Microbiologia Alimentar, v. 230, p. 16-20, 2016.

LI, Ying et al. A surveillance of microbiological contamination on raw poultry meat at retail markets in China. Food Control, v. 104, p. 99-104, 2019. https://doi.org/10.1016/j.foodcont.2019.04.037 
MEHDIZADEH, Tooraj; LANGROODI, Ali Mojaddar. Chitosan coatings incorporated with propolis extract and Zataria multiflora Boiss oil for active packaging of chicken breast meat. International journal of biological macromolecules, v. 141, p. 401-409, 2019. DOI: https://doi.org/10.1016/j.ijbiomac.2019.08.267

MENEZES, L. D. M. et al. Caracterização microbiológica de carcaças de frangos de corte produzidas no estado de Minas Gerais. Arquivo Brasileiro de Medicina Veterinária e Zootecnia, v. 70, p. 623-627, 2018. https://doi.org/10.1590/1678-4162-9912

MUCHINSKI, Mônica; DEGENHARDT, Roberto. Qualidade microbiológica de carne de frango temperada comercializada em açougues. Jornada Integrada em Biologia, p. 91-91, 2016. Recuperado de: https://portalperiodicos.unoesc.edu.br/ jornadaintegradaembiologia/article/view/10336

OLIVEIRA, A. L. et al. Qualidade microbiológica da carne de frango irradiada em embalagem convencional e a vácuo. Arquivo Brasileiro de Medicina Veterinária e Zootecnia, v. 61, n. 5, p. 1210-1217, 2009. https://doi.org/10.1590/S0102-09352009000500026

PERINI, F. et al. Emerging genetic tools to investigate molecular pathways related to heat stress in chickens: A review. Animals, v. 11, n. 1, p. 46, 2021. https://doi.org/10.3390/ani11010046

PIMENTEL, Camila Nayara Monteiro; DA COSTA GODOT, Talita Mayara; FIGUEIREDO, Elaine Lopes. Avaliação microbiológica de carne de frango comercializadas no município de Castanhal, Pará. Brazilian Journal of Development, v. 5, n. 10, p. 21863-21871, 2019.

RORTANA, Chea et al. Prevalência de Salmonella spp. e Staphylococcus aureus em carnes de frango e porco dos mercados cambojanos. Patógenos, v. 10, n. 5, p. 556, 2021.

SALES, Willian Barbosa et al. Avaliação microbiológica da carne de frango. Cadernos da Escola de Saúde, v. 2, n. 12, 2014.

SILVA, Anderson Clayton; RODRIGUES, Marjory Xavier; SILVA, Nathália Cristina Cirone. Methicillin-resistant Staphylococcus aureus in food and the prevalence in Brazil: a review. Brazilian Journal of Microbiology, v. 51, n. 1, p. 347-356, 2020.

https://doi.org/10.1007/s42770-019-00168-1

WANG, Xiaoyang et al. Determination of virginiamycin M1 residue in tissues of swine and chicken by ultra-performance liquid chromatography tandem mass spectrometry. Food Chemistry, v. 250, p. 127-133, 2018. https://doi.org/10.1016/j.foodchem.2018.01.024 


\title{
CAPITULO VII
}

AVALIAÇÃO DA SEGURANÇA MICROBIOLÓGICA E DO PERFIL DE BACTÉRIAS PRODUTORAS DE HISTAMINA

EM CAVALA (SCOMBEROMORUS CAVALLA) E DOURADO (SALMINUS BRASILIENSIS) COMERCIALIZADOS EM MACEIÓ, ALAGOAS, BRASIL

DOI: 10.51859/AMPLLA.DES1788-7

\author{
Jammilly de Oliveira Vieira Moreira ${ }^{1}$, \\ Michelle Teixeira da Silva ${ }^{1}$, \\ Clara Andrezza Crisóstomo Bezerra Costa ${ }^{1,2}$, \\ Jacilene Eliziario da Silva ${ }^{1}$, \\ Emanoel Guilhermino da Silva Júnior ${ }^{2}$, \\ João Victor Lessa de Oliveira ${ }^{2}$, \\ Anderson Lopes Pimentel ${ }^{2}$, \\ Fernanda Geny Calheiros Silva ${ }^{1,2}$, \\ Maria Aline Barros Fidelis de Moura ${ }^{2}$, \\ Lara Mendes de Almeida 1,2, \\ Giselda Macena Lira ${ }^{1}$, \\ Maria Cristina Delgado Silva ${ }^{1,2}$, \\ Ticiano Gomes do Nascimento ${ }^{1,2}$,
}

\footnotetext{
${ }^{1}$ Laboratório de Controle de Qualidade Microbiológico de Alimentos, Programa de Pós-Graduação em Nutrição, Faculdade de Nutrição, Universidade Federal de Alagoas (UFAL), Maceió, Alagoas, Brasil. Postcode: 57072-970.

2 Laboratório de Análises Farmacêuticas e Alimentícias (LAFA), Programa de Pós-Graduação em Ciências Farmacêuticas, Instituto de Ciências Farmacêuticas (ICF), Universidade Federal de Alagoas (UFAL), Maceió, Alagoas, Brasil. Postcode: 57072-970.
} 


\section{RESUMO}

Os peixes e os frutos do mar podem ser veículos de doenças de origem alimentar causadas por perigos físicos, biológicos e químicos. A histamina é uma amina biogênica produzida por bactérias que causa a degradação natural de aminoácidos em certos tipos de peixes. Portanto, os objetivos deste estudo foram avaliar a segurança microbiológica de Cavala e Dourado dentro dos limites microbiológicos estabelecidos pela legislação em vigor, e investigar a presença de bactérias produtoras de histamina extraídas dessas espécies de peixes. Foram coletadas 40 amostras de peixes frescos, das quais 20 de Dourado e 20 de Cavala foram adquiridos aleatoriamente em pontos comerciais no município de Maceió ( $\mathrm{AL}$ ) e entregues ao Laboratório de Controle de Qualidade de Alimentos da Universidade Federal de Alagoas para identificação de Staphylococcus spp. coagulase-positiva, Enterobacteriaceae, Salmonella spp., e investigação de bactérias produtoras de histamina. Utilizou-se a metodologia recomendada pela APHA para avaliação microbiológica e meios Niven com o Sistema Bactray ${ }^{\circledR}$ para identificação de bactérias produtoras de histamina. As 40 amostras (100\%) foram aprovadas para consumo, com ausência de Salmonella spp. e contagens de Staphylococcus spp. $<10$ UFC/g. A contagem de enterobactérias variou de $<10$ a $10^{5} \mathrm{UFC} / \mathrm{g}$. Quanto à prevalência de bactérias produtoras de histamina, foram identificadas as seguintes espécies: $27 \%$ Morganella morganii, 15,4\% Citrobacter diversus (koseri), 11,5\% Proteus vulgaris, $11,5 \%$ Klebsiella oxytoca, 11,5\% Enterobacter asburiae, 3,8\% Citrobacter freudii, 3,8 \% Enterobacter cloacae, 3,8\% Klebsiella ozaenae, 3,8\% Escherichia coli, 3,8\% Citrobacter amalonaticus e 3,8\% Enterobacter sakazakii.

Palavras-chave: Bactérias produtoras de histamina. Enterobacteriaceae. Histamina. Peixe.

\section{INTRODUÇÃO}

Os peixes e os frutos do mar são uma importante fonte de proteína animal na maior parte do mundo. Dentre esse tipo de alimento, o peixe é o mais consumido (BRASIL, 2014), e sua demanda tem sido estimulada pela divulgação de estudos recentes que apontam que o aumento na frequência do consumo de pescado está associado a uma melhor qualidade de vida (SARTORI; NAPOLITANO; VOSS, 2012). Em 2014, a produção global de capturas foi de 93,4 milhões de toneladas, sendo 81,5 milhões de toneladas em águas marinhas e 11,9 milhões de toneladas em águas interiores. No Brasil, a produção no mesmo ano foi de 235.527 toneladas e é esperado um aumento significativo de $104 \%$ na pesca e aqüicultura até 2025 , devido ao aumento do consumo e dos investimentos no setor (FAO, 2008). No litoral do Estado de Alagoas, onde foi realizado o presente estudo, a pesca é considerada uma importante atividade econômica, pois o sustento de muitos pescadores depende dessa atividade. Além disso, 
os pratos de peixes e frutos do mar não só fazem parte da alimentação da população litorânea, mas também são muito apreciados pelos turistas (MENEZES et al., 2009).

Apesar da importância econômica e nutricional desses produtos, atenção especial deve ser dada ao consumo de pescados no que se refere à segurança alimentar. Peixes e frutos do mar apresentam características físico-químicas e microbiológicas suscetíveis ao processo de deterioração, principalmente devido à alta atividade hídrica, alto teor de nutrientes disponíveis para a atividade microbiana e $\mathrm{pH}$ próximo do neutro (TAVARES, 2012). Outras razões pelas quais os peixes são altamente perecíveis estão relacionadas à estrutura coloidal de suas proteínas musculares, uma grande quantidade de substâncias extrativas nitrogenadas livres, como aminoácidos e óxido de trimetilamina, e o rápido desenvolvimento de argamassa de rigor (MUJICA; LIMA; CARNEIRO, 2014). A falta de cuidado na conservação dos peixes, principalmente, quando armazenados em temperaturas inadequadas e manuseados sem higiene, pode levar à formação de metabólitos tóxicos como as aminas biogênicas (TAO et al., 2011). Altos níveis dessas substâncias podem causar intoxicação alimentar. Dentre elas, a histamina é reconhecida como a amina mais tóxica, estando principalmente associada a casos de surtos (LADERO et al., 2010).

O conteúdo de histamina em peixes recém-pescados é muito baixo e seu aumento está relacionado à contaminação dos peixes após a captura, ao processo de deterioração, ao manuseio inadequado do produto em altas temperaturas de armazenamento e às más condições de higiene (VECIANA et al., 1997). Segundo Huss (2000), essa é uma preocupação mundial e pode ser definida como uma doença benigna com curto período de incubação, que pode variar de alguns minutos a algumas horas, e geralmente dura pouco. O Japão é o líder mundial no consumo de peixes, bem como o lugar onde o maior número de infecções tóxicas foi registrado (HERRERO, 2001). No Brasil, surtos de intoxicação por histamina têm sido relatados em todo o território nacional (EVANGELISTA, 2001; TAKEMOTO et al., 2018). Quando ingeridos em grandes quantidades, ou quando a atividade das enzimas catabolizantes é inibida, os indivíduos sensíveis podem desenvolver intoxicação alimentar por histamina e apresentar sintomas como náuseas, vômitos, diarreia, dor abdominal, hipotensão e, em casos graves, dor torácica e respiratória distúrbios (LADERO et al., 2010). Fisiologicamente, a histamina está envolvida em processos inflamatórios, anafilaxia, processos alérgicos e 
certos tipos de reações a medicamentos e na regulação da secreção gástrica (OBRINK, 1991).

A histamina é produzida principalmente devido à descarboxilação do aminoácido L-histidina que aparece em sua forma livre devido à atividade da enzima histidina descarboxilase de bactérias que ocorrem naturalmente nos alimentos. É um perigo químico estável em altas temperaturas. Uma vez formado nos alimentos, não pode ser eliminado pelos processos tecnológicos usuais, nem mesmo pelo calor (TAO et al., 2011). Dentre os microrganismos produtores de histamina, Enterobacteriaceae são os mais ativos na formação desse composto. As principais cepas bacterianas geralmente associadas ao desenvolvimento de histamina estão comumente presentes no ambiente aquático (FDA, 2011). Essas bactérias pertencem à microbiota natural das guelras, pele, intestino e cavidade abdominal de peixes vivos de água salgada, onde não causam nenhum dano à espécie. No entanto, durante a fase post-mortem, quando as condições de temperatura adequadas não são mantidas, eles podem produzir histamina nos peixes.

A temperatura entre $20^{\circ} \mathrm{C}$ e $37{ }^{\circ} \mathrm{C}$ é considerada ótima para a formação de aminas biogênicas por bactérias mesófilas, enquanto essa produção diminui em temperaturas abaixo de $5{ }^{\circ} \mathrm{C}$ ou acima de $40{ }^{\circ} \mathrm{C}$ (EFSA, 2011). Além disso, o manuseio inadequado dos alimentos contribui para a aquisição e desenvolvimento de outros microrganismos (FRANCO \& LANDGRAF, 2008). Essas bactérias, tendo adquirido a enzima histamina descarboxilase, atuam sobre o aminoácido histidina, produzindo histamina. Além de ser um problema de saúde pública, o estudo da histamina em alimentos mostra correlação direta com a qualidade da matriz alimentar. Os níveis de aminas biogênicas têm sido usados como um índice de qualidade para a medição da atividade microbiana indesejável de acordo com a pesquisa de (LU et al., 2010) e a histamina é considerada o mais importante indicador de frescor do peixe citado por NTZIMANI et al., 2008.

Diferentes tipos de alimentos foram identificados como causas potenciais de envenenamento por histamina, incluindo vinhos, cervejas, peixes, produtos fermentados de carne e queijos (GOMES et al., 2014). Em relação aos peixes, segundo (BRASIL, 1997), as espécies produtoras de histamina são aquelas que podem formar na musculatura um teor superior a 100 ppm dessa amina. A mesma portaria classifica como 
espécies formadoras de histamina aquelas pertencentes às famílias Scombridae, Scomberesocidae, Clupeidae, Engraulidae, Coryphaenidae e Pomatomidae. Para peixes de água doce, o limite de $100 \mathrm{mg} / \mathrm{kg}$ no músculo de espécies pertencentes a essas famílias é tolerado pelo Mercosul (ABIA, 1997), limite também estabelecido pela legislação brasileira. A União Europeia estabeleceu um nível aceitável de 100 a 200 $\mathrm{mg} / \mathrm{kg}$ de histamina em peixes pertencentes às famílias Scombridae e Scomberesocidae (BRASIL, 2005). No entanto, os Estados Unidos, para garantir maior proteção à saúde do consumidor, revisou o guia de conformidade para a decomposição e intoxicação da histamina em 1995, e a Food and Drug Administration (FDA) estabeleceu que os peixes podem ser considerados em decomposição quando o nível de histamina atinge $50 \mathrm{mg} / \mathrm{kg}$ em peixe fresco e $100 \mathrm{mg} / \mathrm{kg}$ em produtos enlatados (FDA, 2011). A mesma agência relata ainda que o resfriamento rápido dos peixes imediatamente após a captura é a melhor estratégia para limitar a formação de histamina nos peixes. Em relação à segurança microbiológica, a Diretriz no 12/2001 (BRASIL, 2001) publicada pela Agência Nacional de Vigilância Sanitária, Ministério da Saúde, exige a ausência de Salmonella spp. em 25 gramas para peixes in natura e um Staphylococcus spp. limite de contagem de $103 \mathrm{UFC} / \mathrm{g}$.

Foi constatado que peixes contaminados com altos níveis de histamina nem sempre apresentam sinais de deterioração, embora sua toxicidade possa ser prejudicial ao consumidor (MORENO, 2001). Assim, o teor de histamina pode ser utilizado como índice de qualidade alimentar, uma vez que permite determinar a atividade microbiana indesejada e as condições higiênicas sanitárias dos produtos (LU et al., 2010). Vários surtos de intoxicação por histamina têm sido relatados no país, daí a importância da investigação de bactérias produtoras de histamina em alimentos (TAKEMOTO et al., 2018; TORIDO et al., 2012). Nesse contexto, o presente estudo teve como objetivo avaliar a segurança microbiológica e determinar o perfil das bactérias produtoras de histamina em Cavala (Scomberomorus cavalla Cuvier, 1829) e Dourado (Salminus brasiliensis Cuvier, 1816) comercializados em Maceió (AL), comparando o que foi observado com os achados da literatura. 


\section{MATERIAIS E MÉTODOS}

\subsection{CEPAS BACTERIANAS E COLETA DE AMOSTRA}

Foram avaliadas 40 amostras de peixes frescos (20 dourado e 20 cavala) de cinco estabelecimentos comerciais do município de Maceió ( $A L)$. Os peixes, pesando aproximadamente $300 \mathrm{~g}$, haviam chegado recentemente em barcos pesqueiros, o Dourado e Cavala foram adquiridos aleatoriamente em cada um dos locais comerciais. Caixas isotérmicas em temperaturas de $-0,5^{\circ} \mathrm{C}$ a $-2^{\circ} \mathrm{C}$ foram utilizadas para entrega dos peixes ao Laboratório de Controle de Qualidade Microbiológica de Alimentos da Universidade Federal de Alagoas para análise microbiológica e investigação de bactérias produtoras de histamina.

\subsection{ANÁLISE MICROBIOLÓGICA}

A contagem de Staphylococcus spp. e a identificação de Salmonella spp. foram realizados para investigar a segurança microbiológica e a qualidade das amostras de peixe fresco, de acordo com as diretrizes nacionais número (BRASIL, 2001). As amostras (25 g) foram homogeneizadas em $225 \mathrm{~mL}$ de solução salina tamponada com fosfato (PBS). A partir desta diluição de $10^{-1}$, foi obtida uma diluição em série de $10^{-3}, 10^{-4}$ e $10^{-}$ 5. O método de ágar com contagem em placa padrão (SPC) foi usado para Contagem de Staphylococcus spp. de acordo com (LANCETTE \& BENNET, 2001). Um volume de 1,0 mL da diluição $10^{-1}$ e $0,1 \mathrm{~mL}$ das diluições $10^{-2}$ e $10^{-3}$ foram semeados em ágar Baird-Parker e incubados a $35^{\circ} \mathrm{C}(24 \mathrm{~h})$.

A deteç̧ão de Salmonella spp. foi realizado usando métodos convencionais baseados em cultura, conforme descrito anteriormente por (ANDREWS \& HAMMACK, 2003). Um volume de $0,1 \mathrm{~mL}$ das amostras previamente enriquecidas em solução de PBS foi inoculado em $10 \mathrm{~mL}$ de caldo Rappaport Vassiliadis, enquanto 1,0 mL foi inoculado em $10 \mathrm{~mL}$ de caldo de selenito cistina. Após a incubação a $41^{\circ} \mathrm{C} \pm 0,5(24 \mathrm{~h})$, as culturas foram semeadas em meios diferenciais: Xilose Lisina Desoxischolato (XLD) e Vermelho-fenol-Lactose Sacarose (BPLS) verde brilhante e incubada a $36^{\circ} \mathrm{C} \pm 1(24 \pm 2$ h). Colônias suspeitas foram bioquimicamente identificadas usando meios TSI, LIA e SIM. 


\subsection{DETECÇÃO QUALITATIVA DE BACTÉRIAS PRODUTORAS DE HISTAMINA}

Bactérias produtoras de histamina foram isoladas de amostras de peixe fresco usando um método de ágar Niven modificado (NIVEN; JEFREY; CORLETT, 1981; APHA, 2001). Cerca de $10 \mu \mathrm{L}$ de cada cultura durante a noite da diluição em série em PBS foram inoculados em placas de ágar Niven enriquecidas com histidina e incubadas a $35^{\circ} \mathrm{C}(24-$ 72h). Posteriormente, colônias presuntivas de bactérias produtoras de histamina foram inoculadas em caldo Niven e incubadas a $35^{\circ} \mathrm{C}(24 \mathrm{~h})$, para confirmar a presença de cepas produtoras de histamina. A identificação das enterobactérias produtoras de histamina foi realizada pelo teste da oxidase seguido dos sistemas Bactray I e II, de acordo com as instruções do fabricante. Os testes de Bactray compreendem análises bioquímicas convencionais, como: ONPG, arginina, lisina, ornitina, $\mathrm{H}_{2} \mathrm{~S}$, ureia, VP, PD, indol, citrato, malonato, rhamnosus, adonitol, salicina, arabinose, inositol, sorbitol, sacarose, manitol e rafinose. O meio de ágar vermelho violeta de glicose biliar (VRBG) também foi usado para a detecção de enterobactérias (Figura 1).

\section{RESULTADOS E DISCUSSÕES}

Em relação à segurança microbiológica, 40 (100\%) amostras de peixes foram seguras, com ausência de Salmonella spp. em 25 gramas do produto e um Contagem de Staphylococcus spp. <10 UFC /g, atendendo aos padrões da legislação vigente (Tabela $1)$.

Tabela 1 - Análises microbiológicas do pescado fresco com base no padrão microbiológico estabelecido pela legislação vigente.

\begin{tabular}{llll}
\hline Microorganismos & IN 60/2019* & Cavala & Dourado \\
\hline
\end{tabular}

Staphylococcus spp.

Coagulase-positiva

$10^{3}$

$<10$

$<10$

Salmonella sp

Ausente

Ausente

Ausente

* Instrução Normativa no 60, de 23 de dezembro de 2019 - Diretoria Colegiada da Agência Nacional de Vigilância Sanitária/ MS / Brasil.

Fonte: Autores, 2021. 
Figura 1 - Sequência para identificação de bactérias histamínicas positivas: (A) e (B) Placa de meio Niven com colônias características (presuntiva), (C), (D), (E) teste confirmatório, com produção de gás e coloração roxa média, (F) teste bioquímico para identificação de histamina positiva em peixes, (G) software utilizado para identificação e confirmação de histamina positiva em amostras de peixes.

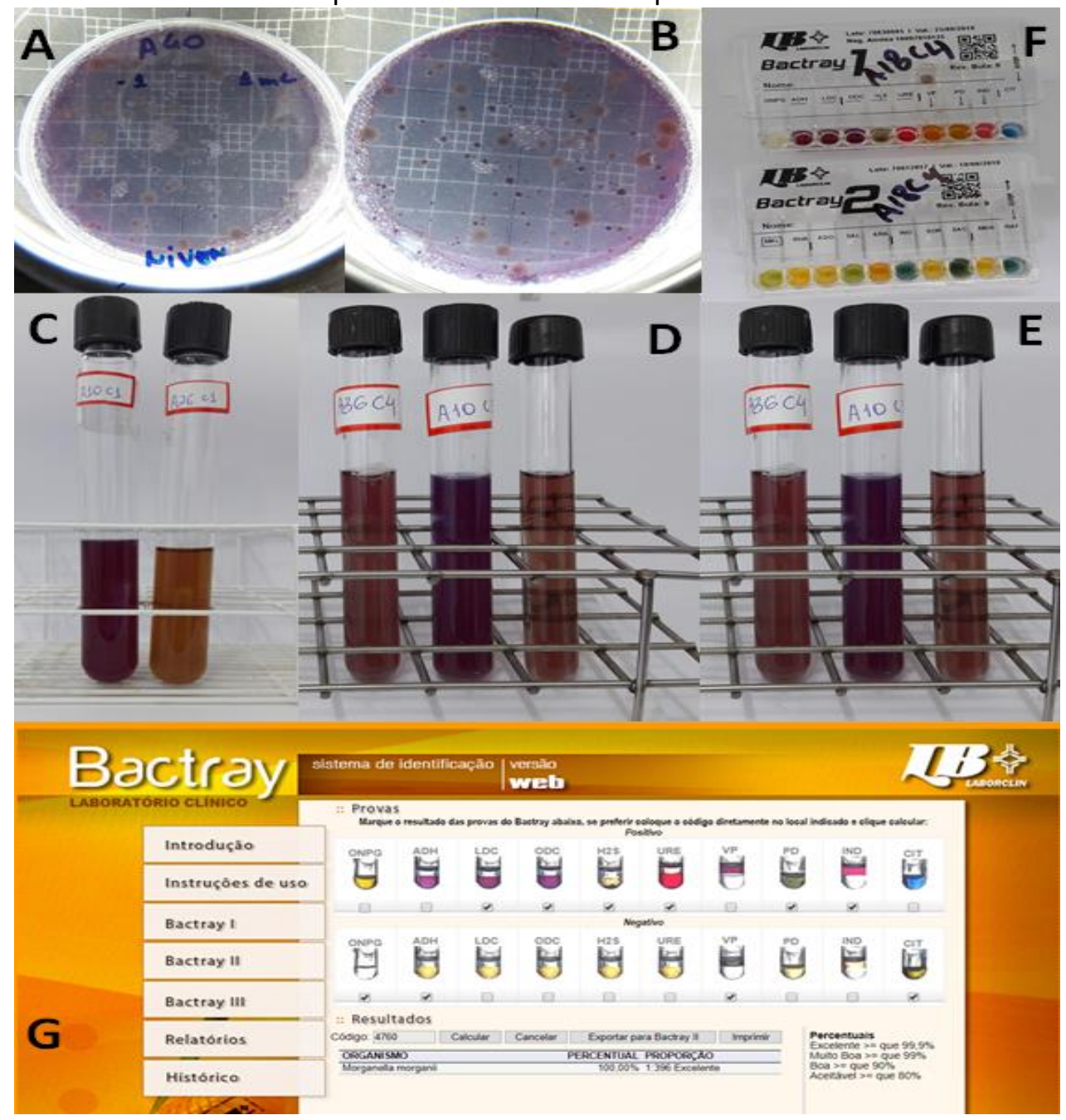

Fonte: Autores, 2021.

Quanto à contagem de Enterobactérias, observou-se que nas 40 amostras de peixes frescos houve uma variação de 0 a $10^{5} \mathrm{UFC} / g$ no ágar VRBG, com o maior número de contagens de amostras (13) entre $10^{3}$ e $10^{4}$ UFC / g, enquanto no ágar Niven a contagem variou de 0 a $10 \mathrm{UFC/g}$, e a maioria das amostras (27) não cresceu neste meio (Tabela 2). Das 13 amostras cultivadas em ágar Niven, 4 (20\%) eram Cavala e 9 (45\%) Dourado. C. amalonaticus, E. cloacae, K. oxytoca, K. ozaenae, M. morganii e P. vulgaris foram identificados em ambas as espécies de peixes. Destas, 46 cepas produtoras de histamina foram isoladas no teste presuntivo e apenas 27 foram confirmadas como bactérias produtoras de histamina no caldo Niven, as quais foram então submetidas à identificação das espécies no sistema Bactray. 
Tabela 2 - Distribuição do número de amostras de peixes frescos de acordo com a contagem de Enterobactérias nos meios de ágar VRBG e Niven.

Contagem de

Número de amostras em diferentes tipos de meio ágar

Enterobacteriaceae (UFC/g)

VRBG agar Niven agar

$\begin{array}{ccc}0 & 3 & 27 \\ 1-10 & 0 & 13 \\ 10-102 & 1 & 0 \\ 102-103 & 11 & 0 \\ 103-104 & 13 & 0 \\ 104-105 & 12 & 0\end{array}$

Fonte: Autores, 2021.

A Tabela 3 mostra os resultados obtidos em relação à presença de bactérias produtoras de histamina nas amostras de Cavala e Dourado.

Tabela 3 - Distribuição do número de amostras de peixes com presença de bactérias produtoras de histamina.

\begin{tabular}{cccc}
\hline Amostras & $\begin{array}{c}\text { Amostras } \\
\text { analisadas }\end{array}$ & $\begin{array}{c}\text { Número de amostras } \\
\text { positivas para bactérias } \\
\text { produtoras de histamina em } \\
\text { ágar Niven }\end{array}$ & $\begin{array}{c}\text { Espécies bacterianas identificadas } \\
\text { usando o sistema Bactray }\end{array}$ \\
Cavala & 20 & $4(20 \%)$ & $\begin{array}{c}\text { C. amalonaticus, E. cloacae, E. coli, K. } \\
\text { oxytoca, K. ozaenae, M. morganii e } P . \\
\text { vulgaris }\end{array}$ \\
Dourado & 20 & $9(45 \%)$ & $\begin{array}{c}\text { C. freundii, C. amalonaticus, } C . \\
\text { diversus, E. asburiae, E. cloacae, E. } \\
\text { sakazaki, K. oxytoca, K. ozaenae, M. } \\
\text { morganii e P. vulgaris }\end{array}$ \\
\hline
\end{tabular}

Fonte: Autores, 2021.

Os testes bioquímicos para Enterobactérias produtoras de histamina usando os sistemas Bactray I e II são apresentados na Tabela 4. 
Tabela 4 - Testes bioquímicos para bactérias produtoras de histamina (sistema Bactray).

\begin{tabular}{clll}
$\begin{array}{c}\text { Número de cepas } \\
\text { produtoras de } \\
\text { histamina isoladas no } \\
\text { teste presuntivo* }\end{array}$ & $\begin{array}{c}\text { Números de cepas } \\
\text { confirmadas no teste } \\
\text { confirmatório ** }\end{array}$ & \multicolumn{1}{c}{$\begin{array}{c}\text { Testes } \\
\text { bioquímicos }\end{array}$} & $\begin{array}{c}\text { Números de cepas } \\
\text { com reações } \\
\text { positivas }\end{array}$ \\
\hline & ONPG & $22(81.5 \%)$ \\
& Arginina & $10(37 \%)$ \\
& Lisina & $14(51.8 \%)$ \\
& Ornitina & $15(55.5 \%)$ \\
& H2S & $9(33.3 \%)$ \\
& Ureia & $18(66.7 \%)$ \\
& VP & $3(11.1 \%)$ \\
& PD & $11(40.7 \%)$ \\
& Indol & $20(74 \%)$ \\
& Citrato & $19(70.4 \%)$ \\
& Malonate & $17(63 \%)$ \\
& Rhamnosus & $16(59.2 \%)$ \\
& Adonitol & $9(33.3 \%)$ \\
& Salicin & $15(55.5 \%)$ \\
& Arabinose & $15(55.5 \%)$ \\
& Inositol & $7(25.9 \%)$ \\
& Sorbitol & $14(51.8 \%)$ \\
& Saccharose & $16(59.2 \%)$ \\
& Manitol & $16(59.2 \%)$ \\
& Raffinose & $11(40.7 \%)$ \\
\hline
\end{tabular}

Fonte: Autores, 2021.

Fomos capazes de identificar 11 espécies bacterianas, todas pertencentes à família Enterobacteriaceae, conforme mostrado na Tabela 5.

Tabela 5 - Bactérias produtoras de histamina isoladas de amostras de peixes "in natura" coletadas no comércio de Maceió (AL).

\begin{tabular}{lll}
\hline Enterobacteriaceae & Número de isolados & $\%$ \\
\hline Morganella morganii & 8 & $29.7 \%$ \\
Citrobacter diversus & 4 & $14.8 \%$ \\
Proteus vulgaris & 3 & $11.0 \%$ \\
Klebsiella oxytoca & 3 & $11.0 \%$
\end{tabular}




\begin{tabular}{lll}
\hline Enterobacteriaceae & Número de isolados & $\%$ \\
\hline Enterobacter asburiae & 3 & $11.0 \%$ \\
Citrobacter freundii & 1 & $3.7 \%$ \\
Enterobacter cloacae & 1 & $3.7 \%$ \\
Klebsiella ozaenae & 1 & $3.7 \%$ \\
Escherichia coli & 1 & $3.7 \%$ \\
Citrobacter amalonaticus & 1 & $3.7 \%$ \\
Enterobacter sakazakii & 1 & $3.7 \%$ \\
\hline
\end{tabular}

Fonte: Autores, 2021.

A enterobactéria mais prevalente nas amostras de peixes deste estudo foi Morganella morganii, que foi isolada em $8(29,7 \%)$ amostras. M. morganii é considerado como tendo o maior potencial de produção de histamina em comparação com outros (SILVEIRA et al., 2017; BJORNSDÓTTIR-BUTLER, 2010). Em nosso estudo, Proteus vulgaris e Klebsiella spp. corresponderam, respectivamente, a $11 \%$ e $14,7 \%$ das bactérias isoladas. Enterobacterias como P. vulgaris e Klebsiella spp. fazem parte da microbiota de peixes e são os principais produtores de histamina (CHANG et al., 2008; CHEN et al., 2010). Chung-Saint (2014) analisou peixes frescos e salgados Mahi-Mahi (Coryphaena hippurus) e encontrou Raoultella ornithinolytica como o principal produtor de histamina em produtos salgados e P. vulgaris em peixes frescos.

A presença de Enterobacter spp. indica condições higiênicas sanitárias insatisfatórias das águas poluídas onde os peixes foram pescados. Em nosso estudo, Enterobacter spp. foram identificados em 18,4\% dos isolados. Enterobacter spp. também foram encontrados em camarões capturados (ANDRADE et al., 2018), bem como em Mahi-Mahi (Coryphaena hippurus) fresco e seus produtos salgados (CHUNGSAINT, 2014). Huang (2010) analisou peixes de água salgada e descobriu que $30,4 \%$ das amostras tinham níveis de histamina superiores aos permitidos pelo FDA, e Enterobacter spp. foram o principal fator na contaminação dessas amostras.

Citrobacter freundii isolado de amostras de Dourado foi identificado em 3,7\% dos isolados, concordando com os achados de (HSU et al., 2009) para a amostra de Coryphaena hippurus e Huang (2010) em uma amostra de peixe salgado. Investigando diferentes tipos de peixes, Torido et al. (2012) detectou Photobacterium como o mesofilo predominante $(42,7 \%)$, e M. morganii como a segunda espécie bacteriana mais 
prevalente (23,0\%), e isolado C. freundii. A pesquisa de Andrade et al. (2018) avaliou a presença de histamina em camarões cativos e concluiu que a maioria das bactérias presentes nessas amostras pertenciam à família Enterobacteriaceae, principalmente Enterobacter cloacae e Klebsiella oxytoca, correspondendo a 60,8\% das bactérias produtoras de histamina bactérias. Ambas as espécies também foram encontradas em nosso estudo, correspondendo, respectivamente, a 3,7\% e 11,0\% dos isolados.

A microbiota dos peixes é um indicativo das condições da água onde vivem esses animais, uma vez que os tecidos internos de peixes saudáveis são estéreis (BENNER et al., 2001). A microbiota dos peixes geralmente é encontrada em três locais: a superfície externa, as guelras e os intestinos. A importância de condições higiênico-sanitárias adequadas em toda a cadeia produtiva, desde a captura até a distribuição ao consumidor final, é enfatizada para garantir a qualidade do pescado (HAYES, 1993). O relatório de Germano et al. (2003) também destaca o papel desempenhado pelo manipulador de alimentos na contaminação cruzada.

É importante ressaltar que as amostras utilizadas neste estudo foram coletadas de peixes recém-chegados em barcos de pesca e devidamente armazenados em caixas isotérmicas a temperaturas de $-0,5^{\circ} \mathrm{C}$ a $-2^{\circ} \mathrm{C}$, e que essas amostras foram testadas para consumo de acordo com a legislação vigente. Mesmo assim, a presença da bactéria pode representar riscos à qualidade e segurança dos peixes, principalmente por sua capacidade de produzir histamina quando em condições inadequadas de armazenamento e manuseio. Quantidades de histamina que causam intoxicação podem ser adquiridas antes mesmo de ocorrerem alterações nas propriedades organolépticas do produto.

\section{CONSIDERAÇÕES FINAIS}

Os resultados obtidos no presente estudo permitem concluir que as amostras de peixes cavala e dourado apresentam-se próprias para consumo, entretanto a presença de enterobactérias produtoras de histamina pode comprometer a qualidade e segurança desse pescado, pois a possível presença de histamina produzida por essas bactérias acarretará risco à saúde do consumidor. 


\section{AGRADECIMENTOS}

Os autores agradecem ao CNPq, CAPES e FAPEAL pelas bolsas do Curso de Mestrado em Nutrição (PPGNUT) e Ciências Farmacêuticas (PPGCF) e CNPq para apoio financeiro (Bolsa no 446630 / 2014-4) conforme apoio financeiro aos pesquisadores Edital Universal 14/2014 do MCT/CNPq e FAPEAL pelo apoio financeiro ( $n^{\circ} 60030$ 000431/2016). Os autores agradecem também ao Laboratório de Controle de Qualidade de Alimentos Microbiológicos da Universidade Federal de Alagoas, na pessoa de Cantídio Franscisco de Lima Filho, pelo apoio em análises microbiológicas.

\section{REFERÊNCIAS}

ANDRADE CS, DRUZIAN JI, LEITE CC, CARVALHO-FILHO CD, MIRANDA MPS, MACÊDO CS, GUIMARÃES AG (2008) Determinação da microbiota histamina positiva em camarão histamina. Revista do Instituto Adolfo Lutz 67:46-51. <http://periodicos.ses.sp.bvs.br/pdf/rial/v67n1/v67n1a05.pdf> Accessed 29 december 2018.

ANDREWS WH, HAMMACK TS (2003) Salmonella. In: Food and Drug Administration. Bacterial Analitical Manual. Revision A. $8^{\text {th }}$ ed. AOAC International, Arlington, pp 501-519.

APHA - American Public Health Association. Committee on microbiological methods for foods (2001) Compendium of methods for the microbiological examination of foods. $4^{\text {th }}$ ed. American Public Health Association, Washington DC, pp 676.

BENNER RA, MCCARTHY S, NICKELSON R (2001) Fish, crustaceans and precooked seafoods. In: Compendium of Methods for the Microbiological Examination of Foods. APHA, 4 (ed), pp 497-505.

BJORNSDÓTTIR-BUTLER K, BOLTON GE, JAYKUS L-A, MCCLELLAN-GREEN PD, GREEN DP (2010) Development of molecular-based methods for determination of high histamine producing bacteria in fish. International Journal of Food Microbiology 139:161-167.

BRASIL (1997) Ministério da Agricultura, Pecuária e Abastecimento. Portaria no 185, de 13 de maio de 1997. Aprova o regulamento técnico de identidade e qualidade de peixe fresco. Diário Oficial da República Federativa do Brasil.

BRASIL (2019) IN no 60, de 23 de dezembro de 2019. Estabelece Padrões Microbiológicos para Alimentos. Brasília, DF: ANVISA Diário Oficial da República Federativa do Brasil, publicado em 26/12/2019, Edição 248, Seção 1, Página 133. 
BRASIL (2014) Ministério da saúde. Guia alimentar para a população brasileira. 20 edição. Brasília: Ministério da saúde, 156.p.:Il.

BRASIL (CE). no 2073, de 15 de novembro de 2005. Relativo à critérios microbiológicos aplicáveis aos gêneros alimentícios. Jornal Oficial das Comunidades Europeias, Luxemburgo, L 338/1-26, 2005. <https://eur-lex.europa.eu/legalcontent/PT/TXT/PDF/?uri=CELEX:02005R2073-20060101\&from=NL>. Accessed 28 december 2018.

CHANG SC, KUNG H-F, CHEN H-C, LIN C-S, TSAI Y-H (2008) Determination of histamine and bacterial isolation in swordfish fillets (Xiphias gladius) implicated in a food borne poisoning. Food Control 19:16-21.

CHEN H-C, HUANG Y-R, HSU H-H, LIN C-S, CHEN W-C, LIN C-M, TSAI Y-H. (2010) Determination of histamine and biogenic amines in fish cubes (Tetrapturus angustirostris) implicated in a food-borne poisoning. Food Control 21:13-18.

EFSA (2011) Panel on Biological Hazards (BIOHAZ). Scientific opinion on risk based control of biogenic amines formation in fermented foods. European Food Safety Authority Journal 9:2393. < https://efsa.onlinelibrary.wiley.com/doi/pdf/10.2903/j.efsa.2011.2393 > Accessed 29 december 2018.

EVANGELISTA J (2001) Contaminações em Alimentos. In: Evangelista J (ed) Alimentos: um Estudo Abrangente. Atheneu, Rio de Janeiro, pp175-230.

FAO. Food and Agriculture Organization (2008) Fisheries and Aquaculture Departments - Garantia de qualidade dos produtos da pesca. Disponível em: <http://www.fao.org. > Accessed: 20 januray 2017.

FDA. Food and Drug Administration (2011) Fish and fishery products hazards and controls guidance. $4^{\text {th }}$ ed. Office of Seafood, Washington, pp 113-152.

FRANCO BDGM, LANDGRAF M (2008) Microbiologia dos alimentos. Atheneu, São Paulo.

GERMANO PML, GERMANO MIS, OLIVEIRA CF (2003) Qualidade do pescado. In Germano, PML, Germano MIS (Org). Higiene e vigilância sanitária dos alimentos. $2^{\text {nd }}$ edn. Varela, São Paulo, pp125-139.

GOMES MB et al. (2014) O Risco das Aminas biogênicas nos Alimentos. Revista Ciência e saúde coletiva, Rio de Janeiro, v. 19, n. 4, p. 1123-1134.

HAYES PR (1993) Microbiologia e higiene de los alimentos. Acribia, Zagaroza, pp 369.

HERRERO MMH (2001) Pescado a más consumo más control. seguridad alimentaria http://www.consumer.es/seguridad-alimentaria/ciencia-ytecnologia/2001/07/13/309.php. accessed 29 december 2018. 
HSU H-H, CHUANG T-C, LIN H-C, HUANG Y-R, LIN C-M, KUNG H-F (2009) Histamine content and histamine-forming bacteria in dried milkfish (Chanos chanos) products. Food Chemistry 114:933-938.

HUANG YR, LIU K-J, HSIEH H-S, HSIEH C-H, HWANG D-F, TSAI Y-H (2010) Histamine level and histamine-forming bacteria in dried fish products sold in Penghu Island of Taiwan. Food Control 21:1234-1239.

HUSS HH, REILY A, EMBAREK PKB (2000) Prevention and control of hazards in seafood. Food Control 11:149-156.

LADERO V, CALLES-ENRÍQUEZ V, FERNANDEZ M, ALVAREZ MA (2010) Toxicological effects of dietary biogenic amines. Current Nutrition and Food Science 6:145156.

LANCETTE GA, BENNET RW (2001) Staphylococcus aureus and staphylococcal enterotoxins. In Downes FP, Ito K. (ed.) Compendium of Methods for the Microbiological Examination of Foods, $4^{\text {th }}$ ed. American Public Health Association, Washington, DC, pp 387-403.

LIN C-S, TSAI H-C, LIN C-M, HUANG C-Y, KUNG H-F, TSAI Y-H (2014) Histamine content and histamine-forming bacteria in mahi-mahi (Coryphaena hippurus) fillets and dried products. Food Control 42:165-171.

LU S, XU X, ZHOU G, ZHU Z, MENG Y, SUN YL (2010) Effect of starter cultures on microbial ecosystem and biogenic amines in fermented sausage. Food Control 21:444-449.

MENEZES ES, LIRA GM, OMENA MB, FREITAS JD, SANT'ANNA AEG (2009) Valor nutritivo de peixes da costa marítima de Alagoas, Brasil. Revista do Instituto Adolfo Lutz 1: 21-28. <http://revistas.bvs-vet.org.br/rialutz/article/view/6972>. Accessed 07 june 2017.

MERCOSUL-ABIA (Associação Brasileira das Indústrias de Alimentação) (1997) Identidad y calidad de pescado fresco. Mercosur/GMC, Resolução 40/94. In: Compêndio das Resoluções do Mercosul. São Paulo, pp 76-78.

MORENO RB (2001) Avaliação dos níveis de histamina em sardinhas frescas comercializadas na CEAGESP de São Paulo. Thesis, Universidade de São Paulo.

MUJICA PIC, LIMA MM, CARNEIRO PH (2014) Avaliação da qualidade microbiológica de peixes comercializados nas feiras livres de Palmas, TO. Revista Higiene Alimentar 28: 147-152.< https://www.bvs-vet.org.br/vetindex/periodicos/higienealimentar/28-(2014)-236-237/avaliacao-da-QUALIDADE-MICROBIOLOGICA-DEPEIXES-COMERCIALIZADOS-NAS-FE/> . ACCESSED 28 DECEMBER 2018.

NIVEN CF JR, JEFREY MB, CORLETT DA Jr (1981) Differential plating medium for the quantitative detection of histamine producing bacteria. Applied Environmental Microbiology, 45:321-322. 
NTZIMANI AG, PALEOLOGOS EK, SAVVAIDIS IN, KONTOMINAS MG (2008) Formation of biogenic amines and relation to microbial flora and sensory changes in smoked turkey breast fillets under various packaging conditions at 4 degrees. Food Microbiology 3:509-517.

OBRINK KJ (1991) Histamine and gastric acid secretion. Scandinavian Journal of Gastroenterology 26:4-8.

SARTORI I, NAPOLITANO A, VOSS K (2012) Net zero energy buildings: A consistent definition framework. Energy and Buildings 48:220-232. https://doi.org/10.1016/j.enbuild.2012.01.032

SILVEIRA NFA, LEITÃO MFF, BALDINI VLS, TEIXEIRA-FILHO AR (2017) Bactérias Produtoras de Histamina e Potencial para sua Formação em Peixes de Origem Fluvial ou Lacustre. Brazilian Journal of Food Technology, 4:19-25.

TAKEMOTO EE, MINAZZI-RODRIGUES WP, MARSIGLIA RS, OLIVEIRA DAP, GLÓRIA CAF, ABREU MA (2014) Histamine intoxication outbreak associated to canned tuna intake in the state of São Paulo, Brazil. Boletim Epidemiológico Paulista 11:2932. < http://www.saude.sp.gov.br/resources/ccd/homepage/bepa/edicao2014/edicao_126_-junho.pdf> Accessed 29 december 2018.

TAO ZH, SATO M, YAMAGUCHI Y, NAKANO T (2011) Formation and diffusion mechanism of histamine in the muscle of tuna fish Food Control, 21:923-926.

TAVARES RDO (2012) Avaliação da estabilidade térmica de histamina em conservas de pescado por CLAE. Dissertation, Federal Rural University of the Rio de Janeiro.

TORIDO Y, TAKAHASHI H, KUDA T, KIMURA B (2012) Analysis of the growth of histamineproducing bacteria and histamine accumulation in fish during storage at low temperatures. Food Control 26:174-177.

VECIANA-NOGUÉS MT, MARINÉ-FONT A, VIDAL-CAROU MC (1997) Biogenic amines as hygienic quality indicators of tuna. Relationships with microbial counts, ATPrelated compounds, volatile amines, and organoleptic changes. Journal of Agricultural and Food Chemistry 45:2036-2041. 


\title{
CAPITULO VIII
}

\section{CONTROLE BIOLÓGICO DE PODRIDÃO EM FRUTOS DE TOMATE}

\author{
DOI: 10.51859/AMPLLA.DES1788-8
}

\author{
Bruno Marcos Nunes Cosmo ${ }^{1}$ \\ Tatiani Mayara Galeriani ${ }^{2}$ \\ Willian Aparecido Leoti Zanetti ${ }^{3}$ \\ Adolfo Bergamo Arlanch ${ }^{4}$ \\ Bruno César Góe ${ }^{5}$ \\ Gabriel Lima Barbosa ${ }^{6}$
}

\begin{abstract}
${ }^{1}$ Doutorando em Agricultura (Agronomia). Universidade Estadual Paulista "Júlio de Mesquita Filho" - UNESP. 2 Doutoranda em Agricultura (Agronomia). Universidade Estadual Paulista "Júlio de Mesquita Filho" - UNESP.

${ }^{3}$ Doutorando em Agronegócio e Desenvolvimento. Universidade Estadual Paulista "Júlio de Mesquita Filho" - UNESP.

4 Doutorando em Irrigação e Drenagem (Agronomia). Universidade Estadual Paulista "Júlio de Mesquita Filho" UNESP.

${ }^{5}$ Doutor em Agronegócio e Desenvolvimento. Universidade Estadual Paulista "Júlio de Mesquita Filho" - UNESP.

${ }^{6}$ Mestrando em Gestão e Regulação de Recursos Hídricos. Universidade Estadual Paulista "Júlio de Mesquita Filho" UNESP.
\end{abstract}

\section{RESUMO}

O agronegócio representa uma parcela significativa da economia. Contudo, em todo o planeta ocorrem elevadas perdas no período pós-colheita. Dentre os agentes vinculados com tais perdas, encontram-se fatores físicos, químicos, fitopatogênicos e afins. Os agentes fitopatogênicos podem ser potencializados pelas condições ambientais. Neste contexto, o objetivo do trabalho foi avaliar o tratamento de frutos de tomate com diferentes agentes de controle biológico (leveduras, bactérias e controle) para estender o período de sanidade dos frutos em pós-colheita. O delineamento empregado foi inteiramente casualizado com quatro repetições. Os tratamentos foram compostos pela: i) Testemunha ou controle; ii) Controle biológico com solução de $1 \%$ de bactéria; e iii) Controle biológico com solução de $1 \%$ de levedura. Na implantação do experimento, os frutos foram desinfestados com hipoclorito, sendo em seguida submetidos ao respectivo tratamento e acomodados em bandeja. Nas bandejas realizou-se a inoculação de Alternaria sp. e sem seguida vedou-se as. Os frutos foram avaliados em intervalos de 5 dias até os 30 dias após a inoculação para quantificar a incidência e severidade de doenças. Os dados obtidos foram submetidos à análise de variância $(p<0,05)$ e comparados pelo teste de médias de Tukey $(p<0,05)$. Também foram construídas curvas de progressão da doença. Para incidência da doença não houveram diferenças entre tratamentos, porém, para severidade a partir de 20 dias após a inoculação, o controle com levedura gerou resultados mais eficientes. Conclui-se que as leveduras possuem potencial como agente de controle biológico em pós-colheita, inferindo sobre a necessidade de mais estudos com essa temática.

Palavras-chave: Fitopatológica. Biocontrole. Sustentabilidade. Tecnologia de alimentos. 


\section{INTRODUÇÃO}

O agronegócio representa parcela significativa da economia nacional, sendo responsável por cerca de $25 \%$ do Produto Interno Bruto (PIB) e 35\% da mão-de-obra do país, dentre as cadeias presentes no agronegócio cerca de 2/3 são referentes às cadeias produtivas da agricultura e $1 / 3$ da pecuária (GONÇALVES et al., 2018; FARIAS, 2018). Contudo, estima-se que no mundo aproximadamente $1 / 3$ de todos os alimentos produzidos são perdidos durante o processo produtivo, cenário este que não é diferente no Brasil (KUMMU et al., 2012).

As perdas de hortifrútis no Brasil muitas vezes estão vinculadas ao processo de comercialização e manipulação dos produtos (MORAES; SOUZA, 2018). Dentre os principais fatores vinculados às perdas nestas etapas destacam-se a redução da qualidade física, providas de fatores relacionados ao metabolismo interno do produto ou a fatores externos a ele, como danos de ordem mecânica, fisiológica e fitopatológica (SOUSA et al., 2018).

Dentre os fatores citados anteriormente os danos de ordem fitopatológica são potencializados por fatores como temperatura, umidade, ferimentos no tecido do produto e outros itens que facilitam a entrada dos patógenos e/ ou favorecem o seu desenvolvimento após a instalação no produto (FERRO; SALVADOR; NGUENHA, 2017). Doenças em plantas são o resultado da interação entre um hospedeiro suscetível, um agente causal e um ambiente favorável, nesse contexto as formas de classificação podem utilizar-se de critérios baseados no hospedeiro ou no agente causal da doença (MUNHOZ, 2013).

Visando agrupar ambos os critérios (hospedeiro e agente causal), George L. McNew propôs em 1960 a classificação das doenças segundo os processos fisiológicos vitais da planta que são interferidos pelos patógenos. Estes processos foram classificados em seis grupos: I) Acúmulo de nutrientes em órgãos de reserva; II) Desenvolvimento de tecidos jovens utilizando os nutrientes armazenados; III) Absorção de água e minerais; IV) Transporte de água e minerais no sistema vascular; V) Fotossíntese e VI) Utilização pela planta dos fotoassimilados (AMORIM; REZENDE; BERGAMIN-FILHO, 2011). 
Seguindo essa classificação Bettiol e Morandi (2009), consideram as doenças do grupo I, como as mais agressivas e menos específicas, caracterizadas por diversos tipos de podridão tanto duras, quanto moles que podem ocorrer em sementes, frutos e outros órgãos. São doenças que podem acontecer no campo, antes, durante ou após a colheita, sendo favorecidas por alta umidade e temperatura.

As formas de controle podem iniciar no próprio planejamento do cultivo, cuidados na colheita, transporte, embalagem e armazenagem. Dentre outras medidas, pode-se mencionar o controle biológico, que consiste no controle de um microrganismo utilizando-se de outro, ou ainda pode-se definir como a redução do inóculo ou das atividades de certa doença utilizando-se de um ou mais organismos que não o homem para tal (MACHADO et al., 2012; PEREIRA; PINHEIRO, 2012; SBRAVATTI JÚNIOR et al., 2013).

Diversos agentes podem ser utilizados na realização do controle biológico, como fungos, bactérias, vírus e afins. Segundo Buriti e Saad (2007), dentre as bactérias, os Lactobacillus são bactérias láticas heterogêneas fenotípicamente e geneticamente, capazes de colonizar diversos ambientes naturais e antrópicos. As $L$. casei são muito estudadas devido às funções benéficas que o organismo humano apresenta ao consumir regularmente tais organismos, favorecendo seu emprego na indústria alimentícia, entretanto estudos voltados para a aplicação desses organismos no controle biológico são poucos, o trabalho de Bettiol e Morandi (2009), menciona o uso destes organismos na redução de até $20 \%$ de aflatoxinas.

Dentre os fungos, pode-se mencionar as leveduras como as Saccharomyces sp., consideradas fungos unicelulares, diplóides com reprodução assexuada por brotamento ou sexuada por esporulação e cruzamento com formação de diplóides. O gênero é composto por dez espécies divididas em três grupos (Sensu stricto, Sensu largo e a espécie S. kluyveri formando o terceiro grupo), sendo conhecidas como fungos do açúcar e consideradas muito importantes em diversos processos industriais como a produção de bebidas alcoólicas, pães e utilizações médicas, entretanto os estudos tratando de seu uso como controle biológico são mais focados em S. cerevisiae, alguns trabalhos concluem seu uso como antagonista viável para controle de Penicillium digitatum em frutas (SILVA, 2009; KUPPER et al., 2013). 
Considerando os possíveis organismos de controle biológico é importante caracterizar alguns dos possíveis patógenos nos quais os organismos citados anteriormente podem ser empregados para controle. Dentre tais patógenos a Alternaria $s p .$, compõe um dos gêneros de doenças mais frequentes e destrutivas na olericultura, afetando folhas, hastes, caules, frutos e tubérculos de diversas famílias como solanáceas, crucíferas, cucurbitáceas, asteráceas e outras, podendo causar danos de 6 a 100 \% (TOFOLI; DOMINGUES, FERRARI, 2015).

O patógeno sobrevive em restos de cultura, hospedeiros alternativos, equipamentos agrícolas, caixas, estacas e sementes. Para o seu controle pode-se empregar técnicas integradas como plantio de sementes e mudas sadias, tratadas com fungicidas, evitar o tombamento de plântulas e utilizar materiais resistentes/tolerantes embora muitas vezes existem poucas opções para determinadas culturas (BECKER et al., 2016; ZAMBOLIM, 2018).

Para realizar o acompanhamento do desenvolvimento das doenças em diferentes culturas e/ou órgãos da mesma cultura, dois aspectos muito importantes são a incidência e a severidade da doença. A incidência é a porcentagem de plantas ou partes de plantas doentes, ou seja, quantas plantas foram afetadas, enquanto a severidade é a porcentagem de área ou volume de tecido doente, ou seja, o quanto da planta está afetado (MICHEREFF, 2001; BETTIOL; MORANDI, 2009).

Diante do exposto o presente trabalho teve como objetivo avaliar o tratamento de frutos de tomate com diferentes agentes de controle biológico (leveduras, bactérias e controle), visando comparar qual dos agentes proporciona um maior período de sanidade aos frutos considerando a incidência e a severidade da doença.

\section{MATERIAL E MÉTODOS}

Para realização deste experimento foram selecionados alguns frutos de tomate em um mercado popular, prezando-se pela escolha de frutos muito semelhantes, visando garantir a igualdade nas condições experimentais, em seguida separou-se estes frutos em 3 grupos (tratamentos). Empregou-se delineamento inteiramente casualizado com 3 tratamentos e 4 repetições, totalizando 12 unidades experimentais. Os tratamentos empregados foram o controle biológico com solução de $1 \%$ de levedura, 
controle biológico com solução de $1 \%$ de bactéria e o tratamento controle ou testemunha, sem uso de controle biológico.

Realizou-se o preparo de uma solução de $1 \%$ de hipoclorito e das soluções de tratamento: $1 \%$ de levedura (Saccharomyces sp.) e 1\% de bactéria (Lactobacillus casei Shirota). Para a preparação da solução de levedura utilizou-se fermento biológico como elemento base diluindo-se $1 \mathrm{~g}$ deste em $100 \mathrm{~mL}$ de água, igualmente para solução de bactérias, utilizou-se leite fermentado diluindo-se $1 \mathrm{~mL}$ em $100 \mathrm{~mL}$ de água.

Após a preparação das soluções realizou-se a desinfestação inicial dos frutos utilizando-se a solução de hipoclorito a $1 \%$, secando os frutos na sequência com papel toalha. Em seguida mergulhou-se os frutos destinados a cada tratamento nas soluções correspondentes, acomodando-os posteriormente em bandejas forradas com papel toalha, onde realizou-se a inoculação do ambiente interno com Alternaria sp., na sequência umedeceu-se o papel toalha ao fundo da bandeja e vedou-se a mesma com plástico filme, para avaliar posteriormente o desenvolvimento do fungo.

Finalizada a instalação do experimento manteve-se o mesmo em local fresco e protegido da radiação direta, realizando avaliações a cada 5 dias para verificar o desenvolvimento da doença tanto em função de sua incidência (número de frutos afetados pela doença), quanto de sua severidade (volume de tecido doente nos frutos afetados), estas avaliações iniciaram-se na instalação do experimento e seguiram-se por mais 30 dias.

Os resultados de cada dia de avaliação foram submetidos à análise de variância $(p<0,05)$ e quando significativos foram comparados pelo teste de médias de Tukey $(p<0,5)$. Para os dados temporais realizou-se a confecção de curvas de desenvolvimento da doença, ambos os resultados foram apresentados e discutidos na próxima seç̧ão.

\section{RESULTADOS E DISCUSSÃO}

Para iniciar a seção de resultados destaca-se que não houve diferenças na incidência da doença em função dos tratamentos, assim a partir da constatação dos sintomas iniciais da doença, todas as unidades experimentais encontravam-se contaminadas. Assim, optou-se por continuar a avaliação com foco na severidade da doença. A Tabela 1, apresenta os resultados médios de avaliação de severidade da doença para cada tratamento durante o experimento. 
Tabela 1 - Avaliação da Severidade do ataque de Alternaria sp., em frutos de tomate sem controle biológico e utilizando-se controle biológico com solução de bactéria e de levedura

\begin{tabular}{cccccc}
\hline \multirow{2}{*}{$\begin{array}{c}\text { Dias de } \\
\text { Avaliação }\end{array}$} & Controle & Bactéria & Levedura & Média & Variação (\%) \\
\cline { 2 - 5 } & 0,00 & 0,00 & 0,00 & $0,00^{\text {ns }}$ & 0,00 \\
5 & $1,00 \mathrm{a}$ & $5,00 \mathrm{a}$ & $0,50 \mathrm{a}$ & $2,17^{*}$ & 107,14 \\
10 & $4,75 \mathrm{a}$ & $12,75 \mathrm{a}$ & $4,75 \mathrm{a}$ & $7,42^{*}$ & 55,46 \\
15 & $7,00 \mathrm{a}$ & $18,00 \mathrm{~b}$ & $7,00 \mathrm{a}$ & $10,67^{*}$ & 45,29 \\
20 & $16,75 \mathrm{ab}$ & $31,00 \mathrm{~b}$ & $8,00 \mathrm{a}$ & $18,58^{*}$ & 53,29 \\
25 & $60,00 \mathrm{~b}$ & $58,00 \mathrm{~b}$ & $17,00 \mathrm{a}$ & $45,00^{*}$ & 18,23 \\
30 & $84,25 \mathrm{~b}$ & $95,00 \mathrm{~b}$ & $31,00 \mathrm{a}$ & $70,08^{*}$ & 12,63 \\
\hline
\end{tabular}

ns: Não significativo e * Significativo pela análise de variância ao nível de $5 \%$ de probabilidade. Médias seguidas da mesma letra nas linhas não diferem entre si, pelo teste de Tukey a $5 \%$ de probabilidade.

Fonte: Autoria própria.

Conforme a Tabela 1., observa-se que até os 10 Dias Após a Inoculação (DAI), não houve diferença entre os tratamentos empregados e o tratamento controle, sendo a incidência inicial da doença muito similar entre todos os tratamentos, o que levou a continuar com a avaliação apenas da severidade. Seguindo-se os dias de desenvolvimento do experimento nota-se que em 15 e 20 DAl, o tratamento utilizando controle biológico por solução de bactérias apresentou severidades superiores aos demais, contudo em $20 \mathrm{DAl}$, tanto o tratamento com bactérias, quanto o tratamento controle não diferiram entre si.

No terço final do experimento, aos 25 e 30 DAl, nota-se a superioridade estatística na menor severidade da doença para o tratamento com controle biológico por solução de leveduras, diferindo estatisticamente da solução com bactérias e controle. Uma análise interessante está na redução do coeficiente de variação entre os tratamentos ao longo do tempo, o que indica uma estabilização dos mesmos.

Na sequência a Figura 1, demonstra as curvas de comportamento de cada tratamento durante a condução do experimento em função da severidade, sendo complementada pela Tabela 2 , com as equações de regressão e coeficientes de determinação $\left(\mathrm{R}^{2}\right)$. 
Figura 1 - Severidade de Alternaria sp., em frutos de tomate em função do controle biológico

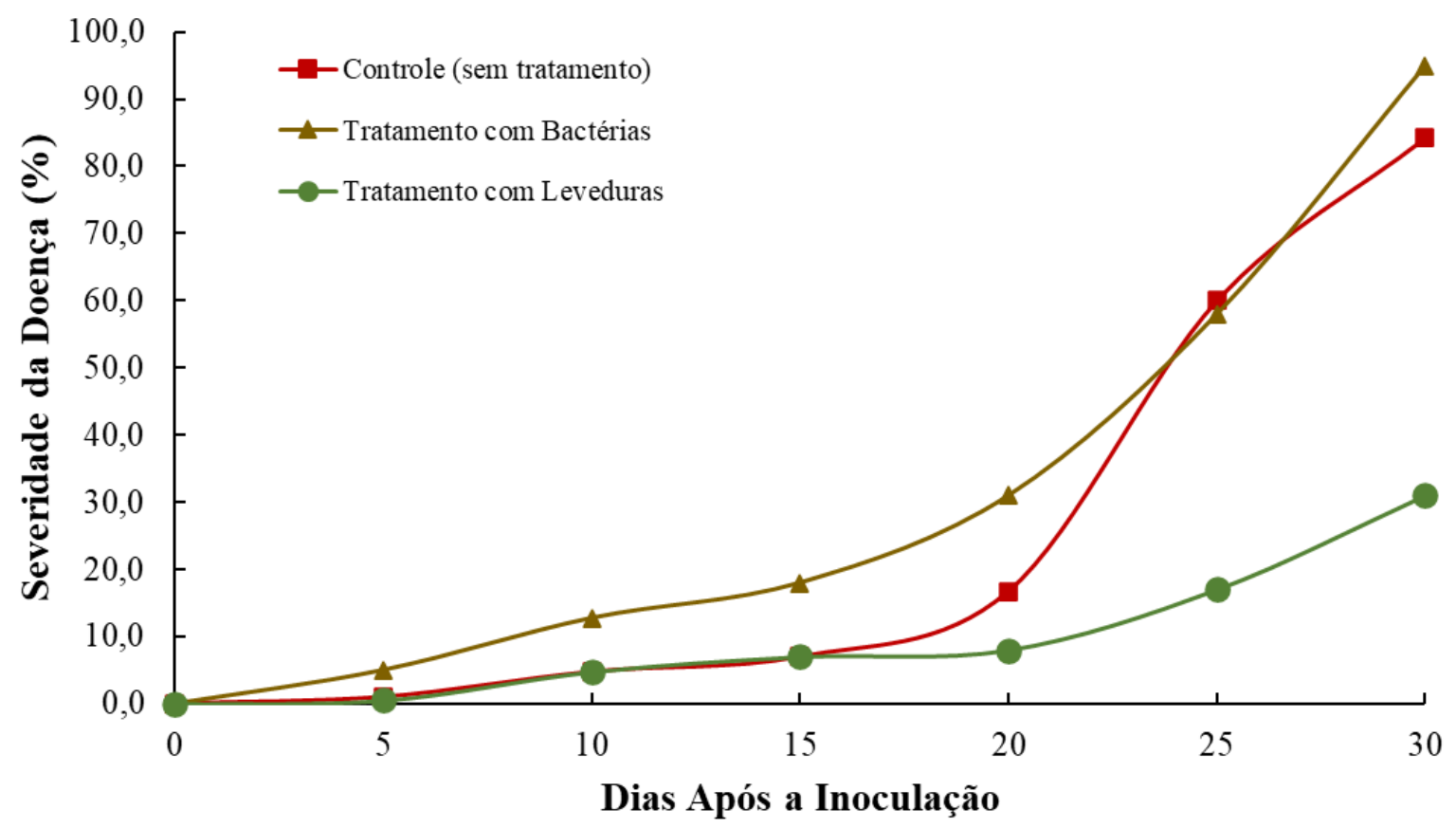

Fonte: Autoria própria.

Tabela 2 - Equações de regressão e coeficiente de determinação $\left(R^{2}\right)$

\begin{tabular}{cccc}
\hline Tratamento & Regressão de Primeiro Grau & Coeficiente de Determinação $\left(\mathbf{R}^{2}\right)$ & $\mathbf{F}$ da Regressão \\
\hline Controle & $\mathrm{Y}=2,734 \mathrm{x}-16,19$ & 0,76 & $84,68^{*}$ \\
Bactéria & $\mathrm{Y}=2,923 \mathrm{x}-12,46$ & 0,82 & $120,18^{*}$ \\
Levedura & $\mathrm{Y}=0,923 \mathrm{x}-4,098$ & 0,61 & $42,84^{*}$ \\
\hline
\end{tabular}

\begin{tabular}{cccc}
\hline Tratamento & Regressão de Segundo Grau & Coeficiente de Determinação $\left(\mathbf{R}^{2}\right)$ & \\
\hline Controle & $Y=0,1565 x^{2}-1,962 x+3,381$ & 0,95 & $254,76^{*}$ \\
Bactéria & $Y=0,1294 x^{2}-0,959 x+3,720$ & 0,94 & $206,70^{*}$ \\
Levedura & $Y=0,0423 x^{2}-0,345 x+1,185$ & 0,70 & $32,17^{*}$ \\
\hline
\end{tabular}

* Significativo ao nível de $5 \%$ de probabilidade pela análise de variância (teste F).

Fonte: Autoria própria.

A análise da Figura 1, complementando-se ao gráfico demonstra que até metade do experimento (15 DAl), o desenvolvimento da severidade tem comportamento muito semelhante entre todos os tratamentos, entretanto, a partir deste momento os tratamentos controle e com solução de bactérias iniciam um processo de aumento de severidade da doença mais acentuado, enquanto o tratamento com solução de levedura apresenta aumentos menores, com crescimento mais acentuado a partir dos 20 DAI, mas ainda menor que nos demais tratamentos. 
As bactérias para este experimento apresentaram a maior severidade da doença superando até o tratamento controle, enquanto o trabalho de Bettiol e Morandi (2009), confirmou o excelente uso desta bactéria para redução de aflatoxinas, para este experimento o controle e/ ou redução de Alternaria sp., não se observou ação positiva das mesmas.

Destaca-se que no final do experimento, outros patógenos de pós-colheita se desenvolveram no recipiente, não apenas a Alternaria $s p$. que foi inoculada inicialmente. $\mathrm{O}$ fato do tratamento com bactérias ter sido o mais afetado, pode ser justificado por vários acontecimentos, como o fato desta bactéria intensificar a ação da doença, a bactéria não conseguir competir adequadamente com o patógeno, dentre outras hipóteses.

Por meio deste experimento foi possível observar a agressividade com que as doenças de órgãos de reserva atuam e a rapidez com que elas tomam o tecido e levam a sua morte (). A utilização do controle biológico embora com alguns estudos, ainda não recebe a atenção merecida por parte da indústria, por exemplo, sua utilização como mostrado no experimento, quando utilizando o agente correto pode aumentar a vida pós-colheita dos frutos nas bancadas dos supermercados por um alto período (OLIVEIRA et al., 2015; MURAKAMI, 2018; RODRIGUES et al., 2020), talvez utilizando-se uma concentração um pouco maior de levedura a severidade nos frutos teria sido ainda menor, sem considerar que o ambiente do experimento estava totalmente voltado para o favorecimento do desenvolvimento da doença.

Muitos processos agrícolas e industriais ainda não se utilizam desta forma de controle devido às dificuldades que muitas pessoas imaginam existir na utilização do método, na crença de que não será uma forma tão eficiente, quanto os controles químicos (a nível de lavoura), mas principalmente devido à falta de conhecimento, o que justifica a necessidade de mais pesquisas e disponibilização de maiores informações sobre o tema.

Portanto, mais estudos devem ser realizados sobre o controle biológico e os agentes possíveis de serem utilizados neste controle, bem como os diferentes processos nos quais o controle biológico pode ser empregado, tanto no nível de lavoura, indústria ou mesmo comercialização, destacando-se que a prática ainda pode ser empregada 
pelos consumidores finais, a fim de manter a qualidade dos produtos adquiridos por maiores períodos.

\section{CONCLUSÕES}

Encerra-se este experimento, destacam-se a importância do conhecimento sobre incidência e severidade de doenças, além da importância do controle biológico para reduzir a ação de um ou mais patógenos em frutos, constatando neste ensaio a eficiência das leveduras em reduzir a severidade da doença em relação ao não uso ou ao uso de outro agente como as bactérias. Contudo, mesmo com essa constatação ainda pode-se notar um uso reduzido do controle biológico nos processos tanto agrícolas, quanto industriais.

Portanto, reforça-se a importância do conhecimento sobre as possíveis formas de utilização do controle biológico, agentes, processos, limitações e afins, esta forma de manejar pragas e doenças tende a crescer nos próximos anos, entretanto, atualmente ainda carece de mais pesquisas e experimentos, para permitir sua utilização da forma mais eficiente possível e seu emprego em larga escala, podendo ser empregado por produtores, pela indústria e/ ou ainda pelos consumidores finais destes produtos.

\section{REFERÊNCIAS}

AMORIM, L.; REZENDE, J. A. M.; BERGAMIN-FILHO, A. Manual de fitopatologia. 4a ed. Piracicaba: Agronômica Ceres, 2011. 704p.

BECKER, W. F.; WAMSER, A. F.; FELTRIM, A. L.; SUZUKI, A.; SANTOS, J. P.; VALMORBIDA, J.; HAHN, L.; MARCUZZO, L. L.; MUELLER, S. Sistema de produção integrada para o tomate tutorado em Santa Catarina. Santa Catarina: Epagri, 2016. 149p.

BETTIOL, W.; MORANDI, M. A. B. Biocontrole de doenças de plantas: Usos e perspectivas. Jaguariúna: Embrapa, 2009. 334p.

BURITI, F. C. A.; SAAD, S. M. I. Bactérias do grupo Lactobacillus casei: Caracterização, viabilidade como probióticos em alimentos e sua importância para a saúde humana. Archivos Latinoamericanos de Nutricion, p.1-8, 2007.

FARIAS, B. E. M. A. Análise da atividade da pecuária utilizando-se o índice de confiança do agronegócio nos anos de 2014 a 2017. 2018. 35f. Trabalho de Conclusão de Curso (Graduação em Zootecnia) - Universidade Federal de Santa Catarina, Florianópolis, 2018. 
FERRO, L.; SALVADOR, B.; NGUENHA, R. Estimativa de perda pós-colheita da batata-reno (Solanum tuberosum). Estudo de Caso: Distrito de Moamba, Bloco I (MoambaSede). Revista de Ciências Agrárias, v.40, n.1, p.154-163, 2017.

GONÇALVES, J. E.; SILVA, S. W.; GONÇALVES, E. S. O.; MELO, T. F. Reflexões atualizadas sobre o contexto Brasileiro do agronegócio brasileiro. Agroalimentaria, v.24, n.46, p.89-101, 2018.

KUMMU, M.; MOEL, H.; PORKKA, M.; SIEBERT, S.; VARIS, O.; WARD, P. J. Lost food, wasted resources: Global food supply chain losses and their impacts on freshwater, cropland, and fertilizer use. Science of the Total Environment, The, v.438, p.477-489, 2012.

KUPPER, K. C.; CERVANTES, A. L. L.; KLEIN, M. N.; SILVA, A. C. Avaliação de microrganismos antagônicos, Saccharomyces cerevisiae e Bacillus subtilis para o controle de Penicillium digitatum. Revista Brasileira de Fruticultura, Jaboticabal, v.35, n.2, p.425-436, 2013.

MACHADO, V.; BERLITZ, D. L.; MATSUMURA, T. S.; SANTIN, R. C. M.; GUIMARÃES, A.; SILVA, M. E.; FIUZA, L. M. Bactérias como agentes de controle biológico de fitonematoides. Oecologia Australis, v.16, n.2, p.165-182, 2012.

MICHEREFF, S. J. Fundamentos de fitopatologia. Recife: UFRPE, 2001. 150p.

MORAES, C. C.; SOUZA, T. A. Panorama mundial do desperdício e perda de alimentos no contexto de cadeia de suprimentos agroalimentares. Revista em Agronegócio e Meio Ambiente, Maringá, v.11, n.3, p.901-924, 2018.

MURAKAMI, K. Efeito do ambiente e uso de produtos alternativos na pós-colheita do mamoeiro. 2018. 56f. Dissertação (Mestrado em Agronomia) - Universidade de Brasília, Brasília, 2018.

MUNHOZ, C. F. Identificação de genes de maracujá azedo diferencialmente expressos durante a interação com Xanthomonas axonopodis. 2013. 175f. Tese (Doutorado em Ciências) - Universidade de São Paulo, Escola Superior de Agricultura "Luiz de Queiroz", Piracicaba, 2013.

OLIVEIRA, T. A. S.; DUARTE, E. A. A.; SILVA, R. M.; MOREIRA, Z. P. M.; CARMO, C. O.; LUZ, E. D. M. N. Biocontrole de doenças pós-colheita de frutas. RAPP, v.23, n.293-325, 2015.

PEREIRA, R. B.; PINHEIRO, J. B. Manejo integrado de doenças em hortaliças em cultivo orgânico. Brasília: Embrapa, 2012. 12p.

RODRIGUES, P. L.; SILVA, J. L.; ALFAIA, J. P.; SOUZA, J. C.; MACEDO, L. P. Potencial de biocontrole das leveduras em pós-colheita de citros pela produção da enzima $\beta$ - 
1,3-glucanase e atividade killer: Uma revisão. Citrus Research e Technology, v.41, e1056, 2020.

SBRAVATTI JÚNIOR, J. A.; AUER, C. G.; PIMENTEL, I. C.; SANTOS, A. F.; SCHULTZ, B. Seleção In Vitro de fungos endofíticos para o controle biológico de Botrytis cinerea em Eucalyptus benthamii. Floresta, Curitiba, v.43, n.1, p.145-152, 2013.

SILVA, A. F. Caracterização genética de linhagens de Saccharomyces cerevisiae isoladas de fermentações espontâneas de cachaças de alambique da Bahia. 2009. $115 f$. Dissertação (Mestrado em Biotecnologia) - Universidade Estadual de Feira de Santana, Feira de Santana, 2009.

SOUSA, A. N. S.; ALMEIDA, E. I. B.; NASCIMENTO, S. S.; MENDES, M. S.; SOUSA, W. S.; MELO, P. A. F. R. Perdas pós-colheita de hortaliças no mercado varejista de Chapadinha, Maranhão, Brasil. Agrotrópica, v.30, n.2, p.127-134, 2018.

TOFOLI, J. G.; DOMINGUES, R. J.; FERRARI, J. T. Alternaria spp. em Oleráceas: Sintomas, etiologia, manejo e fungicidas. Biológico, v.77, n.1, p.1-14, 2015.

ZAMBOLIM, L. Subsídios para produção integrada. Viçosa: UFV/ CEAD, 2018. 


\title{
cAPITULO IX
}

\section{CRAVO-DA-ÍNDIA E CANELA COMO SABORIZANTES NA FORMULAÇÃO DE DOCES DE ABÓBORA}

DOI: 10.51859/AMPLLA.DES1788-9

\author{
Carlos José de Oliveira Melo ${ }^{1}$ \\ Antônia Karoline Teixeira da Silva ${ }^{2}$ \\ André Seiva de Brito ${ }^{3}$ \\ Antônio Thiago Madeira Beirão ${ }^{4}$ \\ Job Teixeira de Oliveira ${ }^{5}$ \\ Priscilla Andrade Silva ${ }^{6}$
}

\section{RESUMO}

A abóbora pertente a família botânica Cucurbitaceae, apresenta frutos com características morfométricas com grandes dimensões, tal características podem diminuir o potencial de comercialização delas pelo tamanho, inviabilizando também o armazenamento e o manuseio, esses fatores podem acarretar perdas econômicas ao longo da cadeia. Uma das alternativas para a diminuição das perdas seria realizar o processamento de doce em massa, propiciando uma alternativa nova para o consumo, agregando mais valor à agroindústria destes produtos e melhorando a renda dos produtores, além de aumentar a diversidade de atividades nas propriedades. A saborização dos doces por meio da utilização do cravo-da-índia e da canela, permite uma melhor experiência sensorial, além de aumentar a diversificação de sabores, agradando diversos consumidores. Essas especiarias atuam como plantas aromáticas, possuidoras de óleos essenciais com ações flavorizantes e por suas ações antibacterianas, fungicidas e antioxidantes, essas características fazem do cravo uma alternativa interessante para conservação de alimentos, em doces. Sendo assim, o objetivo deste estudo é fornecer informações sobre a abóbora, a canela, o cravo-daÍndia e os doces em massa. O trabalho foi conduzido por meio de levantamento bibliográfico que reúnem assuntos relevantes sobre a cultura da abóbora, canela, cravoda Índia e os doces, a fim de disponibilizar um conhecimento mais sucinto, esclarecedor e relevância para a comunidade científica na área de tecnologias agroalimentares.

Palavras-chave: plantas aromáticas, óleos essenciais, agroalimentares. 


\section{INTRODUÇÃO}

A abóbora (Cucurbita sp.), é uma hortaliça cultivada em todo território brasileiro e tem importância relevante principalmente nas regiões Norte e Nordeste (NICK; BORÉM, 2017). Os tipos mais encontrados de abóbora são: seca (caracterizada por ter frutos grandes de até $15 \mathrm{~kg}$ ), baianinha (frutos pequenos e com casca rajada) e japonesa ou cabotiá (fruto com gomos e casca verde escuro). No Brasil são cultivados vários tipos de abóboras, que diferem entre si pelo formato, tamanho, cor da casca, cor da polpa, firmeza, teor de amido, teor de matéria seca, capacidade de armazenamento e sabor (RICCE et al., 2020).

É de fácil colocação no mercado, pois fazem parte da dieta básica das populações de diversas regiões do Brasil e do mundo, sendo utilizadas com finalidades alimentícias, medicinais e industriais, gerando empregos diretos e indiretos, demandando mão-deobra do cultivo à comercialização (RESENDE et al., 2013).

Por apresentar grandes dimensões, as abóboras muitas vezes são de difícil comercialização, armazenamento e manuseio, podendo ocasionar perdas ao longo da cadeia (SASAKI, 2005). E uma das alternativas é o processamento de doce em massa, pois propicia uma alternativa para seu consumo, busca agregar mais valor à agroindústria destes produtos e melhora a renda dos produtores (KOBLITZ, 2011).

O cravo-da-índia e a canela são muito utilizados por suas propriedades aromáticas, possuidores de óleos essenciais com ações flavorizantes e por suas ações antibacterianas, fungicidas e antioxidantes (NASCIMENTO et al., 2000) fazem dessas ervas, uma alternativa interessante para conservação de alimentos, podendo diminuir o uso de produtos sintéticos em doces (DIAS, 2009; SILVESTRI et al., 2010).

A agregação de valor nos produtos cultivados gera vantagens tanto para consumidores quanto para os produtores, mesmo assim ainda são encontrados problemas como falta de conhecimento dos produtores para as etapas de processamento e planejamento para inserir tecnologias na produção, oferecer melhor qualidade nos produtos finais e gerar receitas mais lucrativas ao longo da cadeia (SANCHES et al., 2017).

Segundo a Resolução Normativa no 9 de 1978 publicada no D.O.U de 11 de dezembro de 1978 da Câmara Técnica de Alimentos do Conselho Nacional de Saúde, o 
doce em massa é o produto resultante do processamento adequado das partes comestíveis desintegradas de vegetais com açúcares; com ou sem adição de água; pectina como espessante; ácido cítrico como ajustador de $\mathrm{pH}$, cuja função é diminuir o pH para o nível desejado e também inibir enzimas que deterioram o alimento (SILVA, 1997; JESUS et al., 2008); e outros ingredientes e aditivos permitidos, até atingir consistência apropriada e por fim o acondicionamento de forma a assegurar sua conservação (BRASIL, 1978).

O objetivo deste trabalho é fornecer informações sobre a abóbora, cravo-daÍndia, canela e doces, afim de aumentar a participação da abóbora no mercado dos alimentos saborizados.

\section{METODOLOGIA}

A revisão sistemática da literatura foi realizada, entre junho / 2019 e fevereiro / 2020, por meio do portal da revista Capes e BVCA (Biblioteca Virtual em Ciências Agrárias) utilizando pesquisa avançada com a combinação dos descritores "agro econômico, características da abóbora, do cravo-da-índia e da canela". Essas bases de dados e bibliotecas digitais foram escolhidas por serem referência para muitos pesquisadores brasileiros, concentrando periódicos bem qualificados a nível nacional e internacionalmente.

A seleção dos artigos baseou-se nos seguintes critérios: publicações nacionais e internacionais que responderam a busca avançada, sem restrição de período de tempo, com vistas a compreender a historicidade das pesquisas sobre a temática. Ressalta-se que, apesar da ausência de restrição de tempo, todos os artigos encontrados se enquadraram no intervalo de publicações realizadas. entre os anos de 2000 e 2020.

\section{REVISÃO BIBLIOGRÁFICA}

\subsection{PRINCIPAIS CARACTERÍSTICAS SOBRE A ABÓBORA}

A família Cucurbitaceae, agrupa um amplo conjunto de gêneros e espécies que ocorrem geralmente nas regiões tropicais do mundo, sendo formado por cerca de 120 gêneros, apresentando mais de 800 espécies, sendo considerada uma das famílias mais cultivadas pela sociedade (SILVA et al., 1999; TEPPNER, 2004). 
Segundo Ferreira et al. (2006), no Brasil, destacam-se cerca de 30 gêneros e 200 espécies, onde as mais utilizadas com objetivo alimentar e econômico são as abóboras (Cucurbita moschata) e (Cucurbita maxima) e a abobrinha (Cucurbita pepo). As abóboras apresentam maior relevância na produção em diversas regiões, principalmente no Norte e Nordeste (NICK; BOREM, 2017).

As abóboras são originárias das américas, e apresentam como centro de origem a região central do México, onde conforme descreve Dutcosky (2008), esse fruto já era utilizado como base para a alimentação indígena antes da era das colonizações, destacando-se que o seu uso primário ocorreu devido a palatabilidade das sementes, que atraiu os primeiros coletores (HARLAN, 1975; RESENDE et al., 2013).

As características botânicas da família Cucurbitaceae, geralmente são plantas de ciclo anual, herbácea, e hábito de crescimento rasteiro ou trepador (FILGUEIRA, 2008). O sistema radicular é fasciculado, ou seja, ramificado, superficial, com penetração até mais de $1 \mathrm{~m}$ no solo, concentrando-se em subsuperfície com até $20 \mathrm{~cm}$, baixa capacidade de regeneração quando ocasionado por injúrias, e apresenta raízes adventícias que auxiliam na fixação da planta no solo (PEDROSA, 1992; RIBEIRO, 2008; NICK; BORÉM, 2017).

O caule é característico pela coloração verde-escuro, rastejante, pubescente, ou seja, provido de pelos curtos e finos, robusto, vigoroso, com comprimento em mais de $10 \mathrm{~m}$, onde apresenta gavinhas que auxiliam na fixação da planta (FILGUEIRA, 2000; FILGUEIRA, 2008).

As folhas, em geral, apresentam coloração verde-escuro, podendo apresentar manchas mosqueadas em coloração prateada, com formato alargada, dispostas de forma alternada, com nervura palmeada, base geralmente codiforme e pilosas, com presença moderada de pelos em seu limbo (RIBEIRO, 2008; NICK; BORÉM, 2017).

As plantas dessa família, geralmente expressam a monoicia, com flores unissexuais, ou seja, ocorrência de flores masculinas e femininas, podendo ocorrer também flores hermafroditas, dispostas em locais distintos na planta, mas geralmente sob as axilas foliares onde predomina a fecundação cruzada, e apresentam coloração com tons desde amarelados até alaranjados (WHITAKER; ROBINSON, 1986; SANTOS et al., 2005; NICK; BORÉM, 2017). 
O fruto da aboboreira caracteriza-se por ser uma baga indeiscente, ou seja, o fruto não abre para liberar as sementes, que apresenta coloração do fruto em tons diversos de acordo com a cultivar ou variedade, com a cor da polpa podendo variar de branco, amarelo até alaranjado escuro e apresenta valores médios de sementes por fruto de 100 a 300 sementes (PEDROSA, 1992; FILGUEIRA, 2008).

O cultivo das abóboras possui grande adaptabilidade em seu cultivo, sendo produzido em diversas condições edafoclimáticas, porém conforme descreve Amaro et al. (2014), a cultura possui preferência em solos arenosos, bem drenados, com pH na faixa de 5,8 e 6,8 e temperaturas amenas de 20 a 27 으.

Segundo Amaro et al., (2014), na produção hortícola do país, as abóboras representam a 7ạ posição em volume de produção, devido as características produtivas das plantas e durabilidade dos frutos, econômicas pois contribuem na diversificação de renda e produção da agricultura familiar, e nutricionais, onde em sua composição química apresentam-se ricas em sais minerais, como ferro, cálcio, magnésio, potássio e vitaminas $A, B, C$ e E, que contribuem para a saúde e nutrição da população (AMAYA, 1997; HEIDEN et al., 2007).

$\mathrm{Na}$ alimentação, o uso desse fruto é amplo na culinária brasileira sendo utilizado em diferentes estágios de maturação, sob as formas in natura ou processados, com a preparação de doces até pratos salgados (BARBIERI et al., 2006; HEIDEN et al., 2007; SERRA; CAMPOS, 2010; SANTOS et al., 2015). Estudos com objetivo de elaborar novos produtos alimentícios desse fruto ainda são esparsos, em reflexo a este atual quadro, a oferta de novos produtos proporcionaria o aumento do valor da matéria prima, além de contribuir em geração de renda e subsídio alimentar para os pequenos produtores rurais, pois o maior de volume de produção geralmente é atribuído a esta classe (PROVESI, 2010).

\subsection{ASPECTOS RELEVANTES SOBRE O CRAVO-DA-ÍNDIA}

O cravo-da-índia (Syzygium aromaticum) pertence à família Myrtaceae, a qual contém cerca de 3000 espécies de árvores e arbustos tropicais e subtropicais (MAEDA et al., 1990). O cravo em si é a gema floral seca, usada principalmente como condimento na culinária, devido ao seu marcante aroma e sabor, conferido pelo eugenol, composto fenólico volátil (MAZZAFERA, 2003). 
É uma planta arbórea com copa alongada característica podendo atingir 8 a 10 $\mathrm{m}$ de altura. Suas folhas possuem características ovais, aromáticas e tem de 7 a $11 \mathrm{~cm}$ de comprimento, suas flores são pequenas, dispostas em corimbos terminais em um tom verde amarelado com um pequeno tom impregnado de vermelho, sendo que quanto mais próximas da cor avermelhada, estão melhores para coleta. Os frutos são de drupa elipsoide com coloração avermelhada (AFFONSO et al., 2012).

A utilização do cravo-da-índia como planta aromática, possuidora de óleos essenciais com ações flavorizantes e por suas ações antibacterianas, fungicidas e antioxidantes (NASCIMENTO et al., 2000) fazem do cravo, uma alternativa interessante para conservação de alimentos, podendo diminuir o uso de produtos sintéticos em doces (DIAS, 2009; SILVESTRI et al., 2010).

A ação bactericida, é devido a sua alta penetrabilidade na membrana citoplasmática, promovendo seu rompimento e aumentando sua permeabilidade não específica, desta forma gerando um extravazamento do conteúdo celular e posterior morte da bactéria. Fármacos que promovem a destruição da membrana celular são muito importantes para o uso médico, pois possuem menor probabilidade de selecionar bactérias resistentes (DEVI et al., 2010).

A ação fungicida é devido aos óleos essenciais constituídos por substâncias de baixo peso molecular, geralmente lipofílicas, caraterísticas que permitem uma penetração eficiente na membrana celular e estudos comprovaram que os óleos essenciais penetram nos tecidos cerca de 100 vezes mais rápido que a água, sendo essa alta capacidade de penetração nas membranas conferidas pelos compostos fenólicos, como o eugenol (PAWAR; TAKER, 2006).

Sobre a ação antioxidante: a peroxidação dos lipídeos da membrana celular resulta na sua desestabilização, mudando suas características de transporte e podendo levar à morte celular e a peroxidação lipídica está relacionada às doenças, tais como diabetes, ateroesclerose, isquemia e câncer (OGATA et a., 2000). Segundo o mesmo autor, o eugenol possui capacidade inibitória da peroxidação lipídica na fase de iniciação e propagação através da interferência nas reações em cadeia, sequestrando o $\mathrm{O}_{2}$ ativo e, ao ser metabolizado em um dímero (dieugenol), inibe a peroxidação propriamente dita em nível de propagação da reação em cadeia de radicais livres como o $\alpha$-tocoferol. 


\subsection{INFORMAÇÕES GERAIS SOBRE A CANELA}

A canela (Cinnamomum sp.) é pertencente à família Lauraceae, é uma planta árborea de origem asiática, de importância medicinal (OLIVEIRA et al., 2018), cosmética, farmacêutica e apresentam ações antibacterianas e fungicidas (CARNEIRO; LIMA, 2018). Ocupa um lugar especial entre as especiarias, seu nome possui origem da Indonésia, "kayu manis", que significa "madeira doce", conhecida desde 2.500 anos a.C. pelos chineses, possuía mais valor do que o ouro; Na Arábia, era considerada uma mercadoria preciosa; os egípcios utilizavam-na para embalsamar seus mortos, junto com outros condimentos; em 1498, com a descoberta do caminho para as Índias, os portugueses alcançaram região do atual Sri Lanka, onde a canela era produzida em abundância, onde os mesmos tiveram o monopólio do condimento até serem suplantados, no século XVII, pelos espanhóis que a comercializaram exclusivamente por um longo tempo; no século XVIII, por volta de 1776, o cultivo da canela começou a se espalhar pelo mundo e a canela era utilizada para aromatizar molhos e vinhos brancos, sendo também utilizada para perfumes (NEGRAES, 2003).

Os polifenóis encontrados na canela podem levar a diminuição do risco de fatores associados com diabetes e doenças cardiovasculares, pois estudos em animais e humanos, envolvendo indivíduos com Diabetes Mellitus (DM) tipo 2 e síndrome dos ovários policísticos, demonstram efeitos benéficos utilizando canela e extratos aquosos de canela, relacionados à glicose, insulina, lipídios e antioxidantes; também, podem ocorrer efeitos na massa corporal magra e composição corporal e resposta inflamatória (ANDERSON, 2008). Segundo o mesmo autor, todos esses efeitos poderiam ocasionar redução dos fatores de risco associados ao diabetes e doenças cardiovasculares e consequentemente diminuição da incidência destas doenças.

\subsection{DOCE EM MASSA}

O doce em massa é obtido através do cozimento das frutas adicionando-se o açúcar até atingir a consistência desejada, podendo ser pastoso ou em massa de tal forma que possibilite o corte. Além do açúcar, outros ingredientes podem vir a ser acrescentados como a pectina e o ácido cítrico, que contribuem para a boa liga do doce. A fabricação é simples e eficiente na conservação de frutas, o que torna o doce apreciado pelos consumidores e eleva sua comercialização (SILVA, 1997). 
Os vegetais representam uma fonte importante de nutrientes para a alimentação humana, de suma importância para uma dieta balanceada, e a sazonalidade, dependendo da cultura, representa um entrave para o desenvolvimento de novos produtos. Devido a alta perecibilidade dos vegetais, a formulação de novos produtos, além de agregar valor as matérias-primas, pode elevar o seu período de conservação, assim como oportunizar o consumo de seus nutrientes em tempo integral. Com o intuito de apresentar uma nova alternativa de fonte de renda para o pequeno produtor de abóbora, a elaboração de doces saborizados com canela e cravo-da-Índia surge com alternativa tecnológica para impulsionar esta cadeia produtiva.

\section{CONSIDERAÇÕES FINAIS}

A agregação de valor nos produtos cultivados gera vantagens tanto para consumidores quanto para os produtores, mesmo assim ainda são encontrados problemas como falta de conhecimento dos produtores para as etapas de processamento e planejamento para inserir tecnologias na produção, oferecer melhor qualidade nos produtos finais e gerar receitas mais lucrativas ao longo da cadeia. $\mathrm{O}$ desenvolvimento de doces de abobora saborizados com canela e cravo-da-Índia, além de influenciar de forma positiva vários aspectos nutricionais e econômicos, contribuem na diversificação e renda na agricultura familiar.

\section{REFERÊNCIAS}

AFFONSO, Rafael da Silva; RENNÓ, Magdalena Nascimento; SLANA, Gláucia Barbosa Candido Alves; FRANÇA, Tanos Celmar Costa. Aspectos Químicos e Biológicos do Óleo Essencial do Cravo da Índia. Revista Virtual de Química. v. 4, n. 2. P. 146 -161, 2012.

AMARO, Geovani Bernardo; PINHEIRO, Jadir Borges; LOPES, José Flávio; CARVALHO, Agnaldo Donizete Ferreira de; MICHEREFF FILHO, Miguel; VILELA, Nirlene Junqueira. Recomendações técnicas para o cultivo de abóbora híbrida do tipo japonesa. 2014. (Desenvolvimento de material didático ou instrucional - Circular Técnica 137).

AMAYA, Delia Rodrigues. Carotenoids and Food Preparation: The Retention of Provitamin A Carotenoids in Prepared, Processed, and Stored Foods. Campinas: UNICAMP, 1997. $93 \mathrm{p}$.

ANDERSON, Richard Peter. Chromium and polyphenols from cinnamon improve insulin sensitivity. Proceedings of the Nutrition Society, v.67, p. 48-53, 2008. 
BARBIERI, Rosa Lía; HEIDEN Gustavo; NEITZKE, Raquel Silviana; GARRASTAZÚ Marilice Cordeiro; SCHWENGBER, José Ernani. 2006. Banco Ativo de Germoplasma de Cucurbitáceas da Embrapa Clima Temperado - período de 2002 a 2006. Pelotas: Embrapa Clima Temperado. 30p. (Documento, 176).

BRASIL. Ministério da Saúde. Agência Nacional de Vigilância Sanitária-ANVISA. Resolução da Diretoria do Colegiado no 12, de julho de 1978. Normas Técnicas Relativas a Alimentos e Bebidas. Diário Oficial da República Federativa do Brasil, Brasília. Seção I, p.1-75, 1978.

CARNEIRO, Matheus Andrade; LIMA, Cristina Peitz. Avaliação da atividade antimicrobiana da associação dos óleos essenciais de Cinnamomum verum J. Presl, Melaleuca alternifolia Cheel e Thymus vulgaris L. Space UniBrasil. Trabalho de Conclusão de Curso. 2018.

DEVI, K. Pandima.; NISHA, S. Arif; SAKTHIVEL, R.; PANDIAN, S. Karutha. J. Eugenol (an essential oil of clove) acts as an antibacterial agent against Salmonella typhi by disrupting the cellular membrane. Journal of Ethnopharmacology, v. 130, n. 1, p. 107-115, 2010.

DIAS, Vera Lúcia Neves. Fitodisponibilidade de metais, caracterização nutricional, constituição química, avaliação da atividade antioxidante e antibacteriana do óleo essencial extraído das folhas da Cinnamomum zeylanicum Breyn. Tese (doutorado) - UFPB/CCEN. João Pessoa, 2009.

DUTCOSKY, Silvia Deboni. Análise sensorial de alimentos. Curitiba: Champagnat, 2011. 432p. FERREIRA, M. A. J. da F.; Abóboras e morangas: das Américas para o mundo. In: BARBIERI, R. L.; TUMPF, E. R. T. (Org.). Origem e evolução das plantas cultivadas. Brasília, DF: Embrapa Informação Tecnológica, Pelotas: Embrapa Clima Temperado, 2008. p. 59-88.

FILGUEIRA, Fernando Antônio Reis. Novo Manual de Olericultura: agrotecnologia moderna na produção e comercialização de hortaliças. 1. Ed. Viçosa: Editora UFV, 402p. 2000.

FILGUEIRA, Fernando Antônio Reis. Novo manual de olericultura: agrotecnologia moderna na produção e comercialização de hortaliças. 2008. 3 ed. Viçosa: UFV, 421p.

HARLAN, Jack Rodney. Crop \& Man. Wisconsin: American Society of Agronomy, 1975. 284 p.

HEIDEN Gustavo.; BARBIERI Rosa Lía; NEITZKE Raquel Silviana. 2007. Chaves para a identificação das espécies de abóbora (Cucurbita, Cucurbitaceae) cultivadas no Brasil. Pelotas: Embrapa Clima Temperado. 31p. (Documentos, 197).

JESUS, Moema Mayra Santos de; CARNELOSSI, Marcelo Augusto Gutierrez; SANTOS, Suanne França.; NARAIN, Narendra; CASTRO, Alessandra Almeida. Inibição do escurecimento enzimático de quiabo minimamente processado. Revista de Ciências Agronômicas, v. 39, n. 4, p. 524-530, 2008. 
KOBLITZ, Maria Gabriela Bello. Matérias-Primas Alimentícias: composição e controle de qualidade. 2. Ed. Rio de Janeiro. Guanabara Koogan, 2011. 301p.

MAEDA, Jocely Andreuccetti.; BOVI, Marilene Leão Alves; BOVI, Odair Alves; LAGO, Antonio Augusto do. Craveiro-da-Índia: Características físicas das sementes e seus efeitos na germinação e desenvolvimento vegetativo. Bragantia, Campinas, 1990.

MAZZAFERA, Paulo. Efeito alelopático do extrato alcoólico do cravo-da-índia e eugenol. Revista Brasileira de Botânica, v. 26, n. 2, p. 231-238, jun. 2003.

NASCIMENTO, Gislene G.F., LOCATELLI, Juliana, FREITAS, Paulo .C.; SILVA, Giuliana L. Antibacterial activity of plant extracts and phytochemicals on antibiotic-resistant bacteria. Brazilian Journal of Microbiology. 31:247-256. 2000.

NEGRAES, Paula. Guia A-Z de Plantas: condimentos. São Paulo: Bei Comunicação, p.103106, 2003.

NICK, Carlos; BOREM, Aluízio. (Org.). Abóboras e Morangas do Plantio à Colheita. 1. ed. Viçosa: Editora UFV, 2017.

OGATA, Masahiro; HOSHI, Midori; URANO, Shiro; ENDO, Toyoshige. Chemical and Pharmaceutical Bulletin. v. 48, n. 10, p. 1467-1469, 2000.

OLIVEIRA, Luana da Silva; LIMA, Juliana Bisi; SILVA, Kennefer Leite. Importâncias Econômicas e Botânicas das Plantas em Viveiro de Cuiabá, Mato Grosso, Brasil. Biodiversidade, v. 17, n. 2,2018, p. 80.

PAWAR, V. C.; THAKER, V. S. In vitro efficacy of 75 essential oils against Aspergillus niger. Mycoses. v. 49, n. 4, p. 316-323, 2006.

PEDROSA, J. F. Cultura do Jerimum. Mossoró, RN, 31p, 1992. (Apostila)

PROVESI, João Gustavo. Estabilidade e efeitos do processamento e estocagem sobre os carotenides em pures de abóbora. 2010. Dissertação (Mestrado em Ciências dos Alimentos) - Universidade Federal de Santa Catarina.

RESENDE, Geraldo Magela; BORGES, Rita Mércia Estigarribia; GONÇALVES, Nadja Pollyanna da Silva Gonçalves. Produtividade da cultura da abóbora em diferentes densidades de plantio no Vale do São Francisco. Horticultura Brasileira (Impresso), v. 31, p. 504508, 2013.

RIBEIRO, Dágnon da Silva. Parâmetros agro meteorológicos de ambiente protegido com o cultivo de abóbora italiana sob adubação orgânica. 2008. 103 f. Tese (Doutorado) - Universidade Federal de Pelotas, Pelotas. 2008.

RICCE, Wilian da Silva; PANDOLFO, Cristina; MASSIGNAM, Angelo Mendes; VIANNA, Luiz Fernando de Novaes; SILVA, Paulo Francisco da. Análise de riscos climáticos para a cultura da Abóbora no estado de Santa Catarina. 2020. p.19. 
SANCHES, Alex Guimarães; SILVA, Maryelle Barros da.; MOREIRA, Elaine Gleice Silva.; COSME, Shirley Silva. Análise sensorial e viabilidade econômica da mandioca de mesa in natura e congelada. Revista Brasileira de Tecnologia Agroindustrial, Ponta Grossa, v. 11, n. 2, p. 2332-2349, 2017.

SANTOS, Isabelli Vieira; IENSEN, Daniele; QUAST, Ernesto; QUAST, Leda Battestin; RAUPP, Dorivaldo da Silva. Doce de abóbora com leite contendo alta proporção de abóbora. Revista Nutrir. v. 1, n. 2, 2015.

SANTOS, R. H. S.; SIQUEIRA, R. G.; BARRELLA, T. P.; SOUZA, J. L.; MAPELI, N. C.; FREITAS, G. B. Produção orgânica de hortaliças-fruto. Brasília: SENAR, 2005. 92 p. (Coleção Senar, 119).

SASAKI, Fabiana Fumi. Processamento mínimo de abóbora (Cucurbita moscata Duch.): alterações fisiológicas, qualitativas e microbiológicas. 2005. 145 p. Dissertação (Mestrado em Ciências) - Universidade de São Paulo, Piracicaba, 2005.

SERRA, Bruna Danielle Vieira; CAMPOS, Lucio Antônio de Oliveira. Polinização entomófila de abobrinha, Cucurbita moschata (Cucurbitaceae). Neotropical Entomology, v. 39, n. 2, p. 153-159, 2010.

SILVESTRI, Jandimara Doninelli Fior, PAROUL, Natalia; CZYEWSKI, Eliane; LERIN, Lindomar; ROTAVA, Leda; CANSIAN, Rogério Luis; MOSSI, Altemir; TONIAZZO, Geciane; OLIVEIRA, Débora de; TREICHEL, Helen. Perfil da composição química e atividades antibacteriana e antioxidante do óleo essencial do cravo-da-índia (Eugenia caryophyllata Thunb.). Revista Ceres, v. 57, n. 5, p. 589-594, 2010.

SILVA, Fernando Teixeira. Manual de produção artesanal de doce em massa. Rio de Janeiro. EMBRAPA-CTAA, 1997. 12 p.

SILVA, N. F.; FONTES, P. C. R.; FERREIRA, F. A.; CARDOSO, A. M. Produção da abóbora híbrida em função de doses de fertilizante fórmula 4-14-81. Ciência e Agrotecnologia, v. 23, n. 2, p. 454-461, 1999.

TEPPNER, Herwig. Notes on Lagenaria and Cucurbita (Cucurbitaceae). Phyton, v. 44, p. 245308, 2004.

WHITAKER; T. W.; ROBINSON, R. W. Squash breeding. In: BASSET, M. J. ed. Breeding vegetable crops. Westport: AVI, 1986. p. 209-246. 


\title{
cAPITULO X
}

\section{ANÁLISE SENSORIAL E ACEITABILIDADE DE IOGURTES FORTIFICADOS COM EXTRATO DE PRÓPOLIS VERMELHA DO MANGUEZAIS DE ALAGOAS}

DOI: 10.51859/AMPLLA.DES1788-10

\author{
Michelle Teixeira da Silva ${ }^{1,2}$, \\ Josicleide do Nascimento Oliveira Silvino ${ }^{1,3}$, \\ Mailde Jéssica Liodorio dos Santos ${ }^{2}$, \\ João Victor Lessa de Oliveira ${ }^{2}$, \\ Ariana da Silva Santos ${ }^{2}$, \\ Yalli da Silva Leite Lessa ${ }^{1,2}$, \\ Lara Mendes de Almeida ${ }^{1,2}$, \\ Felipe Mendes Zorzi ${ }^{2}$, \\ Arthur Luy Tavares Ferreira Borges ${ }^{2}$, \\ Emanoel Guilhermino da Silva Júnior ${ }^{2}$, \\ Katiene da Silva Melo ${ }^{1,2}$, \\ Mônica Lopes de Assunção ${ }^{1,2}$, \\ Pierre Barnabé Escodro ${ }^{2}$, \\ Maria Aparecida de Melo Alves ${ }^{3}$, \\ Ticiano Gomes do Nascimento ${ }^{1,2}$,
}

\footnotetext{
${ }^{1}$ Laboratório de Controle de Qualidade Microbiológico de Alimentos, Programa de Pós-Graduação em Nutrição, Faculdade de Nutrição, Universidade Federal de Alagoas (UFAL), Maceió, Alagoas, Brasil.

2 Laboratório de Análises Farmacêuticas e Alimentícias (LAFA), Programa de Pós-Graduação em Ciências Farmacêuticas, Instituto de Ciências Farmacêuticas (ICF), Universidade Federal de Alagoas (UFAL), Maceió, Alagoas, Brasil.

${ }^{3}$ Laboratório de Análises Sensorial, Escola Agroindústria, Instituto Federal de Alagoas (IFAL), Satuba, Alagoas, Brasil.
} 


\section{RESUMO}

logurtes são leites fermentados por bactérias lácticas e muito apreciado pelos consumidores. A própolis vermelha possui muitos compostos bioativos como os isoflavonóides, além de outros compostos como gutiferonas, terpenóides, proteínas, vitaminas B1, B2, B6, C, E, e diversos minerais. A aceitação de um produto é desejo de uma pessoa em adquiri-lo e, nesse sentido buscou-se estudar a aceitabilidade de iogurtes fortificados com própolis vermelha. A própolis in natura foi coletada na cidade de Marechal Deodoro-AL. Foram elaborados iogurtes acrescidos de três flavorizantes: morango, goiaba, mel e um sem adição de flavorizante. Todos os iogurtes receberam percentuais de tintura de própolis vermelha entre $(0,1 \%$ a $0,3 \%)$. As análises sensoriais foram conduzidas em cabines individuais, no Laboratório de Análise Sensorial do IFAL Campus Satuba. Os tratamentos foram servidos em delineamento de blocos completos balanceados. Os julgadores receberam aproximadamente, $25 \mathrm{~g}$ da amostra e ficha de avaliação com a escala hedônica de nove pontos, ancorada nos extremos em "desgostei muitíssimo" e "gostei muitíssimo". Os resultados analisados através da comparação das médias dos tratamentos, com a utilização do teste de Tukey estabelecendo-se $p \leq 0,05$ como nível de significância. Verificou-se boa aceitação (60\%) para o iogurte sem adição do flavorizante com $0,3 \%$ de própolis e aceitação acima de $70 \%$ para os demais iogurtes contendo flavorizante. A combinação de iogurte de mel fortificado com própolis foi menos aceita em relação aos outros sabores e estudos adicionais são necessários. Através desse estudo percebeu-se que o sabor forte da própolis pode ser mascarado pela adição do flavorizante.

Palavras-chave: Análise Sensorial. Leite fermentado. logurte fortificado. Própolis vermelha.

\section{INTRODUÇÃO}

O iogurte é um leite fermentado muito popular, consumido principalmente por suas características organolépticas (AQUARONE et al. 2001). É obtido pela fermentação lática do leite, através da ação de cultivos de micro-organismos específicos Streptococcus salivarius subsp. thermophilus e Lactobacillus delbrueckii subsp. bulgaricus, A atividade destes cultivos contribui para a determinação das suas características sensoriais (FORSYTHE, 2002; CODEX ALIMENTARIUS, 2012). É o leite fermentado mais conhecido e consumido no Brasil e constitui uma rica fonte de proteínas, cálcio, vitaminas e carboidratos (AQUARONE et al. 2001; FORSYTHE, 2002; BRASIL, 2007). Seu sabor delicado é obtido por meio da reação simbiótica das culturas lácteas uma vez que a atividade das culturas empregadas na fermentação do iogurte leva à produção de ácido láctico além de compostos como acetaldeído, diacetil, ácido 
acético e outras substâncias voláteis, que são fundamentais para a qualidade sensorial do produto (TAMINE; ROBINSON, 1991).

Muitos estudos estão voltados para o desenvolvimento tecnológico de iogurtes, buscando melhorar suas características e seu valor nutritivo. A tecnologia para produção de iogurte é bastante antiga e por isso tem-se hoje uma variedade grande de produtos (TAMINE \& ROBINSON, 1999 apud SANTOS, 2012). E, de acordo com as substâncias adicionadas ou do tipo de micro-organismos utilizados, melhoram seu valor nutritivo e podem ser classificados como alimento funcional.

logurtes de diferentes sabores têm sido estudados sensorialmente, geralmente à base de frutos como pêssego (BARBOSA, et al. 2013), açaí (OLIVEIRA et al. 2011), jenipapo (SANTOS et al. 2012) e à base de pitaia (SANTANA et al. 2012) obtendo boa aceitação mediante os julgadores. Outras substâncias como extratos de sementes de uva têm sido adicionadas à iogurtes a fim de conferir-lhe atributos funcionais, como ação antioxidante, por exemplo (CHOUCHOULI et al. 2013). Porém, é a análise sensorial quem determina a aceitação destes produtos.

Diferente do iogurte, a própolis possui sabor forte, em função da sua composição química (PROUDLOVE, 1996). Contudo, esses compostos possuem elevado valor biológico e funcional que podem trazer muitos benefícios à saúde (COSTA; ROSA, 2010). É considerada uma fonte promissora de novos compostos bioativos (ALENCAR et al. 2007). Os principais compostos químicos isolados da própolis podem ser organizados em alguns grupos principais como: ácidos e ésteres alifáticos, ácidos e ésteres aromáticos, açúcares, álcoois, aldeídos, ácidos graxos, aminoácidos, esteróides, cetonas, chalconas e di-hidrocharconas, flavonoides (flavonas, flavonóis e flavononas), Terpenóides, Proteínas, vitaminas B1, B2, B6, C, E, bem como diversos minerais (MENEZES, 2005).

A própolis é uma mistura complexa de substâncias resinosas, gomosas e balsâmicas colhidas por abelhas melíferas (Apis mellifera) de brotos, flores e exsudados de plantas, às quais na colmeia, as abelhas acrescentam secreções salivares, cera, pólen e enzimas para a elaboração do produto final (BRASIL, 2001; FRANCO et al. 2000; PEREIRA et al. 2002). A própolis tem potencial para ser um aditivo alimentar natural, atuando como antioxidante e por sua atividade antimicrobiana bem como sob a forma de ingrediente funcional. A própolis vermelha, da região de Alagoas possui 
características físicas e químicas bastante distintas de quaisquer outras amostras de própolis estudadas atualmente (ACKERMAN, 1991; RIGHI, 2008).

O soro de leite, subproduto da fabricação de queijos é geralmente tratado como resíduo pelas indústrias de laticínios e queijarias sendo descartado inadequadamente, em esgotos e mananciais, tornando-se agressivo ao meio ambiente devido a sua alta demanda biológica de oxigênio. Para sua utilização, o soro vem sendo destinado à alimentação de animais, ou transformado em commodities de valor relativamente baixo, tais como soro em pó e vários tipos de concentrado ou isolado proteico de soro. Sua composição depende da fonte do leite e do sistema de processamento usado. São muito nutricionais, contendo uma mistura de proteínas, lactose, minerais e gorduras (ANTUNES et al. 2003; CHATTERTON et al. 2006; INSTITUTO ADOLFO LUTZ, 2006).

As proteínas presentes no soro de leite bovino desempenham papéis importantes na formulação de alimentos e por isso a utilização do soro integral ou em forma de concentrados proteicos (CPS) tem sido estudado, com diferentes objetivos: modificar as propriedades multifuncionais do alimento como capacidade de gelatinização, elasticidade, aumento da viscosidade e estabilização de emulsões ou espumas, podendo ser utilizados na elaboração de diversos produtos dietéticos. Pode conferir propriedades de interesse em iogurtes, cremes de leite, manteigas, requeijões, entre outros, que nas versões light apresentam custo diferenciado. A utilização do CPS na elaboração de produtos alimentícios como iogurte, favorece o aumento de sua consistência (ANTUNES, et al. 2003; ANTUNES, 2004; RIBEIRO, 2008).

Nesse sentido, o efeito que o soro pode promover às características químicas, físicas, nutricionais e sensoriais dos alimentos tem sido estudado em alguns produtos como gelatina (CORREIA et al. 2009; ALVES et al. 2010), substituto de gordura em iogurtes (VIDIGAL et al. 2010), processamento de requeijão (VIOTTO et al. 2010) e diversos produtos como bolo, bebida láctea achocolatada e com doce de fruta (frapê de goiaba) (FERRARI et al.2010).

Um dos métodos utilizados em análise sensorial é o método afetivo ou teste afetivo ou ainda, teste de consumidores. Por meio deste método, os avaliadores manifestam a aceitabilidade de produtos que são geralmente utilizados para o mercado consumidor. Em geral, os testes afetivos são aplicados para verificação do posicionamento do produto no mercado, otimização da formulação do produto, 
desenvolvimento de novos produtos e avaliação do potencial do mercado (MEILGAARD et al. 2006; TEIXEIRA, 2009; FARIA, 2008).

As provas afetivas consistem na manifestação subjetiva do juiz sobre o produto testado, demonstrando se tal produto agrada ou desagrada se é aceito ou não, se é preferido a outro. Para aplicar estes testes, é necessária uma equipe grande. Um mínimo usual para avaliar um produto no laboratório por provas afetivas é de 30 juízes. Os juízes eleitos para essas provas devem ser consumidores habituais ou potenciais do produto testado (TEIXEIRA et al, 1987; MORAES, 1988; PEDRERO \& PANGBORN, 1989; ANZALDÚA-MORALES, 1994)

A aceitação de um produto refere-se ao desejo de uma pessoa em adquiri-lo (TEIXEIRA et al. 1987). E nesse sentido, buscou-se estudar a aceitabilidade de iogurtes elaborados com soro de leite/leite integral, fortificados com tintura de própolis vermelha.

\section{MATERIAIS E MÉTODOS}

\subsection{PREPARO DO EXTRATO BRUTO DA PRÓPOLIS VERMELHA}

O extrato bruto da própolis vermelha foi obtido por trituração seguido de maceração à temperatura ambiente com adição de álcool de cereal a 85\% como solvente extrator. A maceração ocorreu em três ciclos de extração e para cada ciclo, adicionou-se solvente extrator à amostra na proporção de 3:1, aproximadamente.

Posteriormente, o material resultante foi concentrado em rotaevaporador (Fisatom ${ }^{\circledR}$ ) com velocidade de rotação de $80 \mathrm{rpm}$, acoplado a uma bomba de vácuo $\left(\right.$ Tecna $^{\circledR}$ ) a $600 \mathrm{mmHg}$ e banho-maria $\left(\right.$ Fisatom $^{\circledR}$ ) a $50^{\circ} \mathrm{C}$ para obtenção do extrato bruto da própolis vermelha esticado em temperatura de congelamento para posterior utilização. Obteve-se a tintura a 10\% pesando-se uma quantidade de 5 gramas em balão de $50 \mathrm{~mL}$ do extrato bruto e adicionando-se o solvente extrator para solubilização.

\subsection{PROCESSAMENTO DOS IOGURTES FORTIFICADOS COM TINTURA DE PRÓPOLIS VERMELHA}

O preparo dos iogurtes ocorreu segundo metodologia de Aquarone et al. (2001) com adaptações. Sua produção ocorreu de acordo com o que rege as Boas Práticas de Fabricação (BPFs) e ocorreu conforme descrito a seguir: Após a ordenha, o leite cru foi 
resfriado a $4^{\circ} \mathrm{C}$, transportando para o Laboratório de Análise Sensorial do IFAL - Campus Satuba. Ao leite cru foi acrescido $1 \%$ de leite em pó integral e açúcar, em seguida, préaquecido e homogeneizado. Seguiu-se a pasteurização a $85^{\circ} \mathrm{C}$ por 15 minutos. Os leites foram esfriados a $42^{\circ} \mathrm{C}$ e inoculados com fermento lático em quantidade conforme fabricante. Procedeu-se a fermentação por, aproximadamente 4 horas, estabelecendose como término da fermentação pH 4,6 e em seguida, armazenados em câmara fria a temperatura de aproximadamente, $5^{\circ} \mathrm{C}$ até o dia seguinte. Realizou-se a quebra da coalhada, adicionou-se a calda com o sabor desejado, a tintura de própolis vermelha, seguido de homogeneização e procederam-se as análises sensoriais.

\subsection{ANÁLISES SENSORIAL DOS IOGURTES FORTIFICADOS COM EXTRATO DE PRÓPOLIS}

Em cada análise sensorial, os julgadores receberam uma bandeja com três tratamentos de iogurtes do mesmo sabor, com diferentes percentuais de tintura de própolis vermelha, servidos em copos descartáveis de $50 \mathrm{~mL}$, codificados com números aleatórios de três dígitos contendo, aproximadamente, $25 \mathrm{~g}$ da amostra (Figura 1). Os julgadores receberam, ainda, biscoito do tipo água e sal, além de $200 \mathrm{~mL}$ de água para lavar o palato bem como a ficha para avaliação contendo a escala hedônica estruturada de nove pontos ancorada nos extremos de "desgostei muitíssimo" (nota 1), menor nota a "gostei muitíssimo" (nota 9), maior nota, por meio da qual expressaram a aceitação global (Figura 1).

Figura 1 - Bandeja contendo iogurtes com diferentes percentuais de tintura de própolis vermelha.

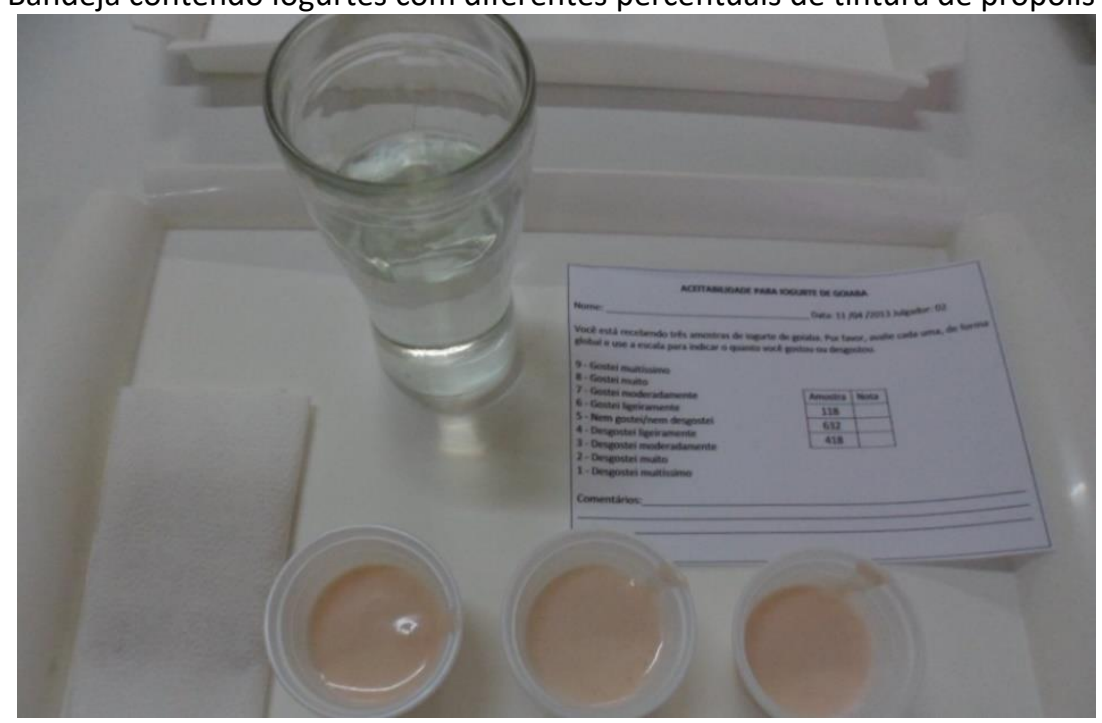

Fonte: Autores, 2021. 


\subsection{DELINEAMENTO EXPERIMENTAL}

Obtiveram-se os seguintes tratamentos: iogurte sabor morango, iogurte sabor goiaba, iogurte sabor mel e iogurte sem sabor (sem adição de calda de fruta). Para cada sabor adicionou-se tintura de própolis vermelha em diferentes concentrações, estabelecidas após pré-testes sensoriais, sendo elas: YA) 0,1\%; YB) 0,2\% e YC) 0,3\%.

Testou-se sensorialmente, iogurte batido adoçado com soro de leite em pó em diferentes percentuais, sendo: YA) $0,5 \%$; YB) $1,0 \%$; YC) 1,5\% e YD) 2,0\%. Os percentuais de açúcar adicionados foram os mesmos para todos os tratamentos, $13 \%$.

Os iogurtes de morango e goiaba receberam $1 \%$ de soro de leite em pó, e diferentes percentuais de tintura de própolis vermelha, obtendo os seguintes tratamentos: YA) $0,1 \%$;YB) $0,2 \%$ e YC) $0,3 \%$. Os tratamentos foram servidos em delineamento em blocos completos balanceados conforme (FERREIRA et al. 2000; FARIA, E. V.; YOTSUYANAGI, K., 2008).

\section{RESULTADOS E DISCUSSÕES}

A tabela 1 expressa às médias obtidas a partir do teste de aceitação dos iogurtes com tintura de própolis vermelha. De acordo com o teste estatístico realizado, observou-se que houve diferença significativa $(p \leq 0,05)$ em relação aos diferentes percentuais de tintura para alguns tratamentos dos iogurtes sabor goiaba assim como para o iogurte sem sabor. Porém, para os iogurtes de morango e mel não houve diferença significativa, sendo igualmente aceitos pelos julgadores obtendo médias entre 6,0 e 7,0 equivalendo a gostei ligeiramente e gostei moderadamente de acordo com a escala hedônica. Contudo, o iogurte sabor mel foi o que obteve menores as médias em relação aos demais flavorizantes, com $70 \%$ de aceitação para o tratamento com maior percentual de própolis. 
Tabela 1- Valores médios do teste de aceitação dos iogurtes formulados com diferentes percentuais de tintura de própolis vermelha.

\begin{tabular}{ccccc}
\hline $\begin{array}{c}\text { Tintura de própolis } \\
\text { vermelha (\%) }\end{array}$ & $\begin{array}{c}\text { logurte sabor } \\
\text { goiaba }\end{array}$ & $\begin{array}{c}\text { logurte sabor } \\
\text { morango }\end{array}$ & logurte sem sabor & $\begin{array}{c}\text { logurte sabor } \\
\text { Mel }\end{array}$ \\
\hline YA - 0,1 & $7,16^{\mathrm{a}}$ & $7,06^{\mathrm{a}}$ & $7,12^{\mathrm{a}}$ & $6,56^{\mathrm{a}}$ \\
YB - 0,2 & $6,9^{\mathrm{ab}}$ & $6,94^{\mathrm{a}}$ & $6,9^{\mathrm{ab}}$ & $6,40^{\mathrm{a}}$ \\
YC - 0,3 & $6,32^{\mathrm{b}}$ & $6,88^{\mathrm{a}}$ & $6,36^{\mathrm{b}}$ & $6,3^{\mathrm{a}}$
\end{tabular}

$\begin{array}{lllll}\text { DMS }^{1} & 0,7295 & 0,6142 & 0,7154 & 0,7201\end{array}$

Médias com letras em comum na mesma coluna não difere entre si a $p \leq 0,05$ pelo teste de Tukey. ${ }^{1} \mathrm{DMS}=$ Diferença Mínima Significativa.

Fonte: Autores, 2021.

As figuras 2 e 3 representam gráficos Box plot das médias dos julgadores para todos os iogurtes elaborados com leite e fortificados com própolis. Através dos gráficos gerados observa-se que alguns iogurtes tiveram maior variabilidade de notas para um mesmo sabor. Na figura 14, as notas variaram entre 1,0 (iogurte natural e mel $0,1 \%$ e $0,2 \%)$ e 9,0 para todos os sabores.

Figura 2 - Médias de aceitabilidade dos iogurtes fortificados com própolis vermelha.

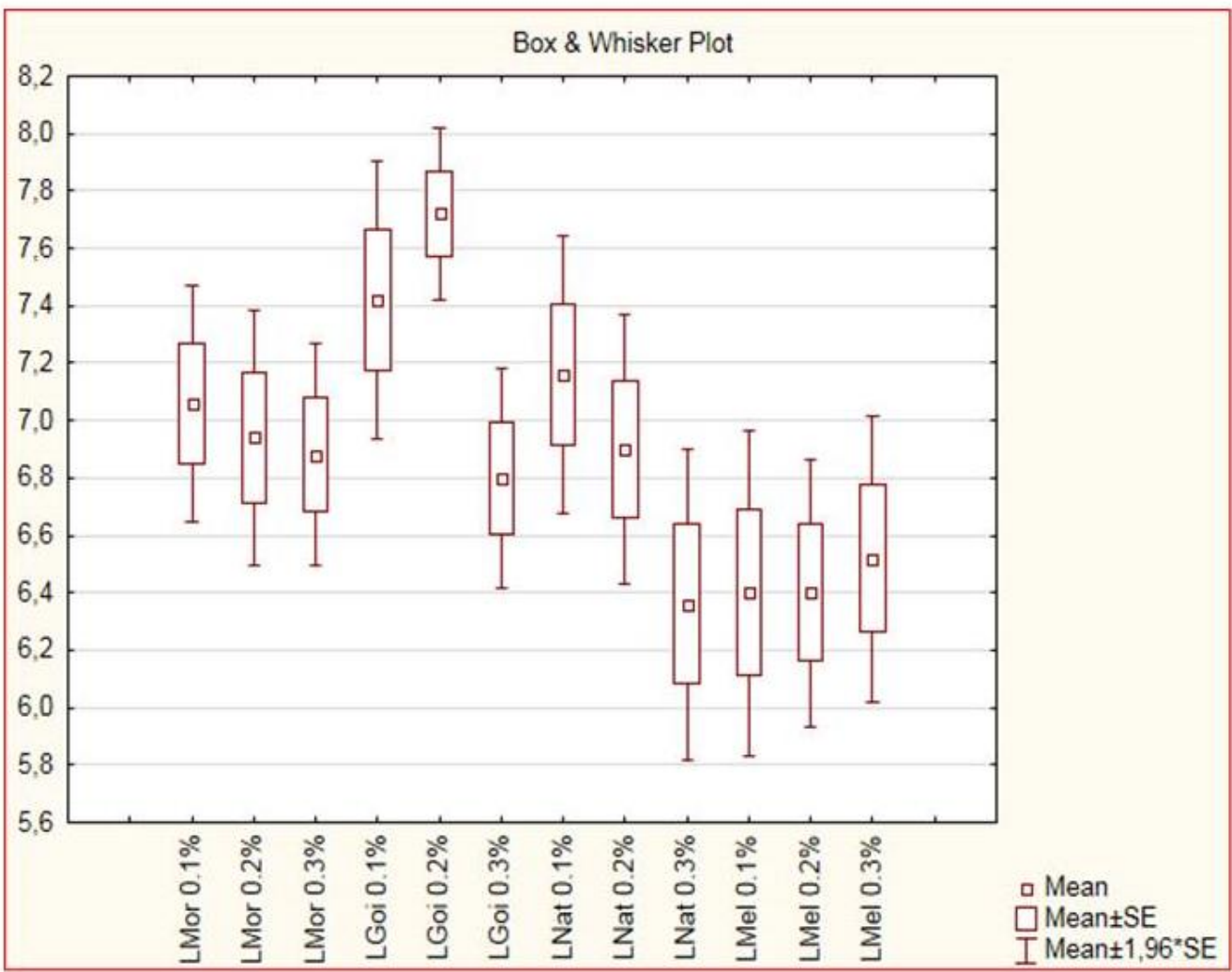

Fonte: Autores, 2021. 
Figura 3 - Médias de aceitabilidade dos iogurtes fortificados com própolis vermelha.

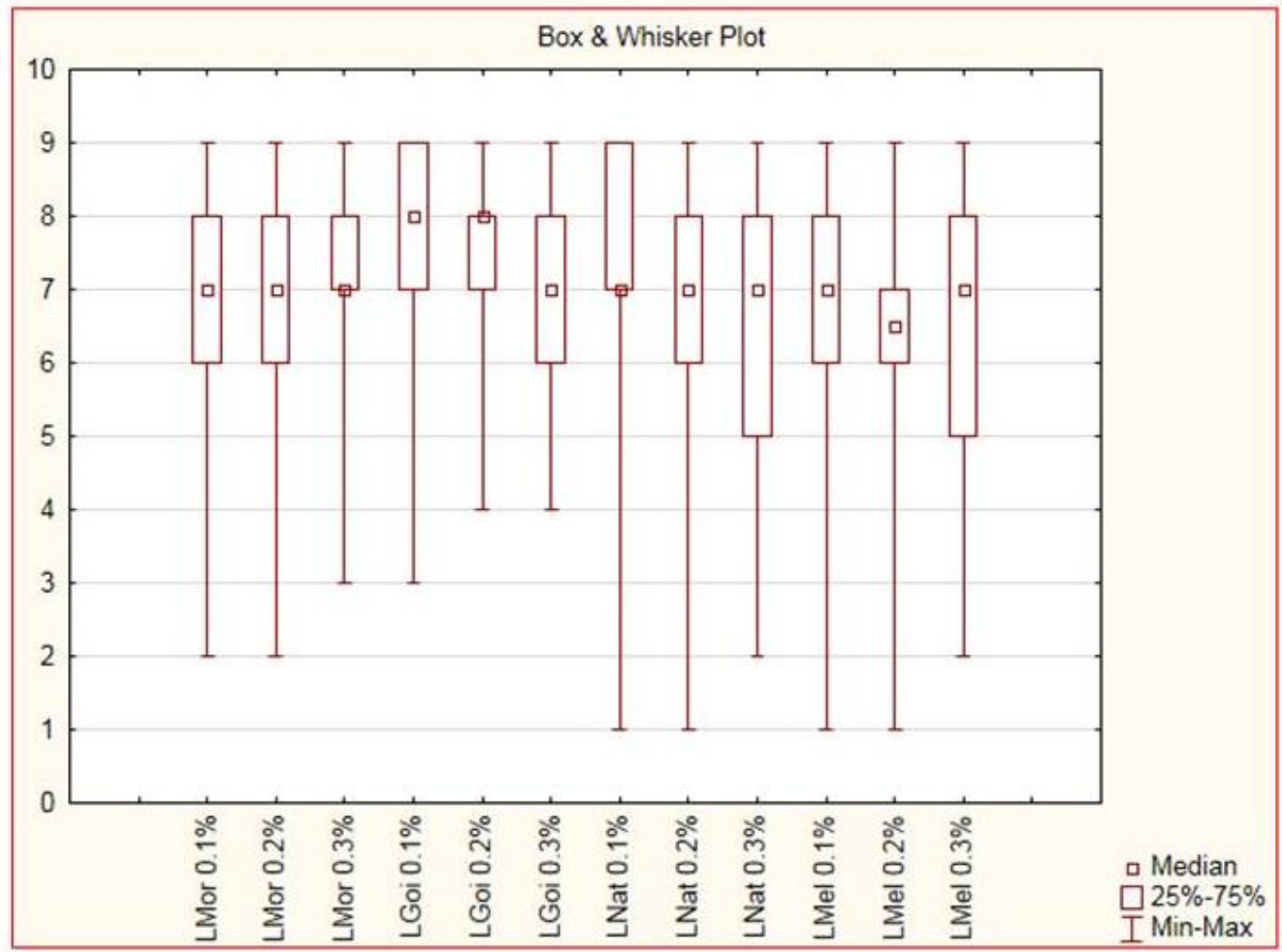

Fonte: Autores, 2021.

A figura 4 mostra as frequências de aceitação, indiferença e rejeição para todos os tratamentos. Verifica-se boa aceitação, acima de $60 \%$ para todos os sabores de iogurtes. Em análise sensorial, 70\% é um requisito mínimo para que se possa considerar que o alimento apresente significante potencial para consumo (FERREIRA et al. 2000). Desta forma, pode-se considerar que, exceto o iogurte sem sabor adicionado de com $0,3 \%$ de tintura de própolis vermelha (62\%), todos os tratamentos apresentaram aceitabilidade superior a 7\% e grande potencial mercadológico. 
Figura 4 - Histograma de aceitação, indiferença e rejeição para iogurtes de goiaba, morango, sem sabor e mel, fortificados com diferentes percentuais de tintura de própolis vermelha.

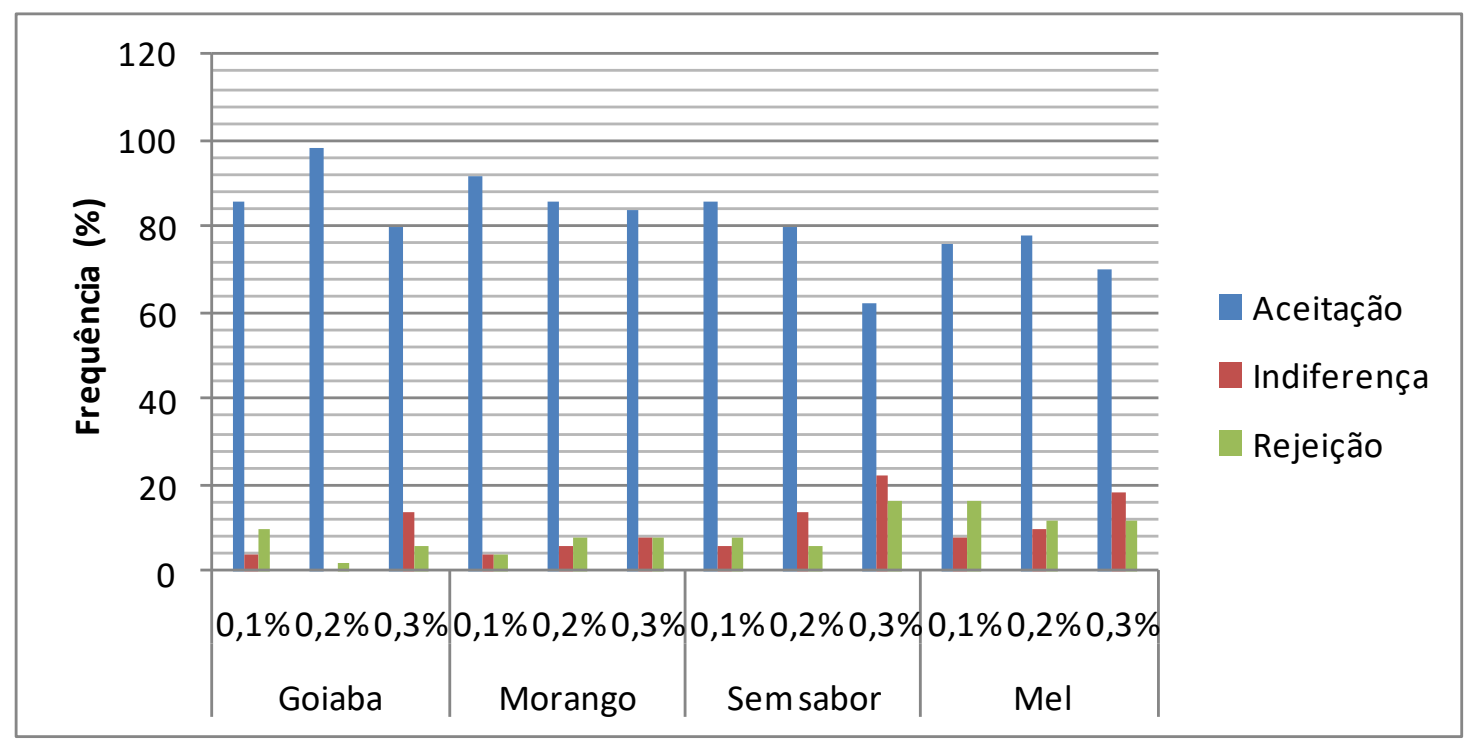

Fonte: Autores, 2021.

O gráfico de empilhamento (figura 5) mostra as notas de cada julgador para todos os iogurtes elaborados com leite, fortificados com tintura de própolis. Observa-se melhor homogeneidade das notas para os iogurtes na base do gráfico, iogurtes flavorizado com morango, seguido de iogurtes flavorizados com goiaba, respectivamente. Os iogurtes sem sabor (LNat) e mel (LMel) foram os que apresentaram maior variabilidade nas notas para todos os percentuais de tintura adicionados.

De modo geral, os iogurtes tiveram bons percentuais de aceitabilidade, sendo o maior percentual atribuído ao iogurte de goiaba (88\%) apesar de este ter recebido maior variabilidade de notas em relação ao iogurte de morango (87,3\%). O iogurte de mel obteve $74,6 \%$ de aceitação enquanto o sem sabor "natural" recebeu $76 \%$ de aceitabilidade. 
Figura 5 - Gráfico de empilhamento para os iogurtes fortificados com própolis vermelha.

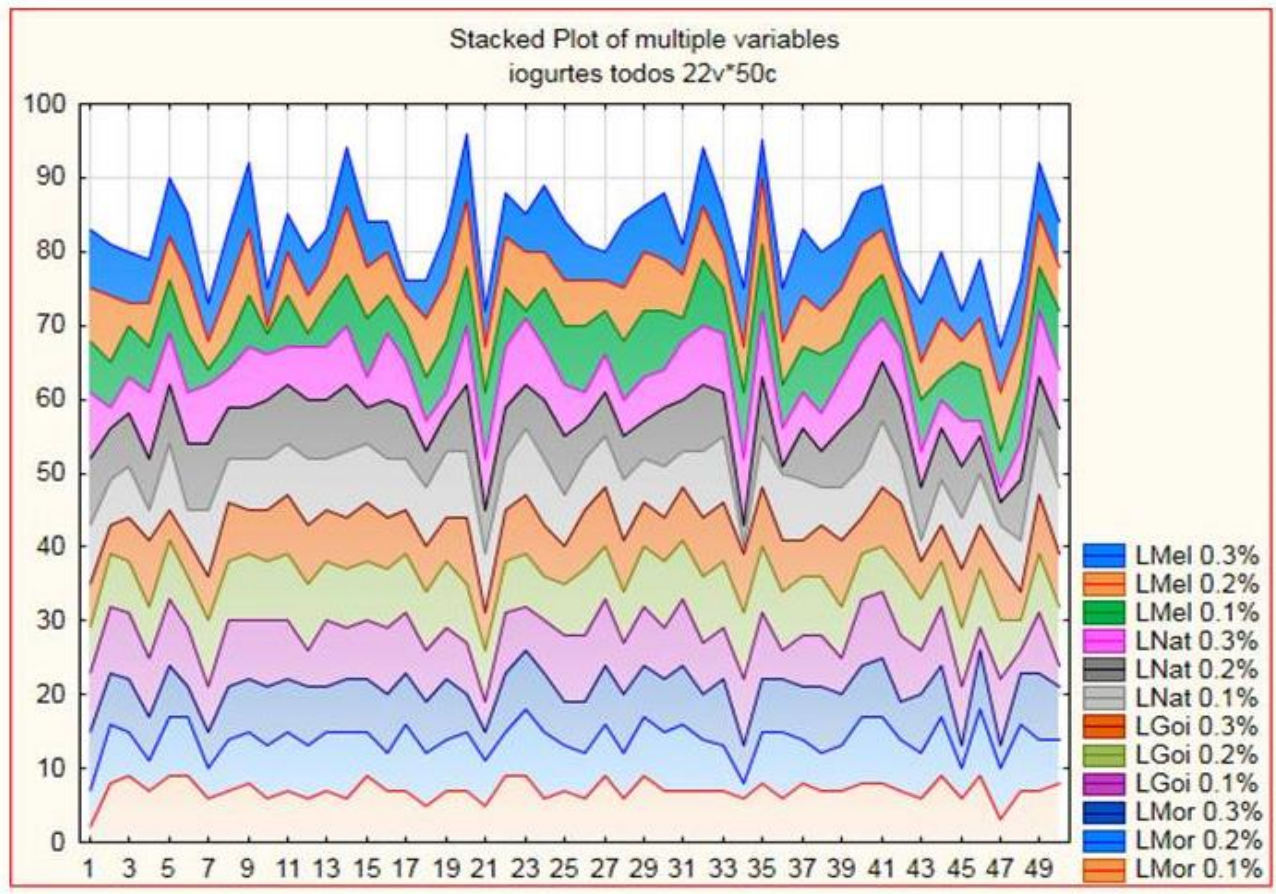

Fonte: Autores, 2021.

Os iogurtes foram submetidos à Análise dos Componentes Principais (ACP), na figura 6 observa-se o gráfico gerado. Apesar dos iogurtes conterem diferentes flavorizantes e diferentes proporções de tintura de própolis, observou-se uma certa semelhança nas notas atribuídas pelos 50 julgadores (tabela 1). Desta forma, utilizou-se análise multivariada para tentar auxiliar os dados de aceitabilidade demonstrados nas figuras 2, 3 e 4. Observando os escores das diferentes formulações de iogurtes contendo própolis vermelha, foi possível diferenciá-las por agrupamentos de formulações testadas por análise do componente principal (ACP). Todas as notas atribuídas pelos julgadores foram alocadas numa matriz 12 colunas $\times 50$ linhas. Pode-se observar diferenças expressivas nos escores entre os iogurtes de goiaba (agrupamento localizado no primeiro quadrante) em relação ao iogurte de morango (agrupamento localizado no segundo quadrante) e iogurte de mel (agrupamento localizado no terceiro quadrante). Porém, o iogurte natural (sem flavorizante) apresentou escores próximo ao iogurte de goiaba e ao iogurte de morango (agrupamento localizado entre o primeiro e o segundo quadrante). Foi observado uma proximidade entre os escores do LNat $0,1 \%$ como LMor 0,3\% e certa proximidade do LNat 0,3\% com o LGoi 0,3\%. Que estas proximidades serão melhores discutidas no gráfico de diagrama de árvore, figura 7. 
Figura 6 - Análise dos Componentes Principais dos iogurtes elaborados com leite em pó fortificados com diferentes percentuais de própolis vermelha. LGoi: logurte sabor goiaba; LMor: iogurte sabor morango; LNat: iogurte sem sabor "natural"; LMel: iogurte sabor mel.

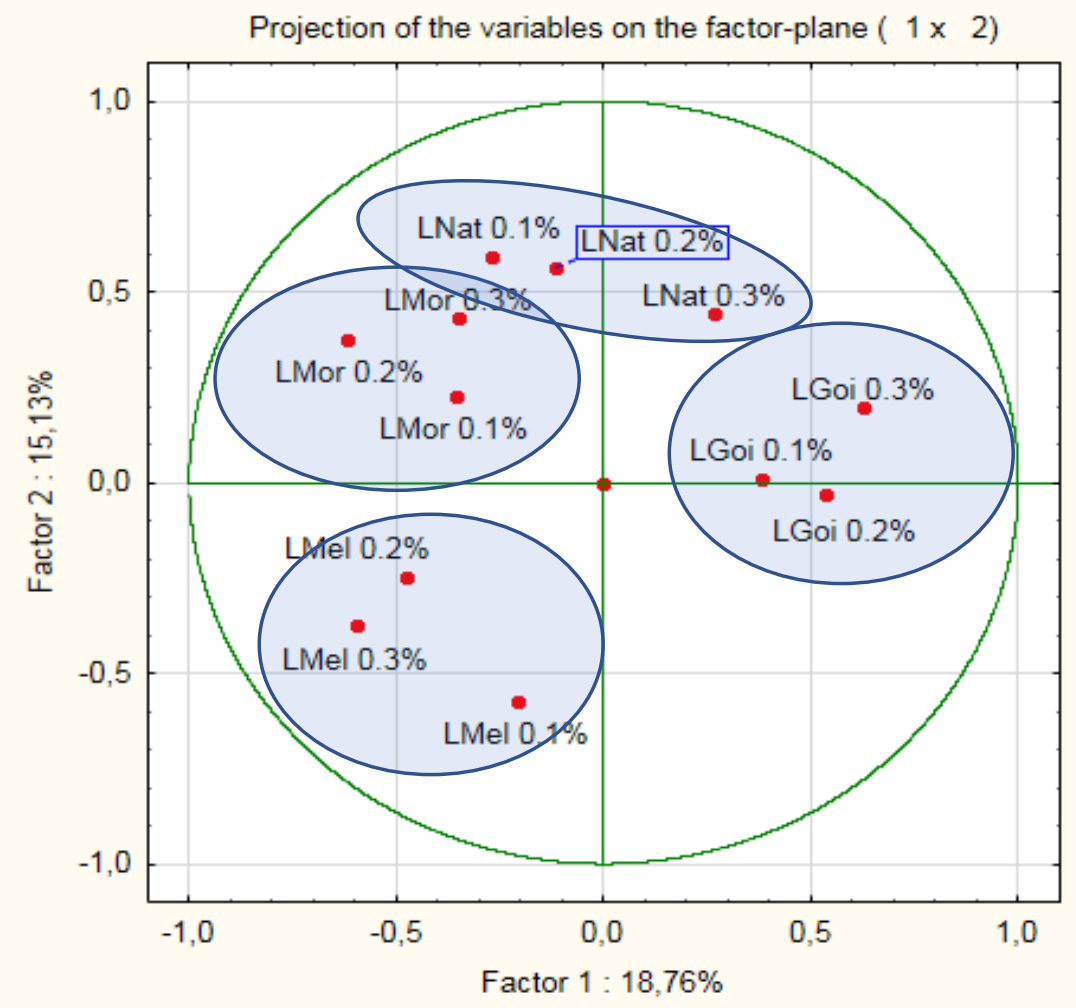

- Active

Fonte: Autores, 2021.

Figura 7 - Diagrama de árvore dos tratamentos de iogurtes elaborados com leite e diferentes percentuais de tintura de própolis vermelha.

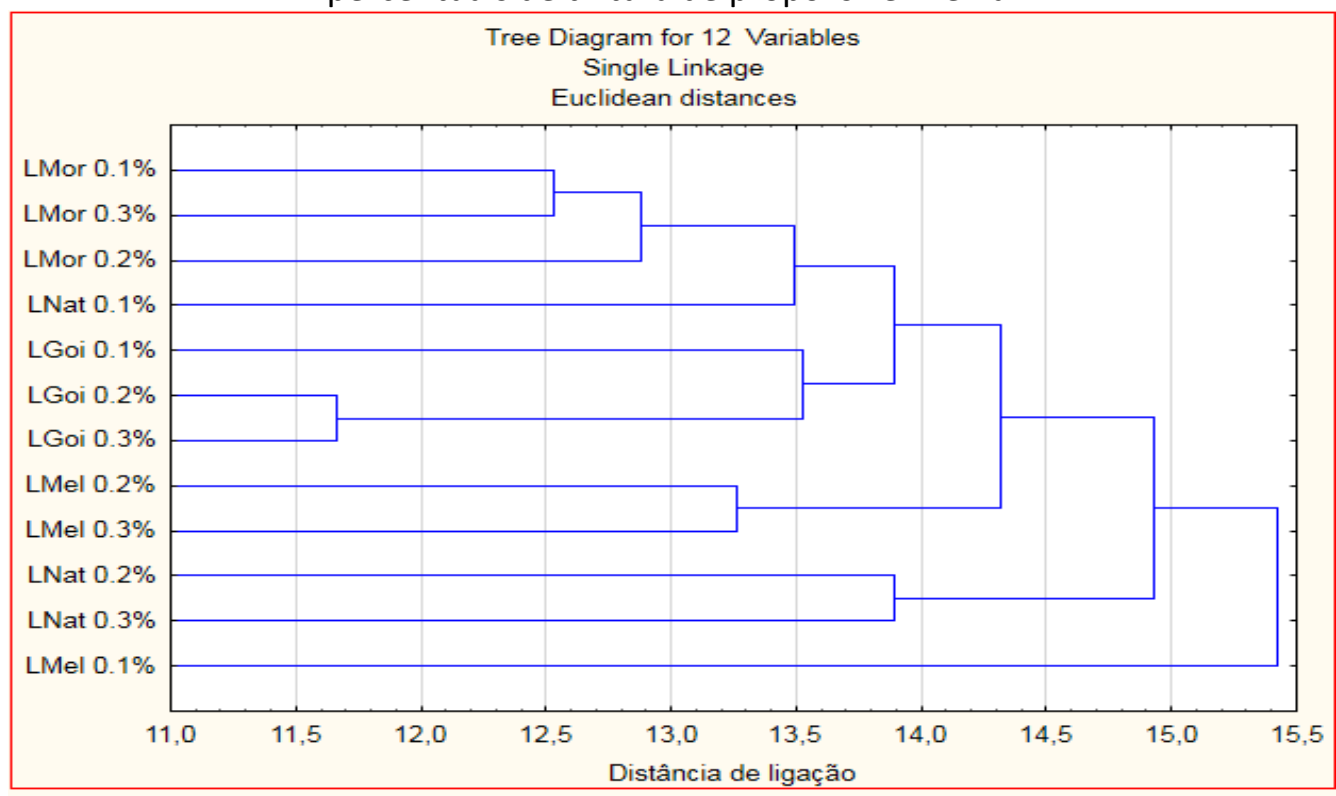

Fonte: Autores, 2021.

De acordo com a análise de Clusters, pode-se interpretar à AHC, principalmente usando o método da ligação completa, no qual o nível mais alto de agregação é o menos similar (a base do diagrama de árvore) e usando o método da ligação simples em que a 
distância entre os dois clusters (aglomerados) é determinada pela distância de dois objetos mais próximos (vizinhos mais próximos) nos diferentes grupos. Esta ferramenta hierárquica irá promover um sistema de classificação entre as amostras analisadas em que cada formulação (objeto), dependendo da sua distância euclidiana apresentará maior ou menor similaridade em relação ao grupo.

O diagrama permitiu identificar que os iogurtes de morango $(0,1$ a $0,3 \%)$ apresentaram uma distância de ligação Euclidiana $<13(\sim 12,5)$ e, portanto, mais similares, enquanto os iogurtes de goiaba (0,1 a 0,3\%) apresentaram uma distância de ligação de 13,5. O iogurte sem sabor $(0,1$ a 0,3\%) apresentou uma distância de ligação de 14,9 , enquanto os iogurtes de mel $(0,1$ a $0,3 \%)$ com uma distância de ligação Euclidiana de 15,4 foram os mais dissimilares entre si.

Podemos destacar também, pela análise AHC que os iogurtes de morango $(0,1 \mathrm{e}$ $0,3 \%)$, iogurtes de goiaba $(0,2$ e $0,3 \%)$, iogurtes de mel $(0,2$ e $0,3 \%)$ e iogurte sem sabor $(0,2$ e $0,3 \%)$ apresentaram certa similaridade entre eles. Assim é possível observar que os diferentes percentuais de tintura de própolis vermelha interferem na aceitação global dos iogurtes, contudo o sabor do flavorizante utilizado tem forte influência na aceitação.

\section{CONCLUSÃO}

O sabor forte da própolis pode ser mascarado pela adição do flavorizante escolhido e nesse estudo, os sabores morango e goiaba demonstraram ser as melhores opções em relação aos demais sabores, diferente do iogurte sabor mel que foi menos aceito pelos julgadores.

Os julgadores demonstraram índice de aceitação considerado satisfatório para os iogurtes de morango e goiaba elaborados com soro de leite em pó e própolis vermelha. As análises multivariadas (PCA e HCA) vêm corroborando com os dados de aceitabilidade, visto que os iogurtes de morango e goiaba apresentaram forte similaridade entre si. Porém a análise foi mais sensível para diferenciar a composição de maior similaridade (morango), em relação às de similaridade intermediária (goiaba) e dissimilaridade (mel e sem sabor). 
logurtes fortificados com própolis vermelha podem ter características de alimento funcional ou alimento com alegação para a saúde pela presença de grande quantidade de compostos bioativos presentes na própolis.

\section{AGRADECIMENTOS}

Os autores agradecem ao CNPq, CAPES e FAPEAL pelas bolsas concedidas aos Cursos de Mestrado em Nutrição (PPGNUT) e Ciências Farmacêuticas (PPGCF), bem como ao apoio financeiro (Bolsa no 446630 / 2014-4) e (no 60030 000431/2016). Os autores agradecem também ao Laboratório de Controle de Qualidade de Alimentos Microbiológicos da UFAL, na pessoa de Cantídio Franscisco de Lima Filho, pelo apoio em análises microbiológicas.

\section{REFERÊNCIAS}

ACKERMAN, T. Fast Chromatrographic Study Propolis Crudes. Food Chemistry. Vol. 42. p. 135-138. Israel, 1991.

ALENCAR, S. M. et al. Chemical composition and biological activity of a new type of brazilian propolis: Red propolis. Journal of Ethnopharmacology, 113, 278-283, 2007.

ALVES, T. L. et al. Análise sensorial de gelatina com soro de leite bovino proveniente do queijo de ricota. In Anais... X Congresso Internacional do Leite. Maceió, 2010.

ANTUNeS, A. E. C. MOTTA, E. M. P. ANTUNES, A. J. Perfil de textura e capacidade de retenção de água de géis ácidos de concentrado proteico de soro de leite. Cien. Tecnol. Aliment., 23 (supl): 183-189. Campinas, 2003.

ANTUNES, A. E. C. Influência do Concentrado proteico do soro de leite e de culturas probióticas nas propriedades de iogurtes naturais desnatados. 2004. 240 f. Tese (Doutorado em Alimentos e Nutrição). Faculdade de Engenharia de Alimentos. Universidade Estadual de Campinas, 2004.

ANZALDÚA-MORALES, A. La evaluación sensorial de los alimentos en la teoría y La prática. Zaragoza: Acribia SA, 1994. 198 p.

AQUARONE, E. et al. Biotecnologia industrial. Biotecnologia na produção de alimentos. vol. 4. São Paulo: Edgard Blücher LTDA, 2001.

BARBOSA, A. F. et al. Aceitação sensorial de iogurte sabor pêssego acrescido de diferentes concentrações de aroma e polpa por meio da técnica de mapa de 
preferência. Instituto de Laticínios Cândido Tostes., Minas Gerais, Brasil. Vol. 68, no 390, p. 52-58, 2013.

BRASIL. MINISTÉRIO DA AGRICULTURA, PECUÁRIA E ABASTECIMENTO. Instrução Normativa no 3 - ANEXOS VI e VIII - A prova os Regulamentos Técnicos de Identidade e Qualidade de Própolis e Extrato de Própolis. Diário Oficial da República da União. Brasília, 19 jan. 2001.

BRASIL. Ministério da Saúde. Agência Nacional de Vigilância Sanitária. Instrução Normativa no 46, de 23 de outubro de 2007. Adota o Regulamento Técnico de Identidade e Qualidade de leites fermentados. Diário Oficial da União, Brasília, 24 de outubro de 2007.

CHATTERTON, D. E. W. et al. Bioactivity of b-lactoglobulin and a-lactalbumin Technological implications for processing. International Dairy Journal, v.16, p. 1229-1240, 2006.

CHOUCHOULI, V. et al. Fortification of yoghurts with grape (Vitis vinifera) seed extracts. Food Science and Technology., Atenas, Grécia. Vol. 53, p. 522 - 529, 2013.

CODEX ALIMENTARIUS COMISSION. Codex Standards for fermented milk. Codex Stan 243-2003. Adopted in 2003. Revision 2008, 2010. Available at: <http://www.codexalimentarius.net/download/standard/400/CXS_243e.pdf> Acessed 31 jan, 2012.

CORREIA, A. G. S. et al. Avaliação Sensorial de sobremesa de gelatina elaborada com soro de leite incluída no cardápio de escolares do IFAL-Câmpus Satuba. Anais... 26을 Congresso Nacional de Laticínios. Juiz de Fora-MG, 2009. 1-CD-ROM.

COSTA, N. M. B; ROSA, C. O. B. Alimentos funcionais. Componentes bioativos e efeitos fisiológicos. Rubio. Rio de Janeiro, 2010.

FARIA, E. V.; YOTSUYANAGI, K. Técnicas de Análise Sensorial. 2. Ed. 120 p. Campinas, SP, 2008.

FERRARI, A. S.; AZAREDO, E. M. C.; BALDONI, N. R.; Análise sensorial de produtos elaborados à base de soro de leite. In Anais... XXI Congresso Brasileiro de Ciência e Tecnologia de Alimentos. Salvador, 2010.

FERREIRA, V. L. P. et al. Análise Sensorial: testes discriminativos e afetivos. Manual: Série qualidade. Campinas, SP: SBCTA, 2000.

FORSYTHE, S. Microbiologia da segurança alimentar. Artmed: Porto Alegre, 2002.

FRANCO, S. L.; BRUSCH, M. L.; MOURA, L. P. P.; BUENO, J. H. P. Avaliação Farmacognóstica da própolis da região de Maringá. Revista Brasileira de Farmacognosia, v. 9, p.1-10, 2000. 
INSTITUTO ADOLFO LUTZ. Métodos Físico-químicos para Análise de Alimentos. 4 ed. 2008.

MEILGAARD, M.; CIVILLE, G. V.; CARR, B. T. Sensory Evaluation Techniques, $4^{\text {th }}$ edition, CRC Press, Inc., Boca Raton, FL. 448 p., 2006.

MENEZES, H. Própolis: Uma revisão dos recentes estudos e suas propriedades farmacológicas. Arquivos do Instituto de Biologia, v.72, n.3, p. 405-411, 2005.

OLIVEIRA, P. D. et al. Avaliação sensorial de iogurte de açaí (Euterpe oleracea mart) "tipo "Sundae". Instituto de Laticínios Cândido Tostes., Minas Gerais, Brasil. Vol. 66, no 380, p. 5-10, 2011.

PEDRERO F., D. L; PANGBORN, R. M. Evaluación sensorial de los alimentos: métodos analíticos. México DF: Alhambra Mexicana. 1989. 251 p.

PROUDLOVE, R. K. Os alimentos em debate uma visão equilibrada. Varela: São Paulo, 1996.

RIBEIRO, M. Desenvolvimento e caracterização sensorial de iogurte diet sabor morango enriquecido com concentrado proteico de soro. 2008.93 f. Dissertação (Mestrado em Ciência e Tecnologia de Alimentos). Universidade Federal de Viçosa, Minas Gerais.

RIGHI, A. A. Perfil químico de amostras de própolis brasileira. 2008. f. 102. Dissertação (Mestrado em Botânica). Universidade de São Paulo, São Paulo. 2008.

SANTANA, A. T. M. C. et al. Avaliação sensorial de iogurte à base de pitaia (Hylocereus undatus), enriquecido com quinoa (Chenopodium quinoa) e sucralose. Instituto de Laticínios Cândido Tostes., Minas Gerais, Brasil. Vol. 67, no 389, p. 21-25, 2012.

SANTOS, G. et al. Avaliação sensorial, físico-química e microbiológica do leite fermentado probiótico desnatado adicionado de jenipapo desidratado osmoticamente. Instituto de Laticínios Cândido Tostes., Minas Gerais, Brasil. Vol. 67, no 388, p. 61-67, 2012.

TAMINE, A. Y.; ROBINSON, R. K. Yogur Ciencia y Tecnologia. Zaragoza: Acribia, 368 p. 1991.

TEIXEIRA, L. V. Análise Sensorial na indústria de alimentos. Instituto de Laticínios Cândido Tostes. Minas Gerais, Brasil. Vol. 64, no 366, p. 12-21, 2009.

TEIXEIRA, E.; MEINERT, E. M.; BARBETTA, P. A. Análise sensorial de alimentos. Florianópolis: Editora da UFSC, 1987. 180 p. 
VIDIGAL, M. C. T. R.; et al. Viscoelasticidade de iogurte contendo concentrado proteico de soro. In Anais...XXI Congresso Brasileiro de Ciência e Tecnologia de Alimentos. Salvador: 2010.

VIOTTO, W. H.; LOIOLA, L. S.; GONÇALVES, M. C.; Efeito da adição de concentrado proteico de soro nas propriedades funcionais do requeijão cremoso. In Anais...IV Congresso Brasileiro de Qualidade do leite. Florianópolis: 2010. 


\title{
CAPITULO XI
}

\section{DESENVOLVIMENTO E CARACTERIZAÇÃO FÍSICO-QUÍ́mICA DE MACARRÃO COM SUBSTITUIÇÃO PARCIAL DA FARINHA DE TRIGO POR FARINHA DE POLPA DE BARU}

DOI: 10.51859/AMPLLA.DES1788-11

\author{
Gabriella Gonçalves Borges Antunes ${ }^{1}$ \\ Joema Rodrigues Cardoso Santos ${ }^{2}$ \\ Marcos dos Reis Vargas ${ }^{3}$ \\ Thairyne Naruan Alves Pereira ${ }^{4}$
}

\footnotetext{
${ }^{1}$ Bacharel em Química Industrial. Instituto Federal de Goiás Campus Goiânia - IFG

${ }^{2}$ Doutoranda em Biotecnologia e Biodiversidade. Universidade Federal de Goiás - UFG

${ }^{3}$ Professor do Departamento de Química. Instituto Federal de Goiás Campus Goiânia - IFG

${ }^{4}$ Mestranda em Engenharia Química. Universidade Federal de Goiás - UFG
}

\section{RESUMO}

A flora do bioma Cerrado é constituída por diversas frutíferas, as quais apresentam potencial biotecnológico de grande importância. A aplicação dessas no desenvolvimento de novos produtos contribui para valorização das espécies regionais. Dentre os vegetais característicos da região, destaca-se o baru (Dipteryx alata Vog.), do qual a amêndoa é amplamente utilizada; porém, a polpa rica em fibras, é comumente descartada. Portanto, o objetivo do presente trabalho foi desenvolver macarrões com substituições de 10 e $20 \%$ da farinha de trigo pela farinha de polpa de baru. Foram realizadas análises físico-químicas e microbiológicas. Os resultados demonstraram que as massas alimentícias com farinha de polpa de baru podem ser classificadas como alimentos com alto teor de fibra alimentar e ainda, apresentaram menor teor de carboidratos que a amostra controle ( $100 \%$ de farinha de trigo). Logo, os resultados apresentados possibilitam a ampliação de aplicação da polpa de baru na indústria alimentícia.

Palavras-chave: Baru. Polpa. Macarrão. 


\section{INTRODUÇÃO}

O macarrão, também denominado de massa alimentícia, é o produto não fermentado, obtido pelo amassamento da farinha de trigo, da semolina ou da sêmola de trigo com água, adicionado ou não de outras substâncias (BRASIL, 1978). Atualmente, tem-se observado uma tendência à substituição parcial de farinha de trigo nas formulações por farinhas de diversos frutos (NETO et al., 2016; GABRIEL PEREIRA et al., 2017; NETO et al., 2013; PIETRO, 2016). A substituição é justificada pela disponibilidade de macarrões desenvolvidos a partir de formulações de baixo valor nutricional, com destaque à deficiência em fibras. Assim, tais deficiências nutricionais podem ser compensadas pela adição de outros ingredientes às massas alimentícias, que aliado ao seu baixo custo, podem torna-lo um item importante na alimentação (NETO et al., 2016).

Dentre os frutos disponíveis para substituição parcial, tem-se o baru (Dipteryx alata Vogel), especificamente a utilização da sua polpa para tal finalidade. O fruto do baru é do tipo drupa, ovóide, levemente achatado e de coloração marrom, com uma única semente comestível, a amêndoa de baru; apresenta diâmetro maior entre 5 a 7cm e o diâmetro menor de 3 a 5cm, com peso entre 26 a 40g (VERA et al., 2009). A amêndoa caracteriza-se por ser rica em lipídeos (41mg/ 100g), proteínas $(26 \mathrm{mg} / 100 \mathrm{~g})$, alto teor de fibra total (11mg/ 100g) e minerais (3mg/ 100g) (TAKEMOTO et al., 2001). A polpa é do tipo carnosa, apresentando aproximadamente $300 \mathrm{kcal}$ em $100 \mathrm{~g}$. Dentre os carboidratos, há predomínio de amido, fibras insolúveis e açúcares (SANO et al., 2004). Porém, essa é pouca inserida na alimentação humana apesar de inúmeras possibilidades de aplicação alimentícia após seu processamento (ROCHA; CARDOSO - SANTIAGO, 2009). Em termos de rendimento, o barueiro (árvore do baru) produz de 2.000 a 6.000 frutos por planta (CRUZ et al., 2011). Tais frutos são compostos por 30\% de polpa, 5\% de amêndoa e 65\% de endocarpo (CARRAZA; ÁVILA, 2010).

O barueiro ocorre geralmente nas áreas férteis do Cerrado (LEFB, 2021). O Cerrado é o segundo maior bioma brasileiro (ficando atrás apenas da Amazônia), ocupando quase toda a área do Brasil central, com aproximadamente 2 milhões de $\mathrm{km}^{2}$ (KLINK; MACHADO, 2005). Ocorre nos estados de São Paulo, Minas gerais, Goiás, Mato Grosso, Mato Grosso do Sul, Tocantins, Bahia, Maranhão, Piauí e Distrito Federal; além 
disso, incorpora ainda partes do território de países vizinhos como Bolívia e Paraguai (CAVALCANTI et al., 2012). Apresentando uma grande variedade de espécies, no tocante à fauna e flora, o cerrado é composto por mais de 10.000 espécies de plantas (SILVA et al., 2001; SCARIOT et al., 2005).

Percebe-se que o desenvolvimento de novos produtos a partir de matrizes vegetais nativas da região constitui uma valorização que contribui para a preservação de tais espécies, uma vez que o Cerrado, depois da Mata Atlântica é o ecossistema que mais sofreu alterações com a ocupação humana (WWF, 2021). Ainda, a incorporação da espécie citada no desenvolvimento de novos produtos incentiva o desenvolvimento regional sustentável, fomentando a agricultura familiar, caracterizada pela produção em pequena escala (CARRAZZA, 2010).

Portanto, o objetivo do trabalho foi desenvolver uma massa alimentícia do tipo macarrão, a partir de formulações com substituição parcial da farinha de trigo pela farinha de polpa de baru, propondo-se obter um produto fonte de fibras.

\section{METODOLOGIA}

O presente trabalho caracteriza - se como documentação direta, uma vez que o levantamento de dados ocorreu no próprio local onde os fenômenos ocorrem, conforme apontado por Marconi; Lakatos (2017). Para obtenção dos dados, utilizou - se a pesquisa laboratorial, a qual descreve e analisa o que ocorrerá em situações controladas, com o objetivo adequado ao que se pretende alcançar (MARCONI; LAKATOS, 2017).

Ainda, o desenvolvimento da pesquisa foi pautado pela utilização de métodos quantitativos, pois realizou -se a coleta de dados por meio do uso de medições e grandezas, obtendo - se por meio da metrologia, números (resultados) com suas respectivas unidades (ADRIANA PEREIRA et al., 2018). Como suporte metodológico, utilizou - se o trabalho desenvolvido por Pietro (2016), para direcionamento do desenvolvimento de formulações e escolha das análises realizadas.

Os frutos da espécie Dipteryx alata Vogel foram adquiridos em outubro de 2017 de um pequeno produtor, cuja plantação está localizada no município de Rio Verde (Estado de Goiás, Brasil). Logo após a aquisição dos frutos, esses foram lavados em água 
corrente e, na sequência, foi realizada a separação entre a castanha de baru e a polpa de baru juntamente com o endocarpo.

O material permaneceu por dois meses sob refrigeração a $-4^{\circ} \mathrm{C}$. Para $\mathrm{O}$ processamento da farinha, a polpa e o endocarpo foram submetidos à secagem a $60^{\circ} \mathrm{C}$ por $12 \mathrm{~h}$ e $30 \mathrm{~min}$ em forno elétrico. Como parâmetros para determinação do tempo suficiente de secagem, foram utilizadas a observação da cor e da textura apresentada pela polpa e endocarpo de baru (PIETRO, 2016).

A moagem da polpa e do endocarpo de baru foi realizada inicialmente em liquidificador industrial e na sequência em moinho de facas tipo willye. A análise granulométrica da farinha de polpa de baru foi realizada a partir da adaptação de método AACC 66-20 (American Association of Cereal Chemistry) (AACC, 1995), utilizando-se peneiras granulométricas taradas previamente, apresentando aberturas

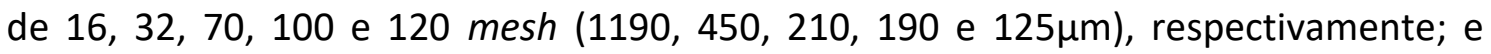
agitador eletromagnético de peneiras. Para produção da massa alimentícia, optou-se por utilizar a porção retida na peneira de 70 mesh, uma vez que para produção de macarrão utiliza-se farinhas com granulometria variando entre 60 e 70 mesh (GUERREIRO, 2006).

As massas alimentícias foram elaboradas na planta didática da Escola SENAI Vila Canaã, localizada no município de Goiânia -GO. Foram realizadas três formulações, sendo uma de controle (contendo somente farinha de trigo tipo 1); e duas formulações com farinha de trigo tipo 1 e farinha de polpa de baru nas proporções de 90:10 e 80:20, respectivamente. As três formulações desenvolvidas estão representadas na Tabela 1.

\begin{tabular}{|c|c|c|c|}
\hline \multirow{2}{*}{ Ingredientes } & \multicolumn{3}{c|}{ Formulações } \\
\cline { 2 - 4 } & FT & F1 & F2 \\
\hline Farinha de trigo & $100 \%$ & $90 \%$ & $80 \%$ \\
\hline Farinha de polpa de baru & - & $10 \%$ & $20 \%$ \\
\hline Ovo & $55 \%$ & $55 \%$ & $55 \%$ \\
\hline
\end{tabular}

Legenda: FT - amostra controle (100\% de farinha de trigo); F1 - amostra com 10\% da farinha de polpa de baru; F2 - amostra com $20 \%$ da farinha de polpa de baru.

Fonte: Autoria própria.

Os ingredientes foram misturados em masseira; a mistura resultante foi transferida para um canhão extrusor, para obter-se macarrão extrusado. Durante 
moldagem ou trefilação, a massa foi prensada por uma trefila de bucatini e o corte feito manualmente, com tamanho padronizado de $10 \mathrm{~cm}$. Após a trefilação e o seccionamento, os espaguetes foram secos a $60^{\circ} \mathrm{C}$ durante 1 hora em estufa com circulação e renovação de ar. As massas alimentícias secas foram empacotadas e armazenadas a $6^{\circ} \mathrm{C}$ para posterior análises, cocção e testes sensoriais.

\subsection{ANÁLISES MICROBIOLÓGICAS}

Após o desenvolvimento das massas alimentícias, reservou-se uma quantidade de macarrão para análise microbiológica. As análises microbiológicas realizadas compreendem: Salmonella sp (ISO, 2002; AOAC, 1997); Bacilus cereus (ISO, 2004); coliformes a $45^{\circ} \mathrm{C}$ (ISO, 2004); e Staphylococcus aureus (APHA, 2001). Tais parâmetros de análise microbiológica foram estabelecidos conforme preconiza a RDC $\mathrm{n}$ o 12 (BRASIL, 2001).

\subsection{ANÁLISES FÍ́SICO-QUIIMICAS}

A determinação da composição centesimal da farinha de polpa do baru e das formulações desenvolvidas foi realizada no laboratório didático da Escola SENAI Vila Canaã e no laboratório de Análises Físico-Químicas do Instituto Federal de Goiás Campus Goiânia. A umidade foi analisada em estufa de secagem com circulação de ar à $105^{\circ} \mathrm{C}$ até obtenção de peso constante (método AOAC no 925.10 - Association Of Official Analytical Chemists), e o resíduo mineral fixo (cinzas) por incineração em mufla a $550^{\circ} \mathrm{C}$ (método AOAC no 923.03) (AOAC, 1997). Os teores proteicos foram obtidos por meio da análise de nitrogênio total por Kjeldahl (método NTK), sendo utilizado o fator adequado para a conversão do nitrogênio em proteína bruta para consumo (método AOAC no 960.52) (AOAC, 1997). A fração de fibra alimentar total foi analisada pelo método gravimétrico-enzimático estabelecido pela Association of Analytical Communities AOAC, adaptado pela Embrapa Agroindústria de Alimentos (método AOAC no 985.29) (FREITAS et al., 2011). Os lipídios totais foram extraídos pelo método de Bligh-Dyer (método AOAC no 920.39C) (AOAC, 1997). Os carboidratos disponíveis foram obtidos por diferença, subtraindo-se de cem os valores obtidos de umidade, cinzas, proteínas, lipídios e fibra alimentar total, de acordo com o estipulado na Resolução RDC no 360 de 2003 que trata sobre rotulagem de alimentos (BRASIL, 2003). A acidez e o pH foram 
determinados conforme estabelecido pelo Instituto Adolfo Lutz (IAL, 2008). O valor energético total (VET) foi estimado considerando-se os fatores de conversão de Atwater, atribuindo $4 \mathrm{kcal}$ g-1 para proteínas e carboidratos e 9kcal g-1 para lipídeos (ATWATER; WOODS, 1986).

\subsection{TRATAMENTO ESTATÍSTICO DOS DADOS}

Avaliou-se os resultados obtidos pelos métodos de análise de variância (ANOVA) e as médias foram comparadas pelo teste de Tukey a 5\% de significância (TEIXEIRA et al., 1987).

\section{RESULTADOS E DISCUSSÃO}

\subsection{SEPARAÇÃO, MOAGEM E GRANULOMETRIA}

Após a etapa de higienização, realizou-se a separação entre polpa e endocarpo e, amêndoa de polpa de baru. Obteve-se uma extração de $8 \%$ da amêndoa de baru e de 92\% para a extração da polpa e do endocarpo de baru. Segundo Martins (2010), tais rendimentos de extração indicam que o beneficiamento do baru apresenta elevados índices de geração de resíduos sólidos. O mesmo autor obteve uma extração da amêndoa variando entre 7,4 a 8,8\%, enquanto que para a polpa e para o endocarpo, um rendimento entre 88 a 95\%. Compreende-se como beneficiamento a separação da amêndoa do baru das demais estruturas do fruto (CARRAZA; ÁVILA, 2010).

$\mathrm{Na}$ etapa de separação do endocarpo do mesocarpo, obteve-se um rendimento de $45 \%$, uma vez que em tal etapa separou-se a polpa do endocarpo do baru.

Na Figura 1, observa-se o gráfico representando os resultados de peneiramento. Ressalta-se que as porcentagens apresentadas referem-se à porcentagem média retida das farinhas em cada peneira. 
Figura 1 - Distribuição granulométrica

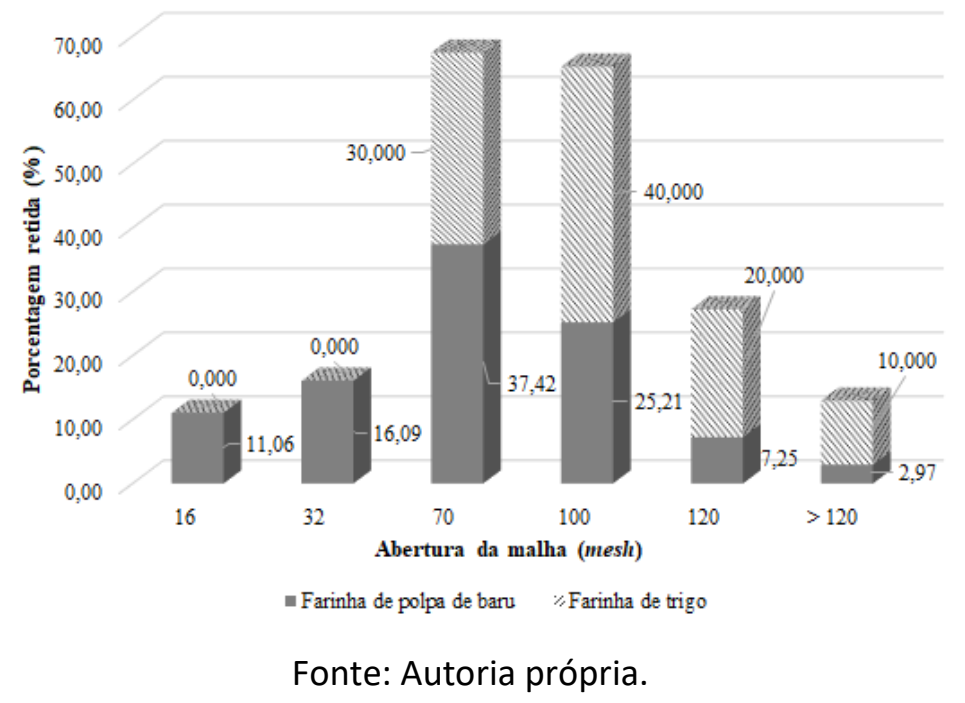

Observou-se que a granulometria da farinha de trigo tipo 1 é mais fina que a farinha de polpa de baru, uma vez que $30 \%$ da farinha tipo 1 ficou retida na peneira de 70 mesh (Figura1), enquanto $37,42 \%$ da farinha de polpa de baru ficou retida na peneira de mesma malha. Na literatura, o tamanho da partícula do alimento após a moagem é um fator determinante no preparo de massas alimentícias, uma vez que a uniformidade da granulometria na farinha resulta em melhor qualidade sensorial. Ainda, durante o cozimento o alimento absorve água de forma homogênea, resultando no cozimento uniforme da massa (SILVA et al., 2009).

A partir do tratamento estatístico da análise granulométrica, observou-se que para a farinha de polpa de baru, há diferença significativa entre as porcentagens retidas nas peneiras de 70 e 120 mesh, a nível de 5\% de significância. O resultado é justificado pela variação entre o tamanho dos grânulos da farinha de polpa de baru, após a etapa de moagem. Em contrapartida, o mesmo não é observado para a farinha de trigo. Para o desenvolvimento das massas alimentícias, foram utilizadas as farinhas de 70 mesh.

\subsection{ANÁLISES FÍSICO-QUÍMICAS DA FARINHA DE POLPA DE BARU E DAS MASSAS ALIMENTÍCIAS}

Os resultados das análises físico-químicas da farinha de polpa de baru e das massas alimentícias desenvolvidas nesse trabalho podem ser observados na Tabela 2. 
Tabela 2 - Resultados das análises físico-químicas

\begin{tabular}{|c|c|c|c|c|}
\hline Análises & FPB & FT & F1 & F2 \\
\hline Umidade (\%) & $11,300 \pm 1,200^{\mathrm{a}}$ & $4,100 \pm 0,153^{\mathrm{b}}$ & $6,223 \pm 0,204^{\mathrm{c}}$ & $7,400 \pm 0,104^{\mathrm{c}}$ \\
\hline Cinzas (\%) & $4,975 \pm 0,638^{\mathrm{a}}$ & $2,185 \pm 0,856^{\mathrm{b}}$ & $4,135 \pm 0,147^{\mathrm{a}}$ & $3,595 \pm, 539^{\mathrm{c}}$ \\
\hline Proteínas (\%) & $4,149 \pm 0,121^{\mathrm{a}}$ & $11,450 \pm 0,728^{\mathrm{b}}$ & $9,643 \pm 0,742^{\mathrm{c}}$ & $9,533 \pm 0,589^{\mathrm{d}}$ \\
\hline Lipídeos (\%) $^{\text {Carboidratos (\%) }}$ & $5,250 \pm 0,120^{\mathrm{a}}$ & $2,460 \pm 0,782^{\mathrm{b}}$ & $3,160 \pm 0,495^{\mathrm{c}}$ & $3,270 \pm 0,783^{\mathrm{d}}$ \\
\hline $\begin{array}{c}\text { Fibra alimentar } \\
\text { total (\%) }\end{array}$ & $35,362 \pm 0,488^{\mathrm{a}}$ & $66,437 \pm 0,061^{\mathrm{b}}$ & $64,878 \pm 0,385^{\mathrm{c}}$ & $61,692 \pm 0,926^{\mathrm{d}}$ \\
\hline $\begin{array}{c}\text { Fibra alimentar } \\
\text { solúvel (\%) }\end{array}$ & 0,6100 & 5,500 & 11,960 & 14,510 \\
\hline $\begin{array}{c}\text { Fibra alimentar } \\
\text { insolúvel (\%) }\end{array}$ & 38,890 & 2,610 & 9,660 & 12,020 \\
\hline pH & $5,433 \pm 0,058^{\mathrm{a}}$ & $6,167 \pm 0,058^{\mathrm{b}}$ & $5,700 \pm 0,100^{\mathrm{c}}$ & $5,633 \pm 0,058^{\mathrm{d}}$ \\
\hline $\begin{array}{c}\text { Acidez (mg 100 g- } \\
1 \text { ) }\end{array}$ & $8,108 \pm 0,125^{\mathrm{a}}$ & $3,051 \pm 0,513^{\mathrm{b}}$ & $2,227 \pm 0,027^{\mathrm{c}}$ & $5,025 \pm 0,824^{\mathrm{d}}$ \\
\hline $\begin{array}{c}\text { Valor energético } \\
\text { (kcal g-1) }\end{array}$ & $223,935 \pm 0,333^{\mathrm{a}}$ & $405,693 \pm 0,282^{\mathrm{b}}$ & $326,527 \pm 0,851^{\mathrm{c}}$ & $323,713 \pm 0,081^{\mathrm{d}}$ \\
\hline
\end{tabular}

Legenda: FPB - farinha de polpa de baru; FT - amostra controle (100\% de farinha de trigo); F1 amostra com $10 \%$ da farinha de polpa de baru; F2 - amostra com $20 \%$ da farinha de polpa de baru.

a, b, c e d - médias seguidas de mesma letra não apresentam diferença significativa entre si pelo teste de Tukey a $5 \%$ de probabilidade.

Fonte: Autoria própria.

A partir dos resultados apresentados na Tabela 2, pode ser observado que o teor de umidade apresentado pela farinha de polpa de baru se encontra dentro do limite estabelecido pela RDC $n^{\circ} 12$ (BRASIL, 1978), a qual enuncia que o limite máximo é de 14\%. A mesma observação pode ser estendida à umidade das massas alimentícias, uma vez que a $\mathrm{RDC} \mathrm{n}^{\circ} 93$ estabelece o limite máximo de 13,0\% para massa alimentícia seca, a qual é caracterizada por ser submetida ao processo de secagem (BRASIL, 2000). Como as massas alimentícias desenvolvidas no presente trabalho foram secas após trefilação, são classificadas como massas secas. Os mesmos resultados não foram encontrados em alguns trabalhos que compõem a literatura (NETO et al., 2016; GABRIEL PEREIRA et al., 2017; PIETRO, 2016), nos quais se observa que os teores de umidade variaram de 28 a $35 \%$. A diferença entre os resultados encontrados e os resultados obtidos por demais autores pode ser justificada pelo tipo de massa elaborada nos trabalhos, a qual apresenta característica de uma massa alimentícia fresca, que pode ou não ser 
submetida ao processo de secagem parcial, de forma que o produto final apresente umidade máxima de 35,0\% (BRASIL, 2000).

Em relação aos teores de cinzas, observou-se que a farinha de polpa de baru apresenta teor de 4,975\%, dos quais segundo Silva (2017), estão presentes potássio, cálcio, fósforo, magnésio como macrominerais. O mesmo autor destaca que em farinhas de polpa de baru, o macromineral potássio é o que se apresenta em maior concentração (SILVA, 2017). Ainda, observa-se que as massas alimentícias com farinha de polpa de baru apresentam teores de cinzas maiores que o macarrão controle $(100 \%$ de farinha de trigo), conferindo assim melhor conteúdo nutricional ao alimento.

Os números encontrados para proteína se aproximam aos determinados por Pietro (2016) para as massas alimentícias com 10 e 20 \% de substituição parcial da farinha de trigo por polpa de baru, trabalho no qual observou-se 11,86 e $10,99 \%$ de proteínas, respectivamente. Ainda, ressalta-se que consumindo as massas com substituição parcial de 10 e $20 \%$ supre-se parte da necessidade diária de ingestão protéica, a qual é necessária para o crescimento, conservação e reparação de órgãos, tecidos e células (NETO et al., 2016).

Para os valores de lipídeos, nota-se que as massas alimentícias desenvolvidas com farinha de polpa de baru apresentam teor acima de 3\%. Assim, de acordo com a RDC 54/ 2012, essas não podem ser consideradas como alimentos de baixo teor lipídico, uma vez que tal classificação se restringe a alimentos com no máximo 3\% de lipídeos (BRASIL, 2012).

A análise de teor de carboidratos mostrou que todos os macarrões desenvolvidos apresentaram percentuais variando de 66 a 60\%, aproximadamente, para cada 100 gramas do produto. Segundo a OMS (2003), a quantidade mínima de carboidrato necessária para promover glicose às células cerebrais é estimada em 130g/ dia para adultos com idade superior a 19 anos. Assim o consumo de 100 gramas das massas desenvolvidas com farinha de polpa de baru fornece, aproximadamente, $50 \%$ das necessidades diárias. $\mathrm{O}$ valor de carboidratos obtido para a farinha de polpa de baru corrobora com o valor encontrado por Mendonça (2008), que foi de 58,04\%. Incluso nesses 50\% de carboidratos estão o amido (componente majoritário) e açúcares (SANO et al., 2004). 
Os teores de fibra alimentar total apresentado pelas massas alimentícias estão acima de 3\%. De acordo com a Resolução n 54 da ANVISA/ 2012 (BRASIL, 2012), um alimento sólido é considerado como fonte de fibra alimentar se apresentar em sua composição no mínimo 3\%; caso apresente no mínimo 6\% de fibra alimentar total pode ser classificado como um alimento com alto conteúdo de fibra alimentar. Portanto, o macarrão desenvolvido com $100 \%$ de farinha de trigo é classificado como um alimento fonte de fibra alimentar, enquanto que as massas alimentícias com substituição parcial da farinha de trigo podem ser classificadas como alimentos com alto conteúdo de fibra alimentar. Ressalta-se que as fibras solúveis são responsáveis pelo aumento da viscosidade do conteúdo gastrointestinal, retardando o esvaziamento e a difusão de nutrientes, além de tornarem mais lenta a absorção de glicose e retardarem a digestão do amido (IAL, 2008). Em contrapartida, as fibras insolúveis, como a lignina, celulose e algumas hemiceluloses, aceleram o trânsito intestinal, aumentam o peso das fezes e contribuem para a redução do risco de alguns males do cólon (NETO, 2012).

$\mathrm{O} \mathrm{pH}$ apresentado pela farinha de polpa de baru corrobora com o resultado obtido por Silva (2017), onde a média de pH para a farinha de endocarpo e mesocarpo de baru seca a $60^{\circ} \mathrm{C}$ foi de $5,66 \pm 0,17$. A constatação se estende para acidez, uma vez que obteve - se um valor de $8,108 \pm 0,125 \mathrm{mg} / 100 \mathrm{~g}$ em comparação com $8,61 \pm 0,17 \mathrm{mg} / 100 \mathrm{~g}$ obtido por Silva (2017). A legislação brasileira não estabelece limite máximo de acidez para farinhas de frutas; porém, a RDC $n^{\circ} 12$ estabelece um limite máximo de $3 \%$ de acidez para a farinha de trigo (BRASIL, 1978). Portanto, observa-se que a farinha de polpa de baru processada no presente trabalho apresenta caráter ácido. Os níveis de acidez de um alimento podem ser resultantes de compostos naturais presentes no alimento (FERNANDES et al., 2008). Alimentos ácidos apresentam vantagens em relação à conservação, uma vez que a acidificação inibe o crescimento de microrganismos (PEREDA et al., 2005). Em relação às massas alimentícias, a legislação (BRASIL, 2000) estabelece limite máximo para o parâmetro acidez, o valor de $5 \%$ (5mg/ 100g). Portanto, observou-se que os macarrões com $100 \%$ de farinha de trigo e com $10 \%$ de farinha de polpa de baru atendem ao parâmetro da legislação vigente. Ainda, a mesma Resolução não estabelece limites para os valores de pH. De acordo com a literatura, dependendo da natureza do alimento (composição química e $\mathrm{pH}$ ), este pode ser classificado em alimentos ácidos $(\mathrm{pH}<4,6)$ e aqueles de baixa acidez $(\mathrm{pH}>4,6)$ (AGUIRRE; GASPARINO 
FILHO, 2002). Assim, as massas alimentícias podem ser consideradas como alimentos de baixa acidez.

Por fim, notou-se a redução do valor energético à medida que substituiu - se a farinha de trigo pela farinha de polpa de baru. Tal redução é resultado do aumento de fibras nas formulações desenvolvidas (PEREDA et al., 2005).

\subsection{ANÁLISES MICROBIOLÓGICAS DA FARINHA DE POLPA DE BARU E DAS MASSAS ALIMENTÍCIAS}

A partir das análises microbiológicas utilizando-se os parâmetros exigidos pela RDC $n^{\circ} 12$ (Brasil, 2001), obteve-se os resultados apresentados na Tabela 3.

Tabela 3 - Resultados das análises microbiológicas

\begin{tabular}{|c|c|c|c|c|c|}
\hline Parâmetros & $\begin{array}{c}\text { Limite segundo RDC } \\
\mathbf{N}^{\circ} \mathbf{1 2}\end{array}$ & FPB & FT & F1 & F2 \\
\hline $\begin{array}{c}\text { Bacillus cereus (UFC/ } \\
\text { g) }\end{array}$ & $3 \times 10^{3}$ & Ausente & Ausente & Ausente & Ausente \\
\hline $\begin{array}{c}\text { Coliformes a } 45^{\circ} \mathrm{C} \\
\text { (NMP/g) }\end{array}$ & $10^{2}$ & Ausente & 1,000 & 3,000 & Ausente \\
\hline $\begin{array}{c}\text { Staphylococcus } \\
\text { aureus (UFC/g) }\end{array}$ & $\begin{array}{c}\text { Naro } \\
\text { especificado } \\
\text { para farinha } \\
5,00 \times 10^{3} \text { para } \\
\text { massa } \\
\text { alimentícia }\end{array}$ & $1,00 \times 10^{2}$ & $1,00 \times 10^{2}$ & $1,00 \times 10^{2}$ & $1,00 \times 10^{2}$ \\
\hline $\begin{array}{c}\text { Salmonella sp } \\
\text { (Salmonella sp / } \\
\text { 25g) }\end{array}$ & Ausência & Ausente & Ausente & Ausente & Ausente \\
\hline
\end{tabular}

Legenda: FPB - farinha de polpa de baru; FT - amostra controle (100\% de farinha de trigo); F1 amostra com $10 \%$ da farinha de polpa de baru; F2 - amostra com $20 \%$ da farinha de polpa de baru.

Fonte: Autoria própria.

Os resultados para Bacillus cereus sugerem que as matérias-primas, bem como os processos utilizados para a produção da farinha de polpa de baru e das massas alimentícias não apresentam riscos à saúde dos consumidores, pois não observou - se o desenvolvimento de tal patógeno. Em relação à Salmonella sp, tal microrganismo é encontrado no trato gastrointestinal do homem e dos animais; sua transmissão por alimentos, bem como as enfermidades causadas é de grande preocupação da saúde 
pública. Portanto, os resultados encontrados são um indicativo de que as condições higiênico-sanitárias em todo o processamento das massas alimentícias desenvolvidas foram adequadas (CARDOSO; CARVALHO, 2006).

\section{CONSIDERAÇÕES FINAIS}

A partir dos resultados apresentados, conclui-se que foi possível o desenvolvimento de um novo extrusado a partir da polpa de baru, uma vez que foram desenvolvidas massas alimentícias com substituição parcial de farinha de trigo pela farinha de polpa de baru; ainda, a partir da análise de fibras, observou-se que as mesmas massas alimentícias podem ser classificadas como alimentos com alto conteúdo de fibra alimentar.

Os resultados apresentados possibilitam a ampliação de aplicação da polpa de baru na indústria alimentícia e nos segmentos da agroindústria familiar (associações e cooperativas de produtores), uma vez que a amêndoa do fruto já é amplamente utilizada. Por fim, a essência da pesquisa foi integralmente alcançada, a partir dos resultados que mostraram o aproveitamento da massa residuária da polpa do baru no processo de extração da castanha.

\section{AGRADECIMENTOS}

Aos Orientadores pelo direcionamento na execução da pesquisa; IFG Goiânia e SENAI Vila Canaã por disponibilizarem laboratórios e plantas didáticas para desenvolvimento das massas alimentícias e das análises.

\section{REFERÊNCIAS}

AACC - American Association of Cereal Chemistry. Methods of the American Association of Cereal Chemists - Method 66-20. Saint Paul: American Association of Cereal Chemists. 8 ed. 1995.

AGUIRRE, J. M.; GASPARINO FILHO, J. Desidratação de frutas e hortaliças. Campinas: ITAL/FUNDEPAG, 2002. 206 p.

AOAC - Association Of Official Analytical Chemists. Official Methods of analysis of the Association of Official Analytical Chemists. Washington: Ed. Washington, 1997. 
APHA - American Public Health Association. Compendium of Methods for the Microbiolo-gical Examination of Foods. Washington: American Public Health Association, 4 ed, 2001.

ATWATER, W.O.; WOODS, C. The Chemical Composition of American Food Materials. Office of Experiment Stations, v. 28, n. 47, 1986.

BRASIL. Resolução CNNPA no 12, de 21 de outubro de 1978. Aprova: Normas Técnicas Especiais relativas a Alimentos e Bebidas. Órgão emissor: ANVISA - Agência Nacional de Vigilância Sanitária. Disponível em: <http://www.anvisa.gov.br/anvisalegis/resol/12_78_massas.htm>. Acesso em: 15 out 2021.

BRASIL. Resolução RDC n. 93, 31 de outubro de 2000. Dispõe sobre o regulamento técnico para fixação de identidade e qualidade de massa alimentícia. Órgão emissor: ANVISA - Agência Nacional de Vigilância Sanitária. Disponível em: < http://www.anvisa.gov.br/anvisalegis/resol/2000/93_00rdc.htm>. Acesso em: 15 out 2021.

BRASIL. Resolução CNNPA no 12, de 02 de janeiro de 2001. Aprova: Regulamento Técnico sobre padrões microbiológicos para alimentos. Órgão emissor: ANVISA - Agência Nacional de Vigilância Sanitária. Disponível em: <http://www.anvisa.gov.br/anvisalegis/resol/12_01_alimentos.htm>. Acesso em: 15 out 2021.

BRASIL Resolução RDC $n^{\circ} 360$ de 23 de dezembro de 2003. Dispõe sobre o Regulamento técnico sobre rotulagem nutricional de alimentos embalados. Órgão emissor: ANVISA - - Agência Nacional de Vigilância Sanitária. Disponível em:< http://www.anvisa.gov.br/anvisalegis/resol/2000/93_00rdc.htm>. Acesso em: 15 out 2021.

BRASIL Resolução RDC $n^{\circ} 54$ de 12 de novembro de 2012. Dispõe sobre o Regulamento técnico sobre informação nutricional complementar. Órgão emissor: ANVISA - Agência Nacional de Vigilância Sanitária. Disponível em:<http://portal.anvisa.gov.br/documents/\%2033880/2568070/rdc0054_12_ 11_2012.pdf/c5ac23fd-974e-4f2c-9fbc-48f7e0a31864>. Acesso em: 15 out 2021.

CARDOSO, T. G; CARVALHO V. M. Toxinfecção alimentar por Salmonella spp. Revista Instituto de Ciências da Saúde, v. 24, n. 2, p. 95 -101, 2006.

CARRAZA, L.; ÁVILA, J. C. Manual Tecnológico de Aproveitamento Integral do Fruto do Baru. Brasília: Instituto Sociedade, População e Natureza. 2010.

CARRAZZA, L. R. Produção e comercialização de produtos agroextrativistas do Cerrado no PPP-Ecos: avanços, limites e desafios. In: LOBO, A.; Figueiredo, I.; ANDRADE, K. (org). Sementes lançadas, frutos colhidos: o Programa de Pequenos Projetos Ecossociais. Brasília: ISPN, 2010. p.151. 
CAVALCANTI, R. B.; CARDINOT, G.; GEOTTO, P; PINHEIRO, R. S. 2012. Cerrado. In: SCARANO, F. R.; SANTOS, I.; MARTINS, A. C. I.; SILVA, J. M. C.; GUIMARÃES, A.; MITTERMEIER, R. A. Biomas brasileiros: Retratos de um país rural. Rio de Janeiro: Conservação Internacional, 2012, 304 p.

CRUZ, K. S.; SILVA, M. A.; FREITAS, O.; NEVES, V. A. Partial characterization of proteins from baru (Dipteryx alata Vog) seeds. Journal of the Science of Food and Agriculture, v. 91, p 2006-2012, 2011.

FERNANDES, A. F.; PEREIRA, J.; GERMANI, R.; OIANO-NETO, J. Efeito da substituição parcial da farinha de trigo por farinha de casca de batata (Solanum tuberosum Lineu). Ciência e Tecnologia de Alimentos, v. 28, n. 1, p. 56-65, 2008.

FREITAS, C. S.; ANTONIASSI, R.; SILVA, T. S.; FELBERG, I. Coletânea de Métodos Analíticos para Determinação de Fibra. Rio de Janeiro: Embrapa Agroindústria de Alimentos. 2011. 37p.

GUERREIRO, L. Dossiê técnico. Rio de Janeiro: Rede de Tecnologia do Rio de Janeiro, 2006.

IAL - INSTITUTO ADOLFO LUTZ. Métodos físico-químicos para análise de alimentos. São Paulo: Instituto Adolfo Lutz. 1 ed, 2008.

ISO. Microbiology of food and animal feeding stuffs - Horizontal method for the enumera-tion of presumptive Bacillus cereus - Colony-count technique at $30^{\circ} \mathrm{C}$ - Method ISO 6579. International Organization for Standardization. Switzerland, 2002.

ISO. Microbiology of food and animal feeding stuffs - Horizontal method for the enumera-tion of presumptive Bacillus cereus - Colony-count technique at 30ㄷ - Method ISO 7932. International Organization for Standardization. Switzerland, 2004.

KLINK, C. A.; MACHADO, R. B. A conservação do Cerrado brasileiro. Megadiversidade, v. 1, n. 1, 2005.

LEFB. Lista de espécies da Flora do Brasil. Rio de Janeiro: Jardim Botânico do Rio de Janei-ro. Disponível em:< http://floradobrasil.jbrj.gov.br/reflora/listaBrasil>. Acesso em: 21 nov 2021.

MARCONI, M. A.; LAKATOS, E. M. Fundamentos de metodologia científica. 8. ed. São Paulo: Atlas. 2017

MARTINS, B. A. Desenvolvimento tecnológico para o aprimoramento do processamento de polpa e amêndoa do baru. Dissertação de doutorado Universidade Estadual de Campinas, Campinas, São Paulo. 2010. 
MENDONÇA, A. L. Avaliação cinética de comportamento de componentes do baru (Dipteryx alata Vog.) para estudo da vida de prateleira da polpa do fruto. Dissertação de mestrado - Universidade Federal de Goiás, Goiânia, 2008.

NETO, A. A. C. Desenvolvimento de massa alimentícia mista de farinhas de trigo e mesocarpo de babaçu (Orbignya sp.). Dissertação de Mestrado - Universidade Federal Rural do Rio de Janeiro, Seropédica, 2012.

NETO, A. A. C.; SOARES, J. P.; PEREIRA, C. T. M.; GOMES, M. S. S. O.; SABAA-SRUR, A. U. O. Utilização de farinha de mesocarpo de babaçu de massa alimentícia fresca tipo talharim. Brazilian Journal of Food Research, v. 7, n. 1, p. 105-115, 2016.

NETO, U. B.; AGUIAR, J. P.; SOUZA, F. C.; LEITÃO, B. Elaboração e caracterização do macarrão caseiro enriquecido com farinha de casca da pupunha (Bactris gasipaes KUNTH). In: Congresso de Iniciação Científica PIBIC/ CNPQ, 2, 2013, Manaus. Anal. Manaus: UFAm, 2013.

OMS - ORGANIZAÇÃO MUNDIAL DA SAÚDE. Manual das necessidades nutricionais humanas. São Paulo: Atheneu, 2003. 69 p.

PEREDA. J. A. O.; RODRÍGUEZ, M. I. C.; ÁlVAREZ, L. F.; SANZ, M. L. G.; MINGUI-LLÓN, G. D. G. de F.; PERALES, L. de la. H.; CORTECERO, M. D. S. Tecnologia de Alimentos. v 1, Porto Alegre: Artmed, 2005. 294 p.

PEREIRA, G. S. L.; BRAGA, R. N.; SOUZA, H. F.; OLIVEIRA, M. L. P.; LIMA, J. P.; VEI-RA, C. R. Análises físico-químicas e tecnológicas em massa alimentícia fresca incorporada de farinha de coquinho-azedo (Butia capitata). Caderno de Ciências Agrárias, v. 9, n. 3, p. 1-5, 2017.

PEREIRA, A. S.; SHITSUKA, D. M., PARREIRA, F. J.; SHITSUKA, R. Metodologia da pesquisa científica. 1. ed. Santa Maria: NTE. 2018. Disponível em: <https://repositorio.ufsm.br/bitstream/handle/1/15824/Lic_Computacao_Met odologia-Pesquisa-Cientifica.pdf?sequence=1>. Acesso em: 15 out 2021.

PIETRO, A. S. Elaboração de massa alimentícia mista fresca tipo macarrão com substituição parcial da farinha de trigo por polpa de baru (Dipteryx alata Vog.) da região centro-sul de Mato Grosso e sua caracterização físico-química e potencial antioxidante. Dissertação de Mestrado - Instituto Federal de Mato Grosso Campus Cuiabá, 2016.

ROCHA, L. S.; CARDOSO - SANTIAGO, R. A. Implicações nutricionais e sensoriais da polpa e casca de baru (Dipteryx alata Vog.) na elaboração de pães. Ciência e Tecnologia de Alimentos, v. 29, p. 820-825, 2009.

SANO, S. M.; RIBEIRO, J. F.; BRITO, M. A. Baru: biologia e uso. Brasília: Embrapa Recursos Genéticos e Biotecnologia, 2004, 52 p. 
SCARIOT, A.; SOUZA-SILVA, J. C.; FELFILI, J. M. Cerrado: ecologia, biodiversidade e conservação. Brasília: Ministério do Meio Ambiente, 2005, 439 p.

SILVA, D. V. Propriedades nutricionais, físicas, químicas e tecnológicas funcionais das farinhas de baru (Dipteryx alata Vogel) em função de diferentes condições de secagem do fruto. Dissertação de Mestrado - Instituto Federal de Goiás Campus Rio Verde, Rio Verde, 2017.

SILVA, R. F. da; ASCHERI, J. L. R.; PEREIRA, R. G. F. A.; MODESTA, R. C. D.; Aceitabilidade de biscoitos e bolos à base de arroz com café extrusados. Ciência e Tecnologia de Alimentos, v. 29, n. 4, p. 815-819, 2009.

SILVA, D. S.; SILVA, J. A.; JUNQUEIRA, N. T. V.; ANDRADE, L. R. M. Frutos do Cerrado. EMBRAPA Informação Tecnológica: Brasília, 2001, 178 p.

TAKEMOTO, E.; OKADA, I. A.; GARBELOTTI, M. L.; TAVARES, M. A.; PIMENTEL, S. Composição química da semente e do óleo de baru (Dipteryx alata Vog.) nativo do município de Pirenópolis, Estado de Goiás. Revista do Instituto Adolfo Lutz, v. 60 , n. 2, p. 113-117, 2001.

TEIXEIRA, E.; MEINERT, E.; BARBETTA, P. A. Análise sensorial de alimentos. Florianópolis: UFSC. 1987. 180p.

VERA, R.; JUNIOR, M. S. S.; NAVES, R. V.; SOUZA, E. R. B.; FERNANDES, E. P.; CALIARI, M.; LEANDRO, W. M. Características químicas de amêndoas de barueiros (Dipteryx alata Vog.) de ocorrência natural no cerrado do estado de Goiás, Brasil. Revista Brasileira de Fruticultura, v. 31, n. 1, p. 112-118, 2009.

WWF. Mapa de abrangência do Cerrado brasileiro. Disponível em: <http://www.wwf.org.br/natureza_brasileira/questoes_ambientais/biomas/bio ma_cerrado/mapa_bioma_cerrado/>. Acesso em: 21 nov 2021. 


\title{
CAPITULO XII
}

\section{DETERMINAÇÃO DE AMINAS BIOGÊNIICAS EM QUEIJO DE COALHO ARTESANAL SUPLEMENTADO COM EXTRATO DE PRÓPOLIS VERMELHA DE ALAGOAS}

DOI: 10.51859/AMPLLA.DES1788-12

\author{
Victor Vasconcelos Carnaúba Lima ${ }^{1}$ \\ Genildo Cavalcante Ferreira Júnior ${ }^{2}$ \\ João Victor Lessa de Oliveira ${ }^{3}$ \\ Fernanda Geny Calheiros Silva ${ }^{4}$ \\ Yalli da Silva Leite Lessa ${ }^{5}$ \\ Katiene da Silva Melo ${ }^{6}$ \\ Emanoel Guilhermino da Silva Júnior ${ }^{7}$ \\ Arthur Luy Tavares Ferreira Borges ${ }^{8}$ \\ Mônica Lopes Assunção ${ }^{9}$ \\ Thays de Ataíde e Silva ${ }^{10}$ \\ Maria Aline Barros Fidelis de Moura ${ }^{11}$ \\ Sâmia Andrícia Souza da Silva ${ }^{12}$ \\ Ticiano Gomes do Nascimento ${ }^{13}$
}

\begin{abstract}
${ }^{1}$ Docente da UNIT/Maceió. Mestre em Nutrição pelo Programa de Pós-Graduação em Nutrição da Universidade Federal de Alagoas. Campus AC Simões, Cidade Universitária, Tabuleiro dos Martins, Maceió, Alagoas.

2 Docente do IFAC/Acre. Mestre em Nutrição pelo Programa de Pós-Graduação em Nutrição da Universidade Federal de Alagoas. Campus AC Simões, Cidade Universitária, Tabuleiro dos Martins, Maceió, Alagoas.

4,5,6 Mestrandas em Nutrição pelo Programa de Pós-Graduação em Nutrição da Universidade Federal de Alagoas. Campus AC Simões, Cidade Universitária, Tabuleiro dos Martins, Maceió, Alagoas.

3,7,8 Mestrandos em Ciências Farmacêuticas pelo Programa de Pós-Graduação em Ciências Farmacêuticas da Universidade Federal de Alagoas. Campus AC Simões, Cidade Universitária, Tabuleiro dos Martins, Maceió, Alagoas. 9,10 Docentes do PPGNUT/UFAL. Docentes do Programa de Pós-Graduação em Nutrição da Universidade Federal de Alagoas. Campus AC Simões, Cidade Universitária, Tabuleiro dos Martins, Maceió, Alagoas. Instagram: @ppgnut_ufal, https://fanut.ufal.br/pt-br/pos-graduacao/mestrado-em-nutricao.

11,12,13 Docentes do PPGCF/UFAL. Docentes do Programa de Pós-Graduação em Ciências Farmacêuticas da Universidade Federal de Alagoas. Campus AC Simões, Cidade Universitária, Tabuleiro dos Martins, Maceió, Alagoas. Instagram: @ppgcg_ufal, https://icf.ufal.br/pos-graduacao/ciencias-farmaceuticas.
\end{abstract}




\section{RESUMO}

Aminas biogênicas são formadas como resultado da descarboxilacão microbiana de aminoácidos livres específicos. A análise desses metabólitos é de grande importância na determinação da qualidade e segurança de alimentos, como os queijos, visto que as aminas biogênicas estão relacionadas com episódios de intoxicação em humanos. A cromatografia é uma técnica de separação que pode ser usada para caracterizar aminas biogênicas. O objetivo deste trabalho é avaliar a segurança alimentar queijos artesanais do tipo coalho produzidos com a suplementação de própolis vermelha de Alagoas pelos ensaios microbianos e aminas biogênicas. Amostras de queijo de coalho contendo extrato de própolis vermelha $(0,1 \% ; 0,3 \%$ e $0,5 \%)$ foram preparados na indústria de laticínio do IFAL/Satuba, Alagoas e submetidos a ensaios de qualidade microbiológica seguindo a RDC 12/2001, ensaios de determinação de isoflavonóides da própolis vermelha e ensaio de aminas biogênicas (tiramina, feniletilamina, cadaverina e putrescina) usando CLAE-Fluor. Os ensaios microbiológicos mostraram ausência de Salmonella sp., Listeria monocytogenes e valores abaixo que o preconizado pela RDC $12 / 2001$ para Staphylococcus coagulase positiva e Coliformes a $45^{\circ} \mathrm{C}$. O método CLAEFluor detectou baixas concentrações aminas biogênicas (tiramina e cadaverina) em relação aos padrões analíticos ensaiados. O ensaio de identificação de isoflavonóides em queijo coalho artesanal suplementado com extrato de própolis vermelha demonstrou presença de liquiritigenina, daidzeína, pinobanksina, isoliquiritigenina, formononetina, pinocembrina e Biochanina A. Os flavonóides da própolis vermelha estão, provavelmente, sendo os responsáveis pelo controle da contaminação microbiana e baixo níveis de aminas biogênicas em queijos coalhos artesanais, podendo ser uma estratégia de uso bioconservantes em laticínios.

Palavras-chave: Queijos de Coalho. Aminas Biogênicas. Controle de Qualidade Microbiológico. Extrato de própolis vermelha. Bioconservantes.

\section{INTRODUÇÃO}

Aminas biogênicas ( $A B)$ são bases orgânicas de baixo peso molecular, de importância biológica em vegetais, animais e células microbianas, formadas principalmente por descarboxilação microbiana de aminoácidos e transaminação de aldeídos e cetonas. A presença de aminas biogênicas é uma condição inerente ao processamento tecnológico de vários alimentos que contenham proteínas ou aminoácidos livres e que estejam sujeitos a condições que permitam a atividade microbiana e/ou bioquímica (DIAS, 2009).

As aminas podem ser classificadas de acordo com o número de grupos amínicos em: monoaminas, diaminas e poliaminas. Quanto à estrutura química, são classificadas em aromáticas (histamina, tiramina, feniletilamina, triptamina, serotonina, dopamina e octopamina), diaminas alifáticas (putrescina e cadaverina), poliaminas alifáticas 
(agmatina, espermina e espermidina) e heterocíclicas (histamina, triptamina, serotonina) (LANGE et al., 2002).

O estudo de aminas biogênicas em alimentos apresenta correlação direta com a qualidade da matriz alimentar e a saúde do consumidor. Questões relacionadas à saúde envolvem, em particular, a intoxicação histamínica, com sintomatologia variada de acordo com a quantidade ingerida e a sensibilidade do indivíduo. Os principais sintomas são náuseas, vômitos, diarreia, dor abdominal, edema cutâneo, urticária, hipotensão, cefaléia, vertigens, rubor e ardência na boca. Em casos graves, em curto espaço de tempo, podem ocorrer dores torácicas e distúrbios respiratórios. Na presença de nitritos, as aminas podem formar $\mathrm{N}$-nitrosaminas, as quais têm ação carcinogênica, mutagênica e teratogênica (INNOCENTE, 2002).

Normalmente, as $A B$ estão ausentes ou encontram-se em concentrações mínimas (<10 ppm) em alimentos frescos. Contudo, em alimentos como pescado, queijos, carnes, ovos e fermentados, podem estar presentes em concentrações significativas (> 50 ppm), sendo assim capazes de induzir uma intoxicação química, também conhecida historicamente por envenenamento escombróide, devido a sua associação com a ingestão de pescado (CHIACCHIERINI et al., 2005).

No Brasil, o setor de laticínios tem grande importância socioeconômica, em especial na fabricação de queijos. Este mercado ocupa atualmente o sexto lugar na produção mundial, oferecendo ainda uma infinidade de produtos lácteos atendendo aos interesses específicos de certos grupos de consumidores que buscam produtos saudáveis e que não causem risco à saúde dos mesmos. O processo de maturação decorrente do processamento tecnológico produz alterações de textura e sabor, associadas principalmente à proteólise da caseína, resultando em aumento no teor de aminoácidos livres, que, por ação de descarboxilases bacterianas, produzem aminas biogênicas (PINTADO, 2008).

Microorganismos com atividade descarboxilase ou microorganismos contaminantes provenientes do leite ou do processo de obtenção tecnológica do queijo, podem estar relacionados com a formação de aminas biogênicas nesses alimentos. É possível também utilizar a determinação de aminas biogênicas como parâmetro de qualidade no processo de fabricação, ou como indicador do grau de proteólise, característico de alguns tipos de queijos especiais (DIAS, 2009). 
Várias técnicas analíticas, como eletroforese capilar (EC), cromatografia em camada delgada (CCD), cromatografia gasosa (CG), cromatografia de troca iônica e cromatografia líquida de alta eficiência (CLAE), têm sido propostas para a determinação de aminas biogênicas em matrizes alimentares. Dentre as técnicas citadas, a CLAE em fase reversa é considerada a mais adequada (CHIACCHIERINI et al., 2005).

Este trabalho justifica-se devido à importância da determinação das aminas biogênicas em queijos de coalho para a saúde pública no Estado de Alagoas e pela carência de literatura abordando esse tema no Brasil. Com isso, os resultados obtidos neste estudo irão fornecer à comunidade técnico-científica informações exploratórias sobre os níveis de aminas biogênicas presentes nas amostras de queijo de coalho correlacionando com níveis de microorganismos patogênicos em alimentos, bem como o uso de extrato de própolis vermelha como bioconservante em alimentos.

\section{MATERIAIS E MÉTODO}

\subsection{PREPARAÇÃO DO EXTRATO BRUTO DE PRÓPOLIS VERMELHA PARA ADIÇÃO NO QUEIJO DE COALHO}

O estudo foi realizado entre setembro de 2013 a fevereiro de 2014 na Universidade Federal de Alagoa e Instituto Federal de Alagoas (IFAL).

O extrato bruto da própolis vermelha foi obtido por trituração seguido de maceração à temperatura ambiente com adição de álcool de cereal a 85\% (V/V) como solvente extrator. A maceração ocorreu em três ciclos de extração e para cada ciclo, adicionou-se solvente extrator à amostra na proporção de 3:1, aproximadamente.

Posteriormente, o material resultante foi concentrado em rotaevaporador (Fisatom ${ }^{\circledR}$ ) com velocidade de rotação de $80 \mathrm{rpm}$, acoplado a uma bomba de vácuo $\left(\right.$ Tecnal $^{\circledR}$ ) a $600 \mathrm{mmHg}$ e banho-maria (Fisatom ${ }^{\circledR}$ ) a $50^{\circ} \mathrm{C}$ para obtenção do extrato bruto da própolis vermelha que em seguida, foi mantido em temperatura de congelamento para posterior utilização. Obteve-se a tintura a $10 \%(\mathrm{~m} / \mathrm{V})$ pesando-se uma quantidade de 5 gramas em balão de $50 \mathrm{~mL}$ do extrato bruto e adicionando-se o solvente extrator para solubilização. 


\subsection{PRODUÇ̃̃O DE QUEIJO DE COALHO}

Foram produzidas no Instituto Federal de Alagoas (IFAL), Campus Satuba em Maceió-AL, 4 amostras de queijos de coalho, sendo 3 com adição de extrato de própolis $(0,1 \%, 0,3 \%$ e $0,5 \%)$, chamada de amostras suplementadas e 1 amostra sem suplementação. Todas foram produzidas segundo a IN DAS no 30 do MAPA/2001 (BRASIL, 2001), conforme apresentado na Figura 1 - A matéria prima (leite cru) foi obtida diretamente do setor de bovinocultura do IFAL, campus Satuba e os demais ingredientes (cloreto de cálcio, fermento, cloreto de sódio e coalho) adquiridos de compra direta da marca "Chr Hansen", da empresa Milk localizada em Garanhuns, Pernambuco. Após produção essas amostras foram submetidas as análises microbiológicas.

Figura 1 - Fluxograma de processamento de queijo de coalho.

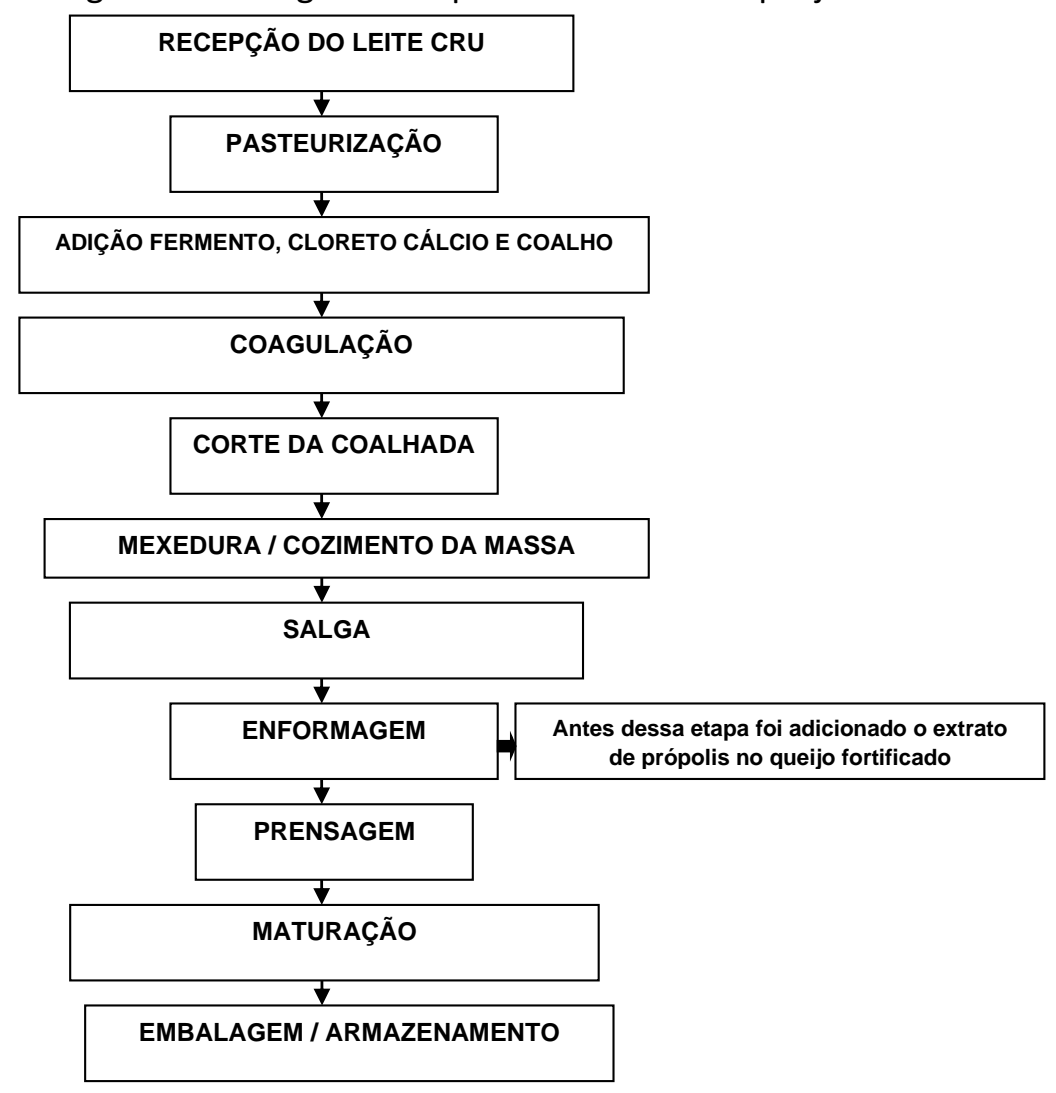

Fonte: (BRASIL, 2001).

\subsection{ANÁLISES MICROBIOLÓGICAS}

As análises microbiológicas foram realizadas no Laboratório de Controle de Qualidade de Alimentos da UFAL, nos produtos finais (amostras de queijos fortificados e não fortificado), segundo parâmetros recomendados pela Resolução RDC 12/2001 
(BRASIL, 2001), que determina os seguintes microorganismos: Coliformes a $45^{\circ} \mathrm{C}$, Staphylococcus coagulase positiva, Salmonella sp. e Listeria monocytogenes.

\subsection{MÉTODO UPLC-DAD-FLUOR DE DETERMINAÇÃO DE AMINAS BIOGÊNICAS EM QUEIJO FORTIFICADOS E NÃO FORTIFICADO}

Preparo das amostras fortificadas: Amostras de queijo coalho contendo extrato de própolis foram pipetadas $(1,0 \mathrm{ml})$ e transferidas para tubos de 1,5 $\mathrm{mL}$ e centrifugadas em minicentrifuga de eppendorf modelo mini Spin usando uma velocidade de rotação de 10.000 rpm/15 minutos. Este processo de clean-up foi utilizado para decantação das proteínas e demais interferentes de alto peso molecular no queijo ou precipitação de lipídios/lipoproteínas e outros interferentes de alto peso molecular. Após centrifugação alíquotas do sobrenadante aquoso $(0,7 \mathrm{~mL})$ foram filtradas em unidades filtrantes de 0,45 ?m e transferidas para os vials de autoinjetor onde foram injetados $20 \mu \mathrm{L}$.

Amostras não fortificadas: Foram utilizadas neste estudo, amostras de queijo frescos recentemente produzidos que foram armazenadas em geladeira ou freezer por período não superior a 30 dias.

Condições de derivatização: Os padrões analíticos de tiramina, histamina, 2feniletilenoamina, putrescina e cadaverina foram adquiridos da sigma-aldrich com pureza superior a 95\%. Reagente derivatizante (cloreto de dansila) também foi adquirido da sigma-aldrich. O reagente derivatizante cloreto de dansila foi preparado pesando $10 \mathrm{mg}$ e solubilizando em acetona $(10 \mathrm{~mL})$ ou em etanol absoluto $(10 \mathrm{~mL})$. Este último foi o preferido e armazenados em frasco âmbar em freezer -20 드 por 5 dias. Os padrões analíticos $(10,0 \mathrm{mg})$ foram pesados e transferidos para frascos tipo ampicilina e solubilizados com $6 \mathrm{~mL}$ de sistema de solvente etanol absoluto:água acidificada com $\mathrm{HCl}$ 0,1M (8:2; v/v). Em seguida as soluções eram transferidas para balão de $10 \mathrm{~mL}$ e completadas os volumes com o mesmo sistema de solvente. As soluções estoques foram estocadas em freezer $\left(-20^{\circ} \mathrm{C}\right)$ por no máximo 5 dias.

Reação de derivatização usando cloreto de dansila: Soluções de trabalho entre $100,00 \mu \mathrm{g} / \mathrm{mL}$ e $333 \mu \mathrm{g} / \mathrm{mL}$ foram utilizadas para estabelecer tempo de retenção dos padrões analíticos (tiramina, histamina, 2-feniletilenoamina, putrescina e cadaverina) na corrida analítica. As soluções estoques recentemente preparadas $(1 \mathrm{mg} / \mathrm{mL})$ e soluções de trabalho de $4,00 \mu \mathrm{g} / \mathrm{mL}$ foram diluídas para concentrações finais de 0,058 
$\mu \mathrm{g} / \mathrm{mL} ; 0,100 \mu \mathrm{g} / \mathrm{mL} ; 0,440 \mu \mathrm{g} / \mathrm{mL} ; 1,100 \mu \mathrm{g} / \mathrm{mL} ; 2,18 \mu \mathrm{g} / \mathrm{mL}$ e $4,00 \mu \mathrm{g} / \mathrm{mL}$. O procedimento geral foi tomar alíquota de $600 \mu \mathrm{L}$ da solução estoque ou solução de trabalho, $300 \mu \mathrm{L}$ do reagente derivatizante (cloreto de dansila) e $200 \mu \mathrm{L}$ de solução tampão de carbonato sódio $(\mathrm{pH} 9,0)$ para obter concentrações finais citadas de aminas biogênicas em soluções de trabalho. As amostras eram submetidas a um leve aquecimento em temperatura de 40 C por 1 hora (promover a reação de derivatização), e em seguida eram filtradas em unidades filtrantes de $0,22 \mu \mathrm{m}$ e injetadas $(2 \mu \mathrm{L})$ no UPLC-FLUOR. As amostras de queijos coalhos comerciais e fortificados sofreram 0 mesmo procedimento de derivatização.

\section{Método UPLC-DAD-FLUOR de determinação de aminas biogênicas em queijo}

coalho: Os padrões analíticos de histamina, tiramina, 2-feniletilenoamina, putrescina e cadaverina foram adquiridos da sigma-aldrich com pureza superior a 95\%. Reagente derivatizante (cloreto de dansila) também foi adquirido da sigma-aldrich. $O$ reagente derivatizante cloreto de dansila foi preparado pesando $10 \mathrm{mg}$ e solubilizando em acetona $(10 \mathrm{~mL})$ ou em etanol absoluto $(10 \mathrm{~mL})$. Este último foi o preferido. Os padrões analíticos $(10,0 \mathrm{mg})$ foram pesados e transferidos para frascos tipo ampicilina e solubilizados com sistema de solvente etanol absoluto:água acidificada com $\mathrm{HCl} 0,1 \mathrm{M}$ $(8: 2 ; \mathrm{v} / \mathrm{v})$ e estocados em freezer (-20C) por no máximo 5 dias.

Soluções de trabalho entre $100,00 \mu \mathrm{g} / \mathrm{mL}$ e $333 \mu \mathrm{g} / \mathrm{mL}$ foram utilizadas para estabelecer tempo de retenção dos padrões analíticos nos cromatogramas. As soluções estoques recentemente preparadas $(1 \mathrm{mg} / \mathrm{mL})$ e soluções de trabalho nas concentrações entre $0,10 \mu \mathrm{g} / \mathrm{mL}$ e $4,00 \mu \mathrm{g} / \mathrm{mL}$ foram diluídas para concentrações de tomando $600 \mu \mathrm{L}$ da solução de trabalho, $300 \mu \mathrm{L}$ do reagente derivatizante e $200 \mu \mathrm{L}$ de solução tampão de carbonato sódio $(\mathrm{pH} 9,0)$ para concentrações finais de $0,058 \mu \mathrm{g} / \mathrm{mL} ; 0,100 \mu \mathrm{g} / \mathrm{mL}$; $0,440 \mu \mathrm{g} / \mathrm{mL} ; 1,100 \mu \mathrm{g} / \mathrm{mL} ; 2,18 \mu \mathrm{g} / \mathrm{mL}$ para obter faixa quantificável de aminas biogênicas nos queijos coalhos comerciais suplementados com extrato de própolis. As amostras eram submetidas a um leve aquecimento em temperatura de $40 \stackrel{\circ}{ } \mathrm{C}$ por 1 hora, e em seguida eram filtradas em filtros de $0,22 \mu \mathrm{m}$ e injetadas $(2 \mu \mathrm{L})$ no UPLC-Fluor. As amostras de queijos coalhos comerciais e suplementados com extrato de própolis sofreram o mesmo procedimento de derivatização.

O sistema cromatográfico apresentava os seguintes módulos: bomba de alta pressão LC-20ADXR, desgaseificador DGU-20A3R, auto injetor modelo SIL-20AXR, forno 
para coluna cromatográfica, detector de fluorescência modelo RF-20A, modelo RF 20A e uma controladora CBM-20A e software Labsolution da Shimadzu. A separação dos cinco marcadores ocorreu no sistema cromatográfico utilizando uma coluna $\mathrm{C}_{18}$ Júpiter $(250 \times 4,6 \mathrm{~mm}, 5 \mu \mathrm{m})$ e uma pré-coluna $C_{18}(10 \times 4,6 \mathrm{~mm}, 5 \mu \mathrm{m})$ ambas da Phenomenex que estava aclimatada no forno a uma temperatura de $33^{\circ} \mathrm{C}$. A fase móvel utilizada para eluição dos marcadores do extrato de queijo de coalho foi constituído de acetonitrila: água, num fluxo de $0,8 \mathrm{~mL} / \mathrm{min}$. A eluição aconteceu em modo gradiente. $O$ detector de fluorescência foi equipado para monitorar 3 comprimentos de excitação e emissão simultaneamente, sendo eles: 320Ex-450Em; 334Ex-450Em; 334Ex - 495Em e 334Ex$520 \mathrm{Em}$.

\subsection{MÉTODO DE DETERMINAÇÃO DE ISOFLAVONOIDES EM QUEIJO COALHO SUPLEMENTADOS COM EXTRATO DE PRÓPOLIS VERMELHA}

Queijos coalhos suplementados com extrato de própolis vermelha foram descongelados de forma lenta em refrigeração de $0^{\circ} \mathrm{C}$ a $5^{\circ} \mathrm{C}$ e pesados em Becker de $250 \mathrm{~mL}$ uma quantidade de 5 gramas.

Extração sólido-líquido foi realizada usando volumes de $54 \mathrm{~mL}$ de etanol absoluto (queijo coalho fortificado com $0,3 \%$ de extrato de própolis vermelha) e $80 \mathrm{~mL}$ de etanol absoluto (queijo coalho fortificado com $0,5 \%$ de extrato de própolis vermelha) por período de 6 horas sem uso de extração vigorosa. Em seguida, mais 2 repetições foram realizadas para extrair completamente todos os flavonoides totais presentes nos queijos coalhos fortificados. Então, a solução etanólica foi filtrada em papel de filtro e submetida a concentração e sistema de rotaevaporação até completa remoção do solvente. O extrato sólido de própolis vermelha oriundos dos queijos coalhos fortificados $0,3 \%$ ou a $0,5 \%$., foram pesados, solubilizado e diluído para concentração de $200 \mu \mathrm{g} / \mathrm{mL}$ para ser injetado $(2 \mu \mathrm{L})$ no CLAE-DAD-UV-Vis e comparados com tinturas padronizadas de própolis vermelha em concentração de $200 \mu \mathrm{g} / \mathrm{mL}$.

O ensaio de determinação de isoflavonóides na tintura de própolis vermelha presente no queijo coalho fortificado foi realizado de acordo com método previamente validado (Nascimento et al. 2016). 


\section{RESULTADOS E DISCUSSÃO}

\subsection{ANÁLISES MICROBIOLÓGICAS}

\subsubsection{CARACTERIZAÇ̃̃O MICROBIOLÓGICA DE QUEIJOS DE COALHO}

\section{FORTIFICADOS E NÃO FORTIFICADO PRODUZIDOS NO IFAL}

Os resultados obtidos nesta pesquisa indicaram possível ação da própolis vermelha sobre a inibição de microorganismos patogênicos estabelecidos para queijos de alta umidade, como queijo de coalho, segundo (Brasil, 2001). A tabela 1 apresenta os resultados microbiológicos obtidos após análise para microorganismos indicadores das condições higiênico-sanitárias. Foi possível constatar que os queijos fortificados com a própolis vermelha alcançaram os padrões microbiológicos para: Coliformes a $45^{\circ} \mathrm{C}$, Staphylococcus coagulase positiva, Salmonella sp e Listeria monocytogenes, segundo RDC 12/2001 (BRASIL, 2001), da Anvisa.

De acordo com a tabela 1 , os resultados para os microorganismos analisados estiveram dentro dos padrões microbiológicos para o queijo fortificado com a própolis vermelha. O queijo sem fortificação obteve resultados desfavoráveis para coliformes e S. coagulase positiva apresentando valor acima do estabelecido pela RDC 12/2001 (BRASIL, 2001), da Anvisa, sendo considerado impróprio para consumo.

Tabela 1 - Resultados das análises microbiológicas de queijos de coalho artesanais produzido no IFAL.

\begin{tabular}{|c|c|c|c|c|c|}
\hline Análises & $\begin{array}{c}\text { Queijo } \\
\text { fort. } 0,1 \% \\
\text { Um. } 49 \% \\
\end{array}$ & $\begin{array}{c}\text { Queijo } \\
\text { fort. 0,3\% } \\
\text { Um. 49\% } \\
\end{array}$ & $\begin{array}{c}\text { Queijo fort. } \\
0,5 \% \\
\text { Um. 50\% }\end{array}$ & $\begin{array}{c}\text { Queijo sem } \\
\text { fortificação } \\
\text { Um. } 49 \%\end{array}$ & $\begin{array}{l}\text { Referências } \\
\text { (RDC 12/2001) }\end{array}$ \\
\hline $\begin{array}{c}\text { Coliformes a } 45^{\circ} \mathrm{C} \\
\text { (NMP/g) }\end{array}$ & $2,8 \times 10^{3}$ & $2,4 \times 10^{3}$ & $1,1 \times 10^{3}$ & $5,4 \times 10^{3}$ & $5 \times 10^{3}$ \\
\hline $\begin{array}{c}\text { Staphylococcus } \\
\text { coagulase positiva } \\
\text { (UFC/g) }\end{array}$ & $<10^{3}$ & $<10^{3}$ & $<10^{3}$ & $<10^{3}$ & $10^{3}$ \\
\hline Salmonella sp. & Ausência & Ausência & Ausência & Ausente & Ausente \\
\hline $\begin{array}{c}\text { Listeria } \\
\text { monocytogenes }\end{array}$ & Ausência & Ausência & Ausência & Ausência & Ausente \\
\hline
\end{tabular}

Fonte: Autoria própria.

De modo geral, constatou-se que os queijos de coalho fortificados com extrato de própolis vermelha tiveram comportamento diferenciado em relação aos queijos sem fortificação. O queijo com própolis vermelha atendeu o padrão microbiológico para coliformes a $45^{\circ} \mathrm{C}$, diferente do queijo sem fortificação (Brasil, 2001). 
Bastos (2011) descreve a atividade antibacteriana significativa da própolis vermelha frente a amostras com E. coli, indicando possível aplicação terapêutica sobre as infecções causadas por essa bactéria. Cabral (2009) concluiu que a própolis vermelha demonstrou alta atividade antibacteriana frente à bactéria Staphylococcus aureus ATCC 25923.

Fernandes Junior (2006) relata sobre a atividade antimicrobiana significativa da própolis sobre as bactérias Gram positivas ( $S$. aureus e Enterococcus $s p$ ) e Gram negativas (E. coli), sendo as Gram positivas mais sensíveis. Orsi et al. (2005) descreve a ação da própolis do Nordeste do Brasil (Mossoró, Rio Grande do Norte) mais eficaz contra Salmonella do que a própolis do Sul (Urubici, Santa Catarina), apesar de ambas as amostras apresentaram atividade bactericida. Silva et al. (2006) relata que o extrato etanólico de própolis (EEP) a uma dosagem de 7,5 ug/mL ou superior teve um efeito bactericida sobre a L. monocytogenes.

\subsection{DETERMINAÇÃO DE AMINAS BIOGÊNICAS EM QUEIJO COALHO SUPLEMENTADOS COM EXTRATO DE PRÓPOLIS VERMELHA USANDO CLAE- FLUOR}

A figura 2 mostra perfil cromatográfico dos padrões analíticos de aminas biogênicas após reação de derivatização com o reagente cloreto de dansila. O método apresentou separação cromatográfica para 4 padrões analíticos dos 5 testados. Apenas a histamina não apresentou perfil cromatográfico definido. A tiramina apresentou pico no tempo de retenção de 25,3 minutos. A 2 feniletilamina apresentou retenção em 31,5 minutos. A putrescina apresentou pico cromatográfico com tempo de retenção de 32,6 minutos, enquanto a cadaverina apresentou tempo de retenção de 33,6 minutos. Em todas as amostras derivatizadas foi comum o pico do reagente derivatizante em aproximadamente 29,6-29,8 minutos. 
Figura 2 - Perfil cromatográfico dos padrões analíticos do pool de aminas biogênicas. (1)

Tiramina, (2) 2 feniletilenodiamina, (3) putrescina (4) cadaverina na concentração de 2,18 $\mu \mathrm{g} / \mathrm{mL}$..
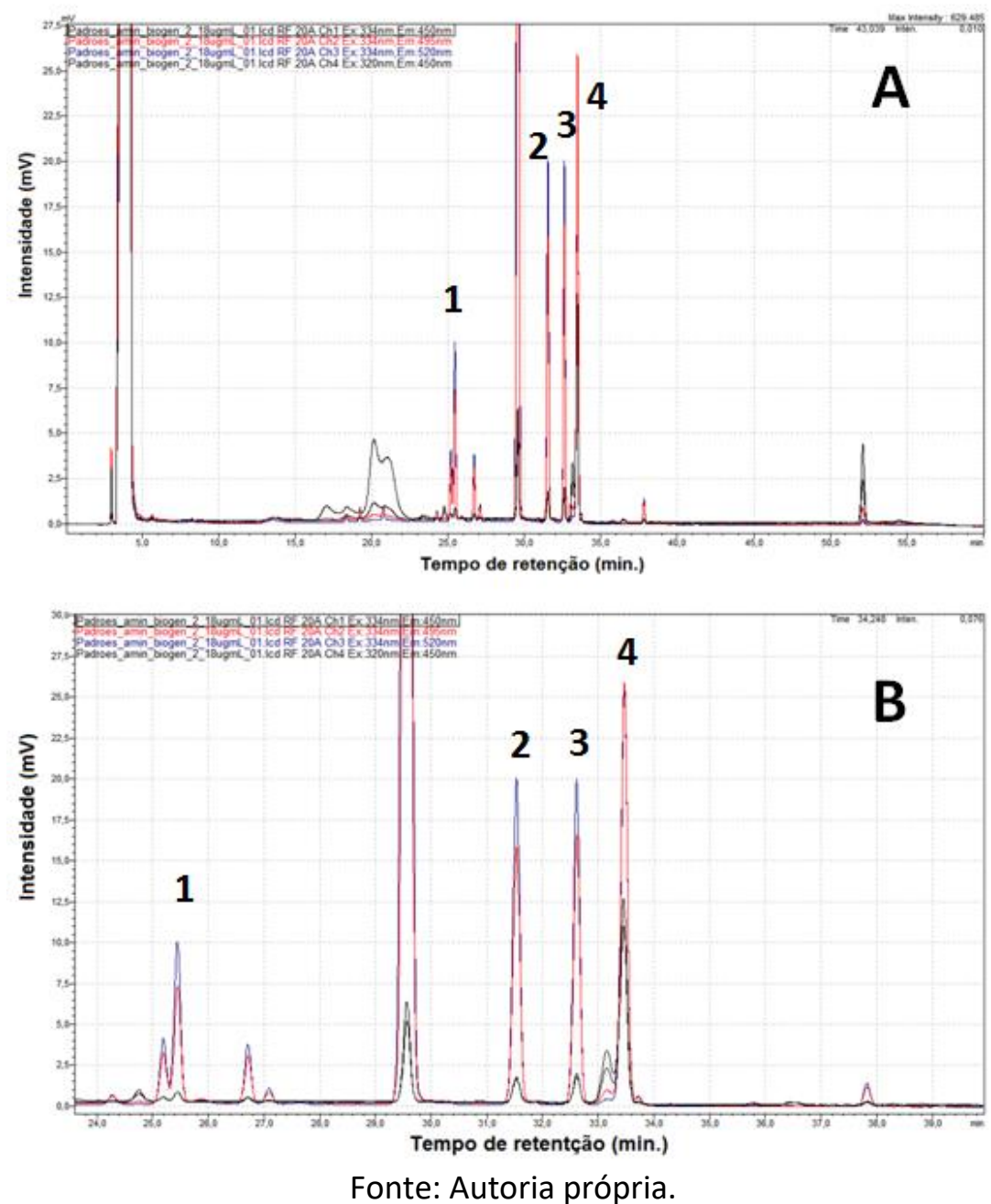

As amostras dos queijos de coalho artesanal suplementados com extrato de própolis vermelha (IFAL 0,1\%, IFAL 0,3\% e IFAL 0,5\%) produzidos na agroindústria do IFAL-SATUBA-AL mostrou as menores intensidades de sinal para as 4 aminas biogênicas padronizadas neste método cromatográfico.

Observando os cromatogramas da figura 3, foi possível observar também a eluição de outros aminoácidos presentes na amostra de queijo de coalho, na faixa de tempo de retenção entre 5 e 24 minutos. Desta forma, pode-se estabelecer 2 principais faixas de tempo de retenção no método cromatográfico estabelecido para determinação de aminas biogênicas. Entre 5 a 24 minutos faixa de eluição para aminoácidos e entre 25 a 55 minutos faixa de eluição para aminas biogênicas. Vale ressaltar que este desenvolvimento de método foi baseado em alguns métodos 
cromatográficos já descritos na literatura (mo Dugo e col. 2006; Gomez-Alonso e col. 2007) para determinação de aminas biogênicas.

Figura 3 - Perfil cromatográfico dos queijos de coalho produzidos na indústria piloto do IFALSATUBA. Cromatograma (A) queijo de coalho fortificado como extrato de própolis $0,1 \%$, (B) queijo de coalho fortificado com extrato de própolis $0,3 \%$, (C) queijo de coalho fortificado com extrato de própolis 0,5\%. Detecção de traços de aminas biogênicas (1) Tiramina, (2) 2feniletilamina, (3) putrescina e (4) cadaverina.
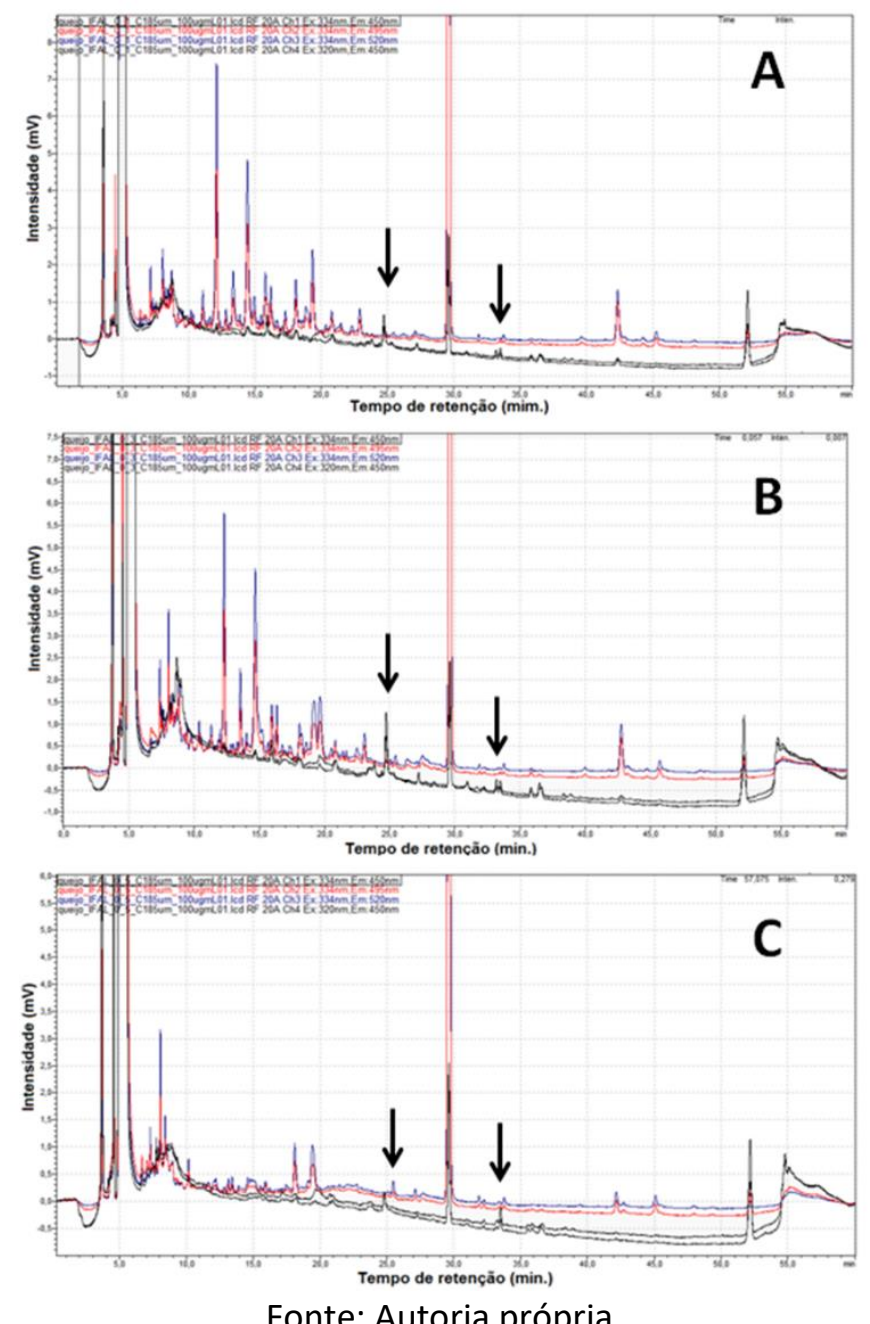

Todas as amostras de queijo de coalho IFAL (IFAL 0,1\%; IFAL 0,3\% e IFAL 0,5\%) mostraram baixa concentração de aminas biogênicas com valores de áreas menores que a intensidade de área da menor concentração quantificável $(0,058 \mu \mathrm{g} / \mathrm{mL})$. Uma das explicações para esta baixa concentração de aminas biogênicas nos queijos de coalho pilotos produzidos pelo IFAL-Satuba-AL, está no fato de flavonoides inibir a bactérias patogênicas, além disso no trabalho de Yauhen Bandaruk e col. (2012) em quercetina, luteolina, isoraminetina e os galatos de catequina inibem fracamente monoaminaoxidades A (MAO-A). 
Os ensaios cromatográficos de determinação de aminas biogênicas das amostras de queijo de coalho artesanais mostraram presença de tiramina, 2-feniletilamina, putrescina e cadaverina, porém as aminas biogênicas mais frequentes foram tiramina e cadaverina.

Tabela 2 - Determinação das áreas cromatográficas de aminas biogênicas em amostras comerciais de queijo de coalho nos comprimentos de excitação $320 \mathrm{~nm}$ e emissão $450 \mathrm{~nm}$

\begin{tabular}{ccccc}
\hline $\begin{array}{c}\text { Concentração } \\
(\mu \mathrm{g} / \mathrm{mL})\end{array}$ & Tiramina & 2-feniletilamina & Putrescina & Cadaverina \\
\hline Padrao 2,180 & 4720 & 13269 & 13417 & 120916 \\
Padrao 1,100 & 3889 & 9819 & 10694 & 198681 \\
Padrao 0,440 & 2220 & 6623 & 3010 & 206899 \\
Padrao 0,100 & - & 1644 & - & 56413 \\
Padrao 0,058 & - & 1411 & - & 41760 \\
IFAL 0,1\% & 1329 & - & - & 2291 \\
IFAL 0,3\% & 2547 & - & - & 2451 \\
IFAL 0,5\% & - & - & - & 3219 \\
\hline
\end{tabular}

Fonte: Autoria própria.

Tabela 3 - Determinação das áreas cromatográficas de aminas biogênicas nas amostras comerciais de queijo de coalho nos comprimentos de excitação $334 \mathrm{~nm}$ e emissão $520 \mathrm{~nm}$

\begin{tabular}{ccccc}
\hline $\begin{array}{c}\text { Concentração } \\
(\mu \mathrm{g} / \mathrm{mL})\end{array}$ & Tiramina & 2-feniletilamina & Putrescina & Cadaverina \\
\hline Padrao 2,180 & 83984 & 174887 & 163647 & 217220 \\
Padrao 1,100 & 54735 & 93711 & 127578 & 185518 \\
Padrao 0,440 & 22896 & 38138 & 32996 & 105304 \\
Padrao 0,100 & 7446 & 3393 & 6385 & 49738 \\
Padrao 0,058 & 6725 & 4719 & 3534 & 18941 \\
IFAL 0,1\% & 1329 & - & - & 2291 \\
IFAL 0,3\% & 2113 & - & - & 1102 \\
IFAL 0,5\% & 2448 & 1058 & - & 1251 \\
\hline
\end{tabular}

Fonte: Autoria própria.

Dentre os sistemas de detecção por fluorescência (Tabelas 2 e 3), os sistemas de excitação e emissão $334 \mathrm{~nm} / 520 \mathrm{~nm}$ vem mostrando-se mais sensível para avaliar as aminas biogênicas de maneira global, enquanto que os sistemas de excitação e emissão $320 \mathrm{~nm} / 450 \mathrm{~nm}$ também foi possível para detectar a presença de tiramina e cadaverina. Os estudos com determinação de aminas biogênicas ainda estão sendo padronizados. 0 volume amostral de soro de queijo de coalho ainda está sendo padronizado, pois quando se utilizou $200 \mu \mathrm{L}$ como volume amostral, apenas cadaverina foi detectada. Fazse necessário realizar um novo estudo com variação do volume amostral até $2000 \mu \mathrm{L}$, porém esta técnica necessita ser co-validadas com estudos microbiológicos. 
Os dados das tabelas 2 e 3 apresentaram valores de um estudo semi-quantitativo quanto a presença pontual de determinadas aminas biogênicas (tiramina, 2feniletilamina, putrescina e cadaverina), porém realizamos um estudo exploratório com todos os picos cromatográfico entre 25 e 55 minutos, pois além dos 4 marcadores de aminas biogênicas já citados, houve presença de outros picos cromatográficos que pode sugerir presença de outras aminas biogênicas importante como espermina e espermidina (Figura 3). Dados da literatura mostram que estas 2 aminas biogênicas eluem em tempos de retenção superior a cadaverina.

\subsection{IDENTIFICAÇÃO DE FLAVONÓIDES DA PRÓPOLIS VERMELHA DE ALAGOAS EM QUEIJOS DE COALHO}

\subsubsection{PERFIL CROMATOGRÁFICO DE QUEIJO COALHO SUPLEMENTADOS COM \\ EXTRATO DE PRÓPOLIS VERMELHA}

Os queijos de coalho produzidos no IFAL fortificados com extrato de própolis vermelha (IFAL 0,3\% e IFAL 0,5\%) foram avaliados quanto a presença dos flavonoides presentes na própolis vermelha. Os dados mostraram que foi possível detectar a presença dos flavonoides presentes na própolis vermelha de Alagoas e nos queijos de coalho fortificados. Os principais marcadores detectados e confirmados pela presença de padrões analíticos foram (1) liquiritigenina, (2) daidzeína, (3) pinobanksina, (4) isoliquiritigeina, (5) formononetina, (6) pinocembrina e (7) Biochanina A (Figura 4). 
Figura 4 - Perfil cromatográfico dos flavonoides e isoflavonóides presentes no queijo de coalho (IFAL $0,3 \%$ ) fortificados com tintura própolis vermelha $0,3 \%$. Cromatograma (A) obtido no comprimento de onda de $277 \mathrm{~nm}$ e Cromatograma (B) obtido no comprimento de onda de $366 \mathrm{~nm}$. (1) Liquiritigenina, (2) pinobanksina, (3) isoliquiritigenina, (4) formononetina e (5) Biochanina A.

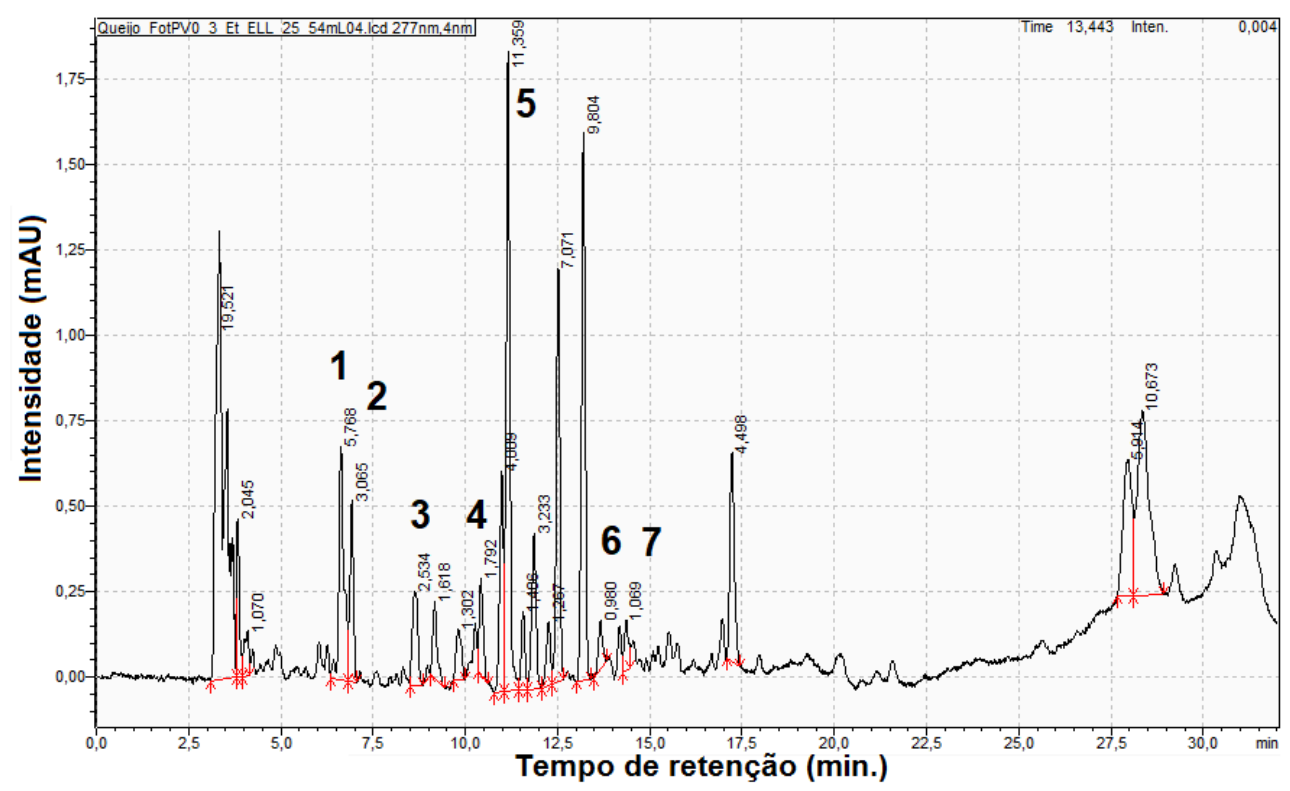

Fonte: Autoria própria.

Os dados cromatográficos mostram que foi possível extrair os flavonoides e isoflavonóides presentes na matriz alimentícia, queijo de coalho, após processo de fortificação dos queijos de coalho com extrato de própolis vermelha. Os dados também mostram que o perfil cromatográfico é bastante semelhante com o extrato de própolis vermelha sem processo de fortificação em matriz complexa.

\section{CONCLUSÕES}

As boas práticas de fabricação, o controle higiênico-sanitário em todas as etapas de produção, a capacitação dos manipuladores e um controle de qualidade adequado, são medidas que podem minimizar contaminação microbiana e a formação de aminas biogênicas nos queijos do tipo coalho bastante consumidos pela população de Alagoas.

Os queijos de Coalho suplementados com o extrato de própolis vermelha demonstraram traços de aminas biogênicas comparando-se com os queijos sem fortificação, indicando que flavonóides da própolis vermelha inibe o crescimento bacteriano e consequentemente a formação de aminas biogênicas podendo ser utilizados como bioconservante. 


\section{AGRADECIMENTOS}

Os autores agradecem ao CNPq, CAPES e FAPEAL pelas bolsas concedidas aos Cursos de Mestrado em Nutrição (PPGNUT) e Ciências Farmacêuticas (PPGCF), bem como ao apoio financeiro (Bolsa no 446630 / 2014-4) e (n 60030 000431/2016).

\section{REFERÊNCIAS}

BANDARUK Y, MUKAI R, KAWAMURA T, NEMOTO H, TERAO J (2012) Evaluation of the inhibitory effects of quercetin-related flavonoids and tea catechins on the monoamine oxidase-a reaction in mouse brain mitochondria. J. Agric. Food Chem. 60: 10270-10277.

BASTOS EMAF, Galbiati C, Loureiro EM, Scoaris DO (2011) Indicadores físico-químicos e atividade antibacteriana de própolis marrom frente à Escherichia coli. Arq. Bras. Med. Vet. Zootec., 63: 1255- 1259.

BRASIL. MINISTÉRIO DA AGRICULTURA, PECUÁRIA E ABASTECIMENTO. Instrução Normativa no 30, de 26 de junho de 2001. Regulamento técnico de identidade e qualidade do queijo de coalho. Diário Oficial da União. Brasília, 16 de julho de 2001.

BRASIL. Ministério da Saúde. Agência Nacional de Vigilância Sanitária. Resolução-RDC no12, de 2 de janeiro de 2001. Dispõe Sobre Padrões Microbiológicos Sanitários para Alimentos. Diário Oficial (da) República Federativa do Brasil, Brasília, 2001.

CABRAL ISR, Oldoni TLC, Prado A, Bezerra RMN, Alencar SM, Ikegaki M, Rosalen PL (2009) Composição fenólica, atividade antibacteriana e antioxidante da própolis vermelha brasileira. Química Nova 32: 1523-1527.

CHIACCHIERINI ED, RESTUCCIA D, VINCI G (2005) Evaluation of two different extraction methods for chromatographic determination of bioactive amines in tomato products. Talanta 69: 548-555.

DIAS SS, LOBATO V, VERRUMA-BERNARDI MR (2009) Metodologias para identificar adulteração em queijos produzidos com leite de diferentes espécies de animais. Rev Inst Adolfo Lutz; 68(3):327-33.

FERNANDES-JUNIOR A, Lopes MMR, Colombari V, Monteiro ACM, Vieira EP (2006) Atividade antimicrobiana de própolis de Apis mellifera obtidas em três regiões do Brasil. Cienc. Rural 36: 294-297.

INNOCENTE N, D'AGOSTIN P (2002) Formation of biogenic amines in typical semi hard Italian cheese. J Food Prot. 65: 1498-14501.

LANGE J, THOMAS K, WITTMAN C (2002) Comparison of a capillary eletrophoresis method with high-performance liquid chromatography for the determination of 
biogenic amines in various food samples. Journal of Chromatography 779: 229239.

MO DUGO G, VILASI F, LA TORRE GL, PELLICANO TM (2006) Reverse phase HPLC/DAD determination of biogenic amines as dansyl derivatives in experimental red wines. Food Chemistry 95: 672-676.

NASCIMENTO TG, SILVA PF, AZEVEDO LF et al. (2016) Polymeric Nanoparticles of Brazilian Red Propolis Extract: Preparation, Characterization, Antioxidant and Leishmanicidal Activity. Nanoscale Research Letters, 11: 301. doi: 10.1186/s11671-016-1517-3.

ORSI RO, Sforcin JM, Rall VLM, Funari SRC, Barbosa L, Fernandes JRA (2005) Susceptibility profile of Salmonella against the antibacterial activity of propolis produced in two regions of Brazil. J. Venom. Anim. Toxins incl. Trop. Dis. 11: 109-116.

PINTADO AIE, PINHO O, FERREIRA IMPLVO, PINTADO ME, GOMES AMP, MALCATA FX (2008) Microbiological, biochemical and biogenic amine profiles of Terrincho cheese manufactured in several dairy farms. Int Dairy J. 18: 631-40.

SERGIO GOMEZ-ALONSO, et. al. (2007) Simultaneous HPLC Analysis of Biogenic Amines, Amino Acids, and Ammonium lon as Aminoenone Derivatives in Wine and Beer Samples, J. Agric. Food Chem. 55: 608-613.

SILVA JFM, SOUZA MC, MATTA SR, ANDRADE MR, VIDAL VN (2006) Correlation analysis beween phenolic levels of Brazilian Propolis extracts and their antimicrobial and antioxidant activities. Food Chemistry, 99: 431-435. 


\title{
CAPITULO XIII
}

\section{TOMATE ( $\angle Y C O P E R S I C O N$ ESCULENTUM) E OS PRODUTOS DERIVADOS À BASE DE TOMATE}

DOI: 10.51859/AMPLLA.DES1788-13

\author{
Thaynna Leocádio Trajano Lacerda Sousa ${ }^{1}$ \\ Indira Maria Estolano Macedo ${ }^{1}$ \\ Maria Karollyna Gomes da Silva ${ }^{2}$ \\ Gerlane Souza de Lima ${ }^{3}$ \\ Aline Gomes Santana 4 \\ Neide Kazue Sakugawa Shinohara 5
}

\footnotetext{
${ }^{1}$ Mestre em Ciência e Tecnologia de Alimentos. Programa de Pós-Graduação em Ciência e Tecnologia de Alimentos UFRPE

${ }^{2}$ Mestranda em Ciência e Tecnologia de Alimentos. Programa de Pós-Graduação em Ciência e Tecnologia de Alimentos - UFRPE

${ }^{3}$ Mestre em Nutrição. Programa de Pós-Graduação em Nutrição - UFPE

${ }^{4}$ Mestre em Consumo, Cotidiano e Desenvolvimento Social. Programa de Pós-Graduação em Consumo, Cotidiano e Desenvolvimento Social - UFRPE

${ }^{5}$ Professor Adjunto do Departamento de Tecnologia Rural. Universidade Federal Rural de Pernambuco - UFRPE
}

\section{RESUMO}

O tomate é considerado importante exemplo de planta comestível, originário da América centro-sul, popularizou-se pelo mundo após a colonização dos europeus. É a segunda hortaliça mais consumida no mundo e contribui para a nutrição e enriquecimento da culinária mundial. Este fruto e seus derivados são a principal fonte de licopeno na dieta humana, propiciando a diminuição dos riscos na incidência de doenças degenerativas não transmissíveis. Os produtos derivados de tomate como o molho, ketchup e extrato de tomate, são alternativas alimentares com propriedade funcional, pois apresentam maior concentração de licopeno, quando comparado com o tomate in natura.

Palavras-chave: Ketchup. Molho de tomate. Licopeno. 


\section{INTRODUÇÃO}

O tomate, Lycopersicon esculentum, é um fruto da família Solanaceae, a mesma das pimentas, pimentões, berinjelas e jiló, é originário da América centro-sul e se popularizou pelo mundo após a colonização dos europeus. O tomate inicialmente era tido como venenoso pelos europeus e foi recebido com desconfiança por sua ligação com a família Solanaceae, que acabaram impondo-Ihe a pecha de planta perigosa, quiçá venenosa, certamente usada em feitiçaria. Apenas no século XIX o tomate passou a ser consumido e cultivado em escala cada vez maior, inicialmente na Itália, depois na França e na Espanha. Durante este século, os europeus que retornavam da América após as viagens ao novo mundo, levaram ao velho mundo a fruta vermelha, que imaginavam ser venenosa (BARBARA; PAGANO, 2005; GISSLEN, 2012).

O tomate foi levado para a Espanha e, com tudo que era enviado da América para o Velho Mundo, foi recebido com profunda estranheza. Alguns autores da época atribuíram-Ihe até propriedades afrodisíacas. A utilização da espécie vermelha despontou na cozinha napolitana com uma receita de molho de tomate "de estilo espanhol". O pequeno fruto dourado adornou os jardins por mais de um século (BELLUZZO, 2004).

A Solanaceae é uma importante família de plantas comestíveis, sendo o tomateiro um importante representante na dieta humana. Apesar de ser uma família cosmopolita, a América do sul é a principal região de sua ocorrência, com produção em larga escala comercial. O tomate é a segunda hortaliça mais consumida no mundo depois da batata; em parte, por causa desse elevado consumo, ocupa o primeiro lugar em contribuição relativa para a nutrição (FENNEMA; DAMODARAN; PARKIN, 2018). O tomate industrial destina-se à produção de derivados, como extratos, polpas, molhos e conservas de tomate sem pele, produtos que aumentam a vida útil (FELIPPE, 2005). Dados da Pesquisa de Orçamentos Familiares 2008-2009 demonstram que o consumo no Brasil de massa de tomate é de 0,665 kg/per capita ao ano e de molho de tomate de $0,634 \mathrm{~kg} /$ per capita ao ano (IBGE, 2010).

O fruto do tomateiro e seus derivados são a principal fonte de licopeno na dieta dos humanos. O tomate cru apresenta, em média, $30 \mathrm{mg}$ de licopeno/kg do fruto; o suco de tomate cerca de 150 mg de licopeno/litro; e o Ketchup contém em média 100 mg/kg 
(CHOUDHARI; ANANTHANARAYAN, 2007; SILVA; SCHNEIDER; PEREIRA, 2009). Observase que o processamento eleva as concentrações de licopeno por unidade de peso, quando comparado com a fruta in natura.

Entre as séries de carotenóides, o licopeno mostrou-se como um dos mais eficientes antioxidantes, podendo doar elétrons para neutralizar as moléculas de oxigênio singleto e outras moléculas oxidantes antes que estes compostos prejudiquem as células. Outras evidências sugerem que o licopeno atua junto a produção hormonal e na modulação do sistema imune. Estudos clínicos e epidemiológicos têm confirmado que dietas ricas em licopeno estão associadas com a redução do risco de desenvolvimento de câncer de próstata e ovário bem como a uma menor incidência de doenças degenerativas crônicas e cardiovasculares (CARVALHO et al., 2005; FENNEMA; DAMODARAN; PARKIN, 2018).

\section{HISTÓRIA DO TOMATE}

A julgar pelos registros arqueológicos, os antigos habitantes da América central se alimentavam de milho, feijão, abóbora, abacate e tomate. Esses alimentos eram a base da alimentação desses povos por volta de 3500 a.C. (McGEE, 2011).

O tomate é originário dos Andes - região que atualmente corresponde aos territórios do Equador, Peru e Bolívia. O tomateiro forma um caule ramificado com folhas pinadas grandes com flores brancas que formam panículas (cada uma com cerca de vinte flores). As panículas saem das axilas das folhas. Os frutos (bagas) são inicialmente verdes e vermelhos quando maduros. Possuem pele firme e brilhante e encerram uma polpa avermelhada de cor atrativa e que caracteriza o grau de amadurecimento e opção de escolha para consumo (FELIPPE, 2005).

O tomate foi levado para Itália sob o nome de pomo d'oro, por ser amarelo e ter supostos poderes afrodisíacos. Mas, continuou sendo desprezado até que alguns camponeses conseguiram desenvolver uma variante vermelha. Em meados de 1700, o cozinheiro italiano Francesco Leonardi preparou uma massa com molho de tomate, dando início ao caso de amor profundo entre uma gama de pastas e pomodoro (BARBARA; PAGANO, 2005). O tomate foi usado pela primeira vez em Nápoles na preparação de molhos no século XVIII, iniciando a lenta assimilação desses ingredientes. 
Pouco a pouco o milho, o feijão, o tomate, a pimenta, o pimentão e a baunilha, propagaram-se pelo Velho Continente, seduzindo gerações (BELLUZZO, 2004).

Já o molho ketchup segundo Reyes (2013), surgiu no oriente, pois o nome original era ke-tsiap ou ketchap, derivado de um dialeto de terras próximas à China. Esse condimento era preparado inicialmente com um caldo de peixe escabeche em salmoura, conferindo sabor umami. Com a introdução, pelos espanhóis, dos produtos do novo mundo, o tomate se mostrou um fruto rico em sabor umami, incorporando mais sabor ao caldo de peixe. Em 1690, pela primeira vez foi apreciado o ketchup feito à base de tomate, porém, a popularização mundial somente ocorreu em 1711.

As hortaliças são complemento e reforço da dieta. O português manteve o quanto pôde, no Brasil, a tradição dos quintais e hortas. Não podiam viver sem as hortaliças e semeou-as ao redor das casas, criando o cinturão verde dos vegetais, circundando cidades como Olinda, Recife e Salvador (LIMA, 1999). No caso do tomate, devido a seu apreço pela população, entrou no vocabulário da linguagem popular considerando "tomate" como sendo uma pessoa que tomou muito sol e ficou vermelho (MAIOR, 2013).

\section{COMPOSIÇÃO NUTRICIONAL E ATIVIDADE ANTIOXIDANTE DOS TOMATES E DERIVADOS}

O tomate é um alimento pouco calórico, fonte de fibras, sais minerais e o pigmento licopeno, principal responsável pela coloração vermelha do fruto e derivados, bem utilizados na culinária pela sua cor atraente, aumentando a aparência agradável dos pratos. O licopeno é um carotenoide, funciona como antioxidante que atua na neutralização de radicais livres, proporcionando proteção contra danos oxidativos e estimulação do sistema imunológico. Quanto maior a concentração de tomate em uma receita culinária, maior o teor de licopeno e os benefícios por este proporcionado. E quanto mais intensa for à cor vermelha do tomate, mais antioxidantes haverá em sua composição (BÔTO et al., 2019).

Os carotenóides têm esse nome porque o primeiro membro dessa família a ser identificado químicamente foi encontrado nas cenouras. Esses pigmentos absorvem os comprimentos de onda relacionados ao azul e ao verde, e são responsáveis pela maioria 
das colorações amarelas e alaranjadas que encontramos em frutas e hortaliças, e também pelo vermelho de tomate, melancias e certas pimentas (McGEE, 2011).

Quimicamente os carotenóides são estruturas tetraterpenoides que são divididas em dois grupos, hidrocarbonetos e xantofilas. Dos hidrocarbonetos o mais simples é o licopeno (COULTATE et al., 2004). Os carotenóides são compostos lipossolúveis e moderadamente estáveis ao calor, perdendo a cor por reações de oxidação. Do ponto de vista nutricional, esses pigmentos desempenham funções importantes, como a atividade provitamina $A$, sendo necessários 12 moléculas de $\alpha$ caroteno para produzir uma molécula equivalente de retinol; ação antioxidante e prevenção da catarata e a degeneração muscular (DEVELIN, 2002; ARAÚJO et al., 2011).

Estudos acadêmicos sobre nutrição e medicina, demonstraram que o licopeno é um potencial agente anticâncer (GANN et al., 1999; MILLER et al., 2002). Espera-se que o consumo adequado deste carotenóide na dieta possa ser fator importante na diminuição do risco de câncer de próstata e ovário (DEVELIN, 2002).

Os principais componentes dos carotenóides no tomate são o $\alpha$-caroteno (amarelo) e o licopeno (vermelho), cuja síntese e decomposição são acentuadas na fase de transição entre a maturação e senescência do fruto (ZAMBON, 1984; ZAMBRANO; MOYEJA; PACHECO, 1995). Em tomates, há intensa degradação de clorofila durante o amadurecimento, com síntese gradual de licopeno (CHITARRA, CHITARRA, 1990). A cor vermelha dos frutos é considerada como sendo o acúmulo de licopeno. O estágio verde maduro, início de mudança de cor, é considerado o primeiro sintoma visual para o índice de maturação (ZAMBON, 1984).

O licopeno encontrado no tomate, melancia, mamão, pêssego e toranjas alaranjadas, possuem propriedades antioxidantes e anticancerígenas. Cerca de $80 \%$ do licopeno alimentar é encontrado no tomate e seus derivados. Vários estudos têm sugerido que o consumo de produtos processados de tomate reduz o risco de câncer de próstata. Da mesma forma, a diminuição do risco de câncer e doença cardiovascular tem sido associada ao consumo elevado de produtos que contém o tomate (FENNEMA; DAMODARAN; PARKIN, 2018).

Os tomates são, de longe, a fonte mais rica em licopeno, poderoso antioxidante que combate os radicais livres, retarda o envelhecimento e pode proteger contra 0 câncer, inclusive o de próstata. Ainda, o licopeno é mais bem absorvido pelo nosso 
organismo quando os produtos do tomate são ingeridos com azeite de oliva. O licopeno de produtos processados é, também, muito melhor absorvido do que o dos produtos in natura (COELHO, 2010).

O consumo do tomate é recomendado pelos nutricionistas por se constituir em um alimento rico em licopeno, mas também possui vitaminas do complexo $A$ e $B$ e minerais importantes, como o fósforo e o potássio, além de ácido fólico, cálcio e frutose. Quanto mais maduro, maior a concentração desses nutrientes (CARVALHO et al., 2005; LUZ, 2008). Ainda segundo Carvalho et al. (2005), o tomate ocupa o primeiro lugar como contribuinte de vitaminas e minerais na dieta humana e o seu valor nutritivo é devido, principalmente, ao seu teor em ácido ascórbico.

\section{PROPRIEDADES ORGANOLÉPTICAS, COMERCIALIZAÇ̃̃O E LEGISLAÇÃO PARA DERIVADOS DE TOMATE}

Entre as hortaliças mundialmente cultivadas para consumo in natura e, sobretudo, industrializado, o tomate (Lycopersicon esculentum Mill), hortaliça cuja parte comestível é o fruto, se sobressai, razão porque é considerado de produção e utilização universal. Este fruto climatérico é altamente perecível e as técnicas de conservação na pós-colheita podem contribuir para minimizar suas perdas e agregar valor ao produto acabado (CAMARGO; HAJ-ISA; QUEIROZ, 2007).

Um dos fatores de qualidade do tomate é o estado fisiológico, que está relacionado com o estágio de maturação do fruto, pois é o que define o momento da colheita. A cor sugere as mudanças de sabor, textura e aroma, decorrentes do processo de maturação (ZAMBON, 1984; SILVA; GIORDANO, 2000). A modificação da coloração do tomate é devida a clorofila e aos carotenóides. A cor verde dos frutos imaturos é atribuída à clorofila. Ao máximo tamanho segue imediata mudança de cor, início da maturação, refletindo a degradação da clorofila, que permanece em pequena quantidade nos tecidos do fruto (MEDINA, MEDINA, 1981; ZAMBON, 1984; ZAMBRANO; MOYEJA; PACHECO, 1995).

Quanto às características de qualidade do tomate, esses devem ser lisos, firmes, com cor uniforme, sem manchas ou rachaduras, sendo vermelho intenso para molhos e alaranjados para saladas. Além do tomate vermelho comum e do tomate-cereja 
pequeno, existem dezenas de variedades de tomates produzidos e distribuídos comercialmente (GISSLEN, 2012). A conservação em refrigeração preserva por uma semana as características organolépticas para uso culinário (DOMENE, 2018).

As frutas e vegetais exercem um papel fundamental na nutrição humana, constituindo fontes indispensáveis de nutrientes, vitaminas e minerais. Por representarem cerca de $80 \%$ de umidade, são altamente perecíveis e devem ser refrigerados ou processados o mais rapidamente possível após a colheita, a fim de diminuir as perdas. Em alguns países de clima tropical e subtropical, estas podem chegar a aproximadamente $40-45 \%$ da produção devido à inadequada refrigeração e armazenamento. O principal objetivo do processamento de alimentos é convertê-los em produtos mais estáveis que possam ser estocados por longos períodos, tendo como técnicas mais importantes o enlatamento, o congelamento e a desidratação (JAYARAMAN; DAS GUPTA, 1992). Essas técnicas de conservação já são aplicadas aos tomates na indústria de alimentos mundial.

O processamento do tomate representa uma alternativa de redução das perdas para o produtor, principalmente nas regiões onde a cultura do tomate constitui a principal atividade econômica. Frequentemente ocorre diminuição na demanda do comércio in natura e, por conseguinte, as perdas de tomates são aumentadas. Dessa forma, os derivados de tomate, por apresentarem maior período de conservação, tornam-se uma alternativa para minimizar essas perdas (FAGUNDES et al., 2005).

São fabricados diversos produtos onde tomates na forma de pedaços ou de massa são as principais matérias-primas, como por exemplos, conservas de molhos para macarrão, saladas, temperos e/ou molhos variados, geléias, tomates secos, conservas de tomates secos e as diversas formas de ketchup. Além desses produtos, em países onde há escassez de tomates, na época de safra são produzidas conservas de tomates pelados ou tomates sem as peles, normalmente utilizados na substituição do tomate in natura, tão perecível sem a adoção de tecnologia de conservação (SENAI, 1993).

O tomate é rico em umami quando maduro, pois esse alimento contém concentrações de nucleotídeos de inosinato e guanilato em sua composição que estimula a percepção deste quinto sabor. Esses nucleotídeos presentes no fruto têm o poder de enaltecer gostos complexos associados durante uma refeição, semelhantes 
como encontramos também em aspargos e Alga kombu do reino vegetal, assim como em queijos e carnes (REYES, 2013).

No Brasil, o tomate é principalmente industrializado como concentrado e na forma de molhos especializados, e a expectativa para o consumo doméstico do tomate processado continua crescente, fazendo-se necessária a diversificação dos produtos derivados (FERREIRA; FREITAS; LAZZARI, 2004).

Os molhos de tomate caracterizam-se por sua cor vermelho intenso e sabor pronunciado do fruto, esses molhos podem ser de 4 (quatro) tipos: ao sugo, que usa a polpa do tomate acrescido de azeite, alho, sal e açúcar; à bolonhesa, molho ao sugo com carne moída; à italiana, molho ao sugo mais carne em cubos; à genovese, molho ao sugo com manjericão, bacon, azeite e parmesão e à calabrês; molho ao sugo com linguiça calabresa (ORNELLAS, 2007).

O molho de tomate pode ser definido, de acordo com a Agência Nacional de Vigilância Sanitária (ANVISA), como um condimento feito à base de tomate e, às vezes, acrescido de presunto, cebola, manjericão, sal, óleo, alho e vários outros condimentos para conferir sabor. Assim, surgem os molhos com variações de sabores e mais sofisticados, além de oferecerem ao consumidor maior praticidade, segurança, entre outros (PEREIRA, 2007).

O ketchup é formulado a partir de polpa de tomate, na forma fresca ou de pasta concentrada, à qual são normalmente adicionados sal, vinagre, condimentos e especiarias e/ou aromatizantes, cebola e/ou alho, sendo o produto geralmente adoçado com sacarose, xaropes de glicose ou misturas destes. Entre as especiarias comumente utilizadas, encontram-se canela, cravo, pimenta, páprica, noz moscada, gengibre e mostarda, que podem ser adicionadas na forma integral, moídas, como óleos voláteis ou ainda através de misturas de especiarias, que podem ser encapsuladas ou não. É importante salientar que o uso das especiarias tem por objetivo acentuar o sabor típico do produto, e não mascará-lo, portanto, deve-se evitar exageros destes componentes. A formulação do ketchup varia consideravelmente conforme o fabricante, principalmente no que se refere às quantidades de especiarias e aromatizantes acrescentados à formulação (BANNWART, 2006).

Segundo a RDC №. 276 de 22 de setembro de 2005, ketchup é o produto elaborado a partir da polpa de frutos maduros do tomateiro (Lycopersicum esculentum 
L.), podendo ser adicionado de outros ingredientes desde que não descaracterizem o produto. Segundo a mesma resolução, ambas as designações ketchup e catchup podem ser utilizadas para denominar o produto. Os aditivos alimentares permitidos pela legislação brasileira para a categoria de molhos e condimentos, bem como suas funções e limites máximos de uso, foram estabelecidos pela Resolução № 382 de 05 de agosto de 1999 (BRASIL, 2005). Segundo Datamark (2005), no ano de 2004 - 84,3\% da participação no mercado de ketchup, foram representadas por somente 9 empresas.

De acordo com o IBGE (2010), a produção de tomate no Brasil é de aproximadamente 3,8 milhões de toneladas/ano, sendo $65 \%$ destinado ao consumo in natura e $35 \%$ para o processamento industrial. Os principais estados brasileiros, responsáveis por esta produção foram Goiás, São Paulo e Minas Gerais. O Brasil ocupa a oitava colocação de produtor mundial de tomate, correspondendo a uma área colhida de 61.025 ha (IBGE, 2010; FAGUNDES, et al., 2005).

A capacidade das indústrias de processamento instaladas no Brasil é de aproximadamente 15.185 ton/dia de pasta de tomate e de 1.495 ton/dia de tomate em cubos. Na agroindústria, existe uma demanda por itens processados de maior valor agregado que combina aroma, sabor e elevada pigmentação vermelha de polpa. A combinação destes fatores é essencial para alavancar os produtos derivados de tomate aos níveis de qualidade necessários para atingir nichos de elevado padrão de exigência, tanto no mercado doméstico quanto no exterior (GIORDANO et al., 2005).

\section{COMBATE AOS RADICAIS LIVRES}

As lesões causadas pelos radicais livres nas células podem ser prevenidas ou reduzidas por meio da atividade de antioxidantes, sendo estes encontrados em muitos alimentos, como no caso dos tomates e derivados. Os antioxidantes podem agir diretamente na neutralização da ação dos radicais livres ou participar indiretamente de sistemas enzimáticos com essa função. Dentre os antioxidantes mais conhecidos na literatura, estão a vitamina C, a glutationa, o ácido úrico, a vitamina E e os carotenóides (SHAMI; MOREIRA, 2004).

Os carotenóides são conhecidos por desativar o oxigênio singlete, proporcionando dessa forma proteção contra danos oxidativos celulares. Nem todos os carotenóides são igualmente eficazes como protetores fotoquímicos. O licopeno, muito 
presente no tomate e derivados, é conhecido por ser uma substância eficaz na desativação do oxigênio singlete, em comparação a outros carotenóides (FENNEMA; DAMODARAN; PARKIN, 2018).

\section{CONSIDERAÇÕES FINAIS}

O tomate é uma hortaliça de produção universal rica em suas características nutricionais e bem como suas possibilidades de consumo. Apesar de sua inclusão nas dietas alimentares ter sido percebida com estranheza, seu consumo foi acendido com sua conversão em molho associado a diferentes massas. Atualmente é classificada como a hortaliça mais consumida no mundo, contribuindo para a nutrição humana, devido ser fonte de fibras, sais minerais e principalmente fonte de licopeno, que auxilia no retardo do envelhecimento e na prevenção do câncer.

Podemos encontrar o tomate em forma de pedaços ou de massa como principal ingrediente de saladas, temperos, geléias, tomates secos e molhos que são os mais consumidos devido a facilidade e disponibilidade de uso no mercado. Seja de forma industrializada, seja no modo in natura, o tomate deve ser considerado como um alimento a estar presente nas dietas alimentares, por seu valor nutricional, pela facilidade de inserção em produções e seu consumo.

\section{REFERÊNCIAS}

ARAÚJO, W. M. C. et al. Alquimia dos alimentos. Brasília: Editora Senac, 2011.

BANNWART, G. C. M. C. Aplicação de neotame em catchup: avaliação de desempenho e estimativa de ingestão. Tese (Doutorado em Ciência dos Alimentos) Universidade Estadual de Campinas, Faculdade de Engenharia de Alimentos, 2006.

BARBARA, D.; PAGANO, S. Aromas e sabores da boa lembrança - Tomate. Rio de Janeiro: Senac, 2005.

BELLUZZO, R. Os sabores da América: Cuba, Jamaica, Martinica, México. São Paulo: Senac, 2004.

BÔTO, E. G. et al. Licopeno e prevenção do câncer de próstata: Uma revisão integrativa. International Journal of Nutrology, v. 12, n. 1, p. 002-012, 2019.

BRASIL. Resolução da Diretoria Colegiada - Resolução no. 276 de 22 de setembro de 2005 da ANVISA. Regulamento técnico para especiarias, temperos e molhos. Brasília, 
2005. Disponível em: <https://www.gov.br/agricultura/ptbr/assuntos/inspecao/produtos-vegetal/legislacao-1/biblioteca-de-normasvinhos-e-bebidas/resolucao-rdc-no-276-de-22-de-setembro-de2005.pdf/view>. Acesso em: 23 jun. 2021.

CAMARGO, G. A.; HAJ-ISA, N.; QUEIROZ, M. R. Avaliação da qualidade de tomate seco em conserva. Revista Brasileira de Engenharia Agrícola e Ambiental, v. 11, n. 5, p. 521-526, 2007.

CARVALHO, W. et al. Estimativa indireta de teores de licopeno em frutos de genótipos de tomateiro via análise colorimétrica. Horticultura Brasileira. v. 23, p. 819-825, 2005.

CHITARRA, M. I. F.; CHITARRA, A. B. Pós-colheita de frutos e hortaliças: fisiologia e manuseio. Lavras: ESAL/FAEPE, 1990.

CHOUDHARI, S. M.; ANANTHANARAYAN, L. Enzyme aided extraction of lycopene from tomato tissues. Food Chemistry, v. 102, n. 1, p. 77-81, 2007.

COELHO, K. D. Secagem de tomate (Lycorpesicon esculentum Mill) em camada delgada: avaliação das características físico-químicas. Dissertação (Mestrado em Engenharia e Ciência de Alimentos) - Universidade Federal do Rio Grande, 2010.

COULTATE, T. P. et al. Alimentos: a química de seus componentes. 3 ed. Porto Alegre: Artmed, 2004.

DEVELIN, T. M. Manual de bioquímica: com correlações clínicas. São Paulo: Editora Edgard Blücher. 2002.

DOMENE, S. M. A. Técnica dietética: teoria e aplicações. Rio de janeiro: Guanabara Koogan, 2018.

FAGUNDES, A. F. et al. Influência do grau de umidade na textura de tomate seco refrigerado ou envasado em óleo. Publicatio UEPG: Ciências Exatas e da Terra, Agrárias e Engenharias, v. 11, n. 01, 2005.

FELIPPE, G. Frutas: sabor à primeira dentada. São Paulo: Senac, 2005.

FENNEMA, O. R.; DAMODARAN, S.; PARKIN, K. L. Química de Alimentos de Fennema. 5 ed. Editora Artmed, 2018. 1120 p.

FERREIRA, S. M. R.; FREITAS, R. J. S.; LAZZARI, E. N. Padrão de identidade e qualidade do tomate (Lycopersicon esculentum Mill.) de mesa. Ciência Rural, v. 34, p. 329-335, 2004.

GANN, P. H. et al. Lower prostate cancer risk in men with elevated plasma lycopene levels: results of a prospective analysis. Cancer research, v. 59, n. 6, p. 12251230, 1999. 
GIORDANO, L. B. et al. Seleção de linhagens com tolerância ao calor em germoplasma de tomateiro coletado na Região Norte do Brasil. Horticultura Brasileira, v. 23, n. 1, p. 105-107, 2005.

GISSLEN, W. Culinária profissional. 6 ed. São Paulo: Editora Manole Ltda, 2012.

IBGE. INSTITUTO BRASILEIRO DE GEOGRAFIA E ESTATÍSTICA. Aquisição alimentar domiciliar per capita Brasil e Grandes Regiões. Pesquisa de Orçamentos Familiares 2008-2009. 2010.

JAYARAMAN, K. S.; DAS GUPTA, D. K. Dehydration of fruits and vegetables - recent developments in principles and techniques. Drying Technology, v. 10, n. 1, p. 150, 1992.

LIMA, C. Tachos e panelas: historiografia da alimentação brasileira. 2 ed. Autora, 1999.

LUZ, L. M. Tomates contra o câncer. Disponível em: $<$ http://arrozdoce.wordpress.com//tomates-contra-o-cancer/2008>. Acesso em: 20 ago. 2021.

MAIOR, M. S. Alimentação e folclore. Recife: Fundação Joaquim Nabuco, Editora Massangana, 2013.

McGEE, H. Comida \& Cozinha: ciência e cultura da culinária. São Paulo: WMF Martins Fontes, 2011.

MEDINA, P. V. L.; MEDINA, R. M. T. Descrição bioquímica e fisiológica da maturação dos frutos do tomateiro. Revista Ceres, v. 155, n. 28, p. 1-7, 1981.

MILLER, E. C. et al. Lycopene, tomato products, and prostate cancer prevention. Have we established causality? Pure and Applied Chemistry. v. 74, n. 8, p. 1435-1441, 2002.

ORNELLAS, L. H. Técnica dietética: seleção e preparo de alimentos. São Paulo: Atheneu, 2007.

PEREIRA, S. Processamento de tomates (Lycopersicom escullentun mill), cv. débora cultivados de forma tradicional e orgânica, para obtenção de extratos. Seropédica. Dissertação (Mestrado em Ciências e Tecnologia dos Alimentos) Universidade Federal Rural do Rio de Janeiro, Instituto de Tecnologia, 2007.

REYES, F. G. Umami y glutamato - aspectos químicos, biológicos y tecnológicos. São Paulo: Editora Plêiade, 2013.

SENAI. Centro de Tecnologia de Produtos Alimentares. Processamento de Tomates. 1993.

SHAMI, N. J. I. E.; MOREIRA, E. A. M. Licopeno como agente antioxidante. Revista de Nutrição, v. 17, p. 227-236, 2004. 
SILVA, A. M.; SCHNEIDER, V. C.; PEREIRA, C. A. M. Propriedades Químicas e Farmacológicas do Licopeno. Revista Eletrônica de Farmácia. v. 6, n. 2, 2009.

SILVA, J. B. C.; GIORDANO, L. B. Tomate para processamento industrial. Brasília: Embrapa Comunicação para Transferência de Tecnologia - Embrapa Hortaliças, 2000.

ZAMBON, F. R. A. Comparação dos processos de maturação de tomate (Lycopersicon esculetum, Mill.), Rada, Mutantes Nor e Rin e seus Hibridos F1. Dissertação (Mestrado em Fitotecnia) - Universidade Federal de Viçosa, 1984.

ZAMBRANO, J; MOYEJA, J.; PACHECO, L. Efecto del estado de madurez en la composición y calidad de frutos de tomate. Agronomia Tropical, v. 46, n. 1, p. 61- 72, 1995. 


\section{CAPITULO XIV}

\section{ANTIOXIDANTES NATURAIS COMO ALTERNATIVA PARA AUMENTAR VIDA} DE PRATELEIRA

DOI: 10.51859/AMPLLA.DES1788-14

Susana Luporini de Oliveira ${ }^{1}$

Camila Carlino da Costa ${ }^{1}$

Mayumi Fernanda Aracati ${ }^{2}$

Leticia Franchin Rodrigues ${ }^{2}$

Ives Charlie da Silva ${ }^{3}$

Marco Antonio de Andrade Belo ${ }^{4}$

\footnotetext{
"Mestranda em Medicina Veterinária Preventiva. Universidade Estadual "Júlio de Mesquita Filho" - UNESP/FCAV

2 Doutoranda em Medicina Veterinária Preventiva. Universidade Estadual “Júlio de Mesquita Filho" - UNESP/FCAV

3 Pós doutorando em Farmacologia. Universidade de São Paulo - ICB/USP

${ }^{4}$ Professor Doutor em Medicina Veterinária. Universidade Brasil - UB
}

\section{RESUMO}

A vida de prateleira pode ser definida como o tempo no qual um produto alimentício se mantém seguro e conserva as características sensoriais, químicas e físicas desejadas quando estocado em condições recomendadas. Os processos oxidativos são os principais fatores envolvidos na deterioração do alimento, consequentemente a perda da qualidade do alimento. Atualmente, as indústrias alimentícias têm investido fortemente em produtos saudáveis e seguros. Neste sentido, o uso de antioxidantes é uma das principais estratégias para retardar a deterioração oxidativa e microbiana do alimento. Dentre os principais antioxidantes naturais destaca-se: Astaxantina, Artemisia, Chlorela e Spirulina que estão entre os ingredientes naturais mais incluídos nos produtos alimentícios para aumentar a vida de prateleira.

Palavras-chave: Astaxantina. Artemisia. Chorella. Spiulina. Antioxidante.

\section{INTRODUÇÃO}

O frescor do alimento é um dos parâmetros mais utilizados para a aceitação do consumidor com intuito de obter alimentos de qualidade (HAMDI et al., 2018). Os principais fatores que levam a deterioração microbiológica, alterações físico-químicas e sensoriais são devido o $\mathrm{pH}$, alta atividade de água, temperatura, aminoácidos livres, 
presença de enzimas autolíticas e ácidos graxos (SANTOS et al., 2017) ocasionando a oxidação e consequentemente a perda da qualidade do alimento, influenciando na cor e provocando sabores e odores desagradáveis (SORIANO et al., 2018) acarretando a uma vida útil mais curta (MESSINA et al., 2015).

A oxidação lipídica é considerada um processo inevitável, irreversível e complexo que ocorre em todas as matrizes alimentares, na qual continua a ser uma grande preocupação em termos de perda de qualidade do alimento (CARBALLO et al., 2018). Embora a oxidação lipídica seja a principal reação produzida, sua deterioração é responsável por afetar as proteínas, pigmentos, vitaminas e carboidratos, acarretando em perdas de nutrientes e redução da qualidade organoléptica (SORIANO et al., 2018). Os processos oxidativos são os principais fatores não microbiológicos envolvidos na deterioração do alimento durante o armazenamento refrigerado, na qual são mediados por radicais livres e produzem reações em cadeia que são favorecidas por luz e oxigênio (HAMDI et al., 2018). Como exemplo, temos a carne post-mortem na qual possuem ácidos graxos insaturados que reagem com o oxigênio, formando uma variedade de produtos oxidantes, essa oxidação induz modificações de lipídios e proteínas afetando as propriedades organolépticas e nutricionais, além de acarretar perdas econômicas e distúrbios a saúde, considerados mutagênicos, citotóxicos e carcinogênicos (BUCHANAN \& THOMAS, 2008; CARBALLO et al., 2018).

Atualmente, as indústrias alimentícias têm investido fortemente em produtos saudáveis e seguros. Neste sentido, o uso de antioxidantes é uma das principais estratégias para retardar a deterioração oxidativa e microbiana do alimento (HAMDI et al., 2018). Embora as bactérias tenham um papel considerável no mecanismo da deterioração, para melhores resultados de vida útil é necessário o equilíbrio entre os niveis de oxidação e a ação dos antioxidantes na qual tem a função de inibir a oxidação (BUCHANAN \& THOMAS, 2008). Antioxidantes sintéticos como dióxido de enxofre, butilhidroxitolueno ou butilhidroxianisol são comumente usados para essa finalidade, porém devido aos seus controversos efeitos à saúde, alternativas naturais para sua reposição estão sendo buscadas (CARBALLO et al., 2018). Dentre os principais antioxidantes naturais mais utilizados na indústria alimentícias são, Astaxantina (CARBALLO et al., 2018), Artemisia (SHARAFATI et al., (2014), Chlorela (TEODOSIO et al., 2021) e Spirulina (BARKALLAH et al., 2017) na qual possuem carotenoides, compostos 
fenólicos, fibra dietética, vitaminas e minerais que estão entre os ingredientes naturais mais incluídos nos produtos alimentícios para aumentar a vida de prateleira (HAMDI et al., 2018).

\section{ASTAXANTINA}

A astaxantina pertence a um grupo de carotenóides chamados xantofilas, que incluem $\beta$-criptoxantina, $\beta$-caroteno, licopeno e zeaxantina, se trata de um pigmento oxicarotenóide natural lipossolúvel e vermelho-laranja (CHANG \& XIONG, 2020). Os carotenoides possuem coloração que varia do amarelo ao vermelho intenso compondo uma classe de aproximadamente 600 pigmentos naturais (AGHAJANPOUR et al., 2017).

A astaxantina é procedente do $\beta$-caroteno por 3-hidroxilação e 4-cetolação, e catalisada pela $\beta$-caroteno hidroxilase e $\beta$-caroteno cetolase, respectivamente. (CAI et al., 2019). Sua estrutura molecular e características o torna mais polar e aumenta significativamente sua propriedade antioxidante (CHANG \& XIONG, 2020), sendo assim, sua estrutura possibilita atravessar as membranas lipídicas das células, protegendo-as da oxidação do meio (MATSUSHITA et al., 2000). A astaxantina possui atividades antioxidantes extremamente superiores que demais compostos, sendo 10 vezes mais potente que os carotenoides (luteína e cantaxantina) (IWAMOTO et al., 2000); 40 vezes mais que o $\beta$-caroteno e 100 vezes mais que a vitamina E (FOCSAN et al., 2014).

A astaxantina é proveniente de fontes naturais ou sintéticas. As formas sintéticas podem conter resíduos se tornando prejudiciais à saúde, além disso, sua estabilidade e atividade antioxidante são menores do que as obtidas naturalmente, desse modo não são admitidas em indústrias alimentícias (LIM et al., 2002). Na sua forma natural, a astaxantina é principalmente biossintetizada por microalgas, fitoplâncton, leveduras e bactérias, consequentemente acumulada em zooplâncton, crustáceos e peixes (CHANG \& XIONG, 2020) por estes se alimentarem das algas, acarretando assim um acúmulo do antioxidante no tecido muscular (AMBATI et al., 2014).

Umas das fontes de extração da astaxantina é através da Haematococcus pluvialis uma microalga verde unicelular que tem sido amplamente estudada e valorizada devido a seu importante potencial produtivo como fonte natural de astaxantina (SAHOO et al., 2005; ARACATI et al., 2021). Atualmente, a maior parte da astaxantina disponível no mercado é produzida sinteticamente para uso em rações. 
(SEABRA \& PEDROSA, 2010). A astaxantina sintética (cetoisoforona) obtida do petróleo, produz mais estereoisômeros diferentes do que os encontrados na forma natural. No entanto, estudos mostram que os produtos petroquímicos para a síntese da astaxantina podem causar câncer, sendo assim, apenas a astaxantina natural é aprovada para consumo humano (NGUYEN et al., 2013).

A astaxantina atinge considerável interesse devido aos seus efeitos farmacológicos, acarretando uma forte propriedade antioxidante, reparo do DNA, tolerância ao estresse, regeneração celular, neuroproteção, antiproliferação, antiinflamatório, antiapoptótico, antidiabético, anticâncer e efeitos protetores da pele (YUAN et al., 2011; GALASSO et al., 2018; DAVINELLI et al., 2018).

A astaxantina apresenta a capacidade química e física de inibir a atividade de ERO (espécies reativas de oxigênio) e consequentemente o estresse oxidativo, atuando no sequestro de radicais livres e inativação dos mesmos, com ação inibidora da peroxidação de lipídios e danos causados pela oxidação das membranas celulares e tecidos (AHMADINEJAD et al., 2017). Devido à sua utilização terapêutica, em especial a alta atividade antioxidante, os carotenoides estão dentre os nutracêuticos mais valorizados (LI et al., 2020; ARACATI et al., 2021). É amplamente utilizado na indústria de cosméticos, farmacêutica e na aquicultura, pois confere coloração vermelha a alguns peixes, crustáceos, bem como em aves e micro-organismos (SHAH et al., 2016). Na produção animal, este composto é usado principalmente na composição da ração de galinhas poedeiras, com o objetivo de atribuir mais coloração a gema do ovo, e na ração de peixes para conferir cor à musculatura do pescado, principalmente em salmão tornando-se mais apresentável ao consumidor (FERREIRA et al., 2014). Estudos realizados indicam os benefícios da astaxantina na vida de prateleira, assim como, Carr et al., (2010) ofereceu suplementação com astaxantina natural na dieta de porcos, e obteve resultados positivos na qualidade da carne fresca, com melhor aceitação no varejo, atrasando o processo de oxidação e a superfície de descoloração tornando-as menos amarelada. No estudo de CARBALLO et al., (2018) o efeito antioxidante da astaxantina resultou em melhor estabilidade oxidativa em rissóis de cordeiro cru e cozidos durante o armazenamento refrigerado.

O uso de antioxidantes em alimentos é de extrema importância pois a cor da carne é considerada um dos fatores mais importantes no mercado, já que os 
consumidores relacionam a cor com frescor e salubridade, no estudo de Pogorzelska et al., (2018) foi confirmada o potencial antioxidante do extrato de $H$. pluvialis sobre a carne suína moída durante o armazenamento refrigerado, na qual houve retardo na oxidação lipídica, melhor estabilidade da cor e melhor aceitação. Neste sentido, a oxidação que ocorre nos alimentos pode ser retardada pela adição de antioxidantes, consequentemente aumentando a vida de prateleira.

\section{ARTEMISIA}

As plantas medicinais têm sido utilizadas há muitos anos e desempenham um papel vital na preservação da saúde (BORA \& SHARMA, 2011). Vários tipos de suplementos dietéticos naturais têm sido explorados recentemente como alternativas sustentáveis para o controle de muitas doenças e obtendo bons resultados (BRISIBE et al., 2009).

O gênero Artemisia é amplamente distribuído, pertencentes da família Astraceae (Compositae). Se trata de um gênero heterogêneo composto por mais de 500 diversas espécies distribuídas nas zonas temperadas da Europa, Ásia e América do Norte. Essas espécies são ervas perenes, bienais e anuais ou pequenos arbustos, caule único, atingindo de 2-3m de altura (BORA \& SHARMA, 2011; DONATO et al., 2015).

Em relação a fitoquímica das espécies de Artemisia contêm principalmente terpenóides, flavonóides, cumarinas, ácidos cafeoilquínicos, esteróis e acetilenos. Entre várias espécies de Artemisia, A. absinthium, A. afra, A. annua, $A$. maritima e A. scoparia são especialmente ricas em terpenóides (BORA \& SHARMA, 2011). A artemisinina é uma lactona sesquiterpênica com uma ponte de endoperóxido que é atualmente o composto mais potente e eficaz contra os parasitas do anel de estágio final e trofozoítos de Plasmodium falciparum, o agente causador da malária, na qual Tu (2016) ganhou o Prêmio Nobel de Medicina em 2015 com essa descoberta.

Juntamente com os seus derivados semi-sinteticos preparados tais como: a dihidroartemisinina, o artesunato, artemeter, arteeter, e a artemisinina também exibiu atividades farmacológicas únicas contra uma ampla gama de organismos incluindo Enterobacter e Klebsiella espécies, Streptococcus faecalis, Staphylococcus aureus, Shigella dysenteriae, Escherichia coli e Pneumocystis carinii, que são bactérias extremamente importantes na saúde pública (DONATO et al., 2015). 
A planta vem mostrando uma opção relevante para a terapêutica em diversas doenças e possui uma gama de propriedades, incluindo atividade antibacteriana, antimalárica, antifúngica, antileishmanial, antioxidante, antitumoral e anti-inflamatória (KONKIMALLA et al., 2008; FERREIRA et al., 2010; EFFERTH, 2017). Além de nas últimas décadas o composto também ter sido amplamente utilizado no tratamento de antiúlcera (FOGLIO et al., 2002), antinociceptiva, com envolvimento do sistema opióide (DE FAVERI FAVERO et al., 2014) e anti-HIV (LUBBE et al., 2012). Esse composto pode ser útil como uma alternativa para o tratamento de muitas doenças inflamatórias (FERREIRA et al., 2011; SPRENGER et al., 2015), incluindo atividade imunossupressora tanto "in vitro" quanto "in vivo", além dos efeitos de aumento das espécies reativas de oxigênio (ROS) como efeitos citotóxicos (CHATURVEDI et al., 2010). Diversas pesquisas tem ganhado atenção na atividade antimicrobiana do óleo essencial de Artemisia annua, com forte atividade contra algumas bactérias e fungos Gram-negativos e Gram-positivos (DONATO et al., 2015).

Existe um interesse crescente no uso de fontes naturais ricas em antioxidantes, ou seus extratos, na alimentação animal, com intuito de melhorar a estabilidade oxidativa da carne (FRANZ et al., 2010). De acordo com ZEDAN et al., (2021) usar Artemisia dracunculus como aditivo alimentar pode prolongar a vida útil em iogurte, pois possui atividades antimicrobianas e antioxidantes na qual impedem o crescimento microbiano em alimentos consequentemente melhorando a qualidade do alimento.

No estudo feito por SHARAFATI et al., (2014), utilizar Artemisia dracunculus como conservantes naturais é um método para aumentar a vida útil em hambúrguer bovino, diminuindo a taxa de crescimento de Staphylococcus aureus, além de aumentar o senso de aceitação do produto.

\section{CHLORELA}

Chlorella é uma microalga verde unicelular (Chlorophyta), cocóides esféricas ou elípticas pequenas $(<15 \mu \mathrm{m})$, consideradas uma das mais importantes comercialmente (CHAMPENOIS et al., 2015), presente tanto em água doce quanto marinha, e cresce em quase todas as condições ambientais na terra, desde as terras congeladas da Escandinávia até os solos quentes do deserto do Saara (SAFI et al., 2014). 
Pertencente a classificação cientifica Ordem: Chlorellales, Família: Chlorellaceae, Gênero: Chlorella (SAFI et al., 2014), e diversas espécies tais como C. pyrenoidosa, C. vulgaris, C. ellipsoidea, C. sorokiniana, C. zofingiensis (YUAN et al., 2020).

A produção anual de Chlorella atingiu 2000 t em 2009, e os principais produtores são Japão, Alemanha e Taiwan (SAFI et al., 2014). Anualmente, milhares de toneladas de Chlorella são produzidas no Leste Asiático, nos Estados Unidos e na Europa, e são amplamente vendidas como alimentos suplementares, produtos nutracêuticos ou medicamentos devido ao alto conteúdo nutricional e várias propriedades de promoção da saúde da espécie (YUAN et al., 2020), além de usados para diferentes fins, como tinturas, ração animal, aquicultura e cosméticos (SAFI et al., 2014).

O principal mercado para a Chlorella é a nutrição humana (CHAMPENOIS et al., 2015), nomeada um "alimento verde saudável" pela Organização das Nações Unidas para Agricultura e Alimentação (FAO). Além disso, tem atraído atenção considerável devido ao alto conteúdo de proteínas, fibras dietéticas, lipídios, vitaminas, clorofilas e carotenoides, ademais contém uma grande quantidade de carboidratos, que são um grupo de açúcares redutores de polissacarídeos, na qual em fontes naturais identificadas como tendo uma variedade de benefícios biológicos tais como antidiabéticas, anti-inflamatória, antitumorais, imunomoduladoras e antimicrobianas com nenhuma ou baixa toxicidade, além de auxiliar no tratamento de hipertensão, colite ulcerosa, doença cardiovascular, sendo que o benefício crucial desta microalga é a atividade antioxidante (YUAN et al., 2020).

Os antioxidantes são responsáveis por prolongar ou inibir a oxidação (KASOTE et al., 2015), eliminando o radical estável dentro da ligação de hidrogênio intramolecular (TAKYAR et al., 2019). Os antioxidantes sintéticos são principalmente compostos fenólicos usados na indústria alimentícia, entretanto problemas deletérios à saúde, como câncer e defeitos congênitos, podem ser efeitos indesejáveis do consumo persistente desses antioxidantes e com isso, atualmente é recomendado o uso alternativo de antioxidantes naturais (TAKYAR et al., 2019).

A Chlorella é uma boa fonte de ácidos graxos poliinsaturados (PUFAs) $(38,94 \%)$ e possui 13,32\% dos lipídios totais (BEHESHTIPOUR et al., 2013). A oxidação de PUFAs é uma das razões mais importantes para a deterioração da qualidade dos alimentos, na qual acarreta diretamente na qualidade e vida útil dos alimentos, ocasionando causa 
sabor estranho e gosto rançoso devido à formação de aldeídos e cetonas, reduzindo o valor nutricional pela destruição de ácidos graxos essenciais, vitaminas lipossolúveis e tem efeitos adversos na saúde humana devido à formação de radicais livres (FALOWO et al., 2014). A Chlorella é usada para a prevenção da oxidação de gorduras em produtos alimentícios e foi comprovado que pode atuar no atraso do processo de oxidação de lipídios e manter ou melhorar as propriedades sensoriais de peixes refrigerados (TAKYAR et al., 2019).

Estudos retratam que frutas revestidas com Chlorella sp. durante armazenamento refrigerado, prolongou a vida útil das frutas retardando o amadurecimento, mantendo a firmeza e a cor, tornando mais apresentável ao consumidor (TEODOSIO et al., 2021). Ainda, SHAFIEI \& MOSTAGHIM (2021) mostraram que Filé de vitela (Calf fillet) revestido com Chlorella vulgaris, prolongou a vida de prateleira reduzindo os níveis de pH, TBA (Ácido tiobarbitúrico) e TVB-N (nitrogênio básico volátil total), aumentou índices de textura, reduziu carga microbiana, além de melhorar os scores gerais de aceitabilidade. A adição de microalgas em leite fermentado a fim de aumentar a viabilidade dos probióticos tem sido objeto de pesquisas recentes. Foi atestado que Chlorella afeta não apenas a viabilidade dos probióticos no produto final, mas também os atributos sensoriais deles (BEHESHTIPOUR et al., 2013).

\section{SPIRULINA}

Atualmente tem se aumentado os cuidados associados a saúde e segurança do alimento quanto ao uso de corantes sintéticos. Embora os antioxidantes sintéticos tenham sido utilizados durante anos, como hidroxianisol butilado (BHA) e hidroxitolueno butilado (BHT) para prevenir a oxidação, atualmente eles estão sendo considerados possíveis fatores de riscos à saúde (MORSY et al., 2019). Diversas autoridades como FDA (Food and Drug Administration) e EFSA (European Food Safety Authority) restringiram o uso de corantes sintéticos em alimentos, devido sua alta capacidade cancerígena e indução de reações alérgicas. Assim, as indústrias alimentícias tendem a investir no uso de aditivos naturais (MARTELLI et al., 2014), pois possuem vantagens na segurança, aceitação do consumidor e principalmente propriedades benéficas à saúde (MORSY et al., 2019). 
A Spirulina foi inicialmente classificada no reino vegetal devido sua capacidade de fotossíntese bem como suas riquezas em pigmentos vegetais. Posteriormente, foi incluído no reino bactéria baseado em uma nova compreensão de sua genética, fisiologia e propriedades bioquímicas (ASGHARI et al., 2016). O suplemento dietético Spirulina é obtido através de cianobactérias do gênero Arthrospira (MORSY et al., 2019), pertencente a ampla variedade de espécies eubacterianas classificadas como filo Cyanobacteria, família Spirulinaceae ou Pseudanabaenaceae, reino Bacteria, divisão Cyanobacteria, classe Cyanophyceae e ordem Spirulinales (MARLES et al., 2011).

A Spirulina (Arthrospira platensis) é uma alga azul esverdeada não tóxica, filamentosa, que cresce naturalmente na água doce, marinha ou cultivada, em reservatórios de água alcalina com alto teor de sal em áreas subtropicais e tropicais, incluindo América, México, Ásia e África Central (ASGHARI et al., 2016). Além disso, contém proteínas que consistem em aminoácidos como serina, glicina, arginina, treonina, alanina, tirosina, valina, metionina, cistina, isoleucina, leucina e fenilalanina, também contém pigmentos naturais na forma de betacaroteno, clorofila, xantofila, ficocianina, de modo que funciona como uma fonte de antioxidantes potentes, eliminadores de radicais superóxidos e atividade antimicrobiana (NOORANNISA et al., 2020). Foi comprovado que extrato de Spirulina apresentam atividades antioxidantes superiores ao $\alpha$-tocoferol (WANG et al., 2007).

As tendências biotecnológicas da microalga Spirulina tem sido extensivamente utilizada na medicina e ciência tais como indústrias alimentícias, produtos farmacêuticos, alimentos e aditivos para rações (SARANRAJ \& SIVASAKTHI, 2014). Nos últimos anos, o efeito antioxidante dos extratos de Espirulina foi investigado em linguiça bovina (LUO et al., 2017), em iogurte (BARKALLAH et al., 2017), snacks (LUCAS et al., 2018).

Pesquisas vem crescendo na área de nanotecnologia, pois é uma técnica promissora e vem trazendo grandes benefícios, com intuito de melhorar a segurança alimentar e prolongar a vida útil, dessa forma, foi comprovado que nanoparticulas de Spirulina platensis como antioxidante em azeite obtiveram melhores resultados em comparação ao $\alpha$-tocoferol e ao BHT (hidroxitolueno butilado), retardando a oxidação, melhorando a cor do óleo e consequentemente estendendo a vida útil (até 475 dias a $25^{\circ} \mathrm{C}$ ) (MORSY et al., 2019). Luo et al., (2017) e Takyar et al., (2019) mostraram que 
Spirulina platensis em linguiça e file de truta arco-íris (Oncorhynchus mykiss) respectivamente, obtiveram melhora nas propriedades sensoriais e aceitabilidade geral, além atrasar o processo de oxidação lipídica.

A microalga provou ser um aditivo eficaz e inovador no processamento de iogurtes, tornando-se um excelente antioxidante, corante natural, aromatizante, estabilizante e conservante para melhor aceitabilidade do produto lácteo (BARKALLAH et al., 2017). Além disso, Spirulina sp mostrou capacidade de melhorar a qualidade de alimento de consumo pratico (Snack), através da melhora nutricional, aceitação de índice sensorial, estabilidade física e melhores condições microbiológica, originando-se numa excelente estratégia para aumentar a vida de prateleira (LUCAS et al., 2018).

\section{REFERÊNCIAS}

AGHAJANPOUR, M.; NAZER, M. R.; OBEIDAVI, Z.; AKBARI, M.; EZATI, P.; KOR, N. M. Functional foods and their role in cancer prevention and health promotion: a comprehensive review. American Journal of Cancer Research, v. 7, n. 4, p. 740769, 2017.

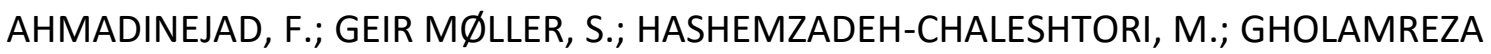
BIDKHORI. G.; JAMI, M. S.; Molecular mechanisms behind free radical scavengers function against oxidative stress. Antioxidants, v. 10, n. 6, p. 51-65, 2017.

AMBATI, R. R.; PHANG, S. M.; RAVI, S.; ASWATHANARAYANA, R. G. Astaxanthin: sources, extraction, stability, biological activities and its commercial applications-a review. Marine drugs, v. 12, n. 1, p. 128-152, 2014.

ARACATI, M. F. Estudo do efeito antioxidante da suplementação alimentar com astaxantina na vida de prateleira de files de tilápias do Nilo (Oreochromis niloticus). Dissertação de Mestrado Programa de Pós-Graduação em Medicina Veterinária, FCAV-UNESP, Jaboticabal, 2021.

ASGHARI, A.; FAZILATI, M.; LATIFI, A. M.; SALAVATI, H.; CHOOPANI, A. A review on antioxidant properties of Spirulina. Journal of Applied Biotechnology Reports, v. 3, n. 1, p. 345-351, 2016.

BARKALLAH, M.; DAMMAK, M.; LOUATI, I.; HENTATI, F.; HADRICH, B.; MECHICHI, T.; ABDELKAFI, S. Effect of Spirulina platensis fortification on physicochemical, textural, antioxidant and sensory properties of yogurt during fermentation and storage. LWT, v. 84, p. 323-330, 2017.

BEHESHTIPOUR, H.; MORTAZAVIAN, A. M.; MOHAMMADI, R.; SOHRABVANDI, S.; KHOSRAVI-DARANI, K. Supplementation of Spirulina platensis and Chlorella 
vulgaris algae into probiotic fermented milks. Comprehensive Reviews in Food Science and Food Safety, v. 12, n. 2, p. 144-154, 2013.

BORA, K. S.; SHARMA, A. The genus Artemisia: a comprehensive review. Pharmaceutical Biology, v. 49, n. 1, p. 101-109, 2011.

BRISIBE, E. A.; UMOREN, U. E.; BRISIBE, F.; MAGALHÄES, P. M.; FERREIRA, J. F.; LUTHRIA, D.; PRIOR, R. L. Nutritional characterisation and antioxidant capacity of different tissues of Artemisia annua L. Food chemistry, v. 115, n. 4, p. 1240-1246, 2009.

BUCHANAN, J. G.; THOMAS, P. M. Improving the color shelf life of farmed southern bluefin tuna (Thunnus maccoyii) flesh with dietary supplements of vitamins $E$ and C and selenium. Journal of Aquatic Food Product Technology, v. 17, n. 3, p. 285302, 2008.

CAI, X.; CHEN, Y.; XIE, X.; YAO, D.; DING, C.; CHEN, M. Astaxanthin prevents against lipopolysaccharide-induced acute lung injury and sepsis via inhibiting activation of MAPK/NF-KB. American journal of translational research, v. 11, n. 3, p. 1884, 2019.

CARBALLO, D. E.; CARO, I.; ANDRÉS, S.; GIRÁLDEZ, F. J.; MATEO, J. Assessment of the antioxidant effect of astaxanthin in fresh, frozen and cooked lamb patties. Food Research International, v. 111, p. 342-350, 2018.

CARR, C. C.; JOHNSON, D. D.; BRENDEMUHL, J. H.; GONZALEZ, J. M. Fresh pork quality and shelf-life characteristics of meat from pigs supplemented with natural astaxanthin in the diet. The Professional Animal Scientist, v. 26, n. 1, p. 18-25, 2010.

CHAMPENOIS, J.; MARFAING, H.; PIERRE, R. Review of the taxonomic revision of Chlorella and consequences for its food uses in Europe. J Appl Phycol v. 27, p. 1845-1851, 2015.

CHANG, M. X.; XIONG, F. Astaxanthin and its effects in inflammatory responses and inflammation-associated diseases: recent advances and future directions. Molecules, v. 25, n. 22, p. 5342, 2020.

CHATURVEDI, D.; GOSWAMI, A.; SAIKIA, P. P.; BARUA, N. C.; RAO, P. G. Artemisinin and its derivatives: a novel class of anti-malarial and anti-cancer agents. Chemical Society Reviews, v. 39, n. 2, p. 435-454, 2010.

DA SILVA SANTOS, F. M.; DA SILVA, A. I. M.; VIEIRA, C. B.; DE ARAÚJO, M. H.; DA SILVA, A. L. C.; DAS GRAÇAS CARNEIRO-DA-CUNHA, M.; DE SOUZA BEZERRA, R. Use of chitosan coating in increasing the shelf life of liquid smoked Nile tilapia (Oreochromis niloticus) fillet. Journal of food science and technology, 54(5), 1304, 2017.

DAVINELLI, S.; NIELSEN, M. E.; SCAPAGNINI, G. Astaxanthin in skin health, repair, and disease: A comprehensive review. Nutrients, v. 10, n. 4, p. 522, 2018. 
DE FAVERI FAVERO, F.; GRANDO, R.; NONATO, F.R.; SOUSA, I. M.; QUEIROZ, N. C.; LONGATO, G. B.; FOGLIO, M. A. Artemisia annua L.: evidence of sesquiterpene lactones' fraction antinociceptive activity. BMC Complementary and Alternative Medicine, v. 14, p. 1-11, 2014.

DONATO, R.; SANTOMAURO, F.; BILIA, A. R.; FLAMINI, G.; SACCO, C. Antibacterial activity of Tuscan Artemisia annua essential oil and its major components against some foodborne pathogens. LWT-Food Science and Technology, n. 64, n. 2, p. 12511254, 2015.

EFFERTH, T. Cancer combination therapies with artemisinin-type drugs. Biochemical pharmacology, v. 139, p. 56-70, 2017.

FALOWO, A. B.; FAYEMI, P. O.; MUCHENJE, V. Natural antioxidants against lipid-protein oxidative deterioration in meat and meat products: A review. Food Research International, v. 64, p. 171-181, 2014.

FERREIRA, J. F.; LUTHRIA, D.L.; SASAKI, T.; HEYERICK, A. Flavonoids from Artemisia annua $L$. as antioxidants and their potential synergism with artemisinin against malaria and cancer. Molecules, v. 15, n. 5, p. 3135-3170, 2010.

FERREIRA, J. F.; PEADEN, P.; KEISER, J. In vitro trematocidal effects of crude alcoholic extracts of Artemisia annua, A. absinthium, Asimina triloba, and Fumaria officinalis. Parasitology research, v. 109, n. 6, p. 1585-1592, 2011.

FERREIRA, M. D. M.; ZAMITH, H. P. D. S.; ABRANTES, S. Astaxanthin: its use as natural food dye. R. Inst. Adolfo Lutz, p. 1-8, 2014.

FOCSAN, A. L.; PAN, S.; KISPERT, L. D. Electrochemical study of astaxanthin and astaxanthin n-octanoic monoester and diester: Tendency to form radicals. The Journal of Physical Chemistry B, v. 118, n. 9, p. 2331-2339, 2014.

FOGLIO, M. A.; DIAS, P. C.; ANTÔNIO, M. A.; POSSENTI, A.; RODRIGUES, R. A. F.; DA SILVA, É. F.; DE CARVALHO, J. E. Antiulcerogenic activity of some sesquiterpene lactones isolated from Artemisia annua. Planta medica. v. 68, n. 6, p. 515-518, 2002.

FRANZ, C.; BASER, K. H. C.; WINDISCH, W. Essential oils and aromatic plants in animal feeding-a European perspective. A review. Flavour and Fragrance Journal, v. 25, n. 5, p. 327-340, 2010.

GALASSO, C.; OREFICE, I.; PELLONE, P.; CIRINO, P.; MIELE, R.; IANORA, A.; SANSONE, C. On the neuroprotective role of astaxanthin: new perspectives?. Marine drugs, $v$. 16, n. 8, p. 247, 2018.

HAMDI, M.; NASRI, R.; DRIDI, N.; MOUSSA, H.; ASHOUR, L.; NASRI, M. Improvement of the quality and the shelf life of reduced-nitrites turkey meat sausages incorporated with carotenoproteins from blue crabs shells. Food Control, v. 91, p. 148-159, 2018. 
IWAMOTO, T.; HOSODA, K.; HIRANO, R.; KURATA, H.; MATSUMOTO, A.; MIKI, W.; KONDO, K. Inhibition of low-density lipoprotein oxidation by astaxanthin. Journal of atherosclerosis and thrombosis, v. 7, n. 4, p. 216-222, 2000.

KASOTE, D. M.; KATYARE, S. S.; HEGDE, M. V.; BAE, H. Significance of antioxidant potential of plants and its relevance to therapeutic applications. International journal of biological sciences, v. 11, n. 8, p. 982, 2015.

KONKIMALLA, V. B.; BLUNDER, M.; KORN, B.; SOOMRO, S. A.; JANSEN, H.; CHANG, W.; EFFERTH, T. Effect of artemisinins and other endoperoxides on nitric oxiderelated signaling pathway in RAW 264.7 mouse macrophage cells. Nitric Oxide. v. 19, n. 2, p. 184-191, 2008.

LI, X.; WANG, X.; DUAN, C.; YI, S.; GAO, Z.; XIAO, C.; LI, J. Biotechnological production of astaxanthin from the microalga Haematococcus pluvialis. Biotechnology Advances, p. 107602, 2020.

LIM, G. B.; LEE, S.; LEE, E.; HAAM, S.; KIM, W. Separation of astaxanthin from red yeast Phaffia rhodozyma by supercritical carbon dioxide extraction. Biochemical Engineering JournaL, v. 11, n. 2-3, p. 181-187, 2002.

LUBBE, A.; SEIBERT, I.; KLIMKAIT, T.; VAN DER KOOY, F. Ethnopharmacology in overdrive: the remarkable anti-HIV activity of Artemisia annua. Journal of ethnopharmacology. v. 141, n. 3, p. 854-859, 2012.

LUCAS, B. F.; DE MORAIS, M. G.; SANTOS, T. D.; COSTA, J. A. V. Spirulina for snack enrichment: Nutritional, physical and sensory evaluations. LWT, v. 90, p. 270276, 2018.

LUO, A.; FENG, J.; HU, B.; LV, J.; CHEN, C. Y. O.; XIE, S. Polysaccharides in Spirulina platensis improve antioxidant capacity of Chinese-style sausage. Journal of food science, v. 82, n. 11, p. 2591-2597, 2017.

MARLES, R. J.; BARRETT, M. L.; BARNES, J.; CHAVEZ, M. L.; GARDINER, P.; KO, R.; GRIFFITHS, J. United States pharmacopeia safety evaluation of Spirulina. Critical reviews in food science and nutrition, v. 51, n. 7, p. 593-604, 2011.

MARTELLI, G.; FOLLI, C.; VISAI, L.; DAGLIA, M.; FERRARI, D. Thermal stability improvement of blue colorant C-Phycocyanin from Spirulina platensis for food industry applications. Process Biochemistry, v. 49, n.1, p. 154-159, 2014.

MATSUSHITA Y. Antioxidant activity of polar carotenoids including astaxanthinBglucoside from marine bacterium on PC liposomes. Fish Sci., v. 66, p. 980-985, 2000.

MESSINA, C. M.; BONO, G.; RENDA, G.; LA BARBERA, L.; SANTULLI, A. Effect of natural antioxidants and modified atmosphere packaging in preventing lipid oxidation 
and increasing the shelf-life of common dolphinfish (Coryphaena hippurus) fillets. LWT-Food Science and Technology, v. 62, n. 1, p. 271-277, 2015.

MORSY, M. K.; MORSY, O. M.; ELBARBARY, H. A.; SAAD, M. A. Enhancing of oxidative stability and quality attributes of olive oil using spirulina (Arthrospira platensis) nanoparticles. LWT, v. 101, p. 444-455, 2019.

NGUYEN K.D. Astaxanthin: A Comparative Case of Synthetic VS. Natural Production. Chemical and Biomolecular Engineering Publications and Other Works. [(accessed on 09 November 2021)]; 2013 Available online: http://trace.tennessee.edu/utk_chembiopubs/94.2013.

NOORANNISA, S.; EKANTARI, N. Stability Of Spirulina platensis Ice Cream and Shelf Life Prediction Using Accelerated Shelf Life Test Method Based On Physical and Antioxidant Analysis. In E3S Web of Conferences (EDP Sciences), v.147, p. 03007, 2020.

POGORZELSKA, E.; GODZISZEWSKA, J.; BRODOWSKA, M.; WIERZBICKA, A. Antioxidant potential of Haematococcus pluvialis extract rich in astaxanthin on colour and oxidative stability of raw ground pork meat during refrigerated storage. Meat science, v. 135, p. 54-61, 2018.

SAFI, C.; ZEBIB, B.; MERAH, O.; PONTALIER, P. Y.; VACA-GARCIA, C. Morphology, composition, production, processing and applications of Chlorella vulgaris: $A$ review. Renewable and Sustainable Energy Reviews, v. 35, p. 265-278, 2014.

SAHOO, P. K.; KUMARI, J.; MISHRA, B. K. Non-specific immune responses in juveniles of Indian major carps. Journal of Applied Ichthyology, v. 21, n. 2, p. 151-155, 2005.

SARANRAJ, P.; SIVASAKTHI, S. Spirulina platensis-food for future: a review. Asian Journal of Pharmaceutical Science and Technology, v. 4, n. 1, p. 26-33, 2014.

SEABRA, L. M. A. J.; PEDROSA, L. F. C. Astaxanthin: structural and functional aspects. Revista de Nutrição, v. 23, p. 1041-1050, 2010.

SHAFIEI, R., \& MOSTAGHIM, T. Improving shelf life of calf fillet in refrigerated storage using edible coating based on chitosan/natamycin containing Spirulina platensis and Chlorella vulgaris microalgae. Journal of Food Measurement and Characterization, p.1-17, 2021.

SHAH, M.; MAHFUZUR, R.; LIANG, Y.; CHENG, J.; DARROCH, M. Astaxanthin-producing green microalga Haematococcus pluvialis: from single cell to high value commercial products. Frontiers in Plant Science, v. 28, n. 7. p. 531, 2016.

SHARAFATI CHALESHTORI, R.; ROKNI, N.; RAFIEIAN-KOPAEI, M.; DERIS, F.; SHARAFATI CHALESHTORI, A.; SALEHI, E. Use of tarragon (Artemisia dracunculus) essential oil as a natural preservative in beef burger. Italian Journal of Food Science, v. 26, n. 4, p. 427-432, 2014. 
SORIANO, A.; ALAÑÓN, M. E.; ALARCÓN, M.; GARCÍA-RUÍZ, A.; DÍAZ-MAROTO, M. C.; PÉREZ-COELLO, M. S. Oak wood extracts as natural antioxidants to increase shelf life of raw pork patties in modified atmosphere packaging. Food Research International, v. 111, p. 524-533, 2018.

SPRENGER, L. K.; BUZATTI, A.; CAMPESTRINI, L. H.; YAMASSAKI, F. T.; MAURER, J. B. B.; BAGGIO, S. F. Z.; MOLENTO, M. B. Atividade ovicida e larvicida do extrato hidroalcoólico de Artemisia annua sobre parasitas gastrintestinais de bovinos. Arquivo Brasileiro de Medicina Veterinária e Zootecnia. v. 67, p. 25-31, 2015.

TAKYAR, M. B. T.; KHAJAVI, S. H.; SAFARI, R. Evaluation of antioxidant properties of Chlorella vulgaris and Spirulina platensis and their application in order to extend the shelf life of rainbow trout (Oncorhynchus mykiss) fillets during refrigerated storage. Lwt, v. 100, p. 244-249, 2019.

TEODOSIO, A. E. M. M.; ARAÚJO, R. H. C. R.; SANTOS, B. G. F. L.; LINNÉ, J. A.; DA SILVA MEDEIROS, M. L.; ONIAS, E. A.; DE LIMA, J. F. Effects of edible coatings of Chlorella sp. containing pomegranate seed oil on quality of Spondias tuberosa fruit during cold storage. Food Chemistry, v. 338, p.127916, 2021.

TU, Y. Artemisinin - a gift from traditional Chinese medicine to the world (Nobel lecture). Angewandte Chemie International Edition, v. 55, n. 35, p. 10210-10226, 2016.

WANG, L.; PAN, B.; SHENG, J.; XU, J.; HU, Q. Antioxidant activity of Spirulina platensis extracts by supercritical carbon dioxide extraction. Food chemistry, v. 105, n. 1, p. 36-41, 2007.

YUAN, J. P.; PENG, J.; YIN, K.; WANG, J. H. Potential health-promoting effects of astaxanthin: a high-value carotenoid mostly from microalgae. Molecular nutrition \& food research, v. 55, n. 1, p. 150-165, 2011.

YUAN, Q.; LI, H.; WEI, Z.; LV, K.; GAO, C.; LIU, Y.; ZHAO, L. Isolation, structures and biological activities of polysaccharides from Chlorella: A review. International Journal of Biological Macromolecules, 2020.

ZEDAN, H.; HOSSEINI, S. M.; MOHAMMADI, A. The effect of tarragon (Artemisia dracunculus) essential oil and high molecular weight Chitosan on sensory properties and shelf life of yogurt. LWT, v. 147, p. 111613, 2021. 


\section{CAPITULO XV I}

\section{ESTUDO DE FATORES RELEVANTES NA MATERIA PRIMA UTILIZADA NA COMPOSIÇÃO DA CARNE MECANICAMENTE SEPARADA DE AVES}

DOI: 10.51859/AMPLLA.DES1788-15

Marcia Scherner ${ }^{1}$

${ }^{1}$ Mestranda em Tecnologia em Alimentos. Programa de Pós-graduação em Alimentos - UTFPR

\section{RESUMO}

A carne mecanicamente separada (CMS) de ave tem sido utilizada pelas indústrias de carne, como matéria-prima para fabricação de produtos derivados. Tal prática tornouse constante e comum nos dias de hoje e, levando em consideração questões produtivas, comportamentais e, até mesmo, pela grande oferta do produto e disponibilidade em nosso país, apresenta perspectiva de crescimento contínuo. Sabese, também, que se trata de uma carne com características extremamente particulares, tanto devido ao seu processo de obtenção, quanto à matéria-prima utilizada para obtêla. O Ministério da Agricultura Pecuária e Abastecimento (MAPA) estabelece as características de qualidade para a CMS, tanto em relação ao seu perfil microbiológico como físico-químico, que deve ser atendido pelos fabricantes com marcas disponíveis no mercado. Nesse sentido, este levantamento visa analisar pontos importantes no contexto de produção e da matéria prima utilizada que podem influência na composição do produto e que possuem pontos importantes que quando corretamente aplicados, auxiliam na produção de CMS dentro dos padrões preconizados através de revisão de literatura de estudos realizados, onde podemos concluir que a composição da matéria prima, o processo produtivo e os equipamentos utilizados são fundamentais para a produção da carne mecanicamente separada.

Palavras-chave: Carne. Frango. Composição físico-química. Matéria-prima. 


\section{INTRODUÇ̃̃o}

O Brasil apresenta atualmente uma posição de destaque na produção e exportação da carne de frango. Em 2019, o Brasil produziu 13,245 milhões de toneladas de carne de frango, sendo o $3^{\circ}$ lugar em produção mundial e exportou 4,2 milhões de toneladas, sendo o maior exportador mundial de carne de frango (Empresa Brasileira de Pesquisa Agropecuária, 2020).

A qualidade da carne de frango no Brasil está totalmente relacionada às boas práticas adotadas nas diferentes etapas do sistema de produção, como bem-estar animal, manejo nutricional de forma correta, já que a alimentação oferecida às aves é composta por excelentes nutrientes, bem como práticas adotadas nas etapas de préabate, como transporte, tempo de descanso, suspensão, imobilização e atordoamento dos animais (GREGORIO et al., 2020).

A carne é um alimento importante, devido a suas características, abrangendo uma grande parte às necessidades nutricionais humanas, sendo fonte de proteínas de alto valor biológico, de vitaminas (principalmente do complexo B) e de minerais, daí sua importância na alimentação humana (GONÇALVES et al., 2009).

Dentro da nova realidade do consumidor na busca por uma alimentação mais saudável, além do fato da sociedade hoje ter um forte esforço no sentido de otimizar processos e minimizar as perdas, diminuir desperdícios, redução de resíduos, faz-se necessária a busca por novas matérias primas, dentre elas destaca-se a produção de carne mecanicamente separada - CMS.

A CMS iniciou a ser produzido no final da década de 50 nos Estados Unidos. 0 surgimento se deu pela preferência dos consumidores por cortes de frangos e filés ao invés dos frangos inteiros. A predileção por cortes de frangos despertou a necessidade de encontrar meios para o aproveitamento de dorsos, pescoços e ossos resultantes da desossa (TRINDADE et al., 2004).

A desossa mecânica é uma tecnologia de processamento industrial usada para a recuperação da carne rica em proteínas das carcaças dos animais. Esse processo envolve a trituração mecânica das carcaças para formar uma pasta de carne e ossos, seguida por passagem da mistura por uma tela fina ou superfície com fendas para separar a carne do resíduo de ossos (WUBSHET et al., 2019) 
Com base na legislação brasileira (Brasil, 2000), a CMS é definida como "a carne obtida por processo mecânico de moagem e separação de ossos de animais de açougue, destinada à elaboração de produtos cárneos industrializados específicos".

Devem ser utilizados unicamente ossos, carcaças ou partes de carcaças de animais de açougue (aves, bovinos e suínos), que tenham sido aprovados para consumo humano pelo Serviço de Inspeção Federal. É vedada a utilização de cabeças, pés e patas das aves (Brasil, 2000).

O grande volume de CMS, a expansão do seu uso em produtos tradicionais como na salsicha, linguiça e hambúrguer; e sua consequente importância econômica, fizeram com que os fabricantes passassem a considerar a separação mecânica não mais como uma operação unitária, mas sim como um processo, no qual há a necessidade da verificação constante da qualidade desse produto.

Por isso se enfoca a necessidade da avaliação físico-química de proteína, gordura, índice de peróxido, cinzas, umidade e cálcio, itens básicos ressaltados como padrões de qualidade pelo Regulamento técnico para fixação de identidade e qualidade de carne mecanicamente separada (CMS) de aves, bovinos e suínos (BRASIL, 2000).

A composição química da carne mecanicamente separada é variável devido à variação natural dentro e entre espécies animais, regimes de dieta, idade dos animais abatidos, pedaços de carne, ossos, pré-tratamento de osso (congelamento) e tipo de máquina no processo de produção. A má instalação do equipamento também pode levar à produção de um tamanho de partícula inaceitável, o que afeta a qualidade dos produtos. Durante a separação mecânica dos ossos da carne, é inevitável que algumas partículas de osso permanecem no produto (TASIC et al., 2017).

Muitos fatores relacionados com equipamento podem afetar a qualidade do produto. Por exemplo, a pressão aplicada sobre a matéria prima, quando aumentada, permite uma maior quantidade de ossos, tendão e outros resíduos não cárneos no produto final, tornando o processo sensivelmente menos eficiente (FRONING; MCKEE, 2001).

Beraquet (2000) e Mori et al., (2006) descrevem que os equipamentos geralmente têm como princípio o uso de dois estágios de compressão: num primeiro estágio o material é submetido a uma pressão suave para remover a carne da superfície dos ossos evitando a incorporação da medula óssea; a carne obtida mantém sua 
integridade e poderia ser considerada carne moída. Num segundo estágio, a carne é comprimida por uma rosca sem fim contra uma peneira similar às máquinas de um estágio só, e a carne obtida é considerada CMS. Esse equipamento tem como rendimento $40 \%$ para operação à baixa pressão e $30 \%$ para operação subsequente à alta pressão, utilizando-se dorsos de frango.

Normalmente a separação mecânica é feita em ossos de forma irregular, mais difícil de ser manualmente desossados, como coluna vertebral e pescoço. Porém, outros ossos com carne presa, ou carcaças inteiras, podem ser submetidos à separação mecânica (TRINDADE et al., 2004).

A relação carne/osso presente na matéria prima, ou seja, a quantidade de carne aderida aos ossos após as operações manuais ou automáticas de desossa, também interfere na composição do produto. Portanto, espera-se que maior proporção de carne retida determine uma CMS com maior teor proteico.

O CMS pode apresentar diversas variações relativa à composição, que ocorrem principalmente devido as matérias-primas como a presença ou ausência de pele e a incorporação da relação carne / osso da desossa mecânica, bem como o tipo de equipamento separador mecânico usado. A pressão exercida durante o processamento do produto, por sua vez, está relacionada ao tipo de equipamento utilizado no processo, sendo que o seu ajuste pode interferir na composição e no rendimento do produto (MELLO et al., 2017).

Durante o processo de produção, importante avaliar as matérias-primas a serem utilizadas, uma vez com quantidade inferior de carne aderida como ossos da coxa, pontas de asa e cartilagem do peito não devem processadas separadamente, uma vez que resultariam em CMS de baixa qualidade. Concomitantemente essas partes são processadas juntamente com o dorso e outros cortes, misturadas evitando afetar a qualidade de CMS produzida (MORI et al., 2006).

O objetivo do estudo foi descrever os fatores do processo produtivo da carne mecanicamente separada que são relevantes para produção dentro dos padrões exigidos na legislação por meio de uma revisão de literatura. 


\section{MATERIAIS E MÉTODOS}

As buscas de artigos para a presente revisão foram realizadas em quatro bases de dados bibliográficas, sendo elas: SciELO (http://www.scielo.org), Science Direct (https://www.sciencedirect.com/), Pubmed (https://pubmed.ncbi.nlm.nih.gov/) Google scholar (https://scholar.google.com.br/). Utilizando a combinação dos termos "Composição da carne mecanicamente separada" em português e inglês. Também foi realizada uma busca manual de publicações com base nas referências bibliográficas listadas nos artigos pesquisados. Este estudo teve como base a pesquisa bibliográfica realizada de forma indireta utilizando fontes secundárias como: legislação, revistas, artigos, teses, dissertações e artigos científicos.

\section{RESULTADOS E DISCUSSAO}

O rendimento da CMS das aves varia de 55 a 70\%. Quanto maior o rendimento maior a porcentagem de cinzas e lipídeos. Desossadores mecânicos podem processar de 230-9100 kg/hora dependendo do tipo e da capacidade do equipamento (FRONING; MCKEE, 2001).

As características sensoriais pertinentes à CMS incluem cor característica, odor característico e textura pastosa. Quanto às características físico-químicas, deve-se considerar a proteína com mínimo de $12 \%$, gordura com o máximo de $30 \%$, teor de cálcio máximo de 1,5\% na base seca e no máximo $1,0 \mathrm{mEq} / \mathrm{Kg}$ de peróxidos (BRASIL, 2000).

Uma série de testes podem ser efetuados para avaliação da qualidade da CMS. Basicamente, a qualidade está ligada a fatores que acarretam influências sensoriais no produto. Muitas vezes, as empresas produtoras de CMS, em função de obter $1 \%$ a $2 \%$ ou mais no rendimento durante a desossa mecânica, obtêm um produto com alto teor de fragmentos ósseos, elevando-se o teor de cálcio (BRASIL, 2000). Ou seja, alto teor de cálcio também é indício de CMS de má qualidade.

A literatura sobre partículas ósseas em CMS é extensa, abrangendo o estudo de quantidades, estruturas e os tamanhos das partículas ósseas, uma vez que são frequentemente considerados indicadores de qualidade de CMS ou de seu uso em produtos processados (EFSA, 2013). No processo de trituração dos ossos, o teor de cálcio 
na CMS pode prejudicar as características tecnológicas, como elasticidade, capacidade de retenção de água, capacidade emulsificante e estabilidade de emulsão, limitando sua utilização como fonte proteica na formulação de produtos industrializados (VICTORINO, 2008)

Nos estudos realizados por Kolsarici et al. (2010) apresentaram os seguintes valores para CMS de diferentes origens: de peito (proteína de 17\%, umidade de $68,8 \%$, gordura de $12,3 \%$, cinzas de $1,5 \%$, ferro de $33,7 \%$ ); de dorso (gordura de $27 \%$, cinzas de 0,9\%, umidade de 59,1\%, proteína de 12,8\%, ferro de 16,1\%); de pescoço (proteína de $12,3 \%$, umidade de $75 \%$, gordura de $11,6 \%$, cinzas de $0,9 \%$, ferro de $20,6 \%$ ). A quantidade de medula óssea em cada produto pode explicar a diferença nos teores de ferro dos itens analisados. Quanto aos teores de ferro e zinco, análises demostram que o CMS de frango é melhor fonte de ferro que a própria carne de frango (GONÇALVES, 2009).

Nas pesquisas realizadas por Chow (2011) utilizando produtos de diferentes empresas, observou-se divergências de padrões de produto em desacordo com a legislação vigente, sendo que produtos da mesma empresa, porém de lotes diferentes, apresentavam diferenças significativas em sua composição, demostrando que as variáveis do processo são fundamentais para a padronização do produto.

\section{CONSIDERAÇÕES FINAIS}

O Brasil possui grande potencial de produção de frango, em constante desenvolvimento e possui muitas práticas de manejo e rígidos controles sanitários tanto dentro como fora das fabricas. A produção de matéria prima é um item fundamental na produção, aumentando o aproveitamento, reduzindo custos e a quantidade de resíduos gerados. Como muitos pontos interferem na produção de CMS, é de fundamental importância um grande conhecimento da matéria prima utilizada, processo e fabricação e regulagem dos equipamentos para confeç̧ão de um produto de qualidade que atenda aos requisitos descritos no Padrão de identidade e qualidade da carne mecanicamente separada. 


\section{REFERÊNCIAS}

BERAQUET, N.J. Carne mecanicamente separada de aves. In: Seminário e curso agregando valor a carne de aves. Campinas: CTC, ITAL, 2000.

BRASIL. Ministério da Agricultura Pecuária e Abastecimento. Secretaria de Defesa Agropecuária. Métodos analíticos físico-químicos para controle de produtos cárneos e seus ingredientes - sal e salmoura. Instrução Normativa n.20 de 21 jul. 1999. Publicado no Diário Oficial, Brasília, 27 jul. 1999.

BRASIL. Ministério da Agricultura Pecuária e Abastecimento. Secretaria de Defesa Agropecuária. Aprova os regulamentos técnicos de identidade e qualidade de carne mecanicamente separada, de mortadela, de linguiça e de salsicha. Instrução Normativa n.4 de 31 mar. 2000 - Anexo I. Publicado no Diário Oficial, Brasília, 05 abr. 2000. Seção 1, p. 6.

CHOW F. C. Avaliação das Características Físico-Químicas e Microbiológicas de Carne Mecanicamente Separada de Frango de Diferentes Marcas Comerciais. Escola de Veterinária da UFMG, 2011. Disponível em http://hdl.handle.net/1843/ALOA8QVL5T.

Empresa Brasileira de Pesquisa Agropecuária. EMBRAPA. Estatística Frango de Corte. Disponível em: <https://www.embrapa.br/suinos-eaves/cias/estatisticas/frangos/mundo>. Acesso em: 26 nov. 2020.

EFSA. European Food Safety Authority. Scientific opinion on the public health risks related to mechanically separated meat (MSM) derived from poultry and swine (pp. 1-78) EFSA J, 11 (2013), p. 3137. Acessado em setembro de 2021. https://efsa.onlinelibrary.wiley.com/doi/10.2903/j.efsa.2013.3137.

FRONING, G.W., McKEE, S.R. Mechanical separation of poultry meat and its use in products. In: SAMS, A.R. (Ed.). Poultry meat processing. Lewis Publishers. Cap. 14, p.243-256, 2001.

GONÇALVES R. M., GONÇALVES, J. R., GONÇALVES, R. M, OLIVEIRA R. R., OLIVEIRA R. A., LAGE M. E. Physical-Chemical Evaluation of and Heavy Metals Contents in Broiler and Beef Mechanically Deboned Meat (Mdm) P. Ciência Animal Brasileira, v. 10, n. 2, p. 553-559, 2009.

GREGÓRIO M. G., DOS SANTOS L. B. A. N., GONÇALVES, A., H. MASCARENHAS, N. M., DA SILVA PAIVA, F. J., MEDEIROS NETO, M. S., F. R. DA SILVA, L. P., N. SILVA, S. Factores que influyen en la calidad de la carne de pollo: una breve revisión. Research, Society and Development, [S. I.], v. 9, n. 9. Disponível em: https://www.rsdjournal.org/index.php/rsd/article/view/6530. Acesso em: 30 aug. 2021.

KOLSARICI N., CANDOGAN K., AKOGLU I.T. Effect of frozen storage on alterations in lipids of mechanically deboned chicken meats. Gida,v. 35,n. 6,p. 403- 410, 2010. 
MELLO M. R. P. A., NETO J. M. M., TORRES E. A. F. S. Application of multivariate analysis to the study of mechanically deboned chicken meat (MDCM). International Food Research Journal, v. 24, n. 3, p. 1102-1109, 2017.

MORI C., GARCIA E. A., ANDRIGHETTO C., PELICIA K. Carne de aves separada mecanicamente (mechanical separated poultry meat). REDVET. Revista Electrónica de Veterinária, v. 7, n. 4, p. 1-6, 2006.

TASIĆ A., KURELJUSIC J., NESIC K., ROKVIC N., VICENTIJEVIC, M. Determination of calcium content in mechanically separated meat. IOP Conference Series: Earth and Environmental Science, v. 85, n. 1, 2017.

TRINDADE M. A., FELÍCIO P. E. DE, CASTILLO C. J. C. Mechanically separated meat of broiler breeder and white layer spent hens. Scientia Agricola, v. 61, n. 2, p. 234239, 2004.

VICTORINO L. D. C. S. Efeito da adição de fibras sobre as propriedades tecnológicas de emulsões com altos teores de carne de frango mecanicamente separada. Dissertação de mestrado, Universidade de Campinas, Campinas, SP, Brasil, 2008.

WUBSHET S. G., WOLD J. P., BOCKER U., SANDEN K.W., AFSETH N. K. Raman spectroscopy for quantification of residual calcium and total ash in mechanically deboned chicken meat. Food Control, v. 95, p. 267-273, 2019. 


\title{
CAPITULO XVI
}

\section{SUPLEMENTOS ALIMENTARES À BASE DE PLANTAS MEDICINAIS: UMA REVISÃO DE LITERATURA NO ÂMBITO DA TOXICOLOGIA CLIINIICA}

\author{
DOI: 10.51859/AMPLLA.DES1788-16
}

\author{
Elayne Barbosa Nunes ${ }^{1}$ \\ Anderson Lopes Pimentel ${ }^{2}$ \\ Maria Júlia Pereira Reis ${ }^{2}$ \\ Arthur Luy Tavares Ferreira Borges ${ }^{2}$ \\ Ariana da Silva Santos ${ }^{2}$ \\ João Victor Lessa de Oliveira ${ }^{2}$ \\ Ticiano Gomes do Nascimento ${ }^{3}$ \\ Maria Aline Barros Fidelis de Moura ${ }^{4}$
}

\footnotetext{
1 Graduanda do curso de Farmácia. Universidade Federal de Alagoas - UFAL

${ }^{2}$ Mestrando(a) em Ciências Farmacêuticas. Programa de Pós-Graduação em Ciências Farmacêuticas - UFAL

${ }^{3}$ Professor Associado IV do Instituto de Ciências Farmacêuticas. Universidade Federal de Alagoas - UFAL

${ }^{4}$ Professora Associada III do Instituto de Ciências Farmacêuticas. Universidade Federal de Alagoas - UFAL
}

\section{RESUMO}

O consumo de suplementos alimentares à base de plantas é uma prática cada dia mais comum, isso está vinculado à ideia de que produtos naturais são isentos de toxicidade. Esta revisão tem como intuito principal avaliar para alertar sobre os possíveis riscos associados ao consumo indiscriminado de suplementos alimentares à base de plantas medicinais. Por meio de pesquisa de campo e análise estatística foram identificadas 11 plantas medicinais mais frequentemente encontradas nos suplementos alimentares comercializados nas lojas de produtos naturais de Maceió-AL e que estão listadas como plantas medicinais na RENAME, RENISUS ou Memento Fitoterápico. Foram selecionados artigos científicos após a busca utilizando os descritores "suplemento", "planta", "erva" e "toxicologia" e em combinação com o nome das espécies de interesse; nas plataformas Google Scholar, PubMed e Web of Science. Os resultados obtidos através da revisão abrangem os riscos toxicológicos clínicos das plantas medicinais encontradas nos suplementos alimentares, sendo a alteração gastrointestinal o principal efeito tóxico relatado. Há nítida necessidade de mais pesquisas sobre a toxicidade de plantas medicinais no uso suplementar, pois os estudos ainda são escassos, inespecíficos e não estão em consonância. Também há poucas informações na literatura a respeito da segurança no uso de preparações contendo misturas destas plantas. Desta forma, tornam-se necessários estudos mais específicos que abordem a toxicidade desses produtos. Não obstante os desafios da pesquisa, conclui-se que este trabalho foi relevante para alertar sobre os riscos toxicológicos do uso não racional de suplementos alimentares à base de plantas medicinais.

Palavras-chave: Plantas medicinais. Toxicidade. Suplementos alimentares. 


\section{INTRODUÇ̃̃o}

Na sociedade moderna as mudanças no estilo de vida têm levado à preocupação com a forma física e a qualidade de vida, sendo que os aspectos físicos se confundem com êxito e felicidade (BAUDRILLARD, 2003 apud KANTIKAS, 2007 p.11), levando ao aumento do consumo indiscriminado de suplementos alimentares por pessoas com diferentes características físicas, na busca de padrões considerados perfeitos (KANTIKAS, 2007).

O usuário de suplementos alimentares no seu comportamento como consumidor apresentou-se como alguém que majoritariamente entende o papel de suplementos, como: 1) suporte à ingestão de nutrientes; 2) suplementos não substituem uma dieta equilibrada; 3) é preciso evitar o consumo excessivo de suplementos; 4) é preciso procurar acompanhamento profissional para iniciar o uso; e 5) suplementos não são considerados remédios (DICKINSON; MACKAY; WONG, 2015). Apesar disto, o uso sem acompanhamento profissional, ou seja, não racional, é elevado.

O uso de plantas e produtos de origem vegetal tem papel importante na cultura da população mundial, desde os tempos remotos são utilizados popularmente para fins preventivos e medicinais, na melhoria da nutrição e do cuidado em saúde. Culturalmente há o hábito de consumo de forma empírica de itens de origem vegetal, que é um comportamento mantido na contemporaneidade, sendo passado por meio das gerações por aqueles que mantêm contato em seu dia-a-dia com a natureza (FIRMO et al., 2011; FRANÇA et al., 2008).

O consumo de produtos à base de plantas medicinais é histórico, entretanto ao longo dos últimos anos o consumo aumentou na população com o objetivo de suplementação nutricional, o uso indiscriminado está aliado à falsa ideia de que produtos naturais são inofensivos à saúde e à constante desinformação passada através das redes sociais (ZAMBON et al., 2018).

O Ministério da Saúde através da RDC N²6, de 13 de maio de 2014, que dispõe sobre o registro de medicamentos fitoterápicos e o registro e a notificação de produtos tradicionais fitoterápicos, define: “Planta medicinal: espécie vegetal, cultivada ou não, utilizada com propósitos terapêuticos" (BRASIL, 2014, p. 4). 
Já de acordo com a RDC no 243, de 26 de julho de 2018 (BRASIL, 2018), que regulamenta os suplementos alimentares, os mesmos podem ser definidos como:

Produto para ingestão oral, apresentado em formas farmacêuticas, destinado
a suplementar a alimentação de indivíduos saudáveis com nutrientes,
substâncias bioativas, enzimas ou probióticos, isolados ou combinados
(BRASIL, 2018, p. 1).

A pesquisa sobre suplementos à base de plantas medicinais deve avançar de modo que o suplemento possua método de produção reprodutível e garantia de segurança e eficácia, em conjunto com informações concretas sobre o uso seguro, os benefícios à saúde e as limitações desses produtos. O rigor na investigação para descobrir e desenvolver medicamentos pode ser aplicado (com pequenos ajustes) à investigação de suplementos alimentares à base de plantas (MIRODDI et al., 2013; VAN BREEMEN, 2015).

A presença de misturas e adulterações deve ser verificada para garantia da qualidade do produto final oferecido ao consumidor, outros fatores que interferem na qualidade são: 1) variação fitoquímica; 2) variação na composição entre as partes da planta; 3) variação na composição dependendo do estágio de desenvolvimento; 4) influências ambientais; 5) plantas selvagens coletadas comparadas às cultivadas; 6) contaminações, a exemplo dos agrotóxicos; 7) colheita; e 8) manuseio pós-colheita (FRANZ et al., 2011).

Reconhece-se que os suplementos alimentares não são medicamentos, no entanto, vale lembrar que os mesmos podem apresentar plantas medicinais que interferem diretamente no organismo, apresentando respostas diferentes a depender de quem faz uso.

A população possui alta confiança em suplementos alimentares à base de plantas por considerarem estes como inofensivos e isentos de atividade biológica, assim o risco de uso inadequado é maior podendo levar aos efeitos indesejados (BROWN, 2017a; FERNANDES, 2017).

Assim, estudos que visem compilar dados acerca de suplementos alimentares, à base de plantas medicinais, e seus usos, são de grande importância para saúde pública, por isso, este trabalho avalia a composição desses suplementos, em termos das plantas medicinais, e a ocorrência de possíveis riscos toxicológicos clínicos decorrentes do uso 
indiscriminado de tais produtos, através de revisão sistemática da literatura, com ênfase para as plantas medicinais encontradas nos produtos comercializados em Maceió-AL.

\section{OBJETIVOS}

Relatar as plantas medicinais encontradas na composição de suplementos alimentares comercializados na cidade de Maceió-AL e avaliar, por meio de revisão sistemática, os possíveis riscos toxicológicos clínicos associados ao consumo não racional desses produtos.

\section{METODOLOGIA}

\subsection{PESQUISA DE MERCADO}

A pesquisa de mercado consistiu em uma pesquisa de campo, onde foram visitadas 4 lojas de produtos naturais da cidade de Maceió a fim de conhecer e listar os suplementos alimentares à base de plantas medicinais comercializados.

A seleção das lojas visitadas considerou aquelas pertencentes às redes comerciais notadamente estabelecidas no mercado de produtos naturais da cidade. Tal escolha teve a intenção de evitar diferenças entre o padrão das lojas, para garantir uma diversidade grande de produtos comercializados, e também abranger diversos padrões socioeconômicos de consumidores.

A lista de suplementos alimentares obtidas a partir da pesquisa de mercado foi tratada e filtrada, de modo a identificar as plantas medicinais presentes nos suplementos. Para caracterizá-las como planta medicinal, foram consideradas aquelas plantas que estivessem elencadas na Relação Nacional de Medicamentos Essenciais (RENAME), Relação Nacional de Plantas Medicinais de Interesse ao SUS (RENISUS) ou no Memento Fitoterápico da Farmacopeia Brasileira.

\subsection{PESQUISA BIBLIOGRÁFICA}

Após coleta e tratamento inicial dos dados, realizou-se pesquisa sistemática na literatura por artigos que abordassem os riscos ou a toxicidade do uso indiscriminado das plantas medicinais presentes nos suplementos alimentares, avaliando se as plantas 
medicinais disponíveis apresentam alguma evidência quanto aos riscos toxicológicos quando consumidas.

A pesquisa bibliográfica foi realizada por meio do acesso Capes nos bancos de dados PubMed e Web of Science, e também no Google Acadêmico, utilizando descritores pré-definidos. Os principais descritores utilizados foram "suplemento", "planta", "erva", "toxicidade" e "toxicologia", utilizados também em inglês e em combinação com o nome científico das espécies citadas neste trabalho.

Nos artigos lidos, buscou-se considerar as referências mais citadas e de maior relevância, como também, excluíram-se artigos sugeridos pelos bancos de dados como sendo semelhantes àqueles já lidos. O critério de inclusão dos artigos foi à presença de mais de um dos descritores utilizados para a busca. Foram analisados, respectivamente, os títulos, os resumos e posteriormente o texto completo para proceder à escolha dos artigos que constam nesta revisão.

\subsection{RESULTADOS}

\subsubsection{DISPOSICÃO DOS DADOS}

Os dados obtidos através de pesquisa bibliográfica foram representados em quadro.

\subsubsection{ANÁLISE ESTATISTICA}

A metodologia utilizada para a análise dos dados fez uso da ferramenta Excel versão 2013 para elaboração de quadro.

\section{RESULTADOS}

Considerando o estilo de vida contemporâneo, em termos da aparência do corpo, ao longo dos anos cada vez mais busca-se resultados estéticos mais rápidos e muitas vezes faz-se uso de recursos que auxiliam no decorrer do processo, por conseguinte o mercado de produtos à base de plantas voltado à suplementação alimentar tem grande representatividade nas vendas de produtos naturais (FERNANDES, 2017; MONTEIRO, 2008).

Durante a pesquisa em lojas de produtos naturais foi possível encontrar diversos produtos que continham plantas em sua composição. A partir da análise inicial dos 
dados surgiu a curiosidade sobre a toxicidade dessas plantas, especialmente pela presença de misturas dessas plantas nas composições dos suplementos. Diante da filtragem voltada às plantas medicinais, descrita anteriormente, foram escolhidas 11 plantas.

A partir da revisão sistemática acerca das plantas medicinais no âmbito da toxicologia clínica, os dados foram compilados no Quadro 1, que representa os elementos fundamentais de interesse deste estudo, a saber: 1) nome (popular e científico) das plantas medicinais encontradas nos suplementos alimentares objeto de análise deste trabalho; 2) ocorrência destas plantas nas listas oficiais de plantas medicinais brasileiras (RENAME, RENISUS ou Memento Fitoterápico); 3) informações referentes à toxicidade dessas plantas; e 4) referências científicas que relatam os possíveis efeitos tóxicos (BRASIL, 2009, 2016, 2020).

Quadro 1 - Plantas medicinais encontradas na composição de suplementos alimentares comercializados em Maceió-AL e seus possíveis efeitos tóxicos clínicos.

\begin{tabular}{|c|c|c|c|c|c|c|}
\hline $\begin{array}{c}\text { NOME } \\
\text { POPULAR }\end{array}$ & $\begin{array}{c}\text { NOME } \\
\text { CIENTÍFICO }\end{array}$ & RENISUS & RENAME & $\begin{array}{c}\text { MEMENTO } \\
\text { FITOTERÁPICO }\end{array}$ & TOXICIDADE & REFERÊNCIAS \\
\hline & & & & & & (ALVES, 2017; BRAI; \\
ADISA; ODETOLA, \\
2014; BRAl; ODETOLA; \\
AGOMO, 2007; \\
CREDIDIO, 2010; \\
\end{tabular}




\begin{tabular}{|c|c|c|c|c|c|c|}
\hline $\begin{array}{c}\text { NOME } \\
\text { POPULAR }\end{array}$ & \begin{tabular}{|c|} 
NOME \\
CIENTí́FICO
\end{tabular} & RENISUS & RENAME & $\begin{array}{c}\text { MEMENTO } \\
\text { FITOTERÁPICO }\end{array}$ & TOXICIDADE & REFERÊNCIAS \\
\hline & & & & & $\begin{array}{c}\text { Alteração } \\
\text { eletrolítica } \\
\text { (desidratação e } \\
\text { perda de } \\
\text { eletrólitos) }\end{array}$ & \multirow[t]{2}{*}{$\begin{array}{c}\text { FOOD SAFETY } \\
\text { AUTHORITY (EFSA), } \\
\text { 2009; MONTEIRO, } \\
\text { 2008) }\end{array}$} \\
\hline & & & & & Hepatotoxicidade. & \\
\hline \multirow[b]{2}{*}{$\begin{array}{c}\text { Castanha } \\
\text { de Caju }\end{array}$} & \multirow[b]{2}{*}{$\begin{array}{l}\text { Anacardium } \\
\text { occidentale }\end{array}$} & \multirow[b]{2}{*}{$\mathrm{x}$} & \multirow[b]{2}{*}{---} & \multirow[b]{2}{*}{---} & Reação alérgica & \multirow{2}{*}{\begin{tabular}{|c} 
(CLARK; \\
ANAGNOSTOU; EWAN, \\
2007; INOUE et al., \\
2018; NOGUEIRA \\
DIÓGENES et al., 2002; \\
VAN DER VALK et al., \\
2014)
\end{tabular}} \\
\hline & & & & & Risco ocupacional & \\
\hline \multirow{6}{*}{ Cavalinha } & \multirow{6}{*}{$\begin{array}{c}\text { Equisetum } \\
\text { arvense }\end{array}$} & \multirow{6}{*}{$\mathrm{X}$} & \multirow{6}{*}{---} & \multirow{6}{*}{$\mathrm{x}$} & $\begin{array}{c}\text { Alteração } \\
\text { eletrolítica } \\
\text { (hipocalemia) }\end{array}$ & \multirow{6}{*}{$\begin{array}{c}\text { (ALVES, 2018; BRASIL, } \\
2010,2016)\end{array}$} \\
\hline & & & & & $\begin{array}{l}\text { Alteração } \\
\text { cardiovascular } \\
\text { (bloqueio } \\
\text { atrioventricular } \\
\text { transitório) }\end{array}$ & \\
\hline & & & & & $\begin{array}{c}\text { Alteração } \\
\text { gastrointestinal }\end{array}$ & \\
\hline & & & & & $\begin{array}{c}\text { Reações alérgicas } \\
\text { (alergia rara pode } \\
\text { acometer } \\
\text { pacientes } \\
\text { sensíveis à } \\
\text { nicotina.) } \\
\end{array}$ & \\
\hline & & & & & $\begin{array}{l}\text { Alterações } \\
\text { hemato- } \\
\text { bioquímicas }\end{array}$ & \\
\hline & & & & & $\begin{array}{c}\text { Deficiência } \\
\text { nutricional } \\
\text { (vitamina B1) }\end{array}$ & \\
\hline $\begin{array}{l}\text { Erva de } \\
\text { Bugre }\end{array}$ & $\begin{array}{l}\text { Casearia } \\
\text { sylvestris }\end{array}$ & $x$ & -- & --- & --- & $\begin{array}{l}\text { (ALBANO et al., 2013; } \\
\text { AMENI et al., 2015; } \\
\text { BRASIL, 2010; BUENO } \\
\text { et al., 2021; DE } \\
\text { CAMPOS et al., 2015; } \\
\text { FERREIRA et al., 2011; } \\
\text { SPÓSITO et al., 2019) }\end{array}$ \\
\hline $\begin{array}{c}\text { Espinheira } \\
\text { Santa }\end{array}$ & $\begin{array}{l}\text { Maytenus } \\
\text { ilicifolia }\end{array}$ & $\mathrm{x}$ & $\mathrm{x}$ & $\mathrm{x}$ & $\begin{array}{l}\text { Secura e gosto } \\
\text { estranho na boca } \\
\text { e náuseas }\end{array}$ & $\begin{array}{l}\text { (BRASIL, 2010, 2016; } \\
\text { ECKER et al., 2017; } \\
\text { SIMÕES et al., 2017; } \\
\text { TABACH; DUARTE- } \\
\text { ALMEIDA; CARLINI, } \\
\text { 2017; WONFOR et al., } \\
\text { 2017) }\end{array}$ \\
\hline
\end{tabular}




\begin{tabular}{|c|c|c|c|c|c|c|}
\hline $\begin{array}{c}\text { NOME } \\
\text { POPULAR }\end{array}$ & $\begin{array}{c}\text { NOME } \\
\text { CIENTíFICO }\end{array}$ & RENISUS & RENAME & $\begin{array}{c}\text { MEMENTO } \\
\text { FITOTERÁPICO }\end{array}$ & TOXICIDADE & REFERÊNCIAS \\
\hline Gengibre & $\begin{array}{l}\text { Zingiber } \\
\text { officinale }\end{array}$ & $X$ & --- & $X$ & --- & $\begin{array}{l}\text { (AHMED et al., 2018; } \\
\text { BRASIL, 2010, 2016; } \\
\text { DENG et al., 2019; } \\
\text { KATO et al., 2006; LI et } \\
\text { al., 2021; MANENTI, } \\
\text { 2010; } \\
\text { PLENGSURIYAKARN; } \\
\text { NA-BANGCHANG, } \\
\text { 2020; RONDANELLI et } \\
\text { al., 2017; STANISIERE; } \\
\text { MOUSSET; LAFAY, } \\
\text { 2018) }\end{array}$ \\
\hline Hortelã & $\begin{array}{l}\text { Mentha } \\
\text { piperita }\end{array}$ & $x$ & $x$ & --- & --- & $\begin{array}{c}\text { (BRASIL, 2010; } \\
\text { CASTILLO-JUÁREZ et } \\
\text { al., 2009; LÓPEZ et al., } \\
\text { 2010; SIMÕES et al., } \\
\text { 2017) }\end{array}$ \\
\hline Maracujá & $\begin{array}{c}\text { Passiflora } \\
\text { spp }\end{array}$ & $x$ & --- & $x$ & $\begin{array}{c}\text { Estado psicológico } \\
\text { alterado } \\
\text { (sonolência) }\end{array}$ & $\begin{array}{l}\text { (BRASIL, 2010; } \\
\text { MONTEIRO, 2008; } \\
\text { PINTO, 2013) }\end{array}$ \\
\hline \multirow[t]{2}{*}{ Soja } & \multirow[t]{2}{*}{ Glycine max } & \multirow[t]{2}{*}{$x$} & \multirow[t]{2}{*}{$x$} & \multirow[t]{2}{*}{$x$} & $\begin{array}{c}\text { Alteração } \\
\text { gastrointestinal } \\
\text { (constipação, } \\
\text { flatulência e } \\
\text { náusea) }\end{array}$ & \multirow[t]{2}{*}{$\begin{array}{c}\text { (BRASIL, 2016; LIU et } \\
\text { al., 2014) }\end{array}$} \\
\hline & & & & & $\begin{array}{l}\text { Hipotireoidismo } \\
\text { (inibe a síntese de } \\
\text { tiroxina) }\end{array}$ & \\
\hline
\end{tabular}

*X: Está presente na referida lista (Renisus, Rename ou Memento Fitoterápico)

**---: Não está presente na referida lista (Renisus, Rename ou Memento Fitoterápico)

Fonte: Autoria própria.

Diante da compilação dos dados, observou-se que alguns suplementos alimentares possuem em sua composição plantas com atividade biológica considerável e com evidências de possíveis efeitos tóxicos. No entanto, é importante considerar que frequentemente plantas são consideradas pela população como sendo isentas de efeitos tóxicos e assim são utilizadas de forma não racional, podendo haver alguns problemas relacionados, como sobredose, uso concomitante com outras plantas ou até mesmo a associação com medicamentos, desconsiderando tais riscos toxicológicos (REIS et al., 2021).

Quanto à toxicidade clínica das plantas elencadas neste trabalho prevaleceu as alterações gastrointestinais, sendo referidas em 4 plantas medicinais dentre as 11 investigadas. 
Esta pesquisa serve de alerta aos profissionais de saúde, especialmente, nutricionistas, médicos, farmacêuticos e outros profissionais prescritores de suplementos e plantas medicinais, sobre a necessidade de investigar e orientar o uso racional pela população, podendo ser usado para futuras ações de educação em saúde e como norteador para pesquisas futuras mais abrangentes, as quais devem preencher lacunas existentes.

\section{CONSIDERAÇÕES FINAIS}

Tendo em vista a importância atual do mercado de produtos naturais, esta revisão de literatura trouxe para debate os riscos toxicológicos decorrentes do uso indiscriminado de suplementos alimentares à base de plantas medicinais, com ênfase àqueles comercializados em grandes lojas de produtos naturais na cidade de MaceióAL.

Constantemente os produtos naturais são vendidos como sendo livres de reações adversas, o que é preocupante, de modo que o presente estudo visou evidenciar os possíveis riscos toxicológicos dos suplementos alimentares à base de plantas medicinais.

Com base na Política Nacional de Plantas Medicinais e Fitoterápicos (BRASIL, 2006), sabe-se que as plantas podem ser um complemento às terapias farmacológicas convencionais, podem ser utilizadas como alimentos funcionais ou também como nutracêuticos, entretanto, deve-se sempre destacar a importância do uso racional de suplementos à base de plantas medicinais, visto que a toxicidade causada por eles é, em sua maioria, gerada pelo uso incorreto. Uma avaliação adequada dos riscos pode tornar a inclusão dos suplementos alimentares à base de plantas viável e benéfica, no entanto, a suplementação deve avaliar a relação risco/benefício e em caso de qualquer risco ao paciente o uso deve ser evitado.

Apesar da escassez de estudos que investigam a toxicologia de plantas medicinais utilizadas de forma suplementar, se comparados aos estudos sobre produtos sintéticos, esta apresenta-se como uma área bastante promissora para novas pesquisas no âmbito da toxicologia. Não obstante os desafios da pesquisa, é plausível dizer que o atual trabalho contribuiu para desmitificar a máxima de que plantas seriam isentas de riscos toxicológicos. 


\section{REFERÊNCIAS}

AHMED, S. M. et al. The use of medicinal plants by pregnant women in Africa: A systematic review. Journal of Ethnopharmacology, v. 224, n. January, p. 297313, out. 2018.

ALBANO, M. N. et al. Anti-inflammatory and antioxidant properties of hydroalcoholic crude extract from Casearia sylvestris Sw. (Salicaceae). Journal of Ethnopharmacology, v. 147, n. 3, p. 612-617, jun. 2013.

ALVES, C. A. DE L. Revisão bibliográfica sobre caracterização de fitoterápicos com potencial de uso para emagrecimento. Brasília: Universidade de Brasília, 2018.

ALVES, L. V. Efeitos da suplementação com óleo de abacate em camundongos swiss jovens submetidos à natação. Cuiabá: Universidade Federal de Mato Grosso, 2017.

AMENI, A. Z. et al. Toxicity study about a medicinal plant Casearia sylvestris: A contribution to the Brazilian Unified Health System (SUS). Journal of Ethnopharmacology, v. 175, p. 9-13, 2015.

BRAI, B.; ADISA, R.; ODETOLA, A. Hepatoprotective Properties Of Aqueous Leaf Extract Of Persea Americana, Mill (Lauraceae) 'Avocado' Against $\mathrm{Ccl}_{4}$-Induced Damage In Rats. African Journal of Traditional, Complementary and Alternative Medicines, v. 11, n. 2, p. 237, 1 jul. 2014.

BRAI, B. I. C.; ODETOLA, A. A.; AGOMO, P. U. Hypoglycemic and Hypocholesterolemic Potential of Persea americana Leaf Extracts. Journal of Medicinal Food, v. 10, n. 2, p. 356-360, jun. 2007.

BRASIL. Política Nacional de Plantas Medicinais e Fitoterápicos. . 2006, p. 1-60.

BRASIL. RENISUS - Relação Nacional de Plantas Medicinais de Interesse ao SUSBrasília, 2009.

em:

<http://portal.saude.gov.br/portal/arquivos/pdf/RENISUS.pdf >

BRASIL. Anexo I da Resolução da Diretoria Colegiada - RDC $n^{\circ} 10$, de 09 de março de 2010. . 2010.

BRASIL. Resolução de Diretoria Colegiada - RDC n 26 de 13 de maio de 2014. . 2014.

BRASIL. Memento Fitoterápico da Farmacopeia Brasileira. 1. ed. Brasília: [s.n.].

BRASIL. Resolução Da Diretoria Colegiada - RDC n² 243, de 26 de Julho de 2018. . 2018, p. 100.

BRASIL. RENAME - Relação Nacional de Medicamentos Essenciais. Brasília: [s.n.]. 
BROWN, A. C. An overview of herb and dietary supplement efficacy, safety and government regulations in the United States with suggested improvements. Part 1 of 5 series. Food and Chemical Toxicology, v. 107, p. 449-471, 2017a.

BROWN, A. C. Liver toxicity related to herbs and dietary supplements: Online table of case reports. Part 2 of 5 series. Food and Chemical Toxicology, v. 107, p. 472501, 2017b.

BUENO, P. C. P. et al. Infraspecific Chemical Variability and Biological Activity of Casearia sylvestris from Different Brazilian Biomes. Planta Medica, v. 87, n. 01/02, p. 148159, 21 fev. 2021.

CASTILLO-JUÁREZ, I. et al. Anti-Helicobacter pylori activity of plants used in Mexican traditional medicine for gastrointestinal disorders. Journal of Ethnopharmacology, v. 122, n. 2, p. 402-405, mar. 2009.

CLARK, A. T.; ANAGNOSTOU, K.; EWAN, P. W. Cashew nut causes more severe reactions than peanut: case-matched comparison in 141 children. Allergy, v. 62, n. 8, p. 913-916, ago. 2007.

CREDIDIO, E. V. Estudo do efeito do abacate nos lipídeos sanguíneos em humanos. Campinas: UNICAMP - Universidade Estadual de Campinas, 2010.

DE CAMPOS, E. P. et al. Healing activity of Casearia sylvestris Sw. in second-degree scald burns in rodents. BMC Research Notes, v. 8, n. 1, p. 269, 26 dez. 2015.

DEMARQUE, D. P. et al. Cytotoxicity of Structurally Diverse Anthranoids and Correlation with Mechanism of Action and Side Effects. Journal of Pharmacy \& Pharmaceutical Sciences, v. 21, p. 347-353, 10 set. 2018.

DENG, X. et al. Promotion of Mitochondrial Biogenesis via Activation of AMPK-PGC1a Signaling Pathway by Ginger ( Zingiber officinale Roscoe) Extract, and Its Major Active Component 6-Gingerol. Journal of Food Science, v. 84, n. 8, p. 2101-2111, ago. 2019.

DICKINSON, A.; MACKAY, D.; WONG, A. Consumer attitudes about the role of multivitamins and other dietary supplements: Report of a survey. Nutrition Journal, v. 14, n. 1, p. 1-5, 2015.

ECKER, A. et al. Safety evaluation of supratherapeutic dose of Maytenus ilicifolia Mart. ex Reissek e xtracts on fertility and neurobehavioral status of male and pregnant rats. Regulatory Toxicology and Pharmacology, v. 90, p. 160-169, nov. 2017.

EUROPEAN FOOD SAFETY AUTHORITY (EFSA). Compendium of botanicals that have been reported to contain toxic, addictive, psychotropic or other substances of concern. EFSA Journal, v. 7, n. 9, set. 2009. 
EUROPEAN FOOD SAFETY AUTHORITY (EFSA). Compendium of botanicals reported to contain naturally occuring substances of possible concern for human health when used in food and food supplements. EFSA Journal, v. 10, n. 5, p. 2663, maio 2012.

FERNANDES, J. J. C. M. Plantas Usadas No Emagrecimento. Lisboa: Universidade de Lisboa, 2017.

FERREIRA, P. M. P. et al. Folk uses and pharmacological properties of Casearia sylvestris: a medicinal review. Anais da Academia Brasileira de Ciências, v. 83, n. 4, p. 1373-1384, 7 out. 2011.

FIRMO, W. DA C. A. et al. Contexto histórico, uso popular e concepção científica sobre plantas medicinais. Cadernos de Pesquisa, v. 18, 2011.

FRANÇA, I. S. X. DE et al. Medicina popular: benefícios e malefícios das plantas medicinais. Revista Brasileira de Enfermagem, v. 61, n. 2, p. 201-208, abr. 2008.

FRANZ, C. et al. Botanical species being used for manufacturing plant food supplements (PFS) and related products in the EU member states and selected third countries. Food and Function, v. 2, n. 12, p. 720-730, 2011.

INOUE, T. et al. Risk Factors and Clinical Features in Cashew Nut Oral Food Challenges. International Archives of Allergy and Immunology, v. 175, n. 1-2, p. 99-106, 2018.

KANTIKAS, M. DAS G. DE L. Avaliação do uso de suplementos nutrionais à base de soro bovino pelos praticantes de musculação em academias da cidade de CuritibaPR. Curitiba: Universidade Federal do Paraná, 2007.

KATO, A. et al. Inhibitory Effects of Zingiber officinale Roscoe Derived Components on Aldose Reductase Activity in Vitro and in Vivo. Journal of Agricultural and Food Chemistry, v. 54, n. 18, p. 6640-6644, 1 set. 2006.

KOUAMÉ, N. M. et al. Comparative Antidiabetic Activity of Aqueous, Ethanol, and Methanol Leaf Extracts of Persea americana and Their Effectiveness in Type 2 Diabetic Rats. Evidence-Based Complementary and Alternative Medicine, v. 2019, p. 1-14, 16 out. 2019.

LI, X. et al. Zingiberis Rhizoma Recens: A Review of Its Traditional Uses, Phytochemistry, Pharmacology, and Toxicology. Evidence-Based Complementary and Alternative Medicine, v. 2021, p. 1-20, 2 mar. 2021.

LIMA, C. R. et al. Anti-diabetic activity of extract from Persea americana Mill. leaf via the activation of protein kinase $B$ (PKB/Akt) in streptozotocin-induced diabetic rats. Journal of Ethnopharmacology, v. 141, n. 1, p. 517-525, 2012. 
LIU, Z. et al. Whole soy, but not purified daidzein, had a favorable effect on improvement of cardiovascular risks: A 6-month randomized, double-blind, and placebocontrolled trial in equol-producing postmenopausal women. Molecular Nutrition \& Food Research, v. 58, n. 4, p. 709-717, abr. 2014.

LÓPEZ, V. et al. Neuroprotective and neurochemical properties of mint extracts. Phytotherapy Research, v. 24, n. 6, p. 869-874, jun. 2010.

MANENTI, A. V. Plantas Medicinais Utilizadas No Tratamento Da Obesidade : Uma Revisão. Criciúma: UNESC - Universidade do Extremo Sul Catarinense, 2010.

MIRODDI, M. et al. Research and development for botanical products in medicinals and food supplements market. Evidence-based Complementary and Alternative Medicine, v. 2013, 2013.

MONTEIRO, A. R. M. Produtos à base de plantas dispensados em ervanárias para o emagrecimento: efeitos terapêuticos, toxicologia e legislação. Porto: Universidade do Porto, 2008.

NASCIMENTO, M. R. F. “Caracterização e aproveitamento das farinhas dos caroços de abacate (Persea gratíssima gaertner f.), jaca (Artocarpus heterophyllus I.) e seriguela (Spondias purpúrea I.) para elaboração de biscoitos tipo cookies". Rio de Janeiro: UFRRJ - Universidade Federal Rural do Rio de Janeiro, 2014.

NOGUEIRA-DE-ALMEIDA, C. A. et al. Perfil nutricional e benefícios do azeite de abacate (Persea americana ): uma revisão integrativa. Brazilian Journal of Food Technology, v. 21, n. 0,18 out. 2018.

NOGUEIRA DIÓGENES, M. J. et al. Paronychia in cashew nut industry workers. Contact Dermatitis, v. 47, n. 2, p. 109-125, 8 ago. 2002.

NOGUEIRA, N. P. A. et al. In vitro and in vivo toxicological evaluation of extract and fractions from Baccharis trimera with anti-inflammatory activity. Journal of Ethnopharmacology, v. 138, n. 2, p. 513-522, nov. 2011.

PINEDA-LOZANO, J. E.; MARTÍNEZ-MORENO, A. G.; VIRGEN-CARRILLO, C. A. The Effects of Avocado Waste and Its Functional Compounds in Animal Models on Dyslipidemia Parameters. Frontiers in Nutrition, v. 8, n. February, 16 fev. 2021.

PINTO, D. C. M. A Fitoterapia no tratamento da obesidade. Porto: Universidade Fernando Pessoa, 2013.

PLENGSURIYAKARN, T.; NA-BANGCHANG, K. Preclinical Toxicology and Anticholangiocarcinoma Activity of Oral Formulation of Standardized Extract of Zingiber Officinale. Planta Medica, v. 86, n. 02, p. 104-112, 27 jan. 2020. 
REIS, M. J. P. et al. ESTUDO DAS PLANTAS DA RENAME NO ÂMBITO DA TOXICOLOGIA CLÍNICA : UMA REVISÃO SISTEMÁTICA DA LITERATURA. Revista Humanidades e Inovação, v. 8, 2021.

RONDANELLI, M. et al. The effect and safety of highly standardized Ginger ( Zingiber officinale) and Echinacea ( Echinacea angustifolia ) extract supplementation on inflammation and chronic pain in NSAIDs poor responders. A pilot study in subjects with knee arthrosis. Natural Product Research, v. 31, n. 11, p. 13091313, 3 jun. 2017.

SALGADO, J. M. et al. O óleo de abacate (Persea americana Mill) como matéria-prima para a indústria alimentícia. Ciência e Tecnologia de Alimentos, v. 28, n. 3, p. 2026, dez. 2008.

SILVA, M. E. M. DA. Estudo de plantas medicinais utilizadas popularmente no tratamento do obesidade em Araranguá. Araranguá: UFSC - Universidade Federal de Santa Catarina, 2013.

SILVEIRA RABELO, A. C.; CALDEIRA COSTA, D. A review of biological and pharmacological activities of Baccharis trimera. Chemico-Biological Interactions, v. 296, n. April, p. 65-75, dez. 2018.

SIMÕES, C. M. O. et al. Farmacognosia: do produto natural ao medicamento. Porto Alegre: [s.n.].

SOLÍS-SALAS, L. M. et al. Antibacterial Potential by Rupture Membrane and Antioxidant Capacity of Purified Phenolic Fractions of Persea americana Leaf Extract. Antibiotics, v. 10, n. 5, p. 508, 29 abr. 2021.

SPÓSITO, L. et al. In vitro and in vivo anti-Helicobacter pylori activity of Casearia sylvestris leaf derivatives. Journal of Ethnopharmacology, v. 233, n. October 2018, p. 1-12, abr. 2019.

STANISIERE, J.; MOUSSET, P.-Y.; LAFAY, S. How Safe Is Ginger Rhizome for Decreasing Nausea and Vomiting in Women during Early Pregnancy? Foods, v. 7, n. 4, p. 50, 1 abr. 2018.

TABACH, R.; DUARTE-ALMEIDA, J. M.; CARLINI, E. A. Pharmacological and Toxicological Study of Maytenus ilicifolia Leaf Extract Part II-Clinical Study (Phase I). Phytotherapy Research, v. 31, n. 6, p. 921-926, jun. 2017.

VAN BREEMEN, R. B. Development of Safe and Effective Botanical Dietary Supplements. Journal of Medicinal Chemistry, v. 58, n. 21, p. 8360-8372, 12 nov. 2015.

VAN DER VALK, J. P. M. et al. Systematic review on cashew nut allergy. Allergy, v. 69, n. 6, p. 692-698, jun. 2014. 
WONFOR, R. et al. Anti-inflammatory properties of an extract of M. ilicifolia in the human intestinal epithelial Caco-2 cell line. Journal of Ethnopharmacology, v. 209, n. July, p. 283-287, set. 2017.

ZAMBON, C. P. et al. O USO DE MEDICAMENTOS FITOTERÁPICOS NO PROCESSO DE EMAGRECIMENTO EM ACADÊMICOS DO CURSO DE FARMÁCIA DA FACULDADE DE EDUCAÇÃO E MEIO AMBIENTE - FAEMA. Revista Científica FAEMA, v. 9, n. edesp, p. 500-506, 15 jun. 2018. 


\title{
CAPITULO XVI
}

\section{A PROPAGAÇÃO DE CONCEITOS ERRÔNEOS NA ROTINA ALIMENTAR PARA PRATICANTES DE EXERCÍCIOS FISICOS}

\author{
DOI: $10.51859 /$ AMPLLA.DES1788-17
}

\author{
Thiago Bruno Souto de Oliveira ${ }^{1}$ \\ Neide Kazue Sakugawa Shinohara ${ }^{2}$
}

${ }^{1}$ Técnico em Enfermagem, Bacharelando em Educação Física- UNIBRA

2 Docente da Universidade Federal Rural de Pernambuco-UFRPE

\section{RESUMO}

O objetivo é apresentar uma revisão sobre a prevalência da alimentação nutricional acompanhada pelo profissional de nutrição para praticantes de exercícios físicos. 0 levantamento bibliográfico foi realizado de 2002 a 2021, nas plataformas Medline, Lilacs, SciELO, a partir dos descritores "alimentação", "exercícios físico", "performance", em combinação com "nutrição esportiva" e "suplementação alimentar". Foram identificados estudos clínicos/nutrição esportiva que abordaram a necessidade da orientação nutricional para praticantes de exercícios físicos para todas as faixas etárias e de gênero. No levantamento foi constatado que o uso de suplementos alimentares é muito comum entre os praticantes de exercício físico do sexo masculino. A procura pelo corpo ideal segue como um dos principais motivos para o uso desses recursos ergogênicos por iniciativa própria, sem acompanhamento profissional. As evidências cientificas indicam que a orientação nutricional para praticantes de exercícios físicos, auxiliam a atingir seus objetivos e anseios, dirimindo dúvidas e desmistificando os muitos conceitos errôneos, visando melhorar o desempenho esportivo aliado aos benefícios de uma alimentação adaptado a demanda energética, a fim de contribuir para obtenção de resultados satisfatórios dos praticantes de atividade física.

Palavras-chave: Alimentação. Exercício Físico. Performance. Nutrição Esportiva. Suplementação Alimentar. 


\section{INTRODUÇÃO}

A nutrição e o exercício físico são áreas do conhecimento humano que emergem fundamentos técnicos, valores individuais e conhecimento científico que ajudam a melhorar o condicionamento físico, aumento da massa muscular, e benefícios de vários outros fatores fisiológicos como melhoria da capacidade pulmonar, cardíaca e intestinal. Vale salientar, que cada indivíduo apresenta uma individualidade biológica diferente, significando a tamanha importância da enfatização da nutrição, juntamente com o profissional de educação física, no contexto da melhora da capacidade física e cognitiva.

Segundo a Pesquisa Nacional de Saúde (PNS, 2019) no Brasil, cerca de 20\% das pessoas com mais de 18 anos estão obesas ou com outro desiquilíbrio nutricional. A busca pelo exercício físico e a reeducação alimentar tem se expandido muito junto à população em geral, assim como a ciência do desporto tem avançado bastante nos últimos, fornecendo diversos materiais sobre nutrição alimentar.

A procura massiva na mídia gerou a facilidade de encontrar as mais diferentes desinformações, muitas vezes sem amparo científico sobre a alimentação pré, durante e pós exercício, levando a população a consumos exagerados de produtos como suplementos industrializados ou com anúncios de garantia de resultados mais rápidos no ganho de massa muscular, promessa de definição corporal, redução de gordura localizada, aceleração no metabolismo, etc.

Muitas vezes essas informações sobre suplementação alimentar veiculadas na rede mundial e televisiva são equivocadas e sem experimentação e validação das informações, o que podem gerar transtornos, confusão, prejudicando a saúde como um todo dos indivíduos. Esse consumo de ergogênicos que propagam informações de entrega a curto prazo e benefícios mais rápidos, coadjuva para falta de tempo dos consumidores, induzindo e levando ao consumo prático e rápido, envolvendo o desconhecimento dos riscos envolvidos no consumo de propostas à disposição para a população praticante de exercício físico.

A alimentação balanceada, equilibrada e assistida pelo profissional de nutrição é primordial para favorecer ao praticante de atividade física um suprimento adequado de nutrientes na dieta e não apenas por fornecer a energia necessária, mas também para garantir o metabolismo ideal do substrato energético (Williams, 2002), uma vez que o 
corpo humano não sintetiza ou não produz quantidades suficientes alguns compostos essenciais, sendo necessário ser ingerido na alimentação convencional ou adicionado através da suplementação complementar.

Segundo a Agência Nacional de Vigilância Sanitária (Anvisa, 2020), para o uso de suplementos alimentares, deve-se promover estudos clínicos a fim de estabelecer limites mínimos e máximos para o consumo adequado, quais populações são indicadas, constituintes autorizados para consumo seguro e alegações com comprovação científica. Nessa categoria estão incluídos 'alimentos para atletas', 'alimentos para gestantes', 'suplementos vitamínicos e minerais para necessidades especiais'. Para fornecer nutrientes, substâncias bioativas e enzimas, só podem ser utilizados nos suplementos constituintes, em que os ingredientes tenham sido autorizados pela Anvisa. Em nenhuma hipótese, um suplemento alimentar pode apresentar indicação de prevenção, tratamento ou cura de doenças. Esse tipo de alegação é restrito a medicamentos com a finalidade estabelecida.

O objetivo da pesquisa é de promover um levantamento sobre a associação da prática de exercício físico regular em consonância com a adoção de dieta equilibrada e ajustada às necessidades nutricionais, melhorando a performance e efetividade do praticante de exercício físico. Anulando os conceitos errôneos e mitificados na perspectiva equivocada midiático sobre a propagação do consumo exagerado de recursos ergogênicos.

\section{METODOLOGIA}

O estudo é constituído de uma revisão bibliográfica com o objetivo de analisar a importância da abordagem nutricional/suplementação associado com a prática do exercício físico regular. Foi realizada utilizando as bases de dados científicos eletrônicos no período de 2002 a 2021, nas plataformas Medline, Lilacs, Scielo, a partir dos descritores "alimentação", "exercícios físico", "performance", em combinação com “nutrição esportiva” e "suplementação alimentar"., nos vernáculos em inglês, espanhol e português.

A seleção inicial foi através da leitura do resumo de cada artigo e posteriormente ocorreu a interpretação de forma exploratória e indicativa daqueles aos quais se enquadravam no objetivo da pesquisa. Por fim, a construção da redação de forma 
analítica e pontual, agrupando as informações de forma coesa, refinando todos os informes dos artigos selecionados, para subsidiar a proposta da pesquisa.

\section{REVISÃO DA LITERATURA}

Suplementos alimentares não são medicamentos e, por isso, não servem para tratar, prevenir ou curar doenças. Os suplementos são destinados a pessoas saudáveis. Sua finalidade é fornecer nutrientes, substâncias bioativas, enzimas ou probióticos em complemento à alimentação. A categoria de suplemento alimentar foi criada em 2018 para garantir o acesso da população a produtos seguros e de qualidade, são destinados a pessoas saudáveis como uma opção para complementação nutricional, no caso de dietas restritivas, alterações metabólicas, atividade física intensa, entre outros (ANVISA, 2020).

O indivíduo que pratica exercício físico regularmente e deseja adquirir resultados satisfatório, tem que ter uma vida que se adapte e aceite aos conhecimentos voltados aos hábitos alimentares adequados (de acordo com as suas necessidades fisiológicas) composta por nutrientes indispensáveis para a sua saúde e desempenho físico. Essa prática de exercício físico associada ao consumo alimentar adequado e equilibrado te leva a obtenção de resultados significantes.

Pacheco e colaboradores (2012), asseguram que a atividade física praticada na forma regular traz muitos benefícios a saúde, entre eles o aumento da massa magra, diminuição da gordura corporal, melhora da resistência muscular e do condicionamento físico ajudando o aparelho cardiorrespiratório. Segundo a Organização Mundial de Saúde (OMS, 2004), a prática de exercício físico, juntamente com uma reeducação alimentar, apresentará uma resposta fisiológica bastante significativa na qualidade de vida e longevidade do ser humano.

A adequação do consumo alimentar associado ao nível de atividade física, é uma excelente combinação de eficiência. Levando a entender que a capacidade do rendimento físico do indivíduo que pratica exercício físico regularmente, tem relação direta com a ingestão equilibrada de todos os nutrientes, sejam macronutrientes: carboidratos, lipídeos, proteínas ou micronutrientes: minerais e vitaminas. De acordo com Ribas et al. (2015), uma dieta para ser equilibrada deve contemplar uma ingesta adequada de macronutrientes e micronutrientes, para suprir as demandas energética 
durante o exercício físico para aumento da massa magra, obtido com treinamento de força, como no caso a prática da musculação, exercícios bem aceito e praticado pelo público das academias no Brasil.

Segundo Roper (2010), comentar sobre promoção de saúde conquistada por meio de uma alimentação saudável em conjunto com a realização de atividades físicas regulares, promovem efeitos positivos no corpo humano, para todas as faixas etárias e de gênero. É importante salientar que os exercícios físicos não são cumulativos, ou seja, quando ficamos sem exercitar, perdemos rapidamente a resistência física adquirida, por isso a palavra de ordem é a regularidade na prática de exercícios, respeitando a necessidade física e nutricional individual.

Portanto, há uma necessidade crescente de orientação e educação em nutrição esportiva para ajudar os indivíduos a adequar seus hábitos alimentares com segurança e de fácil compreensão e que seja factível à sua execução. O nutricionista é o profissional com formação acadêmica necessária para a prescrição de cardápios ajustados às necessidades dietéticas e indicação de produtos de suplementação alimentar, também é o mais habilitado para as orientações de uso e composição dos nutrientes para prática esportiva.

A nutrição é um dos fatores que otimiza o desempenho atlético quando bem equilibrada, reduzindo a fadiga, lesões ou reparando-a rapidamente, otimiza os depósitos de energia e a saúde geral do indivíduo. Um número bastante significativo de praticantes de exercícios físicos recorre a suplementos industrializados, sem tencionar a riqueza de nutrientes que a alimentação variada, equilibrada fornece para a prática esportiva. Segundo Moreira e Rodrigues (2014), informam em seu estudo que a maioria dos consumidores é do sexo masculino, com idade média de 23,28 anos, praticantes de exercício físico com frequência em academia. Destes 78,9\% utilizam algum tipo de suplementos industrializados por conta própria, mostrando conhecimento moderado na área de nutrição.

A nutrição e o exercício estabelecem uma inter-relação importante para a melhoria do desempenho proposto, pois uma alimentação balanceada melhora o rendimento do organismo em todos os aspectos. A associação da alimentação junto com o desempenho físico, promove o reparo e a construção de tecidos corporais, além de potencializar o efeito dos treinos. Os profissionais de educação física quanto à 
prescrição/indicação de suplementos alimentares, deve estar ciente que é uma atividade privativa do profissional de nutrição, que deve ser realizada respeitando o consumo e gasto energético individualizado de cada pessoa e sua necessidade dietética frente a prática do exercício a ser realizado (BARROS, PINHEIRO, RODRIGUES, 2017).

A ciência da nutrição é um importante instrumento dentro da prática esportiva, envolvendo os processos de ingestão e conversão de compostos dos alimentos em nutrientes, ou seja, as substâncias necessárias oriundas dos alimentos é para manter a integridade física, reparando os tecidos e manutenção do sistema esquelético e regulação da fisiologia corpórea, construindo ou mantendo suas funções orgânicas normais, com finalidades energéticos para manutenção do esforço físico. Portanto, a alimentação em atletas amadores e profissionais, devem suprir a demanda energética assim como garantir o balanço hídrico, de nutrientes, vitamínico e mineral, pois uma inadequação nutricional pode prejudicar fortemente a saúde e o desempenho físico (SANDOVAL et al., 2013).

Santos e Santos (2002), relatam em seu estudo com 100 alunos, que 70\% eram homens que praticavam atividade física em academia com frequência e todos usavam algum tipo de suplemento, visando melhorar a performance. Em outro estudo de Moreiria e Rodrigues (2014) com 113 alunos praticantes de exercícios físico, abordando o uso de suplementos a base de proteína e aminoácidos, comparando com alimentação regular, foi encontrado que $58,4 \%$ fazem o uso de suplementos alimentares. Nesta mesma pesquisa também foi encontrado que o público predominante foi o masculino $(55,8 \%)$ quanto ao uso de recursos ergogênicos.

O uso de suplementos alimentares é muito comum entre os praticantes de exercício físico do sexo masculino. A procura pelo corpo ideal segue como um dos principais motivos para o uso desses recursos ergogênicos. Prestes e colaboradores (2016) descrevem em seu livro "Prescrição e Periodização do Treinamento de Força", que os efeitos desses recursos ergogênicos, relacionam com o metabolismo muscular predominante da modalidade do exercício em questão, no caso, o treinamento de força. Assim, os autores classificam os recursos ergogênicos como diretos e indiretos. Os recursos ergogênicos diretos são aqueles utilizados para melhorar o desempenho humano durante o exercício físico e recursos indiretos, são utilizados com a perspectiva 
de promover proteção contra lesões, rápida recuperação tecidual e melhora do perfil anabólico do corpo.

Segundo a Agência Nacional de Vigilância Sanitária (ANVISA, 2010) subdivide-se esses recursos ergogênicos em 5 categorias, que são autorizadas para comercialização da seguinte forma:

1- Repositores Hidroeletrolíticos;

2- Repositores energéticos;

3- Alimentos proteicos;

4- Alimentos compensadores;

5- Aminoácidos de cadeia ramificada.

A Anvisa orienta que os recursos ergogênicos industrializados e autorizado para consumo, são para o uso de atletas profissionais praticantes de exercício físico e desempenho máximos, com o objetivo de participação em esportes individuais e coletivos com esforço muscular intenso (ANVISA, 2010).

O público masculino que pratica exercício físico em academia com frequência, cria sentimentos de pressa em querer obter resultados rápidos de massa muscular e perda de massa gorda, de uma forma brusca e ansiosa, buscam assim recursos ergogênicos industrializados no intuito de acelerar os resultados desejados.

A colaboração do nutricionista, profissional habilitado pelo Conselho de Nutrição (BRASIL, 2020), quanto a prescrição da dieta e suplementos nutricionais, cuja área de atuação se faz necessário para orientar a carência nutricional do praticante de exercício físico amador ou profissional. Por ser o profissional que tem como área de exercícios as competências previstas para a indicação de uma alimentação natural ou suplementada, orientando fontes nutricionais necessárias para minimizar o risco de lesões, de fadiga, e proteção do organismo, ajudando na manutenção de órgãos, restauração e crescimento dos tecidos, condições relacionadas a uma dieta diversificada de macro e micronutrientes.

É sabido que a alimentação natural e equilibrada junto ao exercício físico direcionado, respeitando as necessidades biológicas do indivíduo e quando acompanhado e orientado, corroboram de forma exitosa para ganhos fisiológicos reais o que repercute na melhoria da qualidade de vida. A alimentação adequada em macro e micronutrientes, promove grandes benefícios no pré, durante e no pós-treino, como mostra a Tabela 1, conceitos baseados em Prestes et al. (2016). 
Tabela 1 - Benefícios da alimentação no pré, durante e pós treino.

\begin{tabular}{ccl}
\hline PRÉ-TREINO & $\bullet \quad$ Melhora a performance. \\
\hline DURANTE O TREINO & $\bullet \quad$ Promove combustível energético; \\
& $\bullet \quad$ Adia a fadiga precoce; \\
& $\bullet \quad$ Otimiza a capacidade e a performance \\
& física. \\
\hline PÓS-TREINO & $\bullet$ & Promove a recuperação muscular. \\
\hline
\end{tabular}

Fonte: Autoria própria.

Segundo Schwarcz (2008), se a indústria fosse detentora de um suplemento alimentar que fosse cientificamente comprovada a eficiência na redução de doenças cardíacas, cânceres, hipertensão, diabetes e com efeito complementar na perda de peso, aumento da massa muscular, certamente uma parcela bastante significativa da população consumidora praticante de exercício físico, rapidamente correriam para as lojas especializadas em suplementos, para fazer uso desses recursos industrializados. Infelizmente, um suplemento alimentar que fornece todas essas características metabólicas e funcionais, ainda está distante da realidade e muito menos não estão disponíveis nas prateleiras do e-commerce.

\section{CONSIDERAÇÕES FINAIS}

A partir desses achados, ressalta-se a necessidade da orientação nutricional para praticantes de exercícios físicos, os auxiliando a atingir seus objetivos, esclarecendo dúvidas e desmistificando os muitos conceitos errôneos, visando melhorar o desempenho esportivo com os benefícios de uma alimentação equilibrada e natural. Conscientizar e esclarecer os praticantes de exercício físico amadores, profissionais e público em geral, sobre a importância do nutricionista habilitado para esse fim.

\section{REFERÊNCIAS}

ANVISA. Agência Nacional de Vigilância Sanitária - 16/10/2020. Suplementos Alimentares. Disponível em: <https://www.gov.br/anvisa/ptbr/assuntos/alimentos/suplementos-alimentares>. Acesso em: 14 de out. 2021

ARAÚJO, A. C. M.; Soares, N. G. Perfil da Utilização de Repositores Proteicos nas Academias de Belém, Pará. Revista Nutrição PUCCAMP. v. 12. n. 1. p.81-89. 1999. 
BARROS, A. J. S.; Pinheiro, M. T. C.; Rodrigues, V. D. (2017). Conhecimentos Acerca da Alimentação Saudável e Consumo de Suplementos Alimentares por Praticantes de Atividade Física em Academias. Revista Brasileira de Nutrição Esportiva. p. 301-311. Disponível em: <http://www.rbne.com.br/index.php/rbne/article/view/799>. Acesso em: 15 de out. 2021

DANIEL, R. Moore; Meghann, J. Robinson; Jessica, L. Fry; Jason, E. Tang; Elisa, I. Glover; Sarah, B. Wilkinson; Todd Prior; Mark, A. Tarnopolsky e Stuart, M. Phillips. Resposta à Dose de Proteína Ingerida do Músculo e Síntese de Proteína de Albumina após Exercício de Resistência em Homens Jovens. 2009.

HIRSCHBRUCH, M. D.; Fisberg, M.; Mochizuki, L. Consumo de Suplementos por Jovens Frequentadores de Academias de Ginástica em São Paulo. Rev. Bras. Med. Esporte. v. 14. n.6. 2008.

MOREIRA, F. P.; Rodrigues, K. L. Conhecimento Nutricional e Suplementação Alimentar por Praticantes de Exercícios Físicos. Rev. Bras. Med. Esporte - v. 20, n. 5 Set/Out, 2014.

MOREIRIA N. M.; Navarro A. C.; Navarro F. Consumo de Suplementos Alimentares em Academias de Cachoeiro de Itapemirim-Es. Revista Brasileira de Nutrição Esportiva, São Paulo. v. 8. n. 48. p.363-372. Nov./Dez. 2014. ISSN 1981-9927.

OLIVEIRA, C. E.; Sandoval, T. C.; Silva J. C. D. S.; Stulbach, T. E.; \& Frade, R. E. T. Avaliação do Consumo Alimentar antes da Prática de Atividade Física de Frequentadores de uma Academia no Município de São Paulo em Diferentes Modalidades. Revista Brasileira de Nutrição Esportiva, p.57 -67. 2013

PACHECO, B. M.; Filho, A. D. R.; Santini, E. Impacto da Prática Regular de Exercício Físico Sobre Aspecto Alimentar. Revista Brasileira de Nutrição Esportiva, São Paulo. v. 6. n. 35. p. 376-380. 2012.

PRESTES, J.; Donatto F. F.; Foschini D.; Tibana R. A. Livro Prescrição e Periodização do Treinamento de Força em Academias. 2a Edição. p.226. 2016.

PNS. Pesquisa Nacional de Saúde. Ministério da Saúde, Agência Nacional de Vigilância Sanitária (ANVISA). Disponível em: <https://bvsms.saude.gov.br/bvs/saudelegis/anvisa/2010/res0018_27_04_201 $0 . h t m l>$. em: Acesso em: 11 de set de 2021.

RIBAS, M. R.; Machado, F.; Shuluga Filho, J.; \& Bassan, J. C. Ingestão de Macro e Micronutrientes de Praticantes de Musculação de Ambos os Sexos. RBNERevista Brasileira de Nutrição Esportiva. n. 9. p.91-99. 2015.

ROPER, E. A. Inteligência Alimentar: A nova refeição e os ingredientes do equilíbrio. São Paulo: Elevação. p.228. 2010 
SANTOS, M. A. A.; Santos, R. P. Uso de Suplementos Alimentares como Forma de Melhorar a Performance nos Programas de Atividade Física em Academias de Ginástica. Rev. Paulista de Educação Física, São Paulo. P.174-85, jul./dez. 2002.

SCHWARCZ, J. Uma Maçã por Dia: Mitos e Verdades sobre os Alimentos que comemos. Rio de Janeiro: Zahar. p.306. 2008.

BRASIL. Conselho Federal de Nutrição. RESOLUÇÃO CFN № 656, DE 15 DE JUNHO DE 2020. Dispõe Sobre a Prescrição Dietética, pelo Nutricionista, de Suplementos Alimentares e de outras Providências. Disponível em: <https://www.cfn.org.br/wp-content/uploads/resolucoes/Res_656_2020.html> Acesso em: 01 de dez de 2021. 


\title{
CAPITULO XVIII
}

\section{O CONSUMO DE ALIMENTOS FUNCIONAIS E COMPOSTOS BIOATIVOS NA PRÁTICA DE ATIVIDADES FÍSICAS E NA PROMOÇÃO DE SAÚDE}

DOI: 10.51859/AMPLLA.DES1788-18

\author{
Gabriel Bezerra Pereira ${ }^{1}$ \\ João Pedro Moraes Rodrigues ${ }^{1}$ \\ Jair Marinho da Silva Filho ${ }^{1}$ \\ Bruno Farias Oliveira ${ }^{1}$ \\ Filipe Caetano Siqueira ${ }^{1}$ \\ Thereza Maria Tavares Sampaio ${ }^{2}$
}

\footnotetext{
'Graduando do curso de Medicina. Universidade Federal do Cariri - UFCA

${ }^{2}$ Doutora em Bioquímica. Universidade Federal do Ceará - UFC
}

\section{RESUMO}

Atualmente, vivemos em um período de transição nutricional, em que boa parte da população vive em situação de fome, enquanto outros milhões de pessoas sofrem em virtude do excesso alimentar, constituído pelo sobrepeso e pela obesidade, associados ao sedentarismo. $O$ fato de ambos os extremos serem amplamente prejudiciais faz com que a sociedade procure uma melhor qualidade de vida na sua alimentação, o que tem propiciado uma procura por alimentos que, não só satisfaçam suas funções nutricionais básicas, mas também viabilizem maiores benefícios à saúde. Nesse aspecto, os compostos bioativos, presentes em alimentos funcionais, estão se popularizando, principalmente na ampliação do desempenho nos esportes, vide que são alimentos amiúde presentes nas prescrições e recomendações dos profissionais de saúde ligados à atividade física, e na prevenção de complicações das doenças crônicas não transmissíveis, como diabetes mellitus tipo II e hipertensão arterial sistêmica. No entanto, deve-se ter precaução com alimentos que possuem doses inviáveis de serem administradas para que se adquira determinado efeito, pois, além da falha terapêutica, pode haver um quadro de toxicidade provocado por esses compostos alimentares. Por isso, cabe aos profissionais da saúde se habituarem com essa alimentação e com os objetivo por ela proposto, seguindo sempre o que já há de consolidado na literatura, em que se estabelecem doses e toxicidades aceitáveis, promovendo, assim, o consumo adequado e guiado desses produtos, com o fito de ampliar a promoção de saúde e a qualidade de vida.

Palavras-chave: Nutrição. Alimentos funcionais. Compostos bioativos. Atividade física. Promoção de saúde. 


\section{INTRODUÇ̃̃o}

A população brasileira convive atualmente com o que se denomina de transição nutricional, que inclui tanto a desnutrição causada pela fome, quanto o crescente predomínio do excesso de consumo alimentar, o qual cursa com o excesso de peso, em diferentes fases da vida (COUTINHO; GENTIL e TORAL, 2008). Sabendo dos malefícios ocasionados pela obesidade e por outras doenças crônicas prevalentes, a sociedade vem buscando, por meio da alimentação, um maior monitoramento do perfil nutricional, visando a uma melhor qualidade de vida por meio de alimentos benéficos à saúde, principalmente frutas, hortaliças e cereais, os quais contêm elevado número de alimentos funcionais e compostos bioativos.

Segundo a pesquisa de Vigilância de Fatores de Risco e Proteção para Doenças Crônicas por Inquérito Telefônico (Vigitel), em 2019, a frequência de consumo regular de frutas e hortaliças, ou seja, quando consumidas em pelo menos 5 dias da semana, foi de $34,3 \%$, e a frequência de consumo diária de pelo menos 400 gramas de frutas e hortaliças representou apenas 22,9\%, dados que denotam uma realidade bastante comum na transição alimentar e representam um desafio a ser superado no campo nutricional (BRASIL, 2020).

A Associação Dietética Americana define alimentos funcionais como todo e qualquer alimento ou ingrediente alimentar que promove benefícios à saúde, em adição ao seu valor nutritivo. Os compostos responsáveis por essa função aditiva são denominados de compostos bioativos, os quais naturalmente estão presentes em pequenas quantidades nos alimentos e, quando ingeridos em quantidades significativas, exercem efeitos benéficos à saúde humana. A hipótese-chave para o conceito de alimento funcional é sua capacidade de modular várias funções-alvo no corpo e participar na manutenção de um estado de saúde ao atuar na redução do risco de desenvolvimento de enfermidades, principalmente das doenças crônicas não transmissíveis (GIUNTINI, 2018).

Esses compostos têm sido cada vez mais estudados na literatura acadêmica, embora os estudos não lhes denotem a característica de nutriente. A razão para não os denominar assim se dá em virtude de não serem considerados essenciais ao crescimento e às funções vitais (PASCHOAL, 2014). Essa consideração, no entanto, não anula a 
possibilidade de novos estudos demonstrarem seus efeitos nessas funções, além de ratificarem suas já extensivamente reconhecidas atribuições de caráter profilático e de aprimoramento do desempenho físico em esportistas.

O objetivo deste trabalho é a análise e a listagem de alguns alimentos funcionais já amplamente descritos na literatura, das suas funções e dos compostos bioativos presentes em sua constituição.

\section{REVISÃO BIBLIOGRÁFICA}

As condições de vida, o meio ambiente e os fatores genéticos, nutricionais e culturais exercem enorme influência no processo de redução do desempenho de praticantes de exercício físico (NIEMAN, 1999). A literatura demonstra que uma alimentação natural e equilibrada, com a inclusão de alimentos com propriedades nutricionais e funcionais, tais como vegetais folhosos, legumes, frutas frescas, nozes, castanhas, cereais integrais, carnes magras e ovos, tem a função de fortalecer o sistema imunológico e combater os radicais livres e seus efeitos maléficos sobre o organismo (KLEIN e FASSINA, 2015).

São muitos os alimentos qualificados como funcionais, mas muitos também são aqueles que não possuem efeitos benéficos documentados e que podem até apresentar efeitos danosos ao indivíduo, embora sejam corriqueiramente utilizados pela população. Como forma de identificar os alimentos que possuem essa funcionalidade e que são aprovados para uso, a Agência Nacional de Vigilância Sanitária (ANVISA) documenta nos rótulos a indicação de "alegação de propriedade funcional" (BRASIL, 1999).

\subsection{CONSUMO ALIMENTAR PARA A PRÁTICA DE ATIVIDADES FÍSICAS}

A combinação entre uma dieta saudável e o exercício físico tem sido amplamente recomendada com o objetivo de reduzir os fatores de risco para doenças crônicas degenerativas (BRASIL, 2014). Existem várias categorias de suplementos dietéticos funcionais, como antioxidantes, antimutagênicos, anticarcinogênicos, antimicrobianos, antivirais, estimulantes da função gastrintestinal, imunomoduladores, antiinflamatórios, anti-hipertensivos, hipocolesterolêmicos e hipoalergênicos. Os mais relacionados ao esforço físico são os antioxidantes, modificadores dos mecanismos de 
defesa relacionados ao estresse oxidativo, e os suplementos que agem como imunomoduladores e anti-inflamatórios.

Esses alimentos possuem propriedades de modular, potencializar e antagonizar funções no organismo, as quais aprimoram as funções fisiológicas e metabólicas relacionadas à oxidação de nutrientes, à resistência física, ao anabolismo e ao catabolismo dos tecidos muscular e adiposo e à regulação hidroeletrolítica (BARBOSA e CARDOSO, 2015).

Acerca dos compostos que diminuem o dano oxidativo, ressalta-se a relevância de fatores como duração, intensidade, preparo físico, saúde e condições ambientais exercendo influência na ocorrência e na gravidade dessa injúria oxidativa.

Esse dano oxidativo ocorre devido a uma exacerbação de uma pequena parcela de oxigênio que não é usada como combustível para a respiração celular, o que aumenta a formação mitocondrial de espécies reativas de oxigênio. Quando produzidos em excesso, esses radicais livres podem promover oxidação celular, danos na estrutura do DNA, envelhecimento e uma variedade de doenças, dessa maneira, prejudicando a função musculoesquelética e aumentando a dor durante o exercício, o que prejudica a performance do atleta.

Os praticantes de atividade física, em especial nos exercícios aeróbicos, que mantêm contato ainda maior com essas espécies precisam de um aumentado mecanismo de defesa corpórea que evite a intoxicação por essas espécies, por isso a importância de uma alimentação rica em nutrientes antioxidantes (MAHAN, 2018).

Exercícios aeróbicos de longa duração podem ainda provocar sintomas gastrointestinais, como vômitos, náusea e diarreia, sendo as causas desses sintomas relacionadas à redução do fluxo sanguíneo intestinal, à liberação de hormônios, ao estresse mecânico, à desidratação, aos fatores psicológicos e à própria dieta inadequada (LIRA, 2008).

Destaca-se que muitos compostos, além da ação antioxidante por potencial de oxirredução de determinadas moléculas, apresentam também o mecanismo de disputar por sítios ativos e receptores nas diversas estruturas celulares ou, ainda, de modular a expressão de genes que codificam proteínas envolvidas em mecanismos intracelulares de defesa contra processos oxidativos degenerativos de estruturas celulares (BORGONOVI, 2016). 
O uso de antioxidantes pode atrasar a fadiga muscular, aumentando a capacidade de tolerar o esforço, melhorando a performance dos atletas e reduzindo os danos e as lesões secundárias ao processo oxidativo. Importante ressaltar que muitas enzimas antioxidantes requerem também micronutrientes, como zinco, selênio, cobre e vitaminas $C$ e do complexo $B$, além de quantidades suficientes de aminoácidos essenciais, o que evidencia a necessidade de um enfoque na dieta por completo.

\subsection{PRINCIPAIS ALIMENTOS FUNCIONAIS}

A aveia é um cereal de excelente valor nutricional e atende às características de alimento funcional. Esse alimento apresenta dois tipos de fibras, as solúveis e as insolúveis, ambas benéficas ao nosso organismo. As primeiras, também conhecidas como betaglucanas, conseguem reduzir os riscos de doenças cardiovasculares, pois podem reduzir os níveis de colesterol e de LDL na corrente sanguínea, além disso diminuem o apetite, pois restringem o esvaziamento gástrico. As insolúveis, por sua vez, melhoram o trânsito intestinal (GALDEANO, 2012).

A linhaça é uma das maiores fontes de ácidos graxos essenciais, possuindo ainda vários compostos fenólicos, conhecidos por exercerem atividade antioxidante. Pode auxiliar na prevenção e na redução dos fatores de risco para doenças como, por exemplo, doenças cardiovasculares, câncer e hipertensão arterial sistêmica. Contém vitaminas (vitaminas $B, C, E$ ), minerais (ferro, zinco, potássio, magnésio, fósforo e cálcio), ácidos graxos ômega-3 e fibras. Algumas de suas funções atribuídas estão na formação de ossos e dentes, na manutenção do ritmo cardíaco e na condução neural. Esse alimento pode também auxiliar no incremento da vitalidade física, reduzindo fadiga e ampliando eficácia na produção energética (BARBOSA e FERNANDES, 2014) .

O alho possui diversos compostos bioativos em sua composição. Um deles é a alicina, que detém excelente atividade hipoglicemiante, estabilizando a glicose sanguínea e, dessa forma, auxiliando no controle da diabetes mellitus tipo II (ZAPAROLLI et al, 2013). Além disso, o alimento apresenta efeito inibitório na biossíntese do colesterol e reduz a concentração do mesmo no plasma, protegendo, dessa forma, o sistema cardiovascular (ALMEIDA e SUYENAGA, 2009).

O tomate apresenta como um dos seus principais compostos bioativos o licopeno, o seu principal carotenoide. Este tem excelente efeito antioxidante, 
apresentando proteção contra câncer, principalmente o de próstata e o de estômago, e outras doenças degenerativas em virtude deste efeito contra radicais livres. Doenças cardiovasculares associadas a disfunções vasculares e processos inflamatórios causados, especialmente, pelo estresse oxidativo, também são alvos do licopeno (MARQUES, 2015).

O cacau é uma fruta rica em flavonoides e catequinas, importantes componentes bioativos. O primeiro tem boa ação antioxidante, agindo contra o estresse oxidativo. Além disso, o alimento tem bom efeito no sistema cardiovascular, regulando a pressão arterial e com capacidade antiplaquetária (RIBEIRO e CARVALHO, 2016).

A cebola, devendo ser consumida preferencialmente crua, possui uma substância chamada quercetina, a qual age na redução do colesterol LDL e no combate aos radicais livres. Esse legume pode reduzir o risco de lesões secundárias a danos oxidativos e, principalmente, os riscos do aparecimento de infecções durante treinamentos intensos (BARBOSA e FERNANDES, 2014).

As frutas vermelhas, como jabuticaba, framboesa, groselha e maçã, possuem elevada concentração de vitaminas e compostos bioativos, dentre os quais vitamina C, antocianinas e quercetina. Exercem importantes ações antioxidante e anti-inflamatória no organismo (BARBOSA e FERNANDES, 2014).

O azeite de oliva contém vários compostos bioativos, dentre eles os polifenóis (BARBOSA e FERNANDES, 2014). É uma das principais fontes de lipídios protetores contra doenças cardiovasculares na medida em que diminui os níveis de oxidação do LDL (lipoproteína de baixa densidade), junto à presença de fatores antioxidantes e antiinflamatórios que agregam benefícios concernentes à manutenção e à recuperação dos tecidos ( ANGELIS, 2001) .

Algumas especiarias e ervas aromáticas, como alecrim, orégano, manjericão, manjerona, hortelã, sálvia e tomilho apresentam em sua composição compostos fenólicos, compostos nitrogenados, carotenóides e ácido ascórbico. Esses compostos são essenciais na proteção do dano oxidativo, auxiliando o organismo na prevenção de doenças inflamatórias e com atividades antimicrobianas (MILITÃO e FURLAN, 2014).

O chá verde possui flavonoides e catequinas, com propriedades termogênicas e antioxidantes, viabilizando melhora na resistência física e proteção contra danos 
oxidativos causados pelo exercício e por determinados tipos de cânceres (UNIVERSIDADE FEDERAL DE SANTA CATARINA, 2008).

O café, em virtude da cafeína, relaciona-se ao aumento da termogênese e da oxidação de lipídios e à melhora do desempenho. Além disso, possibilita maior estado de alerta e melhora no desempenho nos exercícios de força e de endurance, já que essa substância causa uma maior liberação de cálcio pelos retículos sarcoplasmáticos das células, aumentando a força de contração dos miócitos e a atividade do sistema nervoso central (GUERRA, BERNARDO e GUTIÉRREZ, 2000).

O gengibre possui na sua composição substâncias fenólicas que têm uma importante ação antioxidante. Assim, devido à sua capacidade de diminuir os efeitos dos elétrons livres que poderiam lesar as membranas das células, esse alimento possui a função homeostática de reduzir as inflamações e melhorar a qualidade da recuperação das células em geral, incluindo o tecido musculoesquelético (SOUSA e PROENÇA, 2021).

\subsection{PRINCIPAIS COMPOSTOS BIOATIVOS}

Compostos fenólicos possuem várias classes, como flavonóides, estilbenos, ácidos fenólicos, cumarinas e taninos. São encontrados em alimentos como maçã, mirtilo, amora, cranberry, uva roxa, cebola e azeite de oliva e exercem efeitos na inibição da produção de radicais livres nos músculos danificados após atividade física e na melhora de seu desempenho. Resveratrol é um exemplo de um estilbeno, presente em casca de uva, nozes e cerejas, ao qual tem sido atribuída relevante função no sistema cardiovascular por redução da agregação plaquetária e da inflamação vascular, podendo atuar como quelante de espécies reativas de oxigênio, com melhora das condições endoteliais (FURLAN e RODRIGUES, 2016).

Flavonoides são compostos bioativos do grupo dos polifenóis encontrados em hortaliças, cereais, chás, cacau e frutas cítricas. Realizam a função de regulação gênica de diversas moléculas e enzimas envolvidas na formação de placas ateroscleróticas, na melhora no perfil lipídico e na prevenção de danos ao endotélio. Pesquisas sugerem que possuem propriedades antivirais, antihemorrágicas, antimicrobianas, anti-inflamatórias e antioxidantes, além de atuarem na proteção da mucosa gástrica (NEVES, 2015). A quercetina, que está presente em muitos alimentos, incluindo maçãs, arandos, mirtilos e cebolas, é um flavonóide que aumenta a resistência no treinamento físico, podendo 
reduzir o risco de infecções pós-exercício físico exaustivo e prolongado. Possui propriedades anti-inflamatórias, anticancerígenas, cardioprotetoras e neuroprotetoras.

Os compostos sulfurados estão presentes em alimentos como alho, brócolis, couve-flor e rúcula. Sua ingestão está associada com risco reduzido de desenvolvimento de câncer, em virtude de sua ação antioxidante, no controle da apoptose e do ciclo celular, além de possuir efeito cardioprotetor, devido a sua atividade anti-inflamatória (ANJO, 2004).

Os carotenóides fazem parte de um grupo de pigmentos naturais com coloração amarela, laranja ou vermelha, como betacaroteno e licopeno. São importantes antioxidantes, com mecanismos de neutralização das espécies reativas de oxigênio (MESQUITA; TEIXEIRA e SERVULO, 2017). Eles são encontrados em cenoura, couve, abóbora, beterraba, manga e mamão. Além das propriedades antioxidantes, possuem associação com redução do risco de câncer, degeneração macular, catarata e doenças cardiovasculares.

Licopeno é um carotenóide, sendo o tomate uma de suas principais fontes, também é antioxidante, com potente ação contra o estresse oxidativo, protegendo moléculas contra processos degenerativos que acontecem com a circulação excessiva de radicais livres. Algumas investigações sugerem efeitos na redução do risco de ocorrência de câncer de próstata, pulmão, esôfago e gástrico. (SHAMI e MOREIRA, 2004).

$\beta$-glicana são fibras viscosas e seu consumo está relacionado à atenuação da resposta glicêmica e insulínica pós-prandial, sendo importante para regular a glicemia em pacientes cardiopatas ou diabéticos. É o principal componente da parede celular de fungos, de leveduras e de alguns cereais como a aveia e a cevada (MIRA; GRAF e CÂNDIDO, 2009).

Prebióticos são oligossacarídeos não digeríveis, cuja fermentação é responsável por promover a saúde da microbiota do indivíduo. Estimulam, portanto, o crescimento de bactérias benéficas, como os lactobacilos, e afetam de forma positiva a microflora intestinal, evitando a ocorrência de infecções intestinais (BLAUT, 2002).

Probióticos são encontrados em leites fermentados, iogurtes e outros produtos lácteos fermentados. Favorecem as funções gastrointestinais e afetam de forma positiva 
a microflora intestinal, reduzindo o risco de constipação, infecção enteral e câncer de cólon (SANTOS e VARAVALLO, 2011).

Betaína está presente em trigo, espinafre, beterraba e mariscos. É um derivado do aminoácido glicina e uma de suas principais funções é manter a retenção de água pelas células do corpo. Pode reduzir a inflamação e também pode contribuir com os compostos necessários para sintetizar a creatina nos músculos (FAVERO, 2012).

\section{CONSIDERAÇÕES FINAIS}

A abordagem nutricional é essencial para promoção da saúde e para a adequada orientação de uma dieta funcional para a modulação de processos inflamatórios, sem que haja prejuízo às adaptações fisiológicas do exercício, proporcionando um equilíbrio necessário à prevenção da redução do desempenho físico, à redução dos efeitos oxidativos deletérios às células e aos tecidos e à minimização dos riscos de infecção. No exercício físico, não é apenas a modulação dos processos oxidativos que deve ser abordada terapeuticamente. Deve-se ampliar o espectro e avaliar a interação entre componentes de cunho genético, ambiental, alimentar e relativo ao estilo de vida, com ênfase neste.

O consumo dietético desses alimentos deve ser regular para que suas funções anti-inflamatórias e antioxidantes possam ser adequadamente cumpridas. A indicação, em geral, que deve ser veiculada pelos profissionais de saúde, refere-se ao maior e regular consumo de legumes, hortaliças, frutas e cereais na alimentação, pois, como foi visto, boa parte dos compostos ativos estudados se encontram nesses alimentos.

A efetiva orientação dietética, a prática regular de atividade física e a mudança no estilo de vida são os elementos imprescindíveis para a promoção de saúde e de qualidade de vida, potencializando qualidades desportivas e protagonizando a profilaxia de diversas enfermidades crônicas não transmissíveis.

\section{REFERÊNCIAS}

ALMEIDA, A.; SUYENAGA, E.S. Ação farmacológica do alho (Allium sativum L.) e da cebola (Allium cepa L.) sobre o sistema cardiovascular: revisão bibliográfica. Nutrire, São Paulo, v.34, n.1, p.185-197, 2009. 
ANGELIS, R. Novos conceitos em nutrição: reflexões a respeito do elo dieta e saúde. Arquivos de Gastroenterologia [online], v. 38, n. 4 , pp. 269-271, 2001.

ANJO, D. L. C. Alimentos funcionais em angiologia e cirurgia vascular. Jornal Vascular Brasileiro. v. 3, n. 2, p. 145- 154, 2004.

BARBOSA, L; CARDOSO, F. Gastronomia funcional para o atleta: a importância da nutrição funcional e exemplos culinários de aplicação. Revista Brasileira de Nutrição Funcional - ano 15, no 63, 2015.

BARBOSA, T.; FERNANDES, D.. Compostos bioativos e doenças cardiovasculares: revisando as evidências científicas. Estudos, Goiânia, v. 41, n. 2, p. 181-192, 1br./jun. 2014.

BLAUT, M. Relationship of prebiotics and food to intestinal microflora. European Journal of Nutrition. v. 41, supplement 1, p.1-16, 2002.

BORGONOVI, T. et al. Atividade antioxidante de leites fermentados probióticos adicionados de subprodutos de laranja e maracujá. 10 Encontro Internacional de Ciências Agrárias e Tecnológicas. Unesp. São Paulo, 2016.

BRASIL. Ministério da Saúde. Cadernos de Atenção Básica: Estratégias para o cuidado da pessoa com doença crônica: obesidade. Ministério da Saúde. Secretaria de Atenção à Saúde. Departamento de Atenção Básica. Brasília, 2014.

BRASIL. Ministério da Saúde. Portaria no 398, de 30 de abril de 1999. Brasília, 1999.

BRASIL. Ministério da Saúde. Vigitel Brasil 2019 : vigilância de fatores de risco e proteção para doenças crônicas por inquérito telefônico : estimativas sobre frequência e distribuição sociodemográfica de fatores de risco e proteção para doenças crônicas nas capitais dos 26 estados brasileiros e no Distrito Federal em 2019. Secretaria de Vigilância em Saúde. Departamento de Análise em Saúde e Vigilância de Doenças Não-Transmissíveis. Brasília, 2020.

COUTINHO, J. G.; GENTIL, P. C.; TORAL, N. A desnutrição e obesidade no Brasil: o enfrentamento com base na agenda única da nutrição. Cadernos de Saúde Pública, Rio de Janeiro, v. 24, supl. 2, p. s332-s340, 2008.

FAVERO, S. M. Efeitos da suplementação de betaína, combinada ou não com a suplementação de creatina, sobre a força máxima, potência e concentrações intramusculares de fosforilcreatina, em indivíduos não treinados em força. 2012. Dissertação (Mestrado em Biodinâmica do Movimento Humano) - Universidade de São Paulo, Escola de Educação Física e Esporte, São Paulo, 2012.

FURLAN, A.S.; RODRIGUES, L. Consumo de polifenóis e sua associação com conhecimento nutricional e atividade física. Revista Brasileira de Medicina do Esporte. Vol. 22, No 6. Nov/Dez, 2016. 
GALDEANO, M.C. Aveia, uma escolha saudável. Revista Plurale, n. 27, p. 56, jan./fev. 2012

GIUNTINI, E. Alimentos funcionais. Editora e Distribuidora Educacional S.A. 216p. Londrina, 2018.

GUERRA, R.; BERNARDO, G. e GUTIERREZ, C. Cafeína e esporte. Revista Brasileira de Medicina do Esporte [online], v. 6, n. 2, pp. 60-62, 2000.

KLEIN, C.S; FASSINA, P. Relação entre o consumo de alimentos funcionais e alterações fisiológicas em praticantes de atividade física. Caderno pedagógico, v. 12, n. 1, p. 22-35. ISSN 1983-0882. Lajeado, 2015.

LIRA, C. et al. Efeitos do exercício físico sobre o trato gastrintestinal. Revista Brasileira de Medicina do Esporte. 2008, v. 14, n. 1, pp. 64-67. Disponível em: https://doi.org/10.1590/S1517-86922008000100012. Acesso em 2 dez 2021;

MAHAN, L. Kathleen. Krause: Alimentos, nutrição e dietoterapia. Elsevier, 14. edição. Rio de Janeiro, 2018.

MARQUES, C. O licopeno como composto bioativo do tomate. 2015. Dissertação (Mestrado em qualidade e tecnologia alimentar). Instituto Politécnico de Viseu. Escola Superior Agrária de Viseu. Viseu, 2015.

MILITÃO, F.L.; FURLAN, M.R. Alimento funcional através do uso de Ocimum basilicum L.(manjericão) como aromatizante e tempero. Rev. Acadêmica Oswaldo, 2014.

MIRA, G; GRAF, H; CANDIDO, L. Visão retrospectiva em fibras alimentares com ênfase em beta-glucanas no tratamento do diabetes. Brazilian Journal of Pharmaceutical Sciences [online]. 2009, v. 45, n. 1 pp. 11-20. Disponível em: <https://doi.org/10.1590/S1984-82502009000100003>. Acesso em 5 dez 2021.

MESQUITA S.; TEIXEIRA, C; SERVULO, E. Carotenóides: propriedades, aplicações e mercado. Rev. Virtual Quim., 2017, 9 (2).

NEVES, P. Importância dos compostos fenólicos dos frutos na promoção da saúde. Repositório UFP. Monografia - Universidade Fernando Pessoa - Faculdade de Ciências da Saúde. 2015;

NIEMAN, D.C. Exercício e saúde. Manole. São Paulo, 1999.

PASCHOAL, V; NAVES, A. Tratado de nutrição esportiva funcional. Roca, 1. ed. São Paulo, 2014.

SANTOS, T.; VARAVALLO, M. A importância de probióticos para o controle e/ou reestruturação da microbiota intestinal. Revista científica do ITPAC, Volume 4. Número 1 ISSN 1983-6708. Tocantins, 2011.

SHAMI, N.; MOREIRA, E.. Licopeno como agente antioxidante. Rev. Nutr. Campinas, abr./jun., 2004. 
SOUSA, L. S. de; PROENÇA D. C. Os benefícios do gengibre para a saúde humana. Revista Multidisciplinar De Educação E Meio Ambiente, 2(3), 31, 2021.

RIBEIRO, L.S; CARVALHO, V.R.J. Cacau: como esse alimento funcional auxilia na saúde. In: II Congresso Internacional do Grupo Unis. Fundação de Ensino e Pesquisa do Sul de Minas, 2016.

UNIVERSIDADE FEDERAL DE SANTA CATARINA. Alimentos funcionais. Jornal Eletrônico no. 5, jun. 2008.

ZAPAROLLI, M.R; NASCIMENTO, N.C; BAPTISTA, D.R; VAYEGO, S.A . Alimentos disponíveis no manejo da diabetes mellitus. Revista Ciências e Saúde, 6 (1), 1217, 2013. 


\section{CAPITULO XIX}

\section{COMPORTAMENTO E ALIMENTAÇÃO DA POPULAÇÃO DE PARAUAPEBAS (PA) DURANTE O ISOLAMENTO SOCIAL EM DECORRÊNCIA DA PANDEMIA DA COVID-19}

DOI: 10.51859/AMPLLA.DES1788-19

Vanessa Christielle Silva de Sousa ${ }^{1}$ Elisangela Oliveira Silva Froz ${ }^{2}$ Kaelem Assis Rocha Silva ${ }^{3}$ Stefane Carvalho da Cunha ${ }^{4}$

Priscilla Andrade Silva ${ }^{5}$

Mariana Leal Oliveira ${ }^{6}$

\section{RESUMO}

A pandemia de COVID-19 é a maior emergência de saúde pública enfrentada mundialmente em décadas, é notável que esse novo cenário acarretou diversas mudanças na vida das pessoas, incluindo o isolamento social e várias restrições. 0 presente estudo tem como objetivo apresentar uma revisão bibliográfico sobre os hábitos alimentares e comportamentais da população de Parauapebas (PA) durante o isolamento social em decorrência da pandemia da COVID-19. O levantamento bibliográfico abrangeu o isolamento social durante a covid-19, sua influência na modificação do cenário atual assim como os fatores emocionais e comportamentais neste período. $O$ presente estudo também destaca o estado nutricional e o índice de massa corporal assim como os hábitos alimentares no atual cenário da pandemia.

Palavras-chave: Hábitos alimentares. Fatores emocionais. Cenário. 


\section{INTRODUÇÃO}

No mês de dezembro do ano de 2019, surgiu na China um vírus desconhecido, denominado como SARSCoV-2 (Severe Acute Respiratory Syndrome Coronavirus 2). Ao assistir as notícias, imaginou-se que, da mesma maneira que já ocorreu com outros agentes patógenos, essa situação não teria tanta repercussão e ligeiramente seria contida, porém não foi o que ocorreu (RIBOLI et al. 2020).

A enfermidade, que passou a ser denominada como COVID-19 (Coronavírus Disease, 2019) foi considerada como pandemia devido a sua rápida disseminação com a propagação pessoa por pessoa, pela sua universalidade, alcançando outros continentes e também pelos recentes surtos associados à propagação comunitária (MARTINS et al. 2020).

A alimentação é uma parte importante na situação de saúde das pessoas, sendo eficaz no fortalecimento e atuação do sistema imunológico. Ressalta-se ainda, que uma boa alimentação se respalda na variedade de alimentos de alto valor nutricional e em quantidades balanceadas, e deve ser mantida constantemente para fortalecer suas vantagens, não assegurando que só a alimentação garanta a imunidade a COVID-19. É muito importante manter a prática de exercícios físicos para intensificar o sistema imunológico e fazendo que os indivíduos, ainda que com obesidade, encontre-se melhor capacitados para encarar a atual pandemia (JUNIOR, 2020).

Considerando a repercussão na vida alimentar das pessoas que a COVID-19 trouxe, torna-se importante avaliar os hábitos alimentares e comportamentais durante o isolamento social, tendo como amostra a população da cidade de Parauapebas no estado do Pará, a fim de fazer um levantamento sobre a influência que o isolamento teve na vida das pessoas.

\section{METODOLOGIA}

A revisão sistemática da literatura foi realizada, entre janeiro / 2020 e fevereiro / 2021, por meio do portal da revista. Capes e BVCS (Biblioteca Virtual em Ciências da Saúde) utilizando pesquisa avançada com a combinação dos descritores "Isolamento social e covid-19, Fatores emocionais e comportamentais, hábitos alimentares, estado nutricional e índice de massa corporal (IMC) e hábitos alimentares na pandemia". Essas 
bases de dados e bibliotecas digitais foram escolhidas por serem referência para muitos pesquisadores brasileiros, concentrando periódicos bem qualificados a nível nacional e internacionalmente.

A seleção dos artigos baseou-se nos seguintes critérios: publicações nacionais e internacionais que responderam a busca avançada, sem restrição de período de tempo, com vistas a compreender a historicidade das pesquisas sobre a temática. Ressalta-se que, apesar da ausência de restrição de tempo, todos os artigos encontrados se enquadraram no intervalo de publicações realizadas. entre os anos de 2002 e 2020.

\section{REVISÃO BIBLIOGRÁFICA}

\subsection{ISOLAMENTO SOCIAL E COVID-19}

Segundo Santos et al. (2017), "o isolamento social é definido como um estado em que o indivíduo carece de sentimento de pertencimento social, não tendo envolvimento com pessoas, possuindo número mínimo de contatos sociais, sendo deficientes em qualidade".

De acordo com Bezerra et al. (2020), o ato do isolamento social, tem provocado muitas discussões no Brasil, visto que, alguns poderes apontam-se devotos no que diz respeito a sua eficiência. O que acontece é que a maioria das autoridades escolheram incitar essa medida, aderindo maneiras de controlar a locomobilidade dos cidadãos, como o fechamento das instituições de ensino, dos estabelecimentos não essenciais e de espaços públicos de entretenimento. Em decorrência disso, a maioria dos cidadãos concordaram e adotaram as medidas de isolamento social com a finalidade de se precaverem da COVID-19 e de contribuírem com a redução da curva de contágio no Brasil. No entanto, o procedimento de isolamento social tem ocasionado algumas consequências na vida dos indivíduos.

Sodré (2020) por sua vez, destacam questões críticas para a gestão da saúde pública no Brasil e as várias interferências na saúde pública suscetíveis de execução que objetivam a gestão da pandemia. Dentre elas, são permitidas medidas de exílio de pacientes, quarentena e distanciamento social.

Para Wilder-Smith e Freedman (2020), o isolamento de pessoas baseia-se no distanciamento de pacientes contaminados com afeç̧ões contagiosas para proteger 
pessoas saudáveis, normalmente ocorrem em locais hospitalares. Niu e Xu (2020) enfatizam que o afastamento social é um método de conter a disseminação de doenças infecciosas, apesar disso sua eficiência pode ser variável.

Antunes et al. (2020), avalia que o esperado em relação a curva de contágio da COVID-19, com a adoção do afastamento social é que haja uma redução, isto é, que o contágio seja contido, em razão disso o sistema de saúde consiga prestar atendimento as pessoas contagiadas e que carecem de assistência hospitalar, sem que exceda a sua capacidade de atendimento.

Antunes et al. (2020) também avaliam que caso os controles para redução do contágio não sejam efetuados a tempo, a curva tende a crescer com a enorme evolução dos registros de casos, visto que, a disseminação da COVID-19 se mostrou muito acelerada. Quanto maior for o crescimento da curva, maior será a probabilidade de saturação do sistema de saúde em não atender um amplo número de pacientes contaminados e dessa maneira entrar em decadência assim como ocorreu em outras regiões.

A “COVID-19 é uma doença causada pelo coronavírus SARSCoV-2, que apresenta um quadro clínico que varia de infecções assintomáticas a quadros respiratórios graves" (BRASIL, 2020). Martins et al. (2020) citam que a patologia foi descoberta no mês de dezembro de 2019, no município de Wuhan, na China, denominado por SARSCoV-2 (Severe Acute Respiratory Syndrome Coronavirus 2) ele é identificado como agente etiológico da pestilência de inflamação aguda nos pulmões. A doença ficou conhecida oficialmente como COVID-19, esse surto foi denominado como pandemia, devido sua acelerada disseminação com contágio de pessoa a pessoa, por sua universalidade, alcançando outros continentes e através de recentes contágios associados à transmissão comunitária.

Schuchmann et al. (2020), consideram que embora não apresente a mesma severidade da SARS (Síndrome Respiratória Aguda Grave), em casos de mortalidade, a COVID-19 possui contágio elevado, o que a torna muito mais mortal em escala crescente. Por ser um novo vírus para humanidade não há uma defesa imunológica precedentemente adquirida, o que o faz mais contagioso. A patologia é infectante e a propagação viral ocorre de um indivíduo contaminado para um indivíduo não infectado, seja através de contato físico ou com utensílios e locais contaminados, ora através de 
gotículas de saliva, espirro, tosse, secreção nasal, acompanhado de contato com a boca, nariz ou olhos.

De acordo com Pellecchia et al. (2015), diante das consequências comunitárias, o distanciamento social possui a capacidade de alterar radicalmente os costumes habituais dos indivíduos, afetar as regras, rotinas e culturas próprias da sociedade. É capaz de estimular sensação como o medo e a insegurança, visto que, em períodos anteriores ações de saúde pública foram aplicadas como argumento para realizar ações obrigatórias contra determinadas populações, acarretando o resultado de efeito contrário de isolar as pessoas (SCHUCHMANN et al., 2020).

\subsection{FATORES EMOCIONAIS E COMPORTAMENTAIS}

A palavra comportamento é determinada como: forma de agir ou administrar; condutas; processos; soma de atitudes de uma pessoa. Pode ser compreendido como um composto de reações do ser humano na presença das ações do local em que está inserido sobre algumas situações (ALVARENGA, 2019).

pandemia de COVID-19 trouxe consequências psicológicas sendo eles comportamentos naturais e aguardados, como estresse agudo devido às adequações dos novos costumes habituais, até danos mais severos no sofrimento psíquico (GREFF et al. 2020).

A respeito dos impactos psicológicos, pesquisas atestam que grandes períodos de distanciamento social podem estar relacionados as consequências de saúde mental das pessoas como depressão, ansiedade e violência doméstica (ABEL; MCQUEEN, 2020).

Malloy-Diniz et al. (2020), enfatizam que "os baixos níveis de atividade física podem ter efeitos negativos nos processos cognitivos dos indivíduos, adicionados ao próprio estresse do momento de isolamento social". Noce e Samulski (2002) pontuam que, o termo estresse foi mencionado pela primeira vez no ano de 1936 por Hans Selye, que conceituou como um grupo de respostas que o corpo desenvolve ao ser sujeitado por um quadro que requer dedicação de adequação.

Assuntos associados as alterações de comportamentos e ações, em relação a aderir medidas protetivas, ora na prevenção da saúde mental ou na programação da vida após o término da pandemia, essas medidas passam a ser indispensáveis nesse momento. Diante da situação atual, é interessante cogitar formas de alteração de 
atitudes visto que, os costumes antes praticados de maneira costumeira, atualmente mostram-se sem aplicabilidade (MALLOY-DINIZ et al. 2020).

\subsubsection{HÁBITOS ALIMENTARES}

“Hábito é definido como a disposição adquirida pela repetição frequente de um ato, uso ou costume. Alimentar significa dar alimento, nutrir, sustentar, munir, abastecer" (VAZ; BENNERMANN, 2014).

Vaz e Bennermann (2014) consideram que, comportamento alimentar relacionase a condutas referentes as rotinas alimentares ligadas a atributos socioculturais, como os fatos subjetivos fundamentais das pessoas e específicos de uma sociedade, que se envolvam com a prática de alimentar-se ou com o próprio alimento.

De acordo com Leônidas e Santos (2011), conforme Vaz e Bennemann, (2014) o costume, rotina ou modo de se alimentar pode ser classificado como todas as maneiras de relação com o alimento, isto é, os hábitos alimentares não se restringem somente as comidas que são consumidas ou que se deixam consumir, apesar disso, compreendem também normas, conceitos e padrões que transpassam as diversas particularidades relacionadas ao hábito da ingestão alimentar.

\subsubsection{ESTADO NUTRICIONAL E ÍNDICE DE MASSA CORPORAL (IMC)}

No Brasil, a população apresenta uma transformação sobre o estado nutricional. O atual momento epidemiológico, definido pela alta predominância de obesidade, sinaliza que as enfermidades cardiovasculares são o principal problema de saúde pública (CALTRAN et al. 2012).

LOPES et al. (2008) mencionam que, o estado nutricional é caracterizado pelo balanço e a carência da oferta dos nutrientes. Existindo uma instabilidade nessa ligação, podem suceder alterações nutricionais, seja pela carência ou exagero. A baixa ingestão desses nutrientes, quando decorrente de uma deficiência de todos os macronutrientes podem ocasionar a magreza e a desnutrição. Em contrapartida a ingestão em excesso pode acarretar em sobrepeso e obesidade.

A análise nutricional rotineira nas desiguais etapas da vida, desde a infância até a velhice é realizada através de dados antropométricos, condição nutricional e de saúde, possibilitando distinguir antecipadamente sujeitos e grupo populacionais de risco (CALTRAN et al. 2012). 
Nos dias de hoje, obesidade e sobrepeso são apontados como prioridades na agenda mundial de saúde pública. O índice de massa corporal (IMC) é utilizado para analisar o estado nutricional e acompanhamento do sobrepeso de grupos populacionais, esse método é indicado pela Organização mundial da saúde (OMS), (MARTINS et al., 2015).

O IMC é um parâmetro para análise da massa corpórea total do indivíduo em relação à altura. É um método acessível, ágil e simples de ser utilizado, por esse motivo é muito utilizado em pesquisas epidemiológicas e na atividade clínica (SAMPAIO, 2012).

É importante destacar que as classes de IMC de adultos não diferenciam de acordo com o sexo e incluem uma vasta faixa etária (18 a 59 anos). Uma condição que restringe a sua utilização é sua capacidade em não oferecer dados relativos à formação corpórea (REZENDE et al. 2010).

Para análise do IMC em geral é realizado por meio da aferição direta do peso e altura, por pessoas capacitadas e com o uso de instrumentos apropriados. No entanto, essas aferições podem possuir alguns problemas funcionais a ponto de impossibilitarem o recolhimento direto das medidas antropométricas. Desses problemas podemos mencionar: alta carga horária do serviço de campo, os problemas para translado dos materiais, encontrar um espaço condizente para coleta dos dados antropométricos e aplicação de capacitação e uniformização dos antropometristas (MARTINS et al., 2015).

Uma possibilidade que vem sendo usada para verificação de informações antropométricas em pesquisas com uma grande amostra da população é a utilização do peso e altura autodeclarados. Esse método torna possível a execução de pesquisas epidemiológicas com um extenso grupo de pessoas, proporcionando a utilização de poucos recursos e facilitando o trabalho de campo (MARTINS et al., 2015).

O cálculo do IMC foi feito segundo a equação 1:

IMC = massa/altura ${ }^{2}$

em que massa é expressa em kg e altura em metro.

As faixas de divisão do IMC consideradas foram: IMC $<18,5 \mathrm{~kg} / \mathrm{m}^{2}$ considerado Baixo Peso; $18,5-24,9 \mathrm{~kg} / \mathrm{m}^{2}$ considerado Eutrofia; $25,0-29,9 \mathrm{~kg} / \mathrm{m}^{2}$ considerado Sobrepeso; 30,0 - 34,9 kg/m² considerado Obesidade grau I; $35,0-39,9 \mathrm{~kg} / \mathrm{m}^{2}$ 
considerado Obesidade grau II; IMC $\geq 40,0$ considerado Obesidade grau III, conforme orientação da OMS (GUIMARÃES et al. 2017).

Tabela 1 - Classificação do estado nutricional de adultos de acordo com Índice de Massa Corporal (IMC).

\begin{tabular}{cc}
\hline Classificação & IMC $\left.\mathbf{( k g} / \mathbf{m}^{2}\right)$ \\
\hline Baixo peso & $<18,5$ \\
Eutrofia & 18,5 a 24,9 \\
Sobrepeso & 25,0 a 29,9 \\
Obesidade grau I & 30,0 a 34,9 \\
Obesidade grau II & 35,0 a 39,9 \\
Obesidade grau III & $\geq 40,0$ \\
\hline
\end{tabular}

Fonte: WHO, 1997

\subsubsection{HÁBITOS ALIMENTARES NA PANDEMIA}

Com o fechamento das estradas e diversos ramos de atividades, aumentou o medo de ficar sem diversos itens fundamentais, o que ocasionou a compra e armazenamento em grande quantidade de produtos alimentícios e outros. 0 crescimento dos alimentos disponíveis, junto ao maior período em casa, a disposição para cozinhar e a desocupação, tende a colaborar para aderir novos hábitos alimentares mais saudáveis, por outro lado também contribui para o aumento na ingestão de calorias e alimentar-se compulsivamente (MALLOY-DINIZ et al. 2020).

Filho e Gomes Junior (2020) mencionam que o programa de fornecimento alimentar do Brasil não possui indícios de desprovimento em ampla escala de itens, mas a diferença entre os recursos e os valores aplicados fortalecerá uma circunstância de insegurança alimentar, que não resultará na falta de produtos alimentícios, mas da formação como refeição/mercadoria. Pode-se instituir, dessa maneira, a predisposição a estabelecimento de rotinas alimentares impróprias por essa diferença, como os ultraprocessados tornam se mais frequentes na mesa no qual a renda é considerável para manter seu padrão de vida e consumo, através da união dos alimentos à concepção de bem estar e satisfação como coragem aos impactos da pandemia.

Malloy-Diniz et al. (2020) mencionam que "durante a pandemia, é natural o aumento de sintomas de ansiedade e depressão, que são fatores de risco para a fome emocional e o comer compulsivo muito prevalente entre os indivíduos que possuem excesso de peso". Levando em consideração os elementos abordados, algumas 
conclusões são plausíveis no decorrer da pandemia da COVID-19, bem como: ganho ponderal, compulsão alimentar, carência alimentar, desnutrição e preservação do peso, progresso na qualidade alimentar.

Até a presente data não existe recurso terapêutico confirmado para o tratamento da COVID-19. Os especialistas estão trabalhando para elaborar métodos de tratamento eficaz no enfrentamento da pandemia. Além de permanecer com hábitos alimentares saudáveis, uma alimentação com imunonutrientes adequados e possuir uma assistência psicológica apta no decorrer dessa pandemia, pode ser uma possibilidade de precaução em combate a COVID-19 (DEMOLINER; DALTOÉ, 2020).

\section{CONSIDERACÕES FINAIS}

A pandemia de COVID-19 é a maior emergência de saúde pública enfrentada mundialmente em décadas, é notável que esse novo cenário acarretou diversas mudanças na vida das pessoas, incluindo o isolamento social e várias restrições. Dentre essas mudanças o presente estudo expõe alguns fatores que influenciaram para novos hábitos alimentares e comportamentais da população do município de Parauapebas (PA) e esses efeitos podem ser prolongados por mais tempo. Em um momento futuro, ressalta-se a importância de aprofundar a discussão sobre o tema, por se tratar de um assunto recente e não possuir muitos estudos sobre o comportamento alimentar durante a pandemia da COVID-19, pois novos estudos poderão contribuir para melhores ferramentas de políticas públicas, possibilitando eficientes investimentos na saúde da população.

\section{REFERÊNCIAS}

ABEL, T., MCQUEEN, D. The COVID-19 pandemic calls for spatial distancing and social closeness: not for social distancing!. Int J Public Health 65, 231 (2020). https://doi.org/10.1007/s00038-020-01366-7

ALVARENGA, M.; ANTONACCIO, C.; TIMERMAN, F.; FIGUEIREDO, M. Nutrição comportamental. 2 ed. Barueri: Manole, 2019. ISBN: 978-85-204-4789-5

ANTUNES, B. B. D. P.; PERES, I. T.; BAIÃO, F. A.; RANZANI, O. T.; BASTOS, L. D. S. L.; SILVA, A. D. A. B. D.; BOZZA, F. A. Progressão dos casos confirmados de COVID-19 após implantação de medidas de controle. Revista Brasileira de Terapia Intensiva, v. 32, p. 213-223, 2020. https://doi.org/10.5935/0103-507X.20200028 
BEZERRA, A. C. V.; SILVA, C. E. M.; SOARES, F. R. G.; SILVA, J. A. M. Fatores associados ao comportamento da população durante o isolamento social na pandemia de covid-19. Ciência \& Saúde Coletiva, v. 25, p. 2411-2421, 2020. https://doi.org/10.1590/1413-81232020256.1.10792020

CALTRAN, P.; SILVA, S. C.; POPE, S.; FORNARI, J. V.; BARBABÉ, A. S.; ARÇARI, D. P.; FERRAZ, R. R. N. Utilização do Índice de Massa Corporal para estimativa do estado nutricional de funcionários de uma empresa do ramo químico. Revista eletrônica Unisepe Saúde em Foco, n. 06, p. 2236-0123, 2012.

GUIMARÃES, M. F. B. R.; PINTO, M. R. C.; RAID, R. G. S. C.; ANDRADE, M. V. M.; KAKEHASI, A. M. Qual o melhor ponto de corte de índice de massa corporal para diagnosticar a obesidade em mulheres com artrite reumatoide? Um estudo que usa a composição corporal pela absorciometria com raios $\mathrm{X}$ de dupla energia. Revista Brasileira de Reumatologia, v. 57, n. 4, p. 279-285, 2017. https://doi.org/10.1016/j.rbre.2016.02.008

GREFF, A. P.; MELO, B. D.; LIMA, C. C.; PEREIRA, D. R.; ALVES, E. G. R.; CORNEJO, E. R.; MOTOYAMA, E. P.; SERPELONI, F.; AVANCI, J. Q.; SCAVACINI, K.; CESCON, L. F.; CACCIACARRO, M. F.; SOUZA, M. S.; MAGRIN, N. P.; SILVA FILHO, O. C. Suicídio na pandemia Covid-19. Saúde mental e atenção psicológica na pandemia Covide19, Fundação Oswaldo Cruz, 2020. https://www.arca.fiocruz.br/handle/icict/41420

JUNIOR, L. C. L. Alimentação saudável e exercícios físicos em meio à pandemia da COVID19. Boletim de Conjuntura (BOCA), v. 3, n. 9, p. 33-41, 2020. DOI: 10.5281/zenodo.3988664

LEÔNIDAS, C.; SANTOS, M. A. Imagem Corporal e Hábitos Alimentares na Anorexia Nervosa:Uma Revisão Integrativa da Literatura. Psicologia: Reflexão e Crítica, v. 25, p. 550-558, 2012. https://doi.org/10.1590/S0102-79722012000300015

LOPES, A. C. S.; CAIAFFA, W. T.; SICHIERI, R.; MINGOTI, S. A.; COSTA, M. F. F. L. Estado nutricional: antropometria, consumo alimentar e dosagens bioquímicas de adultos e idosos-Projeto Bambuí um estudo de base populacional. Revista Mineira de Enfermagem, v. 12, n. 4, p. 483-493, 2008. ISSN: 2316-9389

MALLOY-DINIZ, L. F.; COSTA, D. S.; LOUREIRO, F.; MOREIRA, L.; SILVEIRA, B. K. S.; SADI, H. M.; APOLINÁRIO-SOUZA, T.; ALVIM-SOARES, A.; NICOLATO, R.; PAULA, J. J.; MIRANDA, D.; PINHEIRO, M. I. C.; CRUZ, R. M.; SILVA, A. G. Saúde mental na pandemia de COVID -19: considerações práticas multidisciplinares sobre cognição, emoção e comportamento. Debates em psiquiatria, v. 10, n. 2, p. 4668, 2020. Disponível: https://www.researchgate.net/publication/341255949, acesso em: 08/10/2020. 
MARTINS, D. S.; VIEIRA, J. C. C.; CASTRO, M. S. R.; LIMA, M. S.; PORTELLA, N. M.; FONSECA, R. P. O.; FIGUEIREDO, S. H. G. Da proximidade ao distanciamento social: desafios de sustentar a lógica da atenção psicossocial em tempos de pandemia. Relato de experiência do Centro de Atenção Psicossocial Infantil. Health Residencies Journal-HRJ, v. 1, n. 1, p. 48-64, 2020. https://doi.org/10.51723/hrj.v1i1.21

MARTINS, P. C.; CARVALHO, M. B.; MACHADO, C. J. Uso de medidas autorreferidas de peso, altura e índice de massa corporal em uma população rural do nordeste brasileiro. Revista Brasileira de Epidemiologia, v. 18, p. 137-148, 2015. https://doi.org/10.1590/1980-5497201500010011

NIU, Y.; XU, F. Deciphering the power of isolation in controlling COVID-19 outbreaks. The Lancet Global Health, v. 8, n. 4, p. e452-e453, 2020. https://doi.org/10.1016/S2214-109X(20)30085-1

NOCE, F.; SAMULSKI, D. M. Análise do estresse psíquico em atacantes no voleibol de alto nível. 20 ed. Rev. paul. Educ. Fís, São Paulo, v.16, n.2, p.113-129, 2002.

PELLECCHIA, U.; CRESTANI, R.; DECROO, T.; BERGH, R. V. D.; AL-KOURDI, Y. Consequências sociais das medidas de contenção do ebola na Libéria. PloS one, v. 10, n. 12, p. e0143036, 2015. https://doi.org/10.1371/journal.pone.0143036

REZENDE, F. A. C.; ROSADO, L. E. F. P. L.; FRANCESCHINNI, S. C. C.; ROSADO, G. P.; RIBEIRO, R. C. L. Aplicabilidade do índice de massa corporal na avaliação da gordura corporal. Revista brasileira de medicina do esporte, v. 16, n. 2, p. 9094, 2010. https://doi.org/10.1590/S1517-86922010000200002

RIBOLI, E.; ARTHUR, J. P.; DE FÁTIMA M. M. No epicentro da epidemia: um olhar sobre a Covid-19 na Itália. Cogitare Enfermagem, v. 25, 2020. http://dx.doi.org/10.5380/ce.v25i0.72955

$\begin{array}{llll} & \text { SAMPAIO, } & \text { R. } & \text { Avaliação nutricional. }\end{array}$ https://doi.org/10.7476/9788523218744

SANTOS, W. A.; FULY, P. S. C.; SANTOS, M. L. S. C.; SOUTO, M. D.; REIS, C. M.; BERETTA, L. L. Evidências sobre o isolamento social em pacientes com exsudato em feridas neoplásicas: revisão integrativa: revisão integrativa. Revista Enfermagem Atual In Derme, Brasil, v. 81, n. 19, p. 89-96, 08 abr. 2017.

SCHUCHMANN, A. Z.; SCHNORRENBERGER, B. L.; CHIQUETTI, M. E.; GAIKI, R. S.; RAIMANN, B. W.; MAEYAMA, M. A. Isolamento social vertical X Isolamento social horizontal: os dilemas sanitários e sociais no enfrentamento da pandemia de COVID-19. Braz. J. Hea. Rev., Curitiba, v. 3, n. 2, p.3556-3576, 2020. ISSN: 25956825. 
SILVA FILHO, O. J. S.; GOMES JUNIOR, N. N. O amanhã vai à mesa: abastecimento alimentar e covid-19. Cadernos de Saúde Pública, v. 36, p. e00095220, 2020. Disponível: http://dx.doi.org/10.1590/0102-311X00095220

SODRÉ, F. Epidemia de Covid-19: questões críticas para a gestão da saúde pública no Brasil. Trabalho, Educação e Saúde, v. 18, 2020. https://doi.org/10.1590/19817746-sol00302

VAZ, D. S. S.; BENNEMANN, R. M. Comportamento alimentar e hábito alimentar: uma revisão. Revista UNINGÁ Review, v.20, n.1, p.108-112, Out - Dez, 2014. ISSN: 2178-2571

WILDER-SMITH, A.; FREEDMAN, D. O. Isolation, quarantine, social distancing and community containment: pivotal role for old-style public health measures in the novel coronavirus (2019-nCoV) outbreak. Journal of Travel Medicine, v. 27, 2020. DOI: $10.1093 / \mathrm{jtm} /$ taaa020 


\section{CAPITULO XX}

\section{A GARANTIA DO DIREITO HUMANO À ALIMENTAÇÃO ADEQUADA E SAUDÁVEL EM TEMPOS PANDẾmICOS DE COVID-19: ALGUMAS QUESTÕES ESSENCIAIS}

DOI: 10.51859/AMPLLA.DES1788-20

Regina Márcia Soares Cavalcante ${ }^{1}$

${ }^{1}$ Nutricionista. Universidade Federal do Piauí- UFPI; Especialista em Saúde Pública-UFPI. Mestre em Ciências e Saúde. Programa de Pós-Graduação em Ciências e Saúde-PPCS. UFPI. Doutora em Alimentos e Nutrição. Programa de PósGraduação em Alimentos e Nutrição-PPGAN. UFPI. Professora Adjunta do Curso de Nutrição. UFPI.

\section{RESUMO}

A pandemia de COVID-19 tem se mostrado como um dos maiores desafios da história recente da humanidade, devidos à multiplicidade de impactos que tem causado, que ultrapassam a fronteira do biológico humano e se estendem até a macroestrutura das sociedades. O objetivo do estudo foi analisar como o direito humano à alimentação adequada e saudável está sendo consolidado durante a pandemia de COVID-19. Estudo qualitativo e exploratório, realizado por meio de uma revisão narrativa de literatura. $A$ pandemia tem evidenciado, em países em desenvolvimento como o Brasil, a gigantesca desigualdade social e demográfica, as péssimas condições de vida e saúde bem como o descumprimento de direitos básicos do ser humano, como a alimentação. As medidas adotadas para conter a doença, causaram impactos econômicos em todos os segmentos sociais, como diminuição do acesso à alimentação, tornando ainda mais vulnerável o estado de saúde de grande parte da população. Logo, países em desenvolvimento, com economia frágil e com grande parte da população em estado de vulnerabilidade social, tem sofrido demasiadamente com a pandemia de COVID-19, tendo direitos básicos violados, como o direito à alimentação adequada, o que fragiliza ainda mais a qualidade de vida e saúde, potencializando o risco de contaminação pela doença.

Palavras-chave: Direitos Humanos. Alimentação. Saúde. Covid-19. 


\section{INTRODUÇÃO}

A pandemia de COVID-19 tem provocado uma crise sanitária sem precedentes por todo o mundo, configurando-se como um dos maiores desafios da história recente da humanidade (BIERNATH, 2020) e, seus impactos socioeconômicos não encontram similaridade em nenhum outro evento de proporções globais, como a Grande Depressão de 1929 e a Crise Econômica e Financeira Internacional de 2007-2008 (BLUEDORN, GOPINATH, SANDRI, 2020). A doença tem atingido, de forma descomunal, as populações com maior vulnerabilidade social, que vivem em condições sanitárias precárias, especialmente nos países subdesenvolvidos e em desenvolvimento como o Brasil, onde as desigualdades socioeconômicas e demográficas encontram-se mais evidenciadas (SINGU et al., 2020).

Sendo a COVID-19 uma doença nova, ainda não há definição de condutas terapêuticas eficazes para o seu enfrentamento, logo, as estratégias de isolamento social têm sido utilizadas como as mais importantes medidas na prevenção e controle da doença (TEIXEIRA et al., 2020). Mesmo sendo uma medida necessária, o isolamento social tem causado sérios impactos econômicos e sociais em todos os segmentos da sociedade, com a diminuição do acesso a elementos básicos para a sobrevivência como alimentação e água, afetando o exercício de muitos direitos humanos fundamentais, como do direito humano à alimentação adequada (DHAA), o que pode tornar mais grave a situação de saúde das populações que vivem em situação de pobreza, aumentando, dessa forma, a suscetibilidade à infecção pela doença e suas consequências (GFSC,2020).

Nessa perspectiva, o objetivo deste trabalho foi analisar como o direito humano à alimentação adequada e saudável está sendo consolidado durante a pandemia de COVID-19.

\section{METODOLOGIA}

O estudo foi conduzido por meio de uma revisão bibliográfica do tipo narrativa, realizada com a pesquisa de artigos científicos publicados, nas bases de dados da área de saúde: Pubmed, Science Direct e Scopus no mês de agosto a setembro de 2021. A busca foi realizada utilizando-se como descritores isolados e combinados: Human rights, Food, Health, Covid-19. Foram incluídos no estudo artigos em inglês e português 
disponíveis na íntegra e que apresentaram abordagens relevantes para o tema proposto. Foram excluídos aqueles artigos que em duplicidade nas bases de dados analisadas, bem como, mediante leitura do resumo ou artigo completo, os que não estavam condizentes com o tema abordado. Quanto a interpretação de dados, esta foi realizada a luz da literatura cientifica disponível, reafirmando que os resultados encontrados atendiam aos objetivos propostos nesse estudo.

\section{RESULTADOS E DISCUSSÃO}

A COVID-19, causada pelo novo coronavírus, teve início na China, na cidade de Wuhan em dezembro de 2019 e, devido ao elevado poder de disseminação da doença, tornou-se, em apenas três meses, uma pandemia que gerou impactos significativos por todo mundo, tornando-se um dos maiores desafios de saúde pública deste século (LIPSITCH, SWERDLOW, FINELLI, 2020). De acordo as informações disponíveis até agora, a via de transmissão do novo coronavírus-SARS-CoV-2 ocorre por meio de gotículas respiratórias (expelidas ao falar, tossir ou espirrar) como também por meio do contato direto com pessoas infectadas ou indireto através das mãos, objetos ou superfícies contaminadas, de forma similar com que outros patógenos respiratórios se disseminam (ANVISA, 2020).

Considerando que a COVID-19 é uma doença descoberta recentemente, não foi estabelecido, até o momento, tratamento farmacológico específico e de eficácia comprovada para a mesma (TEIXEIRA et al., 2020). Conforme recomendações da Organização Mundial da Saúde (OMS), o isolamento social é a melhor estratégia para conter a transmissão da doença (CROKIDAKIS, 2020; KERR et al., 2020). E dessa forma, com a adoção obrigatória desta medida de contenção da COVID-19, as atividades econômicas foram paralisadas ou reduzidas no mundo e, no Brasil não foi diferente, o que gerou como consequências o aumento do desemprego, pobreza e fome. Este cenário exigiu ações do governo para minimizar o agravamento das condições de saúde e socioeconômicas da população (OLIVEIRA, ABRANCHES, LANA,2020; DICKINSON, 2020). Aqui no Brasil, o isolamento social, devido a uma falta de coordenação das ações do governo federal, foi colocado em prática em graus variados entre os estados e municípios do país, que se tornou alvo frequente de debates, em função dos impactos 
econômicos, sociais e psicológicos por ele provocados (ARRAIS et al.,2020; MORAES, 2020).

A pandemia de COVID-19 atinge o território brasileiro quando o país atravessa um momento extremamente delicado, onde, após um período marcado pelo sucesso no combate à fome e a insegurança alimentar, o Brasil mergulha em crises políticas e econômicas que deixam a sociedade num contexto de preocupante vulnerabilidade (RECINE, GARCIA, 2020). O cenário criado pela pandemia agrava as desigualdades sociais e enfatiza a Segurança Alimentar e Nutricional-SAN como ferramenta essencial para minimizá-las, bem como para proteger condições de vida dignas. Entretanto, o que pôde ser observado em relação ao compromisso político atualmente existente no Brasil, bem como sobre o empenho demonstrado nas últimas décadas para garantir a SAN, foi a completa ausência de estrutura (RECINE et al., 2020).

Dessa forma, ainda segundo Recine et al.(2020), o país tornou-se o epicentro global da pandemia , não somente devido ao novo coronavírus, mas também devido à negligência de políticas de proteção social dos últimos anos, potencializada por ações do atual governo, inclusive a agenda de SAN, o que se agravou, ainda mais, com a extinção do Conselho Nacional de Segurança Alimentar e Nutricional-CONSEA no ano de 2019, que teve como principal consequência o desaparecimento de um órgão oficial para pressionar e exigir , de forma constante, o cumprimento das medidas necessárias à proteção do DHAA.

Nessa perspectiva, é importante destacar que as pandemias são consideradas mais um problema social do que um problema de saúde e, consequentemente as populações que vivem em condição de miséria, em bairros superpopulosos com precárias condições sanitárias, têm sido afetadas de forma desproporcional pela COVID19 (SINGU et al., 2020). Assim, países subdesenvolvidos e em desenvolvimento como o Brasil, tem demonstrado maior vulnerabilidade aos impactos provocados pela pandemia. Isso ocorre devido à grande desigualdade social e demográfica, característica marcante do país, que traz consigo, péssimas condições de habitação e saneamento, acesso precário ou irregular à água, dificuldades aumentadas de acesso aos serviços de saúde, frequente situação de aglomerações nos núcleos familiares numerosos, alta prevalência de doenças crônicas e, neste contexto a consequente violação de inúmeros direitos humanos básicos (BARRETO et al., 2020). 
Dentre estes direitos pode-se destacar o descumprimento do DHAA que causa forte ameaça à concretização da SAN no país, pois é sabido que esta pode ser afetada pelos impactos sociais e econômicos da COVID-19, especialmente se considerarmos as situações de desigualdade social, de renda, étnicas, raciais, de gênero e de acesso a serviços de saúde (FBSSAN, 2020).

Para melhor compreensão desta situação, primeiramente, se faz necessário a apropriação conceitual de alimentação adequada e saudável, que é a prática alimentar apropriada aos aspectos biológicos e socioculturais dos indivíduos, bem como ao uso sustentável do meio ambiente, ou seja, deve estar em acordo com as necessidades de cada fase do curso da vida e com as necessidades alimentares especiais; referenciada pela cultura alimentar e pelas dimensões de gênero, raça e etnia; acessível do ponto de vista físico e financeiro; harmônica em quantidade e qualidade; baseada em práticas produtivas adequadas e sustentáveis com quantidades mínimas de contaminantes físicos, químicos e biológicos (PNAN, 2012).

Em seguida, entender aspectos históricos envolvidos na edificação deste DHAA. Nesta conjuntura, a construção e consolidação do DHAA vem se estabelecendo no decorrer do tempo, sendo o marco inicial em 1948, instituído no artigo $25, \S 1^{\circ}$ da Declaração Universal dos Direitos Humanos, documento em que ficou determinado que "Toda pessoa tem direito a um padrão de vida capaz de assegurar a si e a sua família saúde e bem-estar, inclusive alimentação, vestuário, habitação" (ONU, 1948). Posteriormente, teve sua definição ampliada em outros dispositivos do Direito Internacional, como o artigo 11 do Pacto de Direitos Econômicos, Sociais e Culturais (PIDESC) (ONU, 1966) e o Comentário Geral no 12 da Organização das Nações Unidas (ONU,1999). Como também este ideário foi ratificado no Marco estratégico global para a segurança alimentar e nutricional: consenso global, que postulou a assunção, pelos estados signatários, das obrigações com objetivo de "respeitar, proteger e cumprir o DHAA mediante políticas globais, regionais e nacionais" (FAO, 2014).

No Brasil, a construção do DHAA foi resultante de amplo processo de mobilização social e, em 2006, com a lei 11.346, foi criado o Sistema Nacional de Segurança Alimentar e Nutricional - SISAN, com vistas em assegurar o DHAA. Vale ressaltar que a SAN compreende a realização do direito de todos ao acesso regular e permanente a alimentos de qualidade, em quantidade suficiente, sem comprometer o acesso a outras 
necessidades essenciais, tendo como base práticas alimentares promotoras de saúde que respeitem a diversidade cultural e que sejam ambiental, cultural, econômica e socialmente sustentáveis (BRASIL, 2006). Alguns anos mais tarde, em 2010, foi aprovada a Emenda Constitucional no 64, que incluiu a alimentação como direito, no artigo 6으 da Constituição Federal do Brasil (BRASIL, 2010). Entretanto, é importante evidenciar que este dispositivo, não necessariamente, veio garantir a realização desse direito na prática, e tem mostrado que este ainda permanece como um dos mais complexos desafios para as políticas públicas na atualidade.

Ainda nesta perspectiva, de acordo com Gamba et al.(2010), O DHAA encontra fundamentação em dois princípios básicos e indissociáveis: da efetivação da garantia à disponibilidade ao alimento de qualidade (contemplando aspectos higiênico-sanitários e da cultura alimentar de uma determinada população), estando em quantidade suficiente para satisfazer as demandas nutricionais do indivíduo e, da garantia de acessibilidade ao alimento de forma sustentável, ininterrupta e sem a interferência no proveito de outros direitos humanos essenciais.

Em síntese, o DHAA trata da disponibilidade, adequação, acesso físico, econômico e estável aos alimentos, respeitando a dignidade humana, garantindo prestação de contas e apoderamento dos titulares de direito. E para efetivação de todos estes atributos são necessárias políticas articuladas entre diversos setores (políticas intersetoriais) e âmbitos da sociedade, que ofereçam condições concretas para que os diferentes grupos sociais, cada um com suas especificidades, acessem, com dignidade, alimentos de qualidade produzidos de modo sustentável e permanente (CONSEA, 2010).

Dessa forma fica evidente o papel do estado para a garantia do DHAA e da SAN de uma nação, especialmente em períodos críticos como o que atualmente o mundo atravessa: a pandemia de COVID-19 (GFSC, 2020). Assim o temor de uma nova recessão e colapso financeiro em tempos como este, requerem uma liderança bem-sucedida e resiliente nos setores de saúde, negócios, governo e sociedade em geral (NICOLA et al., 2020), tendo em vista que a postura adotada pelos países, governos e instituições para responderem politicamente à pandemia podem ter sérias implicações na garantia do DHAA. Dessa forma, respostas políticas com ações desarticuladas com diversos setores do governo e pouco orientadas por dados científicos podem aumentar os impactos 
sociais, econômicos e de saúde na pandemia, ações observadas desde o início no Brasil (GFSC, 2020).

De acordo com o Relatório Global sobre Crises Alimentares, há uma estimativa de que no ano de 2019, 135 milhões de pessoas apresentavam insegurança alimentar. Entretanto, devido aos impactos econômicos e descontinuidades da cadeia de suprimentos decorrentes da COVID-19, economista do Programa Mundial de Alimentos, alertou, por meio de projeções, que este número poderia dobrar, chegando a alcançar 265 milhões de pessoas, o que pode encontrar explicação pelo fato da pandemia afetar a oferta e demanda de alimentos, reduzir o poder de compra e a capacidade de produção e distribuição de alimentos, afetando especialmente os mais vulneráveis (GLOBAL NETWORK AGAINST FOOD CRISES, 2020).

É importante destacar que há o reconhecimento de muitos estudiosos que, medidas adotadas para prevenir e/ou minimizar a propagação da COVID-19 bem como o número de internações e mortes pela doença, especialmente a adoção do isolamento social, apresentam grande potencial de causar impactos no acesso à renda e afetar a curto, médio e longo prazos a regularidade da produção, acesso, disponibilidade, abastecimento e preço de alimentos e, consequentemente, a garantia da SAN e do DHAA (MALUF,2020;IPES-Food, 2020; MARCHISIO, 2020).

Dentre as medidas adotadas, merece destaque a suspensão das aulas presenciais em todo território nacional, onde todas as escolas públicas suspenderam as aulas em março de 2020 e, assim foi dado início ao desafio de operacionalizar a continuidade ao Programa Nacional de Alimentação Escolar (PNAE) para não comprometer o acesso demais de 40 milhões de escolares à alimentação e garantir o acesso a alimentação adequada por esta parcela tão vulnerável da população. Desde o início da pandemia, muitos estados e municípios executaram o PNAE de uma forma incipiente, remetendo aos primórdios do programa, quando apenas determinados públicos eram atendidos, o que reforçava seu caráter assistencialista (AMORIM, RIBEIRO, BANDONI,2020), comprometendo dessa forma o acesso de grande parte desta população à alimentação adequada em tempos de pandemia

Segundo Alpino et al. (2020), as ações do Governo Federal brasileiro para minimizar os efeitos da COVID-19 até então propostas, constituíram-se em medidas emergenciais que focaram principalmente no acesso à renda e aos alimentos. Porém, a 
garantia do DHAA e a concretização da SAN demandam, além da articulação intersetorial, ações coordenadas não apenas emergenciais que objetivem a mitigação dos efeitos provocados pelas crises, mas medidas a médio e longo prazos que sejam capazes de garantir o direito constitucional à alimentação. Enfatizam ainda que a insegurança da população diante das incertezas oriundas do período pandêmico, tem sido aumentada significativamente pela crise política instalada no país neste momento, além das orientações contraditórias do poder público.

Em relação à opções de programas governamentais para o enfrentamento das consequências da COVID-19, particularmente relacionadas ao acesso à alimentação, estudo realizado por Sambuichi et al. (2020), mostrou que o Programa de Aquisição de Alimentos-PAA tem potencial para minimizar as crises sanitária e econômica, em especial para a parcela mais vulnerável da população, pois apresenta ações que vão ao encontro das demandas da sociedade civil organizada e de recomendações de organismos nacionais e internacionais especializados, visando à redução dos impactos econômicos e sociais da pandemia causada pelo novo coronavírus, sendo necessário , no entanto, a destinação de mais recursos, com vistas a contemplar a grande maioria da população mais carente.

É de suma importância enfatizar que a crise nacional causada pela Covid-19, mostra a verdadeira realidade de uma sociedade histórica e estruturalmente marcada pela desigualdade, onde ações do Estado são vitais para manutenção de rendas, empregos e fornecimento de apoio a populações vulneráveis com vistas a prevenir o aumento da pobreza e da fome (TROVÃO, 2020). Como também é relevante pontuar que o atual governo brasileiro foi reconhecido pela ONU, assim como pela comunidade científica internacional como um dos piores do mundo no que diz respeito ao enfrentamento das consequências da pandemia de COVID-19 (ONU, 2020).

\section{CONSIDERAÇÕES FINAIS}

A pandemia de COVID-19 revelou no Brasil, em meio a uma crise política préexistente, a fragilidade do sistema político, econômico, social e de saúde do país. As desigualdades sociais foram mais evidenciadas, revelando a maior vulnerabilidade das populações carentes à contaminação pela doença, o agravamento da privação de direitos humanos básicos, especialmente do direito à alimentação adequada, que 
somado a uma maior dificuldade no acesso aos serviços de saúde, trouxe sérios impactos na qualidade de vida e saúde destas populações, tornando-as ainda mais suscetíveis à COVID-19. Tudo isso sinaliza para a urgência na tomada de decisões mais acertadas, homogêneas em todo território nacional, por parte da gestão central do país, no sentido de mitigar as complexas consequências da atual pandemia, em contraposição às ações atuais que tem mostrado algumas dificuldades gerenciais no tocante à elaboração e implementação de políticas públicas realmente direcionadas a combater efetivamente a situação pandêmica e seus efeitos sobre o desemprego, pobreza e a fome.

\section{REFERÊNCIAS}

ALPINO, T.M.A.; SANTOS, C.R.B.; BARROS, D.C.; et al. COVID-19 e (in)segurança alimentar e nutricional: ações do Governo Federal brasileiro na pandemia frente aos desmontes orçamentários e institucionais. Cad. Saúde Pública, v. 36, n.8, p. e00161320, 2020.

AMORIM, A.L. B.; RIBEIRO, J.R.S.; BANDONI, D. H. Programa Nacional de Alimentação Escolar: estratégias para enfrentar a insegurança alimentar durante e após a COVID-19. Revista de Administração Pública [online]. 2020, v. 54, n. 4, pp. 11341145.

ANVISA - Agência Nacional de Vigilância Sanitária. Serviços de Saúde.2020. http://www.anvisa.gov.br/servicosaude/ organiza/index.htm.

ARRAIS, T.P.A.; OLIVEIRA, A.R.D.; ALENCAR, D.; et al. Relatório: Pandemia COVID-19: o caráter emergencial das transferências de renda direta e indireta para a população vulnerável do Estado de Goiás. Espaço e Economia: Revista Brasileira de Geografia Econômica; v.IX, p.13734,2020.

BARRETO, M.L.; BARROS, A.J.D.D.; CARVALHO, M.S.;et al. O que é urgente e necessário para subsidiar as políticas de enfrentamento da pandemia de COVID-19 no Brasil? Rev Bras Epidemiol, v.23, p. e200032, 2020.

BIERNATH, A. Quais as semelhanças entre a Covid-19 e outras pandemias do passado? Saúde, Abril Editora, abr. 2020.

BLUEDORN, J.; GOPINATH, G.; SANDRI, D. An early view of the economic impact of the pandemic in 5 charts. IMF Blog..., 2020.

BRASIL. Lei no 11.346, de 15 de setembro de 2006. Cria o Sistema Nacional de Segurança Alimentar e Nutricional - SISAN - com vistas a assegurar o direito humano à alimentação adequada e dá outras providências. Diário Oficial da União 2006; 18 set, 2006. 
BRASIL. Emenda constitucional n. 64, de 4 de fevereiro de 2010. Altera o art. 60 da Constituição Federal, para introduzir a alimentação como direito social. Diário Oficial da União, Brasília, DF, 5 fev. 2010.

Brasil. Ministério da Saúde. Secretaria de Atenção à Saúde. Departamento de Atenção Básica.

POLÍTICA NACIONAL DE ALIMENTAÇÃO E NUTRIÇÃO-PNAN / Ministério da Saúde, Secretaria de Atenção à Saúde. Departamento de Atenção Básica.Básica. - 1. ed., 1. reimpr. - Brasília : Ministério da Saúde, 2013.84 p.

CONSELHO NACIONAL DE SEGURANÇA ALIMENTAR E NUTRICIONAL- CONSEA. A Segurança Alimentar e Nutricional e o direito à alimentação adequada no Brasil: Indicadores e monitoramento, da constituição de 1998 aos dias atuais. Brasília, 2010.

CROKIDAKIS, N. COVID-19 spreading in Rio de Janeiro, Brazil: do the policies of social isolation really work? Chaos Soliton Fract. v.136, p.e109930,2020.

DICKINSON, M. Food frights: COVID19 and the specter of hunger. Agric Human Values. 2020.

FOOD AND AGRICULTURAL ORGANIZATION (FAO). O direito humano à alimentação adequada no marco estratégico global para a segurança alimentar e nutricional: consenso global. Roma: FAO, 2014.

FÓRUM BRASILEIRO DE SOBERANIA E SEGURANÇA ALIMENTAR E NUTRICIONAL (FBSSAN). Garantir o direito à alimentação e combater a fome em tempos de coronavírus. Aliança pela Alimentação Adequada e Saudável. https://alimentacaosauda vel.org.br/garantir-o-direito-a-alimentacao-ecombater-a-fome-em-tempos-de-coronavi rus/6243/ (acessado em 28/06/2021).

GAMBA, J.C.M. O direito humano à alimentação adequada : revisitando o pensamento de Josué de Castro. Rev Jurídica da Presidência. v.11, n.95, p.52- 81, 2010.

GLOBAL FOOD SECURITY CLUSTER-GFSC. Coronavirus, impact on well-being, health, food access and food security. https://fscluster.org/sites/de fault/files/documents/covid_19_impact_on_food_security.pdf (acessado em 14/Mai/2020).

Global Network Against Food Crises; Food Security Information Network. Global Report on Food Crises. Joint analisys for better decisions. Washington DC: International Food Policy Research Institute; 2020.

LIPSITCH, M.; SWERDLOW, D. L.; FINELLI, L. Defining the Epidemiology of Covid-19 Studies Needed. The New England journal of medicine, v.382, n.13, p.194-1196, 2020. 
Maluf, R. Comer em tempos de pandemia e após. Jornal GGN 2020; 3 abr. ,2020<https://jornalggn.com.br/agrande-crise/comer-em-tempos-depandemia-e-apos-por-renato-s-maluf/. >

KERR, L.; KENDALL, C.; SILVA, A.A.M.; et al. COVID-19 no Nordeste brasileiro: sucessos e limitações nas respostas dos governos dos estados. Ciênc Saúde Coletiva. v.25, Suppl 2, p.4099-120.

MARCHISIO, M. The potential impact of COVID-19 on SDG 2 (food security) - in China and globally. International Fund for Agricultural Development. https://www.ifad.org/ en/web/latest/blog/asset/41828816 (acessado em 13/06/2021).

MORAES, R.F.D. COVID-19 e medidas legais de distanciamento social: tipologia de políticas estaduais e análise do período de 13 a 26 de abril de 2020. Brasília: Instituto de Pesquisa Econômica Aplicada; (Nota Técnica, 18), 2020.

NICOLA, M.; ALSAFI, Z.; SOHRABI, C.; et al. The socio-economic implications of the coronavirus pandemic (COVID-19): A review. International journal of surgery (London, England), v.78, p.185-193,2020.

OLIVEIRA, T.C.; ABRANCHES, M.V.; LANA, R.M. (In)Segurança alimentar no contexto da pandemia por SARS-CoV-2. Cad Saúde Pública. v.36, n.4, p.e00055220,2020.

ORGANIZAÇÃO DAS NAÇÕES UNIDAS (ONU). Declaração Universal dos Direitos Humanos, 1948.

ORGANIZAÇÃO DAS NAÇÕES UNIDAS (ONU). Pacto Internacional dos Direitos Econômicos, Sociais e Culturais (Pidesc), 1966.

ORGANIZAÇÃO DAS NAÇÕES UNIDAS (ONU). Organizações das Nações Unidas. Comentário

geral n. 12: o direito humano à alimentação adequada (art. 11), 1999.

ORGANIZAÇÃO DAS NAÇÕES UNIDAS (ONU). COVID-19: políticas econômicas e sociais no Brasil colocam milhões de vidas em risco. Chile: ONU para los Derechos Humanos; 2020.

RECINE, E.; GARCIA, G. A sociedade civil e a garantia da Segurança Alimentar e Nutricional. In: Preiss PV, Schneider S, Coelho-de-Souza GA. Contribuição Brasileira à Segurança Alimentar e Nutricional Sustentável. 1ed. Porto Alegre: Editora da UFRGS; 2020. p.107-124.

RECINE, E.;FAGUNDES, A.;SILVA,B.L.;et al. Reflections on the extinction of the National Council for Food and Nutrition Security and the confrontation of Covid-19 in Brazil. Rev. Nutr.;v.33:e200176,2020. 
SAMBUICHI, R.; ALMEIDA, A.;PERIN, G.;SPÍNOLA, P.; PELLA, A. O Programa de Aquisição de Alimentos (PAA) como estratégia de enfrentamento aos desafios da COVID19. Revista de Administração Pública. v.54. p.1079-1096,2020.

SINGU, S.; ACHARYA, A.; CHALLAGUNDLA, K.; et al. Impact of Social Determinants of Health on the Emerging COVID-19 Pandemic in the United States. Frontiers in public health, v.8, n.406, 2020. https://doi.org/10.3389/fpubh.2020.00406

The International Panel of Experts on Sustainable Food Systems-IPES-Food. COVID-19 and the crisis in food systems: symptoms, causes, and potential solutions. Bruxelas: The International Panel of Experts on Sustainable Food Systems; 2020.

TROVÃO, C.J.B.M. A pandemia da Covid-19 e a desigualdade de renda no Brasil: um olhar macrorregional para a proteção social e os auxílios emergenciais: texto para discussão. Natal: Universidade Federal do Rio Grande do Norte; 2020. 


\title{
CAPITULO XXI
}

\section{HÁBITOS ALIMENTARES DE ALUNOS DE UMA ESCOLA PÚBLICA DE TERESINA-PI: UMA PROPOSTA INTERDISCIPLINAR NO CURSO DE LICENCIATURA EM CIÊNCIAS BIOLÓGICAS}

DOI: 10.51859/AMPLLA.DES1788-21

\author{
Francisco Kássio Teixeira de Moura ${ }^{1}$ \\ Laisa Pontes da Silva ${ }^{2}$ \\ Alexandra Lopes Carvalho ${ }^{3}$ \\ Anna Carulina Aguiar ${ }^{4}$ \\ Karen da Silva Tavares ${ }^{5}$ \\ Divamélia Oliveira Bezerra ${ }^{6}$
}

\footnotetext{
${ }^{1}$ Esp. em Ensino de Química-UCAM, graduado em Lic. em Química-UFPI, graduando em Lic. Em Ciências Biológicas pelo Instituto Federal do Piauí- IFPI.

2,3,4,5 Graduandas em Licenciatura em Ciências Biológicas pelo Instituto Federal do Piauí-IFPI

${ }^{6}$ Professora do Departamento de Formação de Professores do Instituto Federal do Piauí- IFPI, Doutora em GeografiaUNESP, Mestre em Botânica- UFRPE, Graduada em Lic. em Ciências Biológicas-UESPI.
}

\section{RESUMO}

O presente trabalho foi realizado por alunos de graduação do curso de Licenciatura em Ciências Biológicas do Instituto Federal do Piauí, Campus Teresina-central, tendo como campo da pesquisa uma escola pública localizada em Teresina-PI (escola da Rede Estadual de Ensino), com o objetivo de verificar os hábitos alimentares dos alunos e conscientiza-los sobre os benefícios de uma alimentação adequada e os riscos de uma alimentação inadequada, integrando diferentes disciplinas do curso e promovendo a interdisciplinaridade no curso de Licenciatura em Ciências Biológicas, durante a disciplina de Projeto Integrador II, com a temática alimentação saudável, realizou-se a coleta de dados através de questionários de acordo com Gil (2008), utilizou-se a bioestatística para quantificar os dados e inserir nos gráficos, os sujeitos da pesquisa foram alunos do segundo e terceiro ano do ensino médio, com faixa etária de idade entre 16 e 20 anos, após a coleta de dados realizou-se uma mesa-redonda no pátio da escola e distribuiu-se folders informativo com os dez passos para uma alimentação saudável.

Palavras-chave: Alimentação Saudável. Interdisciplinaridade. Projeto Integrador. 


\section{INTRODUÇÃO}

A disciplina de Projeto Integrador do curso de Ciências Biológicas do Instituto Federal de Educação, Ciência e Tecnologia do Piauí, tem como proposta desenvolver saberes educacionais e interdisciplinares aos estudantes, assim como, contribuir para o desenvolvimento pessoal e profissional dos graduandos (BRASIL, 2015). Ainda de acordo com Brasil (2015), os Projetos Integradores do IFPI são desenvolvidos do primeiro ao quarto período nos cursos de licenciaturas, sendo que cada projeto tem que ser obrigatoriamente vinculados às disciplinas do período.

Conforme a Lei de Diretrizes e Bases, Brasil (1996) a formação de professores deve atender certos objetivos educacionais, independentemente do nível de e modalidade de ensino, uma tarefa fundamental para o desenvolvimento do educando. Por isso, ainda conforme Brasil (1996) torna-se necessário o docente aliar a teoria e prática, porém, para isso é fundamental uma capacitação, além disso, as experiências acadêmicas e profissionais podem contribuir para a autor formação e para o desenvolvimento, tanto do discente como do docente.

Portanto, a proposta dos Projetos Integradores, é desenvolver pesquisas de forma interdisciplinar, colocando em prática, seja dentro ou fora da instituição, associando à teoria à prática e contribuindo para formação dos futuros professores (BARRETO et al., 2007). Assim como discutir sobre um tema e associando as disciplinas do período do curso de graduação.

A proposta dessa pesquisa, consiste em verificar os hábitos alimentares de alunos de uma escola pública de Teresina-PI e através de uma mesa-redonda destacouse a importância de uma alimentação saudável expondo as consequências relacionadas ao mau hábito alimentar.

\section{REVISÃO DE LITERATURA}

\subsection{ALIMENTAÇÃO SAUDÁVEL}

A alimentação saudável é uma prática alimentar apropriada aos aspectos biológicos e socioculturais dos indivíduos, assim como se constitui em um direito fundamental para a vida, bem como ao uso sustentável do meio ambiente, ou seja, deve 
estar em acordo com as necessidades, nutricionais de cada fase do curso da vida (BRASIL, 2013).

Segundo Philippi (2014), uma alimentação saudável deve ser planejada com vários alimentos de todos os grupos alimentares, constituído de forma segura e conhecida, para consumirmos durante as refeições, levando em consideração as diferenças emocionais e principalmente sociais, de forma a suprir as recomendações nutricionais do corpo e o prazer ao ingerir alimentos.

A alimentação constitui-se de uma sequência que começa pela escolha do alimento em seguida segue certas etapas, seja de pré-preparo e preparo, até ocorrer à absorção do alimento. É através de uma seleção consciente, criteriosa e lúcida, dos alimentos que transformamos a nutrição do nosso organismo e principalmente das nossas células, assim, adquirindo novas condições com o exterior (SCHILLING, 1995).

Uma nutrição desequilibrada pode estar relacionada com a fadiga, alcoolismo e até mesmo com a violência (SCHILLING, 1995). Para Danon e Polini (2002), uma alimentação desequilibrada ou inadequada, adotados pela população, pode acarretar diversos problemas de saúde, como a obesidade que vem aumentando descontroladamente entre adultos, crianças e adolescentes.

Conforme Danon e Polini (2002), um dos principais fatores de uma escolha inadequada de consumo de alimentos, é a falta de informação, principalmente sobre o valor calórico do alimento. E esse fator se torna mais crítico quando levado em consideração as limitações e restrições impostas pela vida moderna urbana, principalmente em hotéis e restaurantes e lanchonetes, lugares onde seus consumidores não se preocupam em saber como é feita a escolha dos alimentos e se são saudáveis.

A alimentação é um direito universal e humano, pois, constitui-se o direito a vida e a cidadania, além disso, é um requisito básico para a melhoria e a proteção da saúde, possibilitando a afirmação plena do potencial de crescimento e desenvolvimento humano, com qualidade de vida e cidadania. (BRASIL, 2013). Para Alves e Jaime (2014), a promoção da saúde vai além de aspectos individuais passa pela garantia de condições que forneça ou criem uma base favorável à integração de estilos de vidas saudáveis.

De acordo com Brasil (2007), as diferenças de renda influenciam e são expressas no padrão de consumo alimentar dos diferentes estados. A dieta dos brasileiros de mais 
baixa renda apresenta melhor qualidade, com predominância do arroz, feijão aliados a alimentos básicos como peixes e milho. A frequência de alimentos de baixa qualidade nutricionais como doces, refrigerantes, pizzas e salgados fritos e assados, tende a crescer com o aumento da renda das famílias.

O interesse por uma qualidade de melhor e mais saudável, despertou um padrão de vida e saúde equilibrado conforme Danon e Polini (2002), os autores destacam que em consequência disso as pessoas têm buscado também um padrão estético de beleza. Ainda segundo Donon e Polini (2002) apesar da busca das pessoas por uma alimentação saudável, houve uma necessidade em informações a respeito desse tema.

O padrão de consumo dos alimentos varia de acordo com os grupos e faixa etária, Entre os mais jovens, a probabilidade de consumo é maior com alimentos ultraprocessados, que tendem a diminuir com o aumento da idade, enquanto o inverso é observado entre as frutas e hortaliças, ou seja, o consumo de frutas é pouco entre jovens é maior entre adultos (BRASIL, 2007). Ainda de acordo com Brasil (2007) os adolescentes são o grupo com pior perfil da dieta, com as menores frequências de consumo de alimentos rico em ferro como o feijão, saladas cruas ou cozidas e verduras em geral, apontando para um prognóstico de aumento do excesso de peso e doenças crônicas.

Conforme Brasil (2013), uma alimentação nutricional saudável constitui como um requisito básico para o ser humano e necessário para promoção de sua saúde e uma vida saudável, possibilitando ainda um desenvolvimento com uma ótima qualidade de vida. Ainda conforme Brasil (2013), uma alimentação saudável é um direto universal promulgada na declaração dos direitos humano.

Conforme o Brasil (2014), a alimentação saudável deve fornecer água, carboidratos, proteínas, lipídios, vitaminas, fibras alimentares e minerais, os quais são insubstituíveis e indispensáveis ao bom funcionamento do organismo. Ainda de acordo com Brasil (2014) a diversidade dietética que fundamenta o conceito de alimentação saudável pressupõe que nenhum alimento específico ou grupo deles, isoladamente, é suficiente para fornecer todos os nutrientes necessários a uma boa nutrição e consequente manutenção da saúde.

A alimentação constitui-se como um recurso fundamental para sobrevivência humana, que pode ser modificada pela cultura e sobre aspectos socioeconômicos, assim, sofre efeitos pela sociedade organizada (BALCHIUNAS, 2014). Ainda conforme 
Balchiunas (2014) a alimentação exerce e concebe um importante papel para sociedade, uma vez que, averiguar as concepções e hábitos alimentares de diferentes grupos sociais, assim, ajudando a compreender o procedimento mudança de hábitos alimentares e verificar as consequências da alimentação.

Balchiunas, (2014, p. 23), afirma que "a presença de um gestor em locais de produção de refeição pode contribuir para uma oferta de um padrão de consumo alimentar adequado." Conforme Bento, Esteves e França (2015) práticas alimentares inadequadas têm grandes causados vários problemas de saúde, distúrbios como a obesidade, que podem estar presentes na adolescência e na vida adulta, acarretando prejuízos psicológicos, sociais e em sua saúde geral.

Uma prática alimentar pode ser compreendida como um ato ou forma de convívio com o alimento. Então a prática alimentar compreende-se como um conjunto de ações realizado por um grupo de indivíduos que decide qual alimento vai consumir, durante a disponibilidade e do hábito alimentar (PHILIPPI, 2012). Os alimentos devem ser consumidos passivamente de forma higiênica e adequada, seja quantitativamente e qualitativamente, preservando seus nutrientes, pois, todo alimento contém energia e nutrientes (PHILIPPI, 2012).

\section{METODOLOGIA}

O presente trabalho é um projeto desenvolvido na disciplina de Projeto Integrador II do curso de Licenciatura em Ciências Biológicas do Instituto Federal do Piauí, que visa à interdisciplinaridade entre as disciplinas de Projeto Integrador II e Bioestatística com o tema Alimentação Saudável.

A metodologia do presente trabalho consiste em uma pesquisa de caráter quantitativa e qualitativa. Conforme Gunther (2006) a pesquisa quantitativa tenta controlar o contexto pesquisado, sempre com a intenção de reduzir ou excluir certas interferências das variáveis existentes que interferem nesse processo sendo irrelevante a pesquisa, enquanto a pesquisa qualitativa segundo Gunther (2006), revela uma certa falta de controle das variáveis existentes, porém, há uma constatação de que não há interferências irrelevantes.

Para coleta de dados utilizou-se questionários com perguntas fechadas, segundo Gil (2008), os questionários consistem em uma técnica de investigação, ou seja, um 
conjunto de questões que visam ou buscam informações a respeito de um determinado tema. Os sujeitos da pesquisa foram alunos do segundo e terceiro ano do ensino médio do turno vespertino, com idade entre 16 e 20 anos, durante a coleta de dados a identidade dos sujeitos pesquisados/entrevistados foram totalmente preservadas.

A primeira etapa do projeto consistiu-se na elaboração de um questionário pelos autores do trabalho (cuja, as perguntas estão inseridas nos gráficos abaixo), com perguntas sobre hábitos alimentares dos alunos, levando em questão os fatores socioeconômicos dos entrevistados.

Na segunda etapa aplicou-se o questionário na Escola para os alunos, na qual, executou-se em cinco turmas diferentes, sendo que em cada turma aplicou-se apenas dez questionários. Foram aplicados apenas dez questionários em cada turma, devido aos recursos financeiros, porém, optou-se por diversificar a quantidade de turmas.

A terceira etapa constituiu-se em uma mesa-redonda ministrada pelos autores do trabalho, sobre alimentação saudável, na escola, na qual, apresentou-se o resultado da pesquisa aos alunos, além disso, entregou-se um folder com os dez passos para uma alimentação saudável, e advertiu a comunidade escolar a importância da alimentação saudável. Durante a mesa-redonda utilizou-se um banner explicativo com uma Pirâmide Alimentar, destacando a importância dos alimentos, explicando os benefícios de uma boa alimentação.

\section{RESULTADOS E DISCUSSÕES}

Por meio do levantamento estatístico obtiveram-se, dados informativos a respeito da alimentação da "comunidade escolar". Além disso, verificou-se como os alunos mantem sua alimentação, se satisfatória ou insatisfatória, como mostra os resultados abaixo. Esses dados foram de grande importância para promover um debate na escola com os alunos e gestores, além de destacar a importância de uma alimentação saudável.

Os questionários foram aplicados para quarenta e oito alunos da escola, a faixa etária de idade dos alunos entrevistados varia entre, 16 e 20 anos de idade, sendo que 41\% dos entrevistados têm 18 anos, 29\% têm 17 anos, 15\% têm 19 anos, 13\% têm 20 anos e apenas $2 \%$ têm 16 anos de idade, ou seja, $69 \%$ dos entrevistados são maiores de idade enquanto apenas $31 \%$ são menores de idade. Sendo $40 \%$ é do sexo masculino e 
$60 \%$ do sexo feminino. Destes, cerca de $37 \%$ estavam cursando o 20 ano do ensino médio enquanto $63 \%$ cursando o $3 \%$ ano do ensino médio.

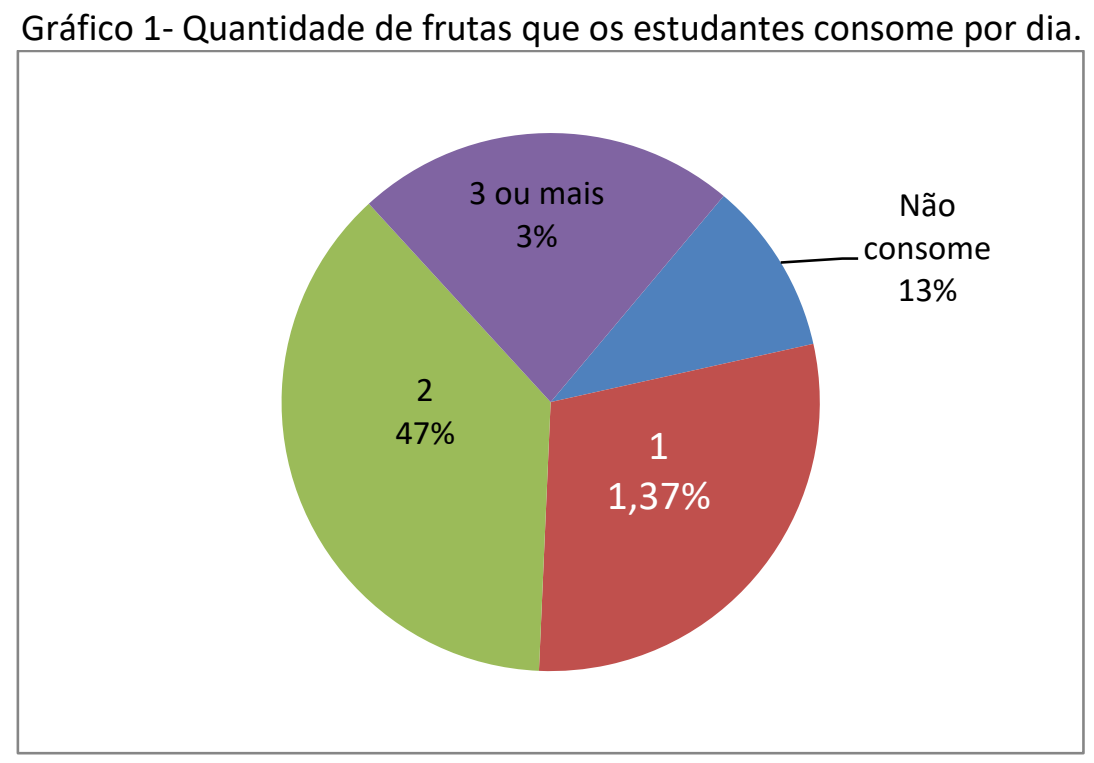

Fonte: Própria dos autores.

Segundo o gráfico 1, 37\% dos entrevistados consome apenas uma fruta por dia, $47 \%$ consomem duas frutas por dia, apenas 3\% consomem 3 ou mais frutas durante 0 dia, enquanto $13 \%$ não consome nenhuma fruta, um percentual quatro vezes menor, em comparação aos que consome 3 frutas ou mais, ou seja, percebe-se um índice muito alto dos entrevistados que não consome fruta. Conforme Almeida e colaboradores (2009) as frutas constituem-se como fontes valiosas, saudáveis, com grandes quantidades de minerais essenciais à saúde humana. 
Gráfico 2 - Bebidas que os entrevistados ingeri: Suco natural, suco industrializado e/ou refrigerante.

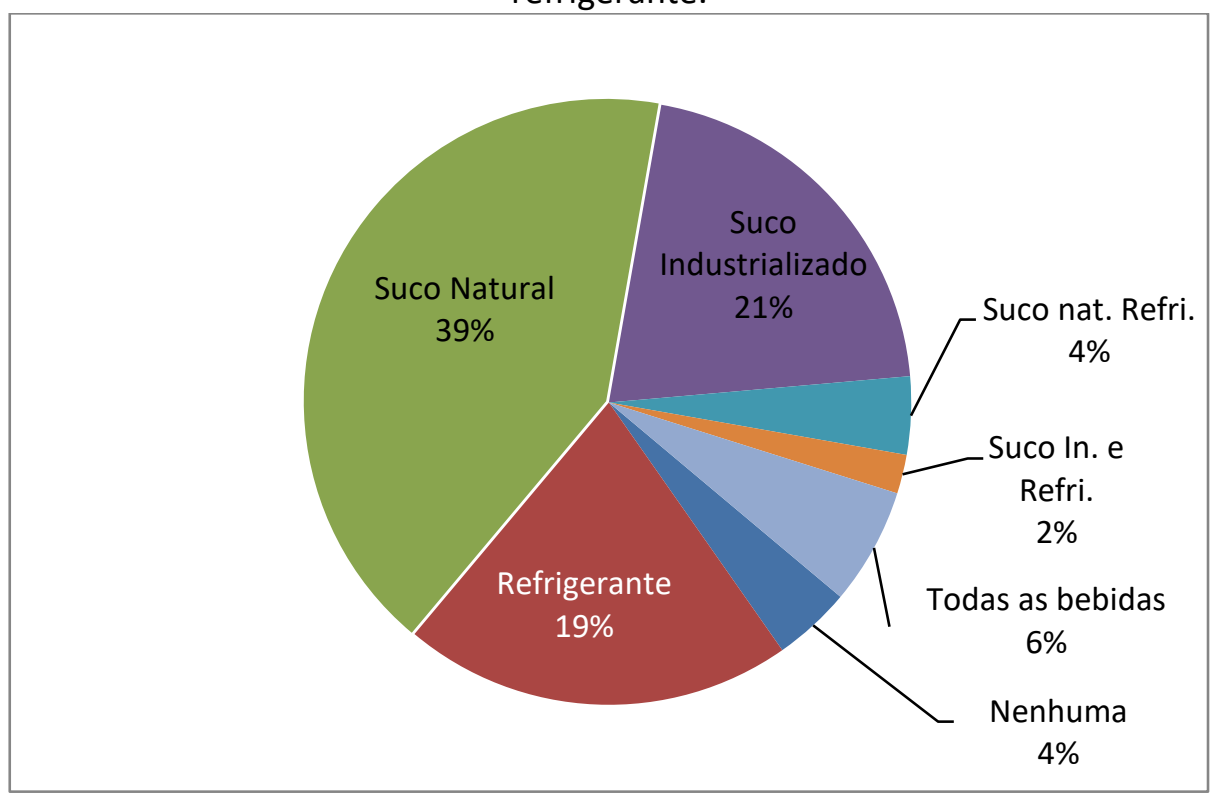

Fonte: Própria dos autores.

Conforme o gráfico $2,39 \%$ dos entrevistados ingeri suco natural, $21 \%$ suco industrializado, $19 \%$ refrigerante, $4 \%$ suco natural e refrigerante, $2 \%$ suco industrializado e refrigerante enquanto $6 \%$ consomem todas as bebidas, apenas $4 \%$ não consome nenhuma das bebidas. Conforme Camargo e colaboradores (2007) o consumo de sucos naturais torna-se uma alternativa de consumo de bebidas saudáveis, ao contrário dos refrigerantes que possui grandes quantidades de açúcar.

Gráfico 3 - Frequência do consumo verduras pelos estudantes.

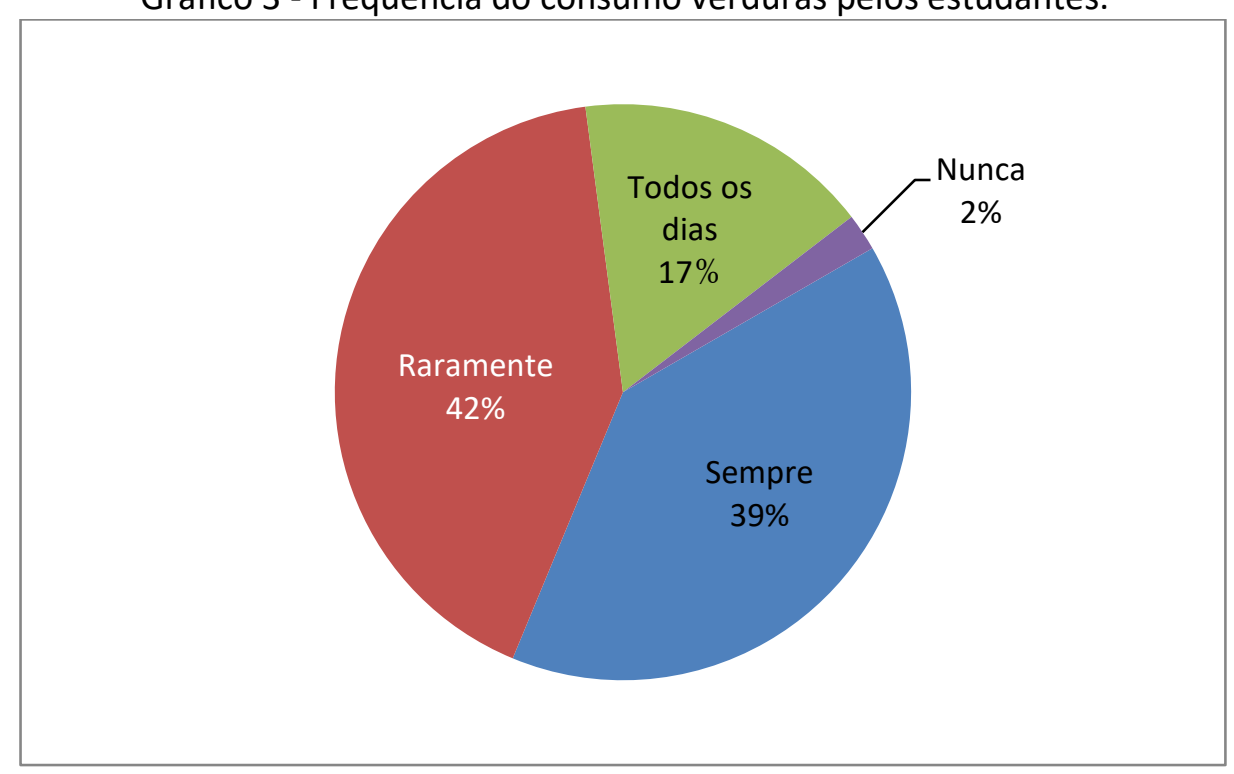

Fonte: Própria dos autores. 
De acordo com o gráfico 3, apenas $2 \%$ dos entrevistados não consomem verduras, enquanto $39 \%$ consomem sempre, $17 \%$ consomem todos os dias, e $42 \%$ consomem raramente, este é um dado preocupante. No estudo de Hoffman e Colaboradores (2015) eles perceberam e concluíram que as verduras são alimentos considerados saudáveis, sendo um estilo benéfico à saúde humana.

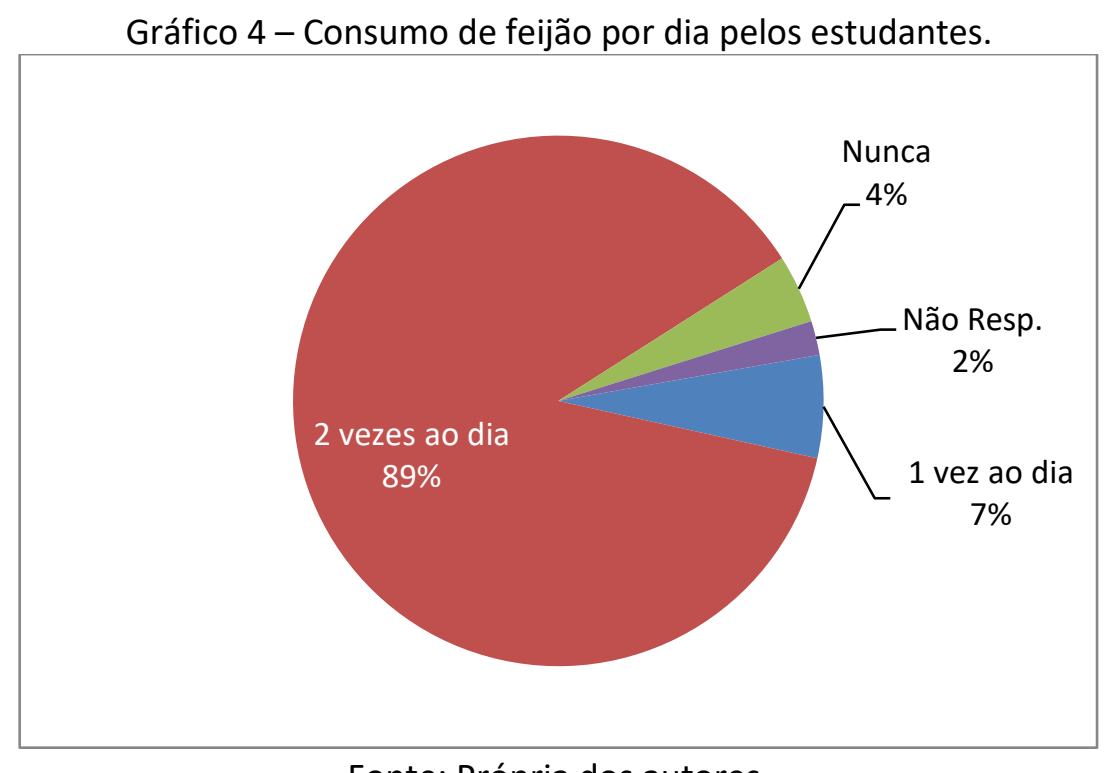

Fonte: Própria dos autores.

Segundo o gráfico 4, 89\% dos entrevistados consome feijão duas vezes ao dia durante a semana, enquanto $7 \%$ consomem feijão uma vez por dia durante a semana e apenas $4 \%$ não consome feijão, um dado preocupante, pois, o feijão e rico em ferro, $2 \%$ dos entrevistados não respondeu ou não soube opinar. Conforme Costa (2002), o feijão possui uma grande proporção de valor nutritivo e diversas proteínas, independentemente de sua cor ou qualidade, sendo assim, um dos melhores alimentos para o combate a desnutrição, pois, possuem vitaminas, sais minerais, fundamental para o crescimento, tornando-se uma alimentação eficiente. 


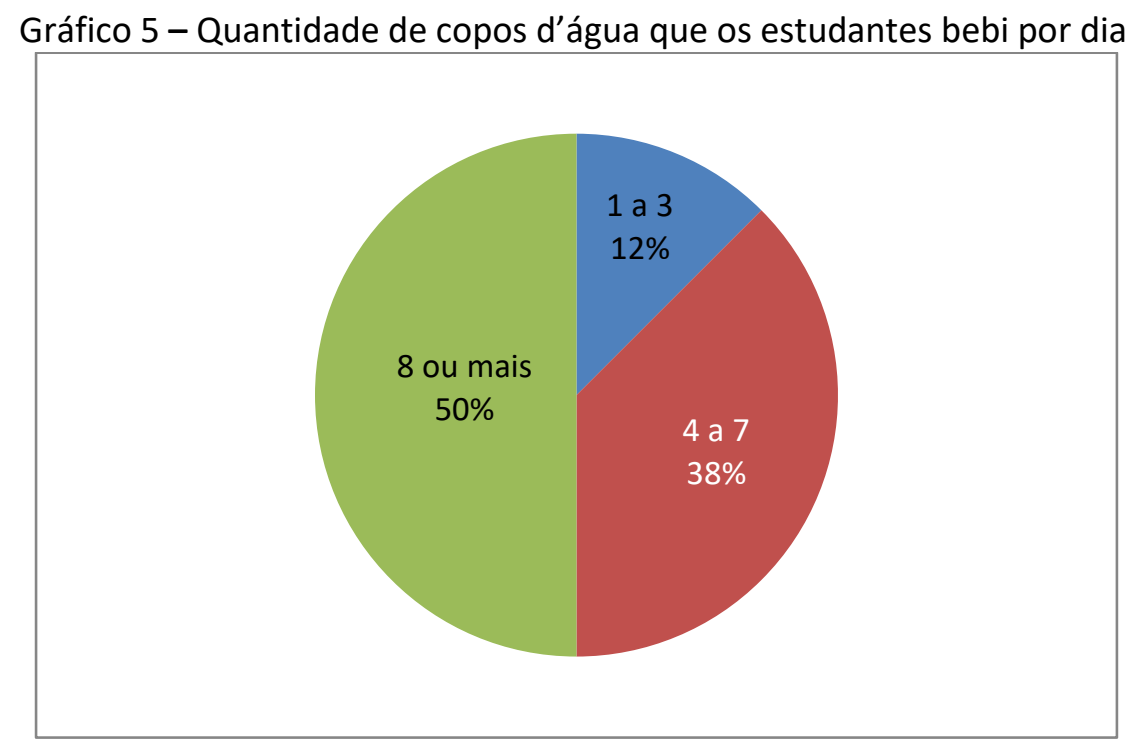

Fonte: Própria dos autores.

Conforme o gráfico 5 , cerca de $50 \%$ dos entrevistados bebi oito ou mais copos d'água por dia, 38\% bebi de 4 a 7 copos d'água por dia enquanto $12 \%$ bebi de 1 a 3 copos d'água, um dado preocupante, pois Teresina é uma das capitais mais quente do país e o consumo excessivo de água hidrata o corpo.

Conforme Cruz Neto (2010) a água é essencial para o ser humano, constitui-se como uma fonte de vida para os seres humanos, pois é responsável por vários processos como: digestão, circulação entre outros, além disso, água desempenha diversas funções no organismo humano, como lubrificar, mastigar além de participar das reações química e metabólicas no corpo humano.

Gráfico 6-Quantidade de ovos você consumidos por semana pelos estudantes.

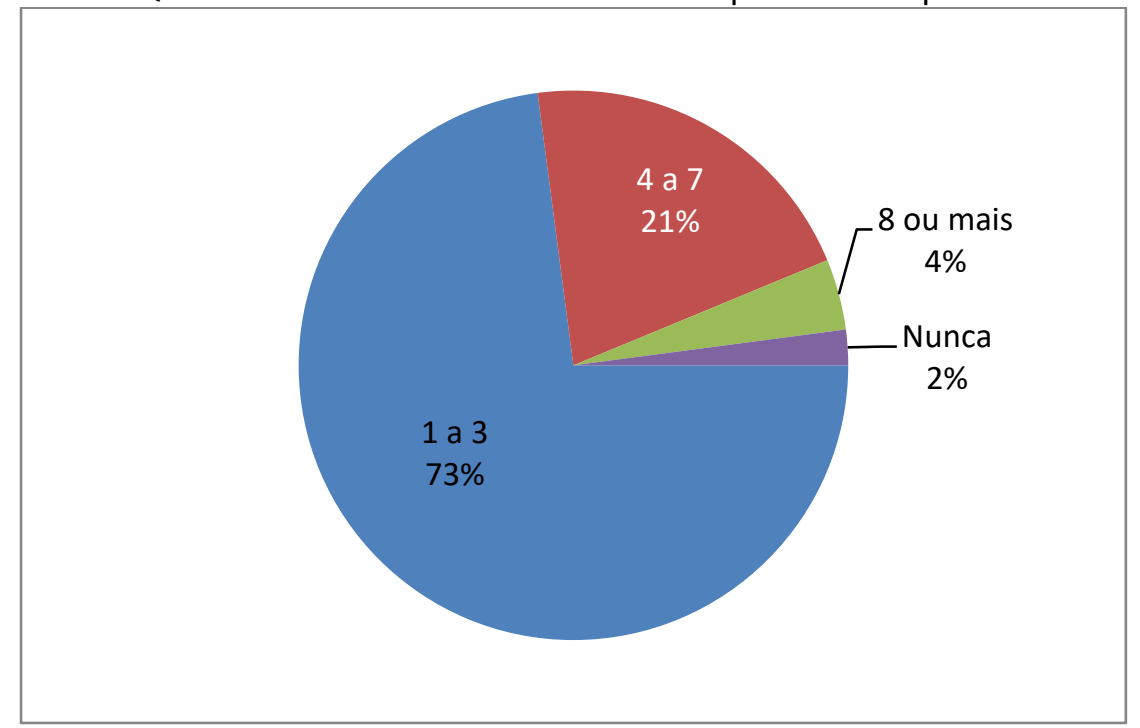

Fonte: Própria dos autores. 
Segundo o gráfico 6, cerca de 73\% dos entrevistados consomem de 1 a 3 ovos por semana, enquanto $21 \%$ consomem de 4 a 7 ovos e $4 \%$ consomem 8 ou mais ovos durante a semana, apenas $2 \%$ não consome ovos, um dado preocupante. Para Costa (2002), os ovos constituem-se em um alimento importante no combate à anemia e para pessoas que sentem fraqueza, pois, é rico em ácido pantatênico, é precursor do colesterol, e contém vitaminas que são adequadas para os tecidos epiteliais, além disso, possuem vitaminas como A, D, E e K, sua clara possui vitamina B12, sabe-se por possui $r$ uma alta taxa de colesterol não é recomendado para pessoas como hipercolesterolemias.

Gráfico 7 - Consumo de carne vermelha pelos estudantes.

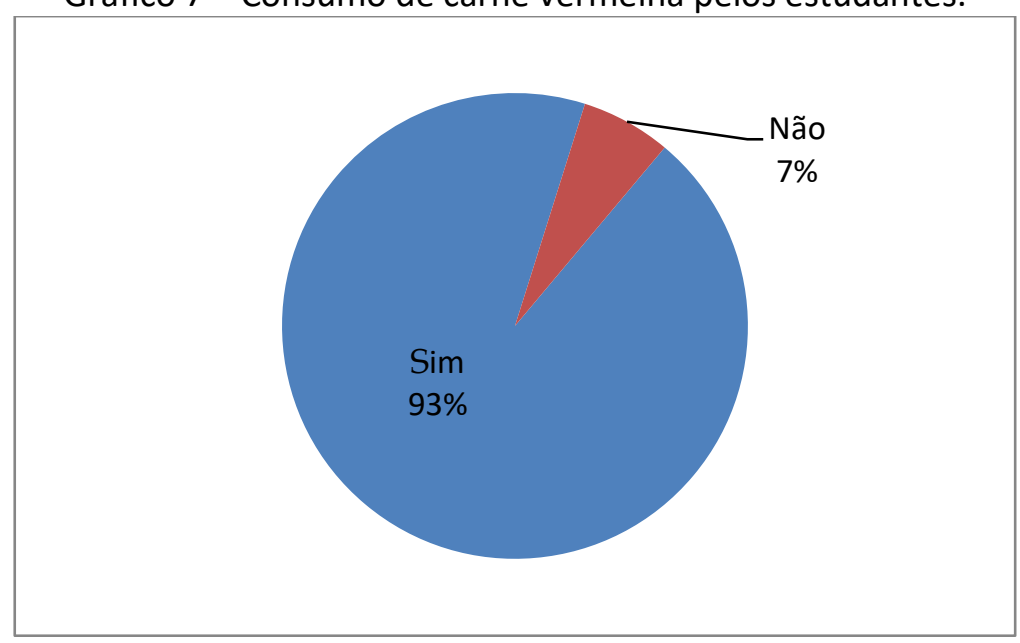

Fonte: Própria dos autores.

De acordo com o gráfico 7, 93\% dos entrevistados consomem carne vermelha, um dado satisfatório, pois, segundo Costa (2002), a carne vermelha como a bovina é rica em proteínas além de proteínas, pigmentos e vitaminas, a carne bovina também possui uma riquíssima fonte de ferro, fosforo e potássio, componentes essenciais para o combate a anemia. Enquanto apenas 7\% não consomem carne vermelha. 
Gráfico 8 - Consumo de alimentos embutidos como: mortadela, linguiça, calabresa pelos estudantes.

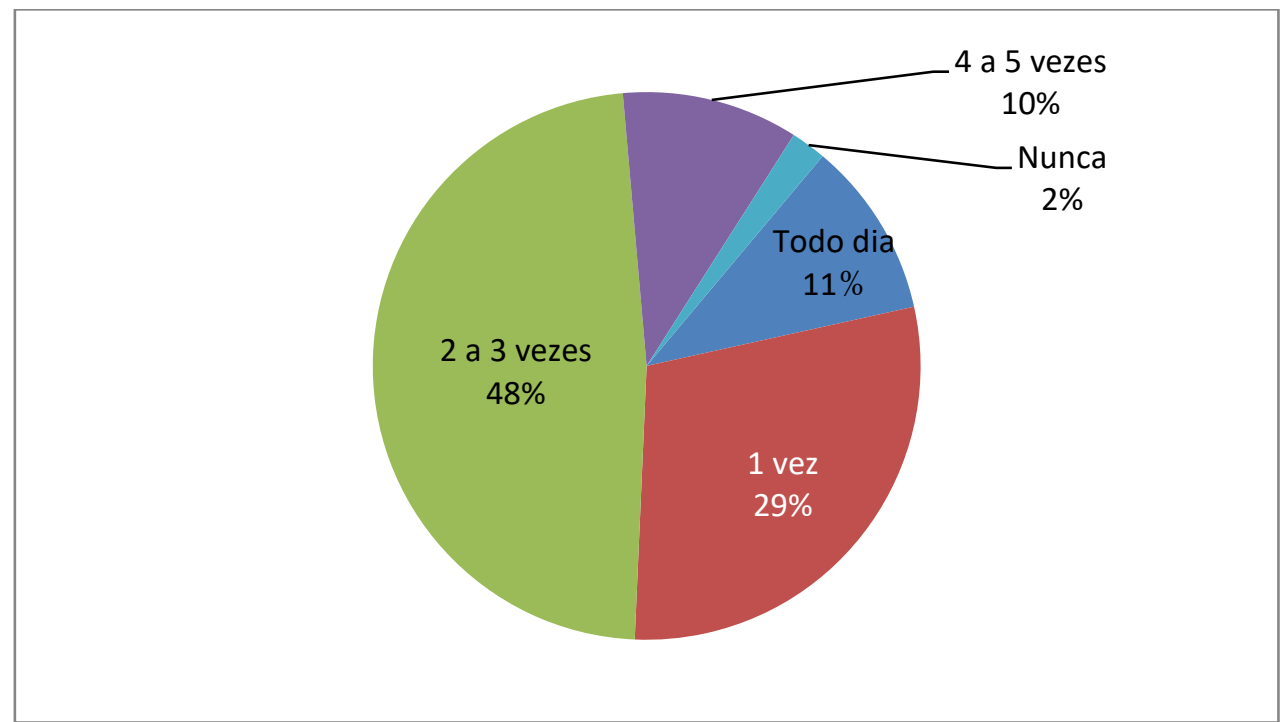

Fonte: Própria dos autores.

Conforme o gráfico 8, 29\% dos entrevistados consomem apenas uma vez por semana embutidos, $48 \%$ de duas a três vezes por semana e $10 \%$ comem de 4 a 5 vezes por semana, $11 \%$ consome embutidos todos os dias e apenas $2 \%$ não come embutidos.

Gráfico 9-Quantidade de estudantes que trocam almoço ou o jantar por lanches.

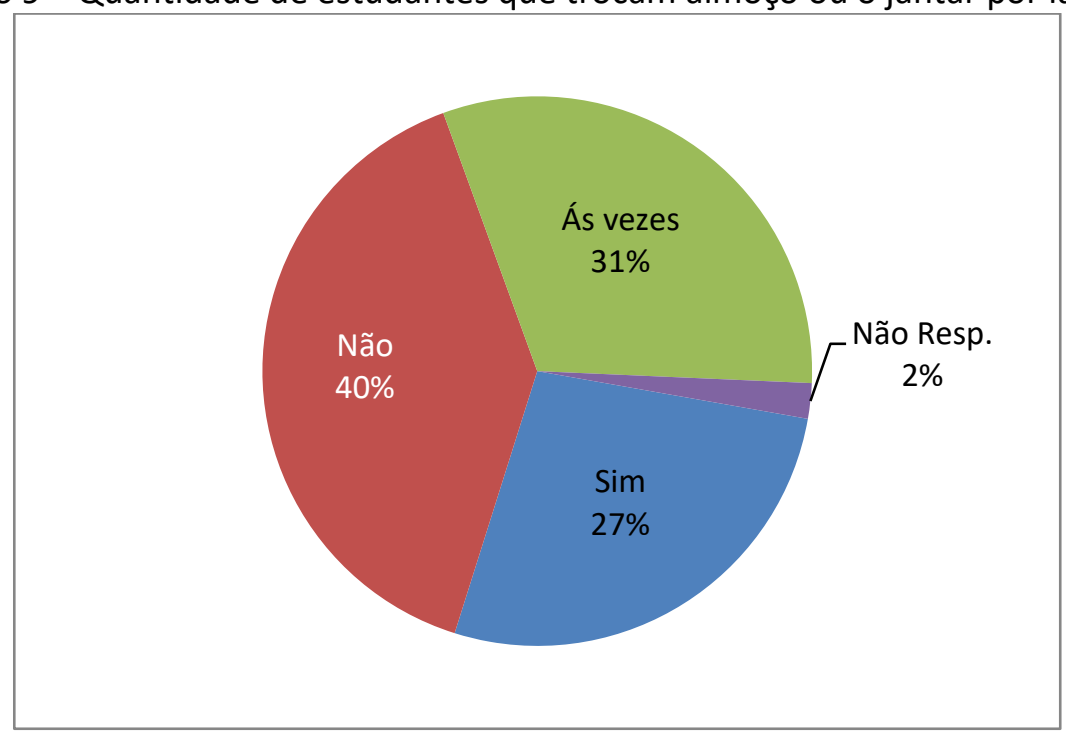

Fonte: Própria dos autores.

De acordo com o gráfico 9, 40\% dos entrevistados não troca refeições por lanches enquanto $27 \%$ trocam refeições por lanches e $31 \%$ às vezes trocam almoço ou jantar por lanches e $2 \%$ não respondeu e não soube opinar sobre a pergunta. 
Gráfico 10 - Consumo de carne branca pelos estuantes.

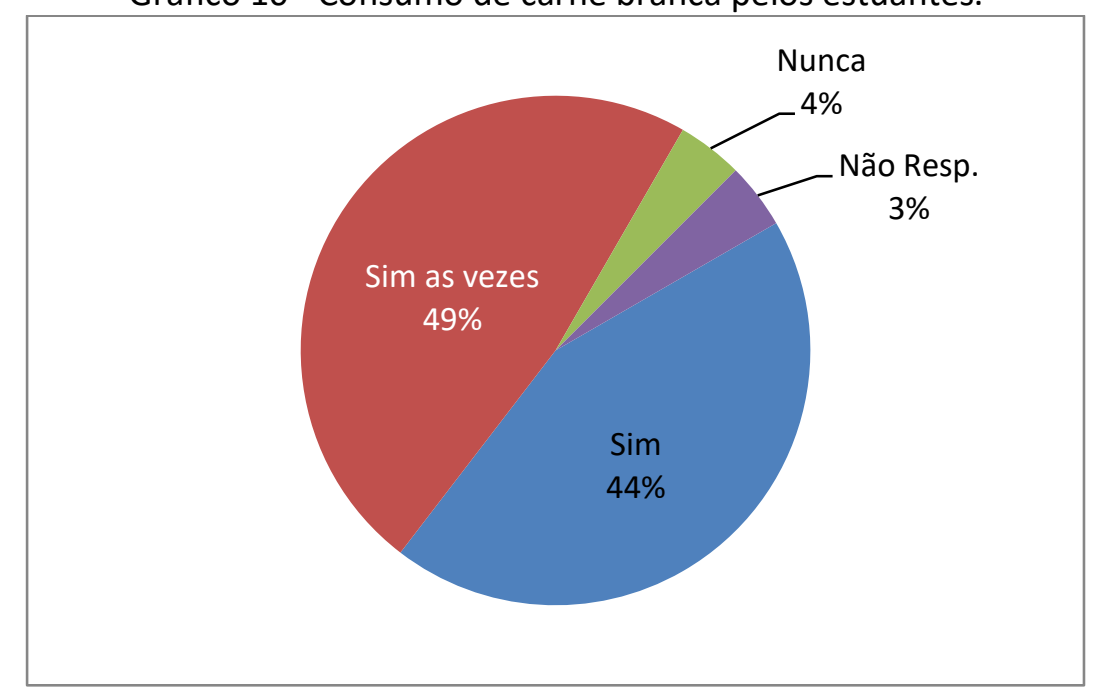

Fonte: Própria dos autores.

Segundo o gráfico 10,44\% dos entrevistados consome carne branca com frequência, enquanto $49 \%$ consomem carne branca às vezes, levando em consideração a soma desses dois percentuais, percebe-se que $93 \%$ dos entrevistados consomem carne branca, um dado satisfatório, pois, segundo Costa (2002), carne branca como a de peixe possuem vitaminas e minerais de grandes valores nutritivos, além de gorduras essenciais, enquanto carne branca como a de aves é rica em ferro, fosforo e vitaminas. $4 \%$ dos entrevistados não consomem carne branca. E 3\% não responderam ou não souberam opinar.

Realizou-se uma mesa-redonda, (palestra) com os alunos e com os gestores da escola, com a intenção de informar aos alunos e a comunidade escolar sobre os benefícios de uma boa alimentação, assim como, os malefícios, o objetivo foi conscientizar os alunos quanto sua alimentação, folders com os dez passos para uma alimentação saudável foram distribuídos para os alunos e professores da escola.

Figura 1- Mesa com folders informativos.

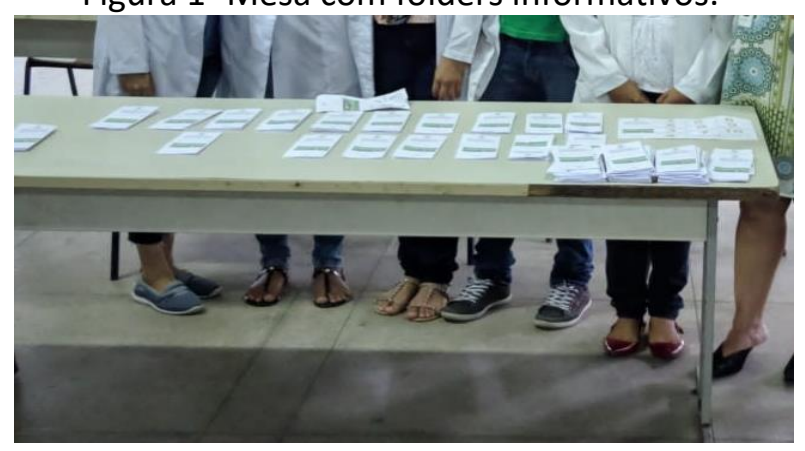

Fonte: Própria dos autores. 
Verificou-se o quanto a comunidade escolar é desinformada quanto aos malefícios que uma alimentação inadequada pode causar, e não sabem os benefícios que uma alimentação adequada pode fazer a saúde humana, percebeu-se que os entrevistados precisam ingerir mais água, pois, segundo a pesquisa a quantidade de água que a maioria dos entrevistados ingere é insuficiente, pois a água é importante para hidratação e para saúde.

Apresentou-se um banner informativo com a pirâmide alimentar, destacando a importância do consumo de cada alimento da pirâmide, explicando quais devem ser evitados, quais os mais importantes para consumo.

\section{CONSIDERAÇÕES FINAIS}

O projeto foi de grande importância não só para os acadêmicos do curso de Licenciatura em Ciências Biológicas do IFPI, mas para toda a comunidade escolar. Tendo em vista, o ganho de informações por parte dos alunos, da escola que aceitou participar do projeto e a experiência que os autores vivenciaram e podem levar para futuros projetos em outras escolas. Atividades como essa promovem um grande aprendizado, e sobre tudo, desperta o lado pesquisador dos graduandos, pois uma graduação de excelência deve ser pautada na pesquisa, na educação e na extensão.

Foi possível promover e perceber a importância da interdisciplinaridade, visto que, integrou-se o tema Alimentação Saudável com o curso de Ciências Biológicas e as dicsiplinas de Bioestatística e Projeto Integrador II em um espaço acadêmico carente de projetos educacionais. A pesquisa serviu para observar como é a alimentação dos entrevistados, uma vez que, a maioria são adolescentes, e principalmente para promover o debate sobre Alimentação Saudável na escola e conscientizando os mesmos sobre a importância de uma alimentação pra saúde humana.

\section{REFERÊNCIAS}

ALMEIDA, M. M. B. et al. Avaliação de macro e microminerais em frutas tropicais cultivadas no nordeste brasileiro. Revista de Ciência e Tecnologia dos Alimentos, v. 29, n.3, 2009.

ALVES, K. P. S.; JAIME, P. C. A política nacional de alimentação e nutrição e seu diálogo com a política nacional de segurança alimentar e nutricional. Revista Ciência e Saúde Coletiva, n. 19, v. 11, p. 431-440, 2014. 
BALCHIUNAS, D. Gestão de UAN um resgate do binômio: alimentação e nutrição. São Paulo: Roca, 2014.

BARRETO, P. C. M. et al. Uma experiência interdisciplinar: o projeto integrador na licenciatura em espanhol do cefet/RN. Revista Holos, v.03, 2007. Acesso em: 18 de abr. de 2019. Disponível em: < http://wwwedal yc./articul ado.oa?id+ 48159274001>.

BENTO, I. C.; ESTEVES, J. M. M.; FRANÇA, T. E. Alimentação saudável e dificuldades para torná-la uma realidade: percepções de pais/responsáveis por pré-escolares de uma creche em Belo Horizonte/MG, Brasil. Revista Ciência \& Saúde Coletiva, v, 20, Rio de Janeiro 2015.

Brasil. Ministério da Saúde. Secretaria de Atenção à Saúde. Departamento de Atenção Básica. Política Nacional de Alimentação e Nutrição / Ministério da Saúde, Secretaria de Atenção à Saúde. Departamento de Atenção Básica. Básica. - 2. ed. rev. - Brasília : Ministério da Saúde, 2007.

Brasil. Ministério da Saúde. Secretaria de Atenção à Saúde. Departamento de Atenção Básica. Guia alimentar para a população brasileira / Ministério da Saúde, Secretaria de Atenção à Saúde, Departamento de Atenção Básica. - 2. ed., 1. reimpr. - Brasília : Ministério da Saúde, 2014.

. Lei no 9.394, de 20 de dezembro de 1996. Estabelece as Diretrizes e Bases da Educação Nacional. Diário Oficial da União, Brasília, DF, v. 134, n. 248, 23 dez. 1996. Seção 1, p. 27834-27841.

. Ministério da Educação, Secretaria de Educação Profissional e Tecnológica. Instituto Federal de Educação, Ciência e Tecnologia do Piauí. Projeto Pedagógico do Curso de Licenciatura em Ciências Biológicas-Campus Teresina Central. Teresina, 2015.

CAMARGO, GISELE ANNE, et al. Bebidas naturais de frutas: perspectivas de mercado, componentes funcionais e nutricionais. Revista Brasileira de Engenharia e Biossistemas, n. 2, v.1, p. 179- 205, 2007.

COSTA, E. A. Manual de nutrientes: prevenção das doenças através dos alimentos. Petrópolis, RJ: Vozes, 2002.

CRUZ NETO, B. F. Benefícios da água com pH alcalino: saúde ou doença, você decide. 2010. Disponível em: < file://C:/Users/Downloads/8-1-29-1-10-20160530.pdf. >. Acesso em: 15 de fev. de 2019.

DANON, J.; POLONI, L. Guia de calorias de A a Z. São Paulo: Estação da liberdade, 2002.

GIL, Antônio Carlos. Métodos e técnicas de pesquisa social. 6. ed. São Paulo: Atlas, 2008. 
HOFFMAN, Maichelei, et al. Padrões alimentares de mulheres no climatério em atendimento ambulatorial no Sul do Brasil. Revista Ciência e Saúde Coletiva, n. 5, v. 20, 2015.

GUNTHER, HARTMUT. Pesquisa Qualitativa Versus Pesquisa Quantitativa: Esta É a Questão? Revista Psicologia: Teoria e Pesquisa, n. 02, v.22, p. 201-210, 2006.

PHILIPPI, S. T. Pirâmide dos alimentos: fundamentos básicos de nutrição. 2 ed. Barueri: Manole, 2014.

SCHILLING, M. Qualidade em nutrição: método de melhorias contínuas ao alcance de indivíduos e coletividades. São Paulo: Livraria varela, 1995. 


\title{
CAPITULO XXII
}

\section{O REFLEXO CULTURAL DA IMIGRAÇÃO ITALIANA NA GASTRONOMIA BRASILEIRA}

DOI: 10.51859/AMPLLA.DES1788-22

\author{
Sergio Monthezuma Santoianni Guerra Filho ${ }^{1}$ \\ Aline Gomes Santana ${ }^{2}$ \\ Neide Kazue Sakugawa Shinohara ${ }^{3}$
}

\footnotetext{
Graduando do curso de Bacharelado em Gastronomia. Universidade Federal Rural de Pernambuco - UFRPE

${ }^{2}$ Mestre em Consumo, Cotidiano e Desenvolvimento Social. Universidade Federal Rural de Pernambuco - UFRPE

${ }^{3}$ Docente do curso de Bacharelado em Gastronomia. Universidade Federal Rural de Pernambuco - UFRPE
}

\section{RESUMO}

O artigo trata dos impactos culturais gerados pela imigração italiana no Brasil. A pesquisa teve como objetivo elucidar as relações entre os imigrantes italianos e os impactos que essas associações sociais causaram em sua cultura gastronômica, assim como as consequências dessas interações com a gastronomia brasileira. De acordo com o estudo bibliográfico desenvolvido foi possível identificar como ocorreu a chegada dos imigrantes vindos da Itália no território brasileiro, assim como as motivações para realizar esse movimento de êxodo coletivo. As divergências entre as regiões italianas que possuíam culturas alimentares distintas ocorreu pela dificuldade de intercâmbio de informações, o que gerou um contexto de isolamento cultural, ao ponto em que a convergência desses grupos no território brasileiro aliado à disponibilidade de alimentos e os costumes encontrados pelos imigrantes em sua chegada, geraram uma ressignificação seguida de adaptações em sua culinária original, que refletiu profundamente na cultura alimentar brasileira. Por fim, a pesquisa constatou a relevância que tiveram os grupos imigrantes na construção de uma identidade gastronômica, com ênfase na cidade de São Paulo, localizado no sudeste brasileiro, onde essas interações moldaram hábitos que se tornaram intrínsecos à alimentação brasileira, como os dias da macarronada, da polenta e a da pizza.

Palavras-chave: Imigração Italiana. Cultura Gastronômica. Hibridismo Alimentar. 


\section{INTRODUÇÃO}

Os camponeses italianos já demonstravam interesse nas terras brasileiras desde o período colonial, uma vez que as condições e a qualidade de vida no território italiano, apresentavam cenários de uma dura realidade de pobreza e escassez de alimentos para grande parte da população. Esses camponeses buscaram migrar para terras distintas em busca de condições mais adequadas de solo e espaços para a criação de animais, encontrando no Brasil uma possibilidade de concretizar esses anseios. No território brasileiro existia a oportunidade de um recomeço em uma terra farta, e a chegada dos italianos ocorreu no porto do Rio de Janeiro em 1875, onde estes estrangeiros cumpriam o período de quarentena na "Casa dos Imigrantes", esperando para serem realocados, com destino para diversas localidades do país, em especial para São Paulo e Rio grande do Sul (SCHINOFF; BEM, 2021).

O intercâmbio culinário é importante para a apresentação de pratos tradicionais e o surgimento de uma nova identidade cultural sob forte contribuição dos imigrantes estrangeiros junto aos nativos brasileiros. Essa troca de sabores e saberes, muitas vezes se mostra tão intensa que determinadas preparações acabam sendo assimiladas pela população local, tornando-se preparações arraigadas à cultura alimentar brasileira.

As adaptações realizadas nas preparações culinárias originais, que têm um caráter de hibridização, são válidas no contexto de imigração uma vez que os imigrantes se deparam com a ausência dos ingredientes originais e encontram a necessidade de adaptar recursos alimentares disponíveis em novos territórios No caso da imigração italiana, temos como exemplos: O milho brasileiro utilizado na confecção da polenta; o ajuste da acidez do molho de tomate que iria compor as pizzas; as massas e os gratinados; o reconhecimento da vitivinicultura própria da região sul com produtos premiados internacionalmente e produzidos no Vale dos Vinhedos.

Partindo de tais observações, o presente texto surge com o objetivo de elucidar quais os efeitos culturais da imigração italiana, na gastronomia brasileira e nos sujeitos italianos que vivenciaram esse processo migratório. 


\section{METODOLOGIA}

O estudo trata-se de uma pesquisa bibliográfica baseada na análise de dados decorrentes da busca usando os seguintes descritores: Cultura italiana; Imigração italiana no brasil; Gastronomia italiana; Hibridismo alimentar. As informações citadas foram encontradas a partir de levantamentos feitos em livros especializados em gastronomia e em sites de referências acadêmicas como o Google Scholar e Scientific Electronic Library. Tais tópicos de referência serviram para orientar a temática do texto a fim de responder a inquietação sobre os efeitos da imigração italiana na gastronomia brasileira.

\section{RESULTADOS}

Para entender melhor a migração, é necessário contextualizar a situação do Brasil quanto à chegada dos imigrantes, uma vez que D. João IV viabilizou a entrada de italianos ao o projeto de migração europeia que ocorreu entre 1875 e 1900 no Brasil, onde o fluxo de europeus que migraram de suas terras aumentou consideravelmente, trazendo para o Brasil cerca de 577 mil italianos que visavam alguma prosperidade e estabilidade financeira, firmando-se principalmente nos estados de São Paulo e Rio Grande do Sul. A situação geográfica privilegiada da península Italiana no Mediterrâneo, centro da grande área de comércio da idade média e da renascença, muito contribuiu para o enriquecimento de Gênova e Veneza, pólos de importante atividade econômica. Simultaneamente, a destruição por via terrestre dos produtos importados estimulou a prosperidade da Florença, Bolonha, Parma e Milão (FRANCO, 2006; PHILIPP, 2014).

Os fluxos migratórios italianos ocorreram de maneiras divergentes com os diferentes grupos étnicos, separados pelos que já detinham conhecimento técnico agrícola e da pecuária aliados de uma situação financeira mais favorável oriundos da região norte da Itália e os que vinham da parte sul, que não possuíam nem acesso ao conhecimento tecnológico agrícola, nem aporte financeiro para sobreviver. A Itália, como um país relativamente novo, talvez a isso se possa atribuir o forte regionalismo, em oposição ao nacionalismo, na população em geral. A cultura, a culinária e até mesmo o dialeto, moldados por impactos históricos, geográficos e pelo clima, constituem motivo de orgulho para cada região italiana, porque criou núcleos originais no terreno 
da gastronomia (SENAC, 2009).

Os imigrantes oriundos de Vêneto, região localizada no norte da Itália, motivados pelos próprios anseios de liberdade financeira e melhor qualidade de vida, vieram ao Brasil buscando trabalhos que envolviam principalmente cultivo e produção independente, com núcleos familiares maiores. Estes, juntaram-se em colônias, instalando-se principalmente nas regiões do interior de São Paulo e também regiões da parte sul do Brasil, e passaram a denominar o Brasil como "paese della cuccagna", que em tradução livre significa "terra da boa sorte". Estes imigrantes trouxeram na bagagem diversas técnicas culinárias do norte da Itália, que possuíam uma gastronomia dominada pelo consumo de carnes, leite (manteiga e queijos) e frutos do mar (enguias e lulas) populares na região de Vêneto. Vale salientar que as pastagens do norte eram ideais para o gado, propiciando queijos com denominações de origem protegida (DOP) como o Fontina Val D'Aosta, o Gorgonzola, o Mascarpone e o Rabiola (SENAC, 2009).

Em linhas gerais, pode-se considerar que a cozinha do norte é mais rica e elaborada, com claras influências das gastronomias centro-europeias, como a alemã e a austríaca. As regiões ao norte são também a terra dos risotti, dos gnocchi e da polenta (ABRIL,

2010).

O outro grupo de imigrantes italianos era constituído pelos que vinham do sul como a Calabria, Campania, Basilicata e Puglia. Era constituído majoritariamente de proletários rurais munidos de capacidade e disposição físicas para vencer desafios. Esses imigrantes foram trazidos para o Brasil para suprir uma demanda particular, pois foi nesse período que ocorreu a abolição da escravatura, criando assim uma urgente lacuna e necessidade de mão de obra para substituir os escravos nos grandes cafezais. Dessa maneira foram criadas na Província de São Paulo, a Sociedade Promotora da Imigração em 1866 e a Associação Auxiliadora da Colonização e Imigração no ano de 1871, com o intuito de promover e facilitar a imigração de europeus por meio da isenção da cobrança das passagens para o Brasil, além do posterior transporte para os cafezais (CERQUEIRA, 2021).

O grande período de imigração durou até meados de 1908, quando a situação econômica brasileira foi se tornando cada vez mais delicada. Considerando as crises que se formavam junto a constante desvalorização do café, provocada pela superprodução do insumo e também decorrente da desvalorização desse mercado no exterior, com as 
crises nos maiores mercados consumidores principalmente nos Estados Unidos. Os trabalhadores mais afetados foram aqueles que desempenhavam funções nas plantações de café, na maioria pelos imigrantes italianos. Tomando noção desse cenário, o governo italiano vigente na época instaura no ano de 1902 um decreto chamado de "Decreto Prinetti", que proibia principalmente que as companhias de navegação realizassem viagens gratuitas de cunho migratórios em direção ao Brasil, o que diminuiu drasticamente o fluxo migratório que existia naquela época. Aliado a esses acontecimentos, outro fator culminou com a redução desse quadro migratório, as grandes guerras ocorridas entre os anos de (1914-1918) e (1939-1945), sendo essas a primeira e segunda guerras mundiais, respectivamente.

No ano de 1951, depois dessa grande lacuna de tempo, uma conferência foi realizada em Bruxelas denominada como "Comitê Intergovernamental para as Migrações Européias" (CIME), que tinha como foco discutir o estado atual e as leis que deveriam ser seguidas para que fosse dada continuidade aos processos migratórios, estando o Brasil presente e sendo de acordo com as propostas que foram apresentadas (CERQUEIRA, 2021).

A partir disso, o fluxo de imigrantes voltou a ser considerável, tendo porém um caráter completamente distinto do que era no início do século. Desta vez os imigrantes, em sua maioria, já vinham ao país com seus interesses definidos e eram acompanhados de uma quantidade relativa de posses, inseridos em um cenário de pós guerra, estando o Brasil no caminho do desenvolvimento industrial. Muitos italianos, com níveis técnicos médios e também com níveis universitários, vieram ao Brasil atraídos principalmente para a cidade de São Paulo, por ser o foco de prosperidade e desenvolvimento tecnológico da época.

São Paulo no início do século XX, passava por um momento de transformação social econômica significativa, que gerou uma desconfiança em torno da presença dos imigrantes italianos que eram sistematicamente alvo de comentários preconceituosos e olhares desconfiados. Esse ambiente de animosidade, normalmente descrito na trajetória da imigração italiana, não impediu que a presença desses estrangeiros se tornasse um importante exemplo da imigração européia na construção da historicidade da cultura alimentar brasileira (COLLAÇO, 2009). O Mercado Municipal de São Paulo é um marco na cultura paulista, onde é 
mantido o espaço tradicional dos empórios, que comercializam produtos refinados e diferenciados. Leonardo Chiappetta, atualmente à frente dos negócios da família, possui um dos mais tradicionais boxes, o Empório Chiappetta, que mantém a tradição quanto a qualidade dos alimentos comercializados, oriundos da importação de alimentos e bebidas italianos, mas que acompanha as tendências gastronômicas do país de origem, visto que as tendências de consumo sofrem modificações e ressignificações frente a globalização (ROIM, 2016).

Os imigrantes italianos localizados nos meios urbanos, costumavam se reunir em bares, que passaram a ser considerados importantes espaços de socialização, especialmente entre os homens naquela época, onde consumiam geralmente o vinho que era tão inerente aos seus costumes originais em sua terra natal (OLIVEIRA, 2006).

A imigração italiana foi o ponto de inflexão para o início do progresso econômico da cidade de São Paulo e serviu como atenuador do doloroso processo de saída da terra natal e as incertezas da nova vida, bem como a desconfiança de quem ficou, mas os avanços e a prosperidades obtidos foram fatores que corroboraram com a construção de um imaginário positivo desse processo de imigração (COLLAÇO, 2009).

\subsection{CULINÁRIA ITALIANA NO BRASIL}

Apesar de hoje existir uma noção básica do que significa a culinária italiana, quando os imigrantes que vieram ao território brasileiro chegaram, esse conhecimento ainda não estava nem próximo de ser estabelecido, uma vez que esse processo de unificação cultural italiano teve um desenvolvimento tardio por volta de 1860, como foi dito por Massimo D’Azeglio (1860, um ex senador italiano “Fizemos a Itália; agora precisamos fazer os italianos", citação que demonstra que até aquele presente momento não existia esse pensamento coletivo de união da população, que não contava com um nível alto de alfabetização nem intensa troca de informação com outras regiões do país, o que dificultou a circulação de compêndios da gastronomia, criando assim um cenário de isolamento cultural e gastronômico entre as diferentes regiões italianas, refletindo posteriormente na convivência dos imigrantes que se instalaram nas regiões urbanas, onde convergiram grupos oriundos de todas as províncias italianas, divulgando a partir desse momento, os novos padrões de alimentação vigentes em cada região da Itália (OLIVEIRA, 2006). 
Esse aspecto foi primordial no cenário da gastronomia posterior que veio a ser uma ampla mistura das diferentes correntes da gastronomia italiana, que se hibridizaram justamente na cidade de São Paulo, metrópole importante localizada na região sudeste brasileiro, onde estavam localizados cerca de $70 \%$ dos imigrantes que eram considerados Bracciante, que podem ser traduzidos como "Trabalhadores Braçais" e que foram atores importantes para influenciar a gastronomia paulista.

Os italianos localizados nas cidades dispunham de uma maior abrangência de alimentos do que aqueles que permaneceram no meio rural, eles se encontravam inseridos em uma realidade mais amena, que proporcionava um melhor padrão de vida e um acesso mais fácil a estabelecimentos que comercializavam uma maior variedade de gêneros alimentícios, principalmente aqueles que dispunham de artigos importados da Itália.

As cantinas e a comida servida nesses estabelecimentos foram diretamente influenciadas pelas práticas gastronômicas introduzidas pelos imigrantes. A cidade de São Paulo passou a contemplar esses alimentos em diversos pontos espalhados pela metrópole, geralmente localizados nas regiões mais populares, por possuírem um caráter de comida caseira, substanciosa, presença da mama à frente do fogão, sem a presença de renomados chefs na condução do serviço de alimentação. Diferente do centro da cidade que era o lugar de circulação das camadas abastadas e onde se encontravam famosas confeitarias paulistas, nos períodos de opulência da cafeicultura no século 19 (COLLAÇO, 2009).

A ausência do feijão na culinária italiana não significava que necessariamente não entrasse no cardápio dos imigrantes. Mesmo que não fosse um gênero alimentício presente nos hábitos italianos, no momento em que os imigrantes se instalaram no interior de São Paulo, este foi incluído em sua dieta alimentar, pelo fato de ser um alimento barato e encontrado em abundância. Porém, existia uma resistência por parte desses imigrantes ao consumo de feijão, prática frequentemente referenciada na literatura da época. Em contraponto a isso, existia a cultura da produção e consumo do vinho, um ponto de referência de suas identidades, mesmo que essa bebida fosse uma regalia de poucos, era com muito orgulho propagada como um costume e era constantemente explicitada como algo benéfico, de modo que frequentemente exaltavam a qualidade do vinho, prática cultural procedente da mãe-pátria (OLIVEIRA, 
2006).

Bento Gonçalves foi pioneira no Brasil no tocante ao desenvolvimento do Enoturismo. O Vale dos Vinhedos é o principal destino enoturístico do Brasil, sendo o roteiro mais visitado desde 2008 . Foi a primeira região do país reconhecida como Indicação Geográfica, obtendo para seus produtos a Indicação de procedência, em seguida a denominação de origem 'Vale dos Vinhedos' para os vinhos e espumantes ali produzidos (BENTO, 2021). Segundo a Embrapa, o Rio Grande do Sul continua sendo o maior produtor de uva de mesa, vinhos, suco de uva e espumantes no território nacional (MELLO; MACHADO, 2019).

A gastronomia italiana não é referenciada por sua sofisticação, diferente de outras gastronomias, esta se vale de sua simplicidade e originalidade em pratos que possuem um caráter familiar. A massa e a pizza, seus dois representantes mais famosos, são o melhor exemplo de versatilidade de uma cozinha que oscila entre a riqueza e a variedade do norte e a rusticidade do sul da Itália (ABRIL, 2010).

Foram estabelecidos acordos entre os italianos da época que buscavam promover uma melhor convivência daqueles que vinham da mesma pátria, o que ressalta o interesse que existia em manter o vínculo com a Itália vivo e pulsante. Existiram movimentos como eventos beneficentes e de caráter cultural promovidos entre os italianos da época com intuito de socialização, mesmo que essas interações sejam pouco referidas, eram primordiais para manter a cultura do grupo ativa mesmo que em outro país. Se na Itália eram Vênetos, Napolitanos e Bareses, essas distinções ainda persistem entre os imigrantes, mas latentes visto que tornavam-se italianos à medida que desejavam interagir com outros grupos estrangeiros e aos habitantes locais (COLLAÇO, 2009).

A pizza na Itália possui variações na pronúncia e escrita dependendo da região, na Calábria "pitta ou petta", em Veneza "pinza". Francesco Tarallo, imigrante italiano, inaugurou em 1957 a Pizzaria “A Esperança” em São Paulo e apresentou aos paulistanos o orgulho dos pizzaiolos, cuja receita levava mozarela, tomate e manjericão, reproduzindo nos ingredientes as três cores da bandeira italiana: branco, vermelho e verde (SALDANHA, 2011).

Além de existirem as clássicas pizzas redondas originárias da região sul da Itália, existem também outras configurações desta receita, como as pizzas com o formato 
quadrangular, produzidas em Roma que compartilham o mesmo método de preparo, onde a massa é coberta por um molho e uma cobertura ao gosto de quem a preparar e são dispostas em um forno bem quente (LODY, 2008).

A realidade de pobreza em que as famílias do sul da Itália estavam inseridas foi fator determinante para a utilização de ingredientes que prezavam pela simplicidade e qualidade das preparações alimentares. Se valendo da imaginação para criar pratos frescos e saudáveis, essa é uma gastronomia que possui uma enorme variedade de preparações. A pizza e as massas desempenham um papel fundamental na difusão da gastronomia italiana por não serem restritas à utilização de ingredientes exóticos. Tratam-se de receitas adaptáveis aos produtos que são encontrados em cada localidade, motivo pelo qual se tornaram pratos que aproximam cozinheiros novatos do fogão (ABRIL, 2010).

A preparação do crostini econômico da Toscana, que também era uma região de relativa escassez material, demonstra as influências da escassez material em sua culinária, onde nem mesmo o pão envelhecido poderia ser descartado. Nessa adaptação dos tradicionais canapés, usa-se esse pão antigo embebido em vinho para preparar uma cobertura sobre o crostini (ABRIL, 2009).

Um fator que auxiliou a adesão da gastronomia italiana na cidade de São Paulo foi sua simplicidade e seu sabor aliados a uma praticidade necessária em uma realidade de bastante concorrência comercial, como era a cidade na época. O preparo sadio e o cozimento adequado fizeram dela um sucesso em todo o mundo. Num recanto qualquer pode não haver um italiano, mas sua cozinha, sem dúvida, estará lá em espírito (LEAL, 1998).

Ocorreram significativas mudanças na cozinha italiana trazida para o Brasil, moldada pela falta de insumos originais assim como a condição financeira de muitas famílias de imigrantes que não dispunham de recursos para praticar a sua gastronomia, porém existia a necessidade de manter um repertório de receitas verdadeiramente clássicas que não podem ser transformadas de uma hora para a outra, mesmo em um cenário de alterações nas relações sociais. A preocupação em dar continuidade aos padrões conhecidos é uma estratégia importante para amenizar os sobressaltos de uma experiência de grande dureza (COLLAÇO, 2009). 
Costumes clássicos de famílias italianas foram modificados, como no momento das refeições principais que costumavam serem servidas ao meio-dia passando a se adaptar ao estilo moderno da vida que tornou esse horário impraticável, especialmente nas grandes cidades, o que transferiu o jantar para a refeição mais importante do dia. Outro costume influenciado pela tendência mundial para uma culinária mais leve transformou o primmo piatto (ou primeiro prato) em preparação única que atendia toda a refeição (PHILIPPI, 2014).

As cozinhas carioca e paulista, não devem ser consideradas típicas. Elas são aos moldes gerais uma base de cozinha portuguesa acrescida de arroz e feijão, mas que também sofreu diversas influências da culinária italiana, francesa, alemã, japonesa, árabe e norte-americana (LEAL, 1998).

A cozinha paulista buscava uma maneira de se consolidar aderindo então influências de imigrantes que foram incorporadas à culinária local. Além dos italianos, com as pizzas e as massas, os árabes contribuíram com os seus quibes, esfirras e charutinhos de folha de uva. Como também os japoneses que levaram o tão típico pastel de feira e os já muito apreciados sushi, sashimi e yakisoba (CHAVES; FREIXA, 2009). A culinária do Japão que é repleta de sutilezas e debruada de requintes tornou-se popular a partir de 1980 no Brasil, onde atualmente vivem o maior contingente de japoneses e descendentes no Brasil, concentrando mais de um quinto deles na capital paulista (LORENÇATO; CWIERTKA, 2008). Todas essas correntes culinárias somaram as imigrações portuguesa e italiana, os primeiros europeus que chegaram às terras brasileiras.

A presença dos imigrantes italianos estendia-se pela cidade de São Paulo, mesmo assim os restaurantes italianos localizados nos bairros étnicos neste momento não eram um lugar tão conhecido no cenário paulistano. Embora já tivessem uma ideia muitas vezes do que era servido, seus consumidores tradicionais eram majoritariamente os imigrantes que se serviam da comida feita pelas mammas para a família, esses pequenos estabelecimentos foram a inspiração para as futuras cantinas, bastante semelhantes aos estabelecimentos que existiam na Itália, porém por originalmente focarem na população imigrante, mantiveram as suas preparações o mais semelhante possível das originais (COLLAÇO, 2009). 
O sistema de intercâmbio culinário, seja ele amistoso ou agressivo, é parte da história de qualquer culinária, ingredientes eventualmente vão parar em pratos tradicionais, eventualmente o novo ingrediente torna-se tão arraigado que pode passar a ser reconhecido como autêntico pelas pessoas mais jovens, enquanto a população mais erudita não o consideraria como original. Um claro exemplo disso é a adoção de muitos ingredientes originários das américas pelos europeus como o tomate, que hoje em dia pode ser considerado intrínseco à culinária italiana ao ponto de qualquer pessoa poder facilmente considerar a Itália como seu país de origem (SENAC, 2009).

Delimitar um tipo de cozinha não é uma tarefa fácil, fatores de caráter geográfico como a presença ou ausência de um litoral exerce tremendo impacto no desenvolvimento de um estilo culinário, assim como o clima, o solo e as técnicas de cultivo. Porém, esses não podem ser os únicos determinantes quando falamos sobre algo que está intrínseco aos indivíduos que se identificam com aquela culinária. Claro que uma cozinha concebida e praticada na mesma região têm suas vantagens evidentes, como possuir os insumos bem definidos, por terem o conhecimento necessário para obter de maneira mais eficiente os alimentos, tornando sua produção constante; porém, principalmente no cenário atual de globalização, um indivíduo pode praticar sua gastronomia em quase qualquer lugar do mundo, podendo ser influenciado pelo sistema de governo e o comércio que encorajam essa "migração" de alimentos e pratos de um lugar para o outro, assim transmitindo sua cultura sem a necessidade de permanência.

Os hábitos alimentares como expressão cultural dos imigrantes, podem muitas vezes passar por adaptações, onde as cozinhas étnicas têm seus sabores e odores mesclados com os de outras populações, o que pode provocar um estranhamento entre os praticantes dessa cultura em um primeiro momento, porém essas assimilações são com o tempo apreciadas e incorporadas aos conceitos daquele grupo. Posteriormente essas manifestações são adotadas pelos seus descendentes, que passam a considerar esses estímulos sensoriais, como fatores de evocação da memória, remetendo aos importantes elos entre o passado e o presente (OLIVEIRA, 2006).

Essa identidade étnica propagada entre as gerações pode ser modificada diversas vezes, porém nunca perde em sua totalidade as características originais da cultura, configurando assim um processo contínuo que se vale de ações sociais para existir e que pode ser desenvolvido por grupos distintos, conferindo a esse tipo de 
interação, um caráter de constante reconstrução, mas nunca uma sobreposição completa (SCHINOFF; BEM, 2021).

Populações que emigraram carregam consigo necessidades específicas para países que muitas vezes não podem atender suas associações e exclusões, a exemplo do Brasil, onde criaram uma cozinha de adaptações, valendo-se de velhos costumes e criando novos. Como é o exemplo dos imigrantes italianos que trouxeram consigo sua cultura que ainda reflete na sua maneira de cozinhar, remetendo ao seu país de origem nas tradições e crenças compartilhadas, transformando essa prática em um elemento importante no desenvolvimento e na manutenção da identidade de um grupo. Provavelmente nunca houve um tempo em que a migração de alimentos de uma parte do mundo à outra não tenha sido um fator que contribuiu no desenvolvimento de uma culinária, embora esse intercâmbio seja mais rápido e frequente nos dias de hoje.

A própria origem familiar da cozinha praticada pelos imigrantes expõe sua necessidade de continuidade, pois é a partir dessas relações primárias que é possível estabelecer os vínculos com a comida delimitando identidades, mesmo que ainda precárias por estarem em outro local, não que isso seja de um determinismo irrefutável, mas a comida no contexto desses imigrantes tinha a força necessária para unir pessoas diferentes. Não se trata somente de uma nostalgia, mas uma questão de seguir normas culturais e sociais que, de alguma maneira, mostravam uma origem em comum (COLLAÇO, 2009).

A trajetória da gastronomia italiana no Brasil foi longa e conturbada, porém, hoje deve-se a esse processo boa parte da cultura alimentar brasileira e que se encontra presente não só na cidade de São Paulo, que invariavelmente foi o foco dessas transformações iniciais, mas nas realidades alimentares de famílias em todas as outras regiões do Brasil.

\section{CONSIDERAÇÕES FINAIS}

Diante do levantamento que foi realizado nesta pesquisa, observou-se como a imigração italiana proporcionou uma reconversão na gastronomia brasileira. A partir do anseio por uma melhor qualidade de vida, os italianos perceberam no território brasileiro uma oportunidade de recomeço e em seu processo migratório, ocorrendo uma ação de hibridização cultural que influenciaram e foram influenciados. A partir da 
convergência dos italianos para uma vivência unificada em um território estrangeiro, tais imigrantes passaram a enxergar sua cultura de origem sob uma nova perspectiva e buscaram nos recursos alimentares locais, meios para manter suas tradições e associálas às novas práticas sociais nas diferentes regiões brasileiras.

\section{REFERÊNCIAS}

ABRIL (Brasil) (ed.). Cozinha do Mundo: Itália. São Paulo: Abril, 2010. 173 p.

ABRIL (Brasil) (ed.). Viagens Gastronômicas: 500 lugares extraordinários para comer no mundo todo. São Paulo: Abril, 2009. 319 p.

ASSIS, Kitty. Viajando na cozinha: dicas, truques e receitas. Rio de Janeiro: Senac, 2008. $368 \mathrm{p}$.

CERQUEIRA, Fábio Vergara (Pelotas). Universidade Federal de Pelotas (org.). Imigração Italiana no Brasil. Disponível em: https://wp.ufpel.edu.br/museumaciel/imigracao-italiana-no-brasil/. Acesso em: $18 \quad$ nov. 2021. CHAVES, Guta; FREIXA, Dolores. Gastronomia no Brasil e no Mundo. Rio de Janeiro: Senac, $2009 . \quad 304 \quad$ p. COLLAÇO, Janine Helfst Leicht. Sabores e memórias: cozinha italiana e construção identitária em São Paulo. 2009. Tese (Doutorado em Antropologia Social) - Faculdade de Filosofia, Letras e Ciências Humanas, University of São Paulo, São Paulo, 2009. doi:10.11606/T.8.2009.tde-22022010-125038. Acesso em: 2021-11-10. 10 nov 2021.

CWIERTKA, Katarzyna Joanna; LORENÇATO, Arnaldo (ed.). Moderna cozinha Japonesa: comida, poder e identidade nacional. São Paulo: Editora Senac, 2008. 383 p. FRANCO, Ariovaldo. DE CAÇADOR A GOURMET: uma história da gastronomia. 4. ed. São Paulo: Senac, 2006. 287 p.

HUTTER, Lucy Maffei. Imigração italiana: aspectos gerais do processo imigratório. Revista do Instituto de Estudos Brasileiros, [S. I.], n. 27, p. 59-73, 1987. DOI: 10.11606/issn.2316-901X.v0i27p59-73. Disponível em: https://www.revistas.usp.br/rieb/article/view/69906. Acesso em: 23 nov. 2021.

LEAL, Maria Leonor de Macedo Soares. A história da Gastronomia. 4. ed. Rio de Janeiro: Senac, 1998. 143 p.

LODY, Raul. Brasil bom de boca: temas da antropologia da alimentação. São Paulo: Senac, 2008. 424 p.

PHILIPPI, Sonia Tucunduva. Nutrição e técnica dietética. 3. ed. Barueri: Manole, 2014. 400 
MELLO, Loiva Maria Ribeiro de; MACHADO, Carlos Alberto Ely. Vitivinicultura brasileira: panorama 2019. Bento Gonçalves: Embrapa, 2019. 21p.

BENTO. História do município de Bento Gonçalves. Bento Gonçalves, 2021. Disponível em: https://bento.tur.br/nossa-historia-bento-goncalves/. Acesso em: 23 de novembro de 2021. ROIM, Talita Prado Barbosa. As relações socioculturais no Mercado Municipal de São Paulo - produção de tradições na formação e no reconhecimento de grupos culturais a partir da alimentação. 2016. 273 p. Tese (Doutorado) - Curso de Ciências Sociais, Filosofia e Ciências de Marília, Unesp, Marília, 2016.

SALDANHA, Roberta Malta. Histórias, Lendas e Curiosidades da Gastronomia. Rio de Janeiro: Senac, 2011.

SCHINOFF, Roberto Amaral; BEM, Judite Sanson de. A etnicidade dos imigrantes italianos representadas pela Ferrovia do Vinho de Bento Gonçalves. Mouseion, [S.L.], n. 38, p. 1, 8 set. 2021. Centro Universitario La Salle - UNILASALLE. http://dx.doi.org/10.18316/mouseion.v0i38.8249. Acesso: em 18 de novembro de

2021. 


\title{
CAPITULO XXIII
}

\section{CULTURA E CRENDICE POPULAR - HÁBITOS ALIMENTARES BASEADOS NA CIÊNCIA, SABEDORIA E PRÁTICA POPULAR}

\author{
DOI: 10.51859/AMPLLA.DES1788-23
}

\author{
Arshiley de Oliveira Carvalho ${ }^{1}$ \\ Maria Eduarda Barreto Bezerra ${ }^{2}$ \\ Neide Kazue Sakugawa Shinohara ${ }^{3}$
}

\footnotetext{
Graduanda do Curso de Gastronomia. Universidade Federal Rural de Pernambuco - UFRPE

${ }^{2}$ Graduanda do Curso de Gastronomia. Universidade Federal Rural de Pernambuco - UFRPE

${ }^{3}$ Docente do Curso de Gastronomia. Universidade Federal Rural de Pernambuco - UFRPE
}

\section{RESUMO}

O presente trabalho traz um apanhado de hábitos alimentares gerados através de tabus e crenças populares. Por meio de pesquisa bibliográfica e também pelas experiências pessoais das próprias autoras, foi realizada seleção de algumas dessas crendices, passando por aspectos culturais, religiosos e nutricionais, buscando encontrar justificativas para tais restrições. Foi percebido que muitos desses tabus que envolvem a alimentação dos brasileiros sofreram a influência das populações dos colonizadores, como portugueses e holandeses, assim como povos africanos escravizados, que deixaram grande influência no modo de viver atual do brasileiro. A polêmica relacionada ao consumo de manga com leite é um clássico presente até hoje nos costumes da população. A restrição no consumo de alimentos remosos é um exemplo da influência religiosa, pois é derivado dos costumes dos judeus, mais precisamente da alimentação kosher. Outros exemplos abordados nessa pesquisa também derivam de hábitos religiosos, como o jejum e os sacrifícios. Por fim, também há os tabus nutricionais, causados, principalmente, pela dualidade da interpretação das informações divulgadas. Desta forma, percebe-se que os tabus alimentares vão muito além de informações isoladas, sem embasamento científico. Trata-se também do que foi passado através dos tempos, da oralidade, sem o devido registro escrito, que pode ter sido alterado em algum momento na transmissão do saber, deixando de fazer sentido no decorrer do tempo.

Palavras-chave: Cultura. Tabu. Alimentação. Hábitos. Crenças. 


\section{INTRODUÇ̃̃o}

Comer é mais que ingerir um alimento, significa também as relações pessoais, sociais e culturais que estão envolvidas naquele ato. A cultura alimentar está diretamente ligada com a manifestação das pessoas na sociedade que estão inseridas (LEONARDO, 2009).

A identidade de um povo se dá, principalmente, por seu vernáculo e por sua cultura alimentar. Um conjunto de práticas alimentares determinadas ao longo do tempo por uma sociedade que passa a identificá-la e muitas vezes, quando enraíza, torna-se patrimônio cultural. $\mathrm{O}$ ato da alimentação, mais do que um ato biológico, envolve as formas e tecnologias de cultivo, manejo e a coleta do alimento, a escolha, seu armazenamento e formas de preparo e de apresentação, constituindo um processo social e cultural (PHILIPPI, 2014; SONATI, 2009).

Estudos socioculturais, ao privilegiarem abordagens compreensivas da alimentação, podem lançar luz sobre questões ainda pouco exploradas, relativas a aspectos culturais da realidade social que se conectam ao cotidiano da vida das pessoas. A cultura aqui é entendida como um conjunto de significados e símbolos compartilhados que modelam as práticas alimentares se manifestando de modo diferenciado entre os grupos sociais. Como uma teia de representações permeáveis às mudanças, funciona como uma matriz de percepção, interpretação e ação que conecta memória e tradição às novas experiências alimentares (SILVA, 2011).

A relação entre ciência e senso comum é abordada na concepção de que a ciência se opõe à opinião pessoal e achismos de grupos. Pois, para que nada seja dado, tudo se constrói. O senso comum representa a experiência imediata, o conhecimento empírico, as opiniões. Ou seja, tudo o que se precisa romper para se tornar possível o conhecimento científico, racional e válido (BOURDIEU, 1983).

A curiosidade de conhecer o mundo, impulsionou o homem a buscar novas fronteiras territoriais e desafios de superação diante das adversidades de sobrevivência, dentre esses aspectos a cozinha sofreu forte influência nos tratos culinários, passando por fases de evolução e reconversão. Segundo Saldanha (2011), o homem constantemente procurava novos ingredientes para compor sua culinária, o que acabou dando voltas no mundo, descobrindo novos continentes, saberes e sabores. Muitas das 
histórias e lendas sobre a culinária e seus ingredientes têm diferentes versões dependendo de interesses econômicos e sociais, surgindo histórias e curiosidades sobre os ritos na alimentação.

O estudo tem como foco questionamentos sobre algumas práticas e crenças que são passadas em diferentes gerações familiares, sendo considerado assim, que as famílias são grupos sociais ricos em cultura e historicidade, consequentemente gerando diferentes crenças e crendices. Baseada nestas definições e em suas diferentes perspectivas, esta pesquisa tem como objetivo tratar de alguns aspectos no âmbito gastronômico atrelados às culturas e crenças populares, abordando o conhecimento popular sobre práticas e hábitos alimentares comumente observados na população brasileira, utilizando esse tema como objeto de estudo, para buscar entender como surgiram e se desenvolveram as crendices e mitos na sociedade brasileira.

\section{METODOLOGIA}

Para o desenvolvimento deste trabalho temos como objetivo apresentar o resultado de uma pesquisa exploratória sobre as diversas crendices populares presentes até hoje no meio de convivência da população brasileira sobre hábitos alimentares que ainda perduram no compartilhamento de conhecimento, história e cultura de grupos sociais.

As fontes de pesquisas foram inteiramente digitais: artigos, livros, textos e dissertações disponíveis em plataformas como Google Acadêmico e Scientific Electronic Library Online. As palavras e expressões de busca utilizadas foram: Crenças e tabus alimentares na população brasileira; história da gastronomia; aspectos nutricionais relacionados a tabus alimentares; crendices alimentares.

Analisando conceitos, ideias e práticas, o estudo é de caráter qualitativo, com intenção de expor resultados de porque temos determinadas visões sobre as práticas e hábitos apresentados nesta pesquisa. O que pode ser fator de influência ou não no modo de se alimentar ou de lidar com o alimento e seus diversos preparos culinários, sem desprezar o senso comum, mas usando como base, principalmente, fatores históricos e científicos. 


\section{REVISÃO BIBLIOGRÁFICA}

Ao pensar, refletir e falar sobre hábitos alimentares, é indispensável ressaltar a importância da Segurança Alimentar e Nutricional (SAN), ou seja, o direito ao acesso à alimentos nutritivos e de boa procedência. A segurança alimentar e nutricional consiste na realização do direito de todos ao acesso regular e permanente a alimentos de qualidade, em quantidade suficiente, sem comprometer o acesso a outras necessidades essenciais, tendo como base práticas alimentares promotoras de saúde que respeitem a diversidade cultural e que sejam ambiental, cultural, econômica e socialmente sustentáveis, de acordo com o Art. 3ำ da Lei № 11.346, de setembro de 2006 (BRASIL, 2006).

Na pesquisa em questão, o ato de alimentar-se deixa de ser apenas benéfico nutricionalmente e passa a ser também expressão cultural, onde pode-se identificar costumes regionais, crenças e tabus, hábitos e tradições familiares. Criando assim padrões que são refletidos nas ações das pessoas, desde escolher um alimento, até seu propósito de consumo e a forma escolhida para melhor preparação.

Um dos fatores que age como bússola nesse momento de escolha é o conhecimento. O conhecimento sobre nutrição e hábitos alimentares vai influenciar diretamente nesta etapa. Percebe-se então a importância da inserção de conceitos de nutrição humana básica no ensino das comunidades, podendo assim estimular a procura do bem-estar alimentar, comida que sacia e que promove a ciência da nutrição para o bem estar do comensal.

O alimento também é considerado como elemento de confraternização e lazer. A comensalidade em si faz parte da cultura e história gastronômica desde a pré-história. O ser humano vê o alimento não só como para "matar a fome" mas também como para se sentir melhor emocionalmente. Ir a restaurantes, bares, lanchonetes, pizzarias, ou fazer um jantar e reunir os amigos, o almoço em família aos domingos, é sinônimo de relaxar e divertir-se, onde o alimento está sempre fazendo parte de momentos e recordações saudáveis.

Dentro deste aspecto sociológico em que a alimentação está inserida, é que aparecem os tabus alimentares. O hábito alimentar dos brasileiros foi desenvolvido durante séculos de influência de diversos povos e, portanto, absorveu particularidades 
que moldaram uma cultura alimentar com caráter próprio (SALDANHA, 2011; TRIGO et al., 1989). Apesar disso, não há como ter um tabu completamente brasileiro, visto que a miscigenação que houve no país e a mistura de culturas, principalmente indígena, africana e européia, fez com que estes costumes se fundissem e se tornassem o que são hoje (FRAGOSO; PAIVA, 2013).

Muito se fala, principalmente pelos idosos, que certos alimentos "fazem mal" ou "ofendem", porém, não há comprovação científica de que isso de fato ocorra. Esta crença, chamada de "tabu alimentar", é passada de geração para geração, e, dificilmente, possuem registros escritos que comprovem a veracidade das informações, que muitas vezes são transmitidas boca a boca. Segundo Trigo et al. (1989), "tabus alimentares são difíceis de serem eliminados, pois estão ligados ao emocional, ao abstrato, à história das pessoas".

\subsection{ASPECTOS CULTURAIS}

A construção do paladar é cultural, contido de notáveis indicadores de histórias, de mitos criados e recriados, sendo que cada alimento é uma combinação de relatos que colabora na formação de lugares enquanto espaço social (LODY, 2008).

A cultura, assim como os hábitos alimentares dos brasileiros, está em constante evolução. A integração de costumes e saberes de diversos povos ao longo do tempo, fez com que fossem absorvidas também as crenças populares de diversas regiões do mundo.

A história humana passou em algum momento pela descoberta de novos recursos alimentares e pelos diferentes saberes da cozinha. $O$ homem diante de adversidades é um ser resiliente e curioso, procurando novas terras e culturas, acabou por dar voltas no mundo, o que levou a surgir muitas histórias e lendas sobre a culinária e seus ingredientes e diferentes versões místicas (SALDANHA, 2011).

Uma das definições de tabu: "o que é proibido por crença no sobrenatural", define condutas alimentares. A ciência da Nutrição é um dos alvos principais para estabelecimento de tabus, mitos e crendices. Existem muitos tabus históricos em torno da alimentação, gerando mitos que são considerados por muitos como dogmas e que acabam por povoar a imaginação e a aversão por determinados grupos de alimentos (VIEIRA, 2010). 


\subsubsection{MANGA COM LEITE}

A crença de que chupar manga e beber leite poderia causar indigestão ou até mesmo ser letal, surgiu na época do Brasil Colônia, quando os fazendeiros inventaram que esta combinação fazia mal, para evitar que os escravos comessem as mangas das plantações, que tinham safras abundantes, e bebessem leite, comprometendo o volume de produção das ordenhas (GASPAR, 2006; VIEIRA, 2010).

A fruta também protagoniza outras crenças populares: "chupar manga e beber muita água, em seguida, dá dor-de-barriga; não convém misturar manga com cachaça, intoxica; chupar manga e comer ovo provoca indigestão; misturar manga com jaca provoca dores intestinais terríveis; Banana de manhã é ouro, de tarde maltrata, de noite mata" (GASPAR, 2006; VIEIRA, 2010).

\subsubsection{CACHACA E LEITE}

Novamente o leite é alvo de restrições alimentares. Os portugueses consideram, desde a idade média, o leite como um alimento completo, não havendo necessidade de misturá-lo com mais nenhum outro alimento. O mito de que leite e cachaça não devem ser misturados provavelmente vem de origem espanhola, onde há um ditado que diz que "la leche con el vino torna se venino" (leite com vinho torna-se veneno, em tradução literal).

Segundo Cascudo (2004), algumas regiões de Portugal usavam o álcool do vinho (grappa), para acelerar a precipitação de substâncias no leite (coalhada), ou seja, esse tabu pode provir da ideia de ter o leite talhado no estômago.

\subsubsection{ALIMENTAÇÃO DURANTE O CICLO MENSTRUAL}

Apesar de ser um evento completamente natural, a menstruação é tida desde a época do Império Romano como algo impuro, fazendo com que o ciclo menstrual fosse cercado de tabus desde então. Com o tempo, alguns tabus alimentares também foram incorporados a essas crenças.

Em vários lugares do mundo, não se é recomendado o consumo de alguns alimentos durante o período menstrual, porém não há nada que justifique cientificamente essa recomendação. Em Pernambuco, por exemplo, há a crença de que não se deve comer abacaxi durante o período da menstruação. A explicação para isso 
pode vir de Cascudo (2004), que diz que "o enfermo de feridas que saboreia o abacaxi, tê-las-á salientes, formando bicos como a fruta servida".

A teoria do impuro também se aplica ao modo de preparar alguns alimentos. Faz mal que a mulher prepare uma massa de bolo com as próprias mãos enquanto está menstruada pois a massa não dá certo, passando energias negativas para a preparação.

\subsection{ASPECTOS RELIGIOSOS}

A religiosidade, assim como os demais fatores, foi crucial para a inserção de hábitos e crenças no nosso modo de viver atual. A maior influência religiosa encontrada no território brasileiro, é, definitivamente, proveniente da Igreja Católica, com datas, práticas de jejum e preparações culinárias bem definidas no calendário litúrgico.

Segundo Roper (2010), existem outros fatores além de uma alimentação saudável e prática de atividades físicas e mentais, que levam a ter uma vida mais longa e saudável. Ter uma crença religiosa e praticá-la faz parte dos ingredientes do equilíbrio e da vida saudável.

\subsubsection{ALIMENTOS REMOSOS}

O seguinte tabu alimentar é um dos mais difundidos atualmente. Quase sempre, por ocasião de alguma cirurgia ou procedimento médico, os alimentos à base de carne de porco são proibidos, pois, acredita-se, que eles estimulem a produção de fluidos e secreções no corpo humano. Essa crença deriva do próprio significado da palavra remosa, derivada do grego rheumas. É provável que este tabu tenha surgido em Pernambuco, graças à presença dos judeus no estado, durante os séculos XVI e XVII. O governo de Maurício de Nassau permitia uma grande tolerância religiosa, o que fez com que os judeus se sentissem à vontade para propagar sua cultura em terras recifenses. Cultura essa, principalmente gastronômica, que acabou sendo rapidamente incorporada pelos demais habitantes da cidade (FRAGOSO; PAIVA, 2013).

Naturalmente, a cultura alimentar judaica é repleta de restrições, conhecidas como Kosher. Na alimentação Kosher, a carne de porco é proibida, pois só é permitido alimentar-se da carne de animais ruminantes, o que caracteriza sua dupla pureza, e que contenham o casco bipartido (BERTOLINO, 2020; OIIVEIRA et al., 2013).

Quando os portugueses retomaram o poder sobre Pernambuco, os judeus começaram a ser constantemente perseguidos pela inquisição católica, forçando-os a 
mudar sua religião e, consequentemente, seus hábitos alimentares. Porém, um fato que contribuiu para o fim da perseguição aos judeus, foi justamente a exclusão da carne de porco de sua dieta, por conta da disseminação da informação de que o consumo desta carne acarretava males à saúde, principalmente ao processo de cicatrização.

\subsubsection{JEJUM}

Voltando a falar do alimento como elemento de prazer, o jejum é uma prática pertinente em diversas religiões espalhadas pelo mundo com o objetivo de abrir mão de algo que Ihe traz felicidade e desperta desejo, ou até mesmo algo essencial como a água, para fins meditativos. Se recolher para meditar e refletir sobre questões pessoais baseadas em suas crenças.

Os jejuns podem também ser praticados em ocasiões específicas de acordo com o calendário de celebrações da região em questão, como forma de marcar um evento muito importante, geralmente ligado a divindades, mensageiros, profetas, líderes, fundadores e outras figuras de grande expressão (SOUZA, 2014).

No cristianismo podemos observar com mais clareza essa prática na Semana Santa. $\mathrm{O}$ ato de comer era visto como uma tentação que levava ao pecado da gula, em meados do século VI, abstendo-se assim de alguns alimentos nessa época do ano para refletir sobre a morte, crucificação e ressurreição de Cristo.

\subsubsection{BANQUETES E ALIMENTOS COMO SÍMBOLOS ESPECIIFICOS}

Em religiões cristãs, como o crsitianismo, há uma abundância de alimentos tidos como símbolos como representação de certos acontecimentos bíblicos. Em algumas passagens bíblicas observamos nas parábolas a quantidade de alimentos que são mencionados, ou cenas de refeições representando diversos conteúdos espirituais.

A própria história humana com Deus, no catolicismo, começa com a clara do homem ao comer o único fruto proibido do paraíso, e mais tarde após muitas passagens envolvendo alimentos, a redenção do homem será novamente feita através da boca, com a incorporação de Cristo através do pão e do vinho; que juntamente com o azeite comporão a tríade de alimentos-símbolo mais importante do Cristianismo (SOUZA, 2014).

O consumo de peixe também entra nesta mesma linha de pensamento. Assim como o vinho, o peixe é um símbolo forte em comemorações cristãs, a Semana Santa, 
mencionada anteriormente, e também nas festas natalinas. São elementos que representam a vivência de Cristo e estão presentes na mesa do brasileiro nestas comemorações a fim de representar atos religiosos que acreditam.

\subsection{ASPECTOS NUTRICIONAIS}

As superstições e tabus também passam pelo âmbito nutricional. Alimentos que antes eram vistos como aliados da saúde e da boa alimentação, de repente passam a ser vilões.

\subsubsection{GLÚTEN}

O glúten é um exemplo clássico da desinformação. Sendo sempre apontado como responsável pela obesidade e diversos outros problemas de saúde de seus consumidores. Porém, para além da doença celíaca, não foi provado que o glúten causa danos reais à saúde, assim como não causa prejuízo grave às pessoas sensíveis à proteína (VIEIRA, 2010).

Infelizmente, para aos pacientes celíacos não é fácil seguir uma dieta isenta de glúten, pois o trigo e a cevada estão presentes em uma ampla variedade de produtos industrializados: sorvetes, chocolate, ketchup, podem conter glúten ou traços desse composto inflamatório (SCHWARCZ, 2008). Cabendo ao celíaco e familiares fiscalizar a compra e consumo de alimentos isentos de glúten, uma vez que pode passar despercebido de forma não intencional, a presença da "gliadina" quando se promove as associações empíricas nas preparações culinárias.

\subsubsection{GRÁVIDAS E LACTANTES}

A gravidez é uma fase de muitas transformações no corpo da mulher. Durante o período de gestação e lactação, é necessário haver muito cuidado com a alimentação das futuras mães, porém, algumas restrições são infundadas, não passando apenas de tabus alimentares.

Durante o período de amamentação, é comum as mães ouvirem que devem evitar determinados tipos de alimentos, para que o gosto destes não passe para o leite. Não há nenhum estudo que aponte a passagem de sabor dos alimentos para o leite materno (GOMES; SILVA; SALAMONI, 2011). 
Os tabus e as crenças alimentares estão fortemente presentes nas mulheres, podendo interferir no estado nutricional das gestantes e lactantes, pois restringem a ingestão de nutrientes necessários à manutenção da saúde, principalmente nesse momento da vida, onde suas necessidades nutricionais se encontram aumentadas (GOMES; SILVA; SALAMONI, 2011).

\subsubsection{AZEITE DE OLIVA}

Elemento chave da dieta mediterrânea, o azeite de oliva é um dos responsáveis pela longevidade e proteção contra doenças entre a população europeia. Esta dieta associa, além do azeite, diversos outros alimentos, como hortaliças, frutas, peixe, laticínios e vinho e em contraposição o baixo consumo de carnes vermelhas e consumo moderado de bebidas alcoólicas (ROPER, 2010).

Há uma crença de que o azeite de oliva torna-se saturado, após ser exposto a altas temperaturas. Porém, esta afirmação não faz sentido, visto que para um óleo tornar-se saturado, ficando sólido a temperatura ambiente, é necessário haver um processo de hidrogenação, impossível de acontecer apenas com o aquecimento em fogão convencional. A hidrogenação se dá sob pressão elevada, através da catalisação do óleo, com uso de níquel (VIEIRA, 2010).

\section{CONSIDERAÇÕES FINAIS}

A cultura de uma determinada localidade perpassa por diversos aspectos. As diversas influências de povos nativos, dominadores e imigrantes, trazem profundidade aos elementos culturais da nação que recebe essas influências. A alimentação é um fator que é diretamente afetado, que evolui e se modifica com o passar dos anos. Com isso, ela também absorve saberes populares que passam, de geração em geração, os chamados tabus alimentares. Estes tabus envolvem, principalmente, aspectos culturais, religiosos e nutricionais, sendo necessário observá-los para compreender a dinâmica cultural de onde estes valores estão inseridos. 


\section{REFERÊNCIAS}

BERTOLINO, M. T. A alimentação kosher: origem, tradição e certificação. Food Safety Brazil. 2020. Disponível em:

$<$ https://foodsafetybrazil.org/alimentacao-kosher-origem-tradicao-e-certificacao/>. Acesso em: 20 de out. de 2021.

BRASIL. Presidência da República. Casa Civíl. Subchefia para Assuntos Jurídicos. LEI № 11.346. Brasília, 15 de set. de 2006.

BOURDIEU, P. Questões de sociologia. Rio de Janeiro: Marco Zero; 1983.

CASCUDO, Luis Camara. A História da Alimentação no Brasil. Rio de Janeiro. Ed. Global. 2004.

FRAGOSO, A. R.; PAIVA, E. P. Estudos dos Tabus Alimentares de Pernambuco. XIII Jornada de Ensino, Pesquisa e Extensão. Recife, 2013. Disponível em: <http://www.eventosufrpe.com.br/2013/cd/resumos/R1878-1.pdf>. Acesso em: 18 de out. de 2021.

GASPAR, L. Tabus alimentares. Pesquisa Escolar. In: Fundação Joaquim Nabuco, 2006. Disponível em: <https://pesquisaescolar.fundaj.gov.br/pt-br/artigo/tabusalimentares/>. Acesso em: 20 de out. de 2021

GOMES, M. R. T. G.; SILVA, L. T.; SALAMONI, R. M. Investigação Dos Tabus E Crenças Alimentares em Gestantes e Nutrizes do Hospital Regional de Mato Grosso do Sul - Rosa Pedrossian. Ensaios e Ciência - Ciências Agrárias, Biológicas e da Saúde. 2011. Disponível em: <https://www.redalyc.org/pdf/260/26024221009.pdf>. Acesso em: 20 de out. de 2021.

LEONARDO, M. Antropologia da Alimentação. Revista Antropos - v.3, n.2, 2009. Disponível em:<https://revista.antropos.com.br/downloads/dez2009/Artigo\%201\%20\%20Anntropologia\%20da\%20Alimenta\%E7\%E30\%20\%20Maria\%20Leonardo.pdf>. Acesso em: 18 de out. de 2021.

LODY, R. Brasil Bom de Boca: Temas da antropologia da alimentação. São Paulo: Senac, 2008. 424 p.

Oliveira, K. K. G., Padilha, M. D. R. D. F., Shinohara, N. K. S., Correia, M. J. As Leis Dietéticas da Culinária Judaica. Contextos da Alimentação - Revista de Comportamento, Cultura e Sociedade, v.1, n.2, 2012.

PHILIPPI, S. T. Nutrição e Técnica Dietética. Barueri: Manole, 2014, 400p

ROPER, E. A. Inteligência Alimentar: A nova refeição e os ingredientes do equilíbrio. São Paulo: Elevação, 2010. 228p. 
SALDANHA, R. M. Histórias, lendas e curiosidades da gastronomia. Rio de Janeiro: Senac, 2011.

SCHWARCZ, J. Uma Maçã por Dia: Mitos e Verdades sobre os Alimentos que Comemos. Rio de Janeiro: Jorge Zahar, 2008. 306p.

SILVA, S. S. A relação entre ciência e senso comum - Para uma compreensão do patrimônio cultural de natureza material e imaterial. Ponto Urbe - n.9, 2011. Disponível em: $<$ https://shortest.link/arelaoentrecinciaesensocomum $>$. Acesso em: 18 de out. de 2021

SONATI, J. G.; VILARTA, R.; SILVA, C. C. Influências Culinárias e Diversidade Cultural da Identidade Brasileira: Imigração, Regionalização e suas Comidas - c.14, 2009. Disponível em:<https://www.fef.unicamp.br/fef/sites/uploads/deafa/qvaf/cultura_alimen tarcap14.pdf>. Acesso em: 18 de out. de 2021

SOUZA, P. R. Religião e Comida - Como as práticas alimentares no contexto religioso auxiliam na construção do Homem. São Paulo, 2014. Disponível em:<https://sapientia.pucsp.br/bitstream/handle/1924/1/Patricia\%20Rodrigue s\%20de\%20Souza.pdf>. Acesso em: 25 de out. de 2021

TRIGO, M.; RONCADA, M. J.; STEWIEN, G. T. M.; PEREIRA, I. M. T. B. Tabus alimentares em região do Norte do Brasil. Revista de Saúde Pública, v.23, n.6, 1989. Disponível em: <https://www.scielosp.org/article/rsp/1989.v23n6/455-464/>. Acesso em: 19 de out. de 2021.

VIEIRA, E. C. Tabus, mitos e crendices em nutrição. Revista Médica de Minas Gerais. Belo Horizonte, 2010. Disponível em: <http://rmmg.org/artigo/detalhes/375>. Acesso em: 19 de out. de 2021. 


\section{CAPlTOLO XXIV \\ TAILÂNDIA: TERRA DOS SABERES E AROMAS QUE SEDUZEM A CULINÁRIA MUNDIAL}

DOI: 10.51859/AMPLLA.DES1788-24

Tácito Henrique Rodrigues Burgos ${ }^{1}$

Neide Kazue Sakugawa Shinohara ${ }^{2}$

${ }^{1}$ Graduando do Curso de Bacharelado em Gastronomia. Universidade Federal Rural de Pernambuco UFRPE

${ }^{2}$ Docente do Curso de Bacharelado em Gastronomia. Universidade Federal Rural de Pernambuco - UFRPE

\section{RESUMO}

Este trabalho teve o intuito de socializar informações sobre as tradições culturais, históricas e a riqueza gastronômica da população conhecida como a terra do "povo feliz e livre". Apesar de não ter sido colonizada por estrangeiros, sua culinária foi Influenciada por diversos outros países do sudeste asiático, que contribuíram para enriquecer ainda mais a gastronomia tailandesa, que já era bastante vasta e rica em ingredientes e técnicas culinárias. Neste levantamento através das buscas em livros especializados e portais acadêmicos, apontaram a Tailândia como um grande destino gastronômico, tornando-a uma cozinha de referência e importante para a valorização da gastronomia mundial.

Palavras-chave: Cultura alimentar. Alimentação asiática. Tailândia. Gastronomia Tailandesa.

\section{INTRODUÇÃO}

Na Ásia, a grande diversidade de diferentes povos, crenças e religião, e juntamente com os colonizadores e imigrantes em sua longa trajetória de histórias de lutas e conquistas, sãos os fatores responsáveis pela imensa riqueza cultural da Ásia. 0 estilo culinário difere muito nas diferentes regiões asiáticas, os ingredientes e receitas variam em produtos e técnicas culinária, porém a importância do alimento permanece com o mesmo espírito e importância na comensalidade (KIME, 2009). 
A Tailândia é um país no sudeste asiático, que faz fronteira com a Malásia, Camboja, Laos e Myanmar, possui a cidade de paisagismo urbano ultra moderno, Bangcoc, como a capital. Assim como o Brasil, a Tailândia fica próxima a linha do equador, o que possibilita ao país ter um clima tropical e sua faixa litorânea, banhada pelo oceano Índico, ser conhecida pelas suas belíssimas praias e recursos alimentares da terra e do mar (ABRIL, 2010).

O turismo na Tailândia não é só pela animada vida urbana do seu centro comercial ou pelas belezas naturais, o país é conhecido também pelos seus esplendorosos palacetes reais, pelos seus templos budistas e por suas ruínas, como Wat Phra Sri Sanphet e Grand Palace. A Tailândia é o perfeito contraste entre tranquilidade e agitação em estado de equilíbrio, o que faz desse país a terra dos sorrisos (ALDEA, 2021).

Esta miscelânea de natureza e cultura se reflete em sua culinária, ou melhor dizendo, levando ao pé da letra a famosa máxima "você é o que você come", a gastronomia tailandesa dita o ritmo de vida do país e de seus moradores, mundialmente conhecidos pela alegria, leveza e solidariedade, não sendo à toa que a Tailândia é conhecida como um país alegre e acolhedor e de uma culinária ímpar e diferenciada (MAITREESOPHON, 2012).

O objetivo do estudo foi promover levantamento sobre fatos históricos, a importância e os impactos globais da corrente Culinária Tailandesa, com seus saberes, sabores e preciosidades aromáticas, que seduzem chefs e gourmets de diferentes culturas alimentares.

\section{METODOLOGIA}

A pesquisa bibliográfica foi baseado na análise de dados decorrentes de ferramentas de busca usando os seguintes termos: cultura alimentar. Alimentação asiática. Tailândia. Gastronomia Tailandesa. As informações foram obtidas a partir de levantamentos feitos em livros especializados em gastronomia, em sites de referências acadêmicas como o Google Scholar e Scientific Electronic Library nos vernáculos em português e inglês. As referências obtidas serviram para orientar a temática na construção do texto, a fim de responder a inquietação sobre a historicidade e os efeitos sociais da cultura alimentar tailandesa, que provoca grande curiosidade sobre os 
ingredientes nativos, técnicas culinárias e uma cozinha saborosa na visão dos gourmets mais exigentes, e que se tornou um trade turístico na rota gastronômica mundial.

\section{REVISÃO BIBLIOGRÁFICA}

O Homo erectus, datado de 1,6 e 0,5 milhões de anos, foi descoberto em terras Tailandesas. Esta mesma região vivenciou o período pré-histórico, posteriormente, viu o surgimento da agricultura, há cerca de 6 a 7 mil anos, e aproximadamente 2 a 3 mil depois, viveu sua Idade do Bronze. Um pico de crescimento populacional aconteceu entre os anos 600 e 1400 d.C, com a organização de cidades e amplos assentamentos construídos entre muros, fossos e cercas. Os reinados de Sukhothai, Lan Na e outros estados tailandeses foram estabelecidos por volta do século 13 d.C, período em que também se formou o estilo clássico e reconhecidamente tailandês de arte, artesanato e arquitetura (TAILÂNDIA, 2011).

Acontecimentos políticos e culturais importantes aconteceram com 0 surgimento do Reinado 8 de Ayutthaya (1350 - 1767 d.C), que se destacou por suas habilidades para a diplomacia e para o comércio internacional. Logo após a destruição de Ayutthaya em 1761, os tailandeses se encaminharam para Thon Buri, no Sul do país, para se reorganizarem e restabelecer o Reino. O centro do poder transferiu-se então para a região dos rios Krung Thep e Chao Phraya que hoje é a capital Bangcoc, estabelecida em 1782. A Tailândia foi o único país no Sudeste Asiático que escapou do colonialismo ocidental durante os séculos XIX e XX, mérito da diplomacia e sabedoria do Rei Mongkut e seu sucessor, o Rei Chulalongkorn. O monarca atual é o 10음 da dinastia Chakri, o rei Maha Vajiralongkorn, que assumiu o trono em 2016 quando seu pai, o monarca Bhumibol Adulyadej, morreu. Este último ficou mundialmente famoso pelo extenso tempo a frente da administração da Tailândia, 70 anos (1946-2016) e venerado pelo seu povo como um ser divino (TAILÂNDIA, 2011; DUNKER \& CHAN, 2021).

A Tailândia devido a seu histórico de muito contato com outras civilizações desde a pré-história, possui uma cultura muito plural agregando comportamentos, tradições e conhecimento indígenas e de outros povos como chineses e indianos. Sua etnia mais popular é o Thai e sua língua oficial é o tailandês, estima-se 61 milhões de pessoas a falem, dentre língua materna e 2 o língua. O tailandês foi originado a partir de vários outros idiomas como o Sânscrito, e é considerado complexo pois possui diferentes 
dialetos e é uma língua tonal, isto é, a entonação das sílabas faz parte da estrutura semântica das palavras, e assim uma mesma palavra pode ter significados diferentes a depender de como ela é dita. Sua escrita foi criada pelo Rei Ramkhamhaeng, o Grande, em 1283. Outros idiomas falados no país incluem chinês, malaio e línguas indígenas. 0 inglês é matéria obrigatória no currículo do ensino médio, é amplamente falado e compreendido em todo o país (EMBAIXADA REAL DA TAILANDIA, 2021).

Os tailandeses são fortemente influenciados pelo animismo, que praticamente diz respeito às crenças e tradições do povo indígena nativo da Tailândia. O animismo tem o entendimento de que tudo que existe possui um princípio espiritual, não havendo uma separação entre matéria e espírito, e assim, os homens e os outros animais, as plantas, os fenômenos, características geográficas, enfim, tudo o que se conhece no universo possuem uma espécie de alma dotada de percepções, sentimentos e/ou pensamentos. A crença anímica está presente na literatura, arte e religiões milenares como o hinduísmo e budismo, que são as principais religiões deste país (DINIZ, 2010; DURAZZO, 2016).

O Budismo praticado na Tailândia, é o Budismo Theravada, ele segue os ensinamentos de Buda, inclusive a língua falada por Buda, Pali. É uma língua morta, porém usada entre os devotos. Quando comparada a outras linhagens budistas, a Theravada é mais restritiva e conservadora. Influenciado pelo animismo, o budismo acredita em espíritos, como o do fogo, da água, dos animais, etc. E, assim sendo, a crença se baseia na harmonia dos vivos e mortos, principalmente entre os humanos encarnados e os desencarnados. Uma curiosidade do país é a Casa dos Espíritos (San phra phum), uma casinha construída na frente da casa de todo tailandês budista, onde se põe oferendas, como flores, doces, para deixar os espíritos felizes e obter proteção e bençãos para a casa (DINIZ, 2010; SAMUITIMES, 2013, LOPEDOTE, 2016).

Já o Hinduísmo, a filosofia Hindu, veio dos peregrinos e mercadores da Índia que tinham a Tailândia como ponto de parada, por volta do século I e III d.C. Pelo grande número desses andarilhos, os reis do antigo Sião (Tailândia) incorporaram alguns costumes Hindus que foram se enraizando e ganhando uma personalidade própria, a tailandesa. Desta forma, nos templos budistas tailandeses pode-se encontrar Buda, Shiva, Ganesha e outros deuses Hindus, assim como o comportamento dos monges serem incomuns a outros monges budistas do mundo (LOPEDOTE, 2016). 
No quesito musical, os tailandeses sofreram forte influência americana e europeia, apesar de não ter sido colonizado por nenhum país ocidental. O rock, metal, punk rock, folk e pop tem grande espaço no cenário fonográfico, principalmente entre os jovens. A Tailândia também possui ritmos próprios como o Luk Thung, uma espécie de sertanejo para eles, pois canta a vida bucólica do interior. Porém, nada mais representativo na música local que a cara oriental das músicas, a velocidade em que é cantada, uma vez que seus fonemas possibilitam serem cantados rápido e a ausência de regras para as melodias, é como se cada músico ou compositor tivesse seu ritmo. As bandas mais famosas do local são: Buddha Bless, Siriporn, Armchair, Lif\&oil e Ampaiphong (CHAN, 2016; CULTURAMIX, 2010).

É muito comum aliar música e teatro na Tailândia, e as apresentações estão sempre nos pacotes turísticos pois encanta os viajantes. O mais incrível é que não são apresentações comuns, como por exemplo, pode-se encontrar os tradicionais Thai Boxing, que são shows com lutas ao vivo. Este fascínio por lutas e artes marciais é o que transforma o Muay Thai no esporte símbolo do país e mais praticado. Outro esporte nativo do reino é Sepak, onde os jogadores batem uma bola de rattan e só estão autorizados a usar os pés, joelhos, peito e cabeça para tocá-la. Outros esportes não nativos são praticados pelos tailandeses, como o futebol, basquete e golfe. Este último tem se popularizado ao ponto do reino ser chamado de capital do golfe na Ásia e ser o destino dos praticantes desta categoria no mundo (JÚNIOR \& SONODA-NUNES, 2020; PEDERCINI, 2006).

Como todo país, a Tailândia possui particularidades bem curiosas quando comparadas com as outras culturas, como por exemplo, o dia 13 de março é o dia Nacional do Elefante, é feriado em todo o território, e é celebrado o papel do elefante na história do reino. Outra peculiaridade é o ano novo tailandês, Songkran, comemorado no primeiro dia da quinta lua crescente do ano e dura 3 dias, geralmente cai na data 13 a 15 de abril (CARRIÓN, 2016).

Outras curiosidades são (THAILAND-TRIP, 2021; TAILAND, 2012; ZABALA OKOSI, 2020):

- Cada parte do corpo tem seu status, e depende este da sua localização, a cabeça tem o maior status, é o mais alto status e o local mais limpo do corpo. Já os pés, a parte mais sujam do corpo, são escondidos ao sentar-se ao chão, pois expor suas solas é considerado ofensivo. 
- A etiqueta local indica que é considerado rude tocar a cabeça de uma pessoa ou apontar para uma pessoa ou uma imagem de Buda.

- Demonstrar muita emoção em público é considerado impróprio.

- Jogar coisas no chão, principalmente livros e dinheiro, é muito desrespeitoso.

- Ao tirar fotografias com estátuas ou outras imagens do Buda, ele sempre deve aparecer acima das pessoas, como uma demonstração de respeito.

- Bangcoc não é o verdadeiro nome da capital tailandesa, a cidade possui o maior nome de lugar do mundo, Krungthepmahanakhon Amonrattanakosin Mahintharayutthaya Mahadilokphop Noppharatratchathaniburirom Udomratchaniwetmahasathan Amonphimanawatansathit Sakkathattiyawitsanukamprasit, e sua tradução literal quer dizer: Cidade dos Anjos, Grande Cidade dos Imortais, Magnífica Cidade das Nove Gemas, Sede do Rei, Cidade dos Palácios Reais, Lar dos Deuses Encarnados, Erguida por Visvakarman no Mandamento de Indra. Para não repetirem todo este nome, os tailandeses se referem a cidade como Krungthep, o início do nome apenas.

No tocante à literatura, a Tailândia não pode ser esquecida, em 2013, Bangcoc foi eleita a capital mundial do livro pela UNESCO. A cidade foi escolhida pela qualidade de seus programas e promoção à leitura e livros. Duas mulheres se destacam na literatura do reino, Marayat Rollet-Andriane ou Emmanuelle Arsan, pseudônimo fictício, homônimo de sua personagem e nome da sua obra mais famosa, que além de livro virou filme sobre uma mulher e sua jornada de autodescoberta sexual, e Ngarmpun Vejjajiva, escritora e tradutora tailandesa, cadeirante, com paralisia cerebral no período perinatal, teve seu primeiro romance, A Felicidade de Kati, considerado best seller. Entre outros nomes, podemos citar Prabda Yoon, trabalhou como tradutor em obras renomadas como Lolita e Laranja Mecânica e Sunthorn Phu, poeta conhecido como Shakespeare tailandês (CHAMPEON, 2003; UNESCO, 2018; KLEMM, 2017).

\subsection{ECONOMIA}

No último relatório do Desempenho Econômico da Tailândia pelo Escritório do Conselho Nacional de Desenvolvimento Econômico e Social (NESDC) em 2020, o PIB per capita nos valores de mercado foi de US\$ 7,579.606. Neste mesmo ano, a Tailândia recebeu o título de "economia menos miserável" em 2020 pela Bloomberg. Os principais produtos de exportação são gêneros alimentícios, que incluem arroz, frutos do mar, mandioca, açúcar, equipamentos para escritório, peças automotivas, peças para computadores, produtos têxteis e roupas (EMBAIXADA REAL DA TAILANDIA, 2021). 
A moeda tailandesa é o Baht e atualmente B 1,00 (Bath) equivale a US\$ 0,03 (dólar americano), ela sofreu um colapso na crise econômica de 1997 e desde então a economia vem em movimento de recuperação. A participação na Asia-Pacific Economic Cooperation - APEC ajuda neste processo de crescimento econômico, uma vez que o objetivo da APEC é de promover a integração comercial e aumentar os investimentos na região da Ásia-Pacífico. Os números da APEC em termos comerciais são gloriosos, de 1998 a 2004 promoveu um aumento comercial de mais de $300 \%$ no bloco como um todo. Os tailandeses, desta forma, ganham não somente em números comerciais, mas em qualidade de vida, pois tópicos como meio ambiente, distribuição de renda, saúde, educação e outros de suma importância social entram em debate e mudam positivamente sob o crivo da APEC (TELLO, 2021; GOH \& GROENEWOLD, 2000; APEC, 2021).

\subsection{GASTRONOMIA}

A Tailândia merece a fama "terra dos milhares de sorrisos", pois sua culinária faz as pessoas sorrirem de prazer, descrita como quente, espantosa e viciante. Apesar de ter raízes profundas nas cozinhas da China e Índia, a Tailândia permaneceu intacta ao longo dos séculos, pois seus regentes sempre tiveram a habilidade política de contornar invasões dos estrangeiros, pois seu território é reconhecido por seus vizinhos por possuir planícies férteis, território excelente para cultivo do arroz (MORRIS, 2009; PHAM, 2011). Ainda hoje, os arrozais na Tailândia abastecem o sudeste asiático, com a espécie de grão longo, em especial o refrescante e aromático arroz de jasmim (KIME, 2009).

Com número crescente de restaurantes típicos, onde cada vez mais pessoas se familiarizam com pratos tradicionais da cozinha tailandesa, suas preparações vêm se tornando cada vez mais populares. A gastronomia tailandesa prima pela mistura de sabores, aromas e cores. A riqueza dos ingredientes, onde sobressaem o arroz e as frutas, o requinte na apresentação dos pratos e a criatividade dos chefs fazem desta cozinha uma das mais ricas de toda a Ásia.

A diversidade da culinária Tailandesa pode ser apreciada tanto ao cozinhar quanto em degustar os pratos. É possível sentir diversos estímulos gustativos, desde uma fritura crocante, um curry curtido sem pressa, até uma sobremesa que derrete na 
boca, os sabores tailandeses são uma verdadeira viagem gastronômica. É comum ao servir pratos tailandeses deixar uma grande tigela de arroz ao centro da mesa. Cada um se serve de uma porção de arroz e um pouco dos outros pratos. As sopas normalmente são consumidas no decorrer das refeições e não antes. Sobremesas geralmente são à base de frutas ao final das refeições. E por sua combinação de texturas e sabores a gastronomia tailandesa se torna inesquecível aos apreciadores da boa comida.

Migrantes do sul da china, os tailandeses no princípio se estabeleceram ao norte e foram se movimentando ao sul. No decorrer de sua migração, descobriram que as planícies centrais férteis e chuvosas tinham as qualidades necessárias para os campos de cultivo, com isso a região ficou conhecida como a tigela de arroz do sudeste asiático. A culinária da Tailândia é o resultado de influências tanto da culinária chinesa, quanto dos mercadores árabes e indianos, os quais apresentaram aos tailandeses as especiarias secas como o coentro, cominho, noz-moscada, o cravo-da-índia e a cúrcuma podendo ser observado no curry tailandês mussaman. Destas, porém, pode-se dizer que a mais significativa importação foi a pimenta vermelha, que possui lugar de destaque na culinária tailandesa (MORRIS, 2009).

Com preparações simples e um método culinário rápido, como refogar e bons ingredientes pode-se ter uma refeição oriental saborosa à mesa rapidamente. Pratos clássicos como frango satay e macarrão de arroz frito, mesclam-se aqui com pratos menos conhecidos, como a sopa cremosa com leite de coco e caldo de frango, e arroz ao leite de coco com manga. As misturas de especiarias são a preparação fundamental, aliada com imaginação e refinamento conseguem passar todo sua expressão nas variadas preparações. Entre as mais conhecidas podemos citar conforme Kime, 2009; Larousse, 2005; Morris, 2009, Pham, 2011:

- SOM TAM (Salada de papaia verde) - O Som Tam é servido como lanche ou parte de uma refeição. Este clássico da gastronomia Tailandesa pode ser degustado sozinha, com folhas de repolho ou com arroz. É preparada no pilão aos poucos, é adicionado o molho e depois misture com o restante dos ingredientes. Sua mistura delicadamente triturada de papaia verde com o molho de peixe (nam pla), pimentas e camarão seco criam sabores únicos. Esta preparação é um dos ícones da comida tailandesa, em cada porção se acham presentes os elementos base dessa corrente culinária: picante, adocicado, 
salgado, ácido e juntando também as sensações do tostado, crocante, consistente, o macio para juntos exercitar um festival do paladar.

- PAD THAI (Macarrão frito Tailandês) - Um dos pratos mais conhecidos da gastronomia tailandesa, se trata de um macarrão de arroz frito e suas principais versões costumam ser preparadas com tofu, moyashi, ovos e nam pla, acrescentando-se uma proteína que geralmente é camarão ou frango. É uma preparação servida tanto em restaurante como em barracas na rua, símbolo da popularização de um prato típico que representa a cultura alimentar tailandesa, prato completo e harmonioso.

- SATAY GAI (Frango Satay) - Tipicamente feito com carne de frango essa preparação popular também pode ser encontrada utilizando carne bovina, suína, de frango ou carneiro, e diferentes especiarias na marinada. A carne do frango é marinada em uma mistura aromática de capim-limão, leite de coco, limão, semente de coentro, cúrcuma e nam pla. Depois é grelhado e servido com um molho de amendoim temperado com geleia de pimenta, molho satay e salada de pepino.

- TOM KHA GAI (Sopa de coco e frango picante) - Uma das sopas mais consumidas na Tailândia, tem sabor instigante por trazer o equilíbrio correto de temperos e a relação perfeita entre leite de coco e caldo de galinha. Usa-se um leite coco saboroso, porém leve, e a geleia de pimenta, para dar profundidade ao sabor. Tem a possibilidade de encontrar uma sopa mais rica e com caldo mais grosso, isso se dá devido a redução da quantidade de caldo de galinha e aumento da quantidade do leite de coco. Em algumas versões acrescenta-se nam pla, limão e folhas de coentro fresco.

- GOI GOONG (Salada de camarão Tailandesa) - Prato bem conhecido no nordeste da Tailândia, chamado de Isan ou Esarn, as saladas como Larb e goi fazem parte da cultura gastronômica local. Esta salada refrescante é feita com o camarão escaldado e depois "cozido" no suco de limão. Geralmente essa salada é servida pura ou enrolada em folhas de repolho ou de alface.

- YUM MALUA YAO (Salada Tailandesa de berinjela grelhada) - Para essa salada é importante preservar a estrutura da berinjela que é assada diretamente na chama do fogão. Depois ela é descascada e misturada com carne de porco e camarão. O molho que traz os sabores picantes, azedo e salgado do nam pla e do camarão seco forma a identidade dessa preparação. Uma outra variação dessa preparação vem do vizinho Mianmar, que acrescenta amendoim, tamarindo e folhas de coentro. 
- KAO NIAO MAMUAN (Fatias de manga acompanhadas de arroz cozido em leite de coco) - Uma das sobremesas mais tradicionais da Tailândia. Seus principais ingredientes são arroz glutinoso, leite de coco fresco ou industrializado, sal, açúcar de palma e mangas. Embora tenha sua origem na Tailândia, é consumida em toda a região Indochina do Sudeste da Ásia, incluindo Laos, Camboja e Vietnã.

\section{CONSIDERAÇÕES FINAIS}

A culinária tailandesa surgiu da exuberância de seus recursos naturais da terra e do mar, de um povo alegre e hospitaleiro que soube traduzir na culinária, toda sua criatividade e alegria do prazer de viver, gerando momentos contemplativos durante as refeições.

O legado dessa cultura alimentar é que ainda temos muito por descobrir em harmonização de novos produtos, que poderão fazer a diferença em novas sensações gustativas, frente a diferentes etnias culinárias. Essas distâncias geográficas devem ser encurtadas através do intercâmbio de experiências na cozinha, e nada melhor do que uma refeição prazerosa e cativante para amenizar as diferenças culturais.

\section{REFERÊNCIAS}

ABRIL. Tailândia: Cozinhas do Mundo. São Paulo: Abril Coleções, 2010. 174p.

ALDEA, Daiana Cristina. El impacto del turismo sobre el medio ambiente en Tailandia. 2021. Trabalho de conclusão de curso (Graduação em turismo) Universitat Jaume I, Castelló de La Plana, 2021. Disponível em: http://repositori.uji.es/xmlui/bitstream/handle/10234/195439/TFG_2020_Alde a_DC.pdf?sequence=1\&isAllowed=y . Acesso em: 01/12/2021.

APEC - Relatório de Política Econômica da APEC 2021. Singapore. Nov. 2021. Disponível em: https://www.apec.org/publications/2021/11/2021-apec-economic-policyreport. Acesso em: 04/12/2021.

CARRIÓN, Javier. Songkran: la fiesta del Año Nuevo en Tailandia. Viajar: la primera revista española de viajes, n. 443, p. 90-97, maio 2016. Disponível em: https://viajar.elperiodico.com/destinos/songkran-la-fiesta-del-ano-nuevo-entailandiaom). Acesso em: 11/09/2021.

CHAMPEON, Kenneth. Thailand's Shakespeare? Sunthorn Phu. Tailândia. 2003. Disponível em: http://thingsasian.com/story/thailands-shakespeare-sunthornphu. Acesso em: 30/10/2021. 
CHAN, Brenda. Luk Thung: The Culture and Politics of Thailand's Most Popular Music. Jornal do Ramo Malaio da Sociedade Real Asiática, v. 89, n. 1, p. 171-172, 2016. Disponível em: https://muse.jhu.edu/article/623003/summary . Acesso em: 02/12/2021.

CULTURAMIX Música da Tailândia. 2010. Disponível em: https://musica.culturamix.com/curiosidades/musica-da-tailandia. Acesso em: $03 / 12 / 2021$

DINIZ, Alexandre Magno Alves. Surgimento e dispersão do budismo no mundo. Espaço e Cultura, Rio de Janeiro, n. 27, p. 89-105, Jan./Jun. de 2010. Disponível em: https://www.e-

publicacoes.uerj.br/index.php/espacoecultura/article/viewFile/3546/2467. Acesso em: 12/11/2021.

DUNKER, N. G; CHAN, C. Sudeste asiático: el puente regional. Asia: Un continente por descubrir, 1aed. Bogotá: Ecoe Ediciones. 2021. p.221 - 310.

DURAZZO, Leandro. Antepassados presentes: o contato entre vivos e mortos no budismo chinês Cadernos do CEIL - Revista Multidisciplinar de Estudos sobre o Imaginário. Lisboa, n. 3, p. 81-93. 2016. Disponível em: https://www.academia.edu/download/47293836/DURAZZO_Leandro__Antepassados_presentes_CCEIL_7-3_2016_LD.pdf. Acesso em: 11/10/2021.

EMBAIXADA Real da Tailândia: Informações gerais. 2021. Disponível em: https://www.thaiembassyinbrazil.com/sumario_tailandia.php?id_m=52\&id=53 2 Acesso em 11/10/2021.

GOH, D; GROENEWOLD, N. Fundamentos e especulações na crise tailandesa baht. International. Journal of Finance \& Economics, v. 5, n. 4, p. 297-308. 2000.

JUNIOR, I. L. M.; SONODA-NUNES, R. J. Muay Thai-O jogo do poder. The Journal of the Latin American Socio-cultural Studies of Sport (ALESDE), Curitiba, v. 12, n. 2, p. 58-76. 2020.

KIME, T. Comidinhas Orientais: Deliciosas Receitas com os Exóticos Sabores do Continente Asiático. São Paulo; Publifolha, 2009. 223p.

KLEMM, Alexander J. The Legacy of Emmanuelle: Oriental Desire and Interracial Encounters in European Films Set in Thailand 1974-1980. In: $13 \mathrm{TH}$ INTERNATIONAL CONFERENCE ON HUMANITIES \& SOCIAL SCIENCES. 2017 Anais [...]. Disponível em: http://iafor.org/archives/journals/iafor-journal-of-culturalstudies/10.22492.ijcs.4.2.05.pdf Acesso em: 19/09/2021. 
LAROUSSE. Cozinha do mundo: Ásia e Oceania. São Paulo: Larousse do Brasil, 2005. 143p.

LOPEDOTE, Bárbara Galle. As mulheres e a experiência religiosa Ideologia de mérito e ordenação monástica feminina em Chiang Mai, Tailândia. Trabalho de conclusão de curso (Graduação em Antropologia). Universidade Federal de Santa Catarina, Santa Catarina, 2017. Disponível em: https://repositorio.ufsc.br/xmlui/handle/123456789/174104. Acesso em: 20/09/2021.

MAITREESOPHON, Bampen. Foreign Tourists' Perspective on Selecting Thailand, the Land of Smile, as a Tourist Attraction. In 4 TH INTERNATIONAL CONFERENCE ON HUMANITIES AND SOCIAL SCIENCES April, 2012. Anais [...] Faculty of Liberal Arts, Prince of Songkla University, 2012. Disponível em: https://so02.tcithaijo.org/index.php/jes/article/view/240601. Acesso em: 01/12/2021.

MORRIS, S. Culinária Tailandesa: Receitas especiais fácil de fazer. São Paulo: Publifolha, 2009. 216p.

PEDERCINI, Raquel. Jogos e esportes tradicionais - Kabaddi e Sepaktakraw in DACOSTA, Lamartine (ORG.). Atlas do Esporte no Brasil: CONFEF Rio De Janeiro. p. 10221023, $2006 . \quad$ Disponível em: http://www.listasconfef.org.br/arquivos/atlas/atlas.pdf. Acesso em 23/09/2021.

PHAM, Mai. Sabores do Oriente. The Culinary Institute of America. São Paulo: Publifolha, 2011. 272p.

TAILÂNDIA O livro na rua. Série diplomacia ao alcance de todos. Embaixada Real da Tailândia. Brasília: Thesaurus Editora, 2011. Disponível em: http://funag.gov.br/loja/download/762_Livro-na-rua-Tailandia.pdf. Acesso em: 20/10/2021.

TELLO, Dagoberto Amparo. La política exterior de Tailandia y su participación en la ASEAN, el ARF y el APEC. México y la Cuenca del Pacífico. Guadalajara, vol. 4, n. 12, p. 22-26, abril 2001.

THAILAND Family law center. Physical contact and personal space in Thailand. Bangcoc, 2012. Disponível em: http://www.thailand-family-law-center.com/physicalcontact-and-personal-space-in-thailand/. Acesso em 02/10/2021.

THAILAND-TRIP. Culture, traditions and customs of Thailand. Bangcoc, 2021. Disponível em: https://www.thailand-trip.org/pt/kultura. Acesso em: 01/12/2021.

TIMES, Samui. San Phra Phum Thai Spirit House. Tailândia, Out. 2013. Disponível em: https://www.samuitimes.com/san-phra-phum-thai-spirit-house/. Acesso em: $14 / 10 / 2021$. 
UNESCO, Atenas: livros em todos os lugares. Paris, 2018. Disponível em: https://pt.unesco.org/courier/2018-2/atenas-livros-em-todos-os-lugares. Acesso em: 04/11/2021.

ZABALA OKOSI, Pilar. La traducción de los nombres geográficos en el ámbito turístico. 2019. Trabalho de conclusão de curso (Graduação em Tradução e interpretação Inglês-Alemão). Universidad de las Palmas de Gran Canaria. España, 2019. Disponível em: https://accedacris.ulpgc.es/bitstream/10553/70254/2/Pilar\%20Zabala\%20Okos i-TFG.pdf. Acesso em: 02/11/2021. 


\title{
CAPITULO XXV \\ PENINNSULA COREANA: HISTÓRIA E GASTRONOMIA
}

\author{
DOI: 10.51859/AMPLLA.DES1788-25
}

\author{
Jessika Alexandre de Melo Andrade ${ }^{1}$ \\ Douglas Antônio Gondim Módolo ${ }^{1}$ \\ Maria Lúcia Gurgel da Costa ${ }^{1}$ \\ Neide Kazue Sakugawa Shinohara ${ }^{2}$
}

${ }^{1}$ Graduanda(o) do curso de Gastronomia. Universidade Federal Rural de Pernambuco - UFRPE
${ }^{2}$ Docente do Curso de Gastronomia. Universidade Federal Rural de Pernambuco - UFRPE

\section{RESUMO}

A Península Coreana está estrategicamente localizada na Ásia oriental, cercada em toda sua extensão pelo Mar do Japão a leste, o Mar da China Oriental ao sul e o Mar Amarelo a oeste; faz fronteira com a China, Rússia e Japão. A Coreia é uma nação antiga, que já passou por vários processos de invasão e dominação, desde a década de 50, por razões diplomáticas, após a 2a Guerra Mundial e uma guerra civil, tornou-se uma nação dividida em dois países. Ao norte, sob um regime socialista - República Popular Democrática da Coreia-RPDC (Coreia do Norte), no sul sob um regime capitalista República da Coreia (Coreia do Sul). O presente estudo trata-se de revisão bibliográfica sobre as bases da culinária desses países, buscando analisar estudos existentes, que abordam história e costumes ligados à alimentação de cada local. Para executar esse material foram utilizadas as bases de dados de SciELO, livros físicos e digitais, além de documentários. A análise dos estudos apresentados permite-nos concluir que as influências sócio históricas de cada região, relacionadas às invasões e acordos políticos, a disponibilidade de alimentos e a escassez destes vinculados a sanções econômicas sofridas, determinaram diferenças na oferta de alimentos, e singularidades relativas a formas de preparo. Destaca-se ainda a renda per capita de cada região e o regime de governo que impacta em maior ou menor demanda de aquisição de alimentos e/ou subsídio à alimentação básica de qualidade.

Palavras-chave: Gastronomia. Coreia do Norte. Coreia do Sul. Comida asiática. Cozinha oriental. 


\section{INTRODUÇÃO}

Artigo construído como parte de um levantamento bibliográfico e estudos conduzidos pela disciplina Cozinha Oriental, no curso de Bacharelado em Gastronomia da Universidade Federal Rural de Pernambuco (UFRPE). O texto discorre sobre a Península Coreana, apresentando uma síntese sobre os principais traços de sua história, geografia, cultura e gastronomia.

A gastronomia é uma das formas de expressão identitária manifestada por uma sociedade. Assim, para compreendê-la, tomando como referência um local específico, é necessário que se conheçam os múltiplos contextos que a constituem. Já que a construção de hábitos alimentares será delineada por fenômenos socioculturais concebidos ao longo do tempo.

A busca por sabores e a experiência na cozinha, compõem momentos de percepção e de prazer. Matar a fome é uma necessidade biológica dos seres vivos, mas a procura por diferentes sabores é uma conquista do homem, independente da biodiversidade alimentar de cada povo (LODY, 2008). A Ásia detém comprovada historicidade à milênios, sua riqueza alimentar e práticas culinárias são registradas por filósofos, pensadores, gourmets, farmacologistas, pois a valorização do alimento não é somente uma questão de nutrientes, também um elemento de promoção de saúde e um elemento agregador social e cultural.

\section{PENÍNSULA COREANA}

\subsection{HISTÓRIA E CULTURA}

Localizada em uma península com fronteiras com a China, Rússia e Japão, apresenta uma área de aproximadamente $220.000 \mathrm{~km} 2$. Atualmente a Coréia é dividida em dois países: ao norte, com uma população de 25.78 milhões de habitantes e sob um regime socialista, a República Popular Democrática da Coreia-RPDC (Coreia do Norte). E, ao sul, com 51.78 milhões de habitantes, sob um regime capitalista, a República da Coreia (Coreia do Sul).

No entanto, a história do espaço territorial como um só país, já que é assim que ainda se enxergam, é milenar e contribuiu com a formação cultural e sociológica que podemos observar em toda península. Os primeiros povos a ocuparam, por volta de 
2333 a.C., e sofreram forte influência e dominação, nesses primeiros momentos de sua história, da China. Inclusive no desenvolvimento da agricultura de cultivares como milho, cevada, trigo e arroz.

Com o desenvolvimento e crescimento da população coreana, pouco antes do século I e até o século VII, mais precisamente entre 57 a.C. e 668 d.C., foram criados três reinos que começaram a formatar os rumos da cronografia coreana. Os reinos de Silla, Baekje e Goguryeo que competiam nos campos econômicos e militares para expansão ou manutenção de seus territórios, e possuíam seus próprios hábitos, inclusive os alimentares.

Em 936 d.C., a Dinastia Goryeo assumiu o poder, unificando todo o território e fazendo imperar a fé budista, que já havia se disseminado pelo contato com outros povos através das rotas marítimas de comércio. $E$, já nos períodos finais que durou este governo, por volta de 1231, os mongóis invadiram a região. O uso principal das terras era como base militar de ataque à China e ao Japão. $E$, entre outras influências na concepção cultural coreana, a gastronomia sofreu intervenção: como o uso de carne que anteriormente era desencorajada pela filosofia budista, os temperos, e pratos como um bolinho conhecido como "mandu".

Essa forma de governar foi substituída pela Dinastia Joseon, em 1392, que deixou um legado substancial às normas sociais coreanas, com desenvolvimento científico e tecnológico. Foi um reino dinástico que durou cinco séculos, o que obviamente culminou em um grande impacto no desenho da atual cultura da Coreia.

O período foi guiado pela doutrina chinesa confucionista, elencando a hierarquização da sociedade por meio das linhagens e primogenitura e promovendo perseguição ao budismo. Apesar de sua autonomia e desenvolvimento, foi um intervalo histórico sob muita influência da China, que passou a interferir diretamente nos assuntos políticos conforme a influência do Japão obteve espaço.

A hierarquia social tinha em sua ordem crescente de importância: os Nobi (escravos ou servos); os Baekjeong (nômades de etnias minoritárias que sofriam discriminação); os Cheonmin (plebeus segregados que não podiam ascender socialmente, e que eventualmente poderiam ser tornar Nobi); os Sangmin (plebeus com trabalhos virtuosos: camponeses, pescadores, artesãos e mercadores); os Chungin (uma classe privilegiada de plebeus que consistia em um pequeno grupo de burocratas que 
desempenhavam atividades técnicas e administrativas); e, os Yangban (aristocracia dominante formada majoritariamente por funcionários públicos e oficiais militares).

A importância que essas classes sociais exerceram sobre a gastronomia coreana se dá nos diferentes acessos alimentares que possuíam. Isso porque, existia um estilo gastronômico coreano tradicionalmente consumido na corte da Dinastia Joseon com variedade de alimentos e diversidade de preparos para cada dia. Enquanto que ao restante da população a possibilidade de refeições variadas era algo sazonal e restrito.

O período Joseon foi responsável por avanços nas ciências naturais, literatura, medicina tradicional e engenharia. O que permitiu desenvolvimento agrícola e comercial. Foram criados mercados regionais que se tornaram o centro econômico das comunidades. E, a partir do século XVI, a agricultura expandiu seu volume de produção para o comércio externo através da importação de produtos das rotas comerciais com China, Japão e Europa, tais como as culturas de milho, batata doce, pimentão, tomate, amendoim e abóbora.

A queda desta dinastia se desenhou de forma progressiva desde o final do século $\mathrm{XVI}$, por volta de 1592, quando começaram a ser levantadas disputas japonesas pela conquista do espaço territorial coreano. Com o apoio chinês, a Coreia conseguiu resistir às invasões até 1910, quando já com uma postura imperialista o Japão conseguiu transformá-la em colônia.

As forças nipônicas foram responsáveis por profundas mudanças como a transferência de alguns setores industriais para a Coreia. Em contrapartida, a levaram a um empobrecimento rural e ao aprofundamento da dependência política. Passaram a explorar poucas variedades agrícolas em campos de grande escala, como o arroz. Entretanto, os rendimentos eram para exportação ao Japão, deixando a população coreana em escassez alimentar. As classes mais baixas recorriam a grãos mais baratos.

A Coreia deixou de ser uma colônia japonesa para adentrar na situação que se mantém até os dias atuais em 1945, com a derrota do Japão na Segunda Guerra Mundial. As forças militares dos Aliados reprimiram a ocupação japonesa em solo coreano que foi dividido na altura do meridiano conhecido como Paralelo $38^{\circ}$, separando em duas zonas: ao norte pela União Soviética, e ao sul pelos Estados Unidos da América. Seus regimes de governos antagônicos passaram a protagonizar parte da 
Guerra Fria que culminou na Guerra da Coreia, em 1950. Anteriormente a isso, em 1948, as duas repúblicas da Coreia foram oficialmente formadas.

O conflito que se sucedeu foi um dos mais violentos do século XX. A decisão norte-coreana de iniciar a guerra se deu pelo desejo que ambos os lados fomentaram de reunificar o país sob seu próprio comando político. O Norte contou com o apoio chinês, e o Sul com o apoio dos Estados Unidos. Foram inúmeros os massacres ocorridos, até mesmo contra a população civil dos dois lados. Houve devastações massivas com perdas industriais, de sistemas hidrelétricos, registros de uso de armas químicas e biológicas, e ameaças de ataques nucleares.

É esperado que com todo esse caos a população se encontrasse com sério comprometimento econômico, que em termos alimentares se refletia na escassez. Também teve um alcance significativo na identidade cultural coreana, já que dividiu um povo de história milenar. O escalonamento do conflito foi elevado de tal maneira que, iniciadas as negociações de paz, jamais chegou-se a um tratado. Foi apenas assinado um armistício, estabelecendo distâncias mínimas entre exércitos e uma zona desmilitarizada.

\subsection{COREIA DO NORTE}

A Coreia do Norte é um Estado socialista autossuficiente e multipartidário que realiza eleições periódicas, a cada 5 anos para a Assembleia Popular Suprema, parlamento coreano, com sufrágio universal e voto secreto. A Frente Democrática para a Reunificação da Pátria, com dominância de $87 \%$ pelo Partido dos Trabalhadores da Coreia, seleciona o nome do único candidato que aparecerá nas cédulas de votação. É possível não votar neste, riscando-o na cédula, porém tal ato deve ser realizado em cabine especial, e além de ser considerado desrespeitoso é um ato arriscado, tendo em vista as repressões que operam sobre a população. Kim Jong-un é o Supremo Comandante do Exército Popular, sendo a principal liderança do país. E, Choe Ryonghae é o Chefe de Estado coreano.

O país abrange uma área de $120.540 \mathrm{~km}^{2}$, e faz fronteira com a China e a Rússia na parte norte. A maior parte do território é composto por montanhas e planaltos, separados por vales profundos, com clima predominantemente continental. 
O país possui um regime muito fechado, seus habitantes não podem usar telefone celular ou internet, por exemplo. Isso torna o processo de pesquisa e acesso à informação bastante limitados.Mantém restrita relação comercial com outros países seguindo os moldes políticos de governo da extinta União Soviética.

Com uma população de quase 26 milhões de habitantes que falam o idioma coreano. Todos os norte-coreanos são classificados em grupos de acordo com Songbun, um sistema de status que tem como base o histórico de comportamento político, social e econômico do indivíduo e de sua família por três gerações. Essa classificação afeta o acesso às oportunidades de educação e de emprego.

Fontes como Human Rights Watch (2021), Anistia Internacional e ONU(2021), acusam a Coreia do Norte de ter um dos piores registros de direitos humanos do mundo, devido às severas restrições às liberdades individuais, políticas e econômicas. Com história de violências e prisões políticas, além disso a sociedade norte coreana vive em uma série de regime de restrições.

A maioria da população norte-coreana pode ser caracterizada como irreligiosa. No entanto, existe ainda uma influência cultural de religiões tradicionais como do budismo e confucionismo na vida espiritual da Coreia do Norte.

Os meios de produção são de propriedade do Estado através de empresas estatais e fazendas coletivizadas, mas não atendem com eficiência a demanda da grande parte da população, privilegiando alguns poucos. A maioria dos serviços, como saúde, educação, habitação e produção de alimentos, também é subsidiada ou financiada pelo governo. Sua produção industrial de base, além de produtos agropecuários são voltados para o mercado interno. Mas, como vivem em um regime de cerceamento de direitos e de pleno desconhecimento de mundo exterior, os norte coreanos dificilmente se revoltam com esta situação.

O país vem sofrendo de estagnação econômica desde a década de 1980, e passou por um longo declínio, quase colapsando após a dissolução da URSS. Em meados da década de 1990 passou a aceitar ajuda da ONU e da Coreia do Sul. E, um dos maiores exemplos desta falta de evolução econômica são suas fontes de energia, com $70 \%$ da geração advinda de termelétricas a carvão, de forma ineficiente e abaixo da demanda. 


\subsection{COREIA DO SUL}

A Coreia do Sul é um Estado independente e autônomo, de regime político presidencialista, multipartidário e com os três poderes tradicionais - Executivo, Legislativo e Judiciário. Faz parte de uma península montanhosa, banhada pelo Mar Amarelo a oeste, pelo Mar do Japão a leste, e ao sul pelo Mar da China Oriental. Possui uma extensão territorial de $100.032 \mathrm{~km}^{2}$. Com clima predominante continental.

Conta com uma população de 52 milhões de habitantes que falam o idioma Coreano. Sua capital é a cidade de Seul com 24 milhões de pessoas vivendo em sua região metropolitana, o que a faz a mais populosa do país. Sua densidade demográfica - $515 \mathrm{hab} / \mathrm{km}^{2}$ - é concentrada nas cidades devido aos centros industriais. Possui a menor taxa de natalidade do mundo, mas uma expectativa de vida entre as mais altas do mundo, em torno de 79 anos.

A bandeira sul-coreana representa algumas simbologias que remetem às crenças filosóficas do país, fruto de sua longa história que ainda aberta às novas influências, preserva suas tradições. Nela estão representados Yin e Yang com a dualidade da natureza - luz e trevas, criação e destruição, fogo e água, terra e ar, feminino e masculino - na busca por harmonizar as energias conflitantes achando o equilíbrio. A parte superior em vermelho é o "yang", e a inferior em azul o "yin". As combinações de barras representam os pontos cardeais e os quatro mares que limitam o globo. Os quatro trigramas dão a ideia de posição e equilíbrio: as três linhas inteiras representam o céu; as três linhas quebradas do lado oposto representam a Terra; na extremidade inferior esquerda com duas linhas inteiras com uma partida no meio, simboliza o fogo; no extremo superior direito está o símbolo da água.

Quanto ao desenvolvimento religioso no país, que era praticamente inexistente no começo do século 20, houve crescimento explosivo na década de 1960 , impulsionado pelo trabalho de missões religiosas que ofereceram conforto material e espiritual na reconstrução do país no pós-guerra. Também demonstra a influência estrangeira na cultura coreana ao se abrir ao capitalismo. Aproximadamente $46,5 \%$ da população sulcoreana não manifesta uma preferência religiosa. Entre os religiosos, $41 \%$ são cristãos, $16 \%$ são budistas, $15 \%$ seguem o confucionismo, e o restante segue uma variedade de movimentos religiosos que incluem o Jeungismo, Daesunismo, Cheondoísmo, Taoísmo. 
Seu desenvolvimento industrial e econômico foi acelerado durante a década de 1970, com alto crescimento de seu Produto Interno Bruto (PIB), considerado uma das taxas mais altas do mundo na época. E, junto com outras regiões expoentes da Ásia Cingapura, Hong Kong e Taiwan - formou o grupo intitulado de Tigres Asiáticos.

Durante sua industrialização poucos esforços foram realizados para preservar o meio ambiente do país, obtendo destruição contínua de ecossistemas e agravando um problema crônico dos sul-coreanos que é a má qualidade do ar. As elevadas concentrações de dióxido de enxofre no ar acabam provocando chuvas ácidas. Ainda assim, seu Índice de Desenvolvimento Humano (IDH) é igual a 0,877, considerado muito alto. Sua moeda oficial é o Won sul-coreano.

\section{GASTRONOMIA COREANA}

No Norte da Coréia, a base das refeições é o arroz e há carência de frutas e vegetais. Há, ainda, déficit de proteínas, o que pode ser um indício da diferença de estatura entre os norte e sul coreanos. Para contornar a situação, é comum que nortecoreanos criem sapos e tartarugas para consumo. Sua culinária preserva características originais e regionais, em que produtos importados são praticamente inexistentes. Baseia-se nos cultivares que conseguem manter de forma recorrente, como: couves, cogumelos, arroz e batatas.

O Instituto Internacional de Pesquisa em Políticas de Alimentação, estima que $40 \%$ da população norte coreana viva em insegurança alimentar crônica e desnutrição $(G 1,2021)$. Já as áreas abertas a turismo guiado, que geralmente ocorre na capital, são ricas e bem guarnecidas, em locais, onde está alocada a população de famílias privilegiadas.

A Coreia do Sul tem culinária rica e variada. Com influências europeias e norteamericanas, o que lhe conferiu a ocidentalização de sabores. Mas, ainda assim tem sua identidade e base culinária. Serão citados nesta pesquisa pratos e referências gastronômicas dessa região, já que informações sobre a culinária da Coreia do Norte, para fins de comparações e estudos, quase não são encontradas. 


\subsection{PREPARAÇÕES E SERVIÇOS}

Como conceitos básicos desta gastronomia temos as seguintes definições:

- Banchan: refeições tradicionais servidas em um pequeno prato. Normalmente, acompanham arroz cozido a vapor.

- Cerimônia do chá: um ritual ancestral perdido durante a ocupação japonesa, mas retomado no final do séc XIII.

- Bangjja: conjunto completo de serviço feito em bronze, parte da tradicional culinária da corte real coreana.

- Práticas de conservação: A comida coreana se desenvolveu a partir da necessidade de preservar os alimentos durante os longos e duros invernos. Portanto, é comum a salga de feijões, peixes e vegetais preservados por fermentação em grandes vasos de argila.

- Higiene alimentar: as características milenares de preservar a segurança alimentar são os usos de utensílios de aço inoxidável, outrora de latão.

\subsection{INGREDIENTES}

Os ingredientes bases são o tofu, o arroz, a carne, o macarrão de preparo artesanal, o doenjang (uma pasta de soja fermentada), óleo de gergelim, alho, molho de soja, sal, gengibre, flocos de pimenta, repolho e gochujang (pasta de pimentão).

Os grãos estão presentes na alimentação há vários séculos, estão entre os alimentos mais importantes da dieta coreana. Podem ser destacados, a cevada, o painço, o trigo, o sorgo e o trigo-sarraceno.

Entre os demais vegetais há os preparados com a soja: banchan, leite, base para pratos, okara (subproduto da produção do leite de soja). Os feijão azuki, pepinos, batatas, batatas doces, espinafre, cebolinha, alho, pimentões, algas, cogumelos, flor e raiz de lótus.

Os Jang, que são os molhos coreanos, têm aumentado graças ao crescimento de uma tendência pelo cultivo de uma vida saudável e pela transmissão das técnicas de consumo e produção. Especialmente os tradicionais como Gochujang, Doenjang, e Ganjang (molho de soja).

Para o consumo de carnes e peixes o mercado é extenso. Aves, bovinos, suínos, peixes e frutos do mar são muito apreciados. Como iguaria a carne de cachorro, que na Coréia do Sul a venda e consumo estão proibidos desde 2018. Entretanto, é provável que ainda ocorra na Coréia do Norte, em geral associados à insegurança alimentar em grande parte da população norte coreana. 


\subsection{CRIAÇÃO DE ANIMAIS}

A península coreana é montanhosa o que dificulta a criação de bovinos. Com o desenvolvimento econômico se criou demanda e produção. Mas, a maior parte dela é focada em animais menores: frango, suínos e patos.

O produto mais produzido na Coreia do Sul costumava ser o arroz (o país é autossuficiente em seu plantio desde os anos 1990), mas em 2016 a suinocultura tomou a liderança. Há emprego de muita tecnologia para manejo na criação do animal, bem como para abate e processamento da carne. Em 97\% das raças suínas consumidas no território passaram por melhoramento genético (Gyeongsang National University).

Os suínos contam com mais de 25 cortes, que sofrem variações para valorizar a proteína. O de maior consumo é a Barriga de porco: Samgyeopsal (corte abaixo do lombo, sem as costelas, até o pernil). As tiras são cortadas com espessura entre 3 a $5 \mathrm{~mm}$. Mas, há o aproveitamento de quase todas as partes: rim, entranhas e cabeça. O Jokbal (pés de porco cozidos com molho de soja e refogado em gengibre, alho e vinho de arroz), é um prato norte coreano, levado para o sul através dos "refugiados". Um dos líderes de venda na crescente cultura de delivery no país.

\subsection{PRINCIPAIS INFLUÊNCIAS}

Tem início em tradições nômades e agrícolas, e incorporação da interação com outras culturas. A China sempre foi forte influenciadora da Coreia. Há ainda fortes influências Japonesas. Mas, hoje já se vê a ocidentalização com a abertura ao crescente capitalismo.

A influência budista levou a Coreia a preservar uma tradição de culinária vegetariana. É uma comida simples, mas com uso de muitos temperos: cúrcuma, pimenta-sichuan, perila, pimenta-do-reino, molho e pasta de soja. Faz uso de ingredientes primários como alho, cebola, cebolete, cebolinha, alho-poró

Os Budistas adotam um estilo de vida que prioriza a harmonia com a natureza. Eles não usam peixes ou carnes, nem qualquer tipo de intensificadores de sabor ou conservantes químicos. A prática budista busca valorizar os ingredientes e abraçar uma culinária saudável e natural, sem impactar em sua cultura alimentar ou inflamar egos em competições. Cinco sentidos utilizados na construção de sabor: corpo, sensação, percepção, intenção e consciência. 


\subsection{COZINHA DA CORTE REAL COREANA}

Essas refeições eram banquetes servidos para a aristocracia durante a Dinastia Joseon. Apresentados em doze pratos com arroz e sopa, que deveriam ser consumidos o "bangjja".

Pratos servidos em tigela:

- Sura: Arroz cozido e com outros grãos.

- Juk, mieum e eungi: são tipos de mingaus de arroz, cada um com uma textura.

- Guksu: noodles preparados com trigo sarraceno ou farinha de trigo

- Ddeokguk: sopa feita com bolos de arroz em fatias finas, Guarnecido com ovos carne marinada e gim

- Tang: e sopa feita com pernil, intestino, osso e peito de boi.

- Jochi e gamjeong: é um guisado feito com carne, frutos do mar ou vegetais em um caldo temperado com doenjang

- Jim e seon: Jim é uma carne de vaca, porco e peixe cozidos ou cozidos no vapor e temperados com vegetais. Seon são vegetais cozidos no vapor, tofu e peixe recheado com recheio feito com carne ou frango e cebola.

Acompanhamentos:

- Saengchae: salada temperada com sal, vinagre, molho de soja ou mostarda

- Namul: qualquer variedade de vegetais cozidos no vapor temperados com pimenta, alho, cebola verde, sal e óleo de gergelim ou perilla

- Jorigae: Alimentos cozidos com temperos pesados. São utilizados principalmente carnes, peixes e vegetais.

- Jeonyuhwa: um prato que lembra uma panqueca. Os ingredientes principais podem ser ligeiramente polvilhados com ovo e farinha de trigo.

- Gui: termo genérico da cozinha coreana para pratos assados e temperados.

- Hoe: é peixe cru ou carne crua temperada.

\subsection{MERCADOS}

Mercado de Gwangjang, é o mercado mais antigo em Seul, com comidas tradicionais. Após a guerra, a forma de sustento de muitas viúvas foi recorrer à venda de comida nas ruas. E, o mercado reflete tanto a gastronomia quanto a cultura local.Mercado Noryangjin, é um dos maiores mercados de frutos do mar da Coréia, e está em operação desde 1927. Há mais de 800 variedades de frutos do mar, tanto no varejo quanto no atacado. O visitante pode provar os frutos do mar coreanos frescos, sendo escolhidos e preparados tradicionalmente no mercado. 


\subsection{PRATOS TÍPICOS COREIA DO SUL}

- Bulgogi: carne bovina cortada em finos pedaços para depois ser marinada em gengibre, molho de soja, alho, açúcar e outros temperos típicos. Depois é grelhada para dar um sabor defumado.

- Baesuk: sobremesa feita com peras apimentadas no molho de gengibre e mel. É servido gelado.

- Kimchi: mistura de acelga fermentada, pasta de pimenta e condimentos, como gengibre e alho.

- Tteokbokki: sopa feita com bolinhos de arroz cilíndricos, anchova, pimenta, ovos cozidos e cebolinha.

- Hongeo-hoe: Fatias de raia fermentada crua. Possui textura, cheiro de amônia e sabor dificilmente encontrados em outras comidas.

- Mandu: bolinhos feitos de trigo ou de trigo sarraceno e recheados de carne, que podem ser preparados cozidos na água, no vapor ou frito.

- Haejang-guk: sopa é feita com carne e vegetais, adicionando sangue de boi.

\section{CONCLUSÃO}

A gastronomia enquanto elemento de diferenciação social representa valores geopolíticos. Isso porque, a posição de um território no espaço global e as políticas aplicadas pelo mesmo interferem substancialmente na seleção e aplicação de recursos para aquisição de alimentos. Bem como em seus rituais de preparação e produção. E, ainda, em seus significados e valores.

Assim, a gastronomia coreana é uma complexa integração de tradições culturais desenvolvidas através de séculos. Que revelam sua individualidade no nordeste asiático. Todavia, as sanções impostas, a restrição de alimentos, bem como as diferenças geopolíticas das "duas Coreias" faz com que cada uma traga em si, oferta de alimentos, pratos e tradições diferentes.

\section{REFERÊNCIAS}

15 Diferenças entre as duas Coreias em $\mathbf{7 0}$ anos de separação. Incrível club. Disponível em: <https://incrivel.club/admiracao-lugares/15-mudancas-impactantes-nacoreia-do-norte-e-coreia-do-sul-em-70-anos-de-sua-separacao-298760/> Acesso em: maio de 2021.

2018: 11 Dias na Coreia do Norte. Direção Bruno Bernardes, Álvaro Pereira Júnior. Produção GloboPlay. Brasil, 2018. (31 min). Disponível em: < https://globoplay.globo.com/2018-11-dias-na-coreia-do-norte/t/sRTpd9sxsZ/> Acesso em: maio de 2021. 
A Coreia em um Prato. Produção Netflix. Coréia do Sul, 2020. (96 min.) Disponível em: <https://www.netflix.com/title/81347666> Acesso em: maio de 2021.

BRITES, P. V. P. A situação na península coreana: estrutura, panorama e cenários. Porto Alegre: UFRGS, 2011. Trabalho de conclusão de curso submetido à Faculdade de Ciências Econômicas da UFRGS para obtenção do título de bacharel em Relações Internacionais. Disponível em: <http://hdl.handle.net/10183/40296> Acesso em: maio de 2021.

Chef's Table - Vol 3. Chef Jeong Kwan. Produção Netflix. EUA, 2019. (58 min.) Disponível em: <https://www.netflix.com/search?q=chefs\%20ta\&jbv=80007945> Acesso em: maio de 2021.

Como é a comida na Coreia do Norte? Deutsche Welle. Disponível em: <http:// https://www.dw.com/pt-br/como-\%C3\%A9-a-comida-na-coreia-do-norte/a42963004> Acesso em: maio de 2021.

COREIA. Consulado Geral da República da Coréia em São Paulo. Disponível em: < https://overseas.mofa.go.kr/br-saopaulo-pt/index.do> Acesso em: maio de 2021.

Coreia do Norte: A Vida Dentro do Estado Secreto. Direção Sarah Collinson. Reino Unido, 2018. Disponível em: <https://globoplay.globo.com/coreia-do-norte-avida-dentro-do-estado-secreto/t/RYnDsmBKtd/> Acesso em: novembro de 2021.

ESCOLA, Equipe Brasil. Yin e Yang. Brasil Escola. Disponível em: <https://brasilescola.uol.com.br/filosofia/yin-yang.htm> Acesso em maio de 2021.

FLORENTINO, J. Coreia do Sul produz alimentos de alta qualidade mesmo em invernos rigorosos. Canal rural. Disponível em: <https:// https://www.canalrural.com.br/sites-e-especiais/coreia-sul-produz-alimentosalta-qualidade-mesmo-invernos-rigorosos-75131/> Acesso em: maio de 2021.

FUNDAÇÃO WIKIMEDIA. Wikipédia: a enciclopédia livre, 2021. Culinária da Coreia. Disponível em: <https://pt.wikipedia.org/wiki/Culinaria_da_Coreia> Acesso em: novembro de 2021.

FRANCISCO, W. C. Coreia do Norte. Brasil Escola. Disponível em: <https://brasilescola.uol.com.br/geografia/coreia-norte.htm> Acesso em: maio de 2021.

FREITAS, E. Coreia do Sul. Brasil Escola. Disponível em: $<$ https://brasilescola.uol.com.br/geografia/coreia-sul.htm> Acesso em: maio de 2021.

GLOBO, Jornal O. Kim consolida poder e imagem próprios com mudanças no alto escalão da Coreia do Norte. O Globo. Disponível em: <https:// 
https://oglobo.globo.com/mundo/kim-consolida-poder-imagem-proprios-commudancas-no-alto-escalao-da-coreia-do-norte-23593763> Acesso em: maio de 2021.

G1. Fome na Coreia do Norte atinge $\mathbf{4 0 \%}$ da população. Disponível em: $40 \%$ da população norte coreana viva em insegurança alimentar crônica e desnutrição.Data da publicação: 18 de nov de 2021 às 19:27. Acesso : novembro de 2021

Human Rights Watch. Relatório mundial 2021: Coreia do Norte. Disponível em : https://www.hrw.org/pt/asia/north-korea. Acesso: novembro de 2021

LIMA, U. M. O debate sobre o processo de desenvolvimento econômico da Coreia do Sul: uma linha alternativa de interpretação. Econ. soc. vol.26 no.3 Campinas: Unicamp, 2017. Disponível em: <https://doi.org/10.1590/19823533.2017v26n3art3> Acesso em: maio de 2021.

LODY, R. Brasil Bom de Boca: temas da antropologia da alimentação. São Paulo: Senac, 2008. 424p.

ONU. Escritório de Direitos Humanos cita persistência em possíveis crimes contra a humanidade na Coreia do Norte. ONU News-Perspectiva Global Reportagens Humanas. Disponível: https://news.un.org/pt/. Acesso: novembro de 2021.

Somebody feed Phil - Temp.3: Seul. Produção Netflix. EUA, 2020. (51 min.) Disponível em: <https://www.netflix.com/search?q=some\&jbv=80146601> Acesso em: maio de 2021.

Street Food Asia: Seul, Coreia do Sul. Produção Netflix. EUA, 2019. (29 min.) Disponível em: <https://www.netflix.com/search?q=chefs\%20ta\&jbv=80244996> Acesso em: novembro de 2021.

TAKADA, K. $\mathbf{O}$ que é Yin Yang? Clube de chines, 2021. Disponível em: <https://clubedechines.com.br/blog/o-que-e-yin-yang/> Acesso em: maio de 2021. 


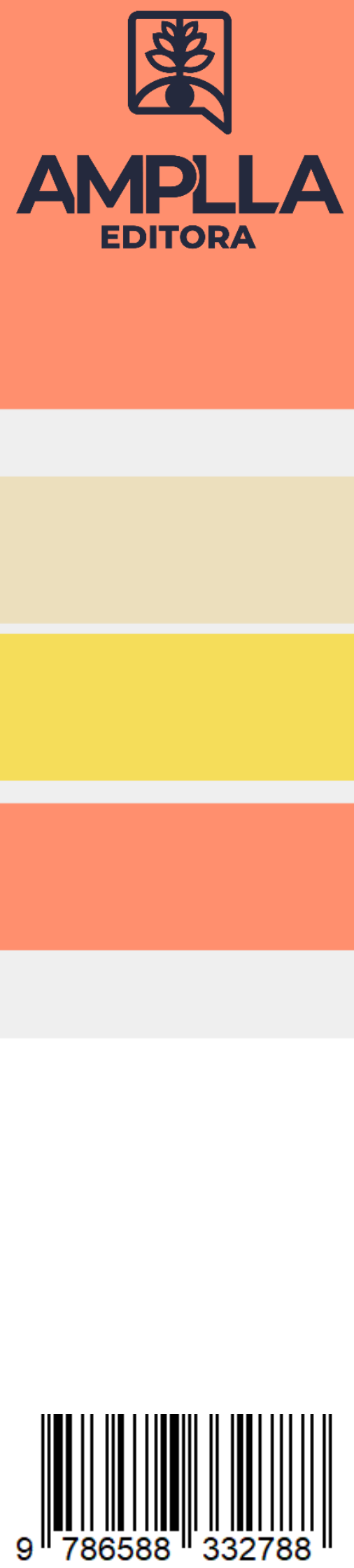